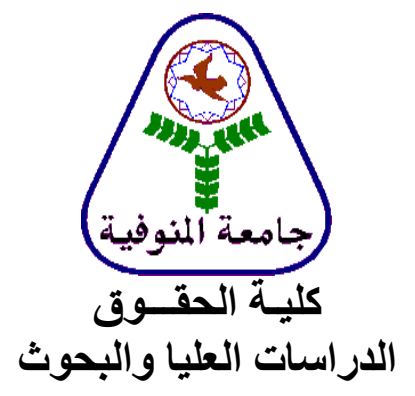

\title{
الإتحاد من أجل السلم(Uniting For Peace) كبديل لحق النقض من مجلس الأمن
}

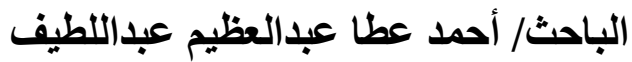

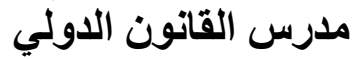 \\ كلية الحقوق-جامعة مدينة السادات المئون
}

$$
\text { مقدمة :- مقا }
$$

طرحت التحو لات الهائلة التي طر أت علي النظام الدولي منذ نشأة الأمم المتحدة

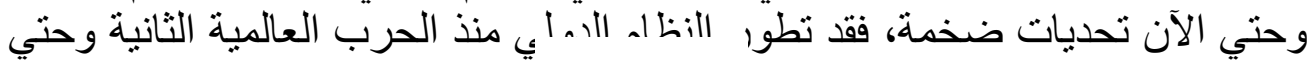

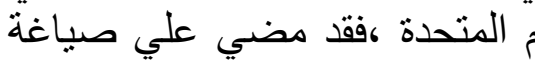
الآن في اتجاه يصعب التطبيق الكاما

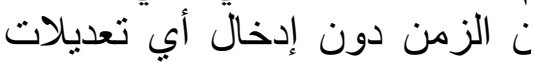
ي طر أت علي الوسط الدون الدولي الذي الذياني

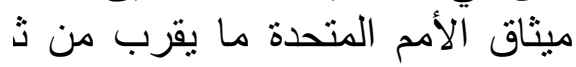

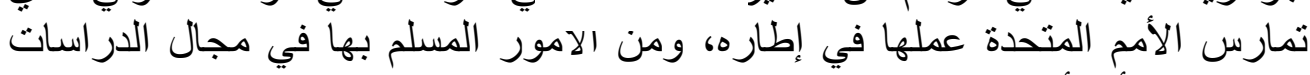

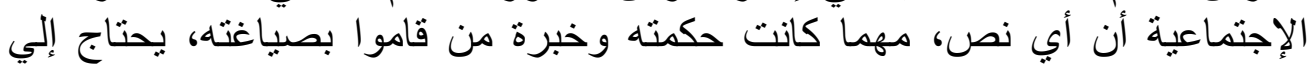


مر اجعة دورية لإز الة أي تعارض أو عدم اتفاق بين أحكامه و التغير ات و التطور ات

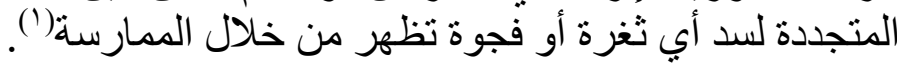

و الحقيقة أنه بعد قر ابة الثمانين عاماً علي إنثاء الأمم المتحدة تبدو الحاجة الحاجة ماسة

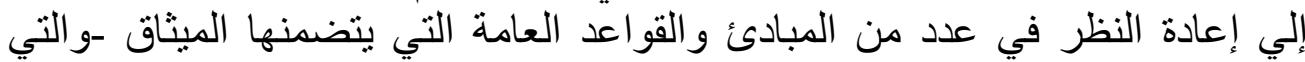

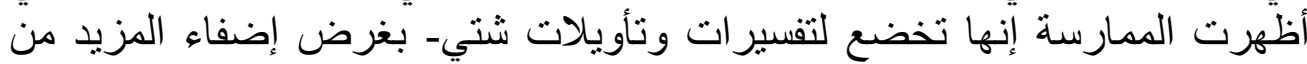

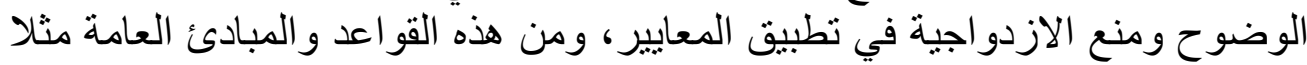

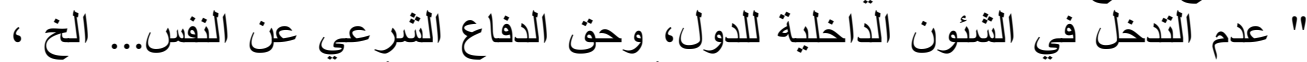

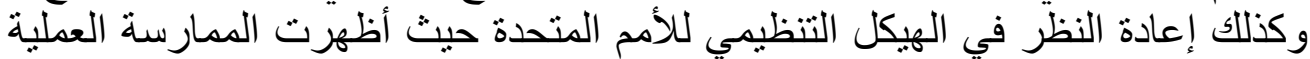

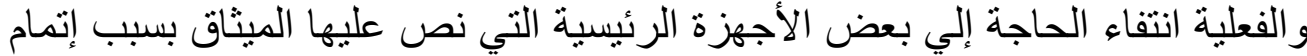

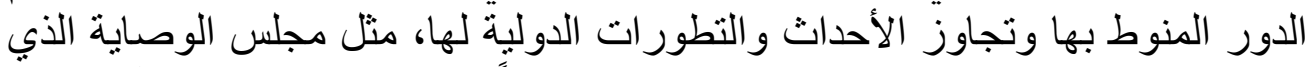

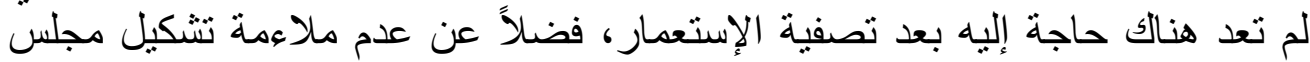

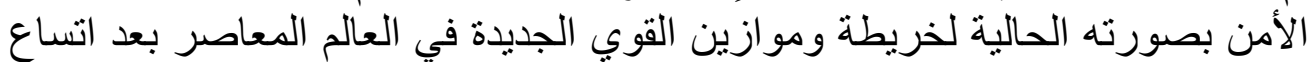

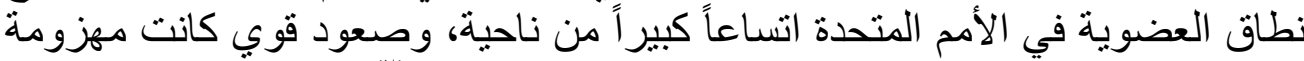

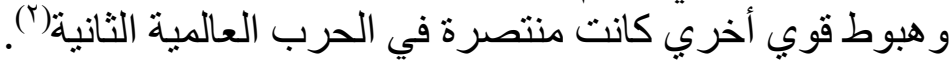

ولقد ساد الإعتقاد و الرغبة عند إنشاء الأمم المتحدة، أن الميثاق قد جاء باء بنظام

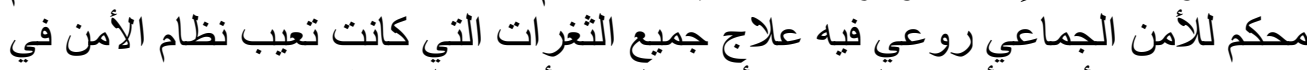

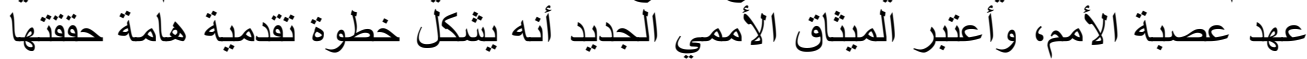

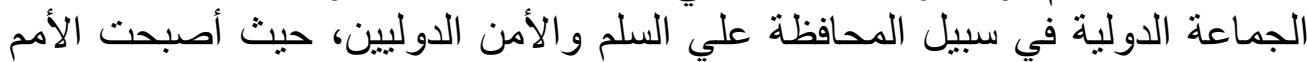

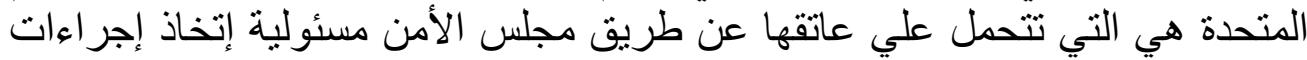

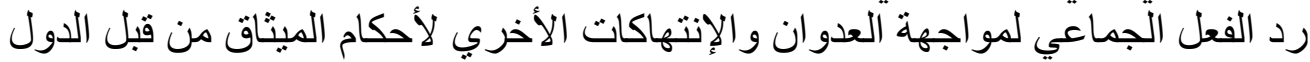
الأعضاء أو غير الفياء

لقد جعل ميثاق الأمم المتحدة من الأمن الجماعي نظاماً وهدفاً لتحقيق الأمن

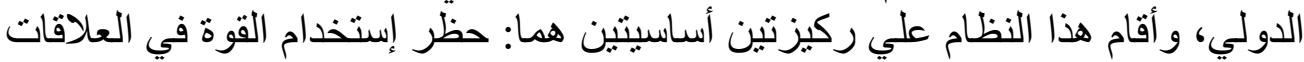

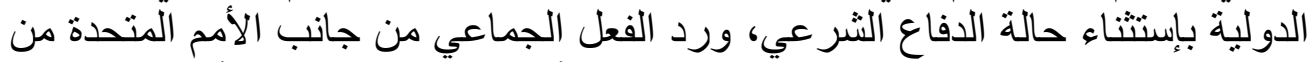

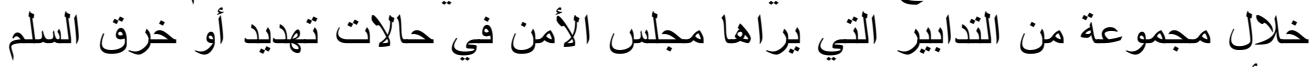
و الأمن الدوليين.

(')د/ عثمان عبد الرحمن إبراهيم- دور الأمم المتحدة المعاصر وفاعلية تنفيذ قرارات مجلس الأمن

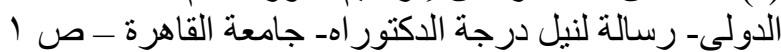

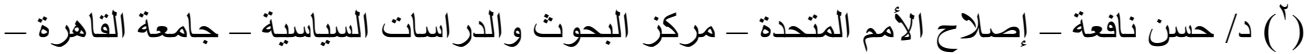
$\leqslant \vee ، \leqslant 7-1990$ 
وفي حالة فنل مجلس الأمن في تحمل مسئوليته في حفظ السلم والأمن

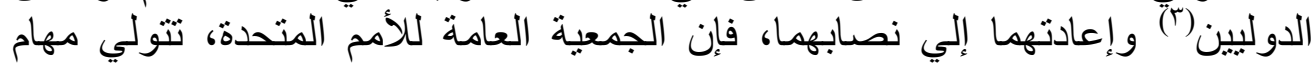
مجلس الأمن من خلال قرار " الإتحاد من أجل السلم ". العية العامة

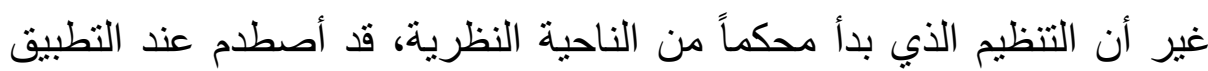

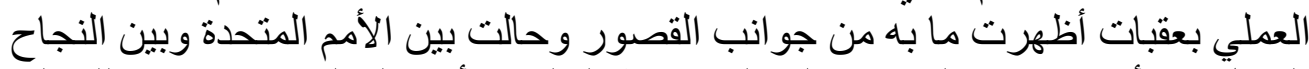

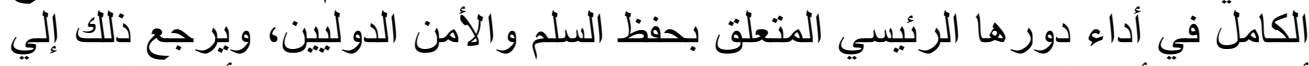

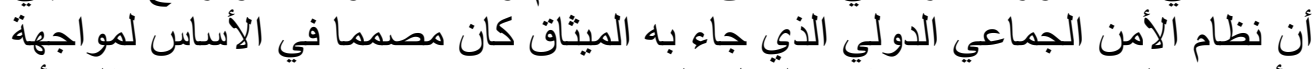

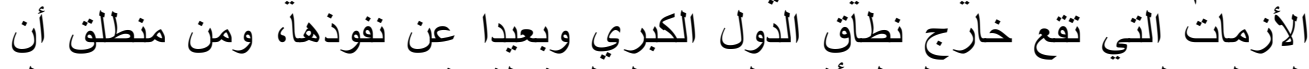

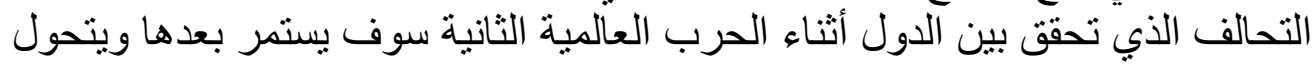
ـ ـ من خلال مجلس الأمن - إلي أداه للمحافظة علي السلم و الأمن الدوليين و الحيلولة لئلة دون

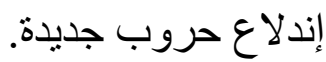

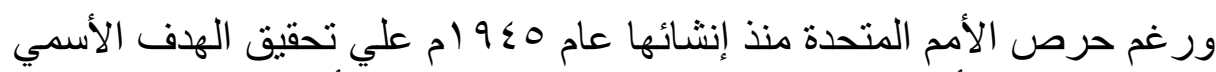

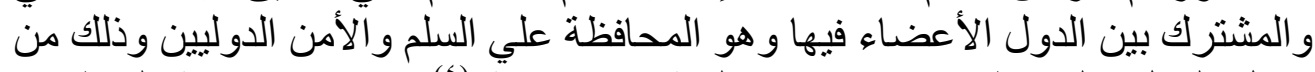

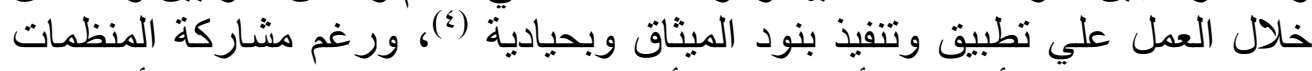

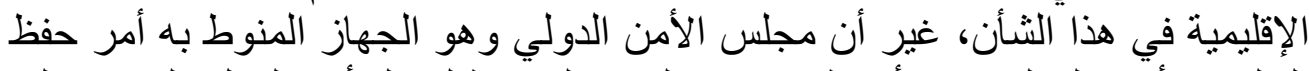

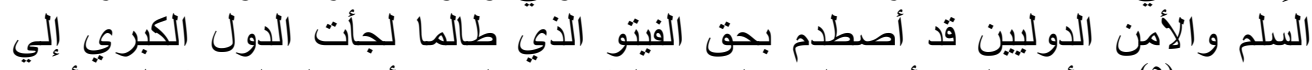

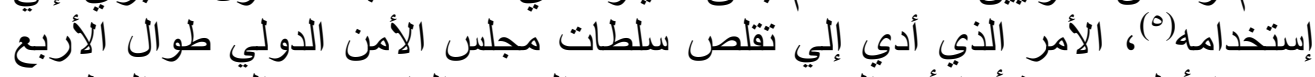

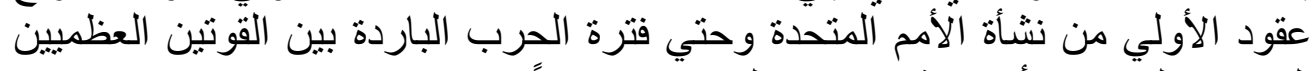
الولايات المتحدة الأمريكية والإتحاد السوفيتي (سابقاً).

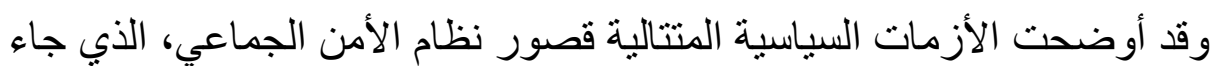

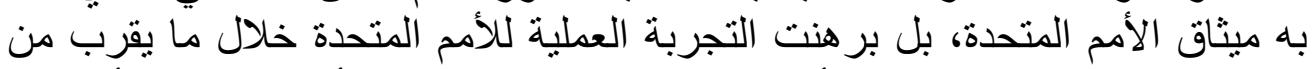

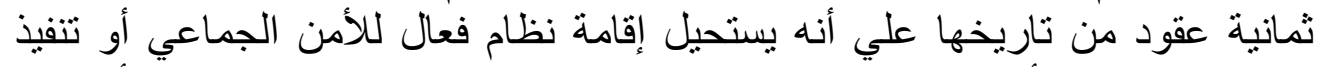

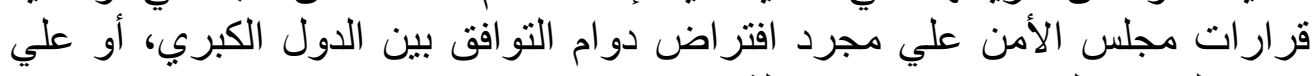
مجرد الركون إلي حسن نيتها في حالة إنفاقها.

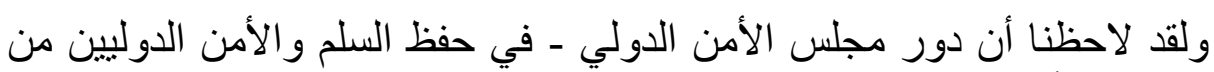

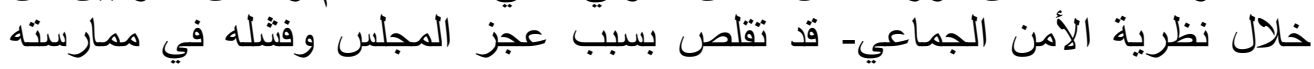
سلطاته المخولة له بموجب التيثاق بسبب عدم تو افق الدول علي القرار اتلئ ألتي اتخذها

(آكأنظر د/ ممدوح شوقى مصطفى - الأمن القومى والأمن الجماعى الدولى - رسالة لنبل درجة

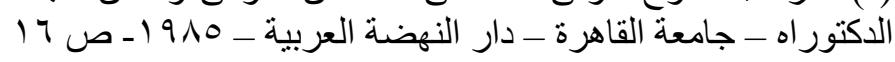
(4)John Terence O' Neill , Nicholas Rees, United Nations PeaceKeeping in the Post-Cold War Era, First published, Routledge, New York, 2005, p33. (0) ما عثمان عبد الرحمن إبر اهيم- دور الأمم الدتحدة المعاصر وفاعلية تنفيذ قرارات مجلس الأمن

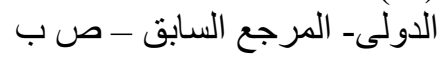




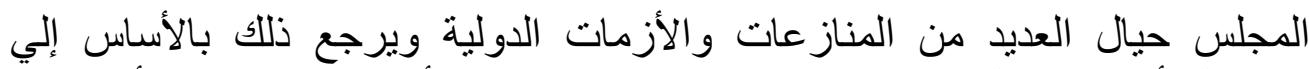

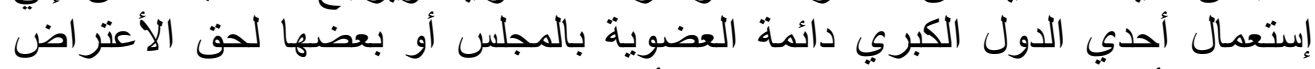

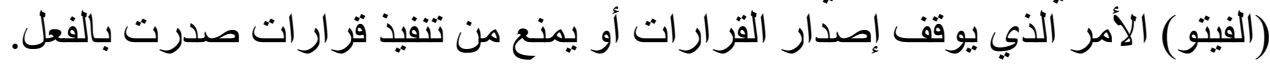

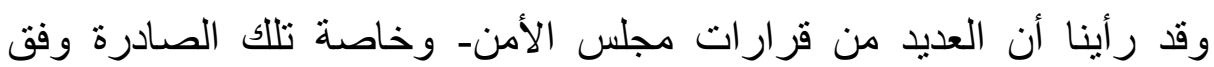

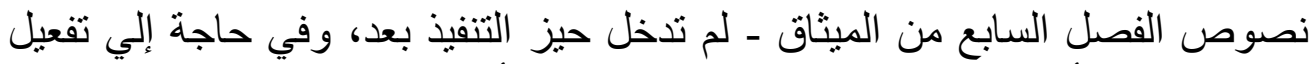

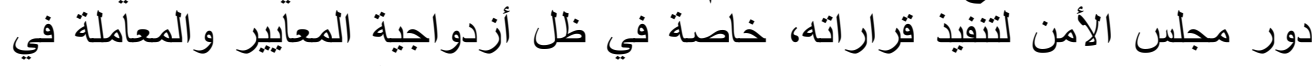

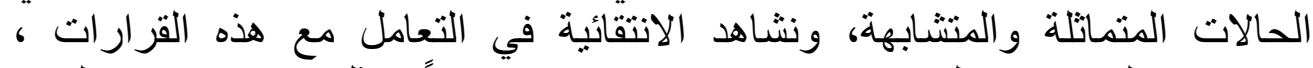

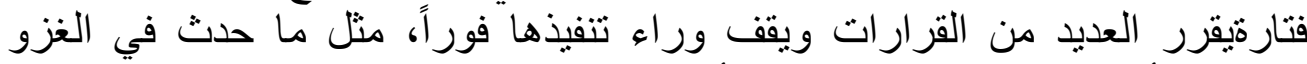

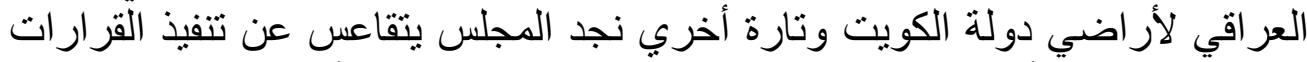

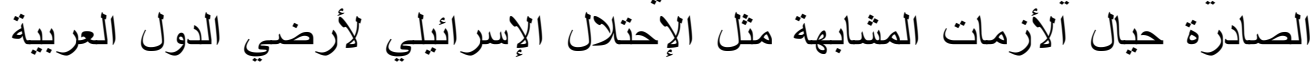

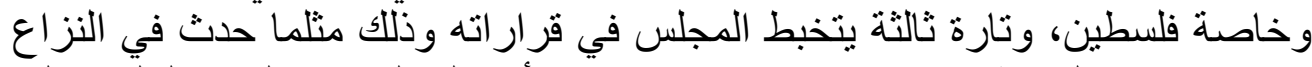

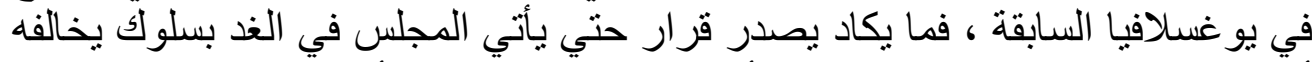

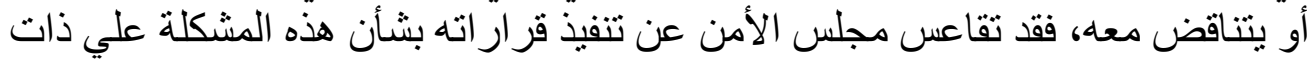

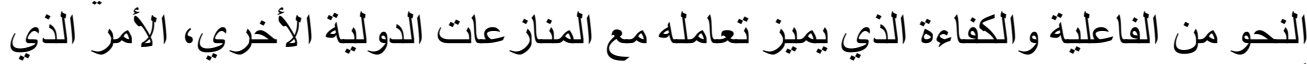

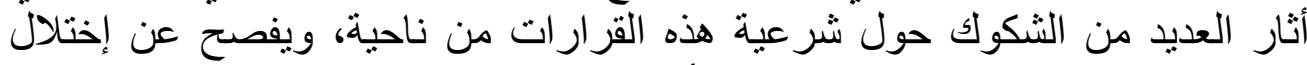

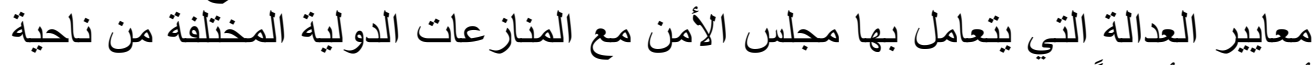

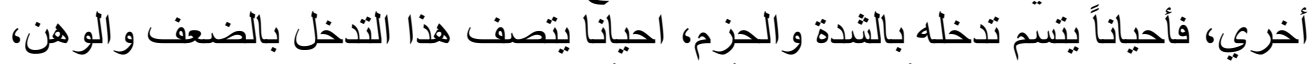

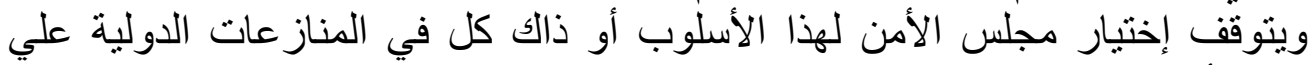

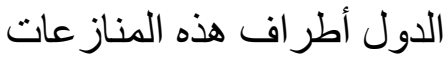

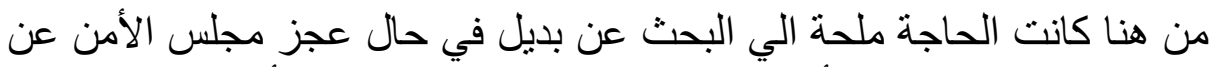

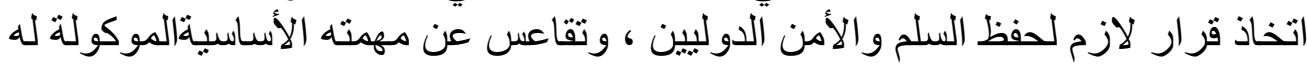

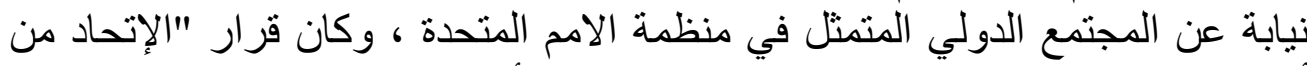

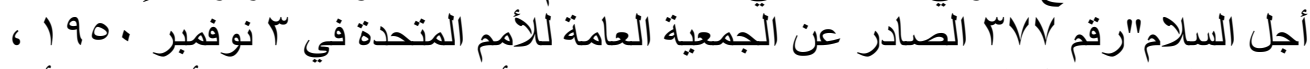

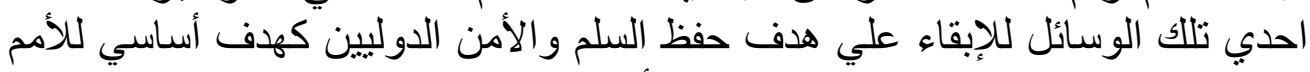

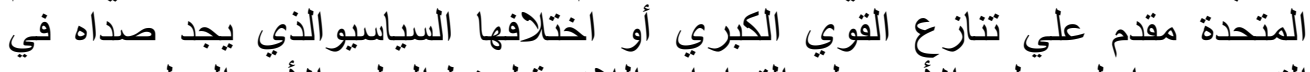
التصويت داخل مجلس الأمن علي القرار الت اللازمة لحفظ السلم والأمن الدوليين .

أهمية البحث

تأتي أهمية البحث في ذلك الموضو عمن وجوه عدة أهمها أهمها :

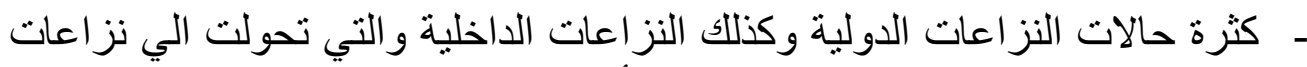

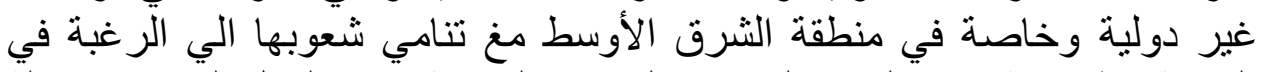

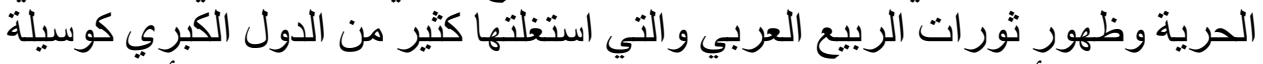

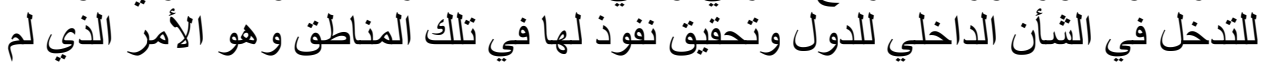


يروق لقوي دولية أخري والتي تريد هي الأخري وضع اقدام لها في المنطقة ،

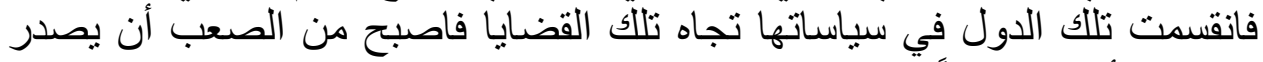

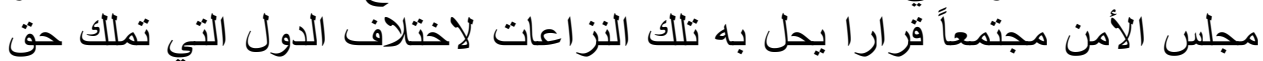

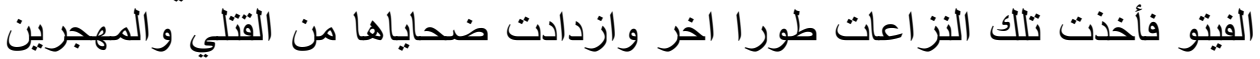

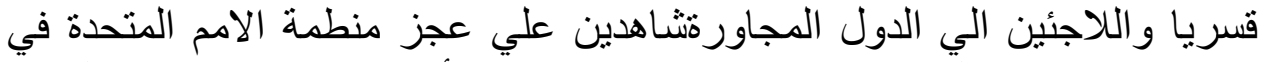

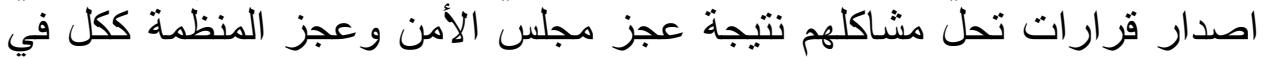
ايجاد بديل في حالة هذا العجز اوتفعيله البديل الموجود وهو هو قرار الإتحاد من أجلّ السلام

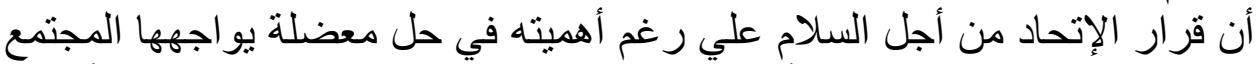

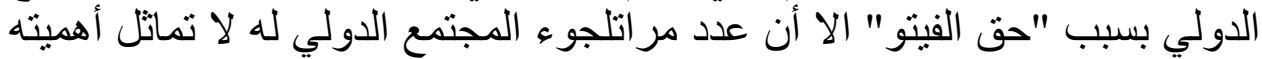

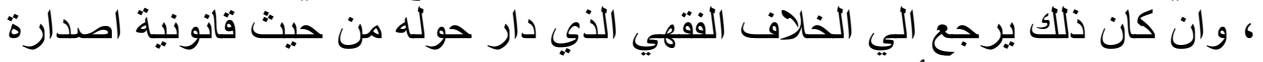

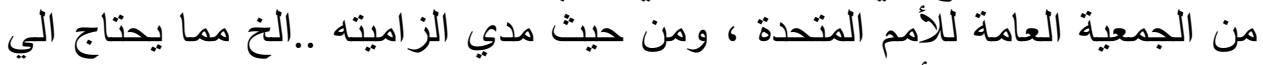

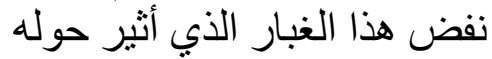

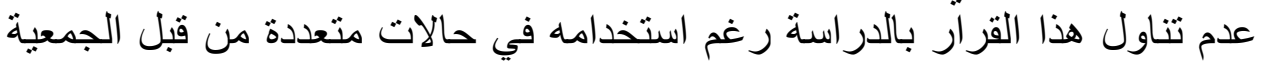

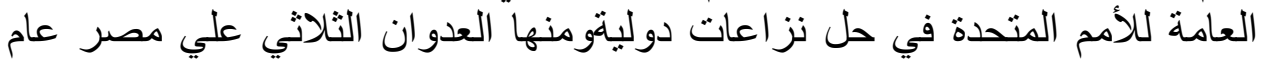

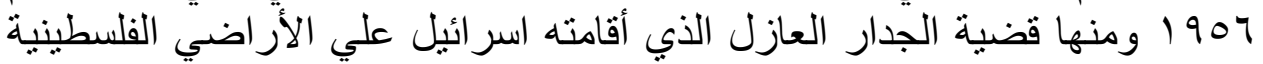

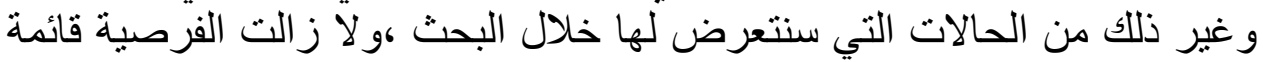

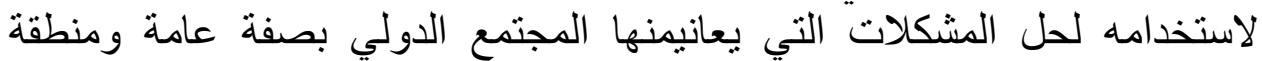

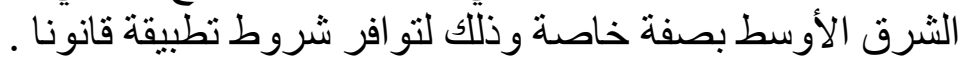

خطة البحث

ان حفظ السلم والأمن الدوليين هو الهدف الأساسي والرئيسي لمنظمة الأمم

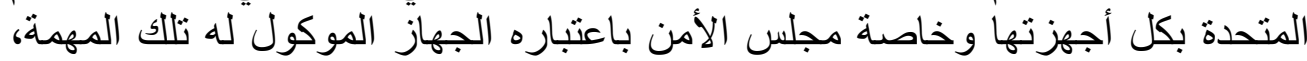

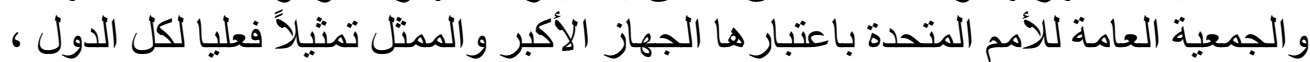

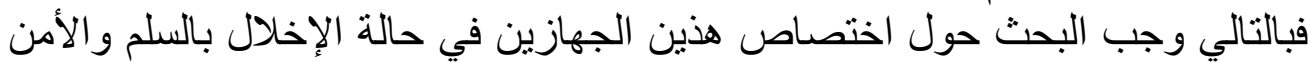

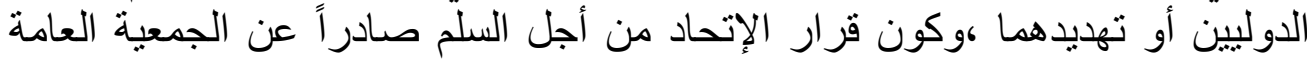

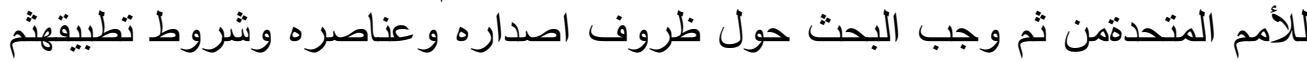

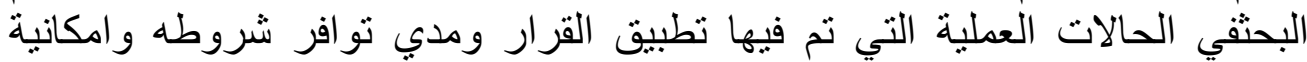

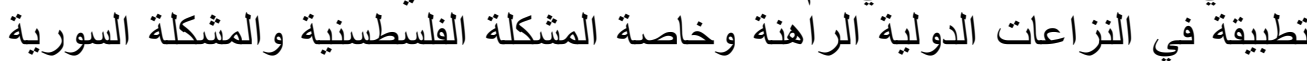

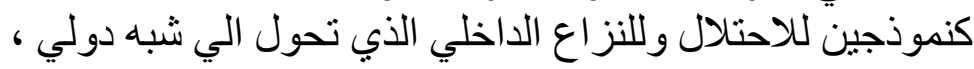

ومن ثم تكون هذا البحث من مبحث تمهيدي وثثلاثة فصول ، تناولت في المبحث

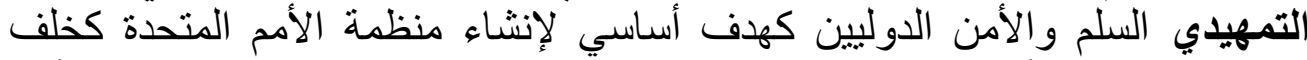

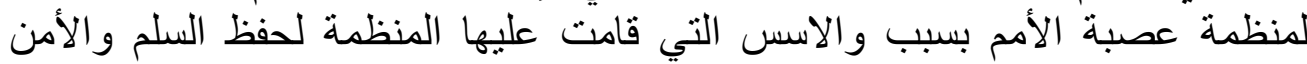

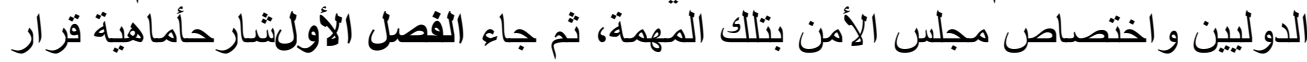


الإتحاد من أجل السلمومضمونة قجاء المبحث الأول مبيناً مضمون القرارو عناصره أما

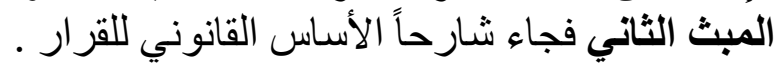

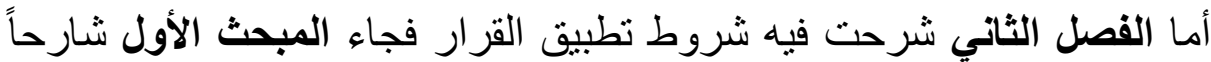

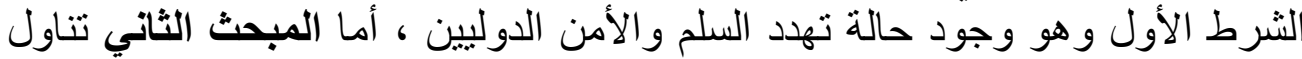

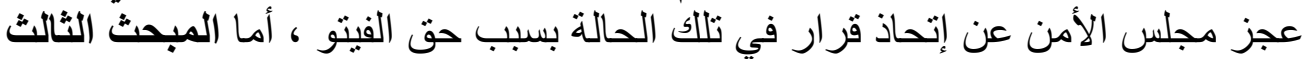
جاء شارحاً الإجر اءات المنطلبة لتمرير قرار من الجمعية العامة طبقاً للإتحاد من أجل الجل

أما الفصل الثالث فجاء ليلقي الضوء علي الحالات العملية التي تم فيها استخدام

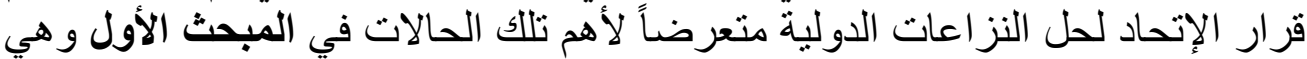

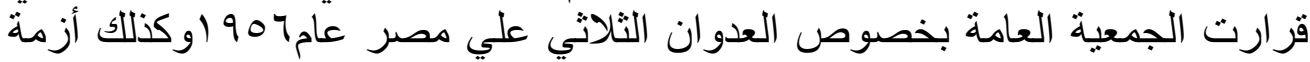

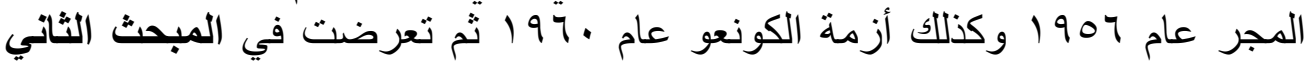

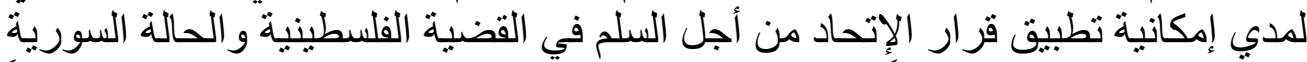

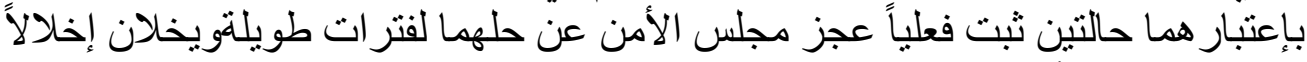

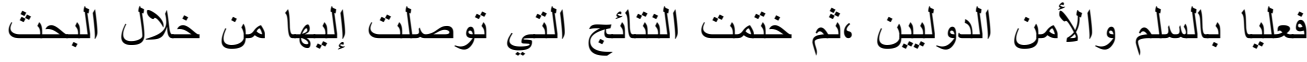

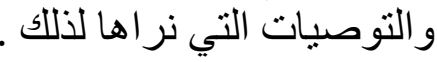

و الله من وراء القصد وهو يهدي السبيل

\begin{abstract}
The most important goals of the United Nations organization is to maintain international peace and security, and the organization entrusted this goal to the UN Security Council, but the Security Council in its current composition no longer reflects an actual representation of the international community, either in terms of the number of its members or on the one hand The method of voting in it, and the right of veto stands in many cases an obstacle to making a decision that preserves international peace, hence the decision of Uniting For Peace issued by the General Assembly in Novemer 1950 to address the failure of the
\end{abstract}


Security Council to take a decision because of the right of veto, if there is a conflict threatening or disturbing the peace And international security has not You can obey the Security Council to take a decision to stop that threat or disturb the peace, then the matter must converge to the General Assembly and transfer its competence to it and take the appropriate decision, and this is what happened in many cases. From the United Nations based on the Union for PeaceAs a legal means and a gain from the gains achieved by the United Nations General Assembly as the main and largest organ in the United Nations and a representative of all its membersHence the research was an explanation of the elements of this resolution, its conditions, procedures and its applicability. . 


\section{مبحث تمهيدي \\ السلم والأمن الدولي كأحد أهداف الأمم المتحدة \\ المطلب الأول المان \\ الظروف المصاحبة لنِشأة الأمم المتحدة المدة}

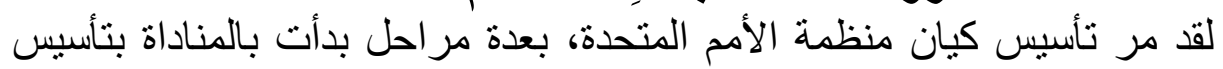

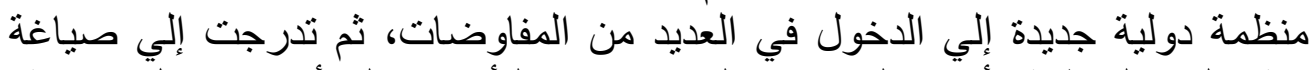

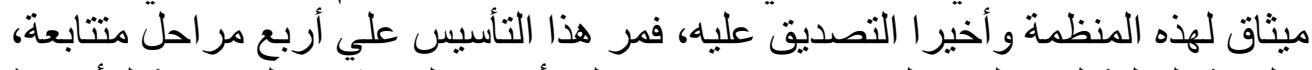

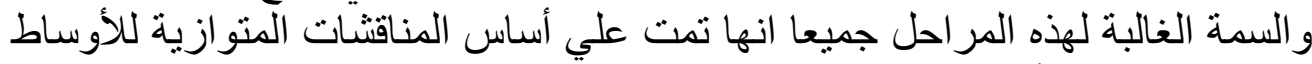

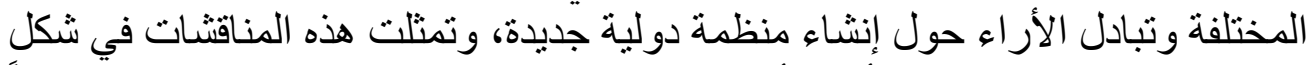

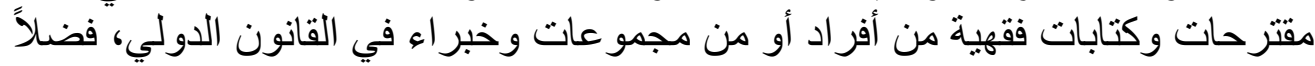

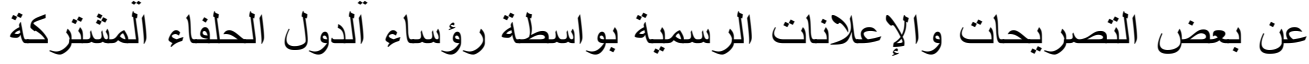
في الحرب العالمية الثانية.

وقد تم في المرحلة الأولي: وهي مرحلة ما قبل إنعقاد مؤتمر "دومبرتون أوكس "

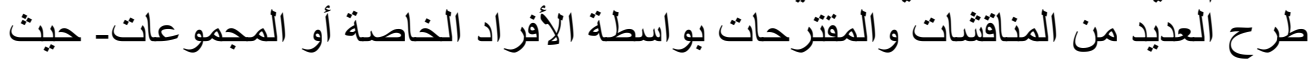

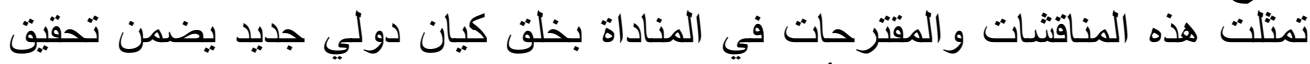

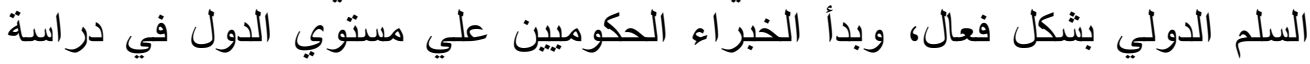

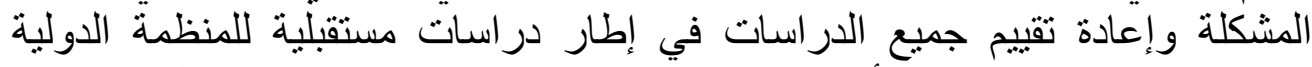

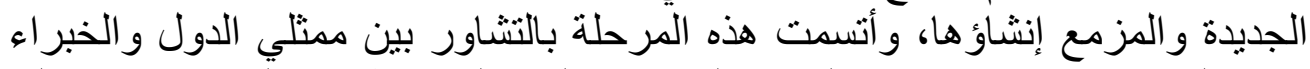

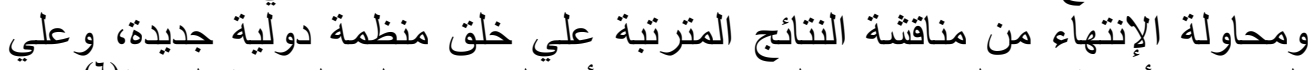

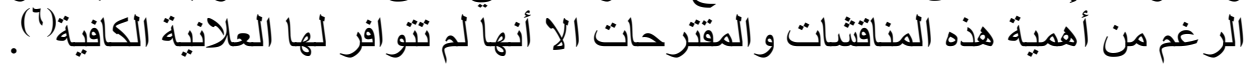

وكان من أبرز ملامح جدية المرحلة صدور تصريح الأطلنطي، الذي أنشار إلي

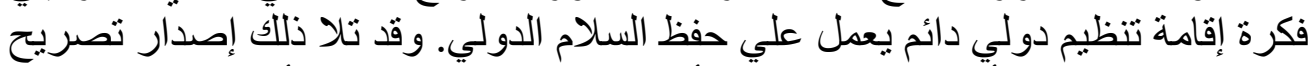

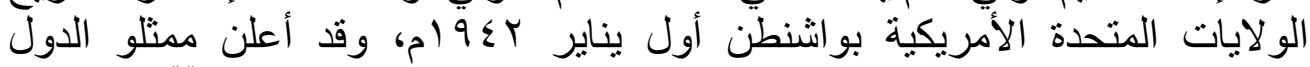

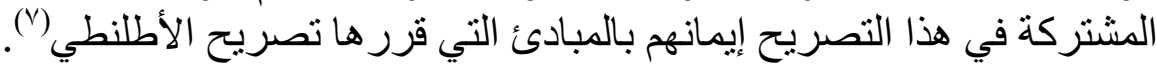

وقد قرر ممثلو كل من الولايات المتحدة الأمريكية وبريطانيا والإتحاد السوفيتي

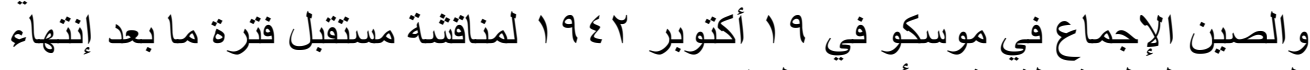

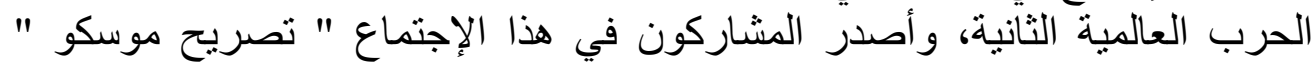

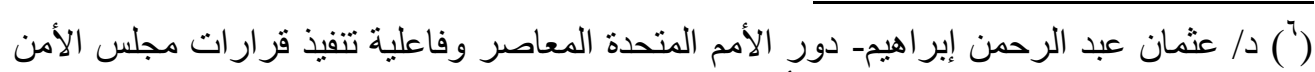

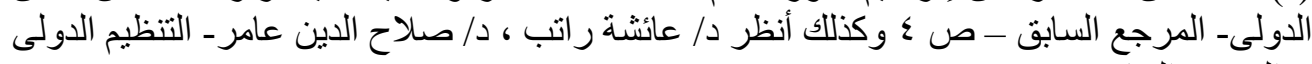

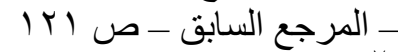

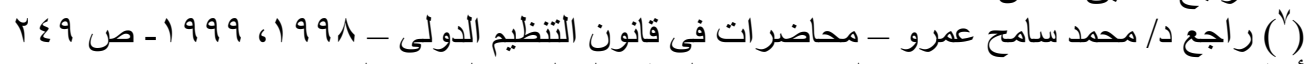

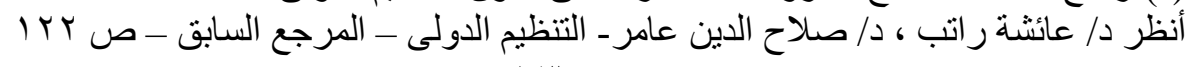




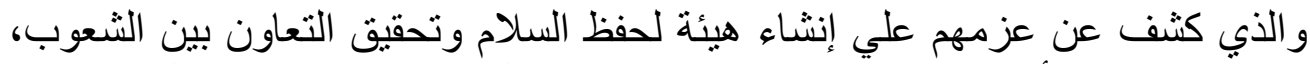

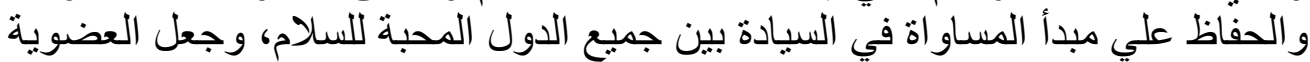

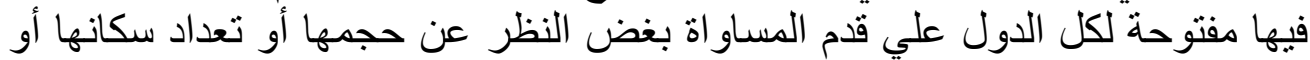
قوتها الإقتصادية(^)

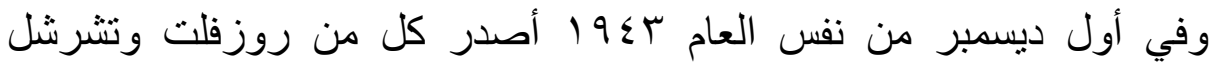

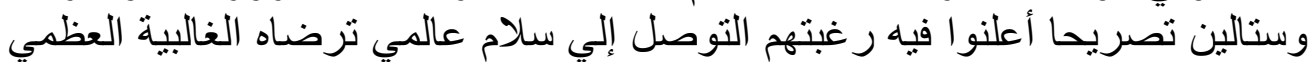

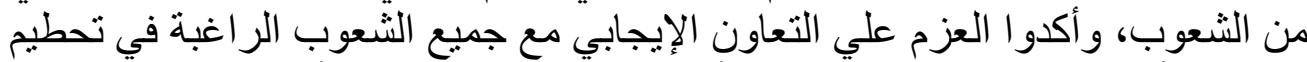

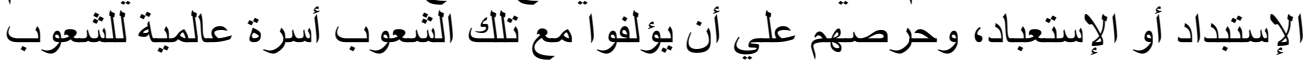

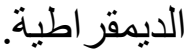

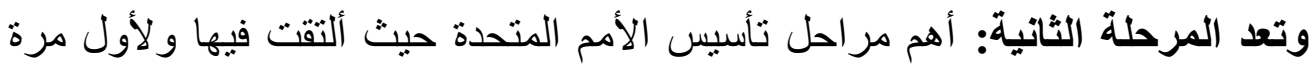

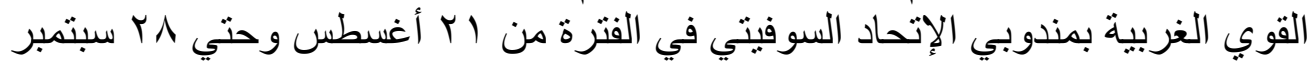

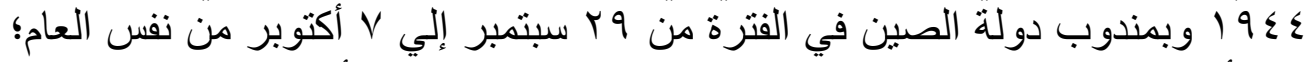

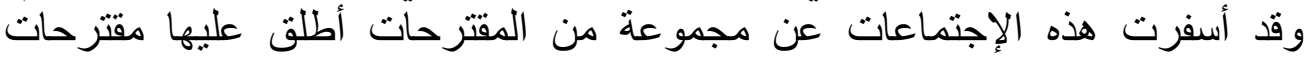

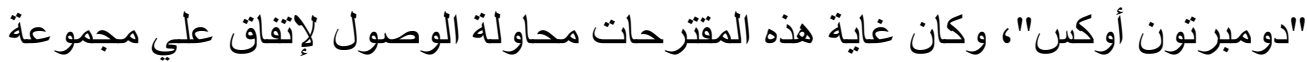

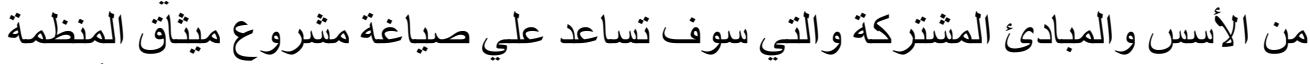

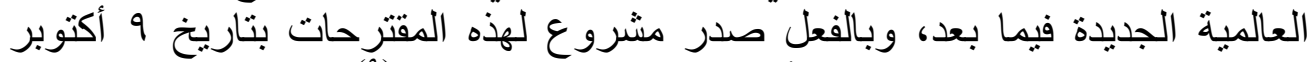

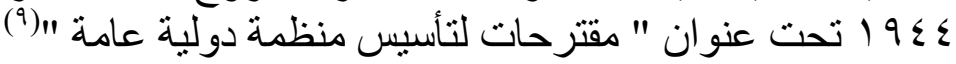

(Proposal For Establishment of General International Organization)

\section{وقد تضمن هذا المشروع مجموعة من المقترحات نوجزها في الآتي:}

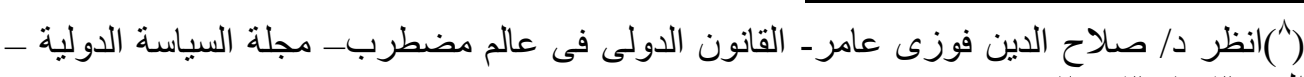

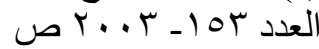
(") دا عثمان عبد الرحمن إبر اهيم- دور الأمم المتحدة المعاصر وفاعلية تنفيذ قرار ات مجلس الأمن

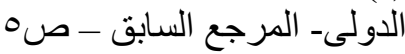


تأسيس هيئة دولية جديدة تعرف بأسم " الأمم المتحدة " تهدف إلي حفظ السلم

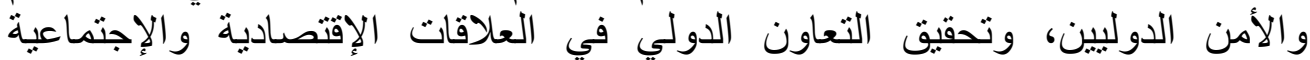

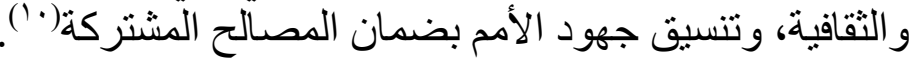

وتناول المشروع مجموعة من المبادئ التي يجب أن تقوم عليها المنظمة الدولية

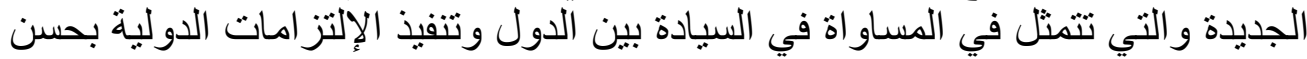

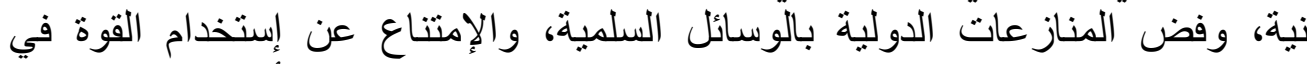

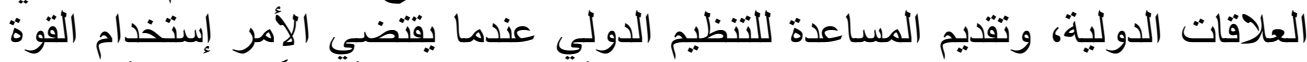

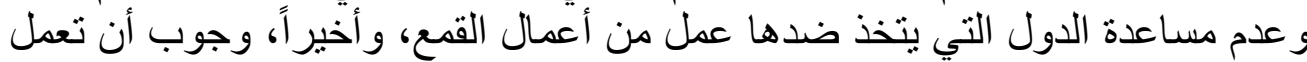

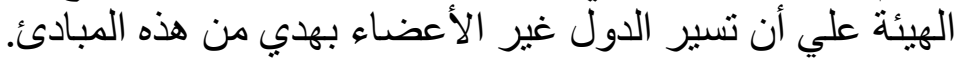
وقد تناول المشروع أيضاً ضرورة أن تتألف المنظمة الدولية الجديدة من عدد من الأجهزة الرئيسية علي النحو التالي:

جمعية عامة: تتولي مناقثة المسائل الخاصة بحفظ السلم و الأمن الدوليين بالإضافة إلي قيامها بدعم الأنشطة و التعاون الإقتصادي و الإجتماعي.

مجلس أمن: ويعهد إليه بمهمة أساسية تتمثل في المحافظة علي السلم و الأمن الدوليين،

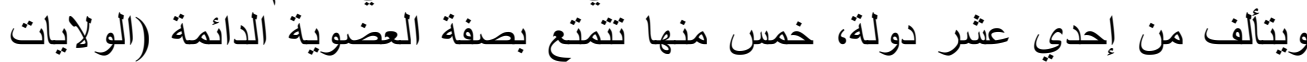

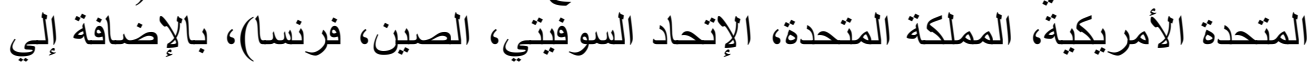

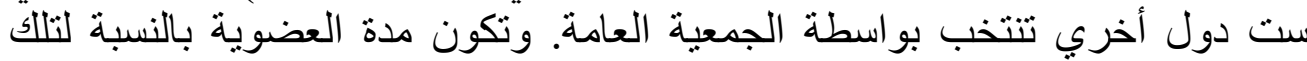

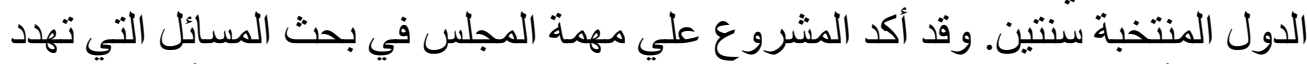

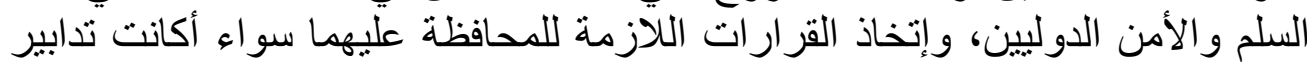
عسكرية أم غير عسكرية'(1') الأن

ولم يتضمن المشروع المذكور بعض المسائل المهمة ومنها علي سبيل المثنال

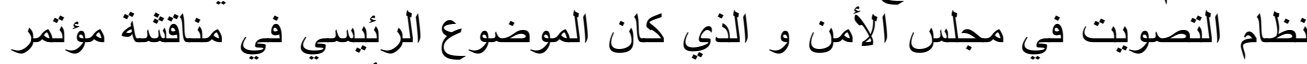

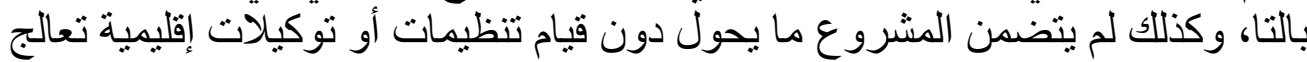

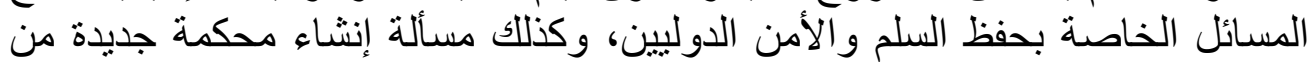
عدمه (Ir)

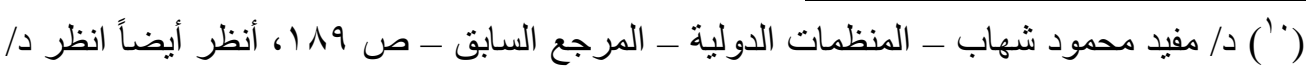

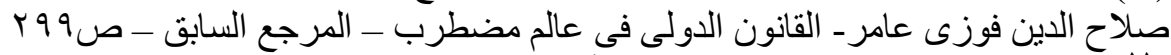

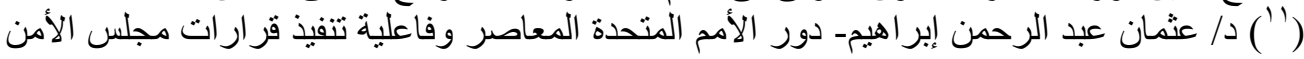

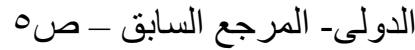

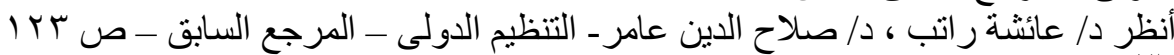

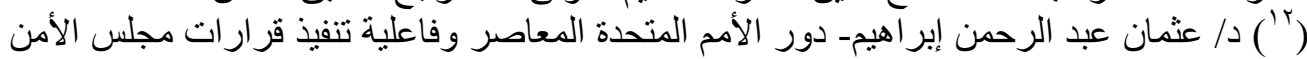

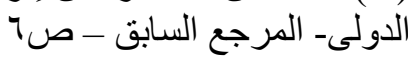


وقد أتت المرحلة الثالثة بخطوة رئيسية ومهمة في طريق إنشاء وتأسيس المنظمة

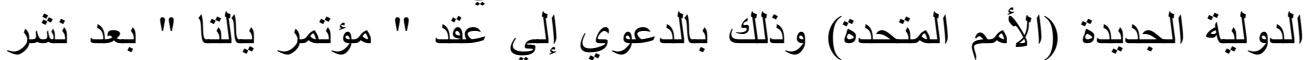

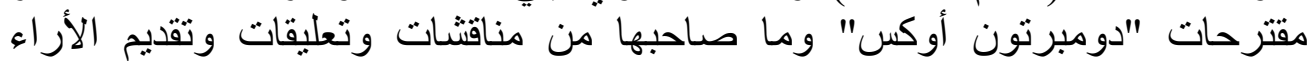

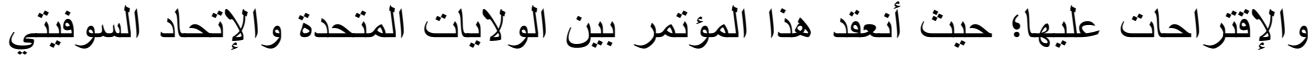

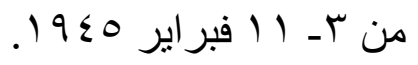

ودارت العديد من المناقثات بين ممثلي تللك الدول والتي تمثل أهمها في محاولة

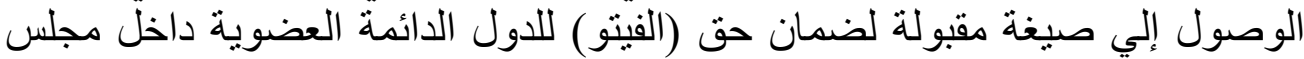

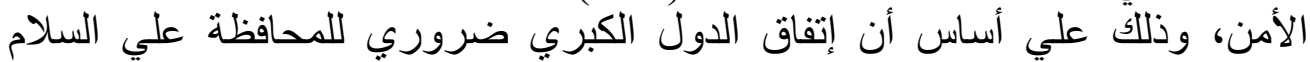

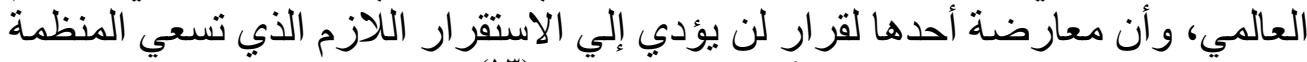

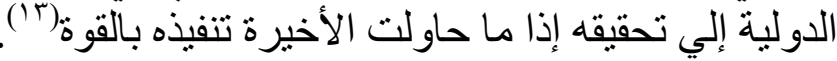

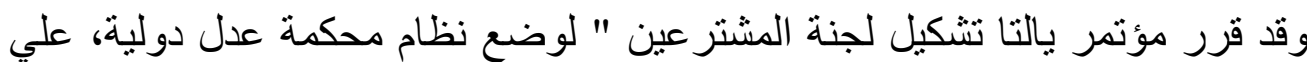

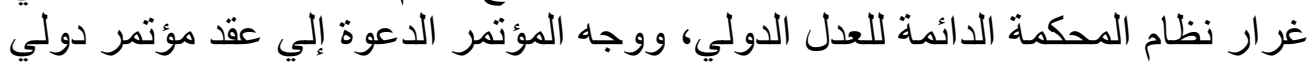

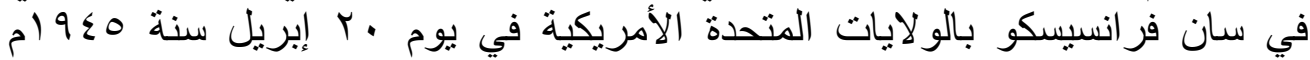

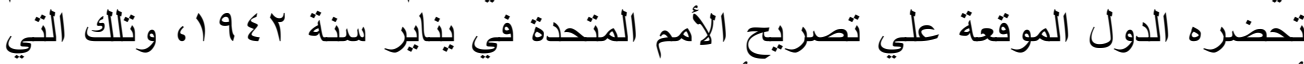

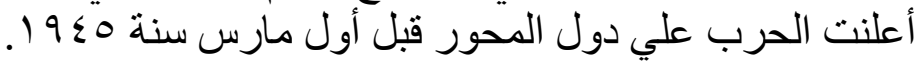

وجاءت المرحلة الر ابعة والأخيرة لفكرة إنشاء وتأسيس الأمم المتحدة بإنعقاد

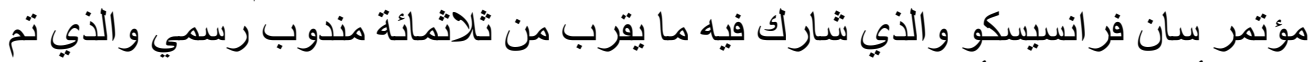

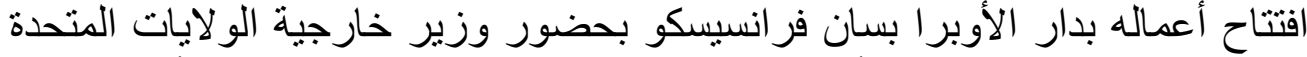

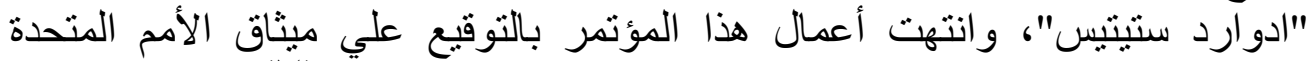

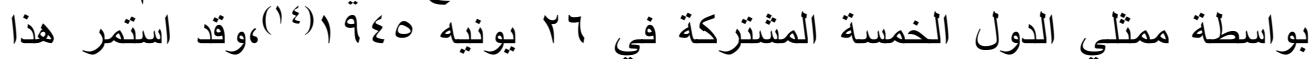

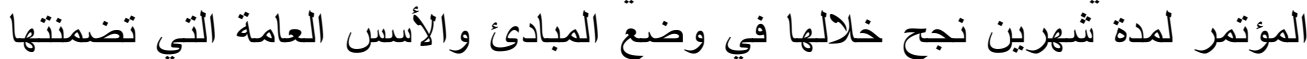

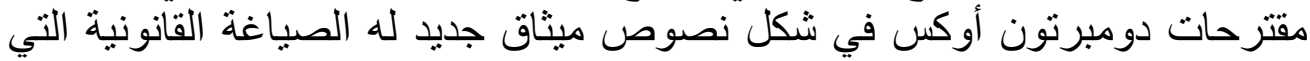

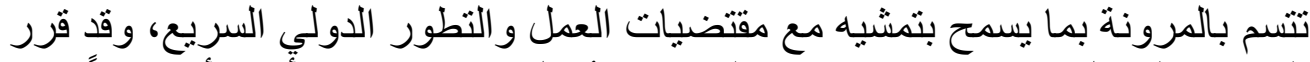

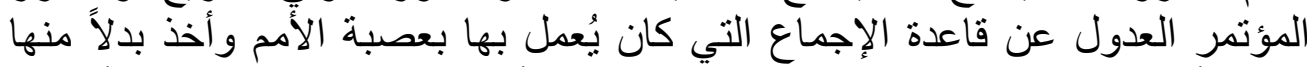

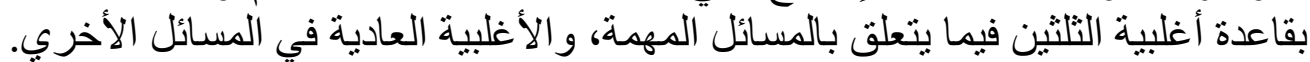

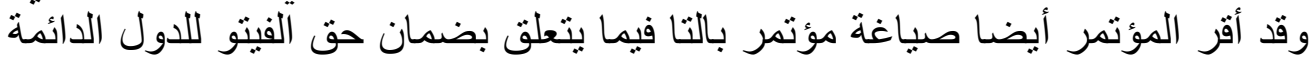
بمجلس الأمن(10) - (10).

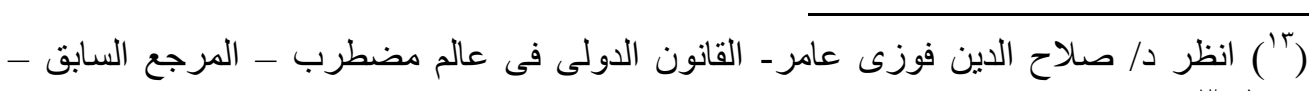

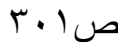

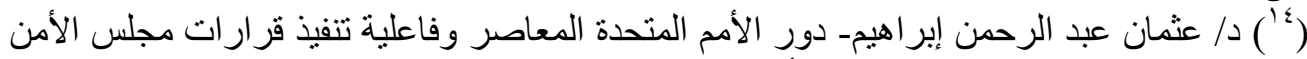

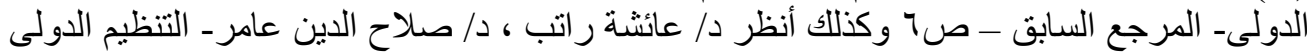

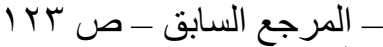

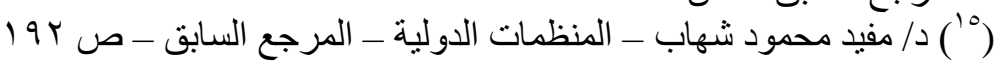


وقد وضع مؤتمر سان فرانسيسكو ترتيبات موفقة منها، إنشاء لجنة تحضيرية

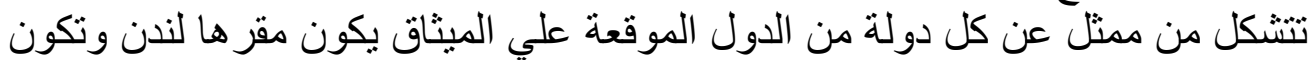

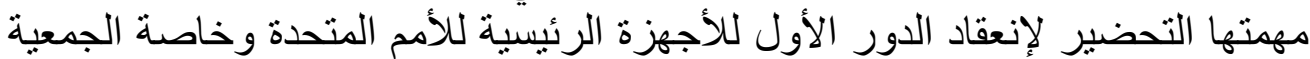

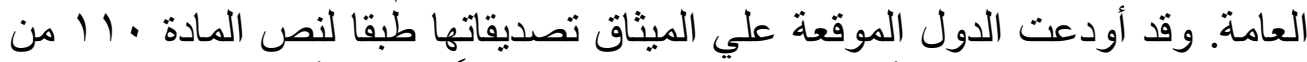

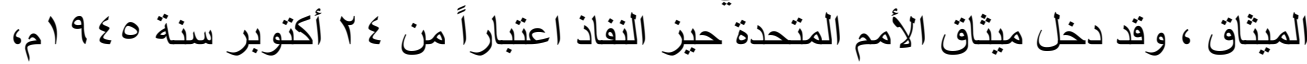

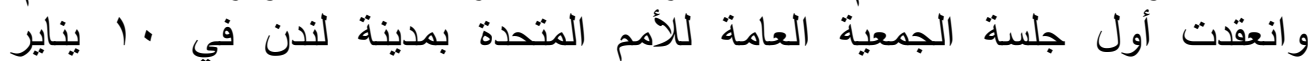
(1) (1) $19 \leq 7$

\section{المطلب الثاني

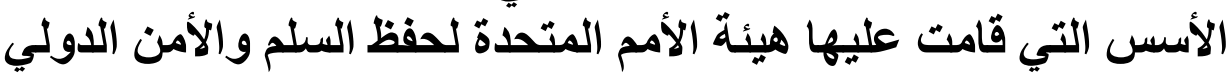

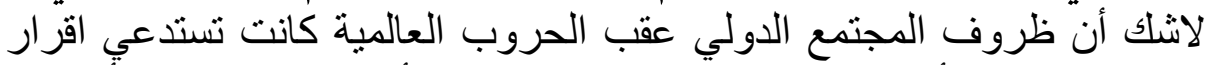

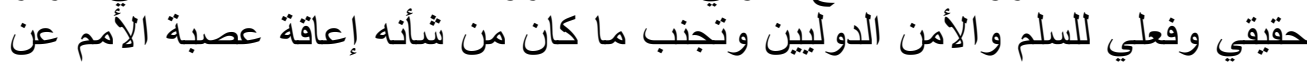

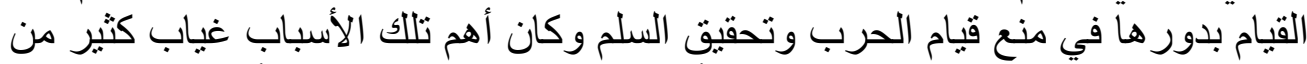

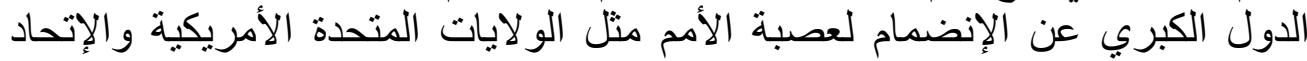

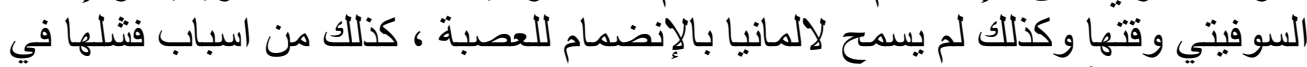

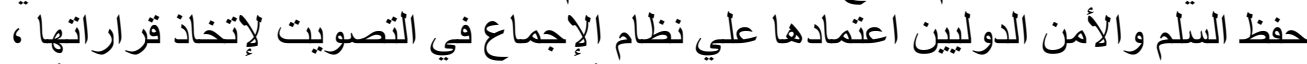

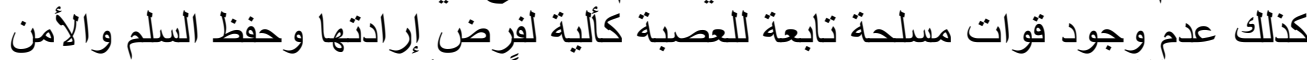

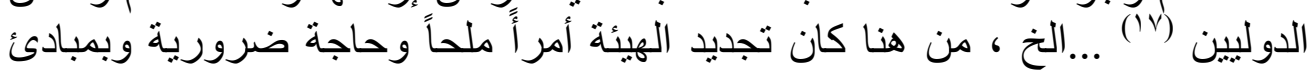

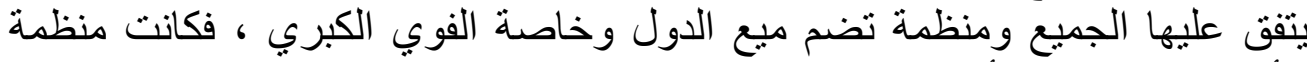
الأمم المتحدة والتي تأسست ودخل ميثاقها حيز النفاذ في اكتوبر عام

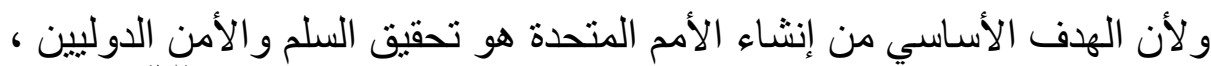

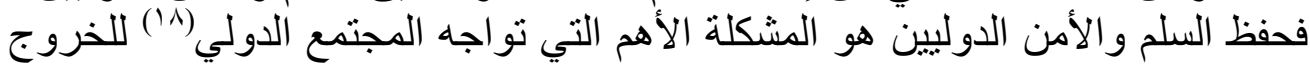

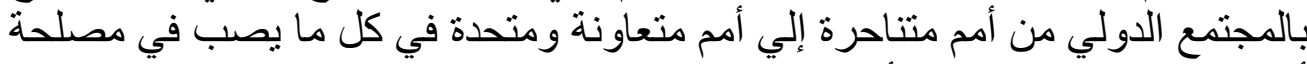

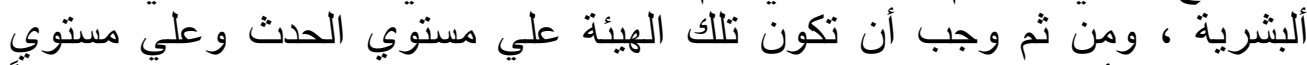

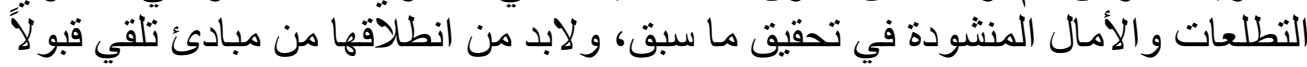

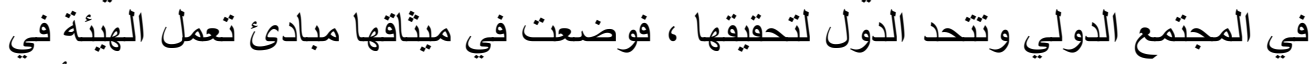

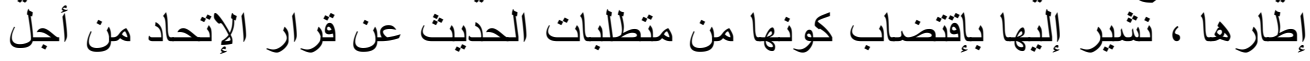

("أ) د/ عثمان عبد الرحمن إبر اهيم- دور الأمم المتحدة المعاصر وفاعلية تنفيذ قرارات مجلس الأمن

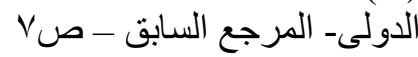
${ }^{17}$-Aspect du systeme des Nations- unies dans Le cadre d,un nouvel ordre mondial(1991) et actualite des conflits internationaux (1992),colloques organises,par L,I.E.p. d,Aix en provence ,pedone ,paris,1991et1992

(1) (1) د/ محمد وليد عبدالرحيم- الأمم المتحدة وحفظ السلم والأمن الدوليين_المكتبة العصرية للطباعة 


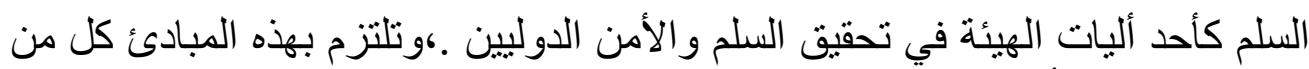

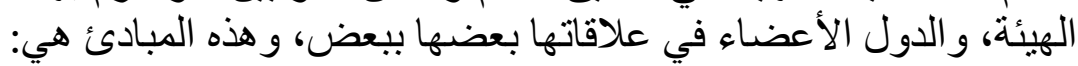

\section{1- مبدأ المساواة في السبادة(9) :}

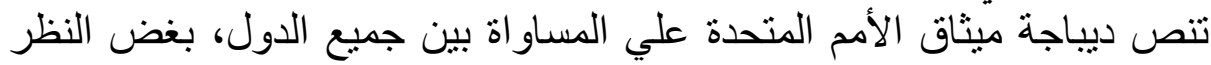

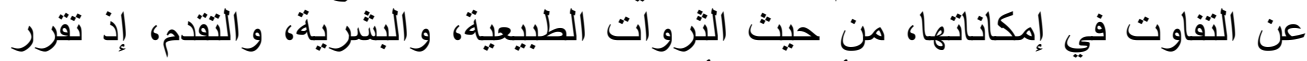

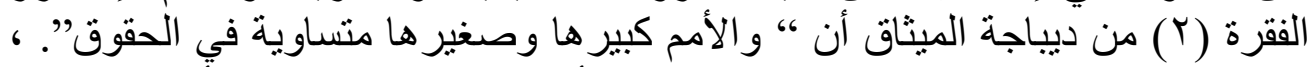

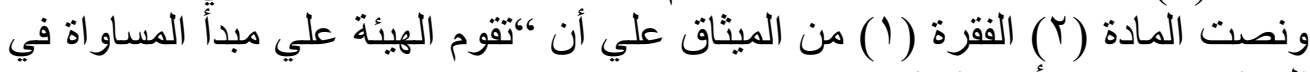
السيادة بين جميع أعضائها”.

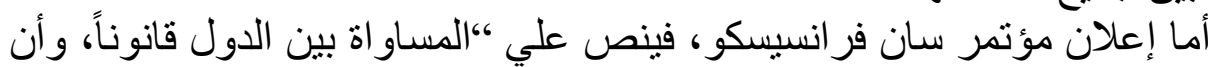

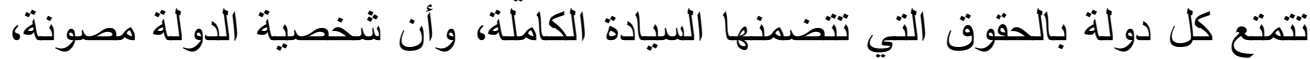

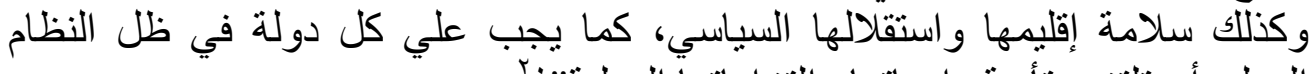

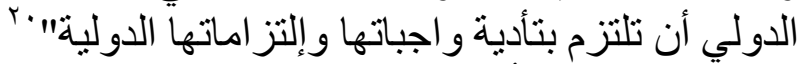

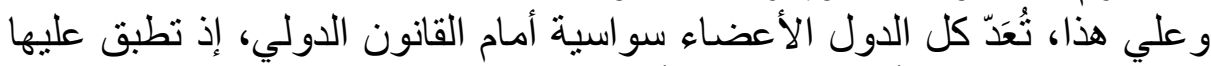

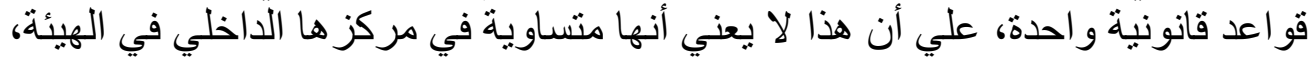

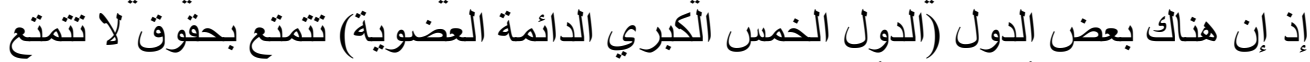

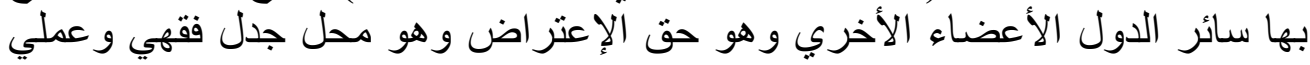

\section{r - كبيرين مبأ فض المناز عات الدولية بالطرق السلمية:}

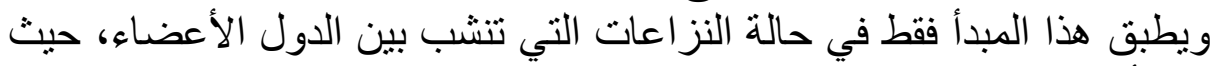

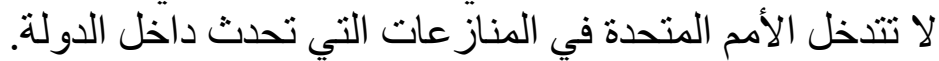

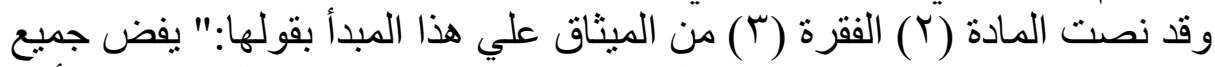

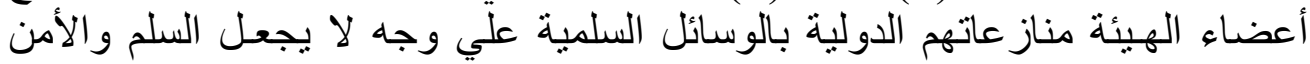

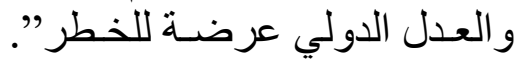

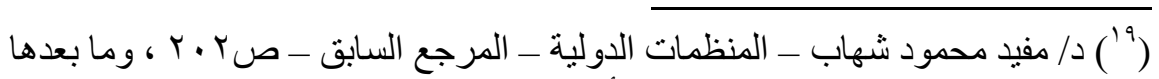

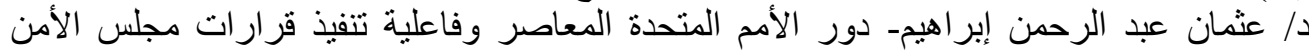

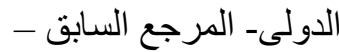

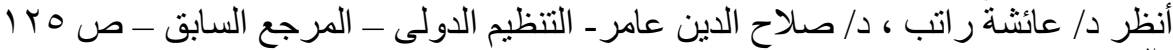

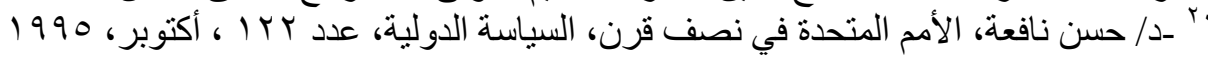




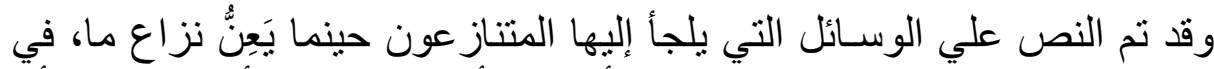

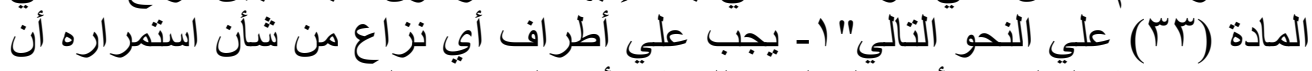

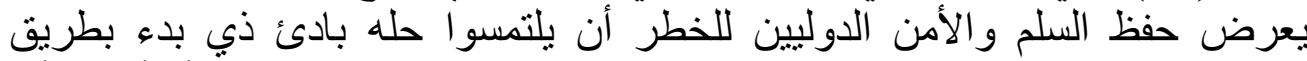

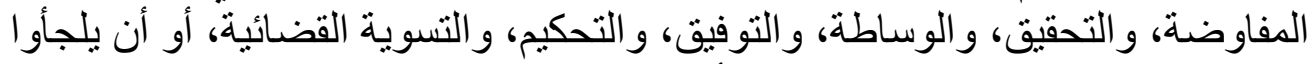

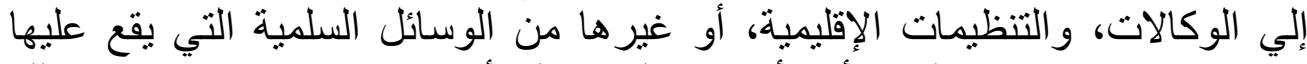

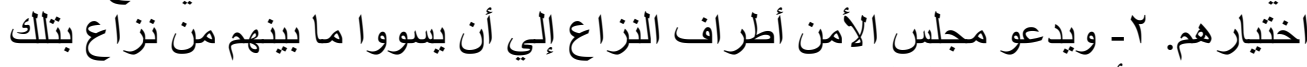

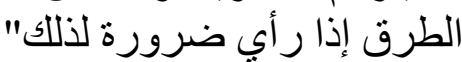

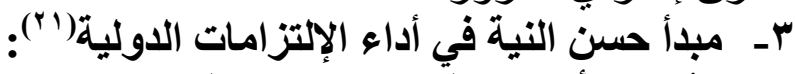

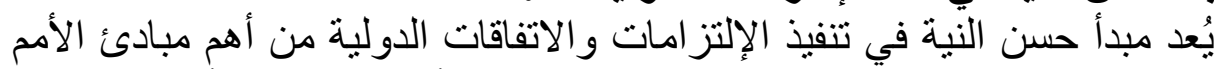

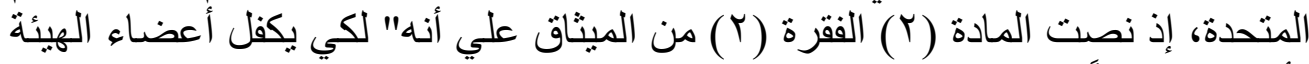

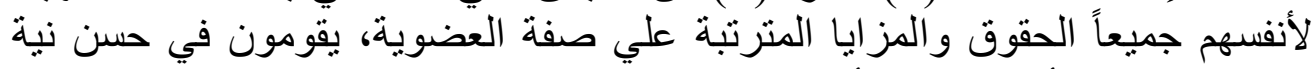

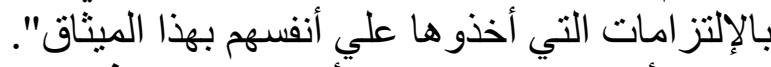

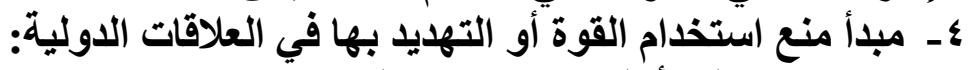

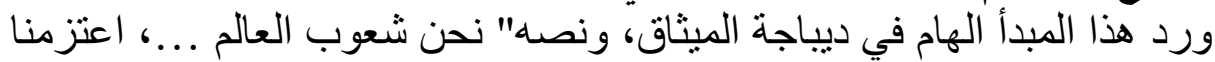

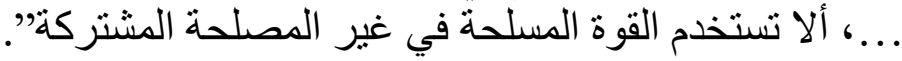

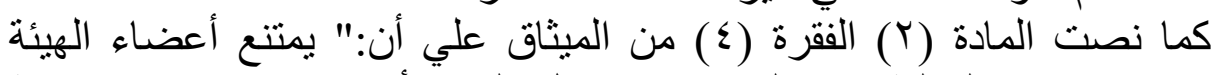

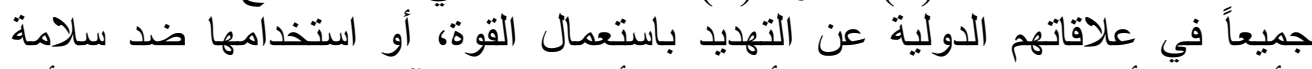

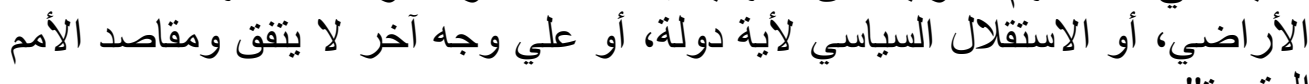

إلا أن الميثاق ترك لمجلس الأمن أن يقرر استخدام القوة في حل المنازعات

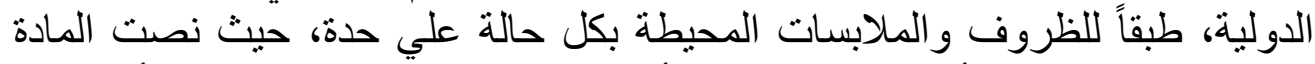

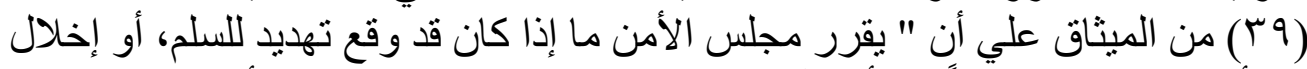

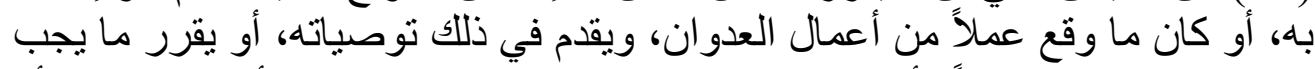

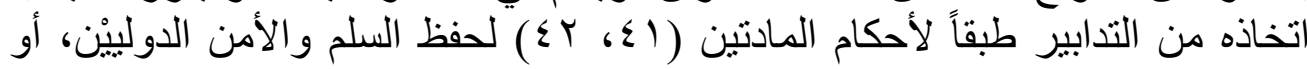

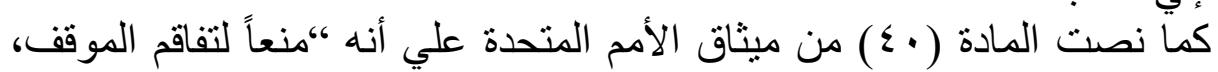

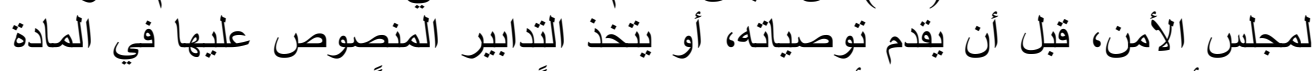

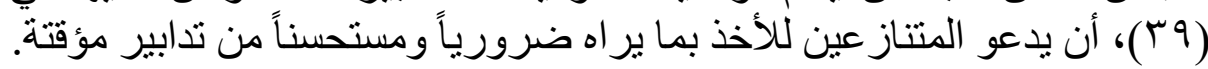

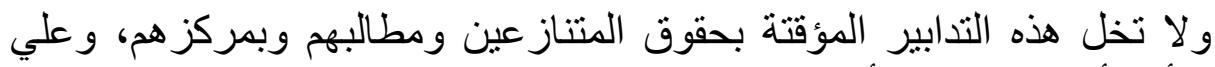

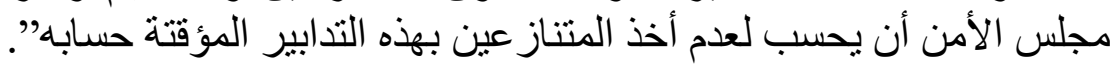

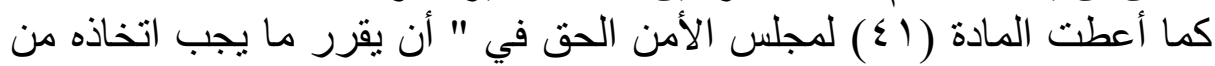

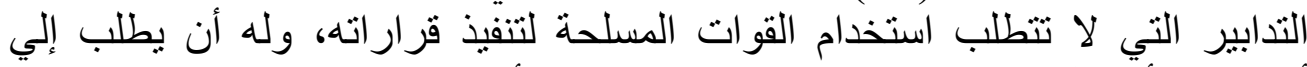
أعضاء الأمم المتحدة تطبيق هذه التدابير، ويجوز أن يكون من بينها وقف الصلات بلات

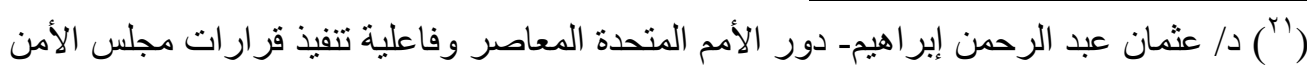


الاقتصادية و المواصلات الحديدية و البحرية و الجوية و البريدية و البرقية و اللاسلكية

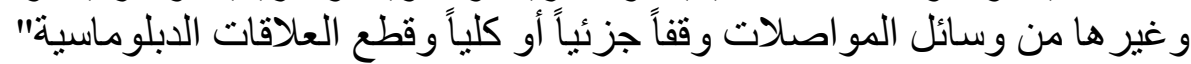

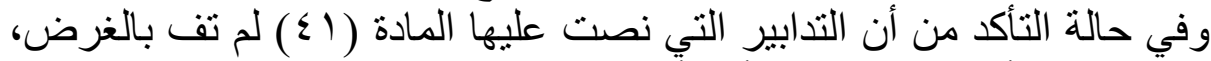

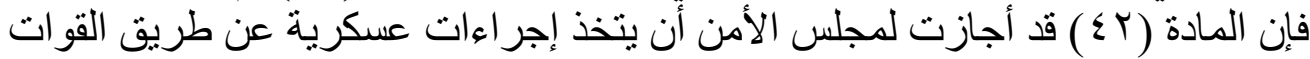

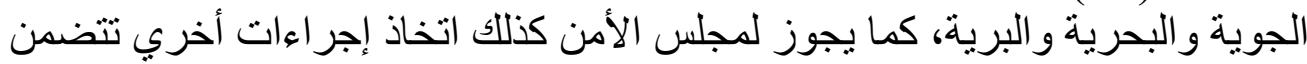
و علي الرغم من أن مبدأ منع استخدام القوة قد جاء ذكره في الديباجة، أباح ميثاق

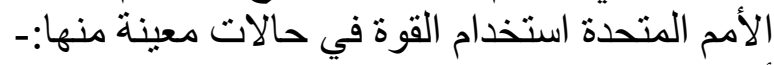

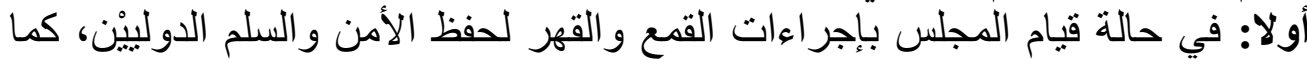

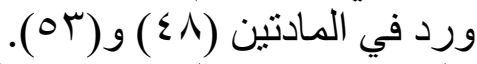

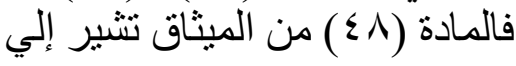

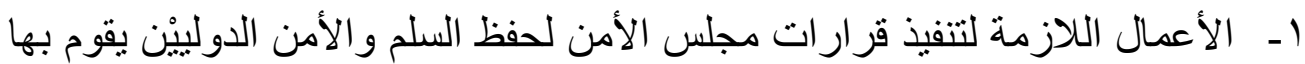

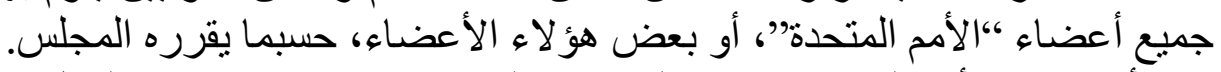

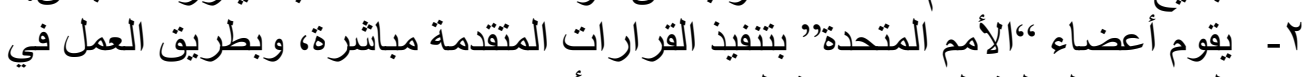

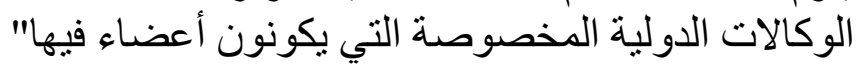

أما المادة (rه) الفقرة (1)، فقد سمحت لمجلس الأمن أن يستخدم التنظيمات

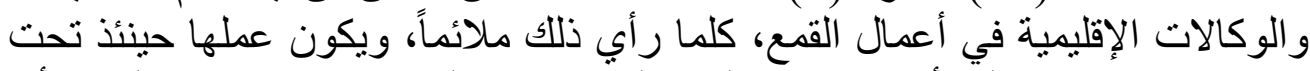

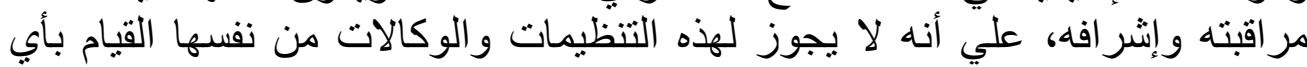

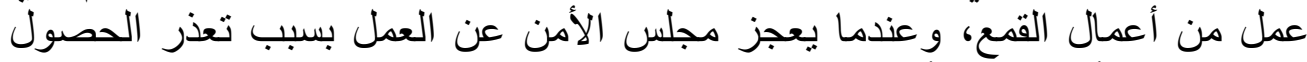

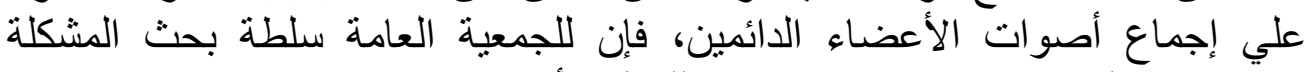

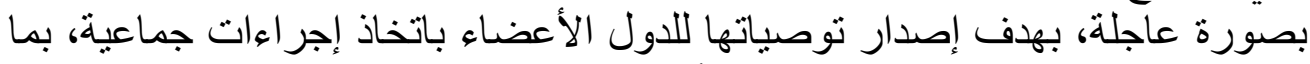

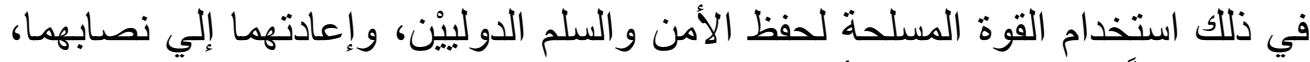

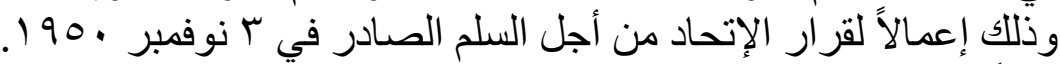

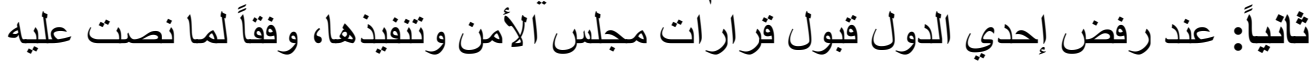

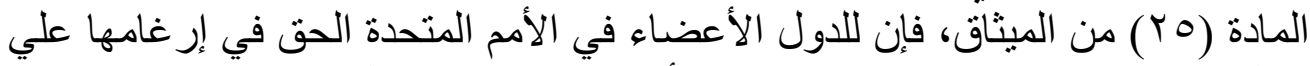

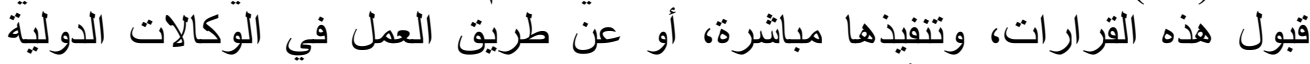
المخصوصة التي يكونون أعضاء فئنهاء فئها

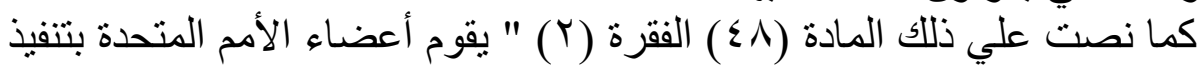

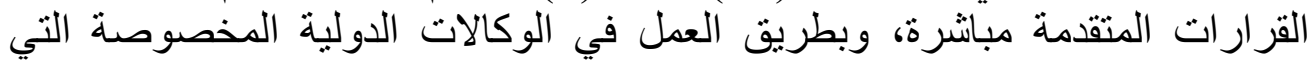

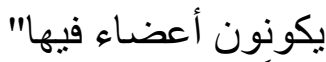

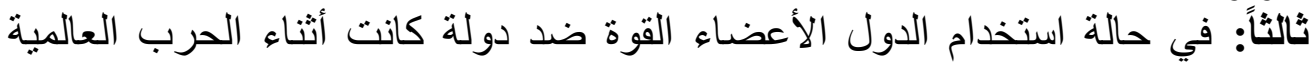
الثانية من الدول المعادية لإحدي الدول الأنان الموقعة علي الميثاق علي نحو ما نصت عليه

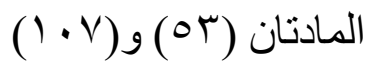


رابعاً: في حالة الدفاع الثرعي، وقد نصت عليه المادة (10 إن من الميثاق " ليس في هذا

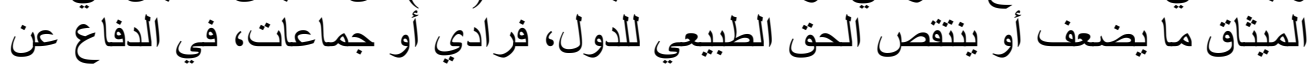

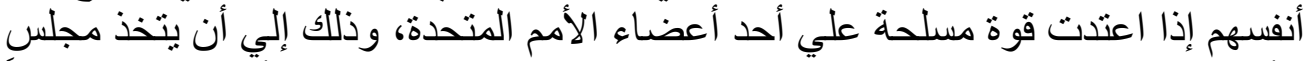

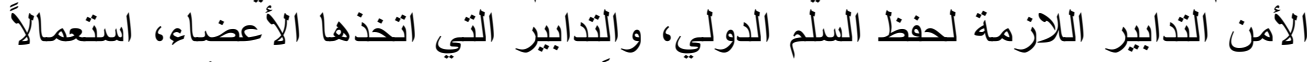

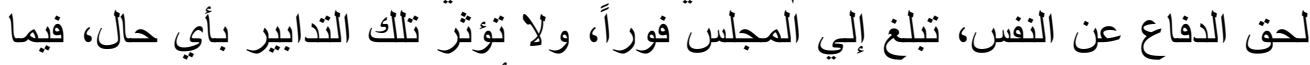

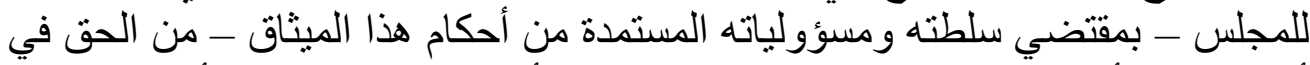

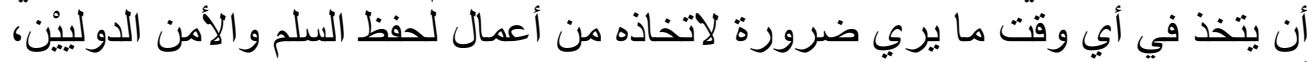
أو إعادته إلّي نُصابه. هـ مبدأ معاونة الأمم المتحدة في الأعمال التي تقوم بها، والامتناع عن مساعدة

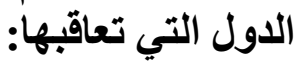

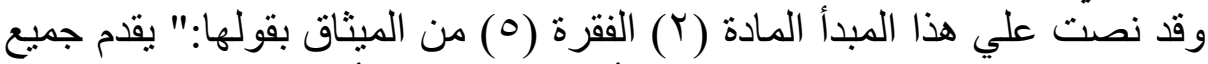

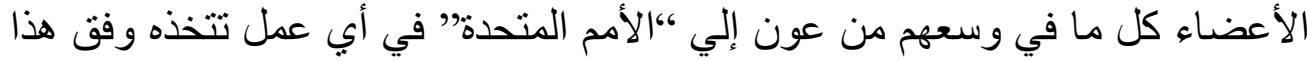

ويتضح من هذا المبدأ، ومن نص الميثاق أنه يتحتم علي الدول أن تلتزم إيجابياً

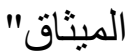

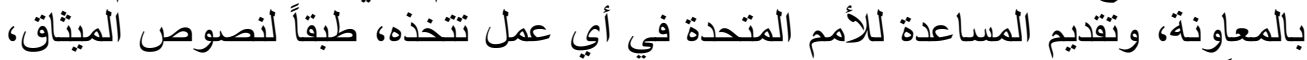

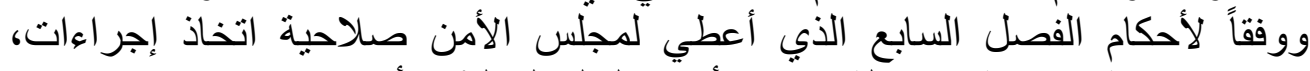

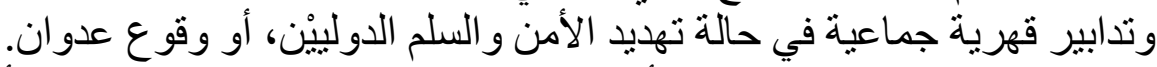

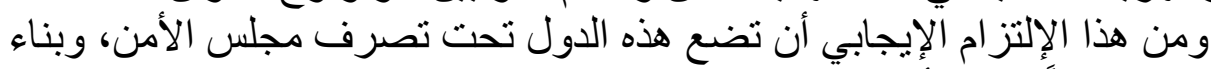

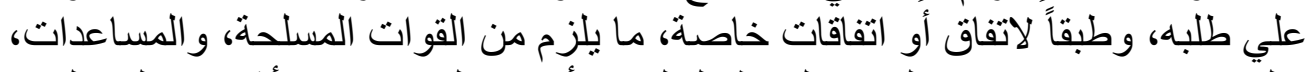

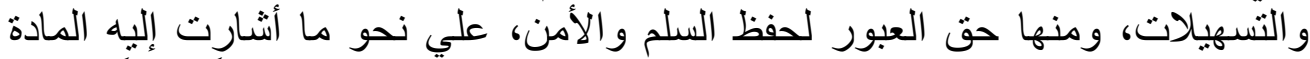

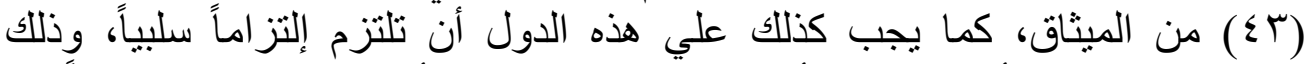

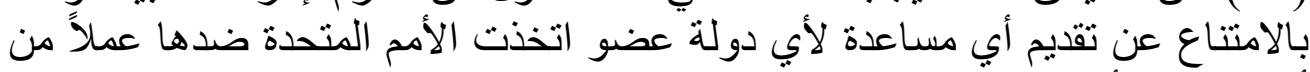

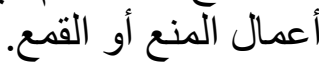

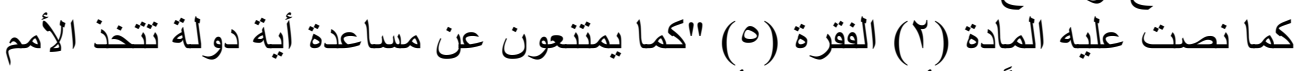

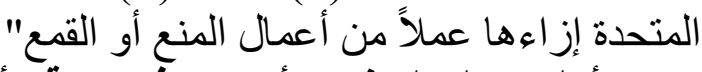

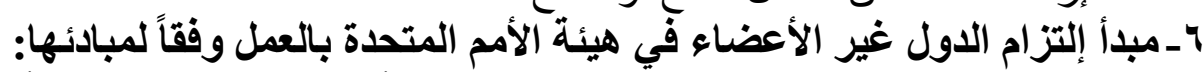

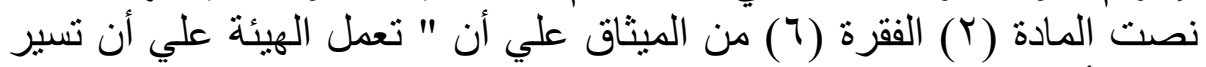

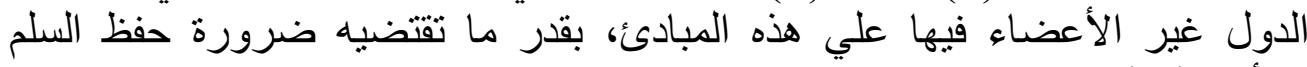

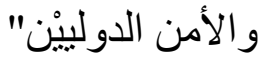

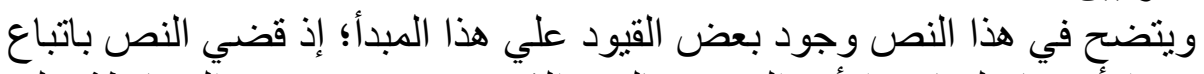

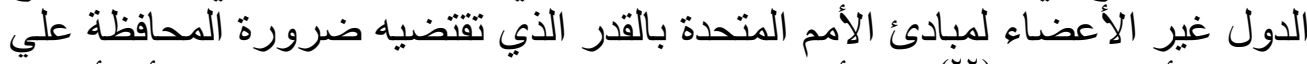

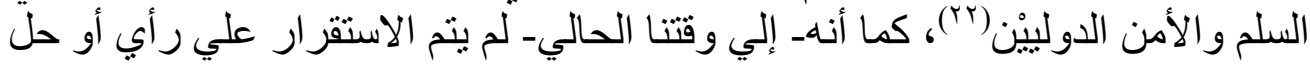

${ }^{(22)}$ Ray Murphy, Katarina Mansson, Peace Operations and Human Rights, First Published, Routledge , London , 2008 ,p47 


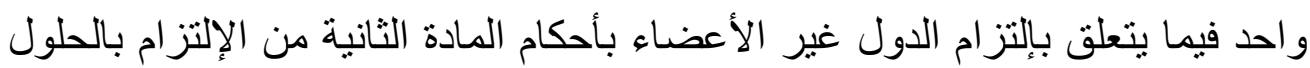

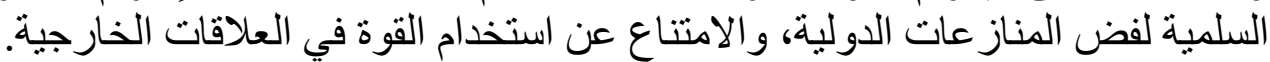

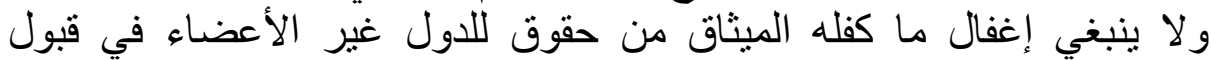

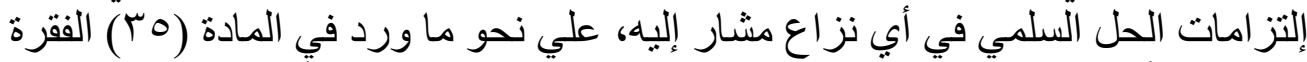

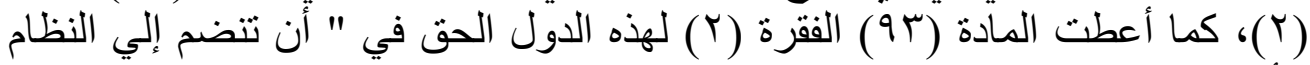

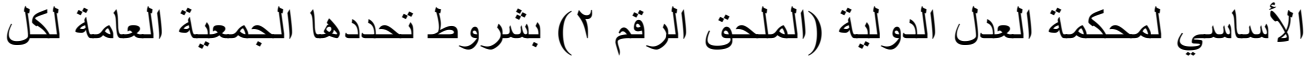
حالة بناء علي توصية مجلس الأمن الأنس

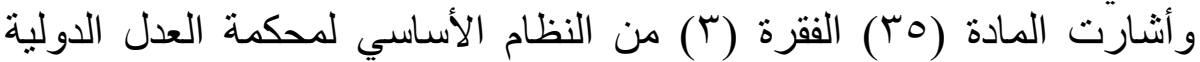

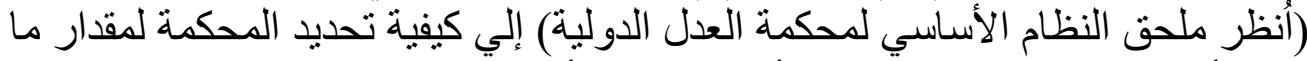

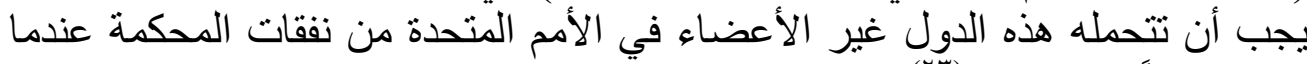

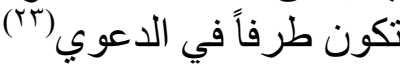

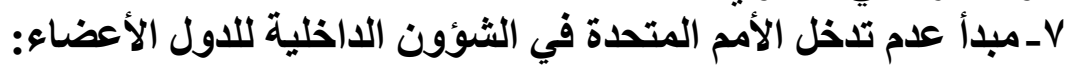

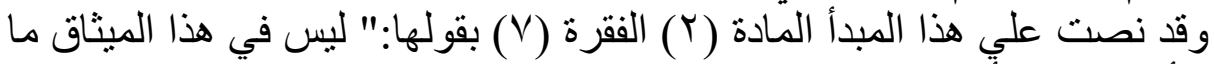

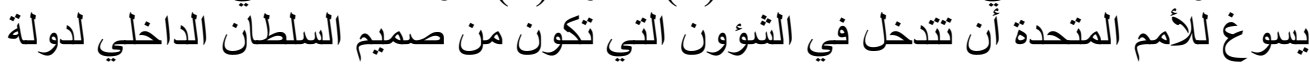

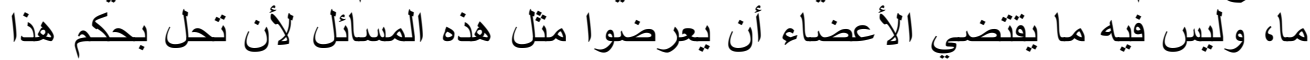

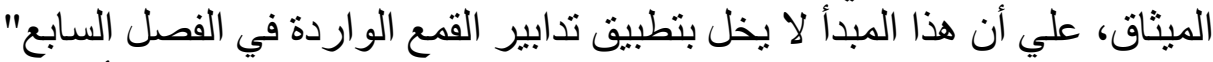

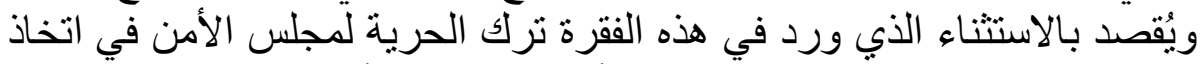

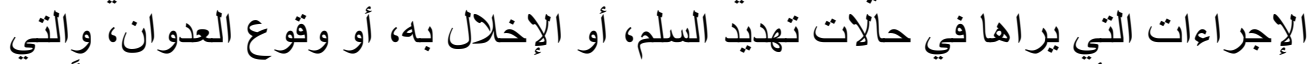

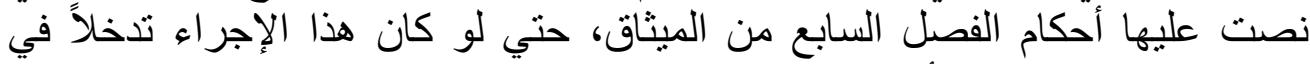
الثؤون الداخلية للاول النام الأعضاء.

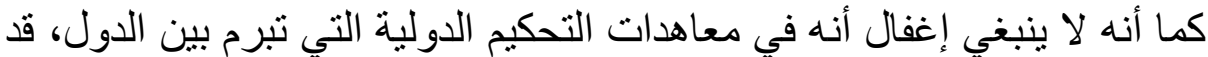

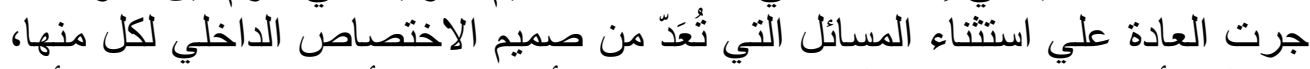

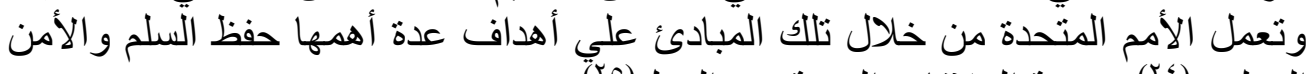

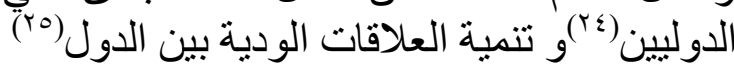
المطلب الثالث

\section{اختصاص مجلس الأمن بحفظ السلم والأمن الدولين}

دون (YT) رشيد مجيد محمد الربيعي، دور محكمة العدل الدولية في تفسيروتطبيق ميثاق الأمم المتحدة،

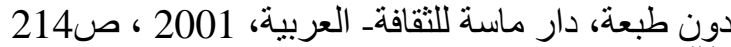

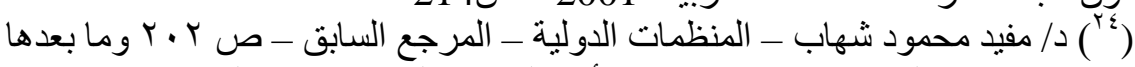

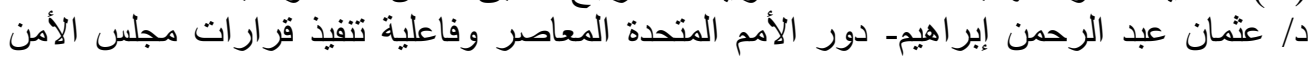

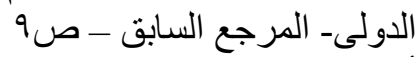

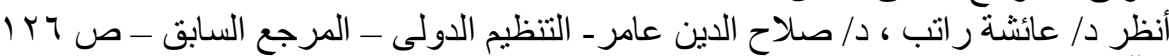

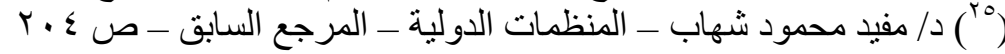

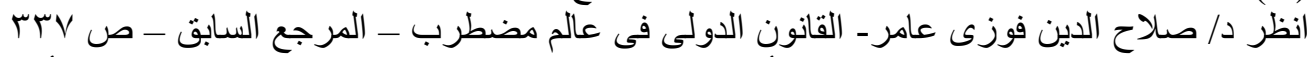

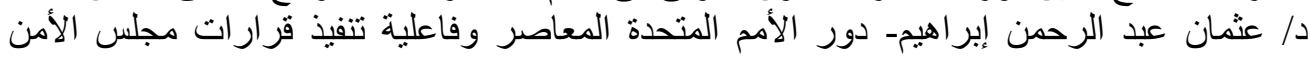
الدولى- المرجع السابق - صل الرحن إلير 
مجلس الأمن هو جهاز من أجهزة الأمم المتحدة وهو الأدابة التنفيذية للأمم

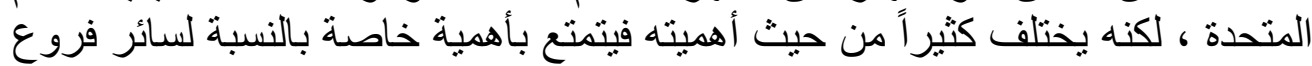

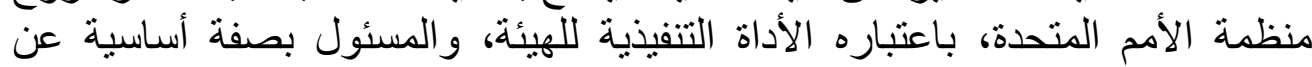

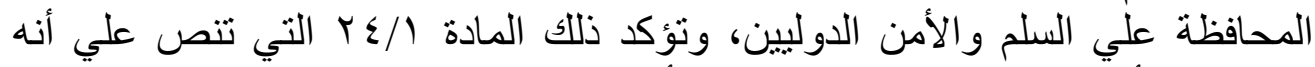

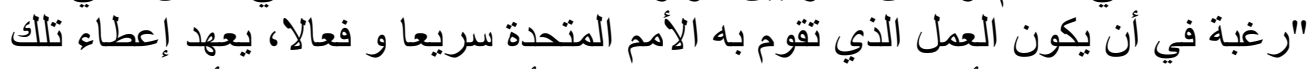

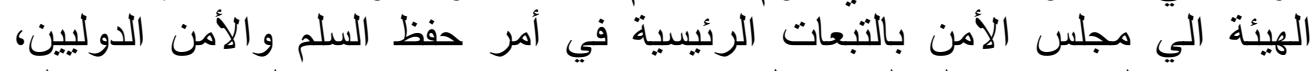

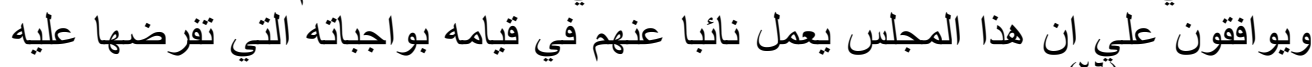

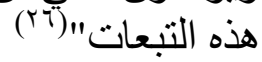

وطبقاً لذلك فإن مجلس الأمن يحمل وبصفة أساسية مسؤولية الدحافظة علي السلم

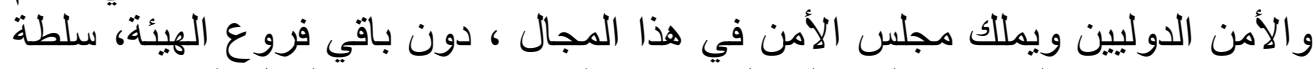

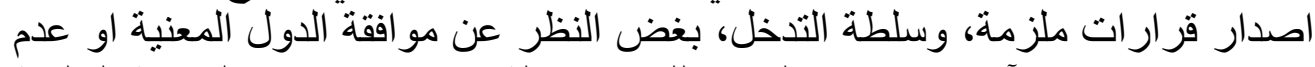

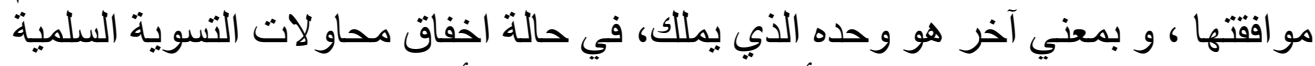

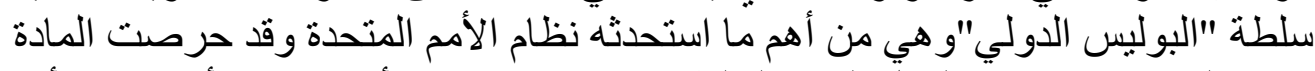

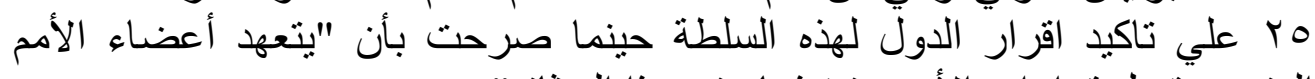
المتحدة بقبول قرار ات الأمن وتنفيذها وفق هذا الميثاق

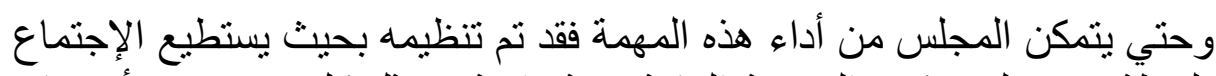

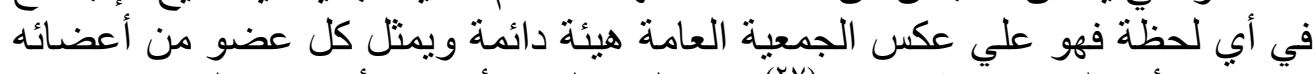

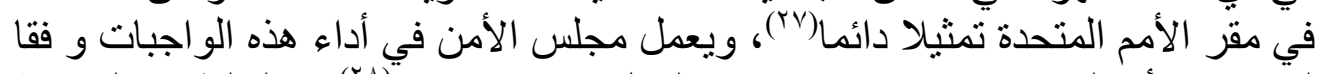

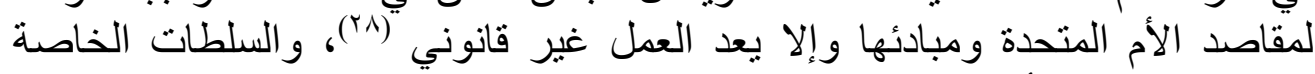

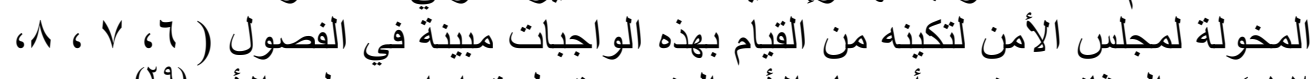

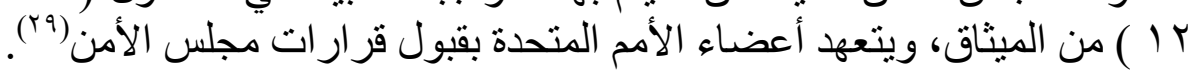

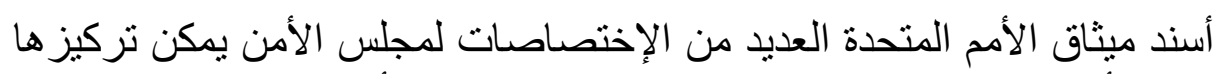

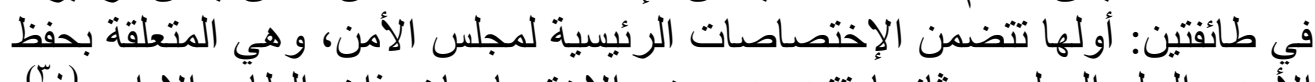

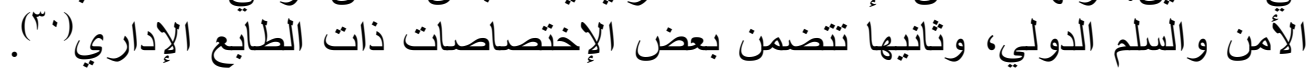

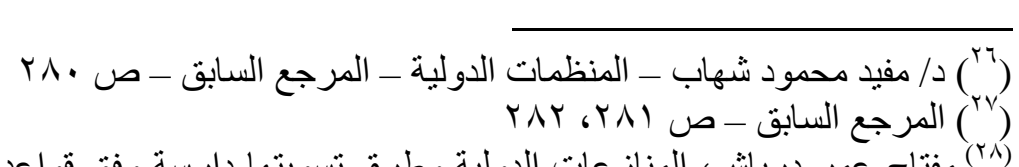

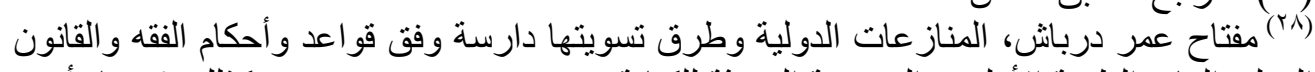

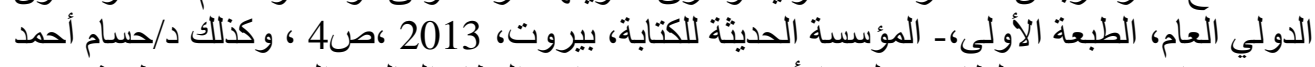

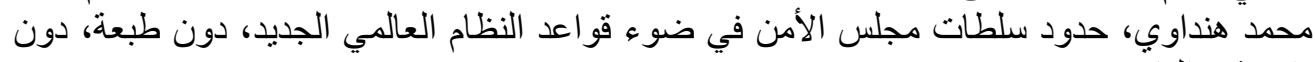

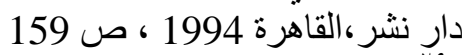

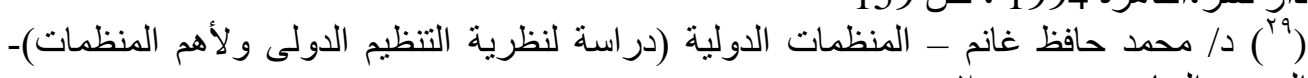

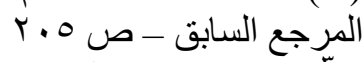

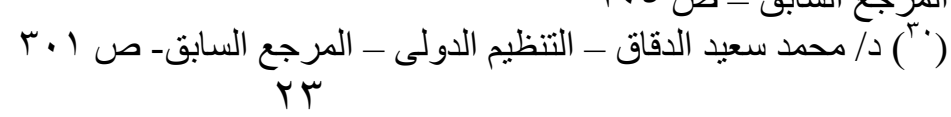


وسنذكر الإختصاص الأول والأهم لمجلس الأمن والذي يخدم بحثنا هذا، وهو الإختصاص بحفظ السلام و الأمن الدوليين. 


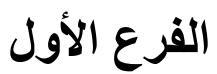

الإختصاص بحفظ السلام والأمن الاوليين طبقا للإصل السادس من الميثاق

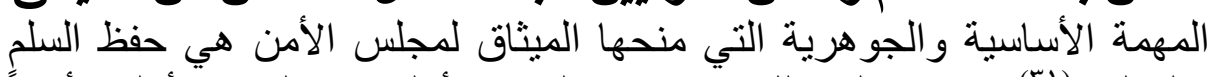

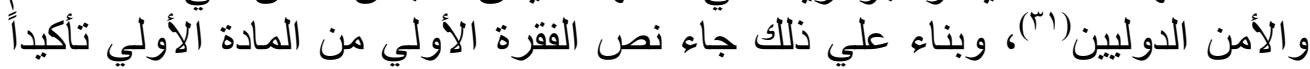

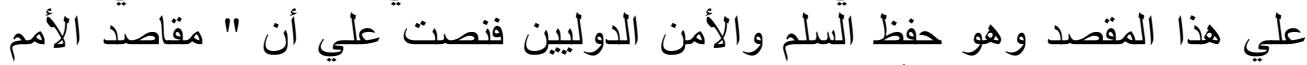

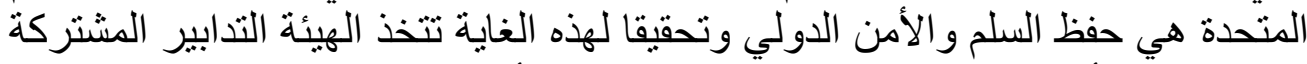

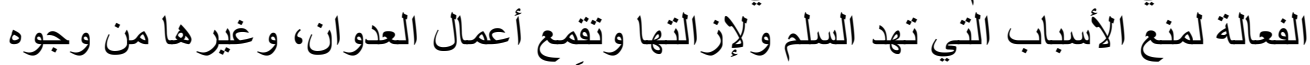

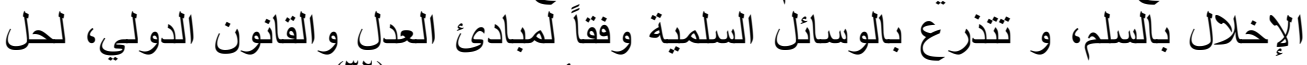

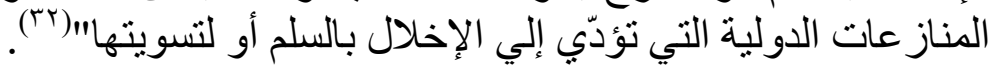

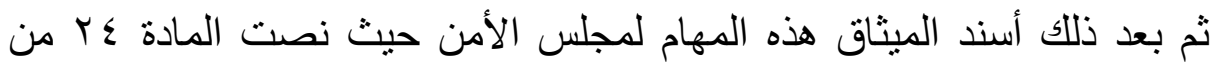

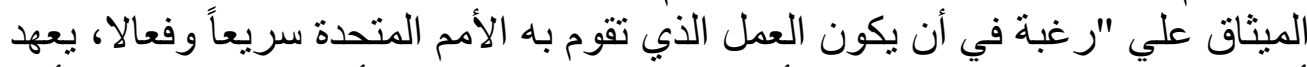

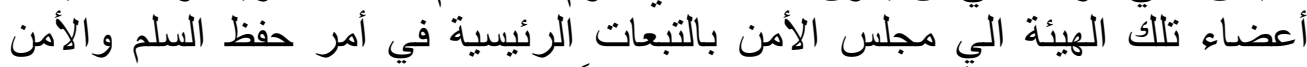

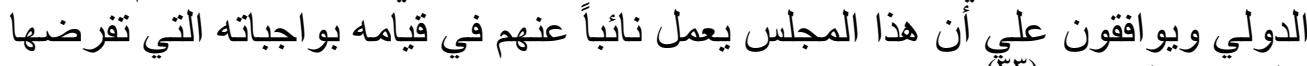
عليه هذه التبعات"(باتئ

و يمارس مجلس الأمن وظيفته في حفظ السلم و الأمن الدوليين من خلال نو عان

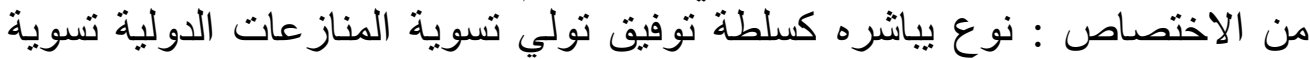

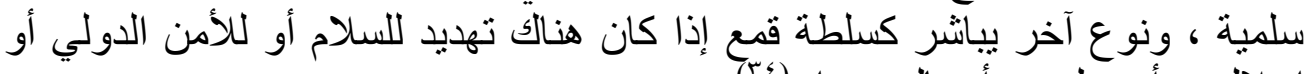

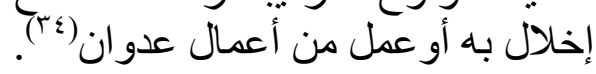

نظم الفصل السادس الأحكام الخاصة بتسوية المنازعات الدولية سلميا علي النحو الأتي

\section{أولاً: الجهات التي لها حق إخطار المجلس بوجود نزاع دولي}

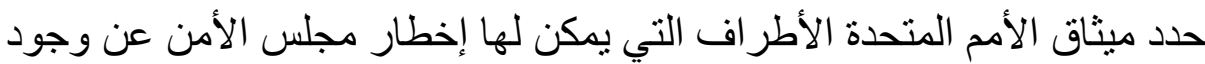

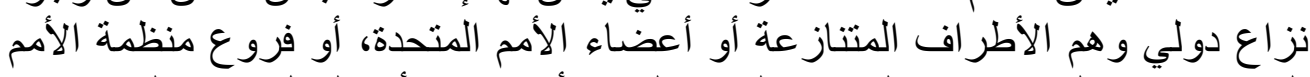

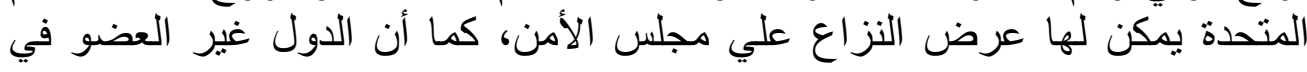

(31)» International Law as Language of International Relations « Abdelwahab BIAD, La Cour Internationale de Justice et le Droit International Humanitaire, Une Lex Specialis Revisitée par le Juge, Ed BRUYLANT, Bruxelles, Belgique, 2011, p 1

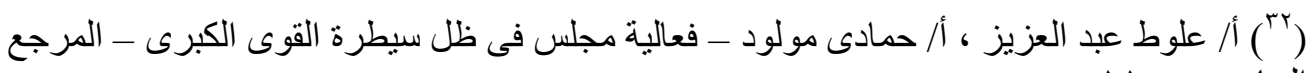

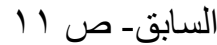

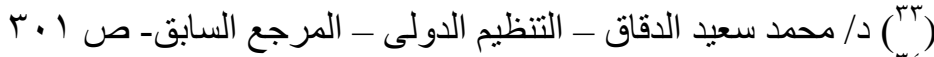

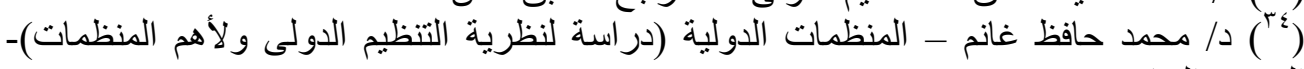


منظمة الأمم الدتحدة بمكن لها عرض النزاع بشرط قبولها للإلتزامات الدولية التي

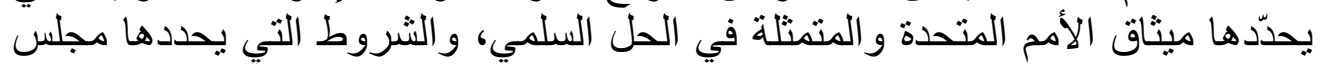

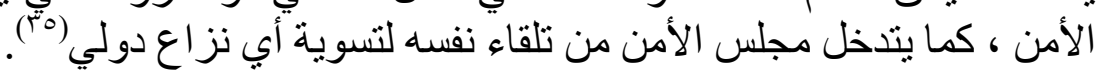

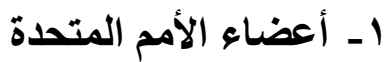

لكل دولة من أعضاء الأمم المتحدة أن تتبه مجلس الأمن إلي أى نزاع أو موقف

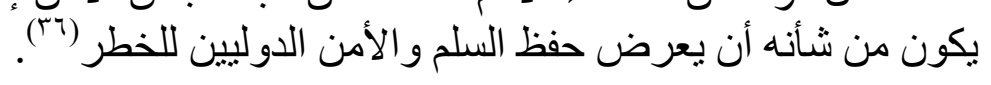

\section{r- الدول غير الأعضاء في الأمم المتحدة}

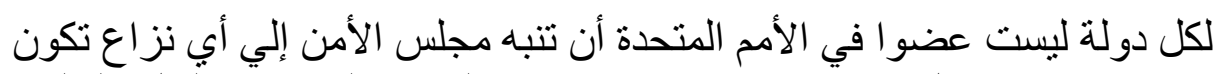

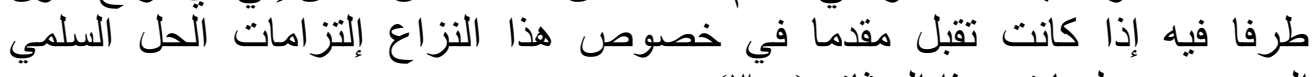
المنصوص عليها في هذا الميثاق (مثن)

وتتقدم الدولة أو الدول الثاكية بطلبها إلي الأمين العام للأمم المتحدة أو إلي رئيس

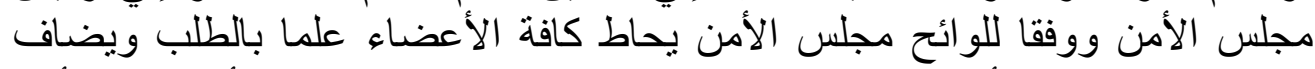

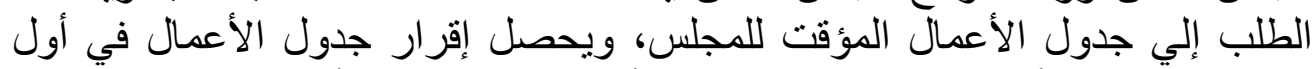

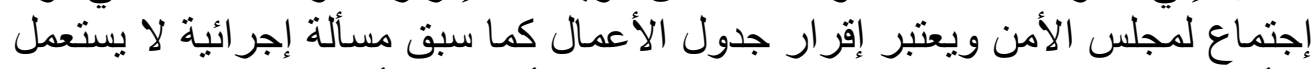

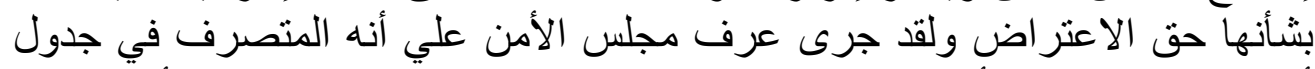

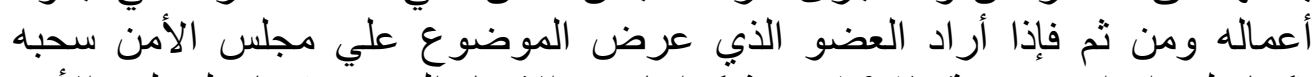

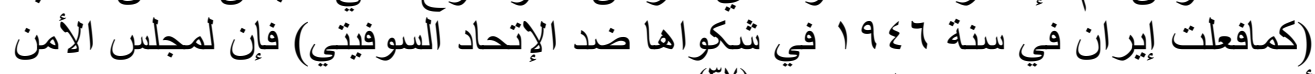

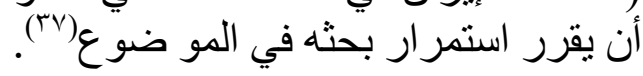

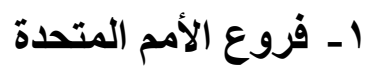

للأمين العام للأمم المتحدة وللجمعية العامة أن ينبه مجلس الأمن إلي أية مسألة

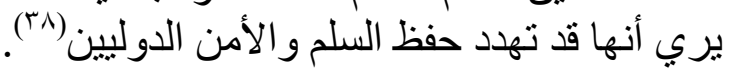

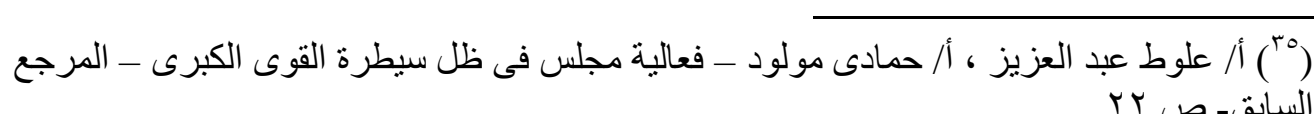

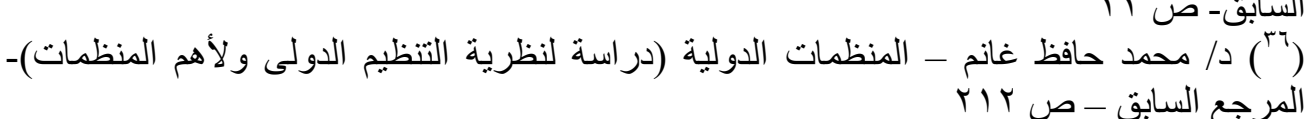

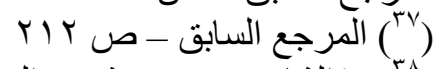

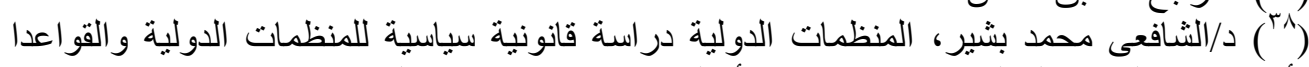
لأساسية في التنظيم الدولي، دون طبعة، منشأة المعارف بالإسكندرية، القاهرة ، 1970 ، ص235 الدية 


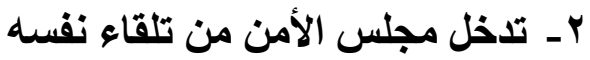

لمجلس الأمن أن يتدخل لفحص أي نزاع أو أي موقف قد يؤدى إلي إحتكاك

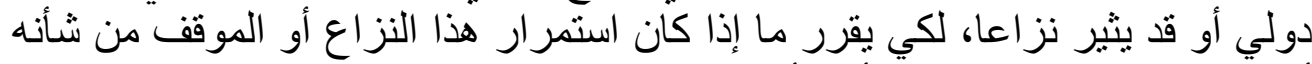
أن يعرض للخطر حفظ السلم أو الأمن الدوليين.

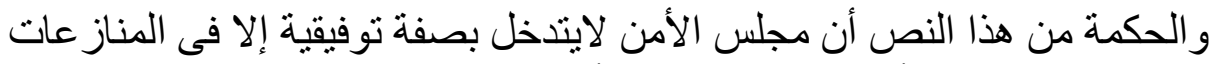

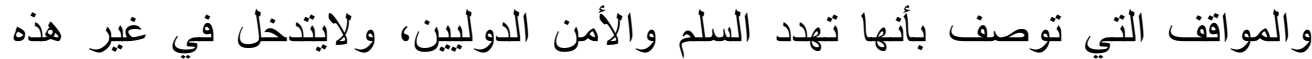

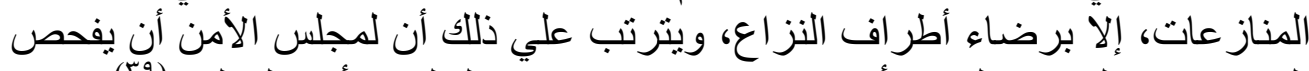

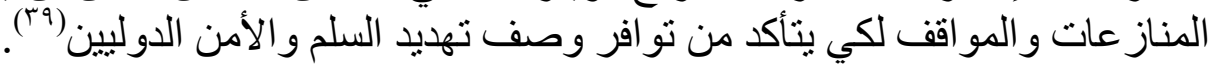

\section{ثنانياً: سلطات مجلس الأمن في التسوية طبقاً للفصل السادس}

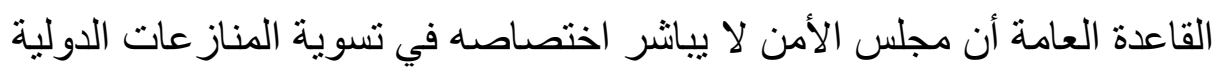

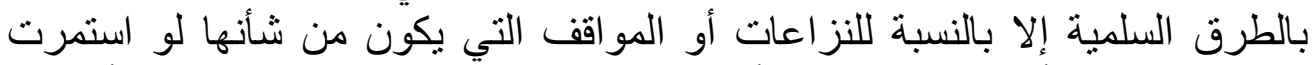

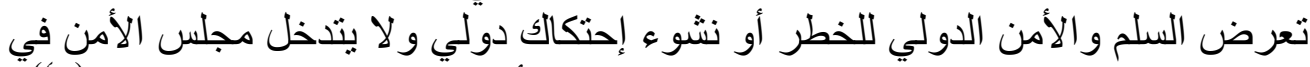

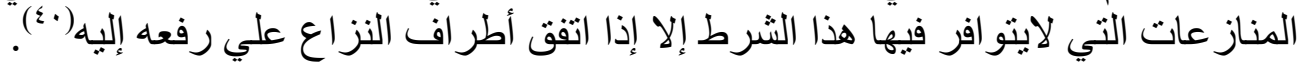

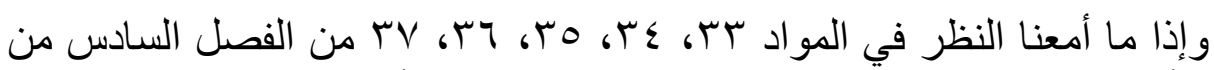

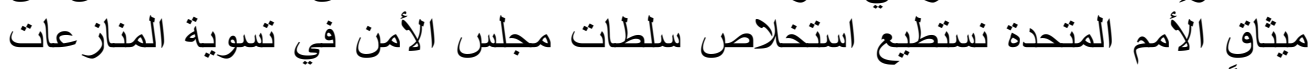

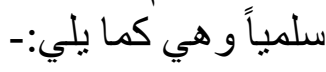

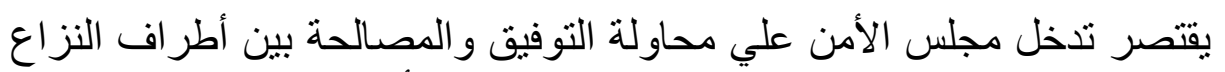

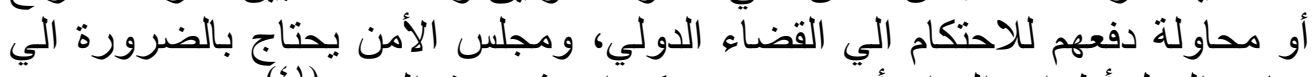

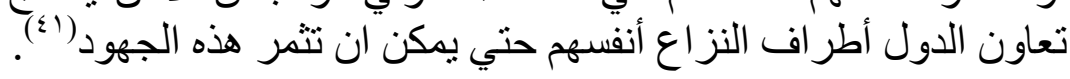

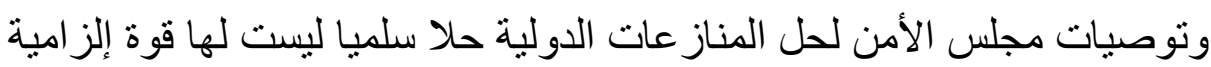

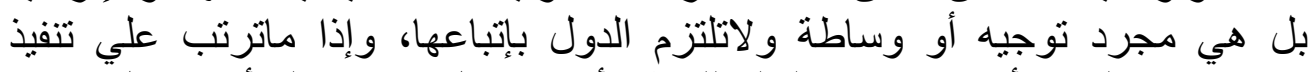

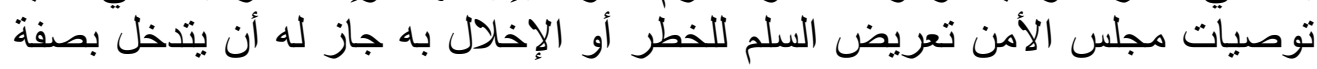

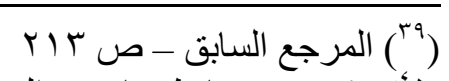

(") (") دا محمد حافظ غانم - المنظمات الدولية (دراسة لنظرية التنظيم الدولى ولأهم المنظمات)-

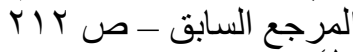

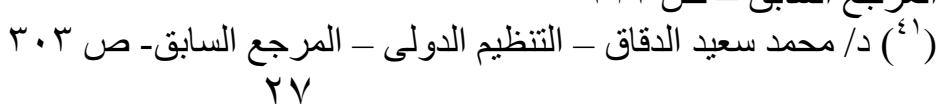




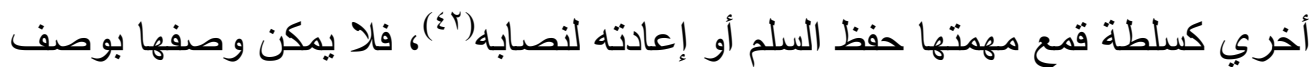

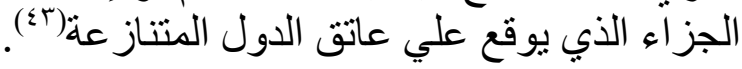

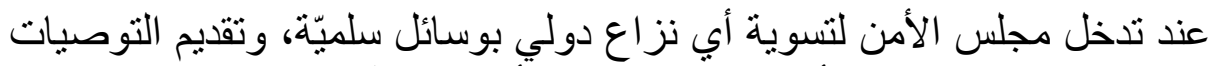

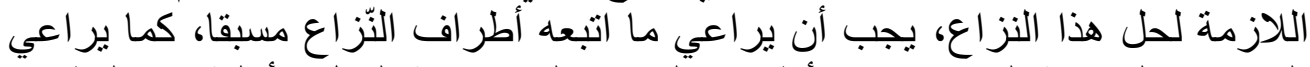

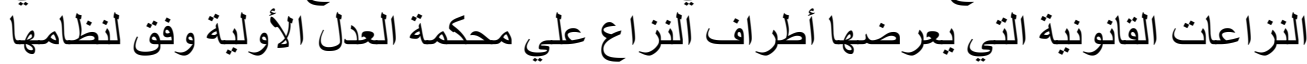

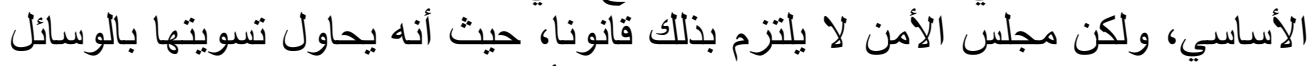

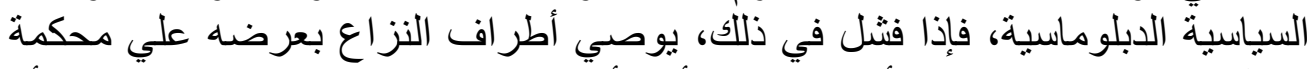

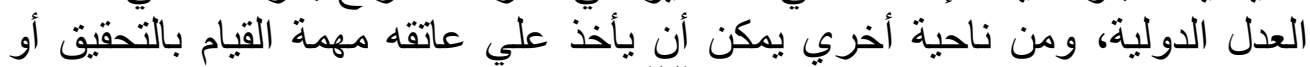

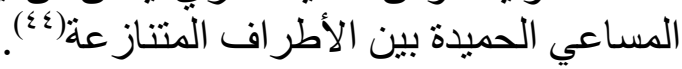

\section{وسائل حل المناز عات سلمياً : - (}

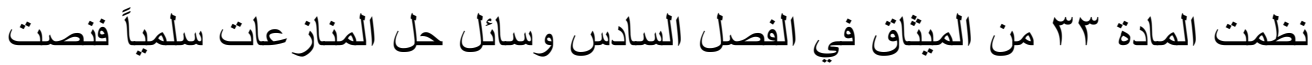

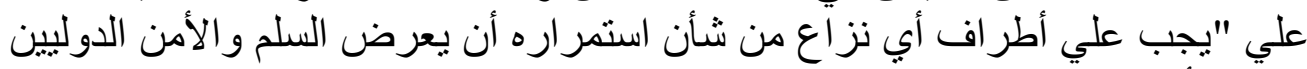

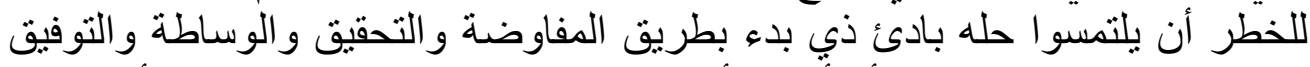

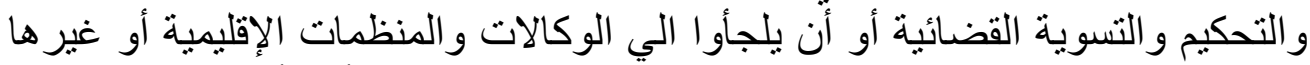

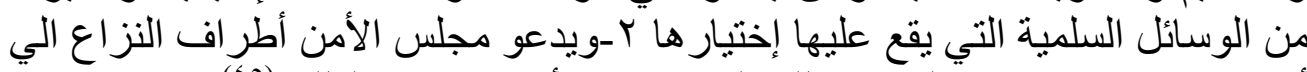

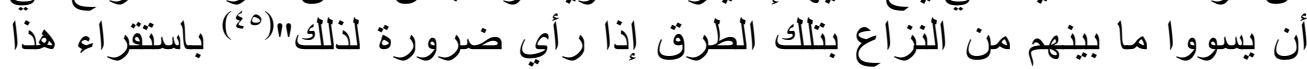

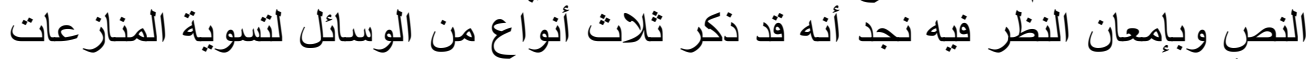

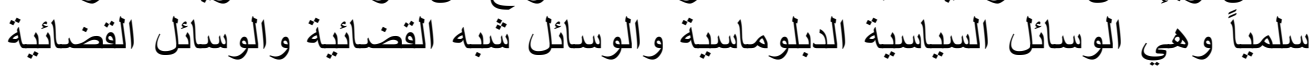
وسنبين هذه الوسائل في الآتي:-

1- الوسائل السياسية الدبلوماسية(") ؛

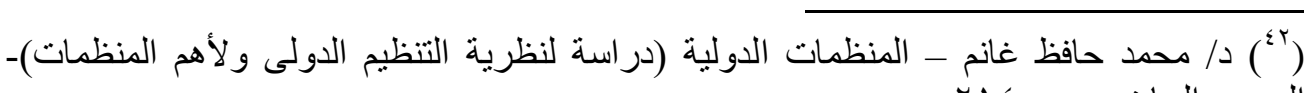

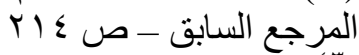

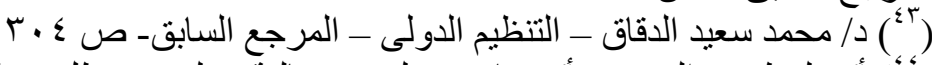

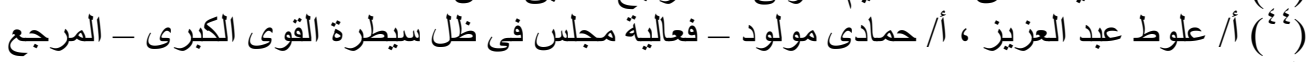

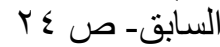
(0) أ) خليل الهادى جمعة - حق الإعتر اض فى مجلس الدولى و القضية الفلسطينيةـ المرجع السابق 1.

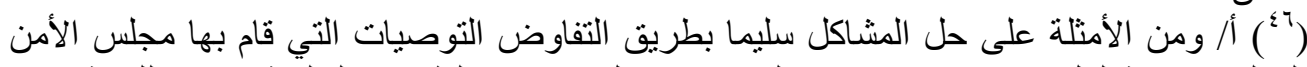

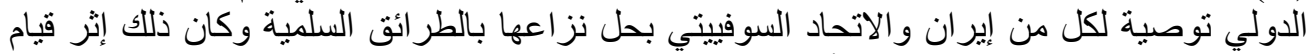

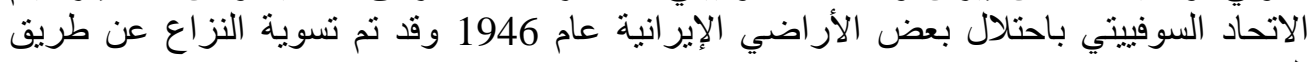




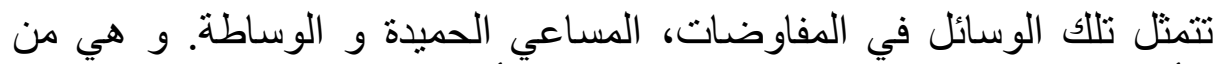

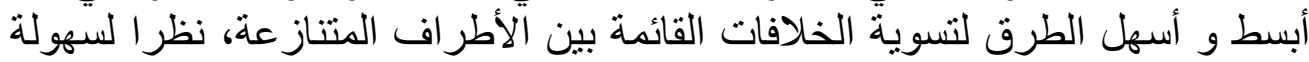
إجر اءاتهاو فعالية نتائجها

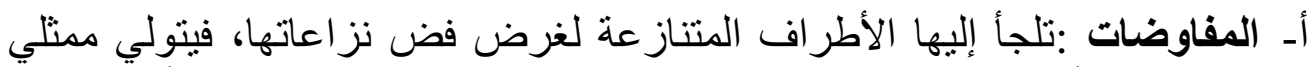

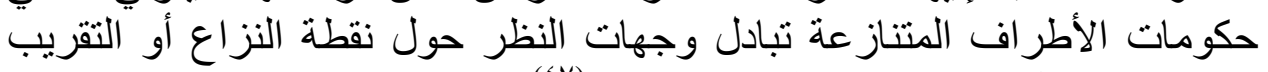

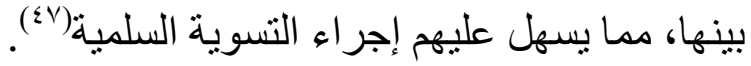

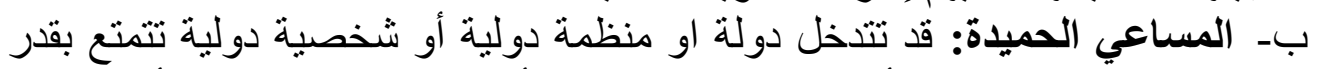

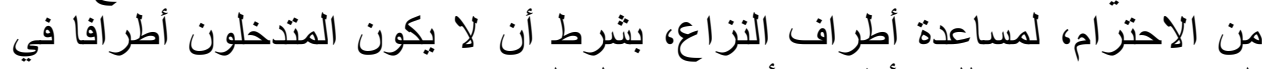

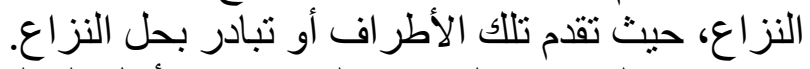

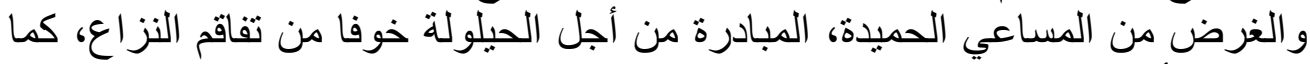

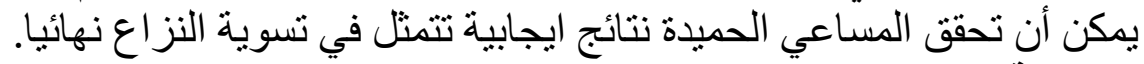

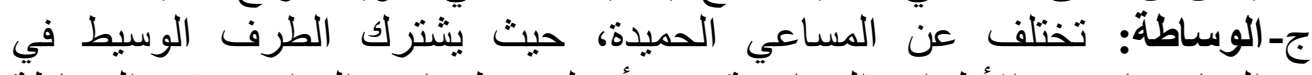

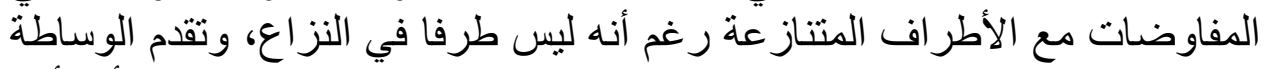

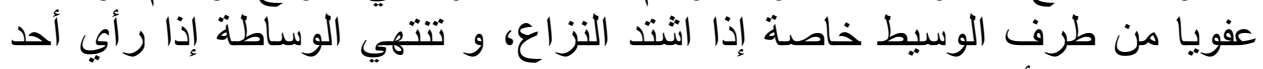

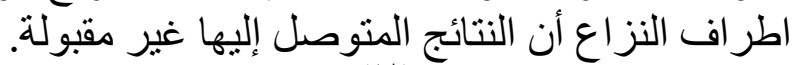

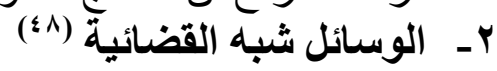
وتتمثل الوسائل شبه القضائية في التحقيق و التوفيق فتتشكل لجان التحقيق ولجان التوفيق للمساهمة في تسوية النزاع لتيه التيائ

أـ- التحقيق: بمكن أن تتفق الأطر اف المتنازعة علي إنشاء لجنة تحقيق و إيضاح

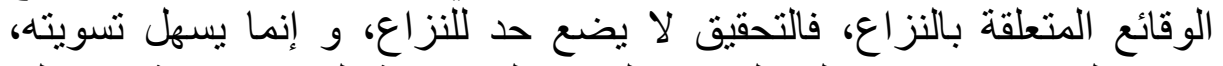

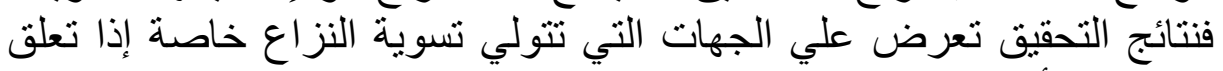
النزاع بمسألة قانونية.

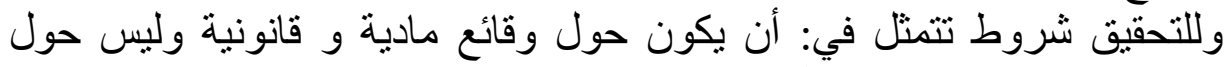

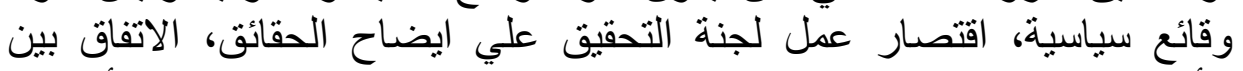

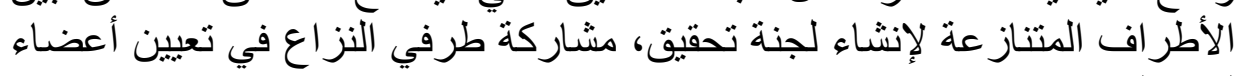

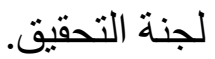

انظرد .أحمد أبوالوفا، الوسيط في قانون المنظمات الدولية، دار النهضة العربية، مصر -

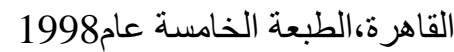

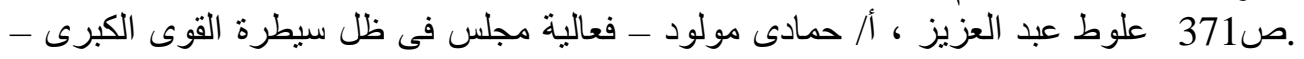

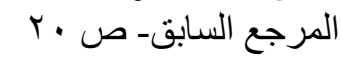

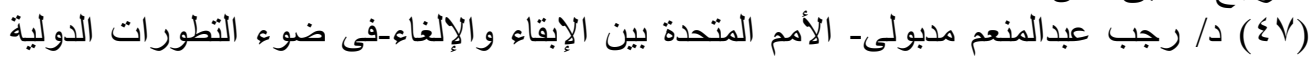

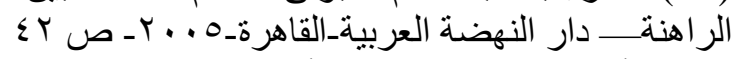

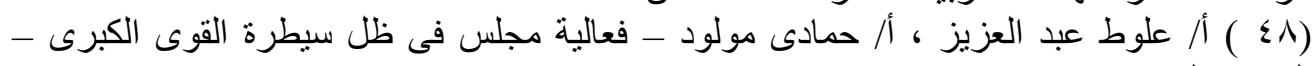

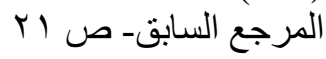




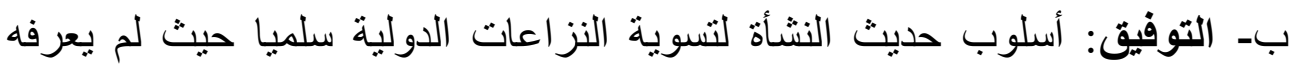

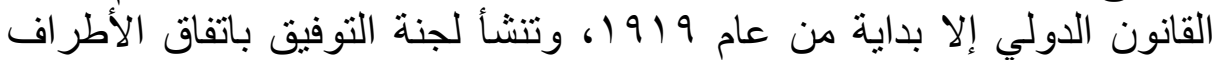

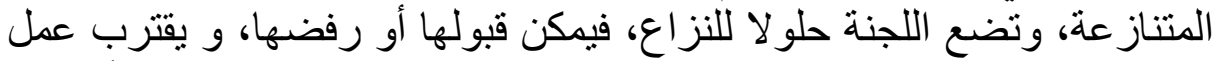

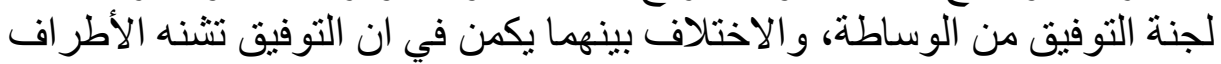

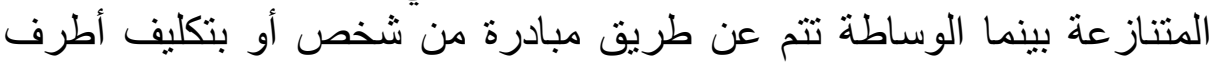

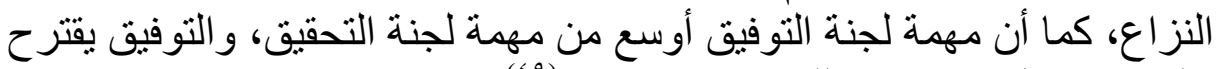

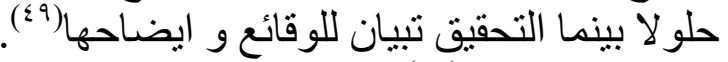

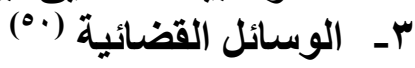

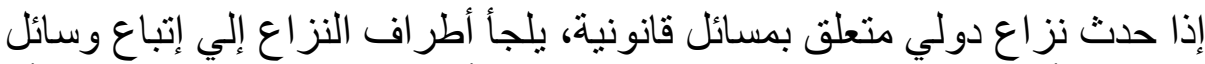

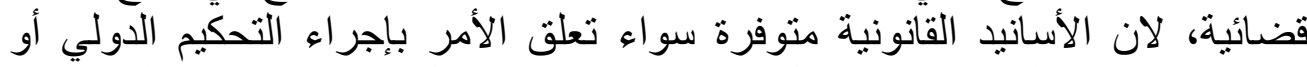

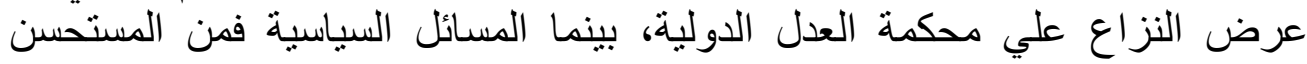
تسويتها بوسائل سياسية دبلوماسية

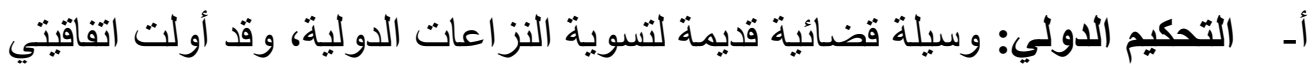

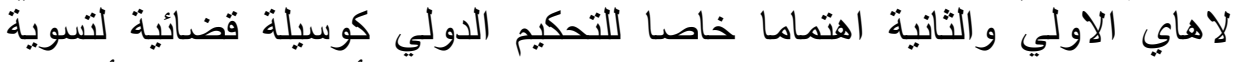

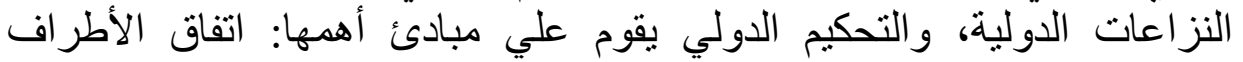

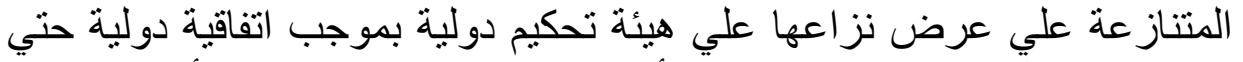

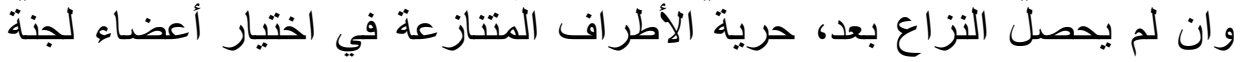

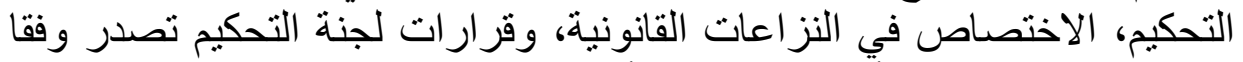

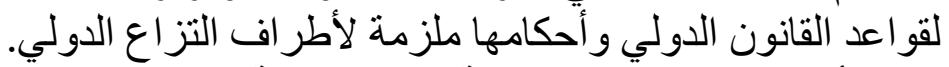

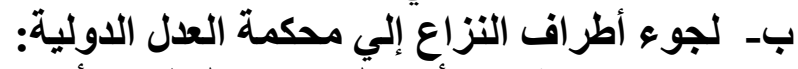

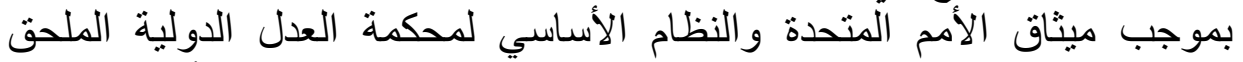

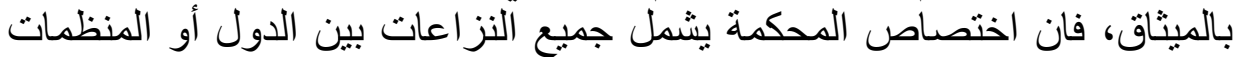

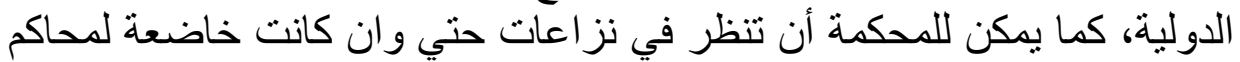

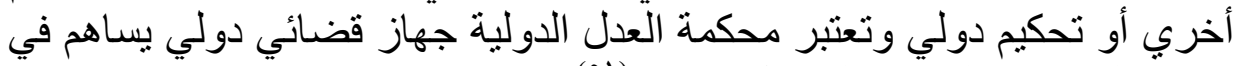

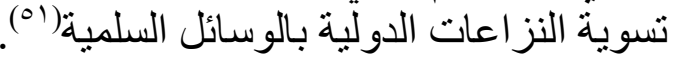

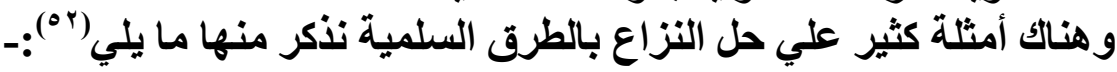

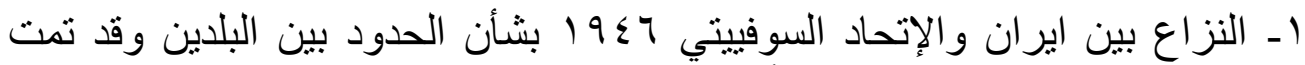

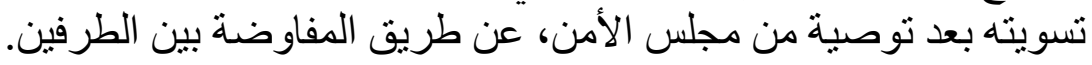

$$
\begin{aligned}
& \text { Y Y }
\end{aligned}
$$

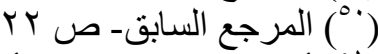

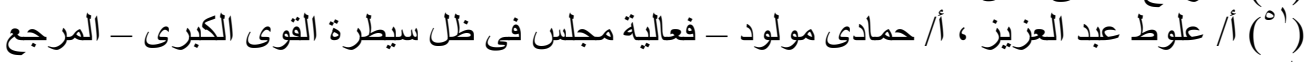

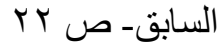

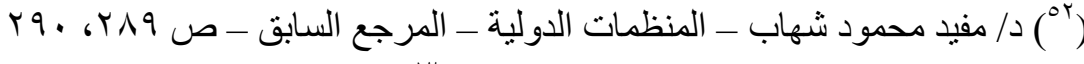




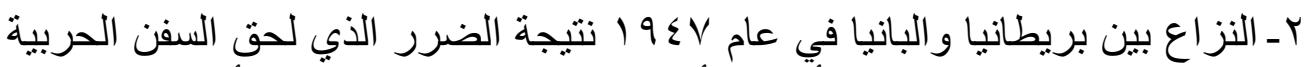

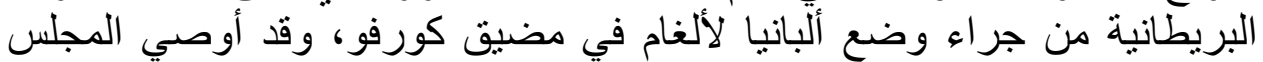

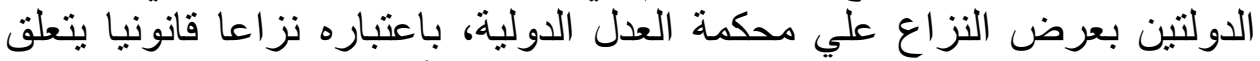

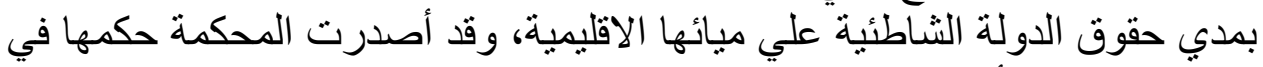

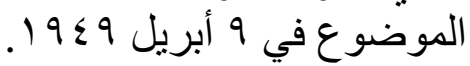

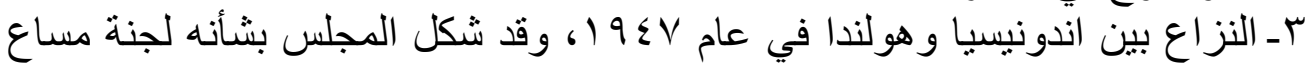
حميدة.

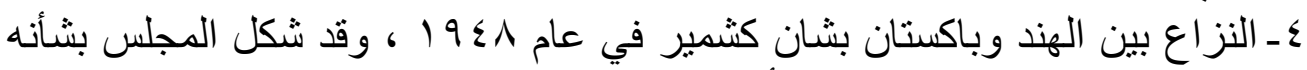

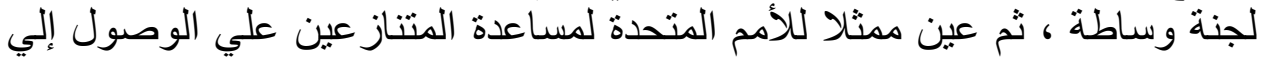

\section{الفرع الثاني

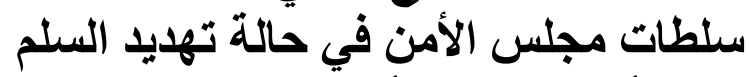

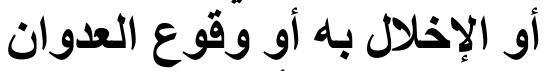

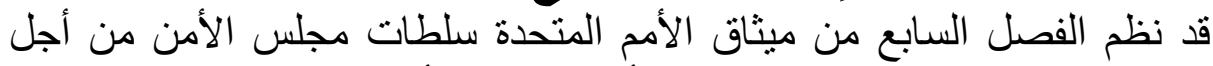

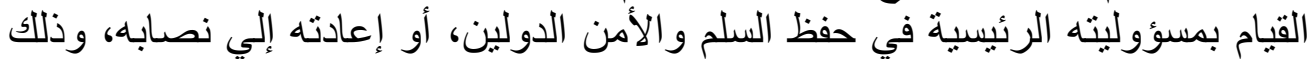

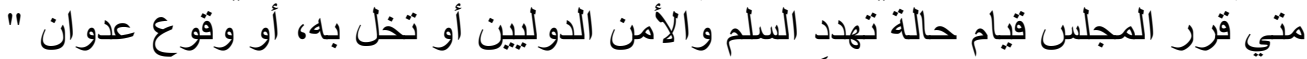

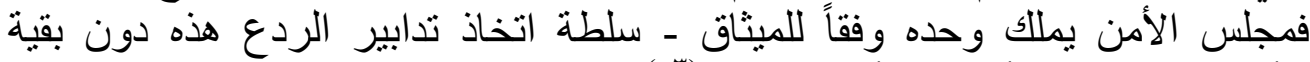

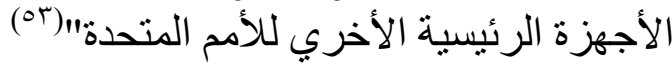

لذا يجب علينا بيان الحالات التي يجوز لمجلس الأمن التدخل واستخدام سلطاته العسكرية و غير العسكرية ثم نبين حدود وسلطات المجلس التس في التدخل و أساليبه العقابية و وذلك كما يلي:-

\section{أولاً :حالات إختصاص مجلس الأمن طبقاً للفصل السابع}

1 - مفهوم الاخلال بالأمن والسلم الدوليين

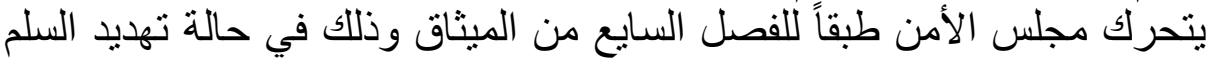

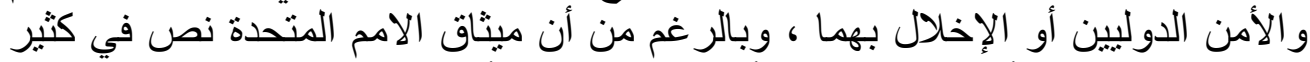

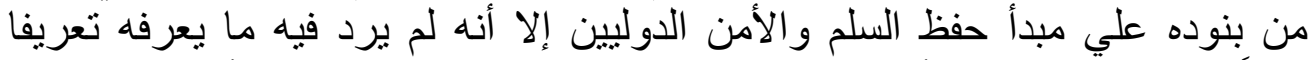

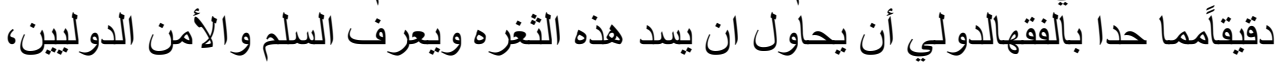

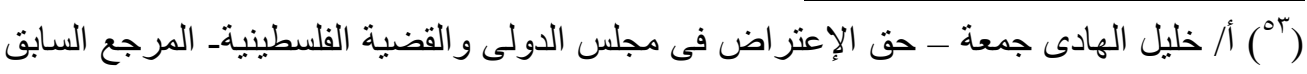

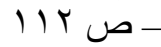
(أه) راجع فى ذلك د/ عامر عبدالفتاح-تدخل الأمم المتحدة فى شؤؤن الدول-مجلة الر افدين للحقوق-

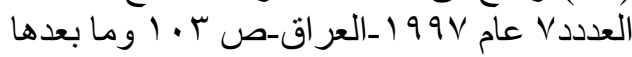


و الجدير بالذكر ان لفظ الدولي ذكر في النص والانجليزي والعربي بصيغه

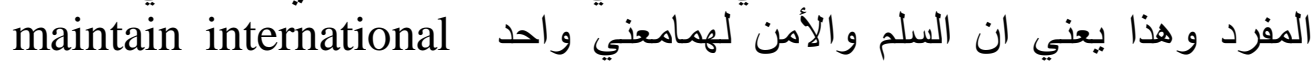

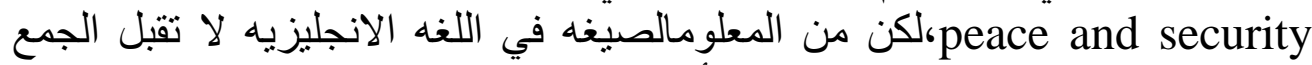

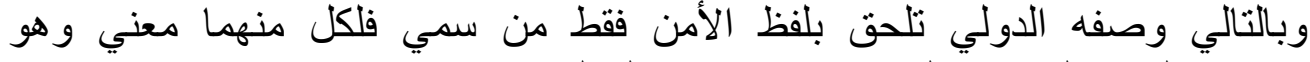

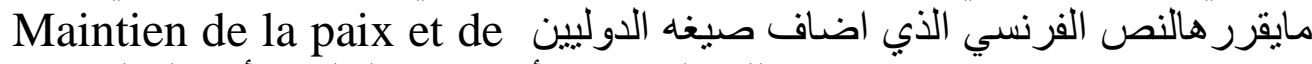
la sécurité internationales

ويعني السلم في فقه القانون الدولي سيادة حالة اللا حرب و الإمتناع عن استعمال

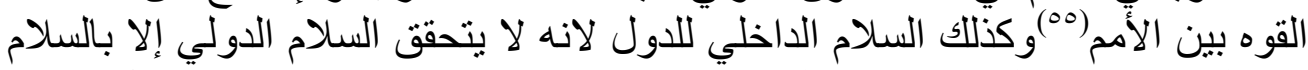

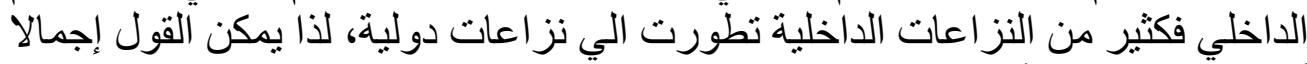

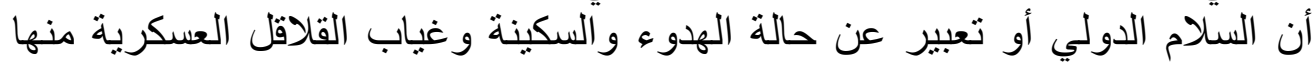

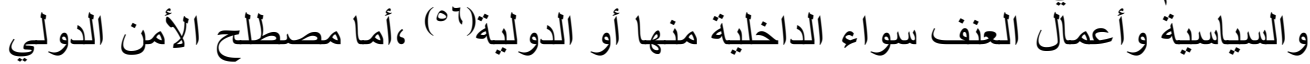

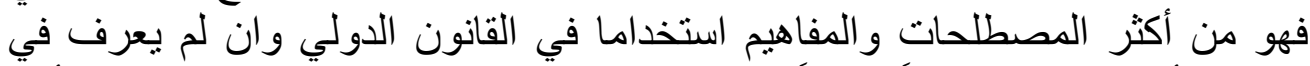

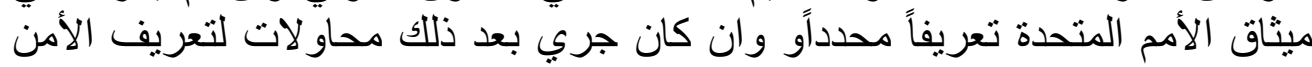

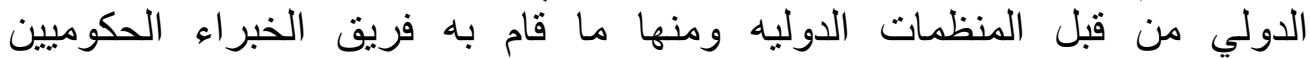

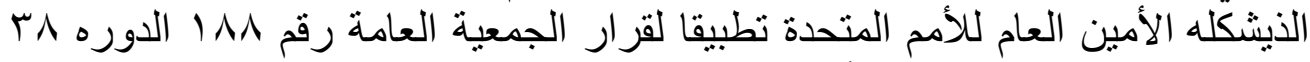

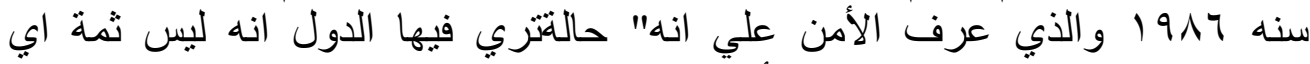

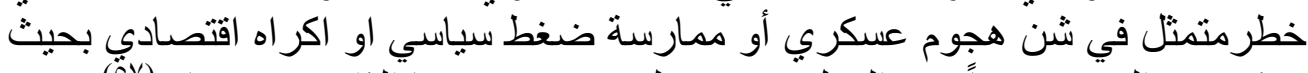

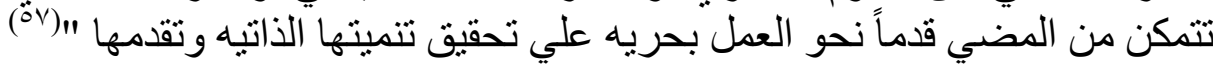

وفي محاوله من الفقه الدولي لتعريف الأمن عرفه الفقيه الأمريكي( Arnold "Wolfers

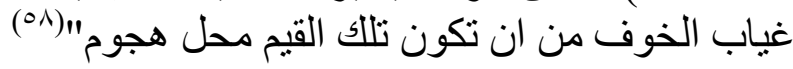

الدقصود بتلك القيم الوحدة الترابية للاولة والإستقلال السياسي والهوية الثقافية

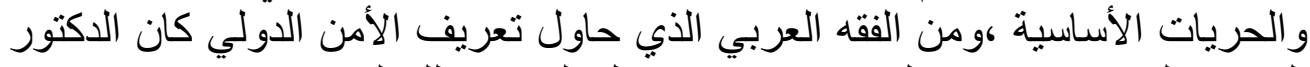

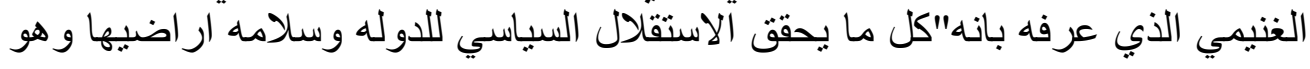

( ) م د سهيل حسين الفتلاوي موسو عه المنظمات الدوليه الامم المتحدة اهداف ومبادئ مرجع سابق

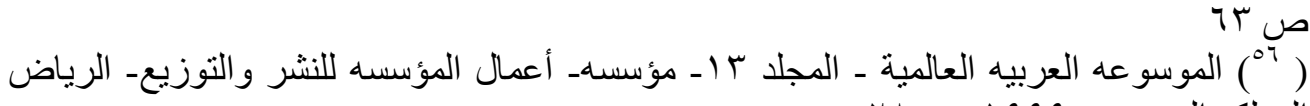

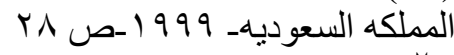

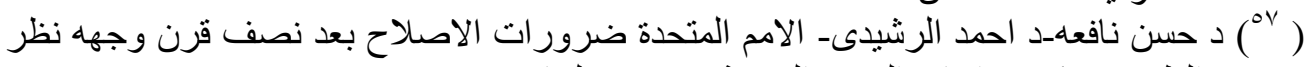

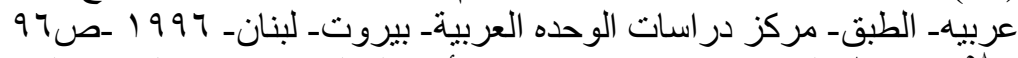

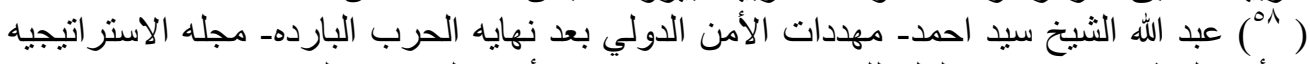

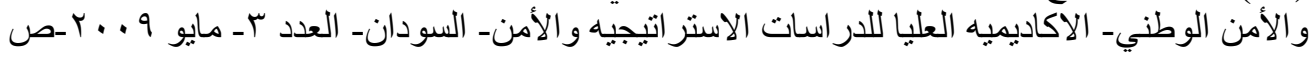


يثمل كل جراء او تدبير من شانه ان يؤثر بطريق مبانشر او غير مباثشر علي كيان

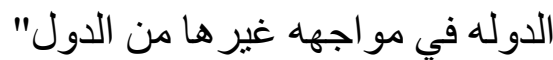

أما نظام حفظ السلم و الأمن الدوليين كمصطلح في ميثاق الامم المتحدة فهو يعني

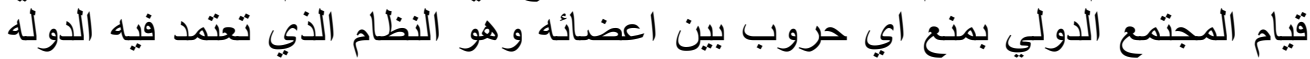

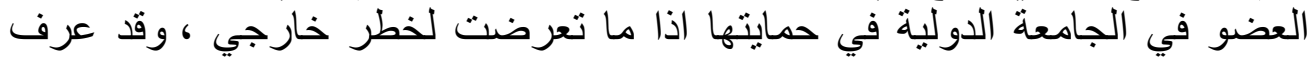

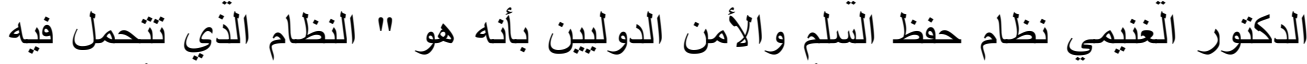

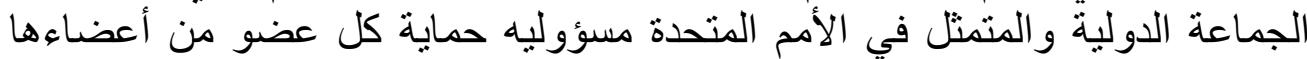

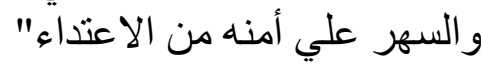

ولا شكك ان حفظ السلم والأمن الدوليين انطلق من مفهوم ان الاعتداء علي اي

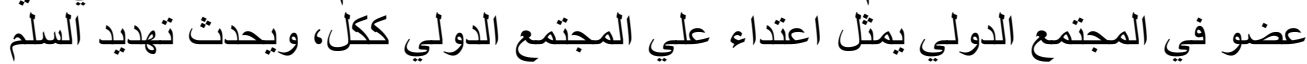

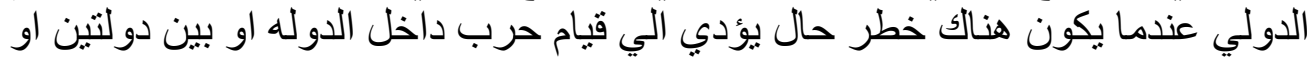

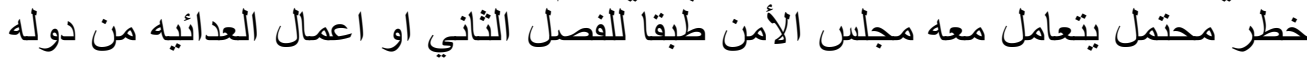

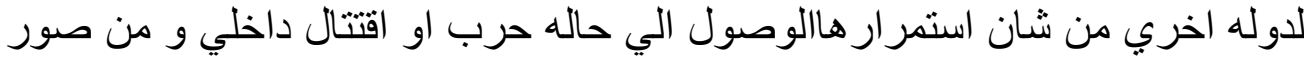
ذلك :- اخر

ـ قيام دوله الماء بتهديد اغراء بالدخول في حرب او استخدام القوه ضدها - وقوع اعمال العنف داخل الدوله ويتسع لدرجه تعرض مصالحها الأمنيه والاقتصاديه خطر

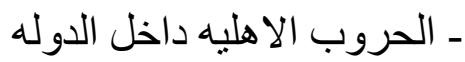

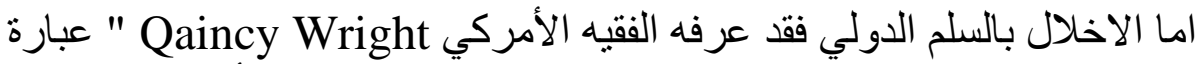
حدود معترف أعها دولياّ", تقع بين قوات التهل مسلحة تابعة لحكومة شرعية أو واقعية وراء

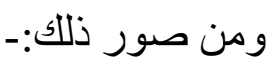

-حدوث أعمال عدائية من قو ات مسلحة تابعة للحكومة الثر عية او بينها وبين الطو ارئ

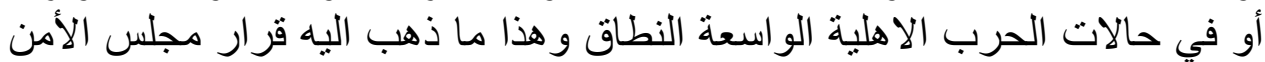

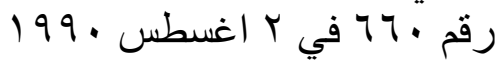

ــ الاعمال التي يقوم بها الصغار داخل اقليم دوله اخري والتي تهذف الي تحقيق التيق

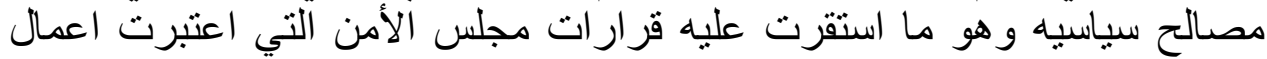

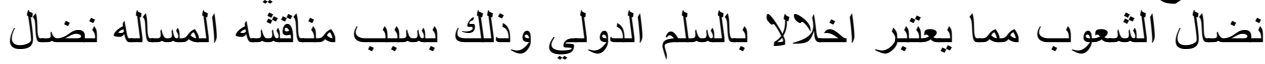
شعب جنوب افريقيا ضد نظام الحكم العنصري الالاي rT 
و لا شك أن الإخلال بالسلم و التهديد به مفهومان متقاربان وإن كان الأول أكثر

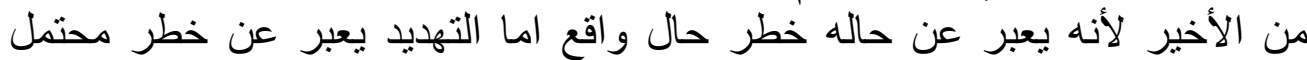

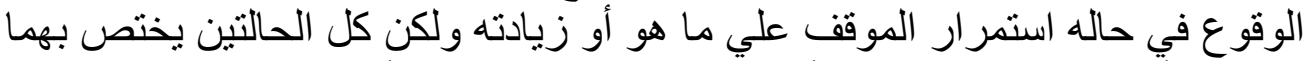
مجلس الأمن طبقا للفصل الثالث أو الفصل السابع من ميثاق الأمم المتحدة .

ثانياً: التدابير التييمن للجلس اتخاذها في حالة التهايد او الاخلال بالأمن والسلم الاوليين

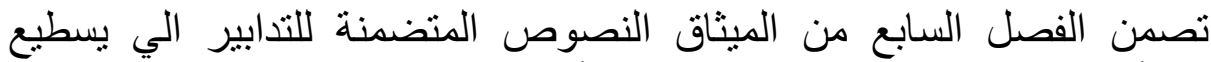

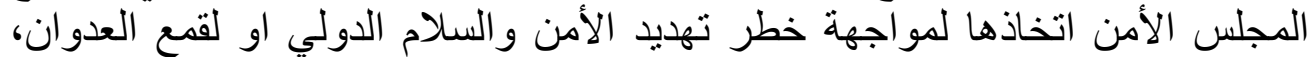

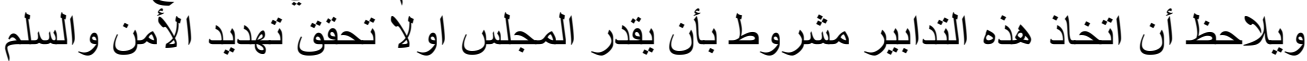

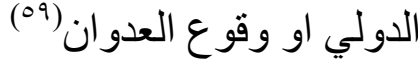

فإذا قرر ذلك فإن مو اد الفصل السابع قد أعطت له سلطات تتفاوت في خطورتها لتتخذ

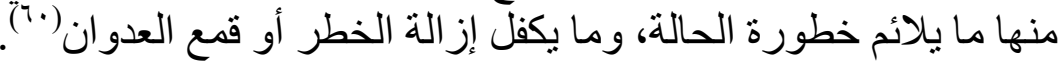
r الـ التدابير التي يتذذها المجلس في حالة الاخلال بالسلم والأمن الدوليين

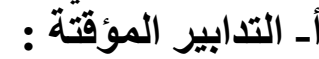

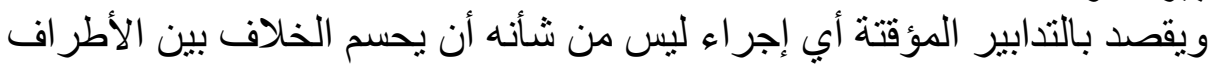

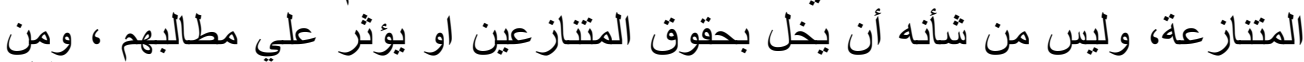

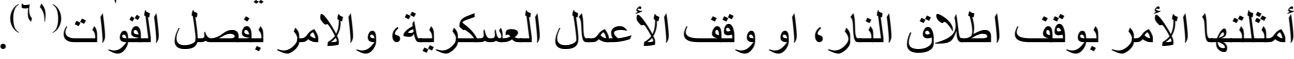

ومن بين هذه التدابير المؤقتة الأمربوقف إطلاق النار والمطالبة بسحب القوات

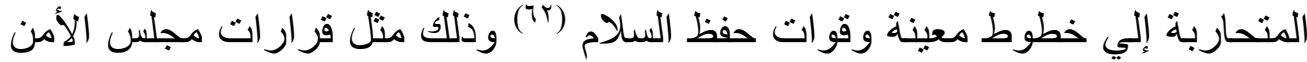

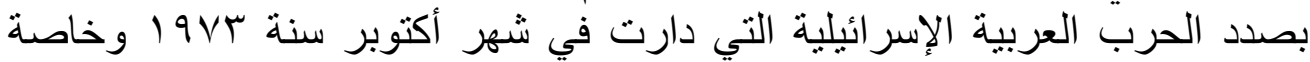

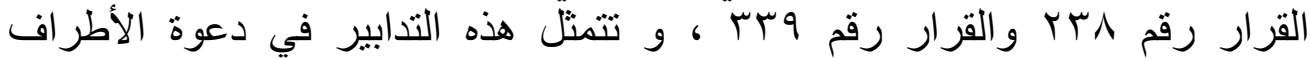

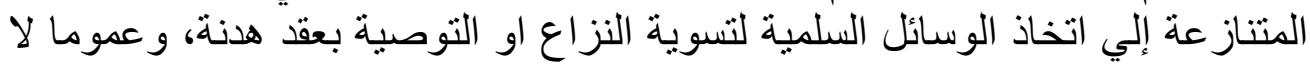
يوجد تحديد موضوعي لتنلك التدابير المؤقتة، فاختيار ها وتحديد مني بمكن تطبيقها

(०९)YVES Petit, Droit international du maintien de la paix, librerie general de droit et de la Jurisprudance, paris, 2000 , p. 24.

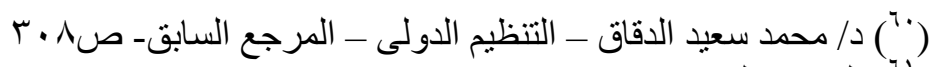

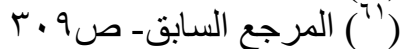

(62)AMINZADEH Elham, The United Nation and International peace and Security: A legalend pratical AnalysisPHD in International law thesis, University of Glasgow, 1997.p 151, 
متروك للسلطة التقديرية لمجلس الأمن و لا يوجد ضابط مشترك بينها سوي أنها لا تخل

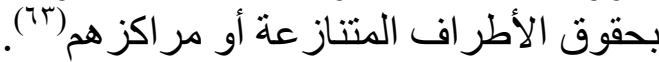

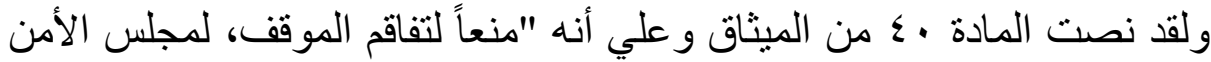

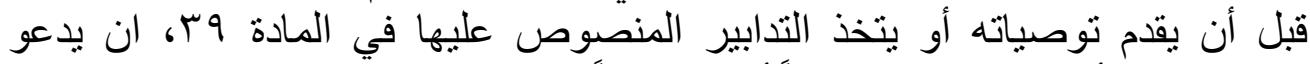

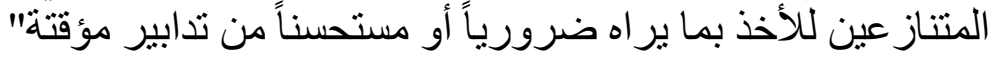

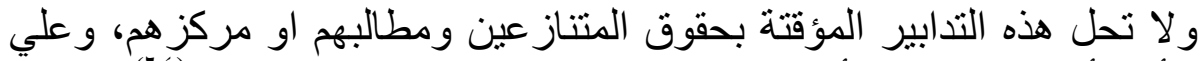

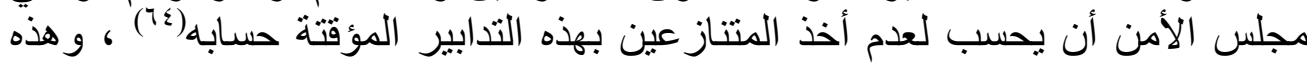

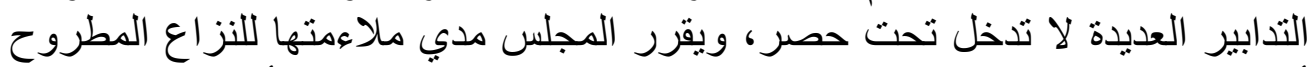

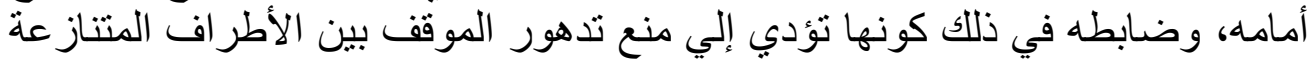

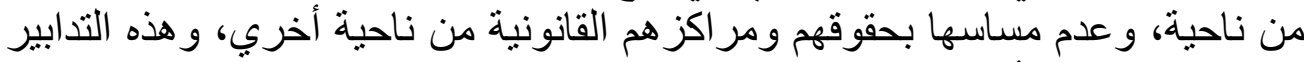

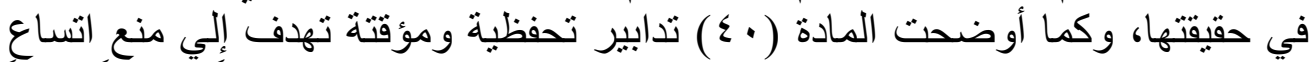

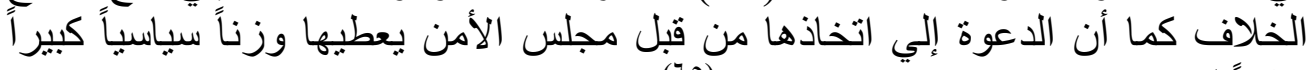

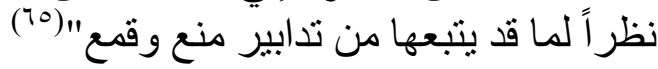

ب-التدابير العسكرية

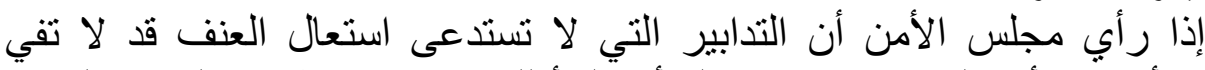

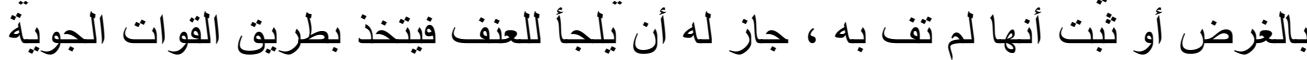

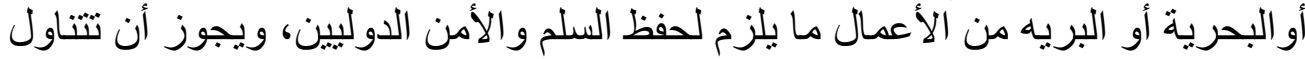

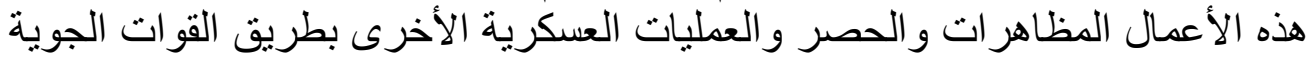

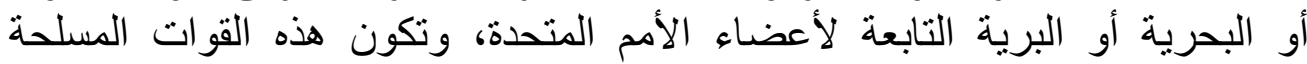

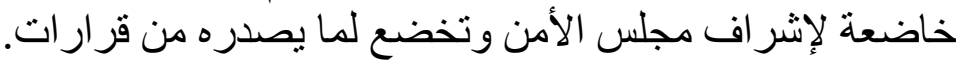

ومن أمثلة الإجراءات التي قررها مجلس الأمن والتي تضمنت استخدام القوة

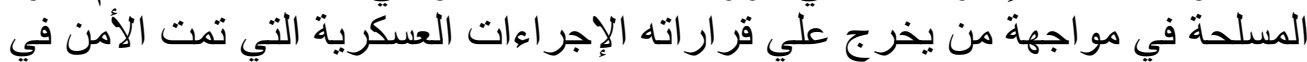

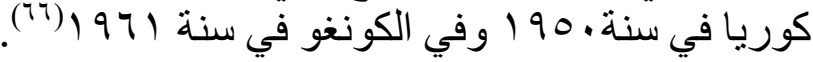

ج-التدابير غير العسكرية

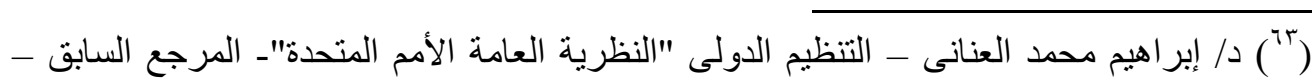

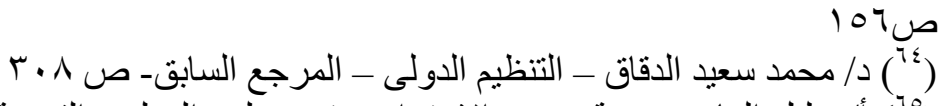

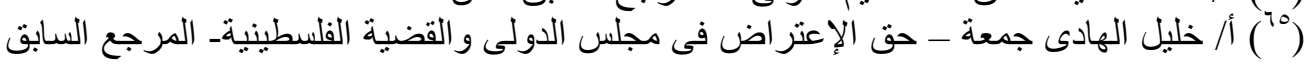

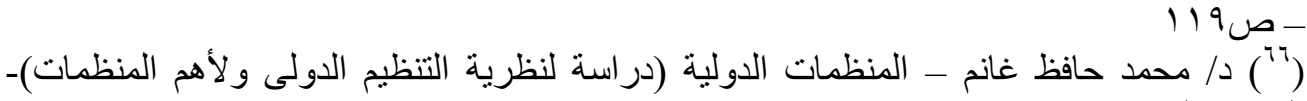

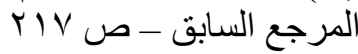


و التدابير الغير عسكرية هي بمثابة وسائل ضغط علي الدول المعتدية وتسخدم في

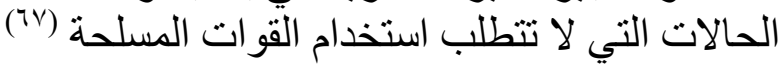

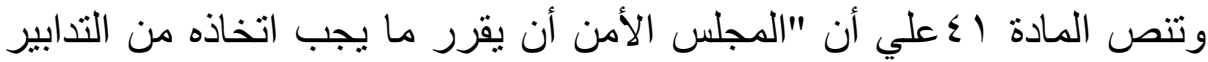

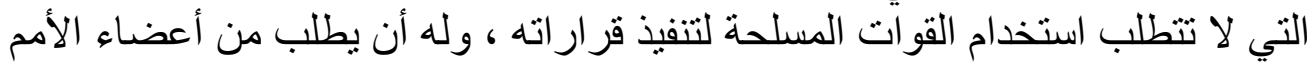

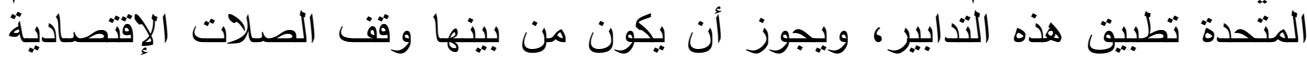

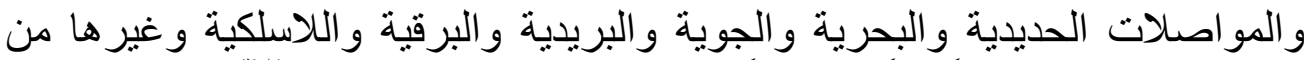

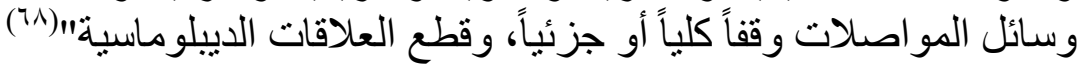

ومن نص المادةاء نلاحظ أن للمجلس وسائل ضغط مختلفة علي الدول المعتدية وأهمها:

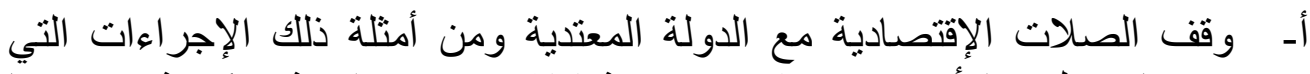

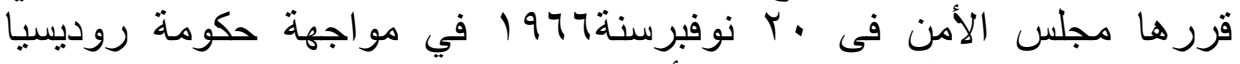
وتتضمن منع وصول بعض الأن فئ المو اد الأساسية إلها.

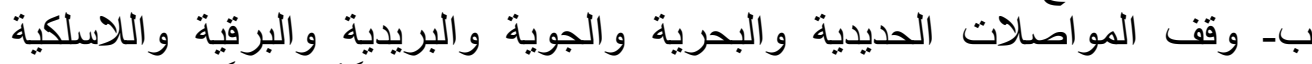

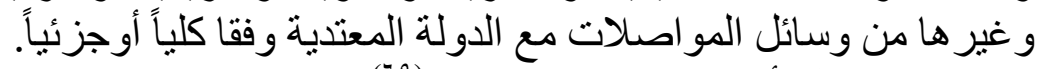
أـ قطع العلاقات كليا أو جزئيا الدولة الدعتدية(19).

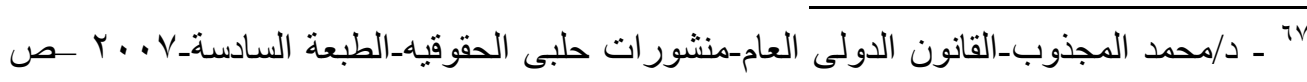

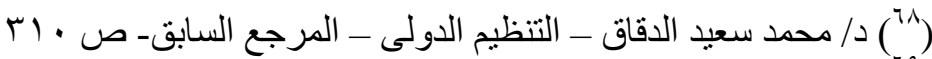

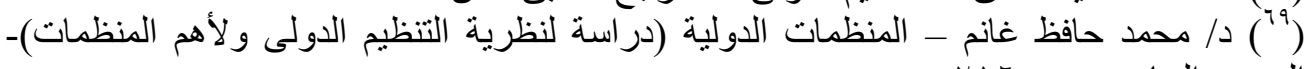
المرجع السابق - ص الن 17 


\section{الفصل الأول \\ ماهية قرار ""الإتحاد من أجل السلام" " \\ the uniting for peace}

\section{وأساسه القانوني}

بعد ثبوت عجز مجلس الأمن عن صون السلم والأمن الدولي في حالات دولية

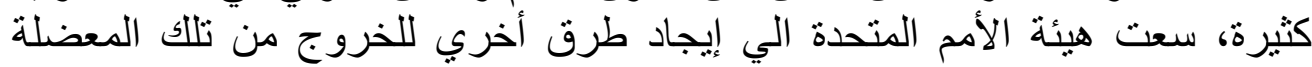

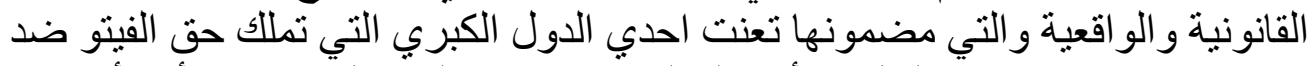

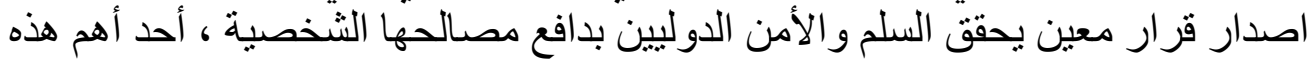

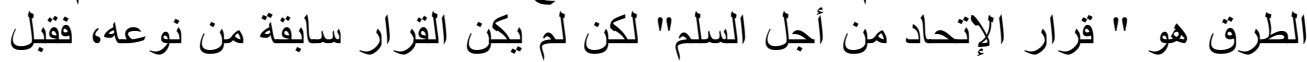

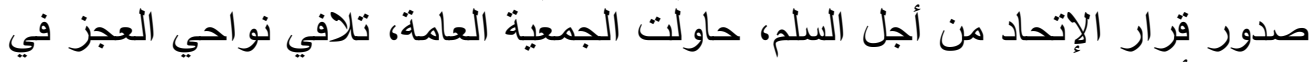

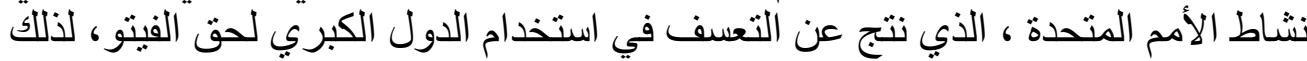

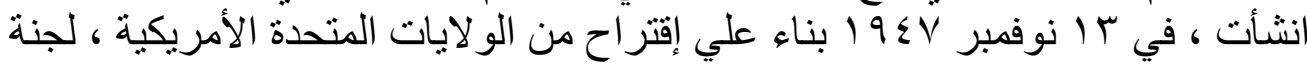

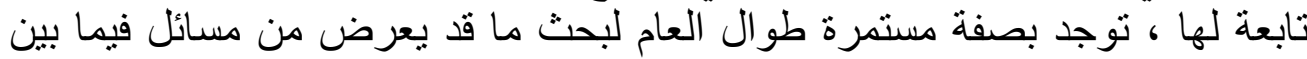

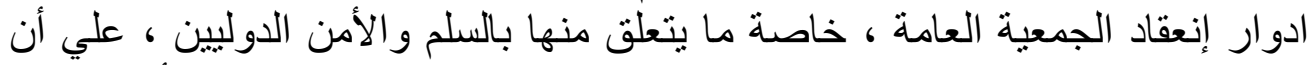

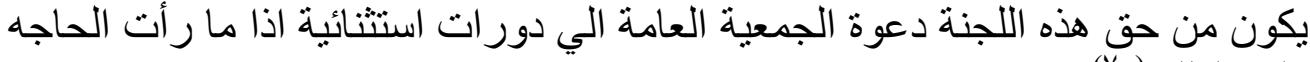

ملحة لذلك من حن (v.)

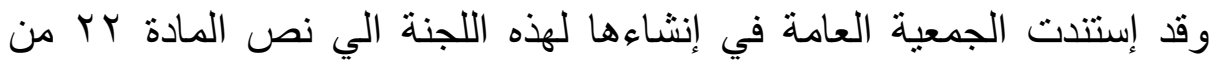

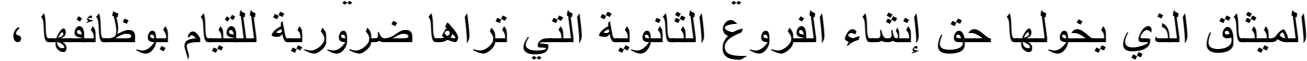

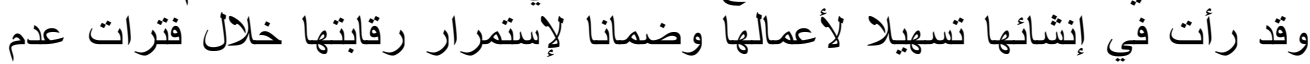
إنعقادها.

وقد عارض الإتحاد السوفيتي وأيده في ذللك ممثلو أوكرانيا وروسيا البيضاء

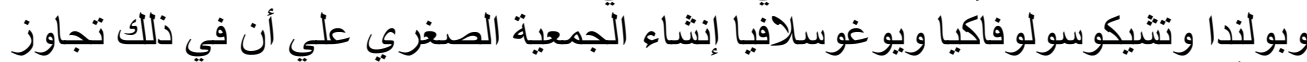

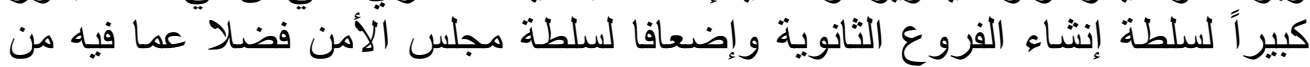

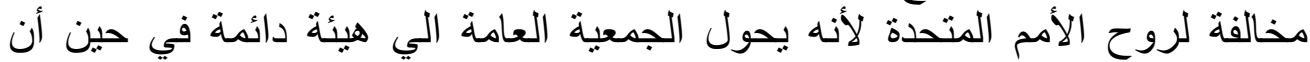

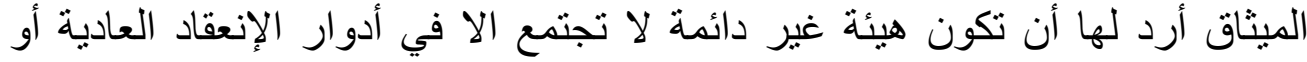

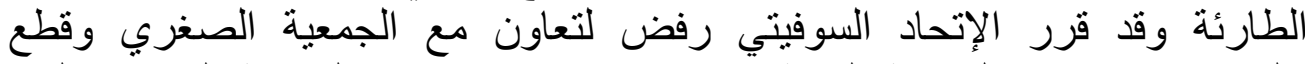

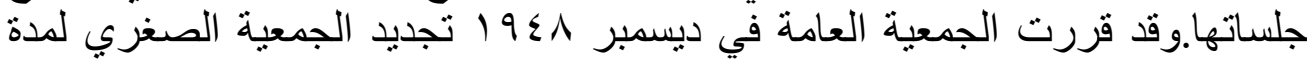

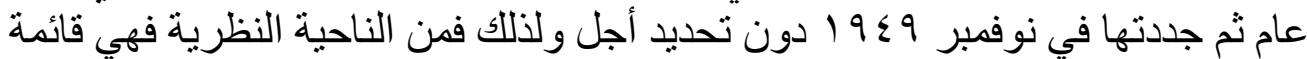

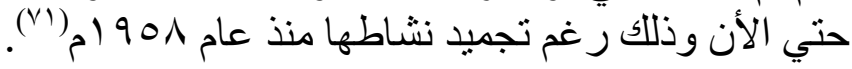

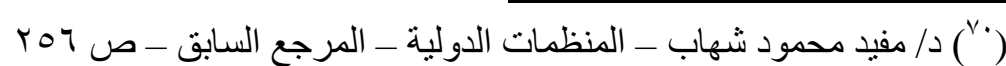

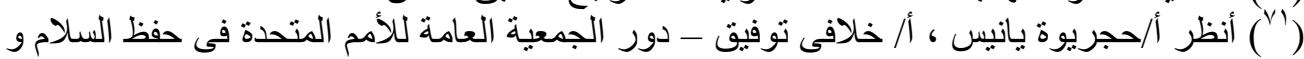

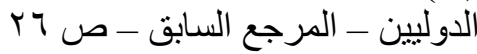


لكن الجمعية الصغري لم تجدي نفعاً، فحاولت الو لايات المتحدة الأمريكية إيجاد

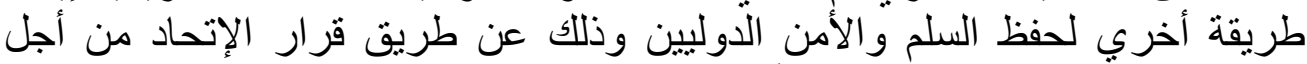

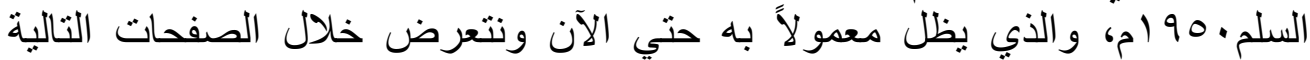

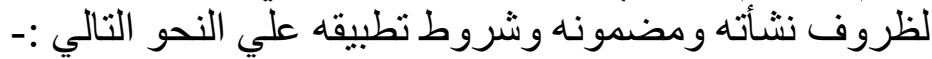

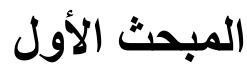 \\ مضمون قرار الإتحاد من أجل السلم الأح

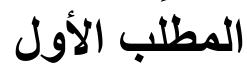 \\ ظروف و أسباب قرار الإتحاد من أجل السلم}

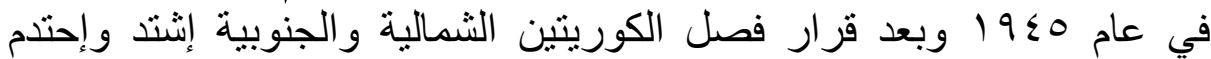

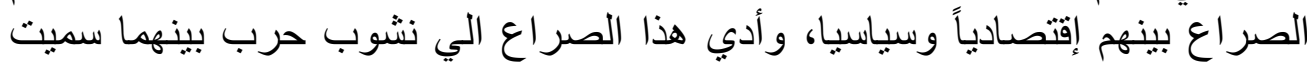

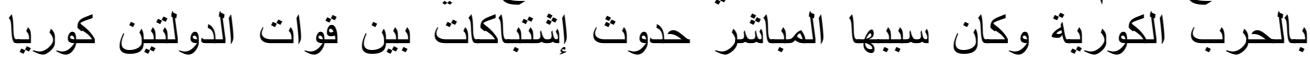

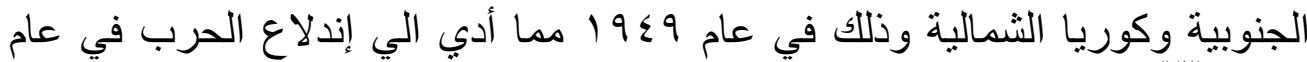

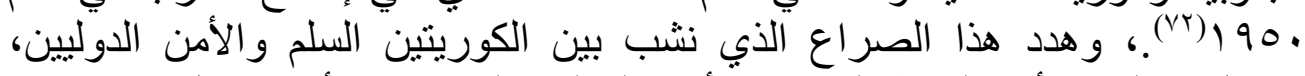
وتدخل مجلس الأمن لحفظ السلام والأمن الدوليين لكن هذا الأخير فنشل في تسوية الألية

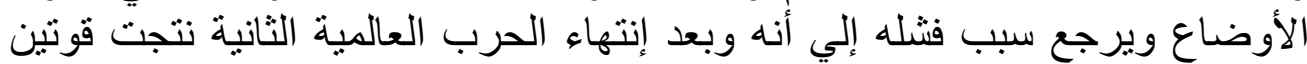

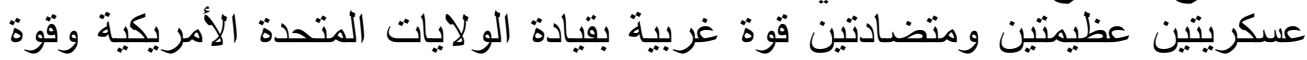

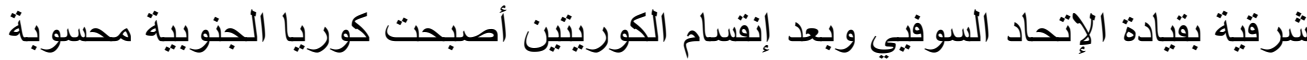

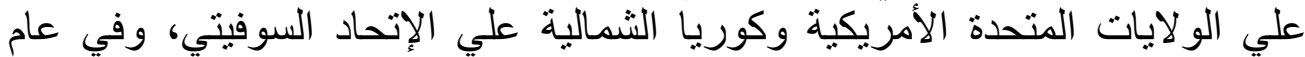

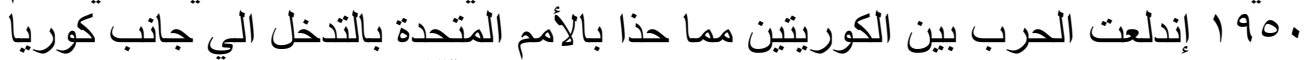
الجنوبية بالإستناد الي قرار ات صدرت الكورين عن مجلس الأمن (VT)

لكن قرار ات مجلس الأمن كانت محل شك كونها صدرت في ظل غياب الإتحاد

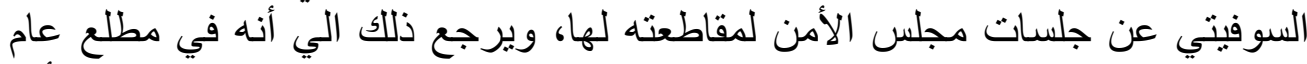

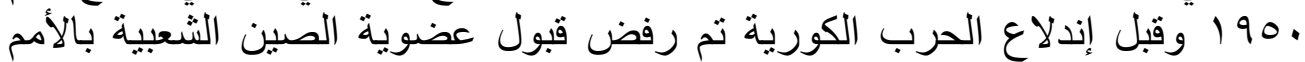

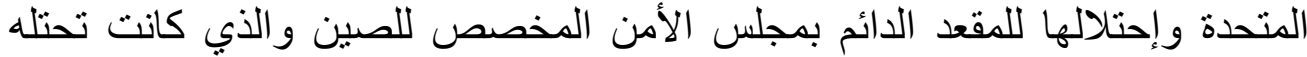

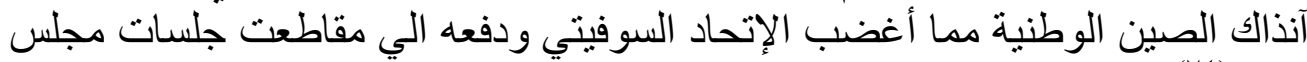

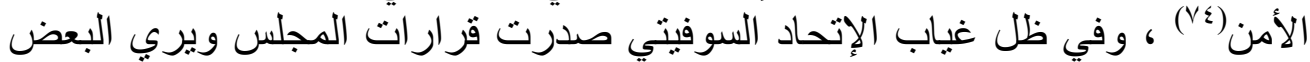

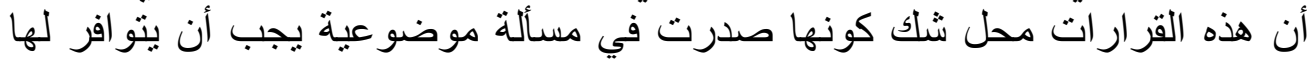

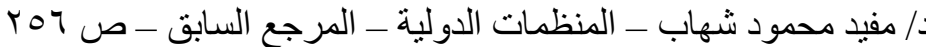

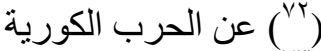

( أنشرف صيام - قرار الإتحاد من أجل السلم: هل هو وسيلة ممكنة لحماية الفلسطنيين- المرجع

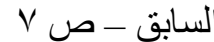

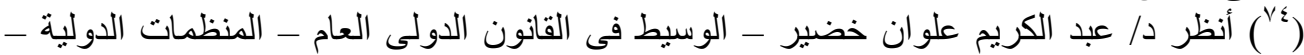

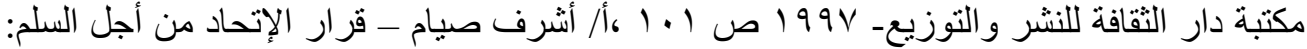

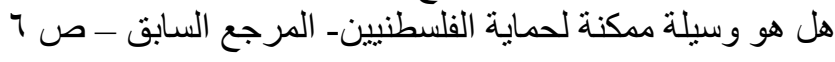
rᄉ 


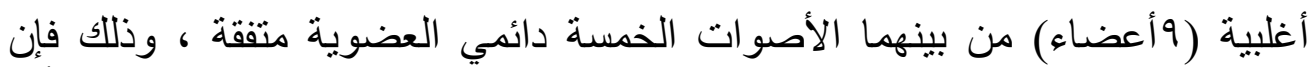

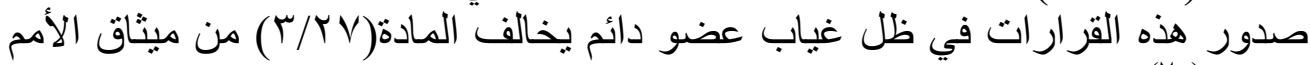

لكننا لا نذهب مع الر ائ القائل بمحل شك القرار وذلك لإتجاه الر اي الغالب داخل

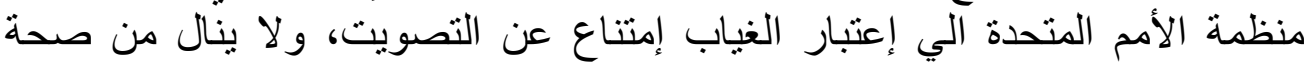

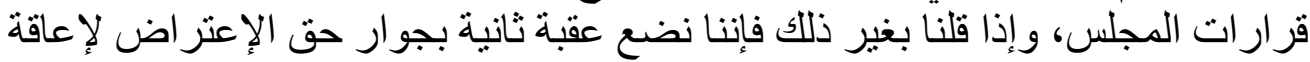

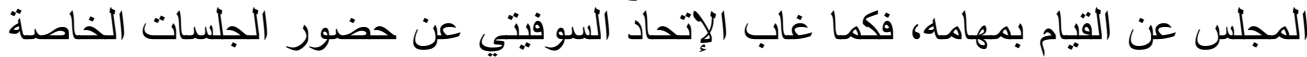

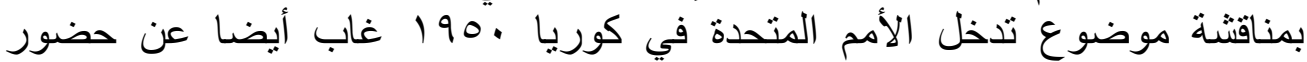

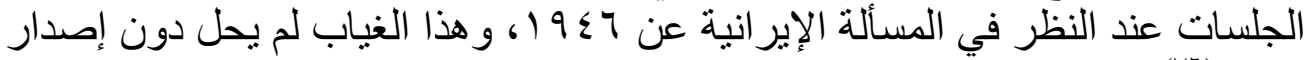

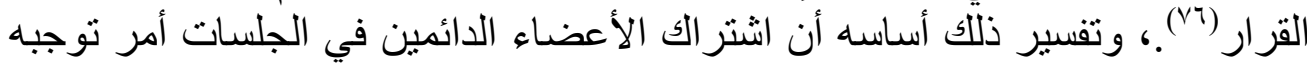

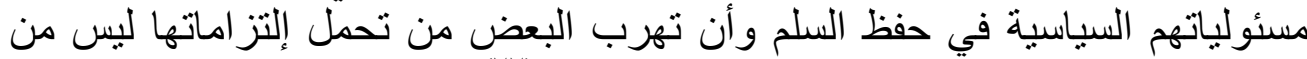

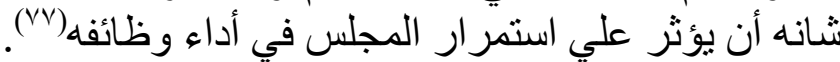

ان قرار تدخل الأمم المتحدة الي جانب كوريا الجنوبية ضد كوريا الثمالية في

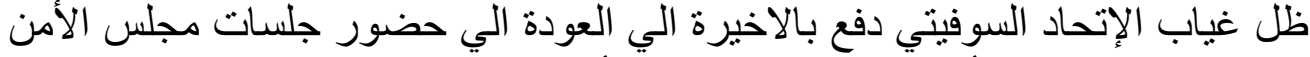

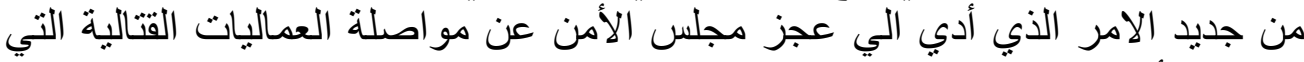

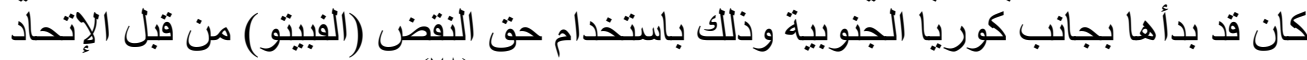

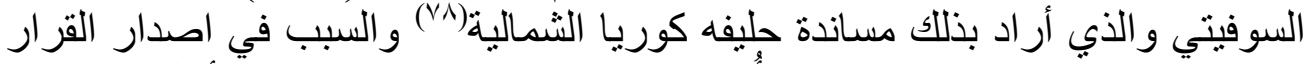

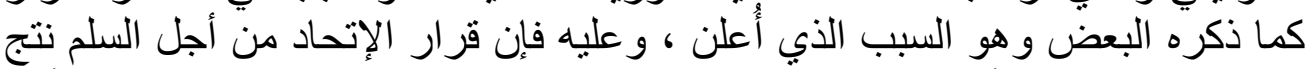

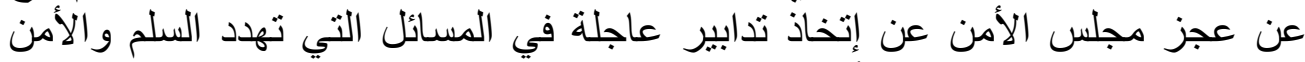

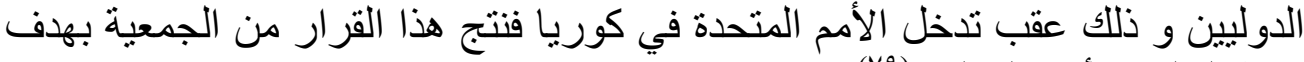

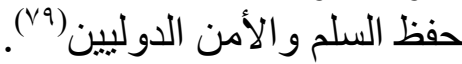

السابق - ص أشرف صيام - قرار الإتحاد من أجل السلم: هل هو وسيلة ممكنة لحماية الفلسطنيين- المرجع

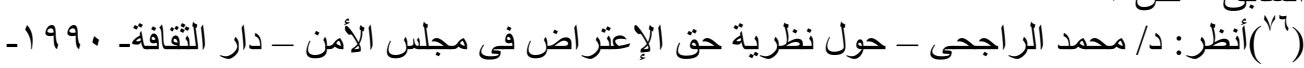

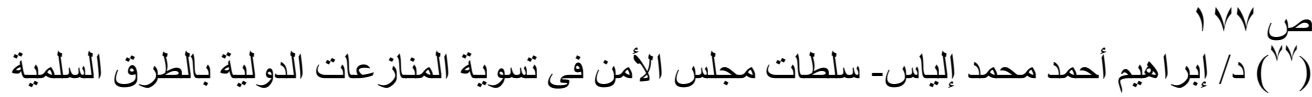

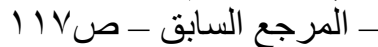

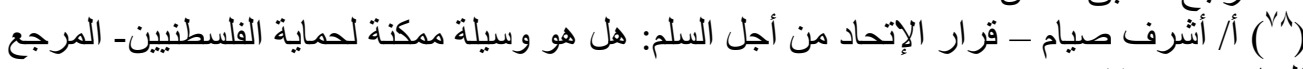

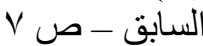
أنظر أيضاً: جيمس باروس - الأمم المتحدة ماضيهاوحاضر ها ومستقبلها- مؤسسة سجل العرب ـ $\vee / 9 \vee 9$ (") د د محمد حافظ غانم - المنظمات الدولية (دراسة لنظرية التنظيم الدولى ولأهم المنظمات)-

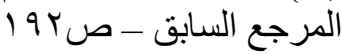


إلا أنتا نري سبب آخر وهو سبب سياسي حيث أن عودة الإتحاد السوفيتي الي

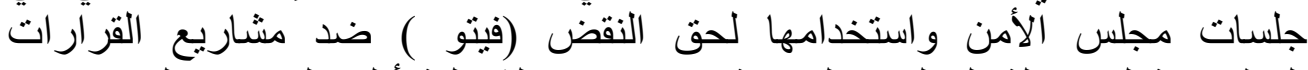

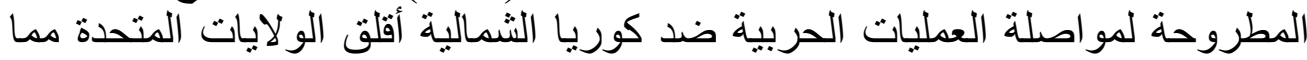

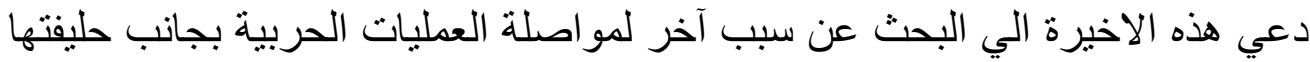

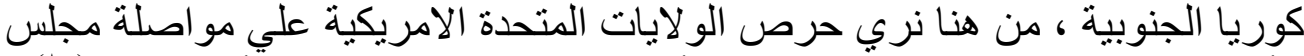

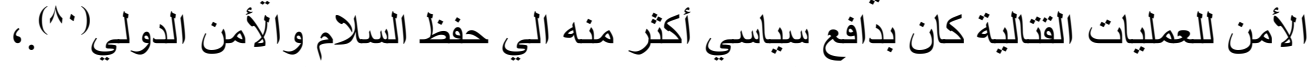

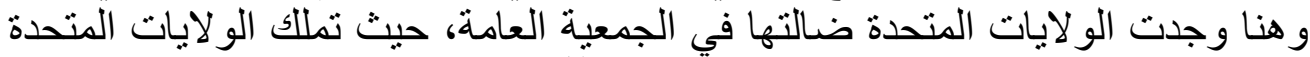

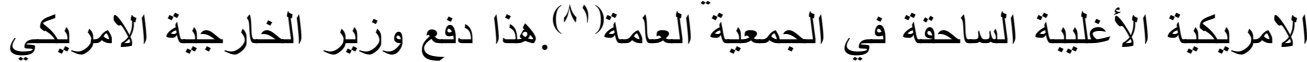

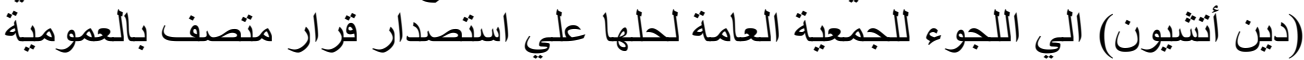
والتجريد ويسمح للولايات المتحدة بمواصلة العمليات الحربية في كوريا الثمالية التئية

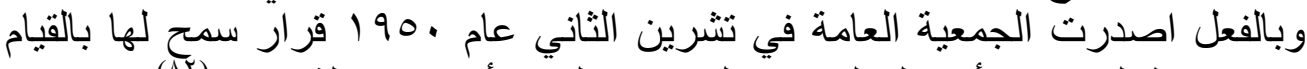

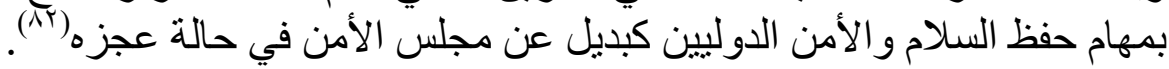

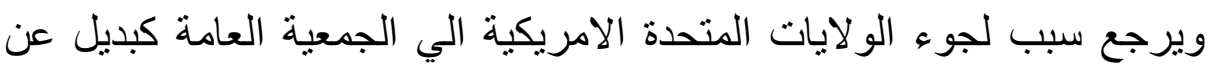

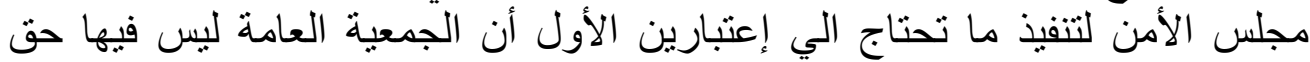

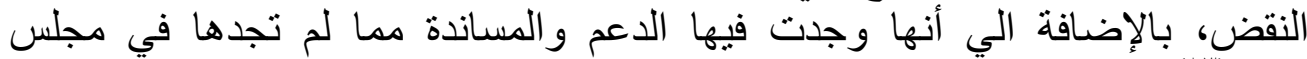

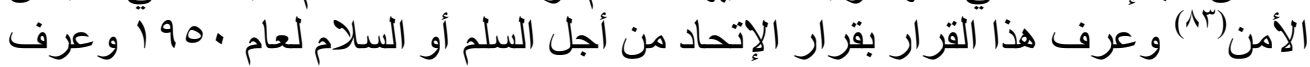
باللغة الانجليزية منه (Uniting for peace)

ولو نظرنا الي العو امل الظاهرة لإنشاء القرار نجد أنه قد نشأ من أجل القانون

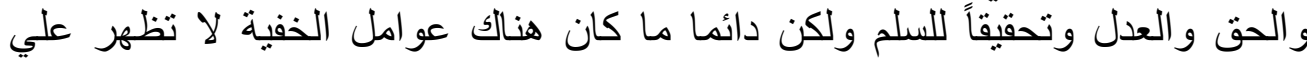

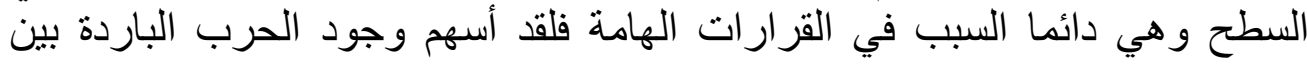

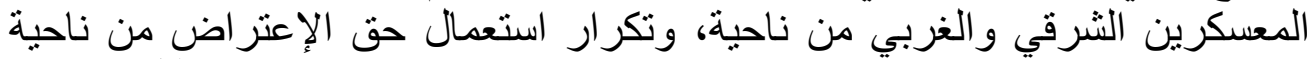

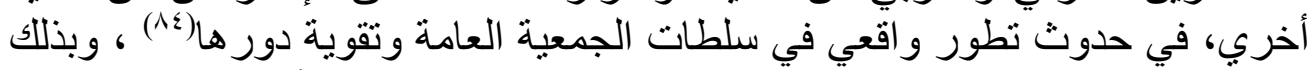

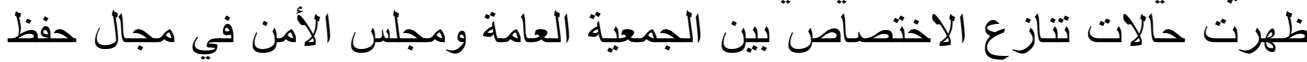

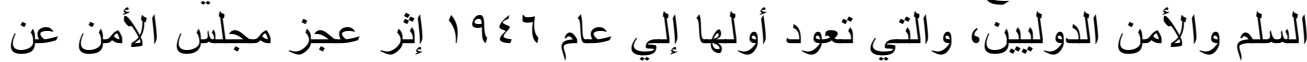

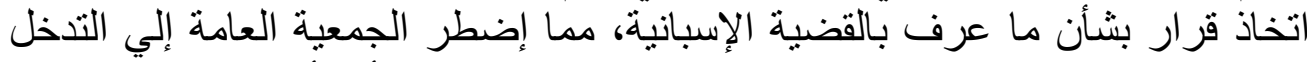

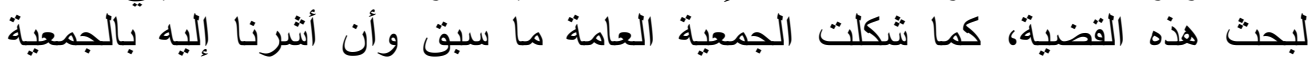

(“) أنشرف صيام - قرار الإتحاد من أجل السلم: هل هو وسيلة ممكنة لحماية الفلسطنيين- المرجع

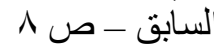

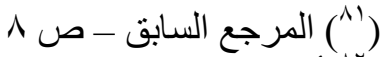

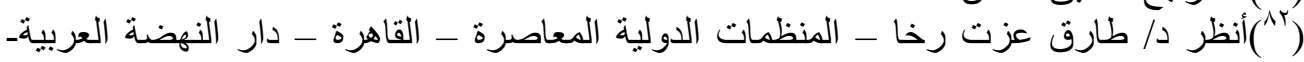

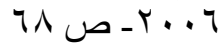

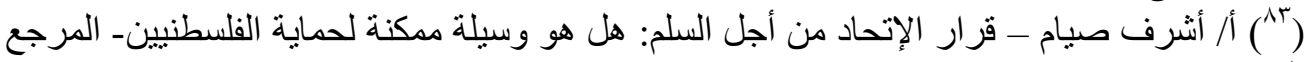

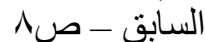

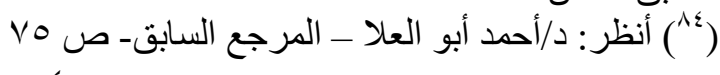




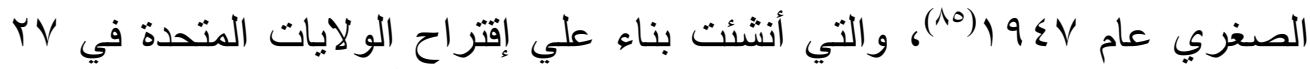

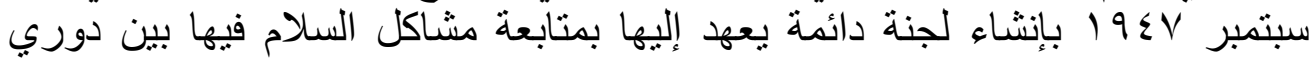

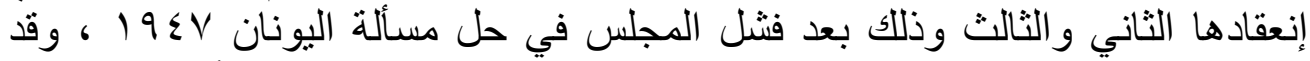

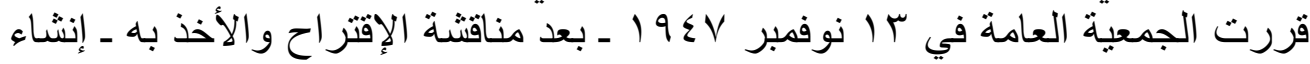

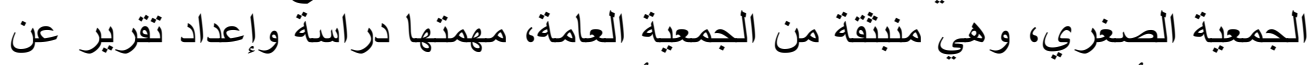

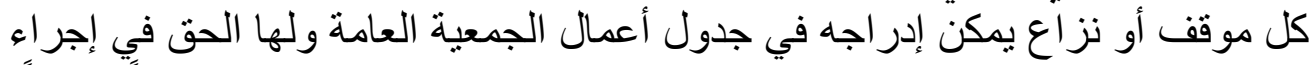

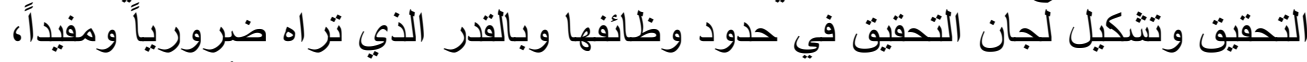

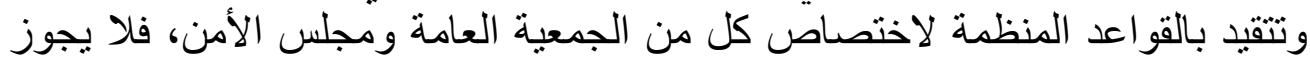

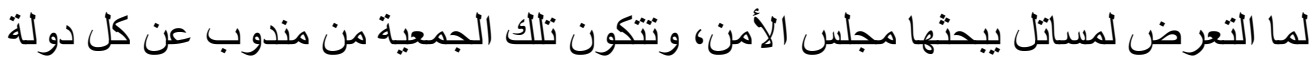
من أعضاء الأمم المتحدة، ولا تستطيع الاجتماع أثناء دورة إنعقاد الجمعية العامة(1). وتجدر الإشارة إلي أن الولايات المتحدة قد استندت في إقتر احها بإنشاء تلألك

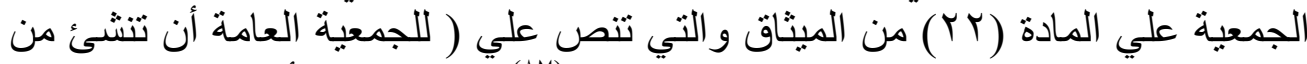

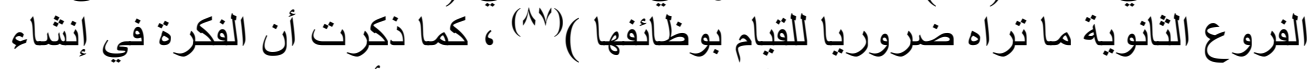

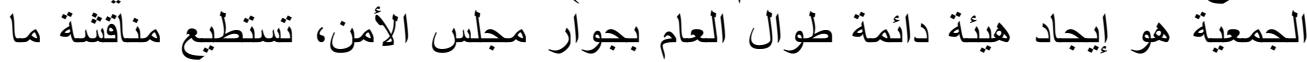

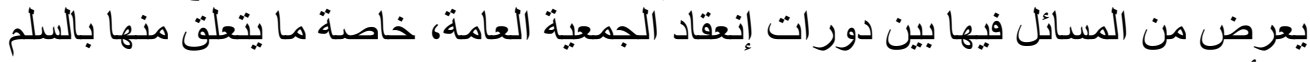

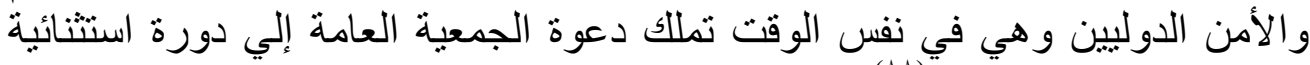

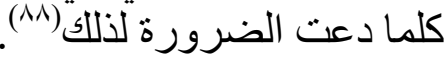

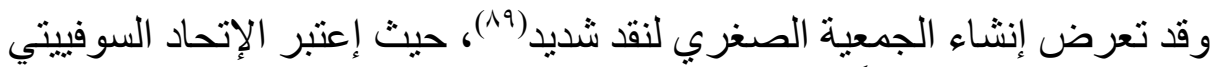

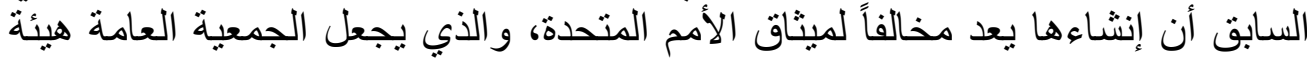

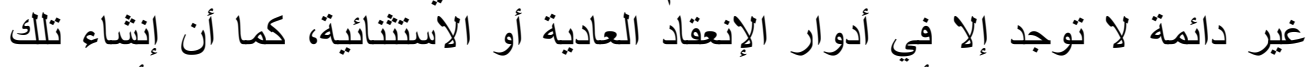

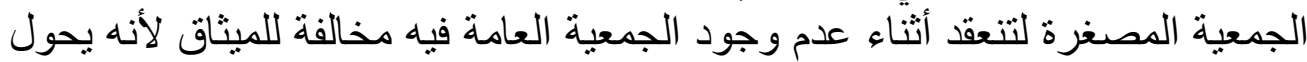

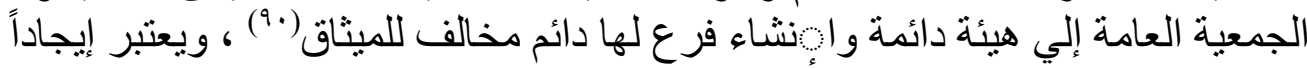

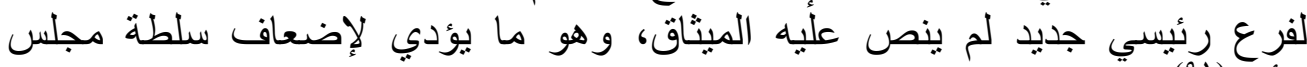
(91) الأمن (9)

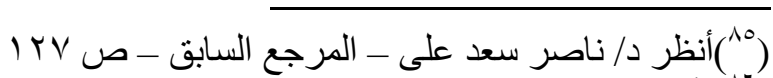

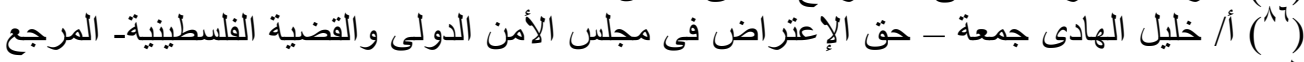

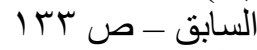

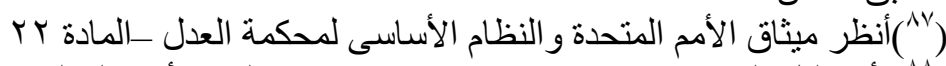

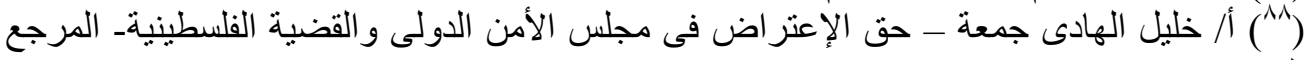
السابق - ص سب السادي

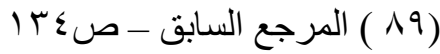
(9) (9/ رشاد السيدعارف، الوسيط في المنظمات الدولية، دار و ائل للنشرو التوزيع،عمان، 2001 (ص ص98،

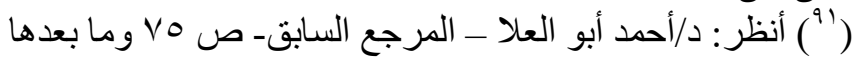




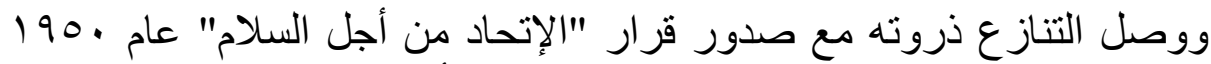

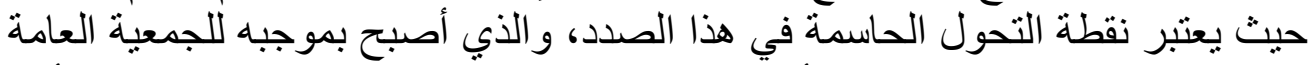

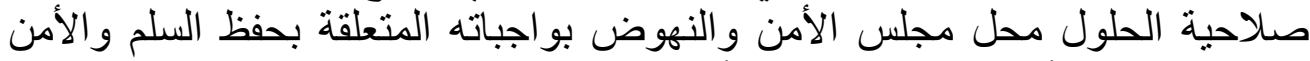

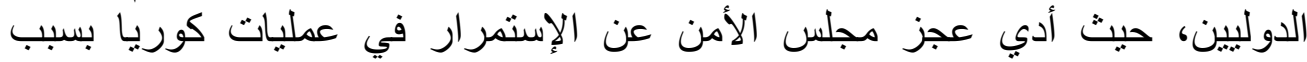

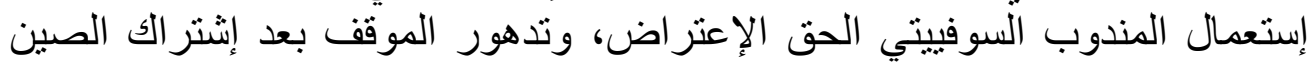

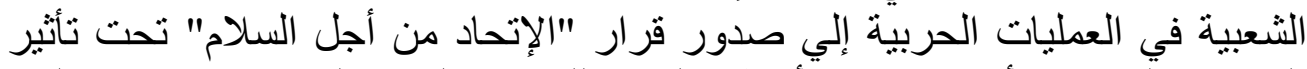

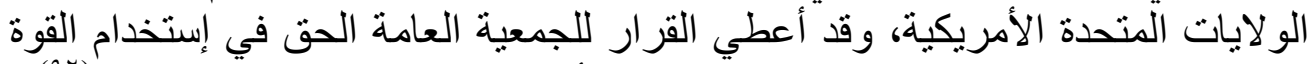

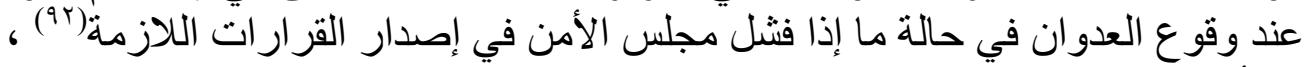

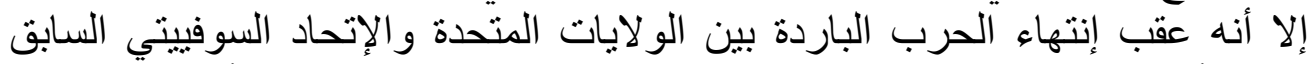

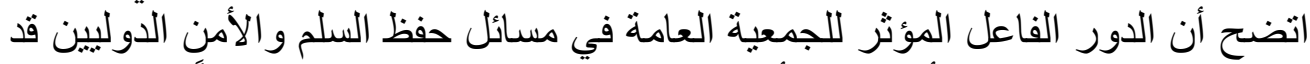

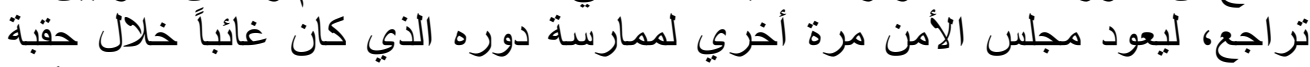

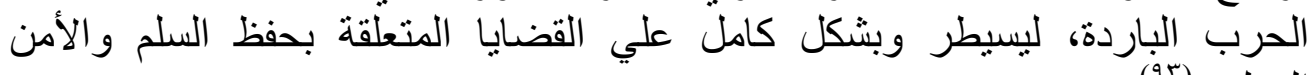
الدوليين("ج)

فكما كانت هناك اسباب سياسية خفية لإنشاء القرار و إعطاء الجمعية مثل هذه

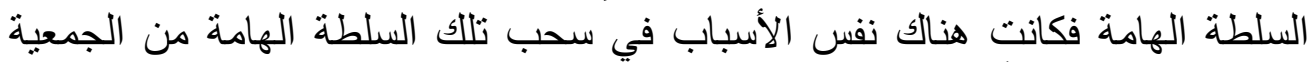

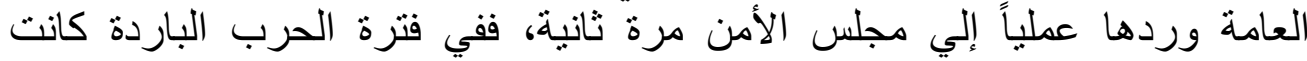

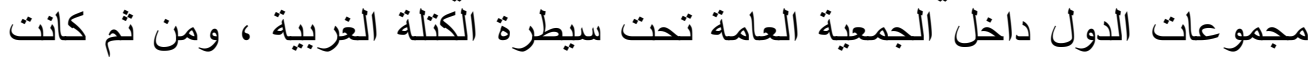

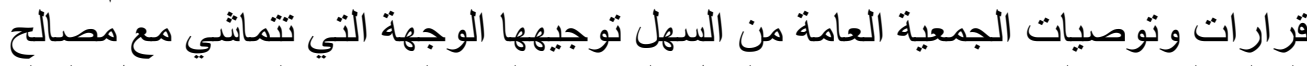

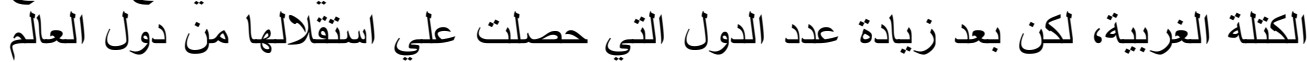

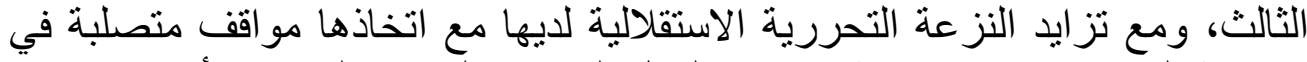

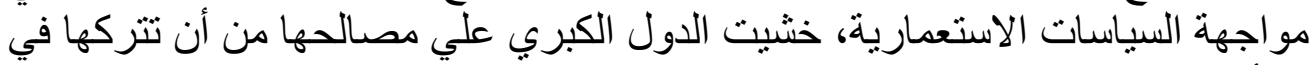

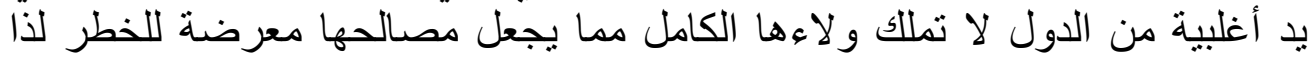

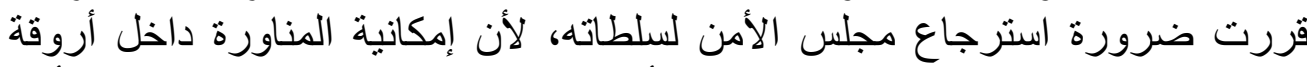

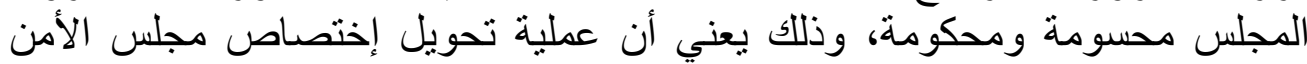

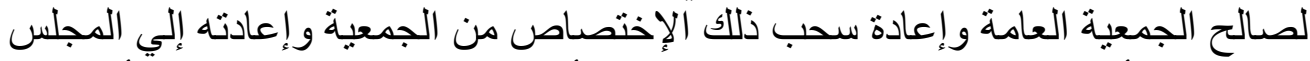

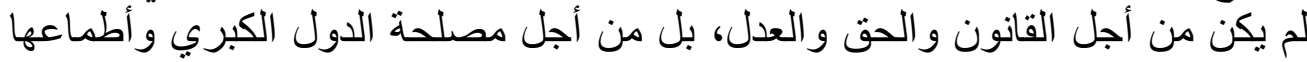

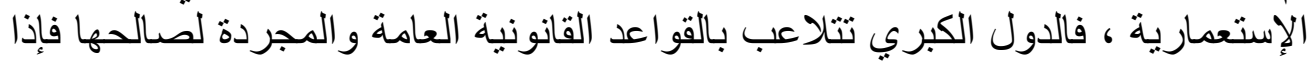
وجدت مصلحتها في تطبيقها طبقتها، و إن وجدت بلت عكس ذللك ضربت بمبادئ القانون

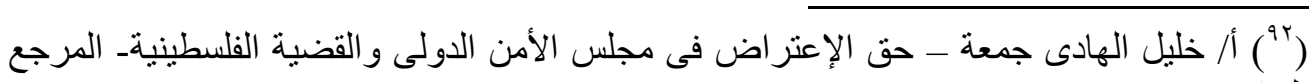

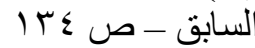

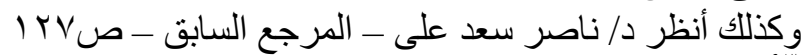

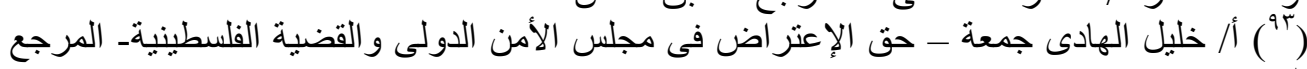

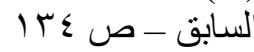


عرض الحائط. أي أن إمكانية تطبيق القانون من عدمه، مرتبط بمدي رغبة الدول الكبري في ذللك(ء9).

\section{المطلب الثاني - المي \\ عناصر قرار الإتحاد من أجل السلم الإنم}

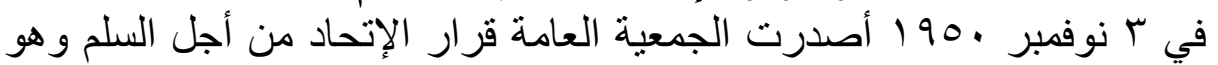

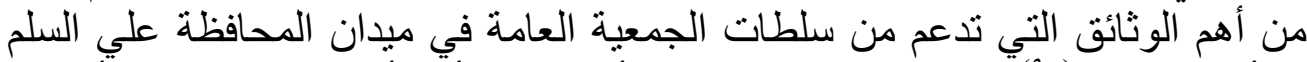

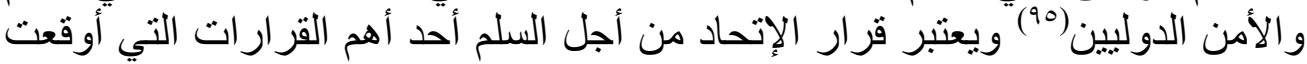

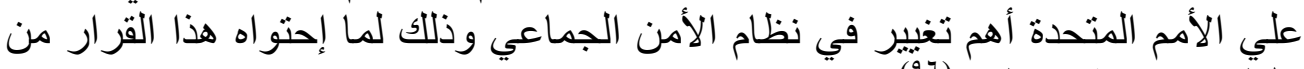

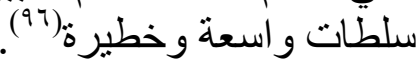

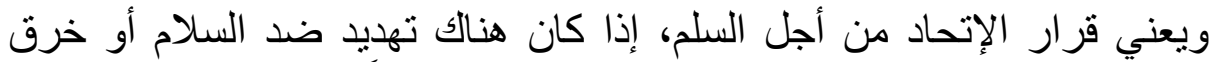

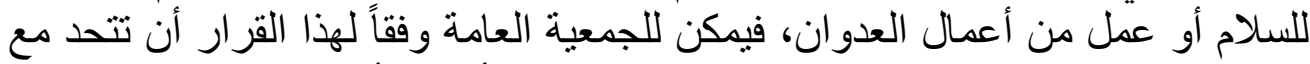

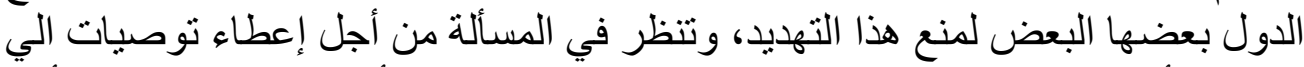

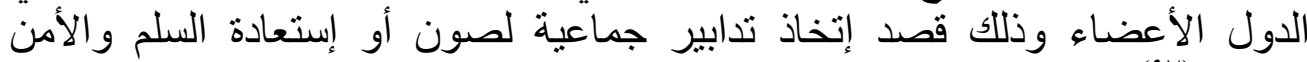

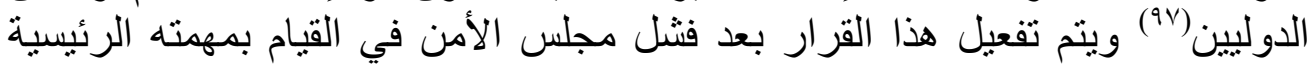

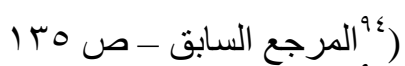

(90) دا محمد حافظ غانم - المنظمات الدولية (دراسة لنظرية التنظيم الدولى ولأهم المنظمات)-

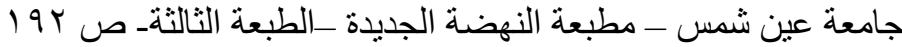

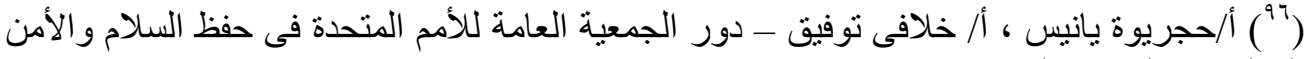

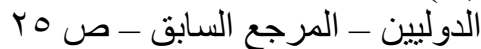

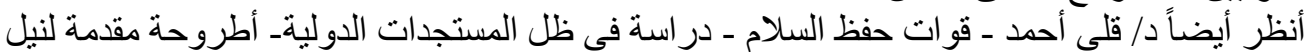

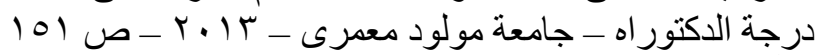

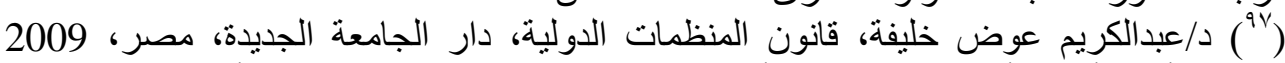

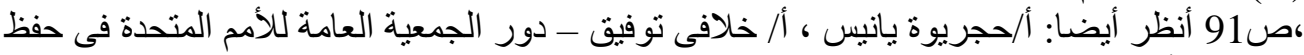

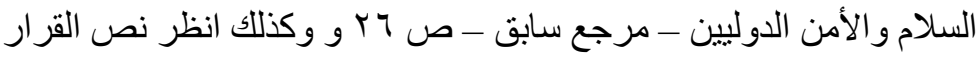
BAN KI-Moon, à l'ouverture du débat général Conformément à la résolution 377 (V): «L'union pour le maintien de la paix» adoptée par l'Assemblée générale en novembre 1950 'l'Assemblée générale peut agir si le Conseil de sécurité s'abstient de le faire par suite du vote négatif d'un de ses membres permanents. Tel pourrainacted'agression.L'Assembléegénérale pourrait examiner la question en vue de formuler des recommandations aux États Membres pour qu'ils adoptent des mesures collectives en vue de maintenir ou de rétablir la paix et la sécurité internationales. Le Rôle De L'assembleé General. Sur le site électronique

: www.un.org/fr/peacekeeping/operation/rolega.shtml,consulterle:17/04/2017 $\underline{16 \mathrm{~h} 09 \mathrm{~m}}$ 
و هي حفظ الأمن والسلم الدوليين، وذللك بسبب إستخدام الحق في الإعتر اض اضلئ (الفيتو)

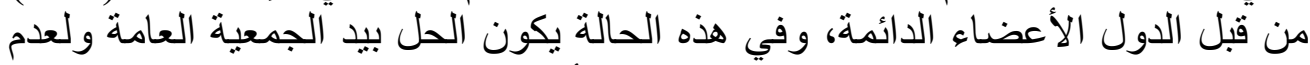

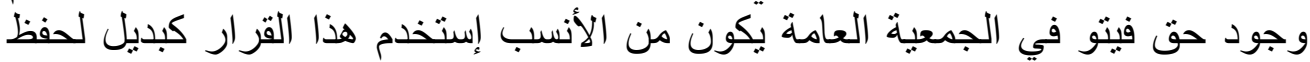
وصيانة الأمن و السلم الدولينين.

وبالتالي فإن الأحكام التي قام عليها قرار الإتحاد من أجل السلم تتضمن ما يلي :-

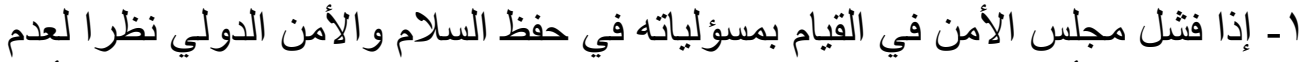

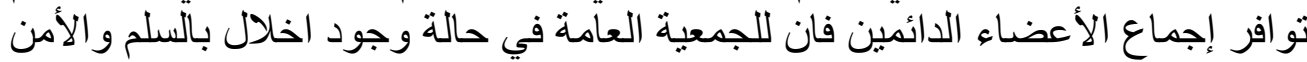

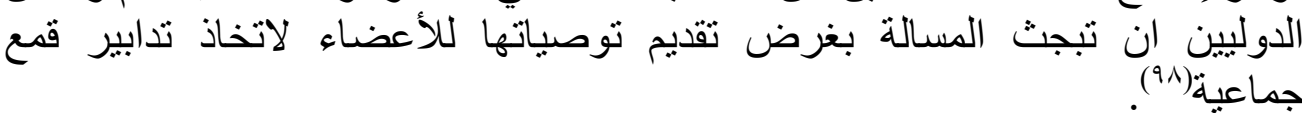

يعتبر هذا الحكم من أهم الاحكام الذي تضمنها القرار حيث بموجب هذا الحكم

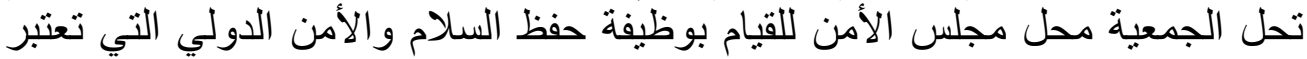

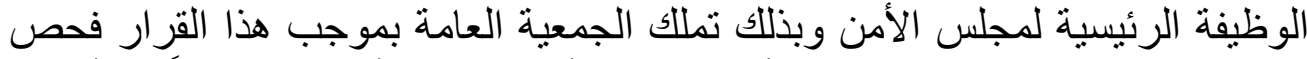

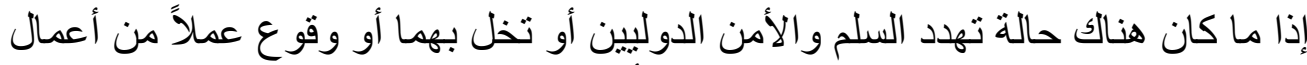

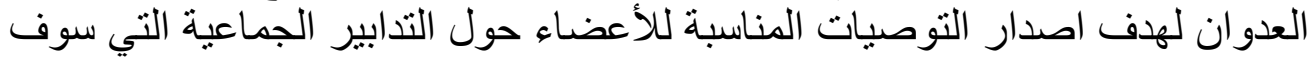

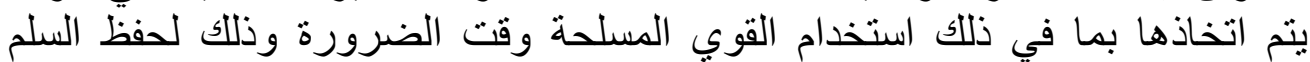

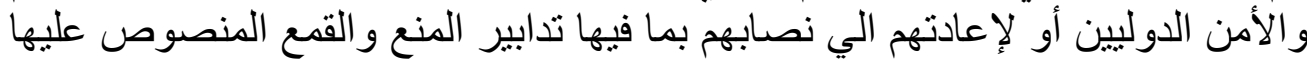

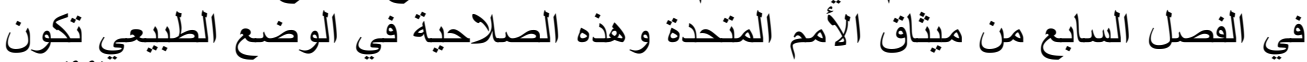

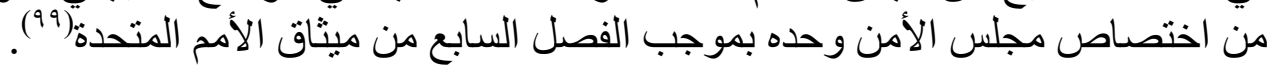

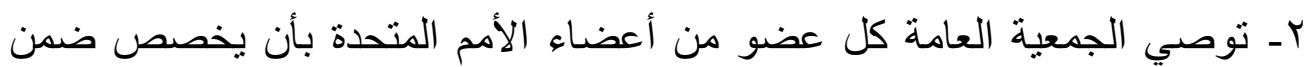

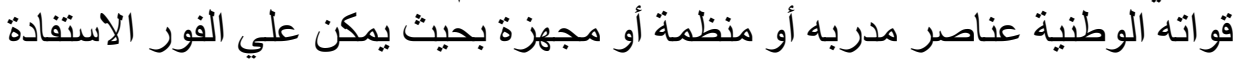

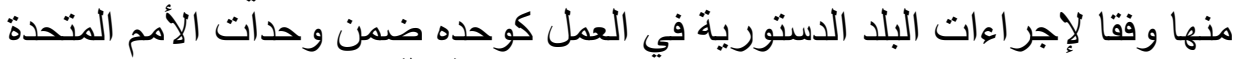

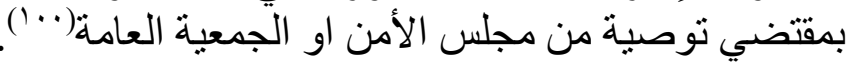

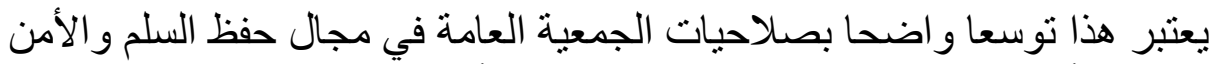

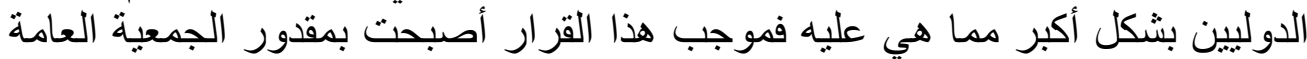
اللجو ء الي استخدام الادوات أو الوسائل الذي يستخدمه مجلس الأمن لحفظ السلم و الأمن

مشار اليه فى أ/حجريوة يانيس ، أ/ خلافى توفيق - دور الجمعية العامة للأمم المتحدة فى حفظ السلام

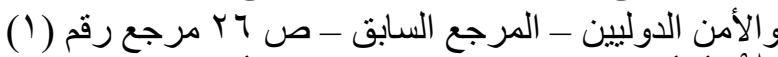

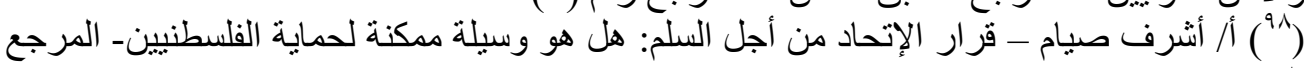
السابق - ص ז'

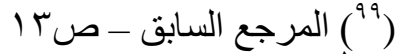

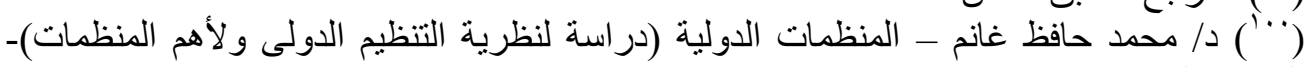

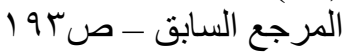


الدوليين بما في ذلك المنع كعقوبات غير عسكرية و القمع كعقوبات عسكرية

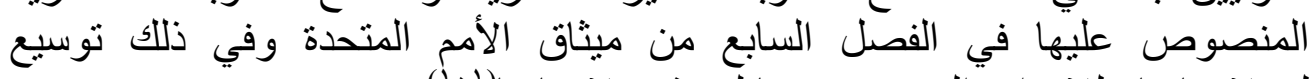

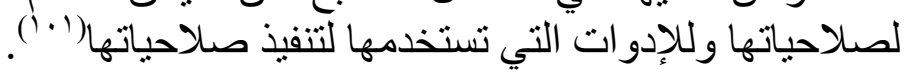
بـ كما نص القرار علي تثكيل لجنتين :

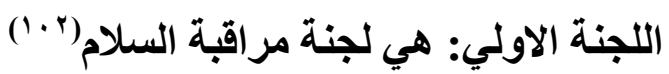

وتتكون هذه اللجنة من ع أ عضوا وهي (الصين، كولمبيا، الولايات المتحدة

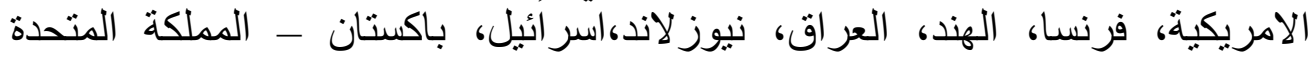

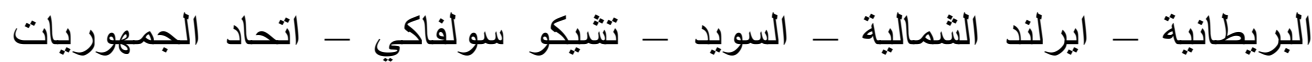

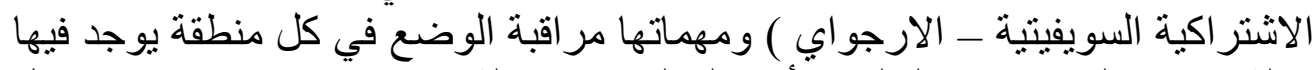

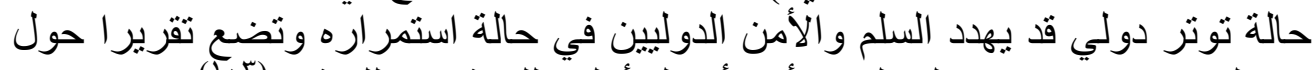

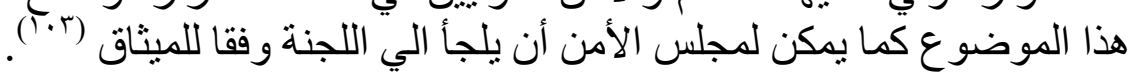

\section{اللجنة الثانية: لجنة الإجراءات الجماعية}

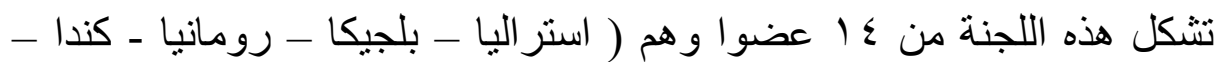

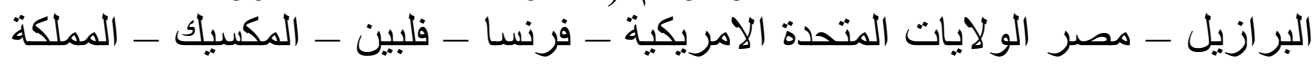

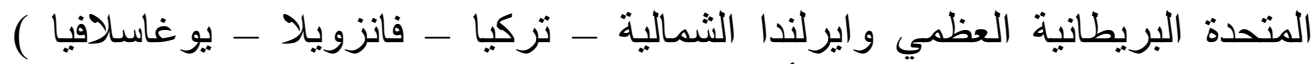

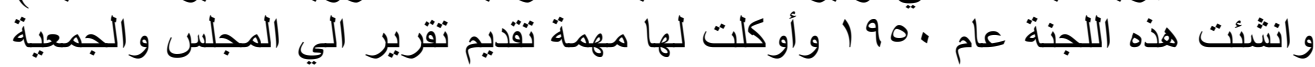

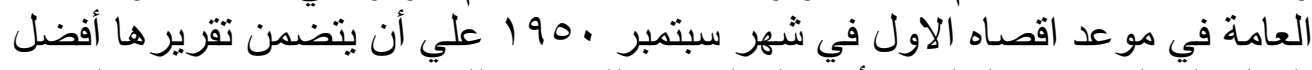

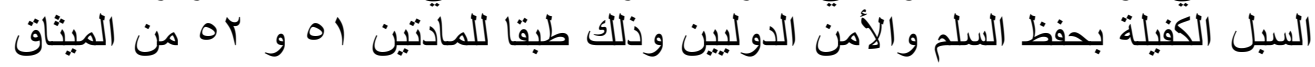

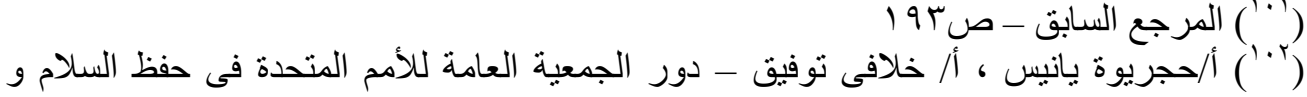

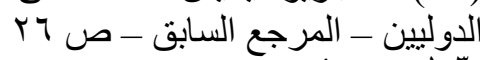

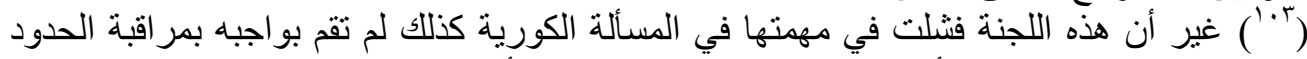

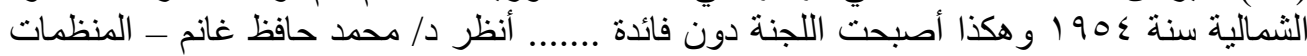

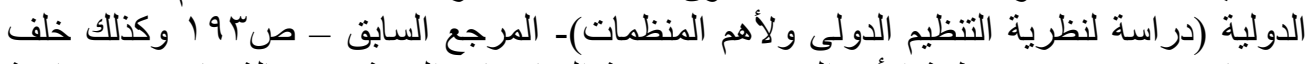

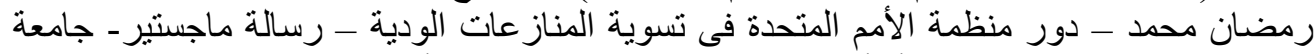

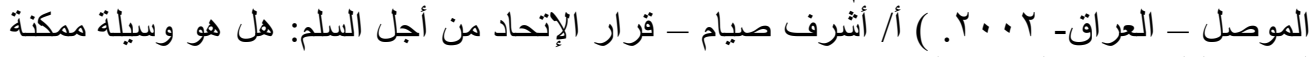

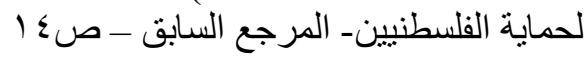




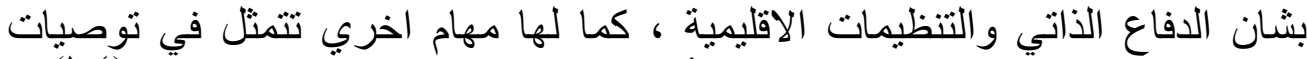

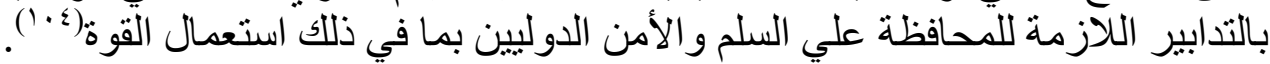

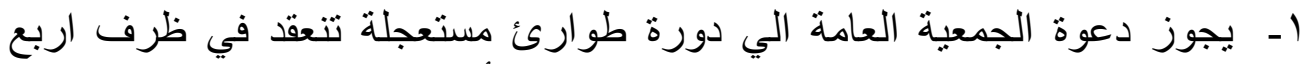

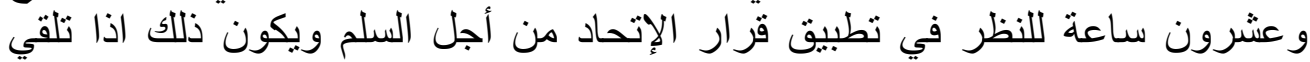
السكرتير العام للأمم المتحدة طلبا بهذه الثنان من مجلس الأمن بمو افقة 9 من أعضاءهاء العناه

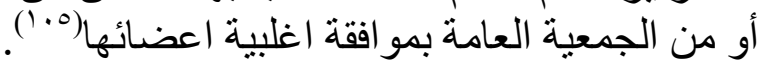

\section{المبحث الثاني}

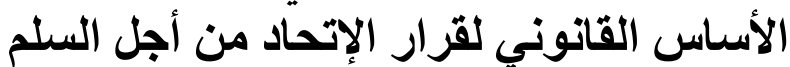

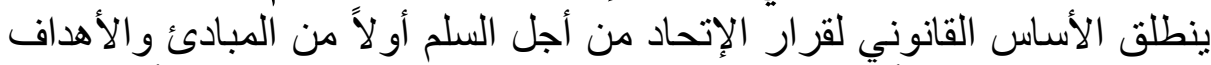

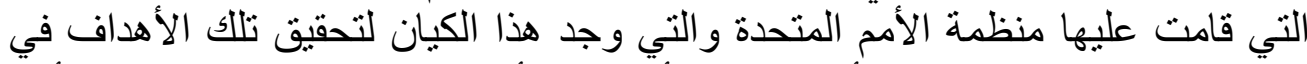

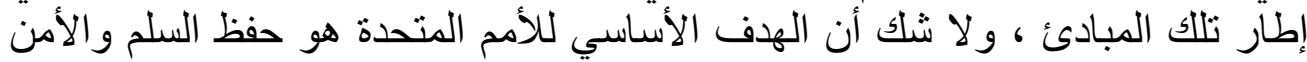

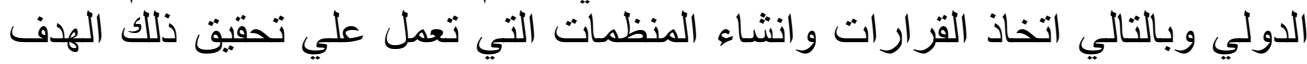

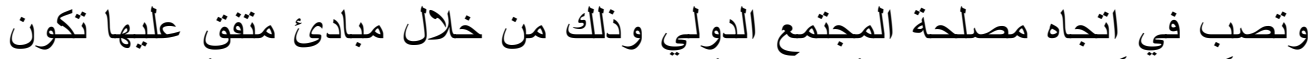

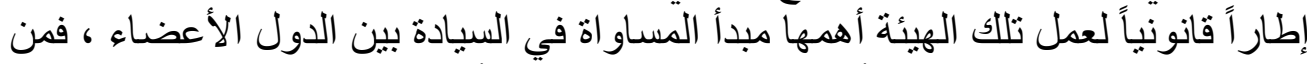

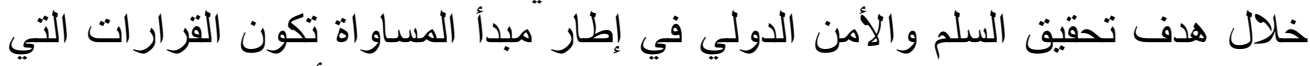

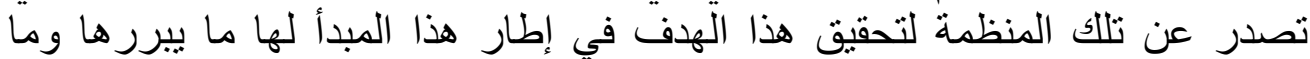

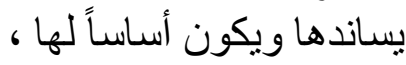

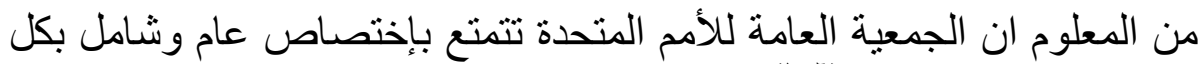

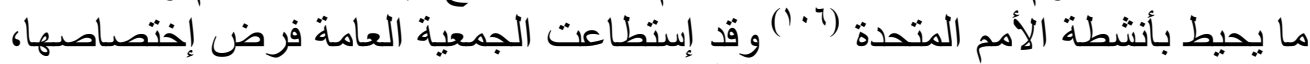

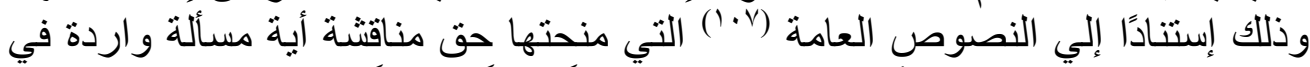

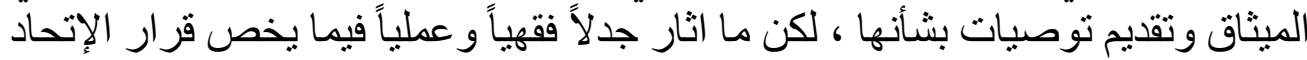

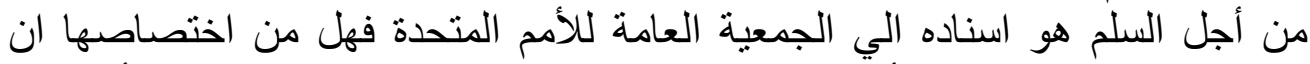

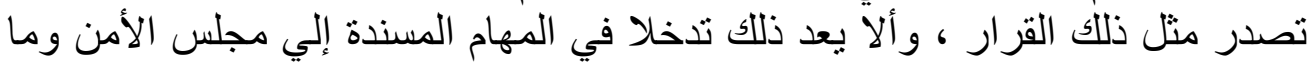

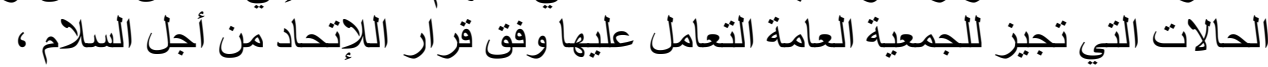

(ء.1أ) أحجريوة يانيس ، أ/ خلافى توفيق - دور الجمعية العامة للأمم المتحدة فى حفظ السلام و

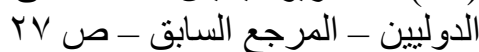
(1.0) د/ محمد حافظ غانم الين - المنظمات الدولية (در اسة لنظرية التنظيم الدولى ولأهم المنظمات)-

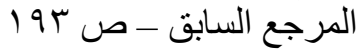
(7 ( 1 ) د / محمد سامي عبدالحميد،أصول القانون الدولي العام، الجزء الأول، الجماعة الدولية،الطبعة

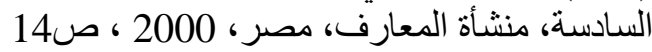
( ع • ( ) د/ جعفر عبدالسلام،المنظمات الدولية، الطبعة السادسة، دار النهضة العربية، مصر، 1990 ، 1400 ص - Max Hilaire, Role of the United Nations in the Post Cold War ERA ,Revue de droit international, Genève, Volume 78, $\mathrm{N}^{\circ} 02$, Mai-août 2000 , p 129 
من هنا كان الخلاف العملي والسياسي والقانوني فيما يخص هذا القرار بين

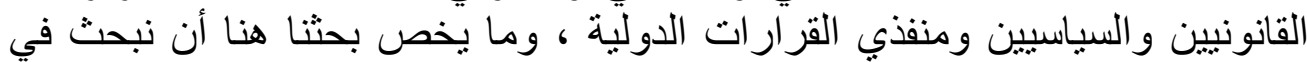

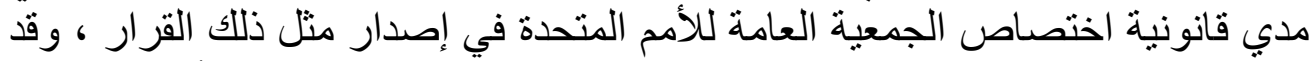

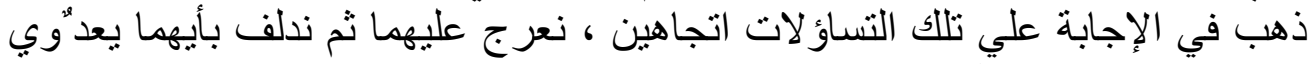

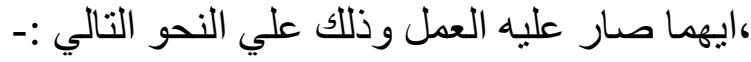

\section{الإتجاه الأول : اختصاص الجمعية العامة بإصدار القرار}

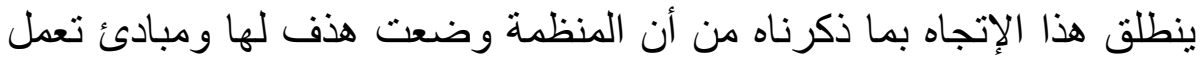

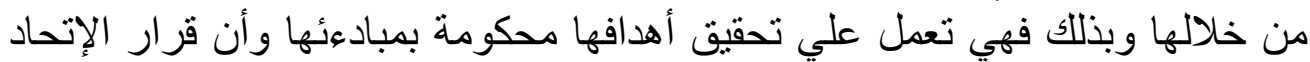

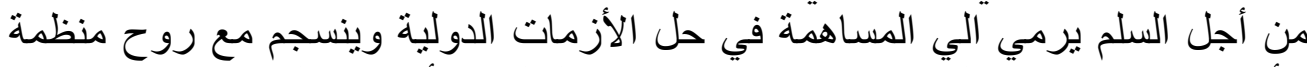

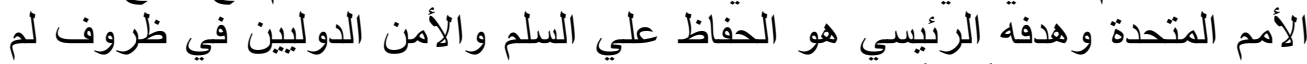

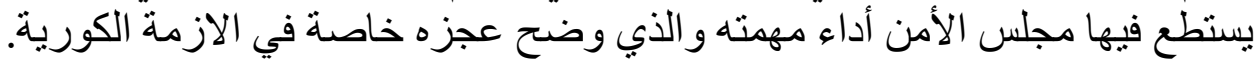

و يستند هذا الر أي في القول بأن الجمعية العامة مختصة في اصدار القرار إلي ما ما يلي :-

ا ـ أنه إذا كانت المادة الرابعة والعشرون من الميثاق قد أسندت في فقرتها الأولي

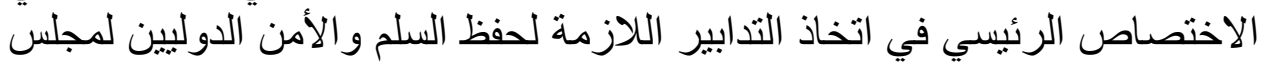

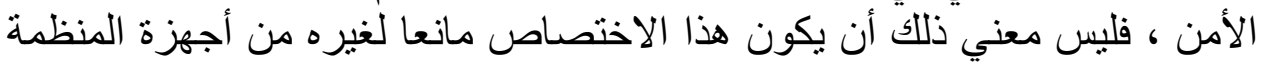

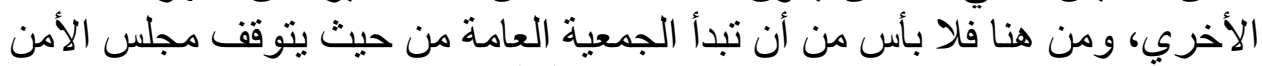

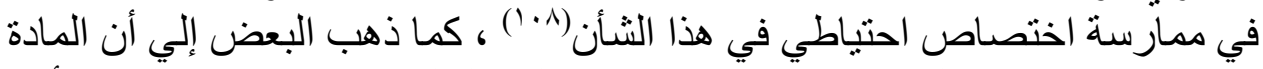

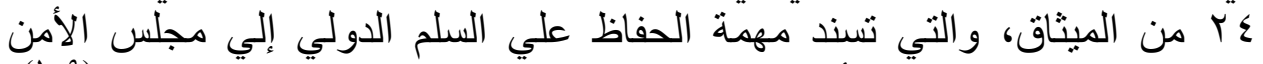

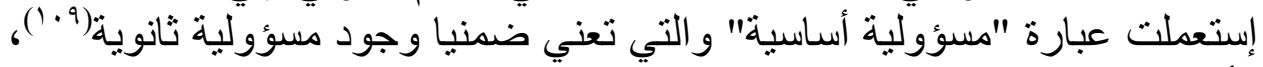

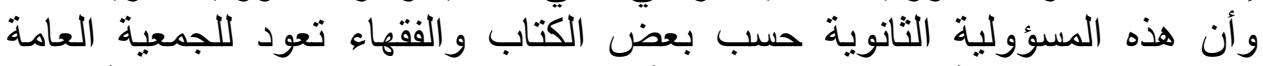

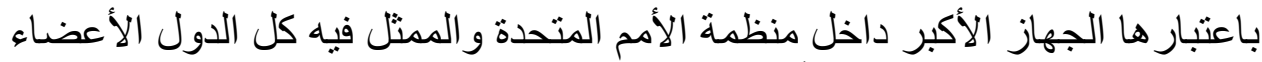

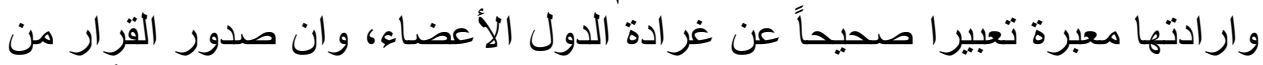

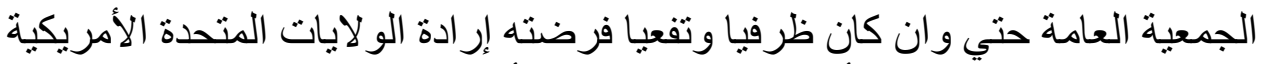

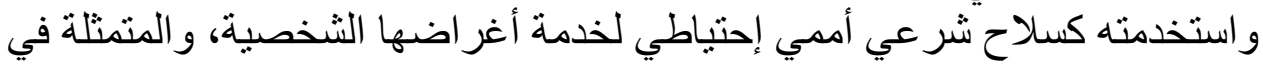

(·1) د/ إبراهيم أحمد محمد إلياس- سلطات مجلس الأمن فى تسوية المنازعات الدولية بالطرق

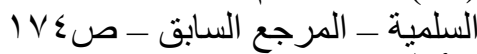

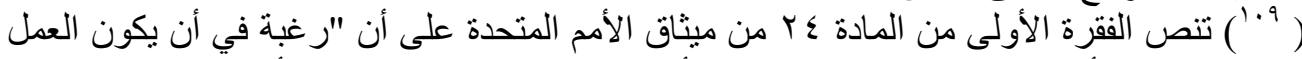

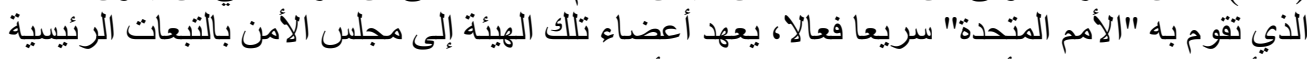

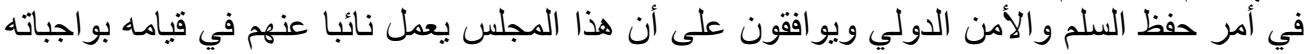

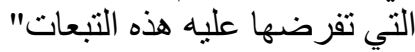
د/جابر ابر اهيم الر اوى_الأسس القانونية لقو ات حفظ السلام الدولية، مطبعة دار السلام، العر اق، 1979 165، 


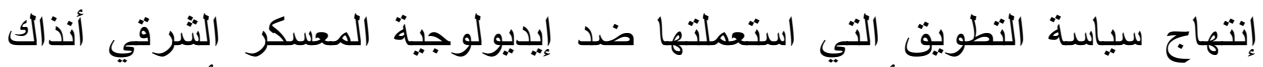

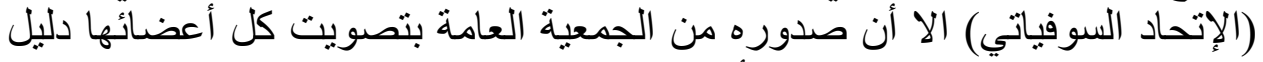

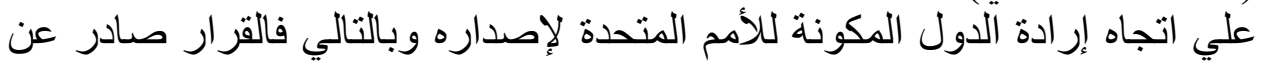

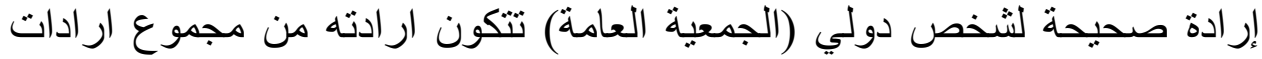

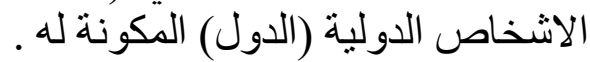

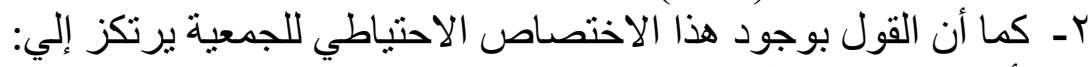

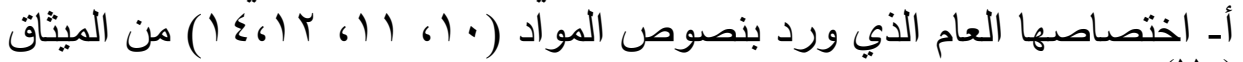

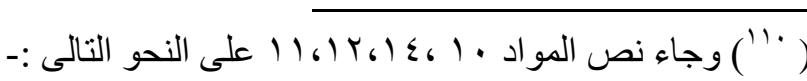

$$
\begin{aligned}
& \text { المادة • } 1
\end{aligned}
$$

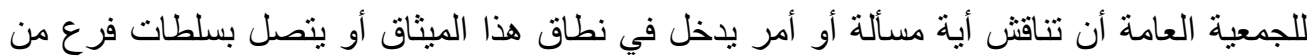

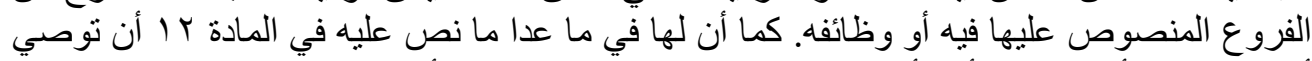
أعضاء الهيئة أو مجلس الأمن أو كليهما بما تر اه في تلألك المسائل و الأمور.

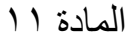

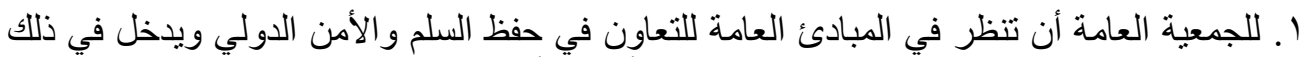

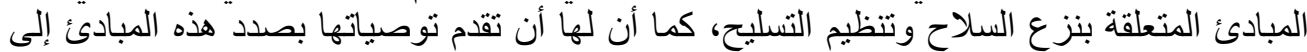

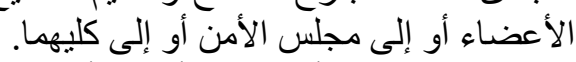

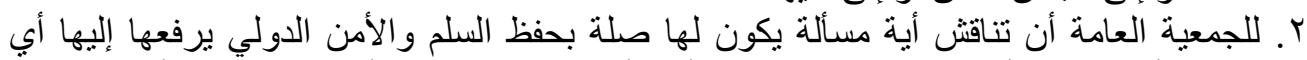

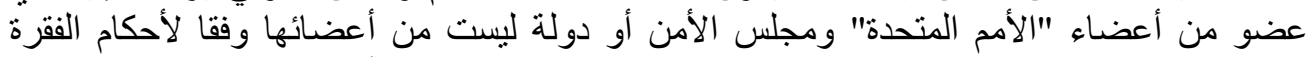

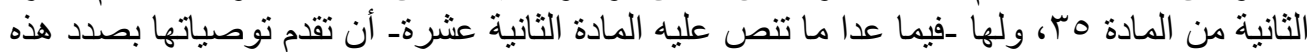

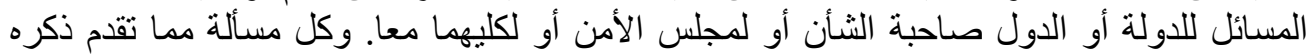

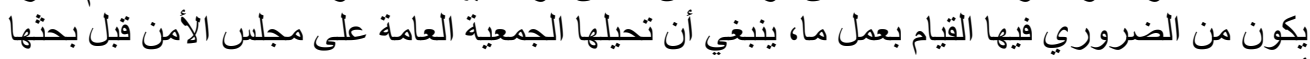

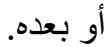
لا. للجمعية العامة أن تستر عي نظر مجلس الأمن إلى الأحوال التي يحتمل أن تعرض السلم والأمن

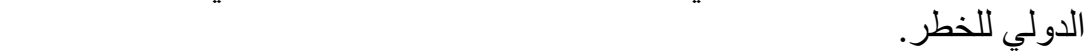
؟ ـ لا تحد سلطات الجمعية العامة المبينة في هذه المادة من عموم مدى المادة العانشرة.

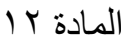

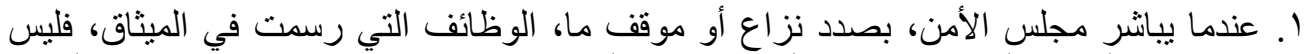

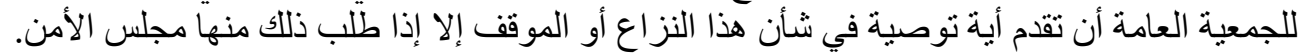

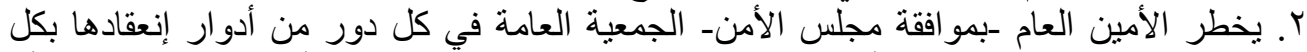

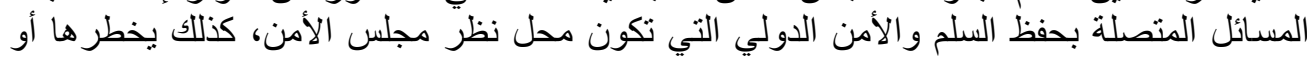

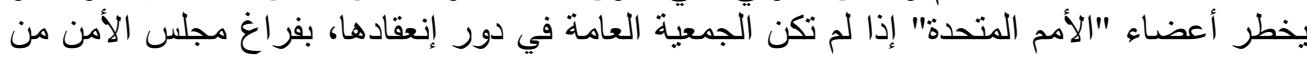
نظر تلك المسائل وذلك بمجرد انتهائه منها.

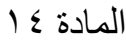

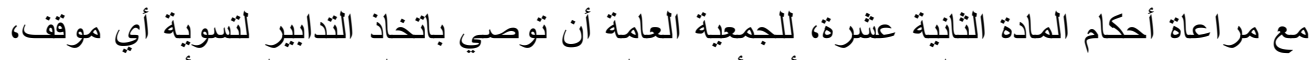

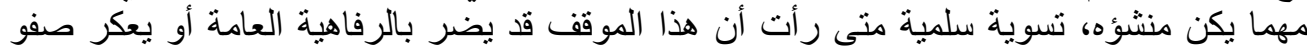

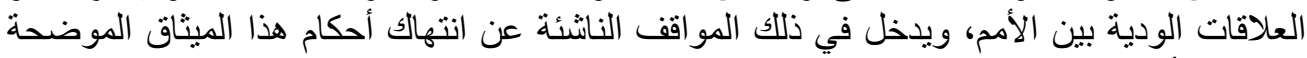

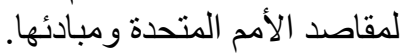


بـ تفسير نص المادة الحادية عشر الفقرة الرابعة من الميثاق علي ضوء المادة (العاثر (11).

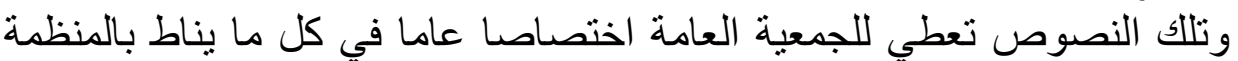

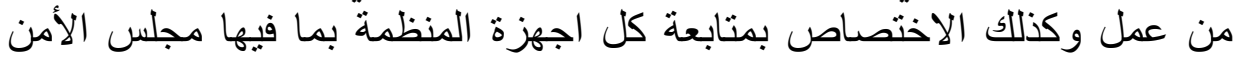

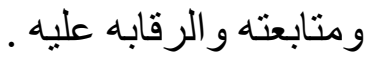

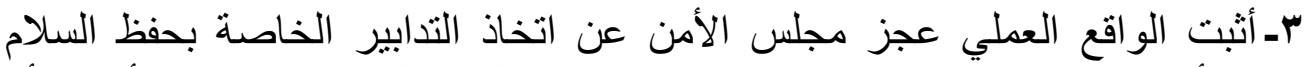

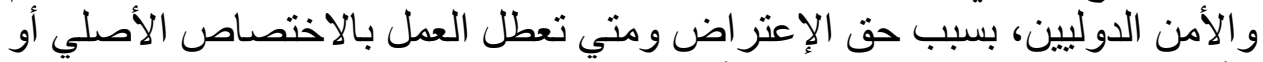

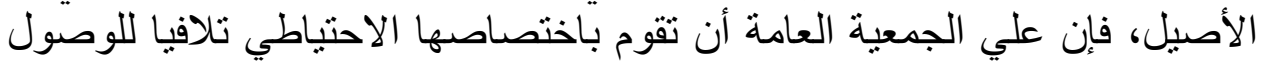

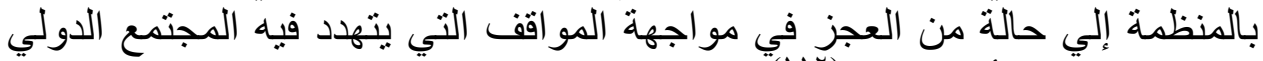

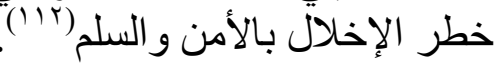

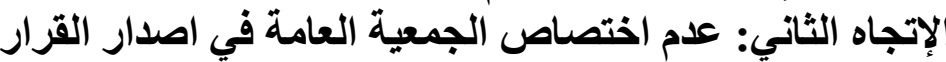

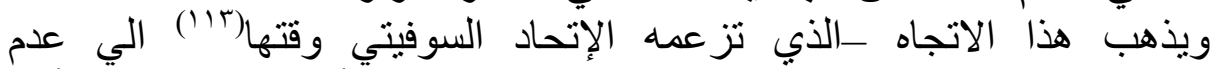

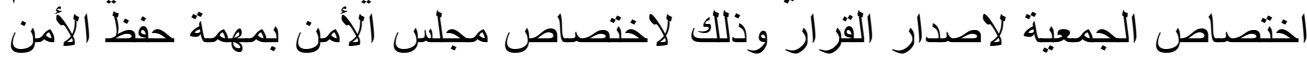

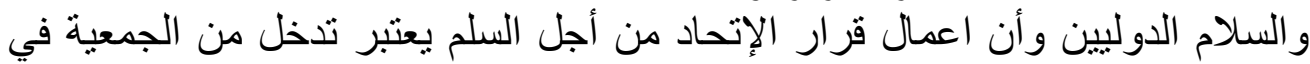

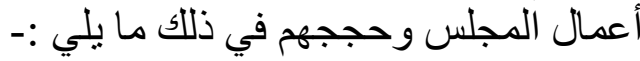

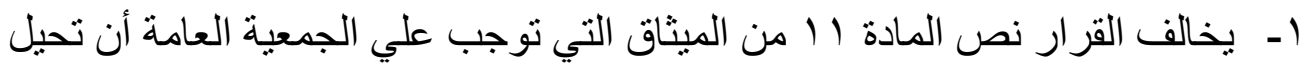

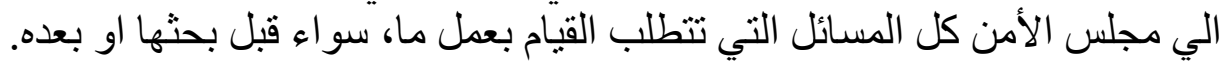

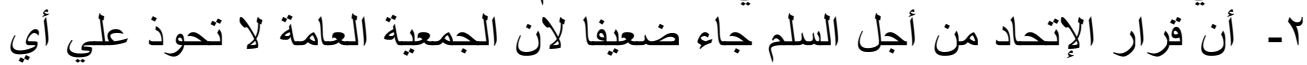

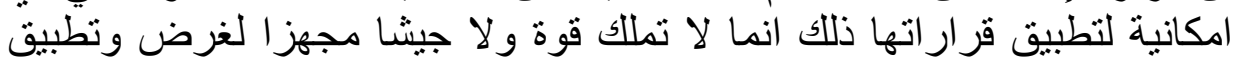

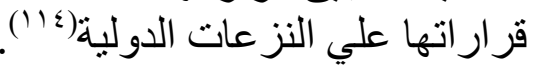

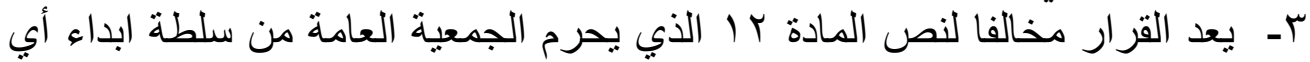

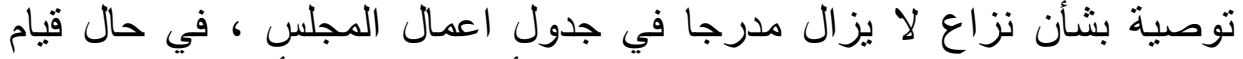

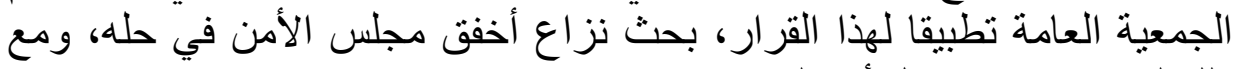
ذللك لم يحذفه من جدول أعماله.

$\left({ }^{112}\right)$ Andrassy. Uniting for peace. A.J.I.L 1956 P.563:582

$$
\text { IV0 - المرجع السابق - ("') }
$$

مشار اليه فى د/ إبراهيم أحمد محمد إلياس- سلطات مجلس الأمن فى تسوية المنازعات الدولية

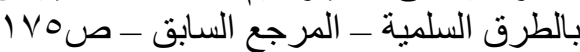

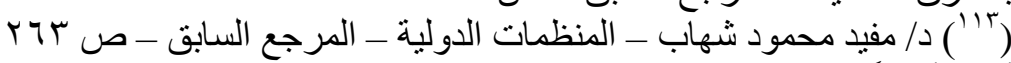
أنظر أيضاً د/ محمد حافظ غانم ـ ـ المنظمات الدولية (در استة لنظرية التنظيم الدولى و لأهم المنظمات)-

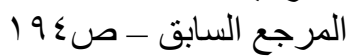
) أر أثرف صيام - قرار الإتحاد من أجل السلم: هل هو وسيلة ممكنة لحماية الفلسطنيين- المرجع

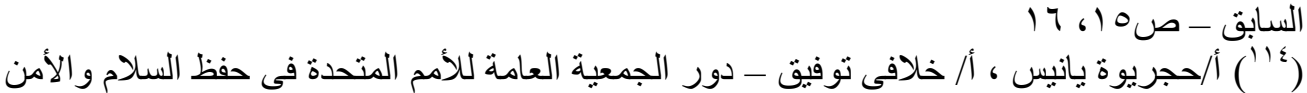

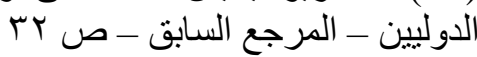


ـ - يذهب أنصار هذا الإتجاه أيضاً إلي القول أن هذا القرار يعد تعديلا لاحكام الميثاق

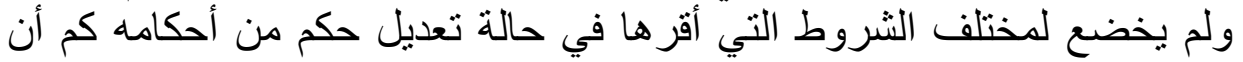

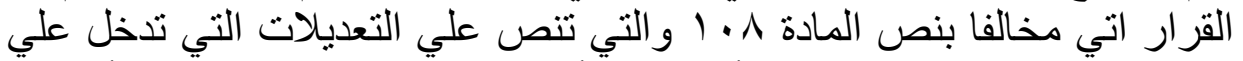

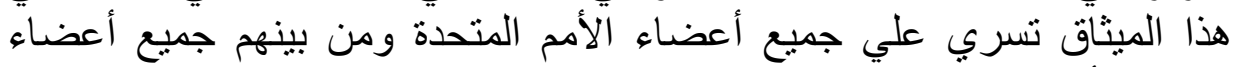

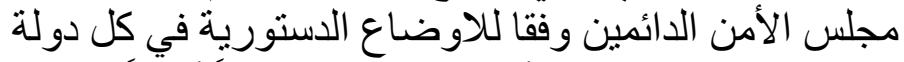

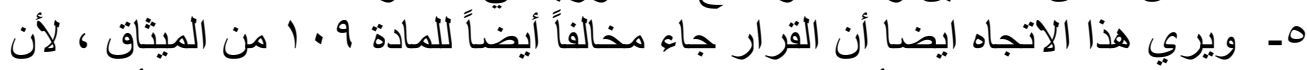

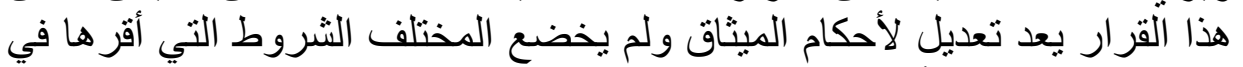
حالة تعديل حكم من أحكامه.

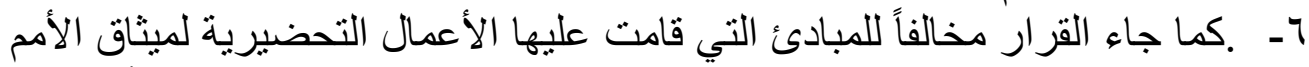

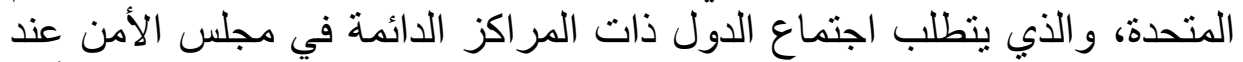

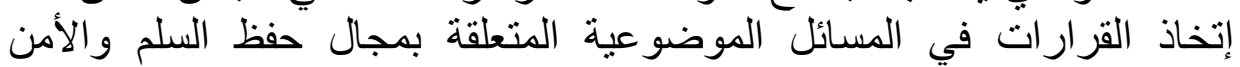

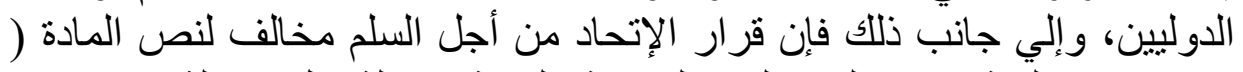

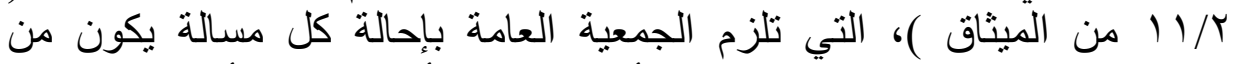

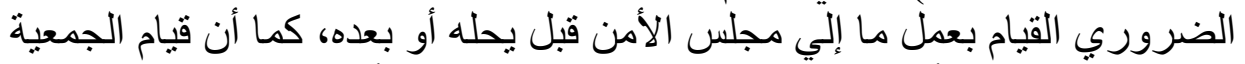

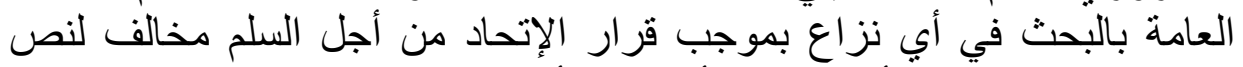

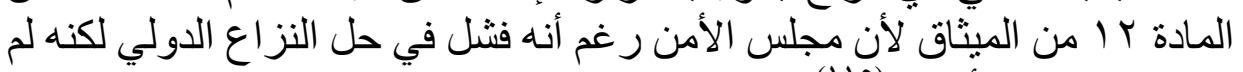

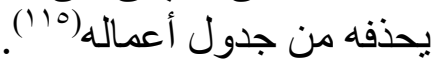

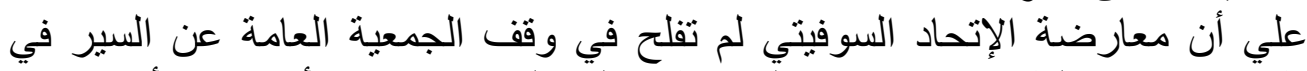

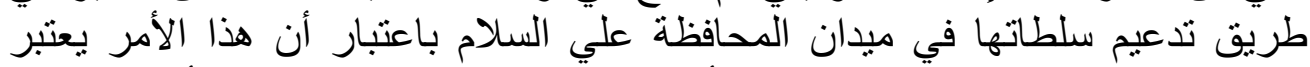

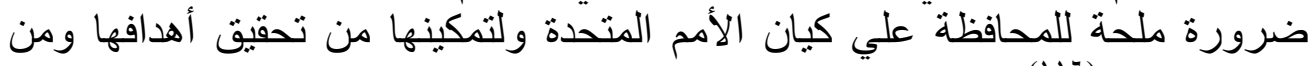

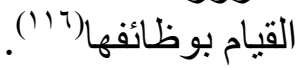

\section{ومن جانبنا}

نؤيد الرأي الأول الذي يري اختصاص الجمعية العامة للأمم المتحدة بإصدار

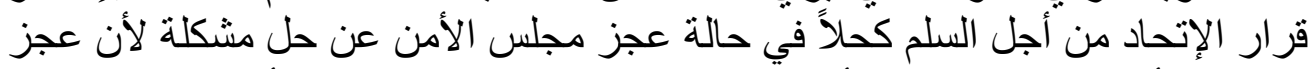

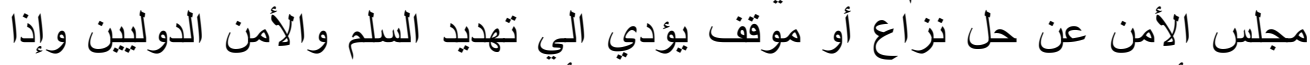

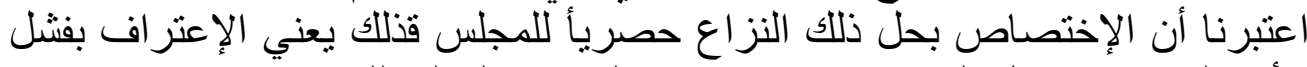

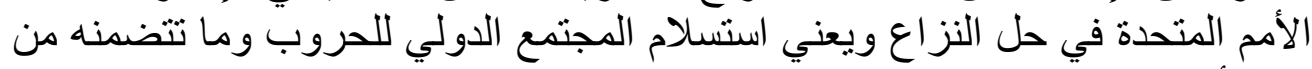

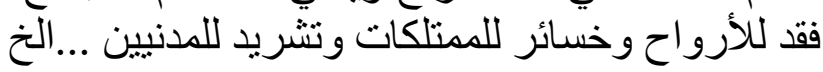

كما أننا نلاحظ أن القرار لم يعطي الإختصاص للجمعية العامة للأمم المتحدة

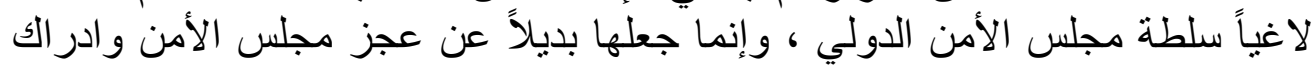

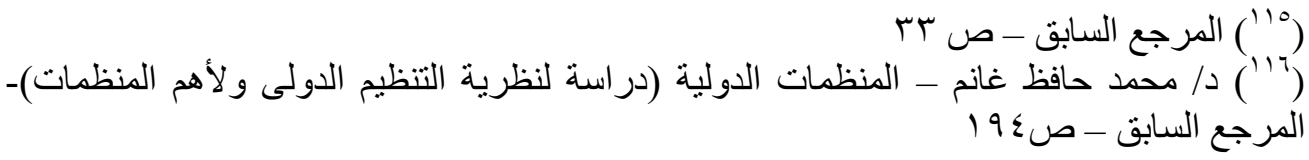




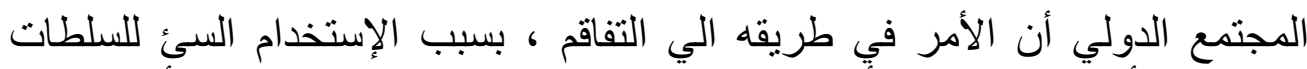

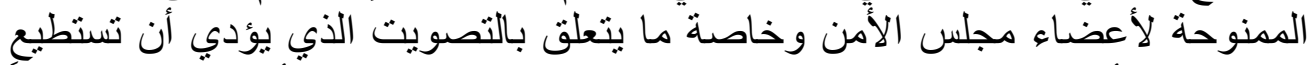

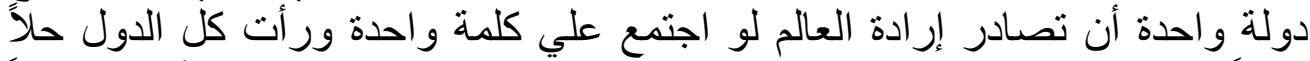

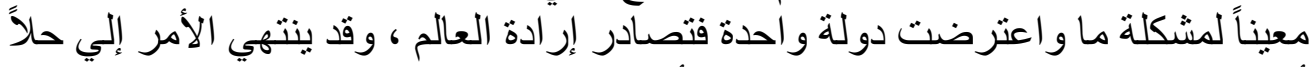

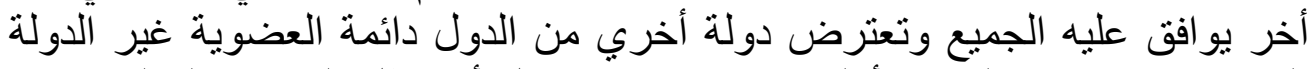

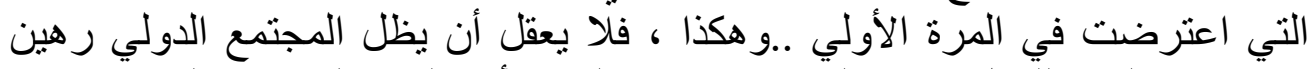

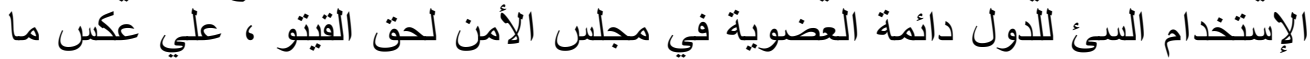

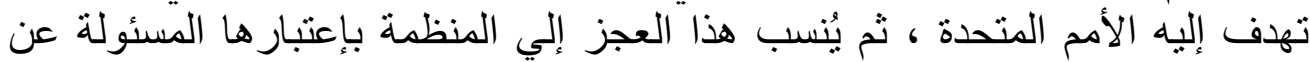

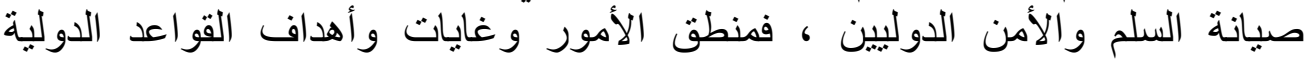

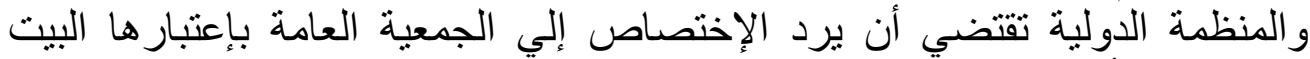

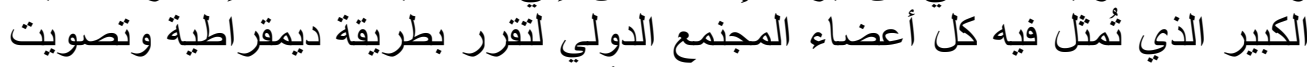

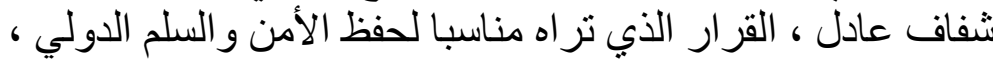

أما عن قانونية إصدار الجمعية العامة للأمم للقر ار rVV (الإتحاد من أجل السلم ) فنري

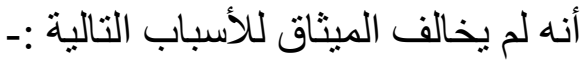

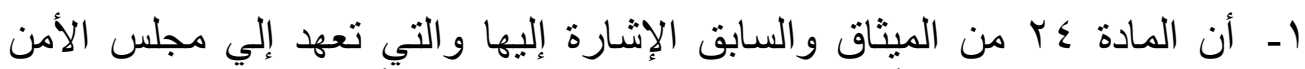

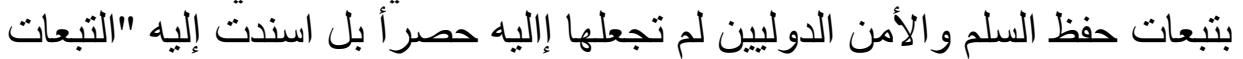

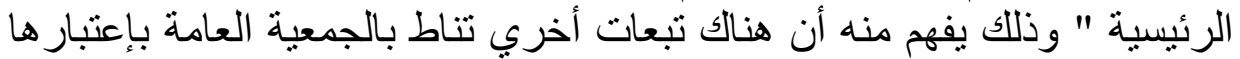

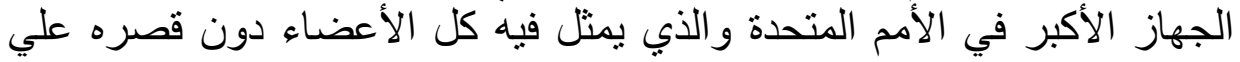

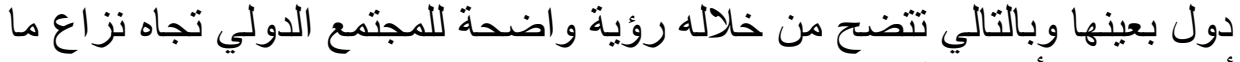

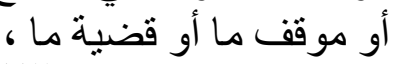

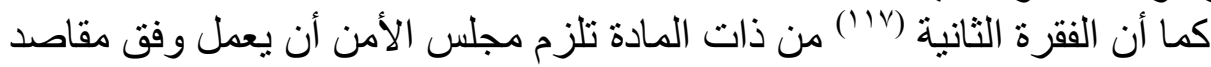

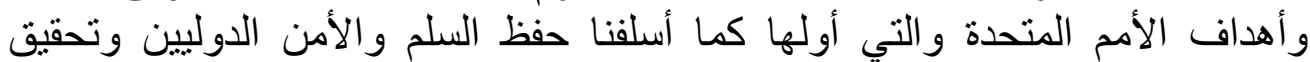

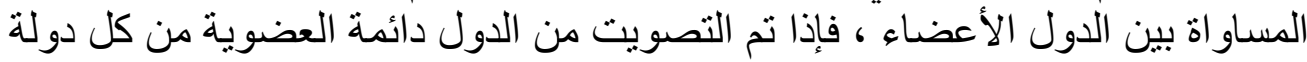

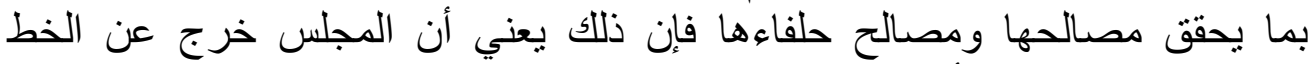

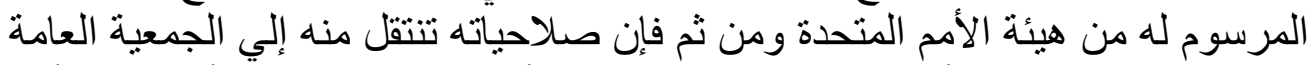

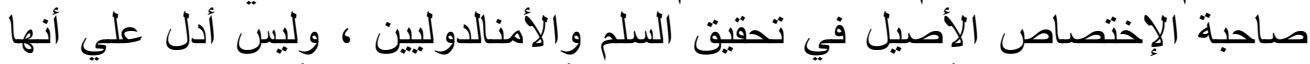

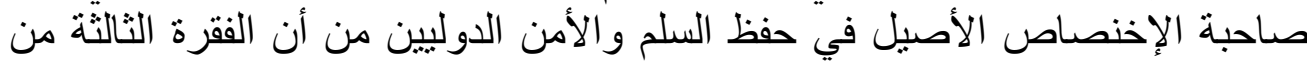

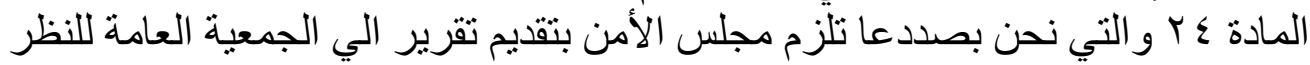

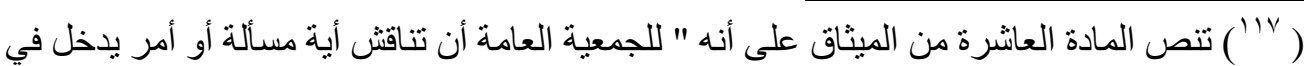

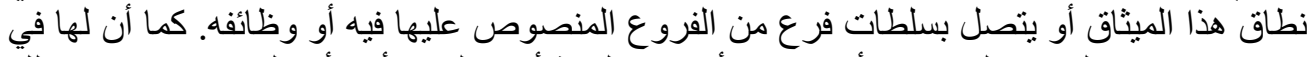

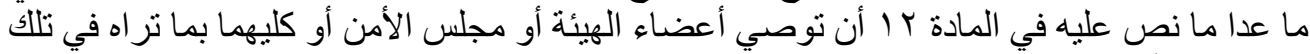

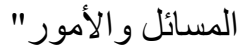


فيها ، ومعني أن مجلس الأمن مرجع تقريرة الي الجمعية العامة انها صاحبة

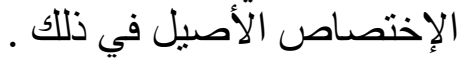
r- أن قرار "الإتحاد من أجل السلام" وضع شرطاً له وهو تطبيقه في حالة عجز

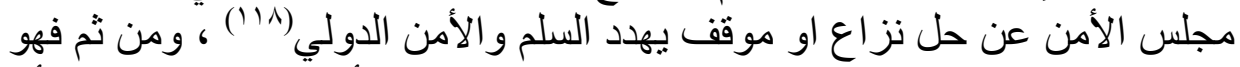

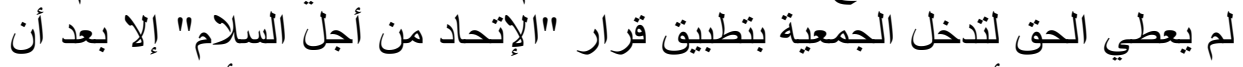

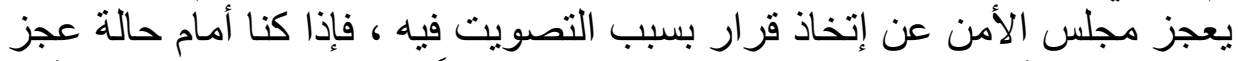

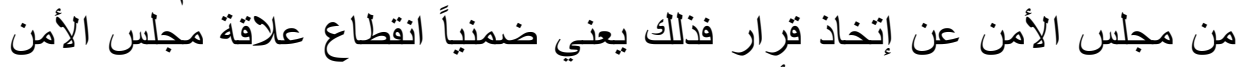

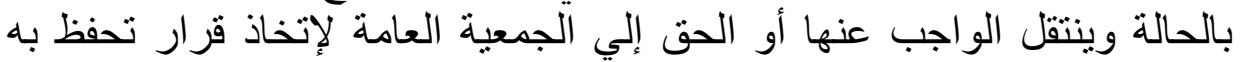

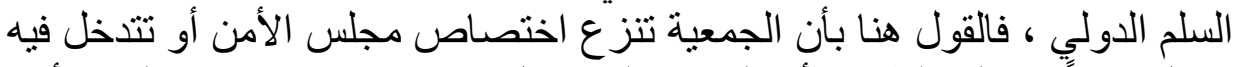

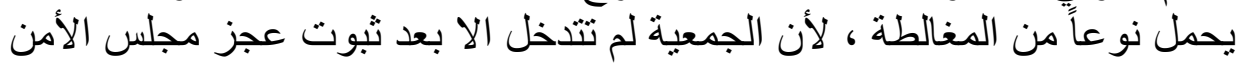

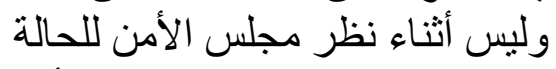

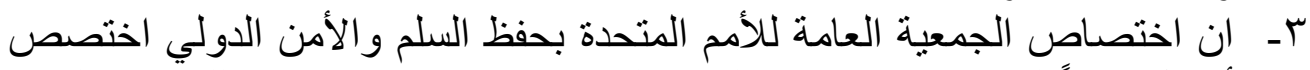

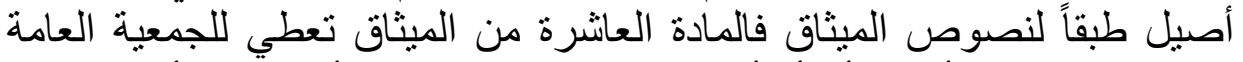

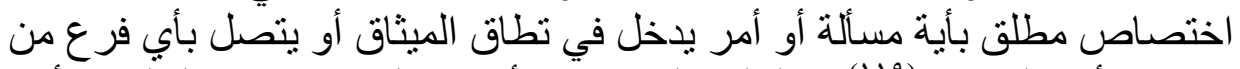

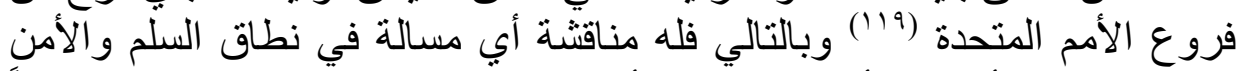

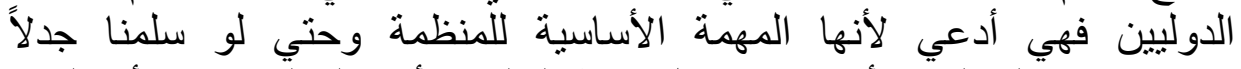

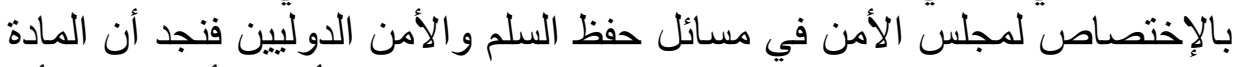

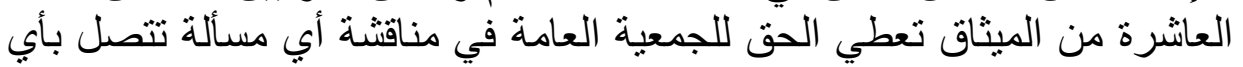

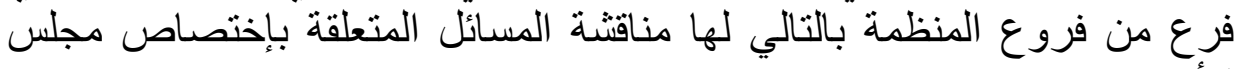

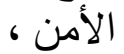

ثم جاءت المادة الحادية عشر لتسير في ذات السياق فتعطي في فقرتها الأولي

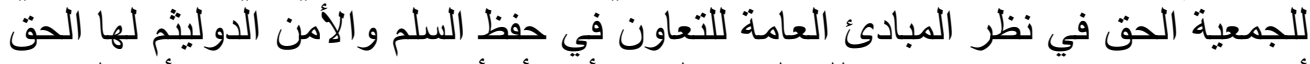

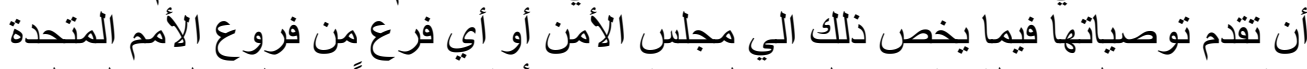

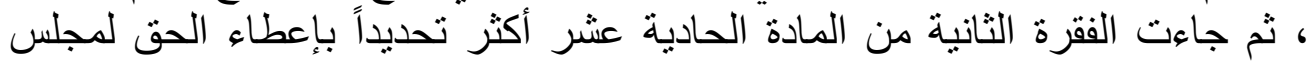

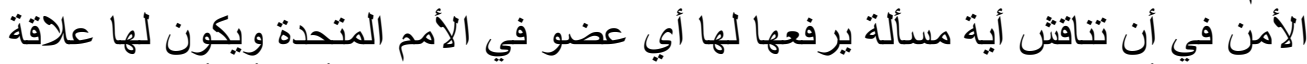

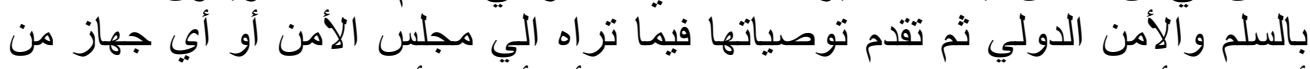
أجهزة الأمم المتحدة ، ثم جاء في عجز المادة أن أي مسألة يكون من المطلوب المبل في فيها

(118) Alex Bellamy, Paul Williams , Stuart Griffin ,Understanding Peacekeeping ,Polity Press , Cambridge, 2004, p47

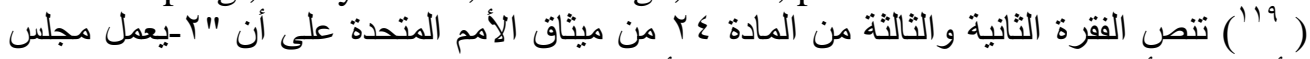

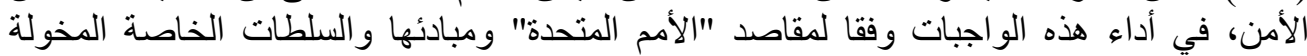
لمجلس الآمن لتمكينه من القيام بهذه الواجبات مبينة في الفصول السادس والسابل السابع والثامن والثاني لئي

يرفع مجلس الأمن تقارير سنوية، وأخرى خاصة، إذا اقتضت الحال إلى الجمعية العامة لتنظر فيها. 


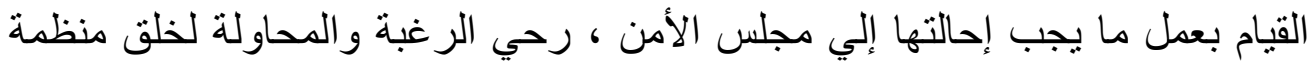

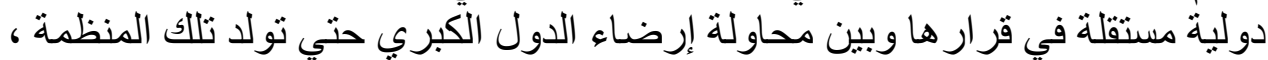

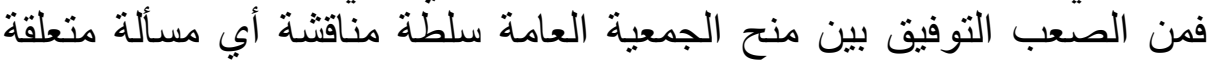

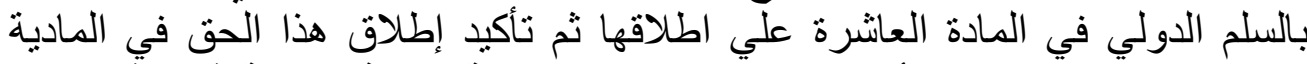

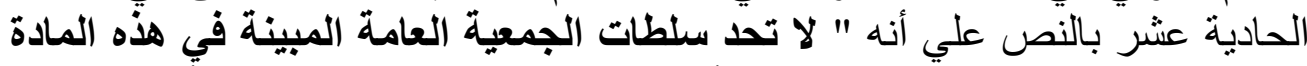

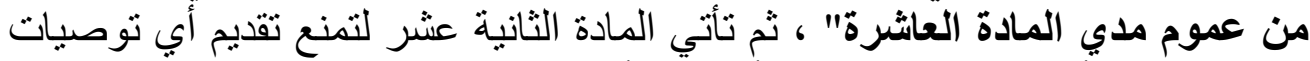

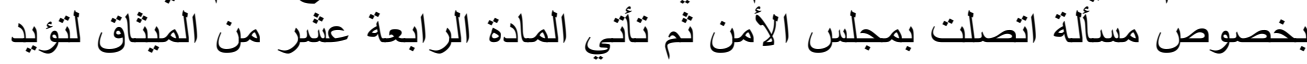

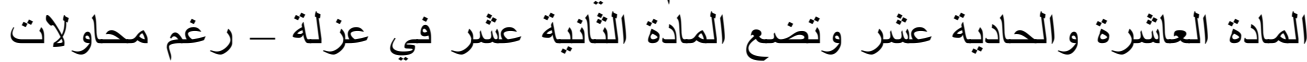

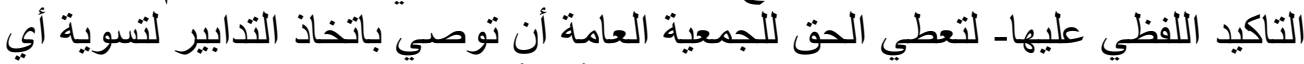

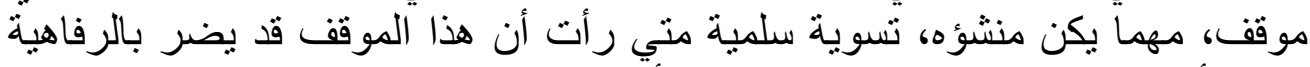

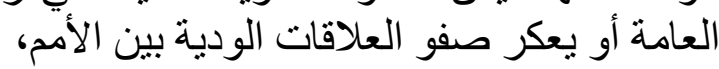

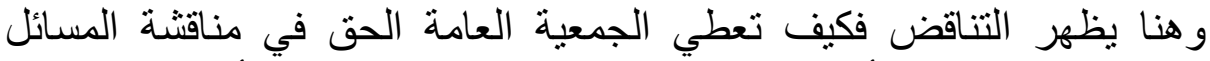

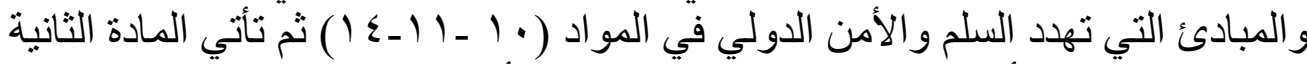

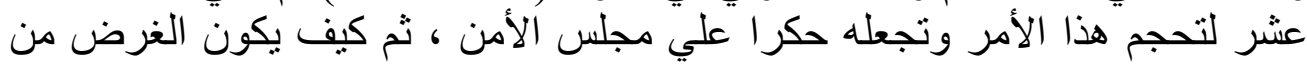

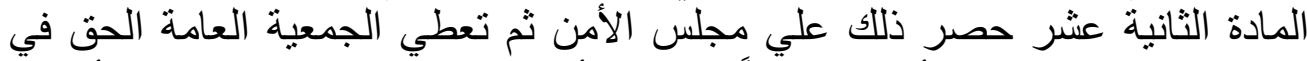

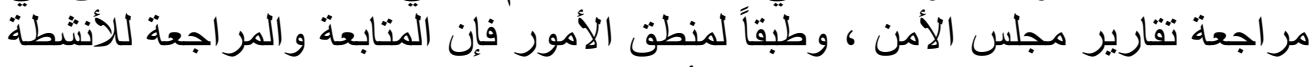

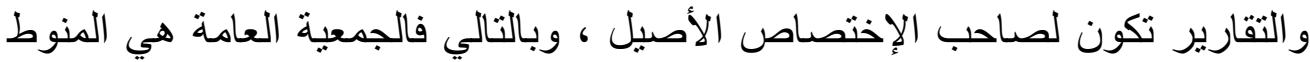

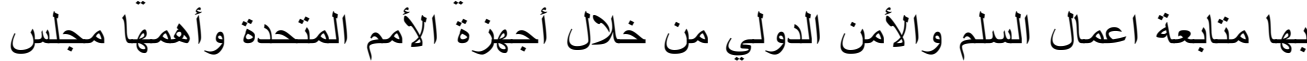

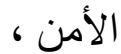
ومن الجدير بالذكر أنه في خلال ممارسة الجمعية العامة لمهمتها في حفظ السلم

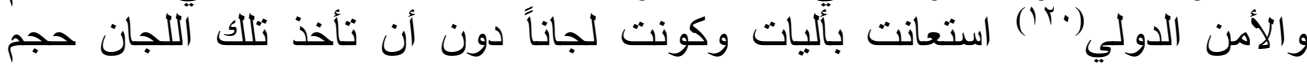

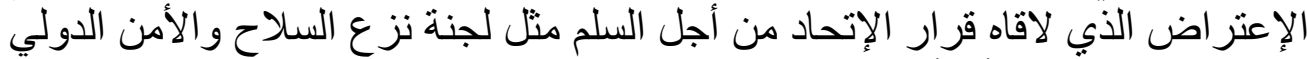

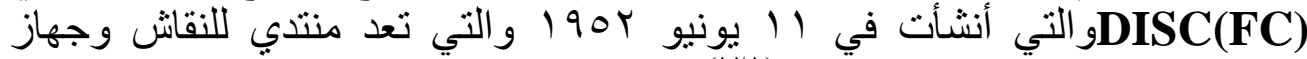

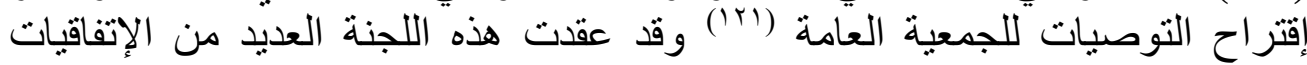

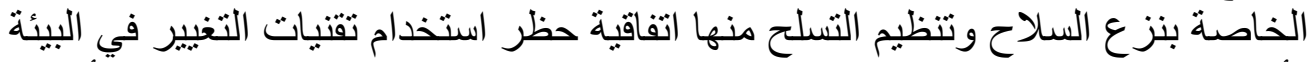
لأغر اض عسكرية وكذلك اتفاقية حظر استحداث وانتاج وتخزين واستخدام الأسلحة

${ }^{(120)}$ Evelyne lagrange, Les opérations de maintien de la paix et le chapitre VII de la Charte des Nations Unies, Edition Montchrestien , Paris , 1999, p 15

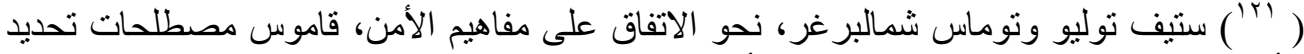

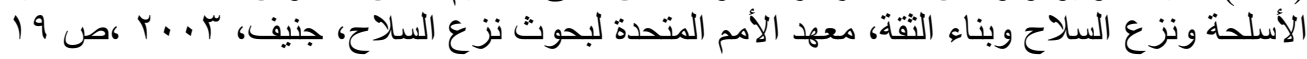

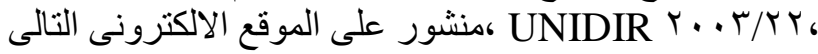
ttps://www.files.ethz.ch/isn/92883/Full-text_AR.pdf : 
الكيميائية و اتفاقية حظر واستعمال وتخزين و انتاج ونقل الألغام المضادة للأفراد

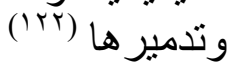

وكذللك أنشأت الجمعية العامة مؤتمر نزع السلاح و الذبي بعد منتدي تفاوض

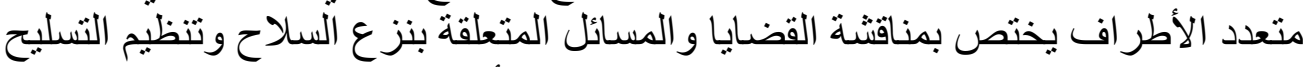

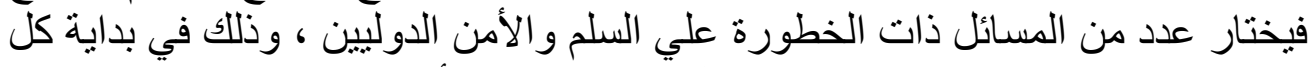

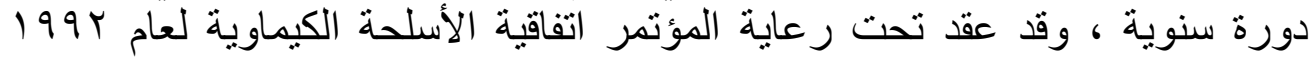

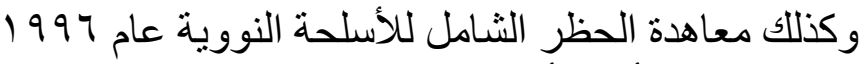

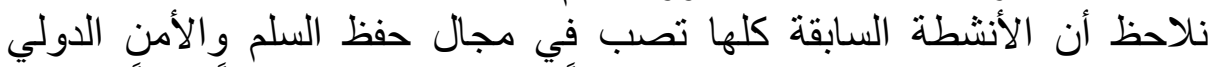

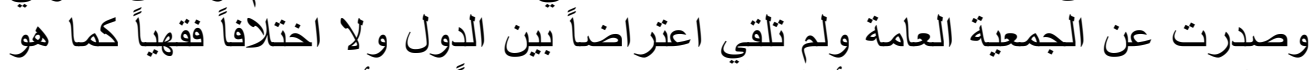
الحال في قرار "الإتحاد من أجل السلام" وذلك اللك إيماناً من أعضاء العاء المجتمع الدولي باصالة الجمعية العامة في حفظ السلم والأمن الدولي الإلي

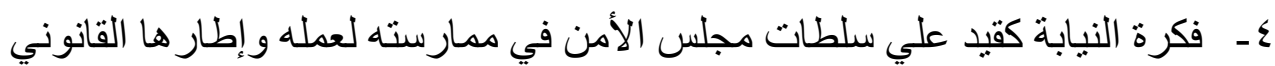

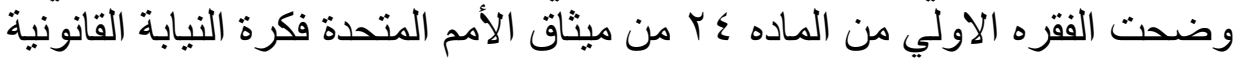

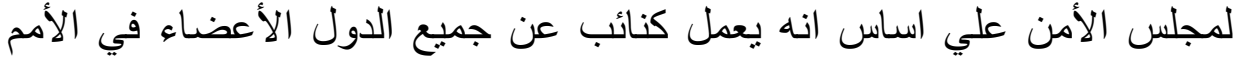

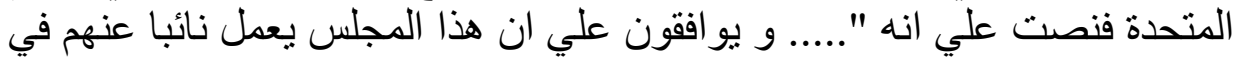

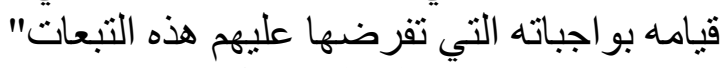

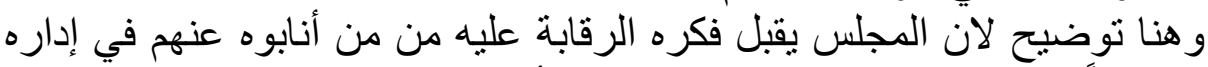

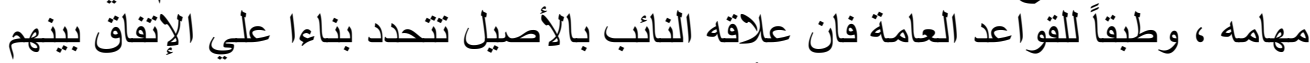

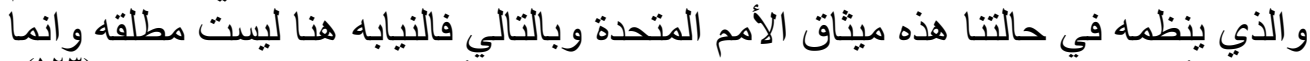

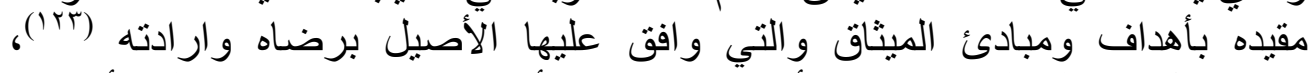

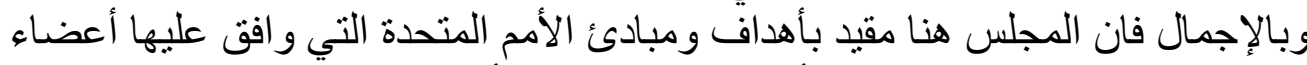

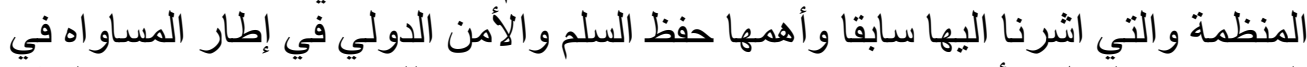

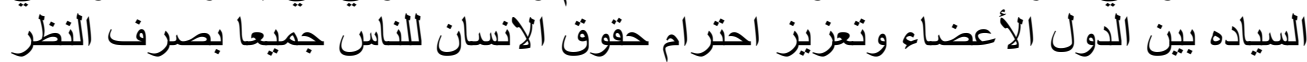
عن الجنس او اللغه او الدين الدين وقد اكد الميثاق علي إطار نلألك النيابة وهي مقاصد ومبادئ الأمم المتحدة بالنص

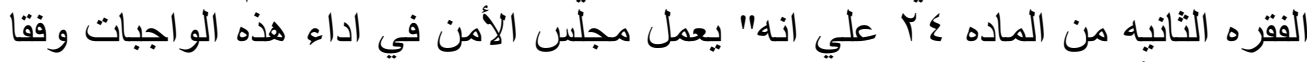

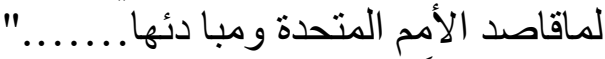

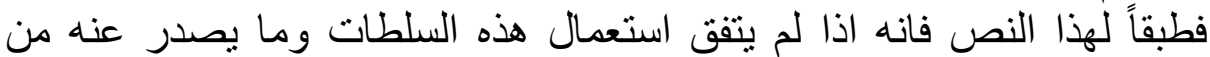
قرارات مع مقاصد الأمم المتحدة ومبادئها فان هذا الاستعمال يكون بهذه الصفه غير لئه

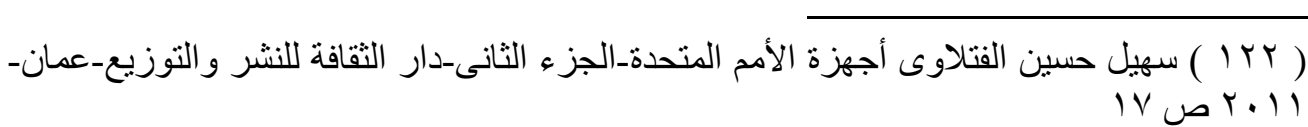

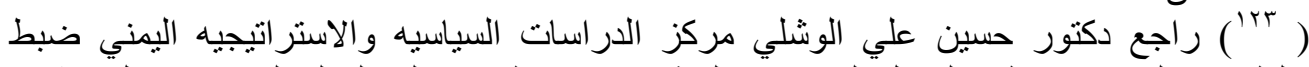
سلطات مجلس الامن طبقا الفصل السابع من الميثاق ومدى تطبيقها على الحاله اليمنيه ــ مقال منثور https://docs.google.com/document/d/1BO05OdhNq2QOlH1ts37i5z

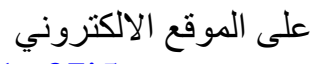




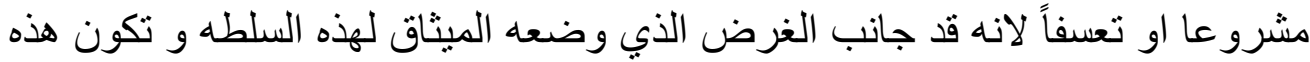

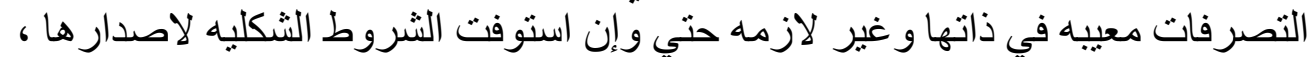

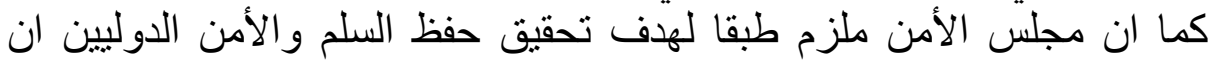

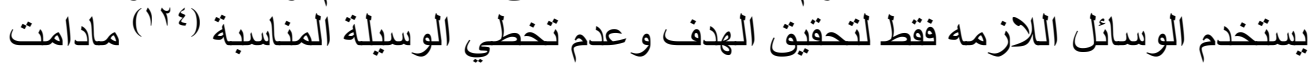

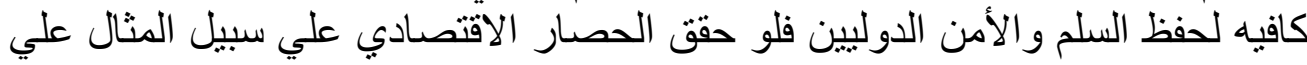

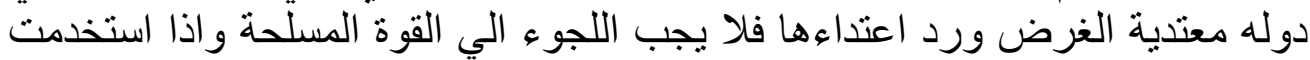

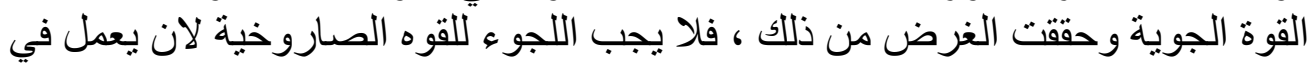

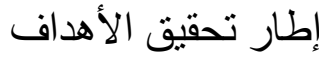

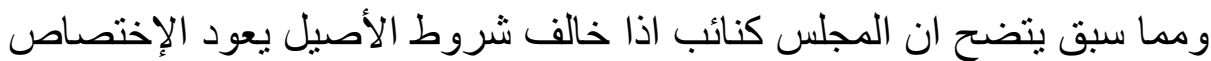

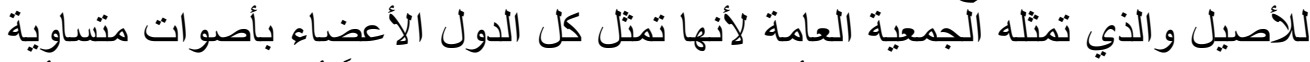

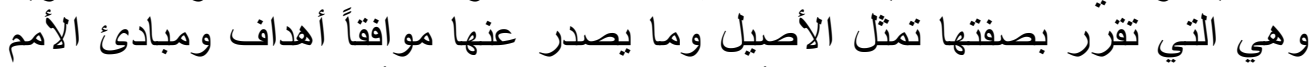

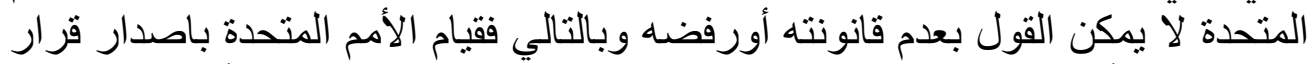

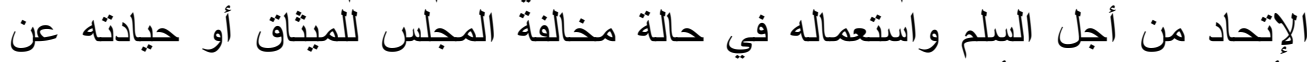

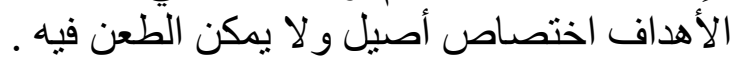

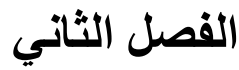

\section{شروط تطبيق قرار الإتحاد من أجل السلم الإئ}

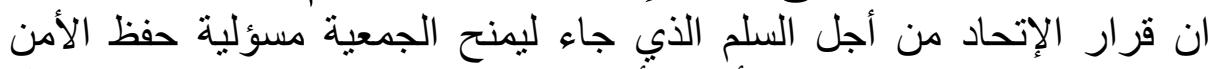

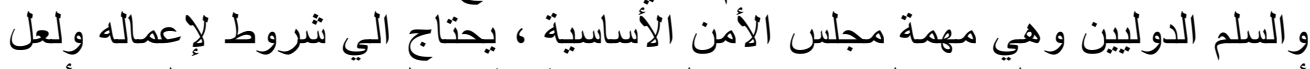

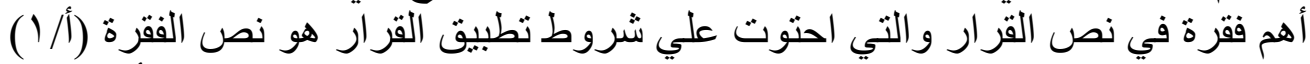

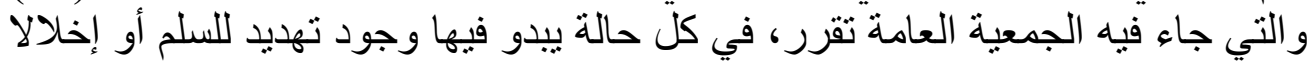
بها أو عملا من أعمال العدوان.

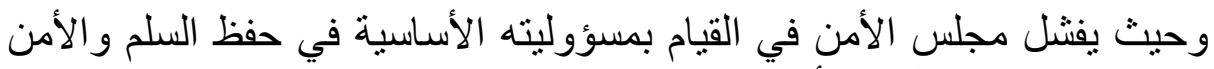

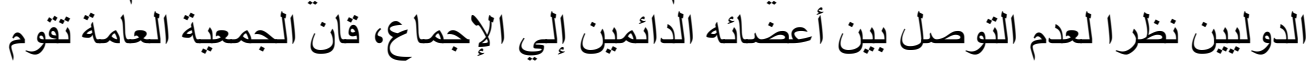

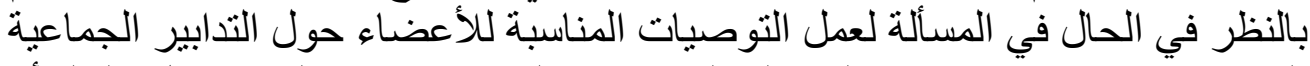

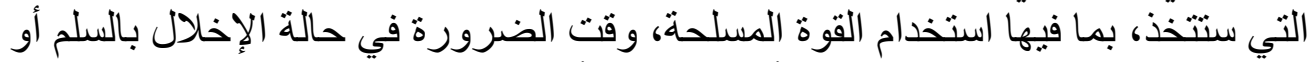

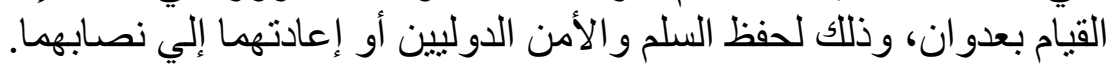

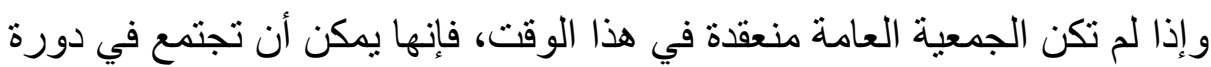

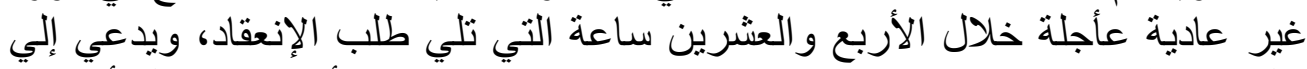

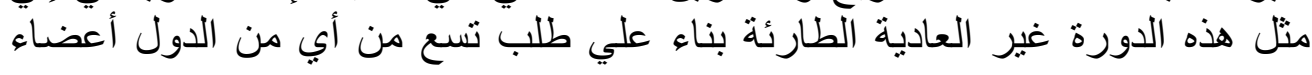


مجلس الأمن أو من أغلبية أعضاء المنظمة(rol). وسنتناول تللك الثروط بشئ من

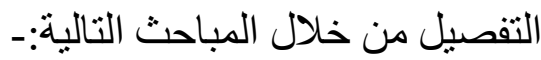

المبحث الأول: وجود حالة تهدد أو تخل بالسلم والأمن الدولي أو عمل من أعمال

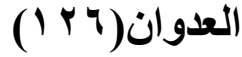

المبحث الثاني: عجز مجلس الأمن في حفظ السلم والأمن الدوليين المبحث الثالث: الإجراعات المطلوبة لإصدار قرار الإتحاد من أجل السلم

\section{المبحث الأول \\ وجود حالة تهدد أو تخل بالسلم والأمن الدولي الأل

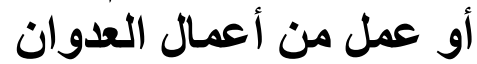

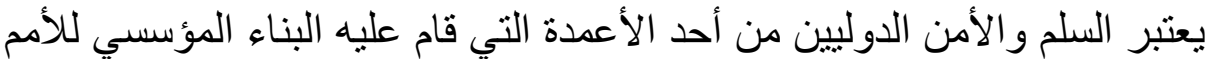

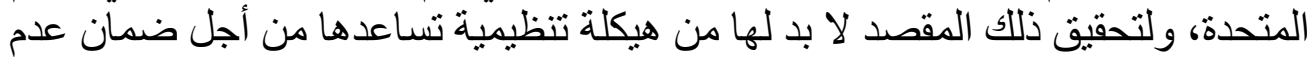

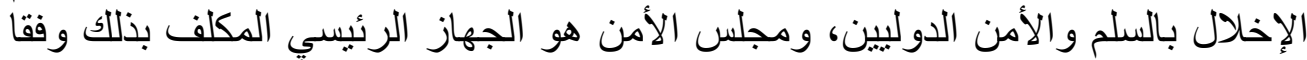

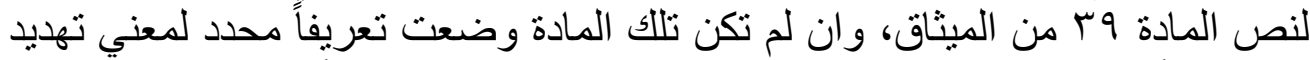

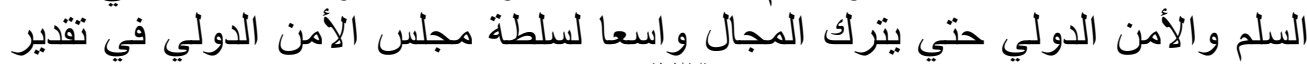

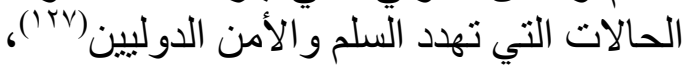

تضمن الفصل السابع من ميثاق الأمم المتحدة الأحكام الخاصة بمباثرة مجلس الإنس

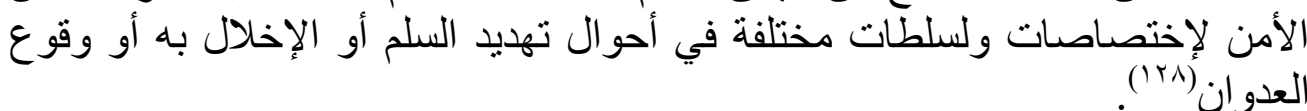

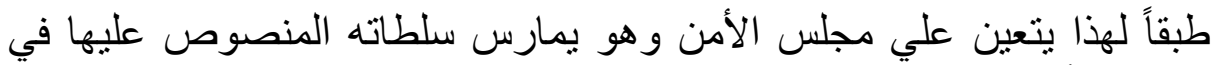

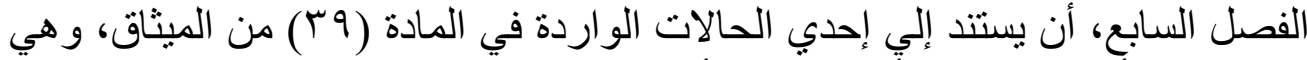

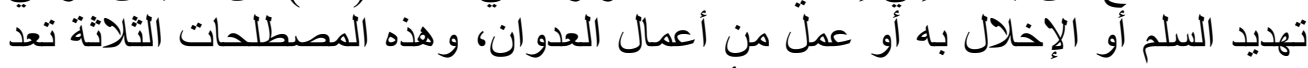
المدخل القانوني الذي يتيح لمجلس الأمن ممارسة التدابير التي يقرر هان التها الفصل السابع

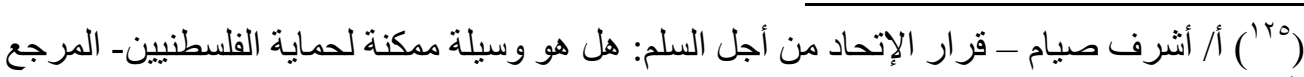

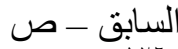
(ז'أ) وقد ذكرنا فيما سبق التعريفات الخاصة بالمصطلحات الأتية تهديد السلم، الإخلال بالسلم، عمل من أعمال العدوان، في المبحث الخاص باص بان. (127 )LAGRANGE Evelyne, Les opérations de maintien de la paix et le chapitre VII de la Charte des Nations-Unies, Edition Montchrestien -paris, 1999, p 15.

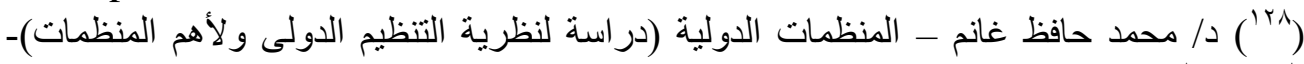


من الميثاق وبالرغم من أهمية تحديد مدلول هذه المصطلحات إلا أن الميثاق قد جاء

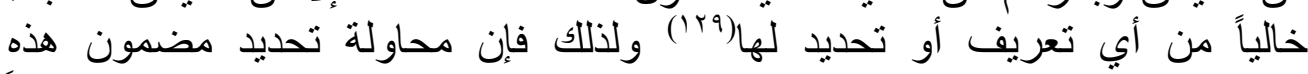

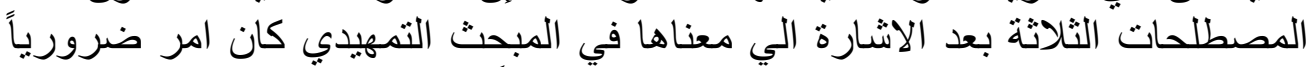
لتحديد الحالات الفعلية لاختصاص مجلس الأمن لئن طبقاً للفصل السابع وذلك علي النحو

\section{1- - تهـيد السلم}

يقصد بذلك إعلان أية دولة عن نيتها في القيام بأي عمل من أعمال التنخل في

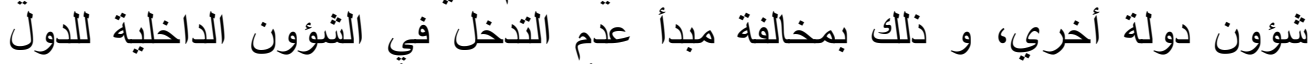
و المنصوص عليه في الميثاق عن طريق القيام بأي عمل من أُعمال العنف ضدها.

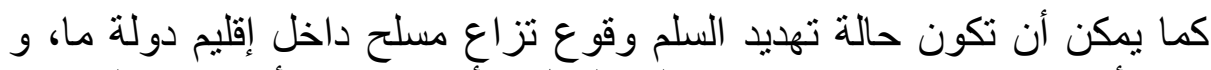

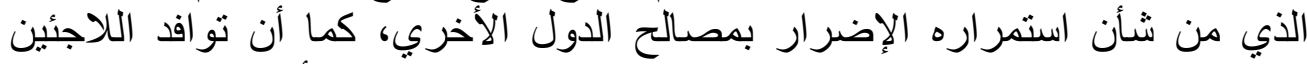

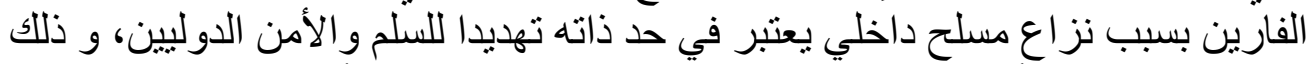

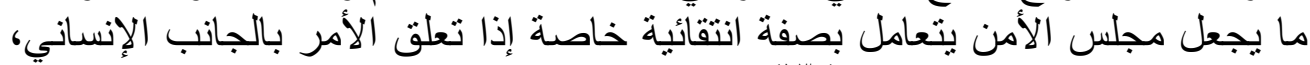
حسب كل منطقة وقع فيها الفعل (r.)".

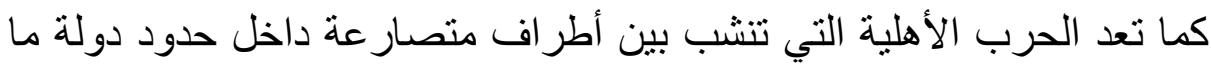

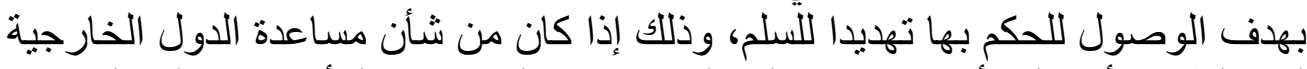

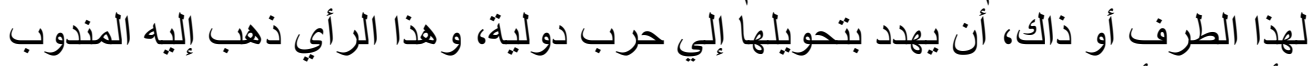

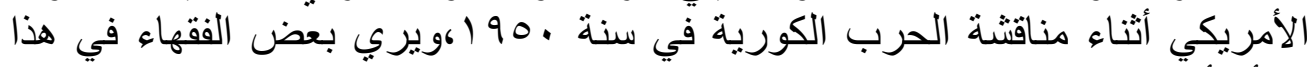

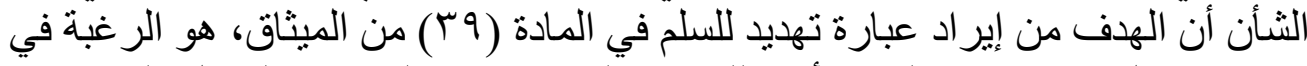

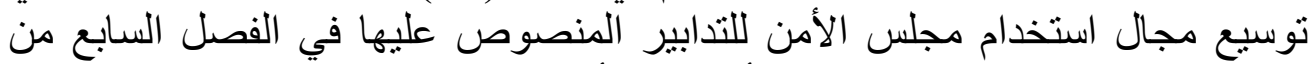

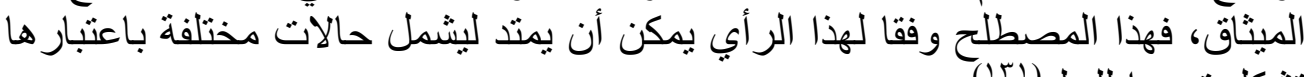

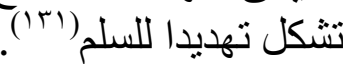

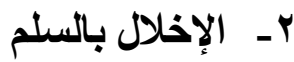

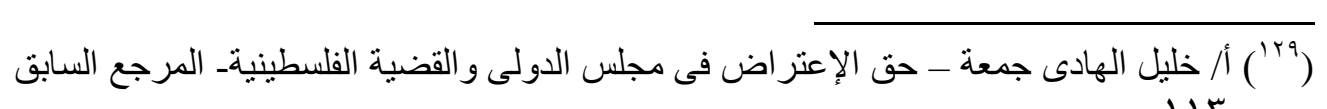

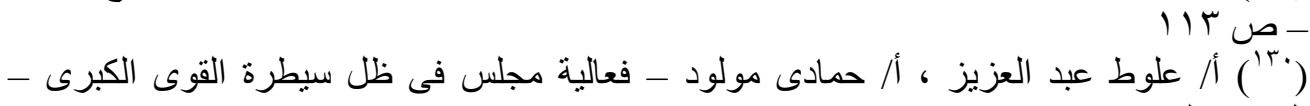

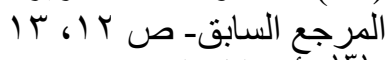

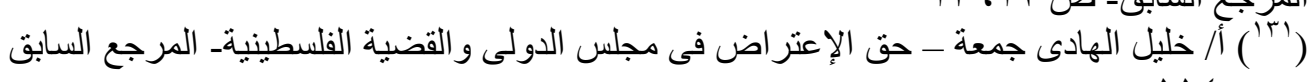
1) 1 ص - 


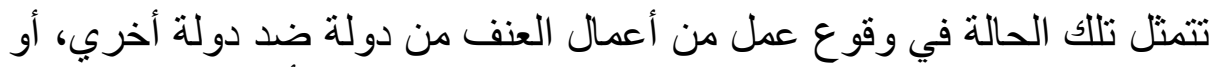

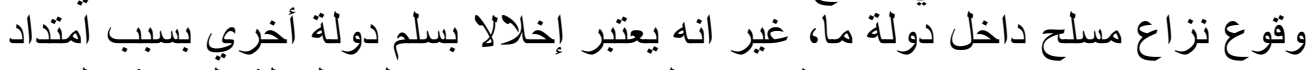

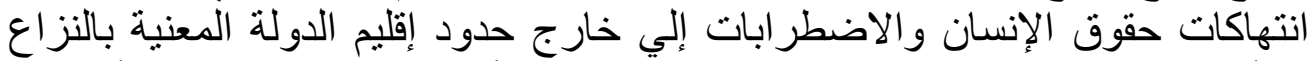

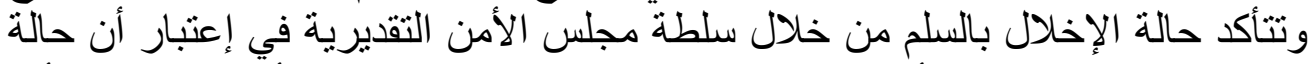

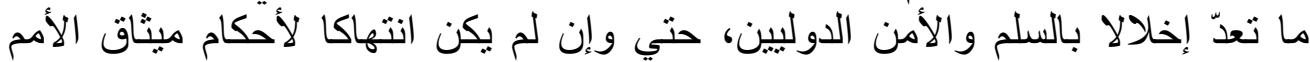

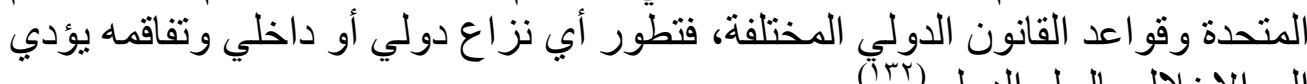
إلي الإخلال بالسلم الدولي (rri)

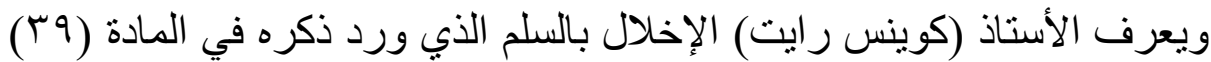

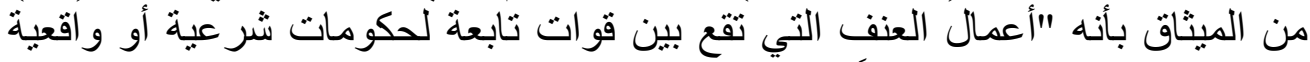

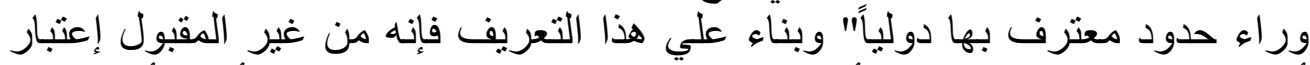

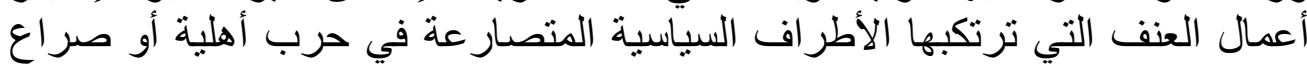

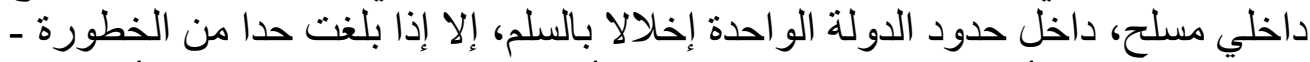

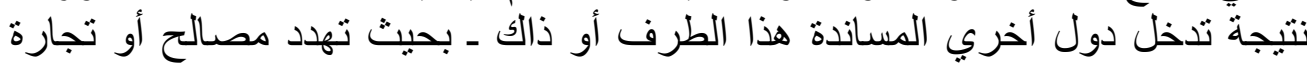

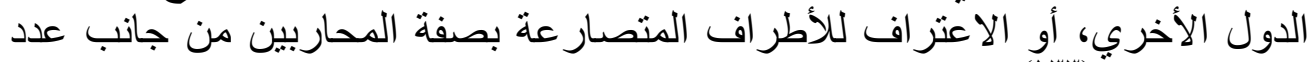

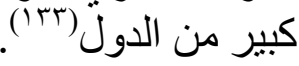

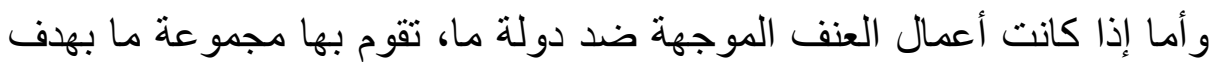
تحقيق أطماع سياسية، انطلافاً من أراضي دولة أخرات أخري، فإنها تعد حالة من حالات الإخلال بالسلم.

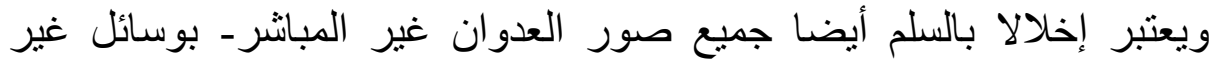

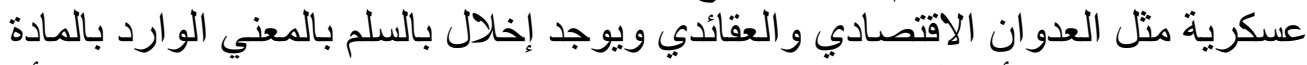

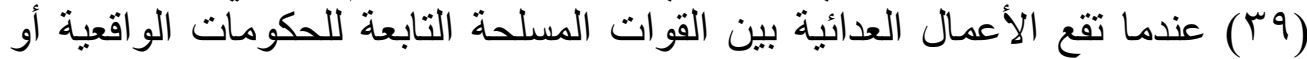
القانونية علي الجانبين من الحدود الإقليمية و المعترف بهات بها دوليا.

ولقد أتيحت الفرصة لمجلس الأمن لتحديد المقصود بالإخلال بالسلم فلقد جاء في

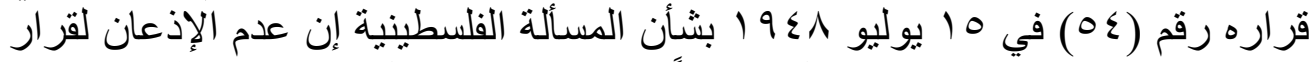

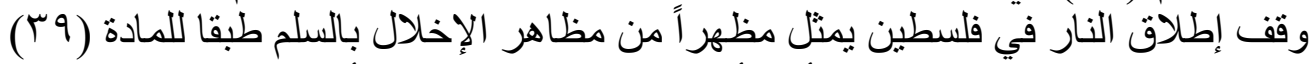

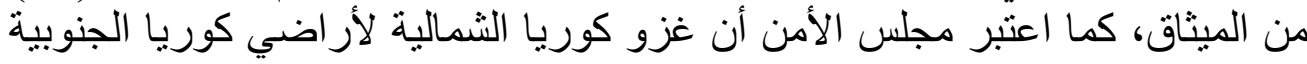

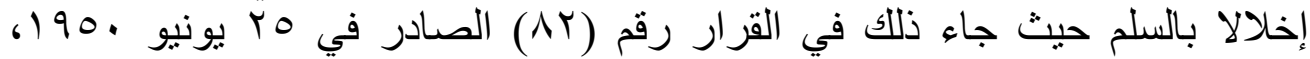

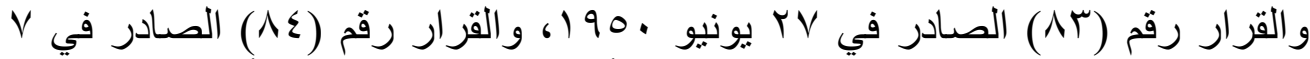

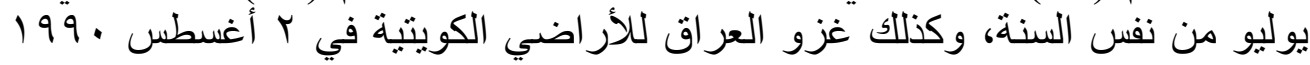

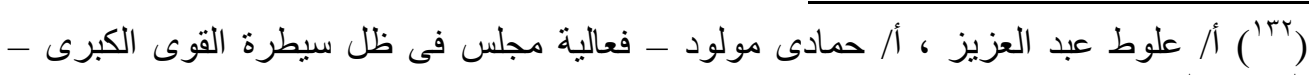

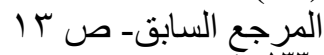

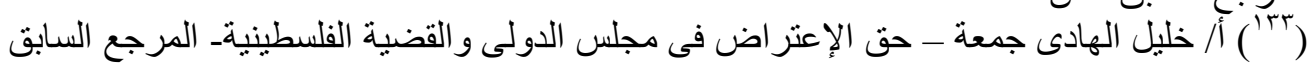
110 - 
أعتبر إخلالا بالسلم، حيث جاء ذلك في القرار رقم (•74) الصادر في r أغطس

إلا أن هنالك من يري بأن نصوص الميثاق لا تسمح بوضع تعريفات محددة

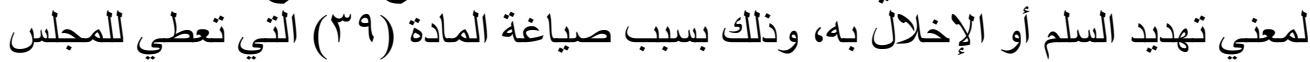

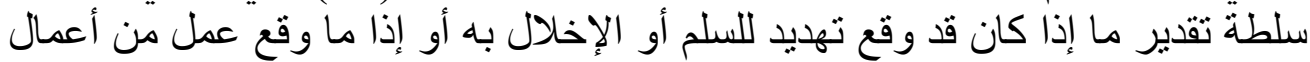

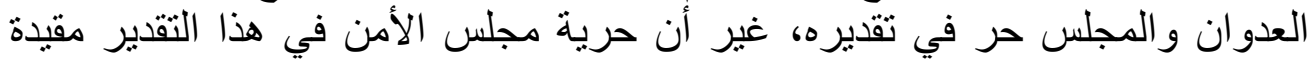

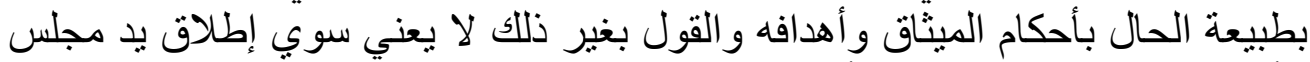

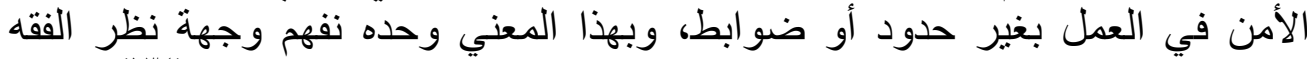

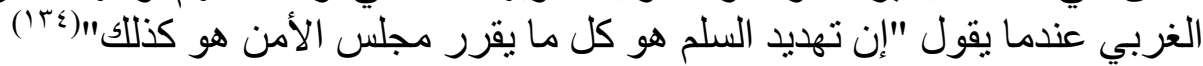

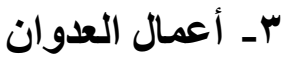

رأي واضعوا الميثاق خلال الأعمال التحضيرية ضرورة ترك مسألة تحديد

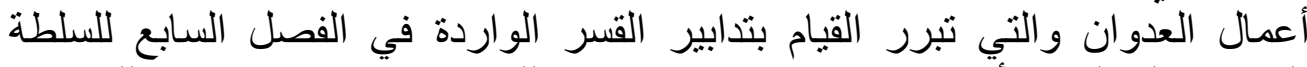

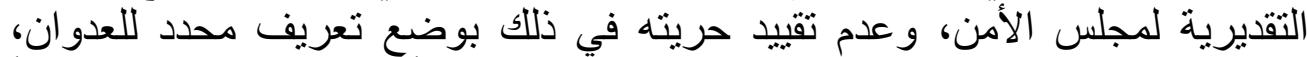

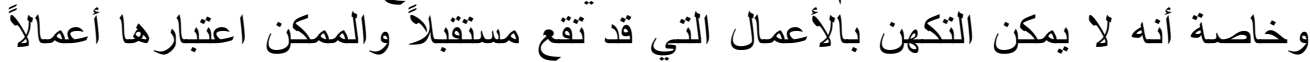

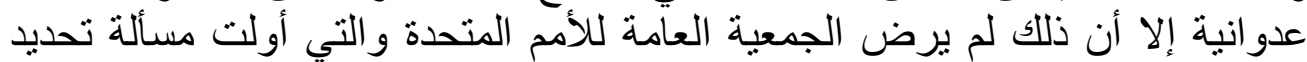

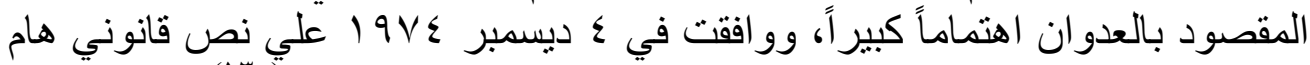

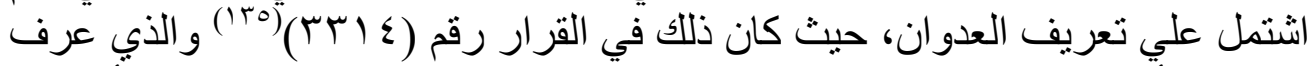

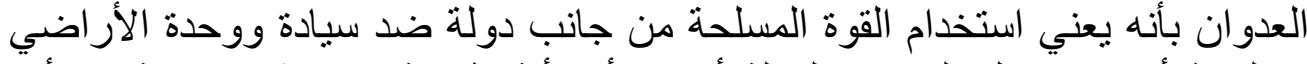

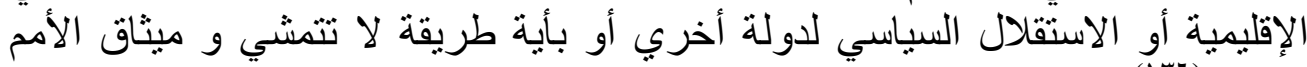

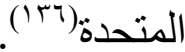

\section{ويتحليل نص التعريف يمكن ملاحظة ما يلي:}

أن جميع مواد التعريف تستند إلي مفهوم قانون اساسي عام، هو تحريم استخدام

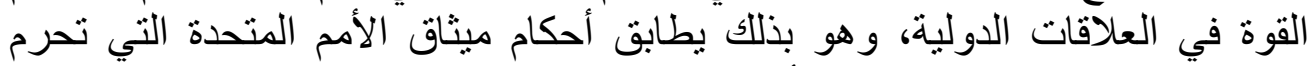

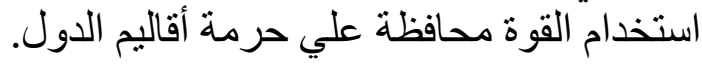

أن نص التعريف تناول صورة واحدة من صور العدوان، وهو العدوان العدوان المسلح مستبعداً كافة صور العدوان الأخري، وهذا أحد عيوبه، لأن العدوان المسلح وإن كان كان العدول

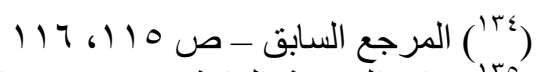

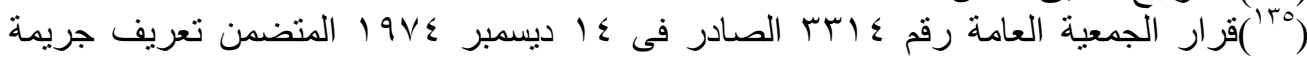

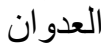
("ז (أنظر فى ذلك أ/ علوط عبد العزيز ، أ/ حمادى مولود - فعالية مجلس فى ظل سبطرة القوى

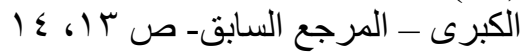


يعد أخطر صور العدوان إلا أن عالم اليوم يعرف صورة أخري للعدوان لا تختلف نتائجها عن حالة العدوان المسلح كالعدوان الان الاقتصادي.

أن واضعي نص التعريف قد أخذوا بتعريف مختلط، فلم يكتفوا بتعريف عام إمريف

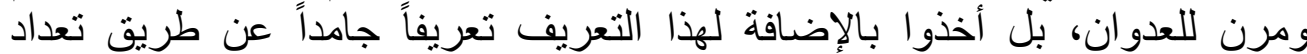

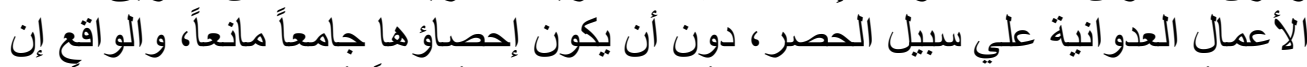

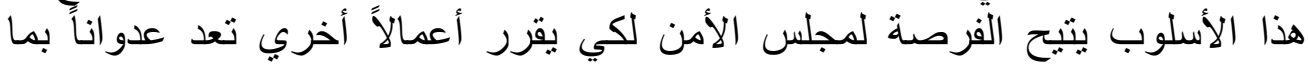
يتماثي مع متطلبات تطور وسائل استخدام القوة وتنو عها.

أن نص التعريف لا يؤثر علي أحكام الميثاق التي بمقتضاها يجوز استخدام القوة

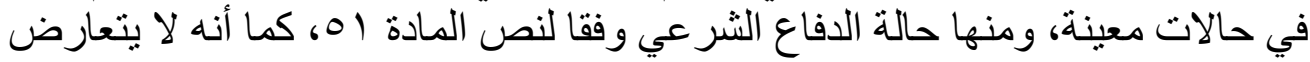

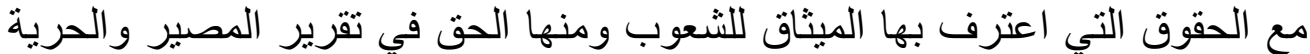

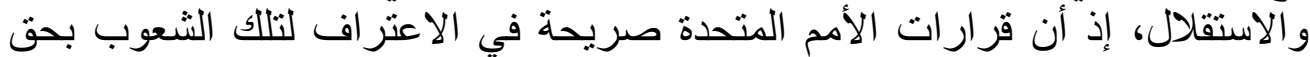

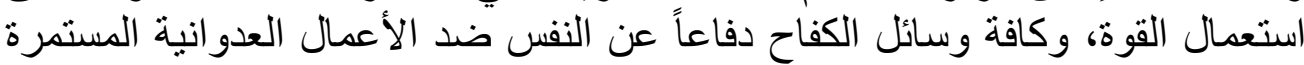

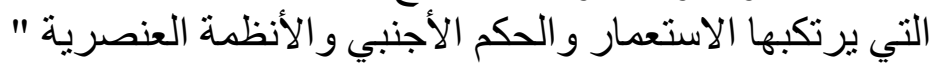

و الو اقع إن توصل الجمعية العامة للأمم المتحدة إلي تعريف العدوان يعد إسهاماً

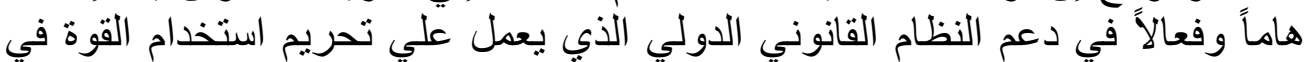

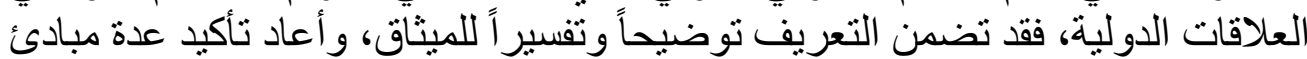

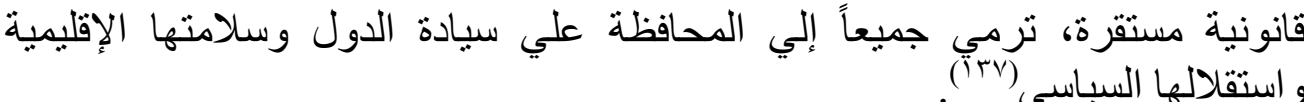

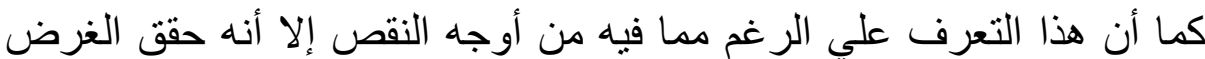

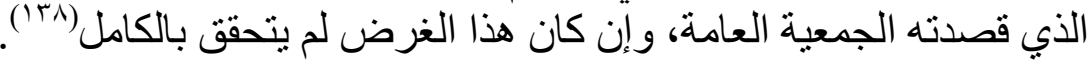

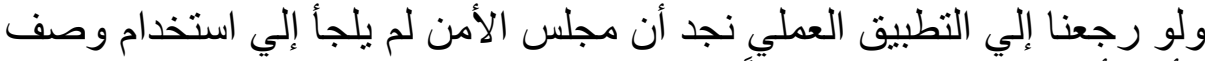

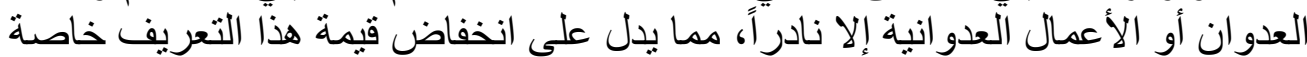

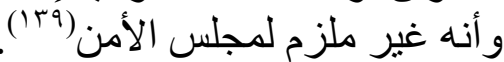

\section{المبحث الثاني \\ عجز مجلس الأمن في حفظ السلام والأمن الدوليين}

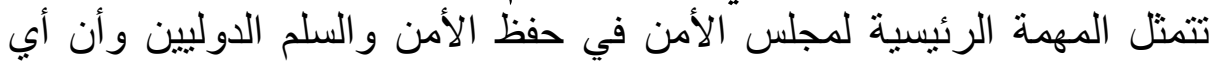
اخلال أو عدوان أو تهديد لهذا السلام والأمن الدولي لا يقابله حل أو تدخل من مجلس الأل

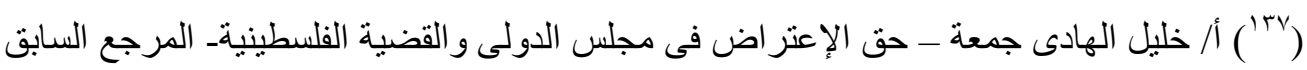
117 ص - n

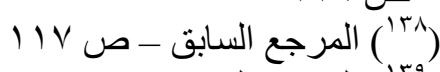


الأمن فأن هذا الاخير قد عجز عن أداء مهيته الرئيسية وفنثل فيما اوكل إليه من

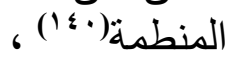

ويرجع عجز مجلس الأمن في كثير من الحالات الي نظام تكوينه وتشكيله

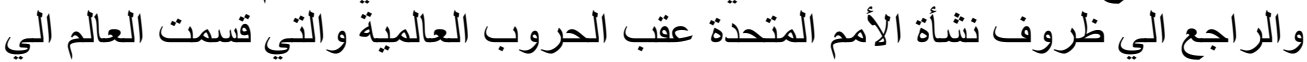
تحالف منتصر وتحالف مهزوم فقامت الدول الكبري المنتصرة داعية الي تكوين منظمة

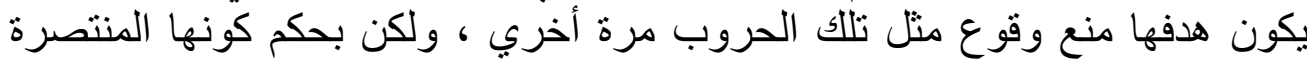
ارادت ان تظل ممسكة بزمام الأمور ومجرياتها من فن الناحية القانونية ومن الناحية السياسية فعدات أن تأخذ في التنظيم الذي ترنوا التي الي تكوينه موقعا يجعل أمر المنظمة

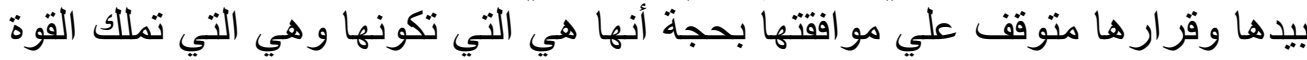

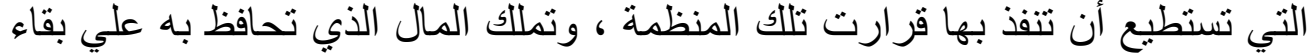

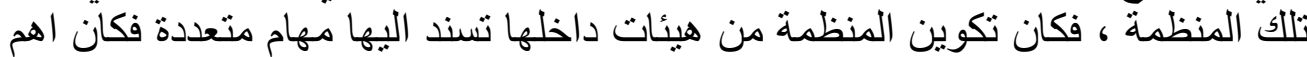

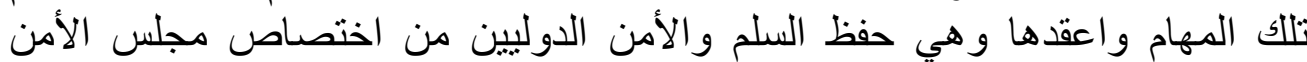

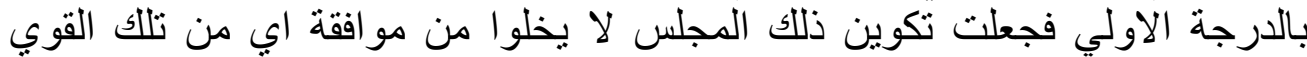

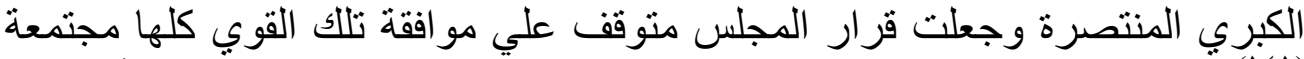

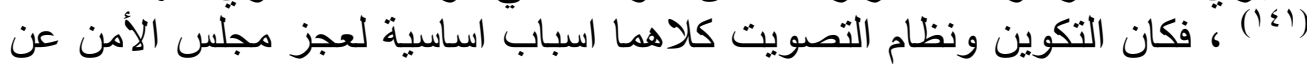
أداء دوره نتناو لهما بشئ من الإجمال من خلال الملبين التهاب التاليين

\section{المطاب الأول}

\section{تشكيل مجلس الأمن كسبب لعجزه عن أداء مهامها}

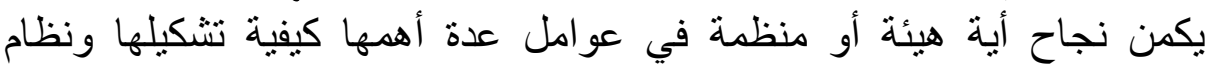

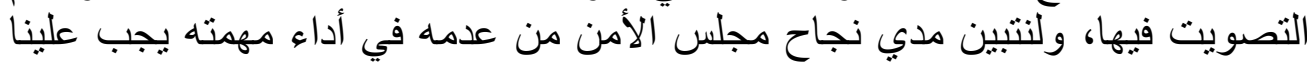

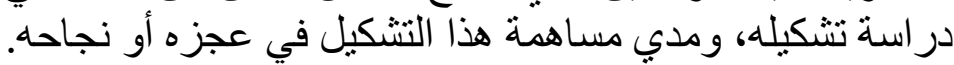

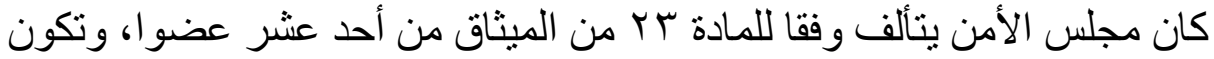

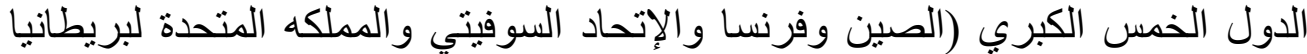

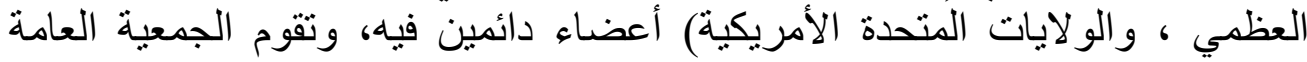

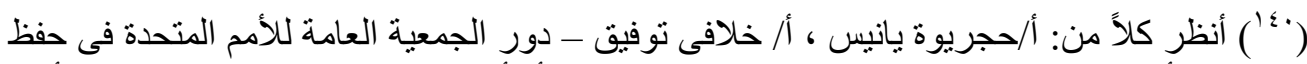

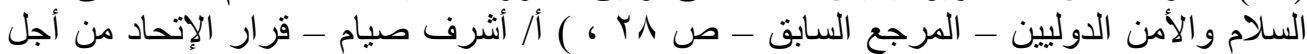

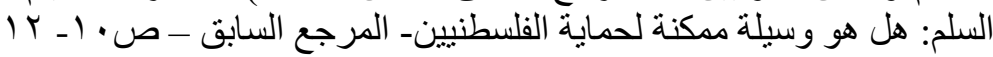
( ${ }^{141}$ )Elham Animzadeh, The United Nations and International Peace and Security : A legal and practical analysis , PHD in International Law Thesis , University of Glasgow, 1997 , p 29. 


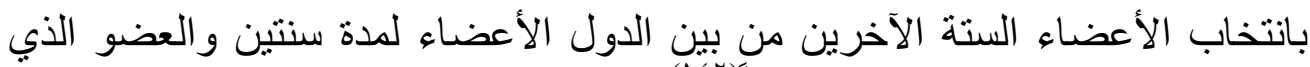

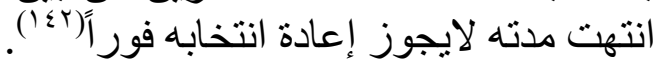

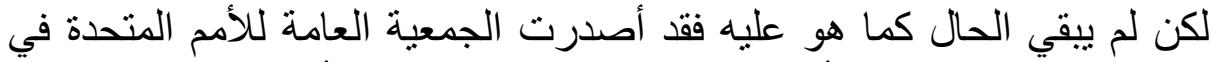

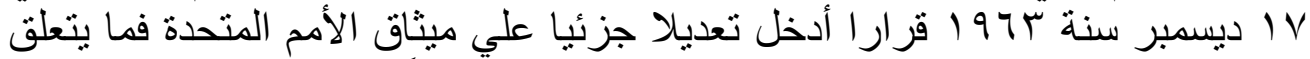

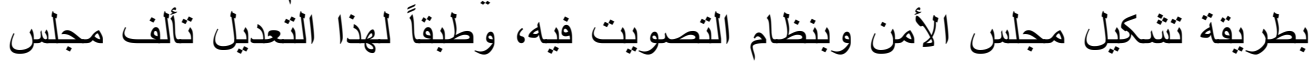

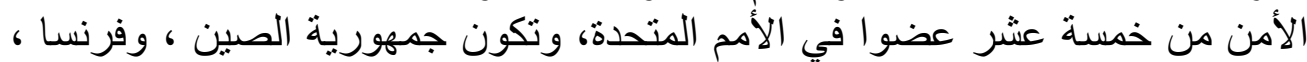

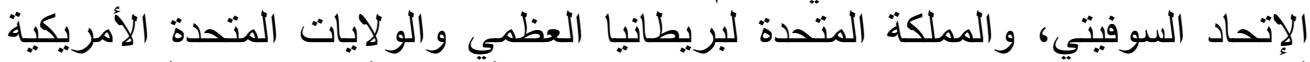

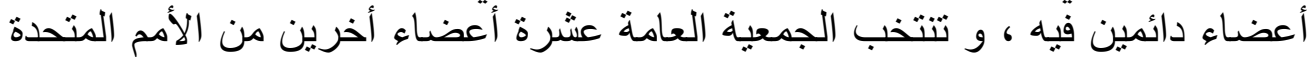

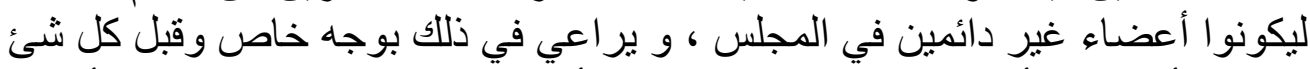

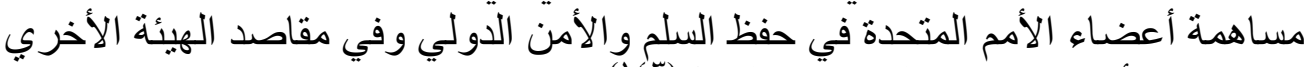

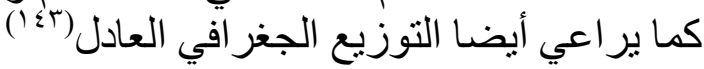

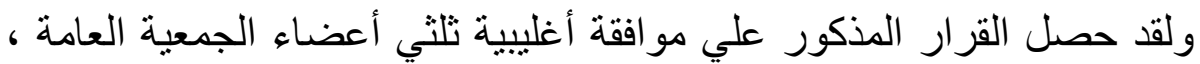

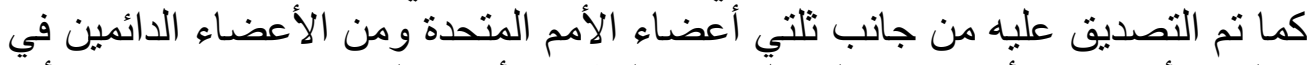

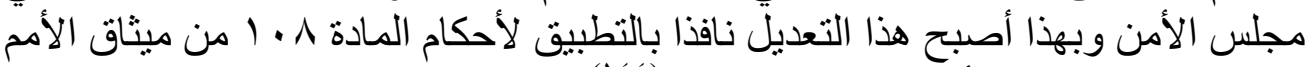

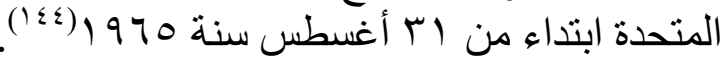

يتضح من هذا أن العضوية في مجلس الأمن نو عين دائمة و غير دائمة، وسنبين ذلك كما بلي.

\section{ا ـ العضوية الدائمة في مجلس الأمن}

وتعني العضوية الدائمة، المقاعد الدائمة في مجلس الأمن والتي لا يجوز إنتخابها

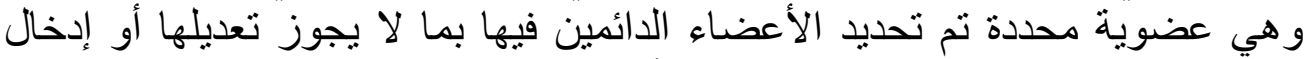
تغيرات عليها إلا إذا تم التعديل في ميثاق الأمم المتحدة.

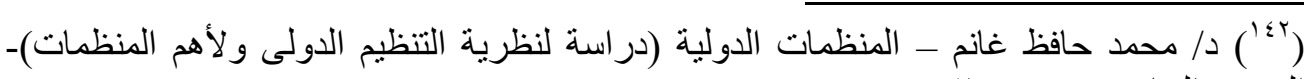

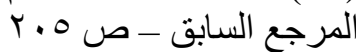

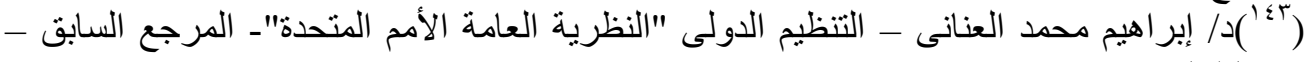

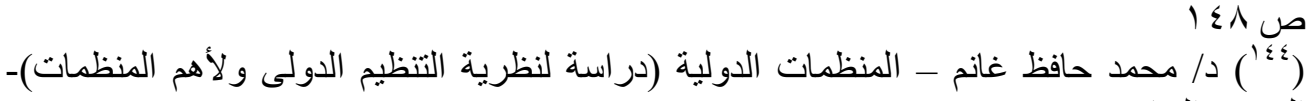

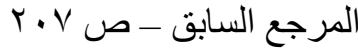


ووفقاً للفقرة الأولي من المادة (r Y) من الميثاق، تتمتع بالعضوية الدائمة داخل

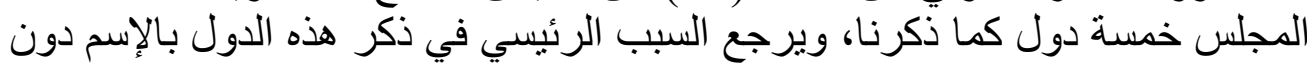

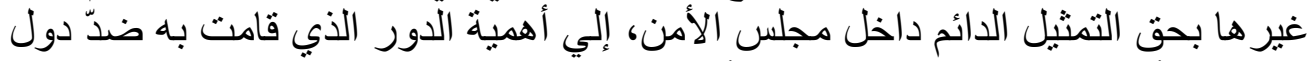

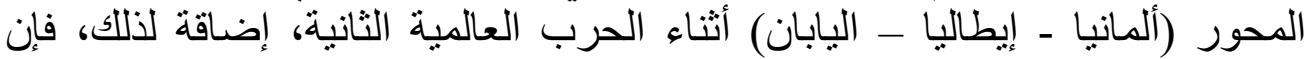

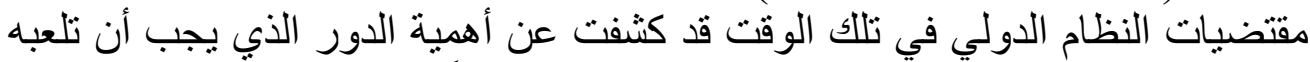

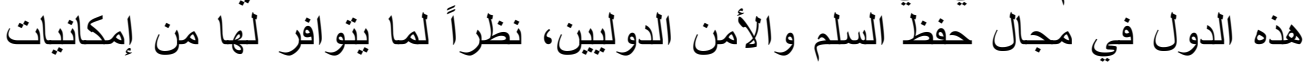

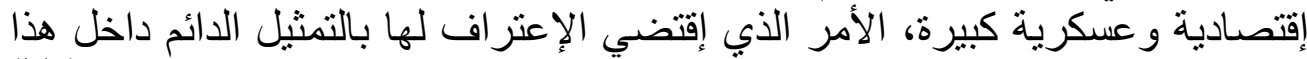

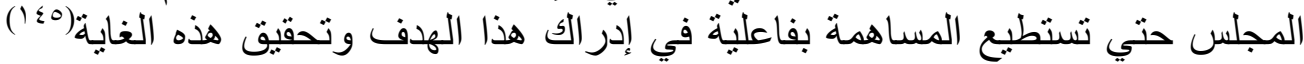
وسنري هل هذه الدول قامت بهذا الواجب الملقي في علي عاتقهم وكانت عند نقة الدول فيهم أم لا، في المبحث المخصص لهذ لهذا.

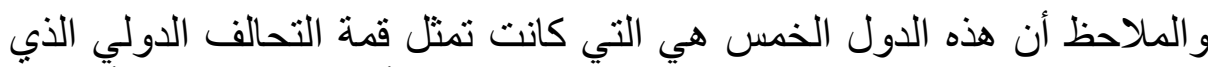

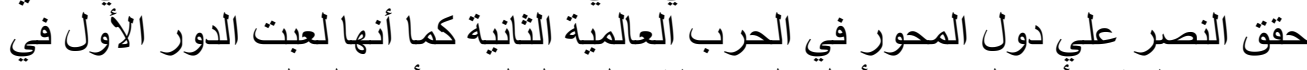

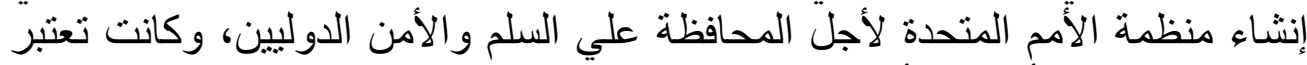

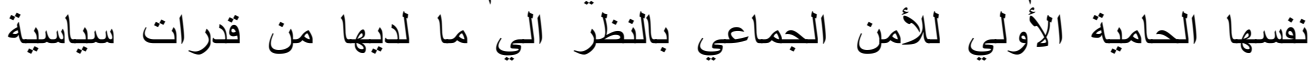
و إقتصادية.

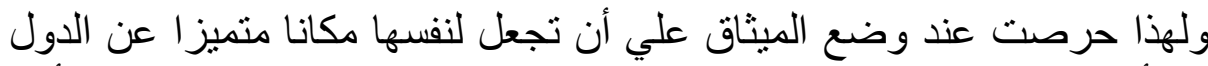

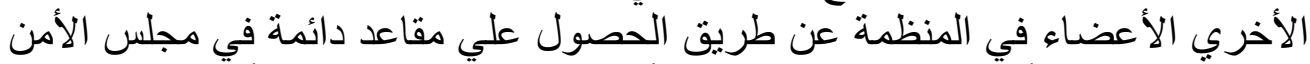

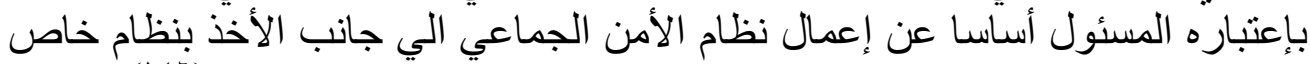

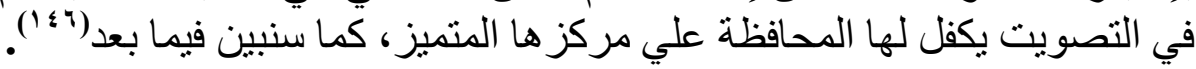
r. العضوية غير الائمة في مجلس الأمن

و هي المقاعد المتغيرة و التي تتم علي أساس الإنتخاب، ويكون هذا الإنتخاب وفقاً

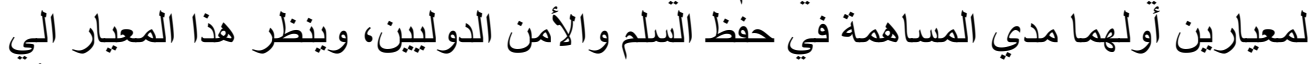

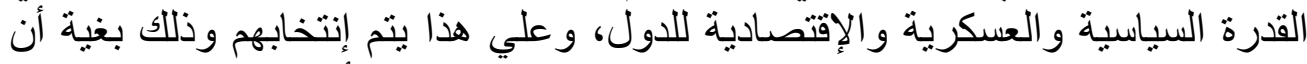

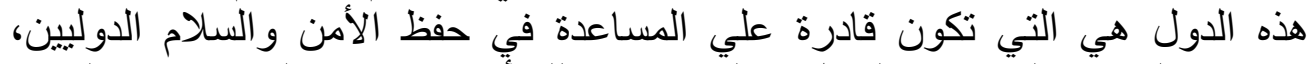

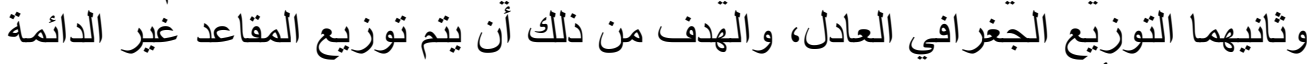

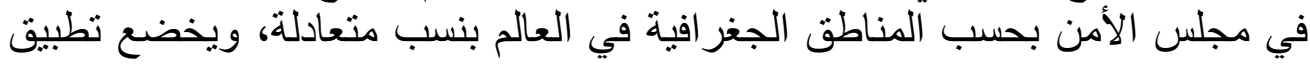

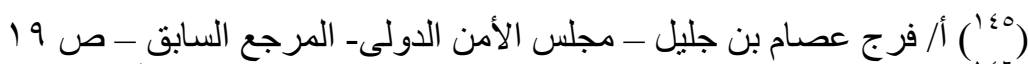

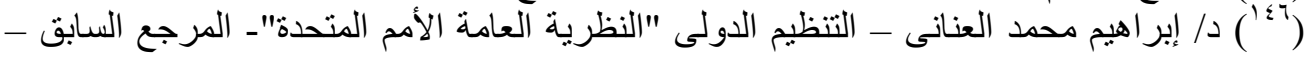


هذا المعيار كذللك لمطلق السلطة التقديرية للجمعية العامة حيث لم يتضمن الميثاق

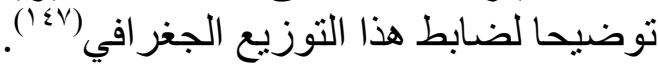

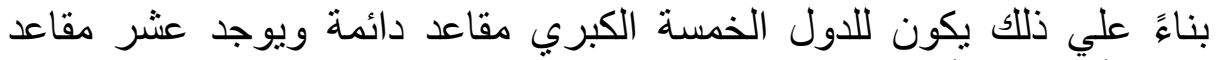

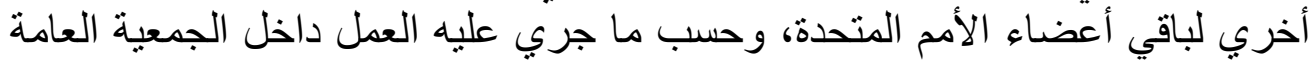

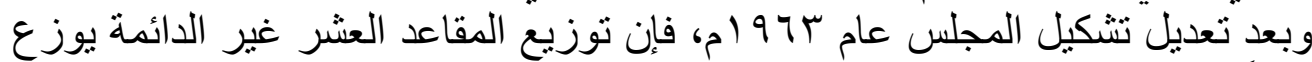

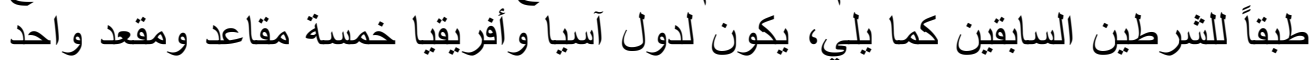

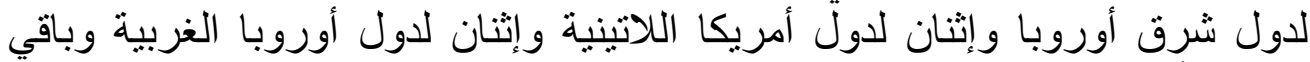

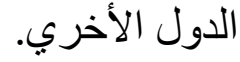

\section{نظرة نقدية لتشكيل مجلس الأمن}

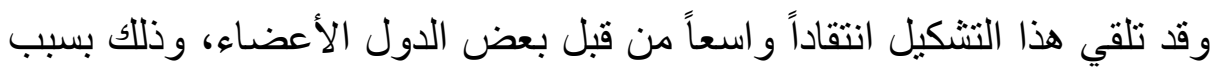

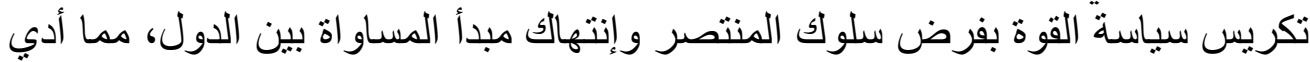

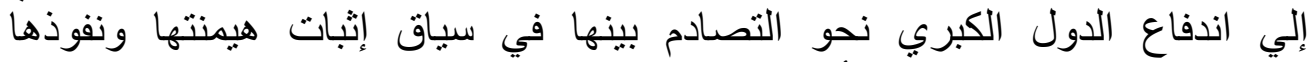

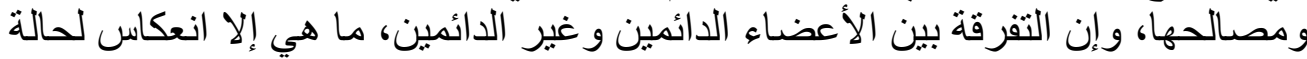

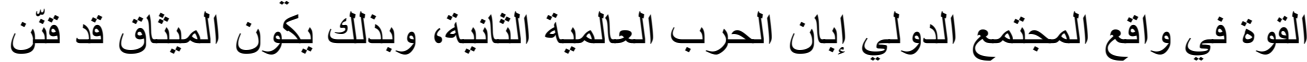

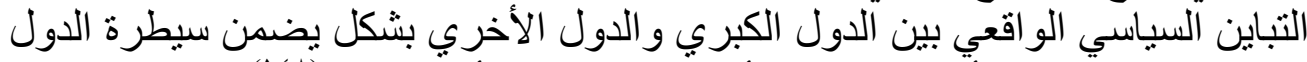

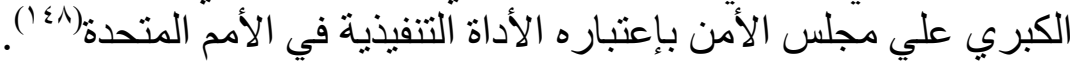

وسنبين أهم الإنتقادات التي وجهت الي تثكيل مجلس الأمن وهي كما يلي (9 ؛ :).

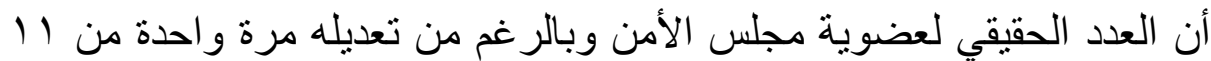

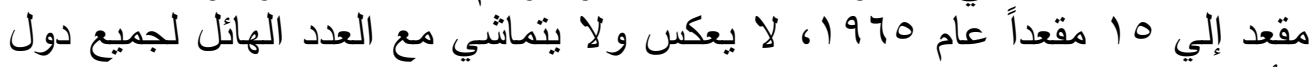

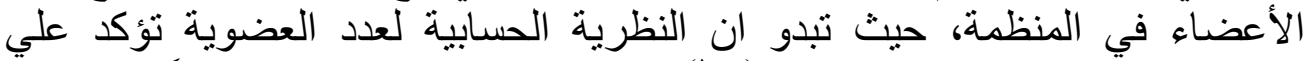

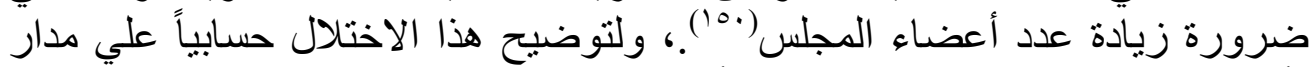

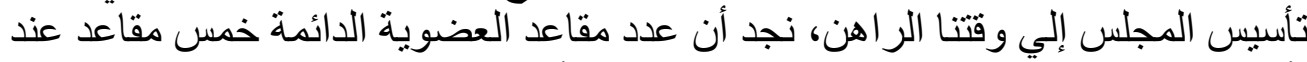

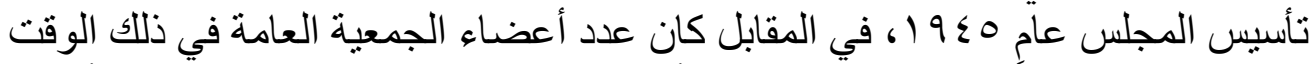

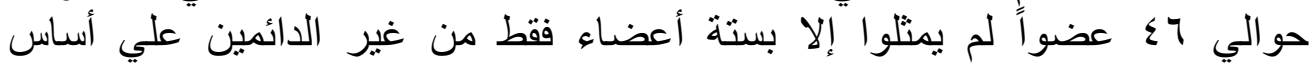

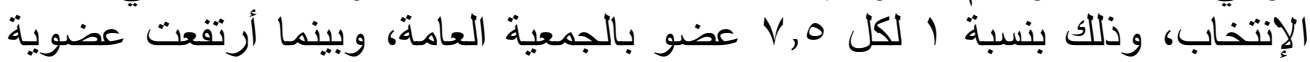

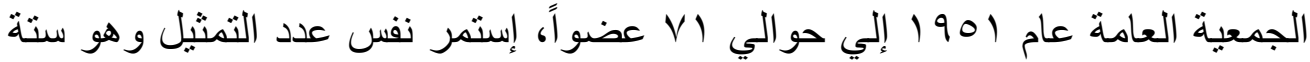

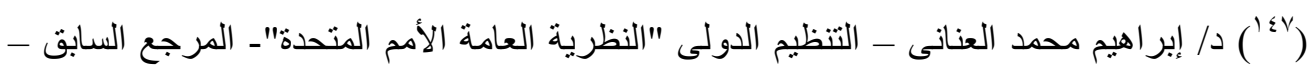
صن

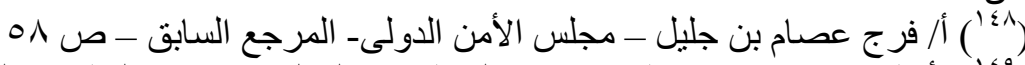

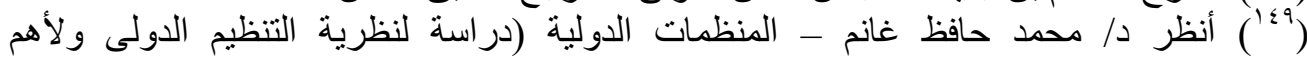

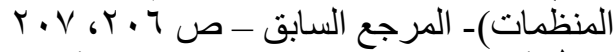

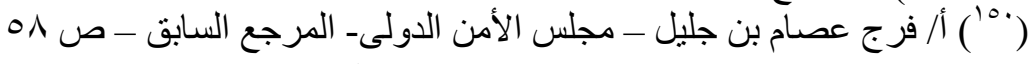




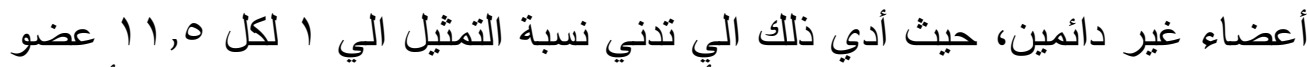

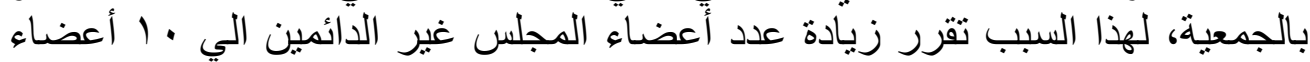

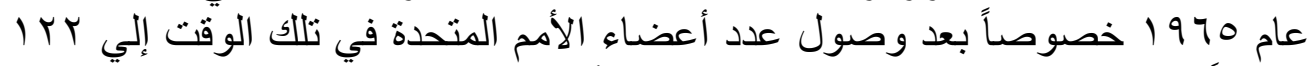

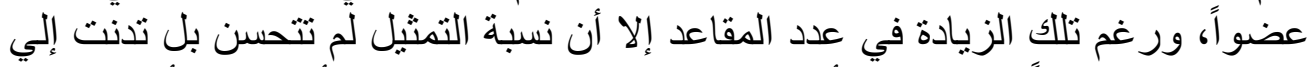

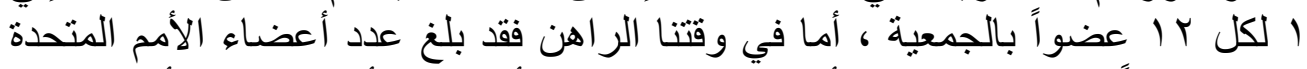

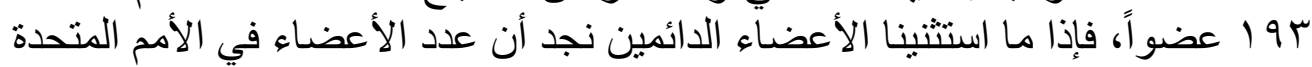

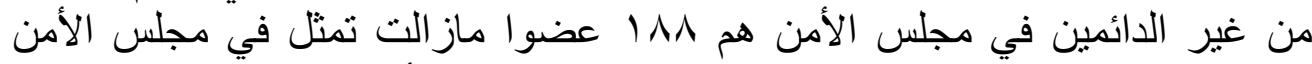

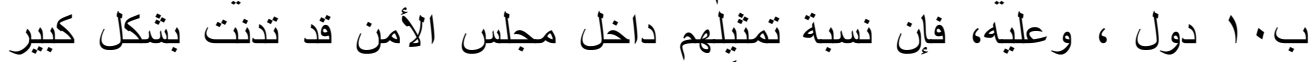

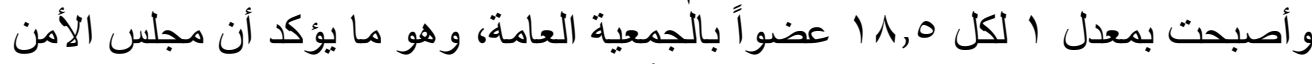

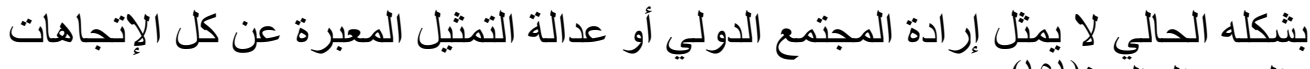
و القوي العالمية(10).

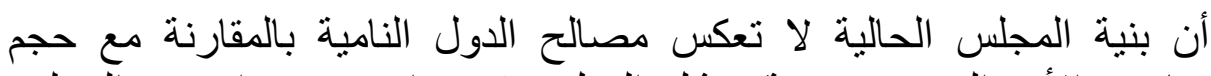

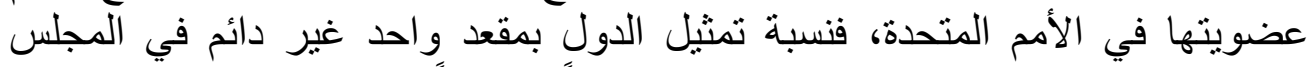

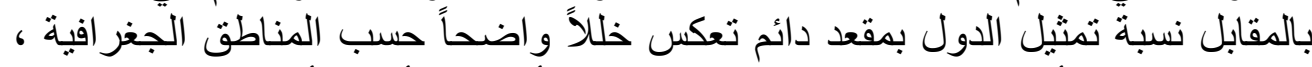

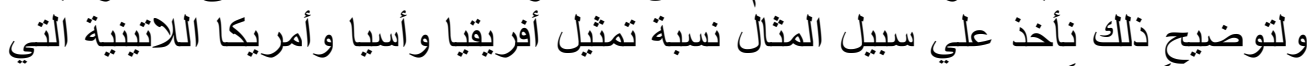

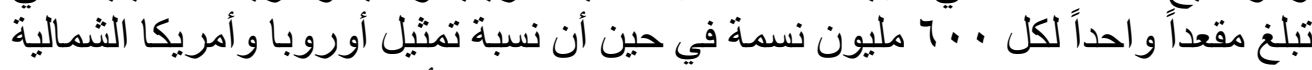

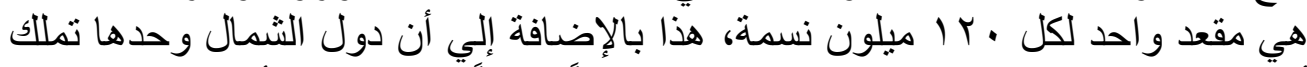

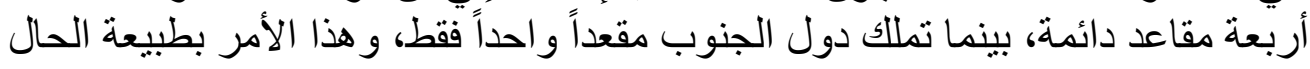

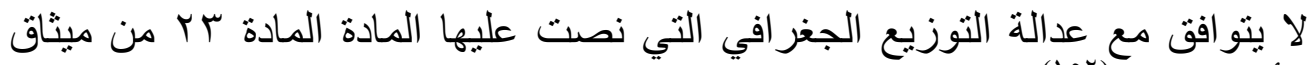

الأمم المتحدة مع (10r)

\section{ونستطيع من خلال التشكيل ان نلاحظ الأتي:-}

1 - إن المعايير التي إعتمدت كأساس لإنتخاب الأعضاء غير الدائمين، ليست معايير

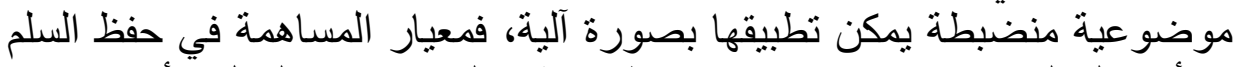

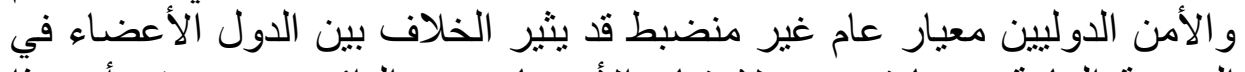

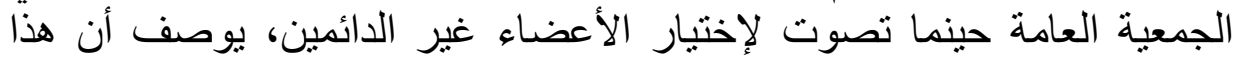

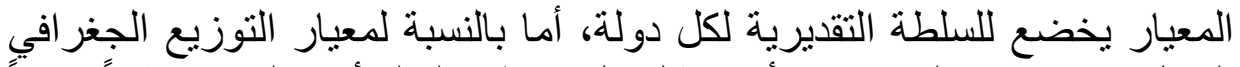
العادل، فهو معيار ليس من شأنه تمثيل كل مناطق لئل العالم أو غالبيتها تمثنيلاً عادلاً

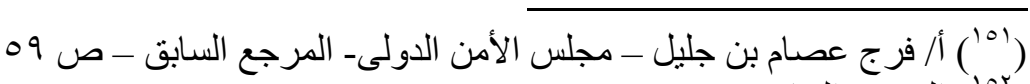

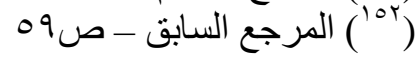


في المجلس ناهيك عن أن إهمال هذا المعيار في الإنتخاب لا ينتهي إلي إبطال الآنتخاب متي تمت هذه العملية بصورة سليمة من الناحية القانونية (10").

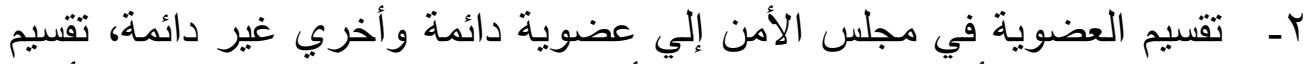

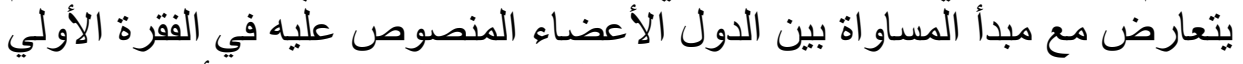

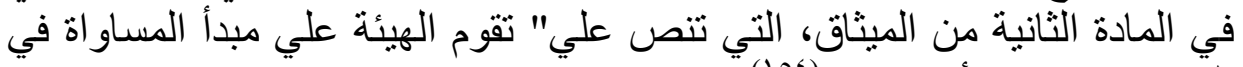

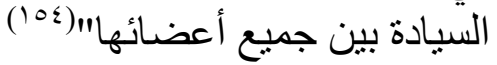

r- إضافة إلي الخلل العددي البنيوي بين عضوية المجلس وعدد أعضاء الأمم

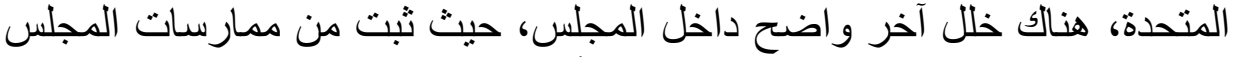

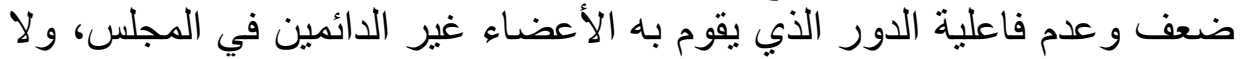

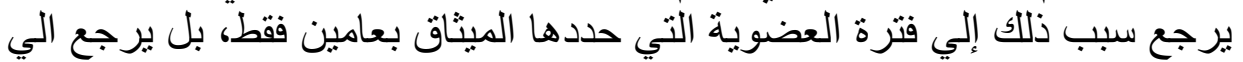

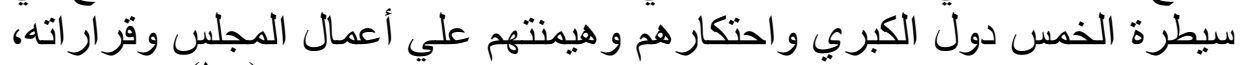
مما جعل دور الدول غير الدائمة مجرد دول مر اقبة داخل المجلس(100).

ـ- إن تحديد الدول دائمة العضوية في المجلس بالإسم في الميثاق وفقاً للفقرة الأولي

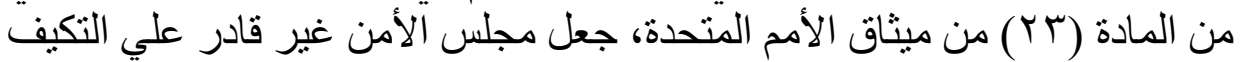

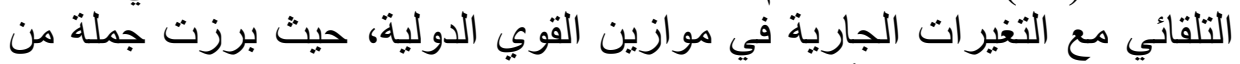

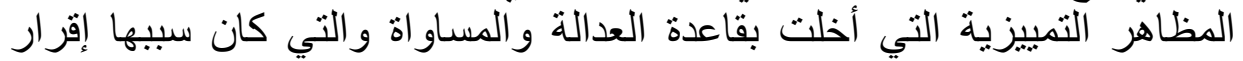

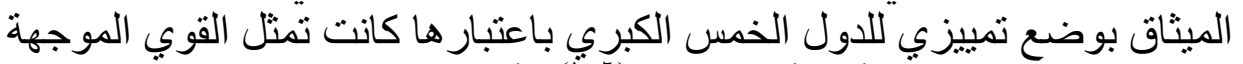

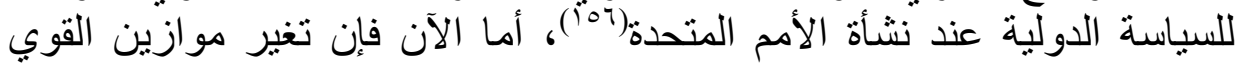

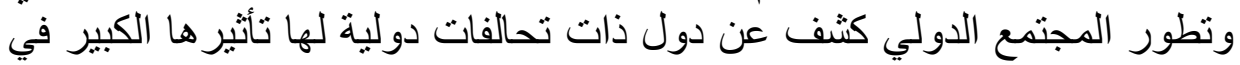

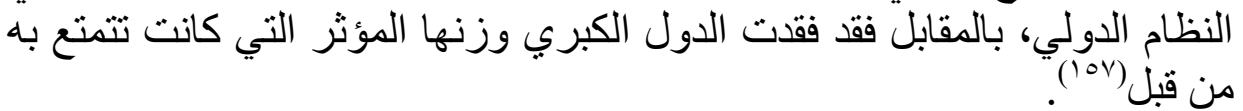
وبذلك تكون المادة (rآץ) من الميثاق قد أبرزت التباين السياسي و الو اقعي بين

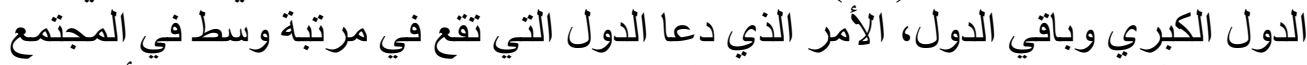

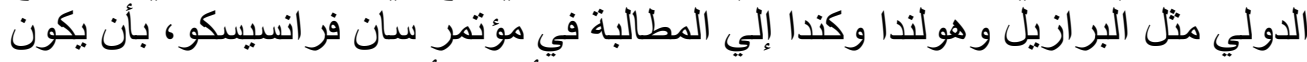

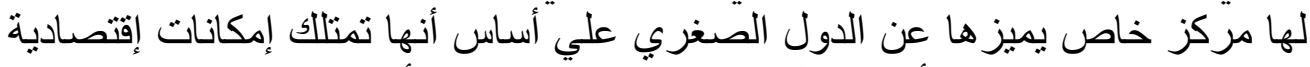
وعكرية ما يمكنها من أن تتحمل تبعات صيانة السلم والأمن الدوليين تفوق ما تقدر

(المر (10r د محمد حافظ غانم - المنظمات الدولية (دراسة لنظرية التنظيم الدولى ولأهم المنظمات)-

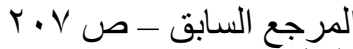

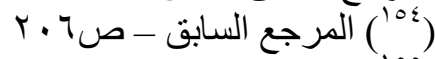
.

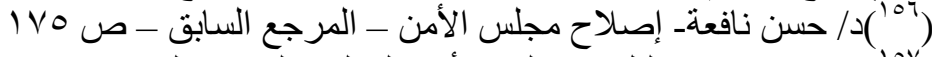

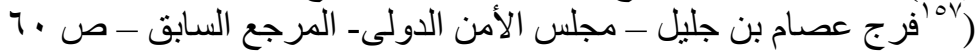

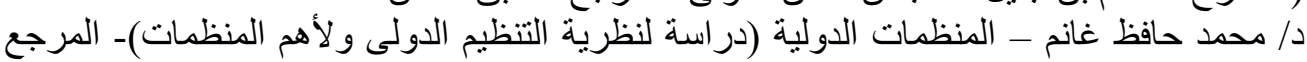

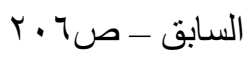




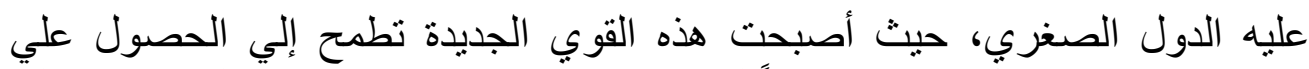

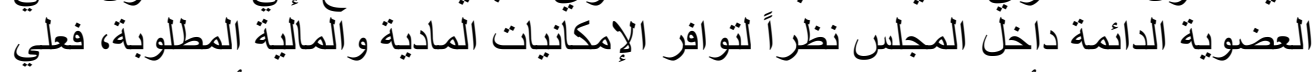

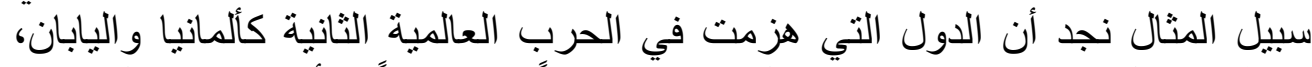

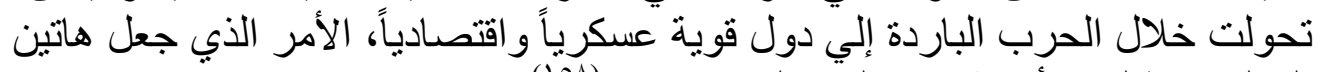

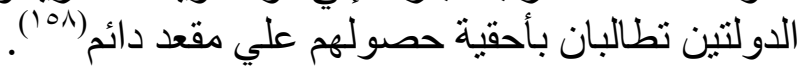

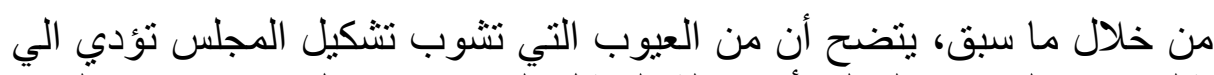

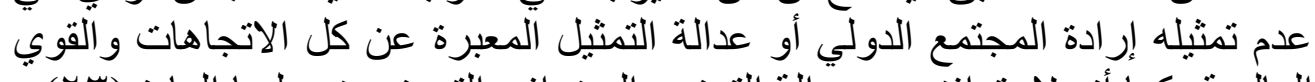

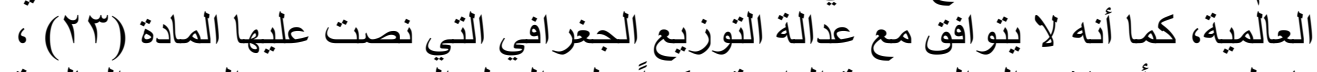

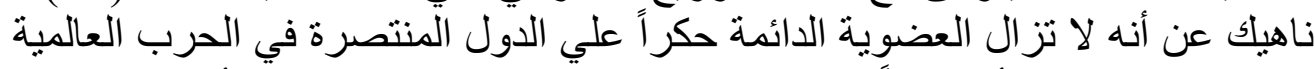

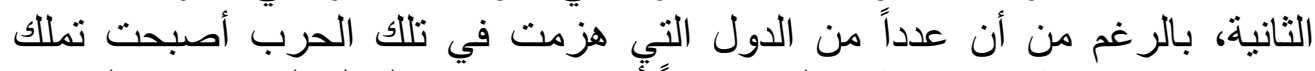

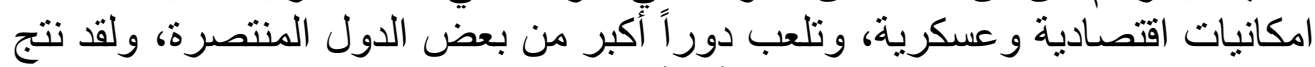

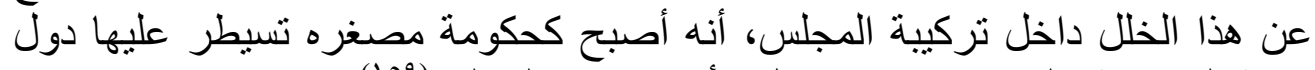

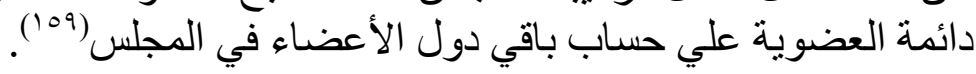

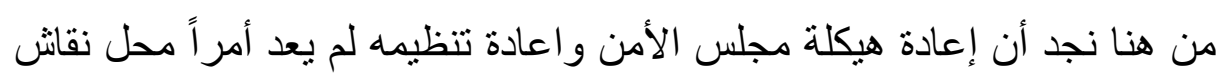

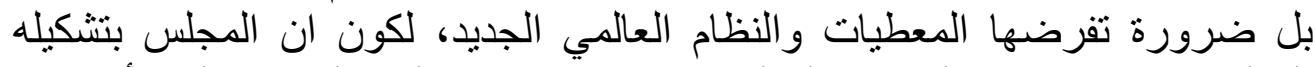

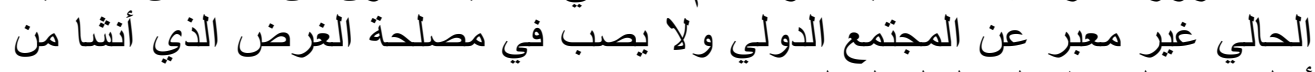
أجله و هو الحفاظ علي السلم الدولي.

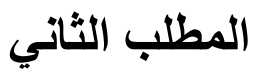 \\ نظام التصويت كأحل معوقات مجلس الأمن الفرع الأول \\ صور التصويت وحالاته}

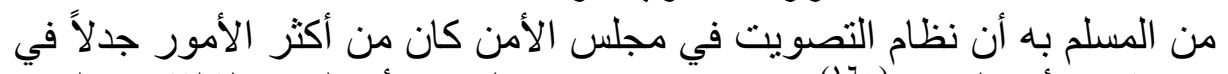

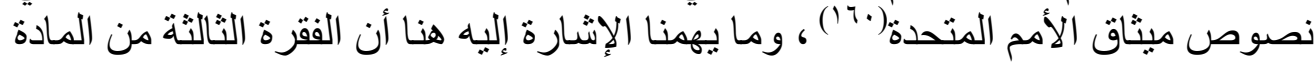

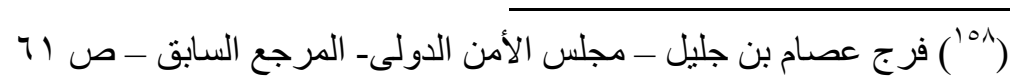

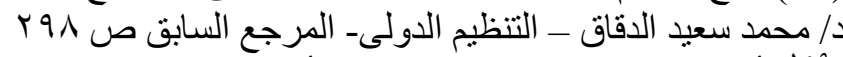

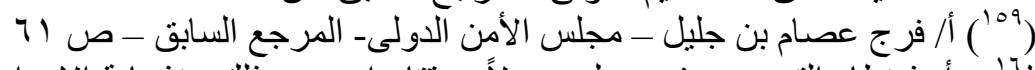

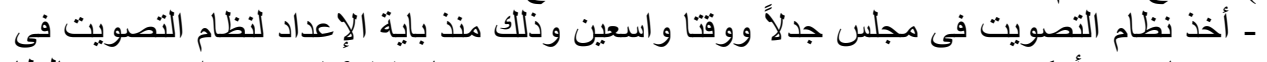

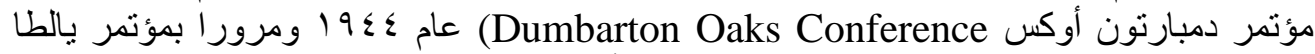
(Yalta Conference

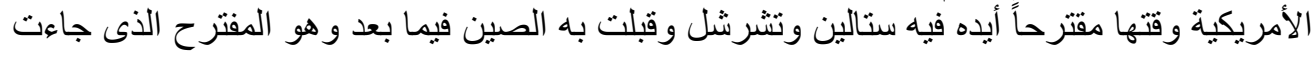


من ميثاق الأمم المتحدة لكي يصدر أعضاء مجلس الأمن قرار في مسألة

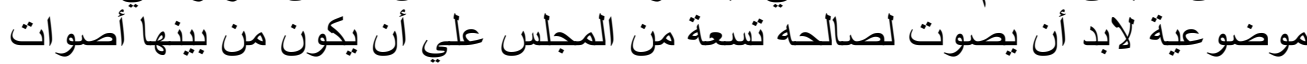

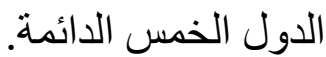

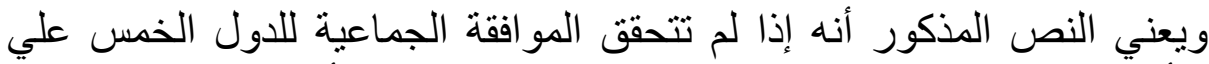

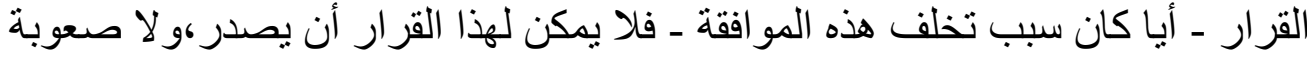

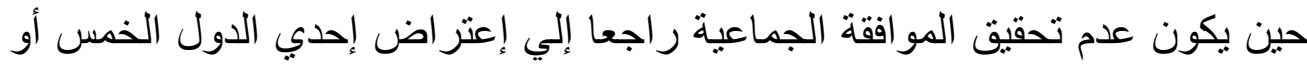

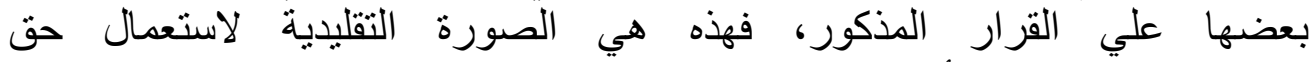

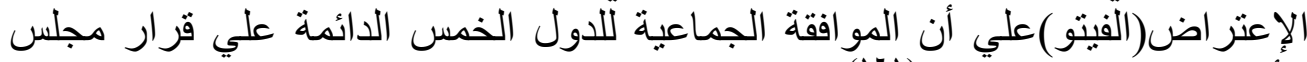

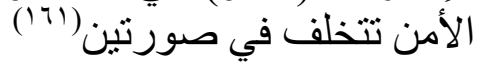

\section{الصورة الأولي : إمتناع العضو الدائم عن التصويت}

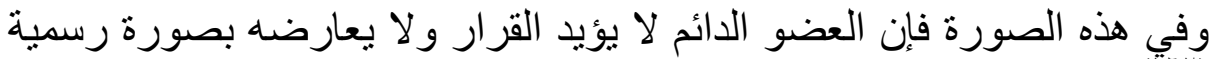

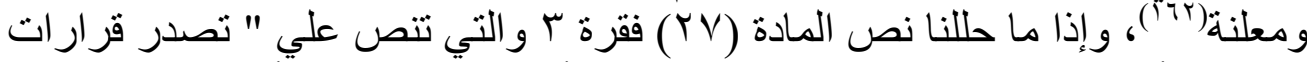

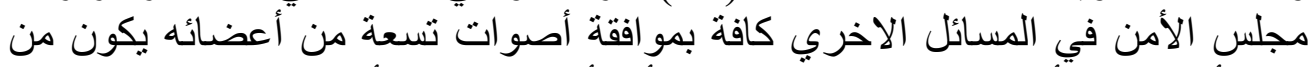

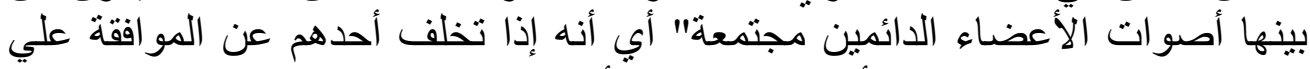

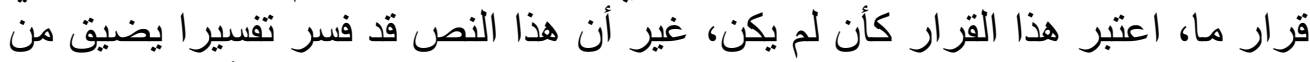

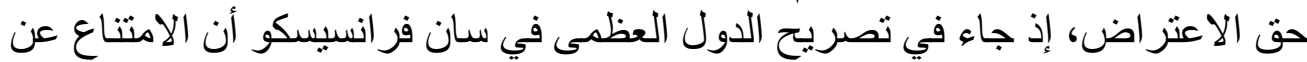

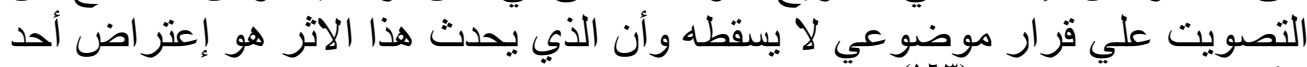

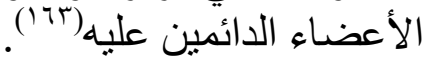

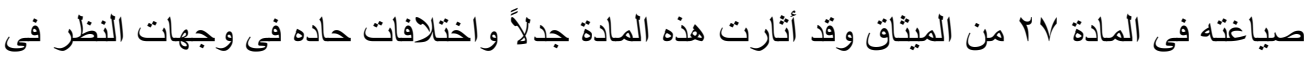

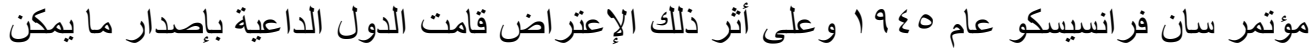

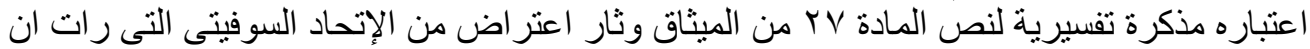

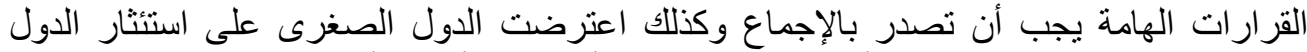

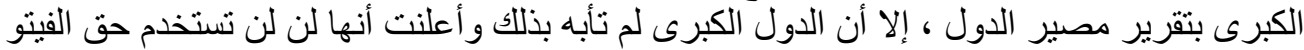

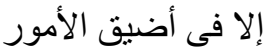
راجع فى ذللك د/محمد طلعت الغنيمى_التنظيم الدولى ـالطبعة الاولى_منشأة المعارف_الإسكندريةـ7 T.

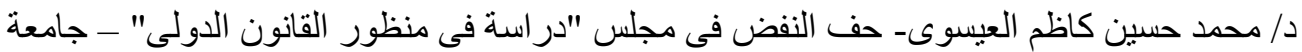

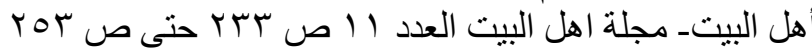

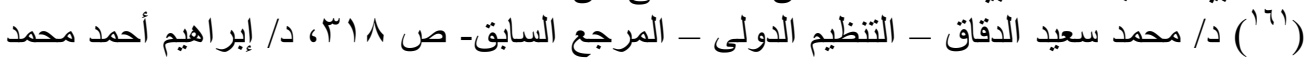

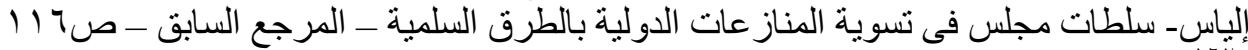

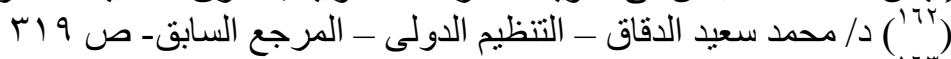

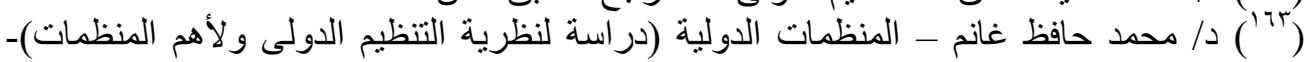

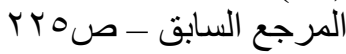




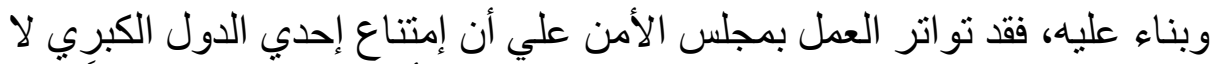

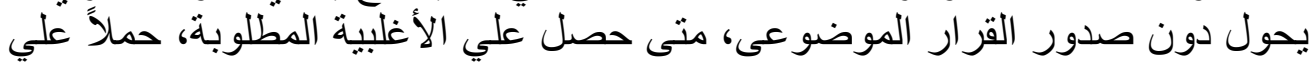

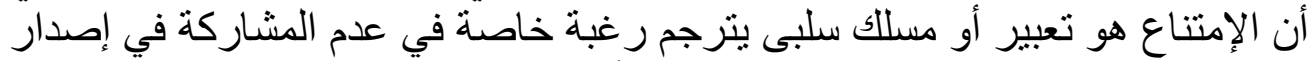

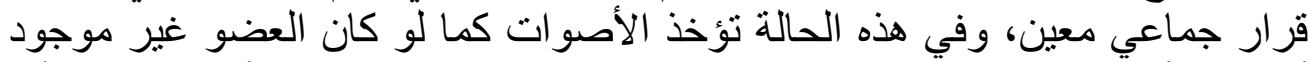

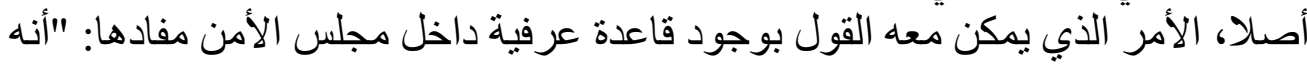

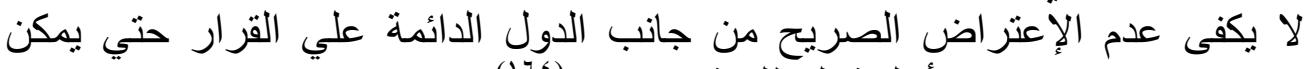
صدوره، متى نو افرت الأغلبية المطلوبة لإصداره(174)

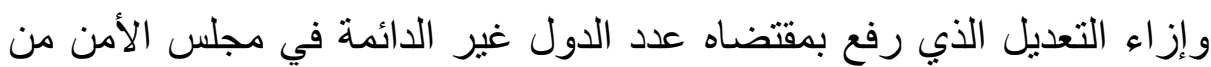

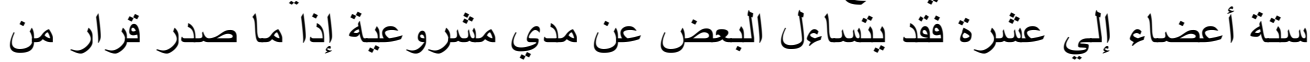

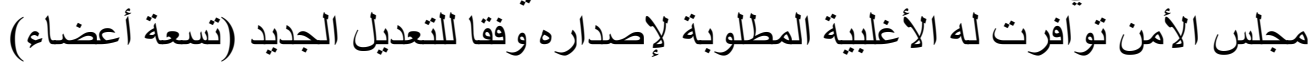

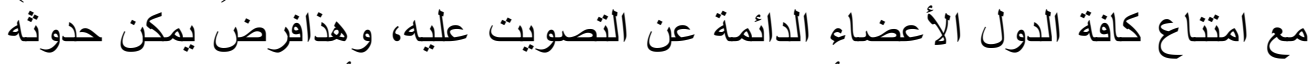
بعد الزيادة المذكورة في عدد الأعضاء غير الدائمة في مجلس الأمن.

ذهب البعض(170) إلي ضرورة العدول عما أستقر عليه العمل في مجلس الأمن الإن الإن

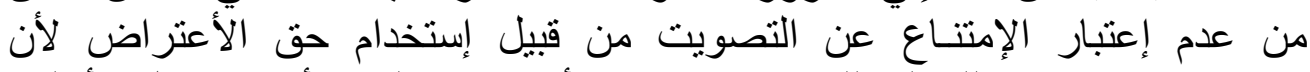

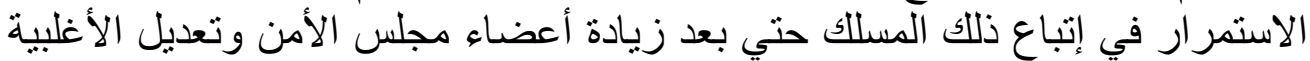

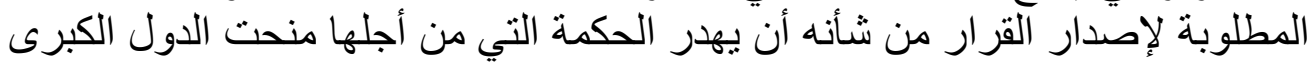

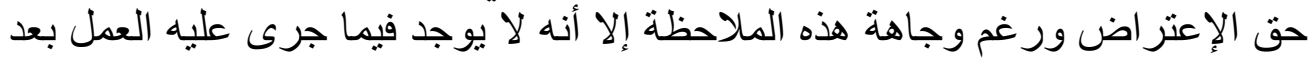
تعديل عدد أعضاء مجلس الأمن ما يفيد العدول عما أستقر عليه مسلك هذا لإن الأخير.

\section{الصورة الثانية: حالة غياب أحد الأعضاء الدائمين أو إمتناعه عن حضور جلسات

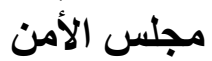

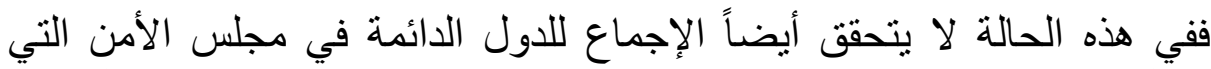

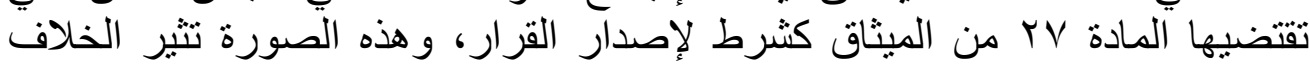

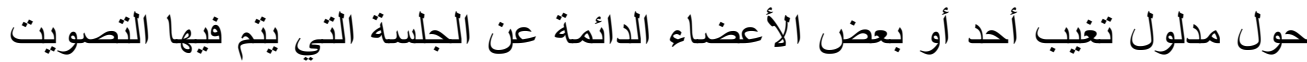

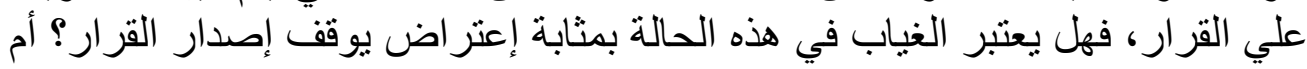

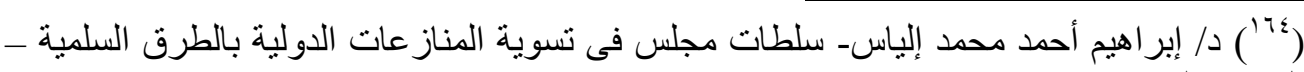

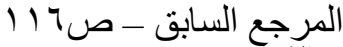

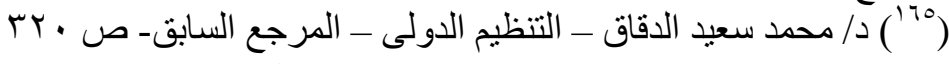


أنه يتساوي في أثره مع أثر الإمتناع عن التصويت بحيث لا يؤدي في نهاية الأمر إلي

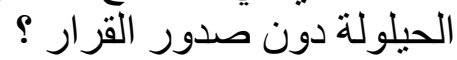

إن قلة السو ابق في هذا الصدد - وبالتالي عدم إمكانية الوقوف علي مسلك حاسم

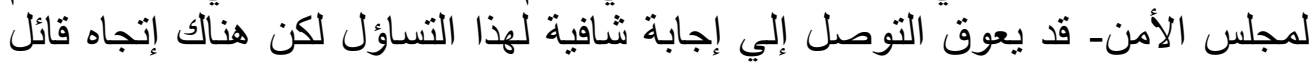

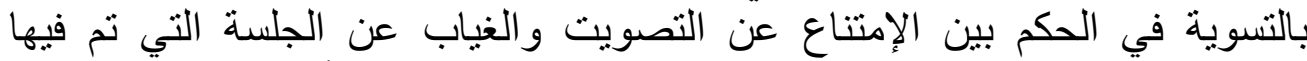

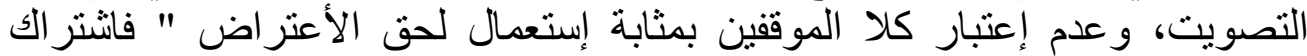

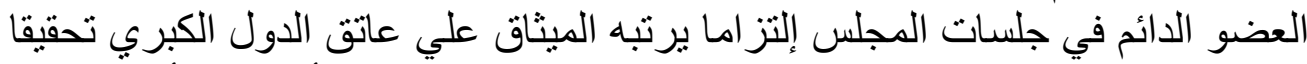

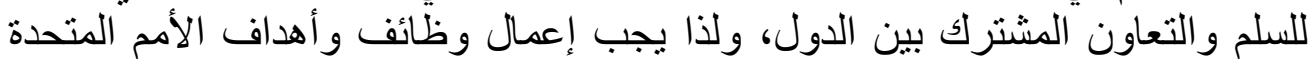

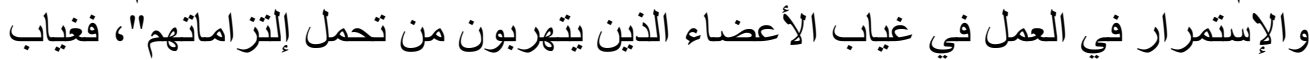

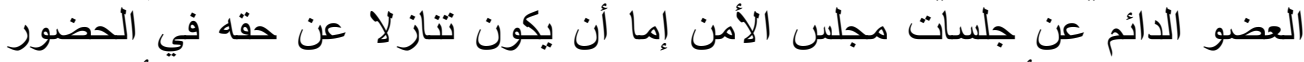

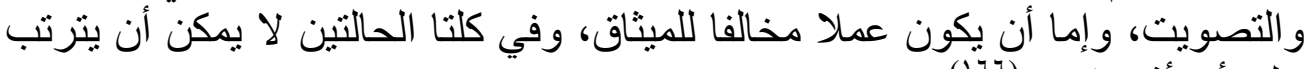

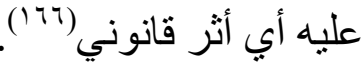

بناء عليه فقد إتجه الرأي الغالب(Vآ) داخل منظمة الأمم المتحدة إلي اعتبار

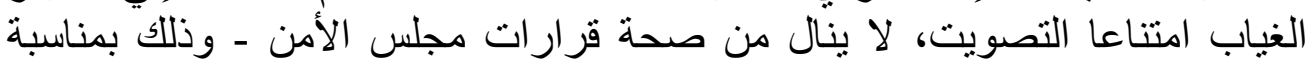

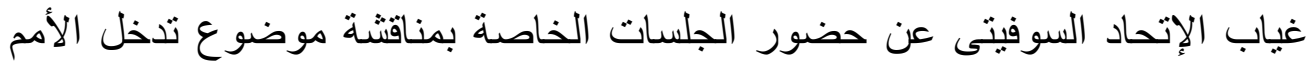

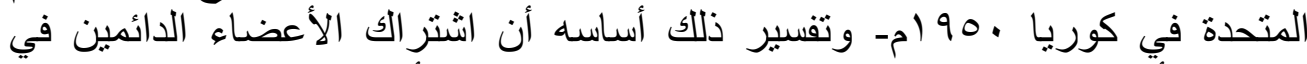

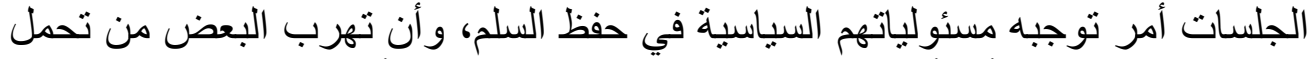

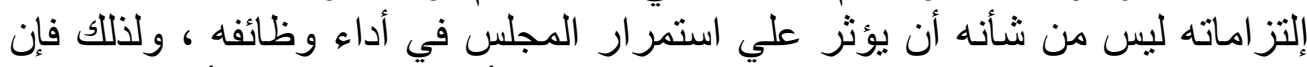

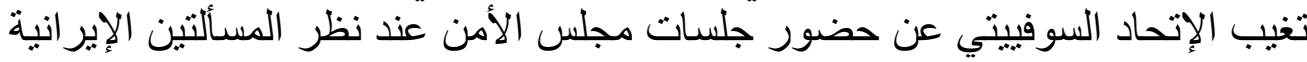

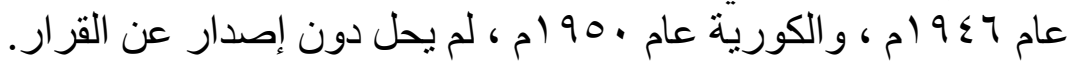

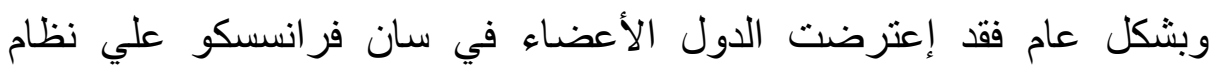

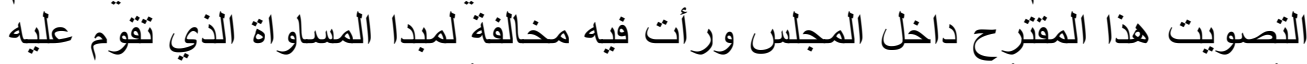

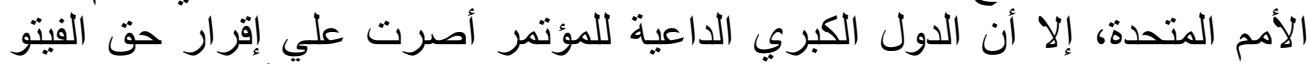

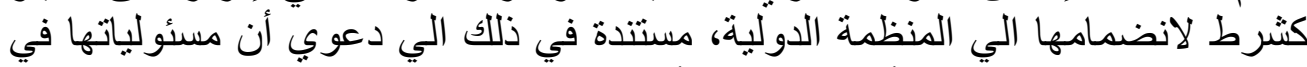

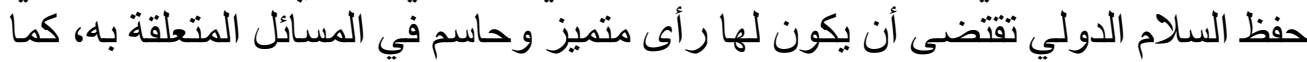

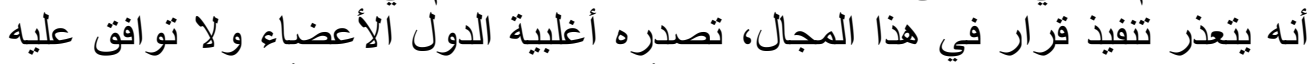

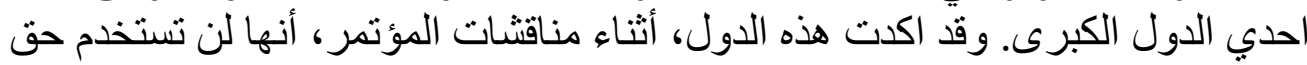

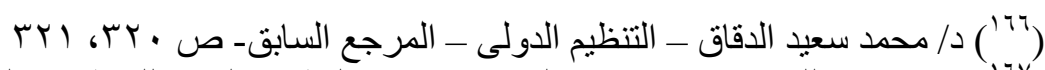

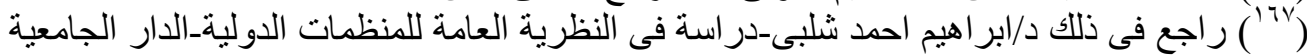

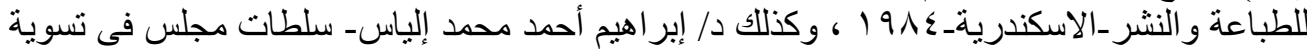

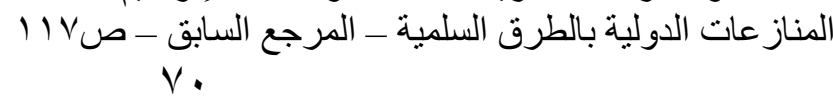


الفيتو الا في أضيق الحدود ، و وانه سيحدو ها دائما عند كل تصويت الإحساس بتبعاتها

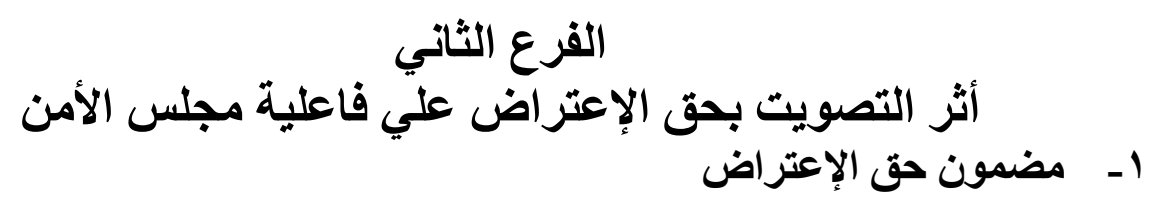

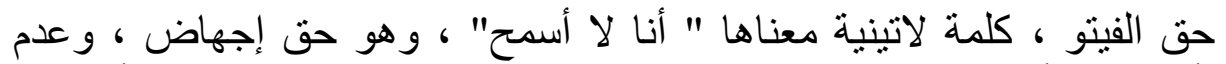

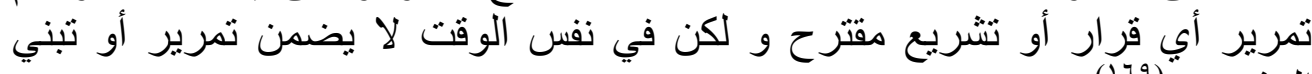

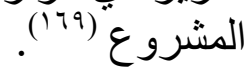

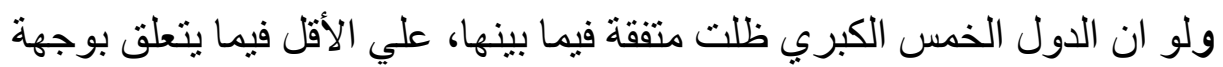

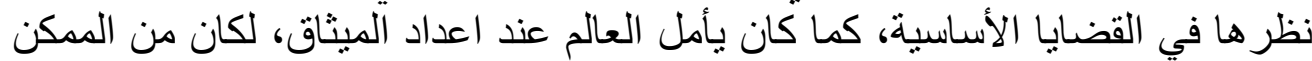

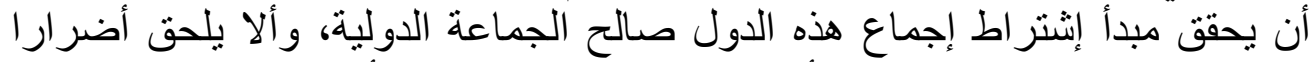

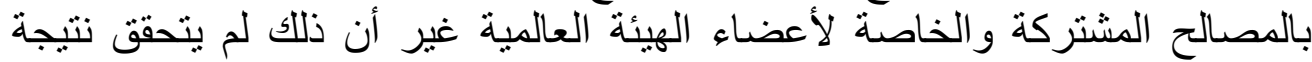

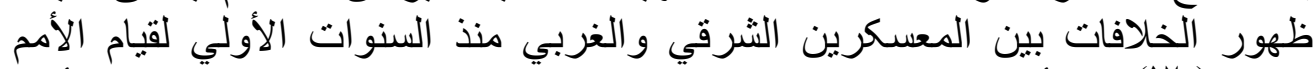

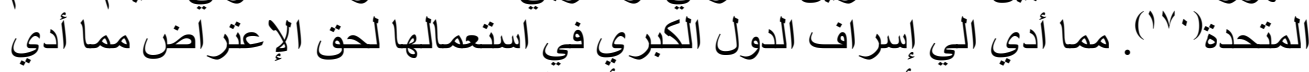

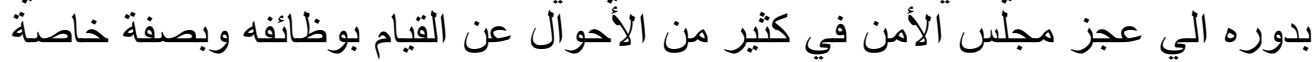

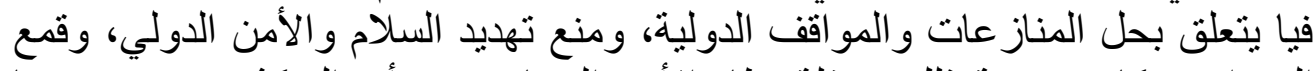

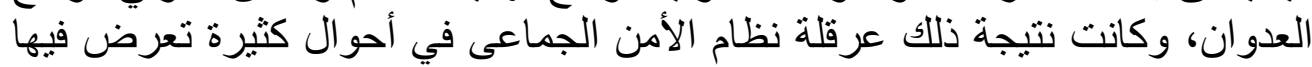

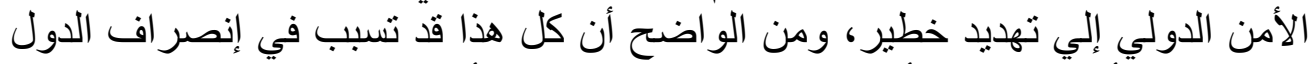

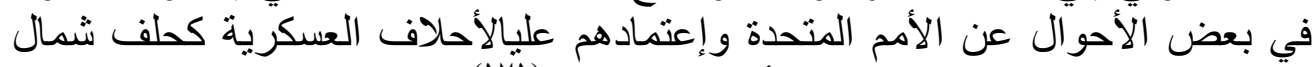

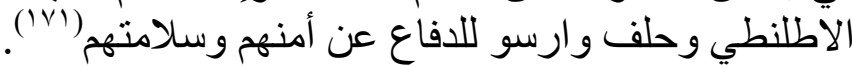

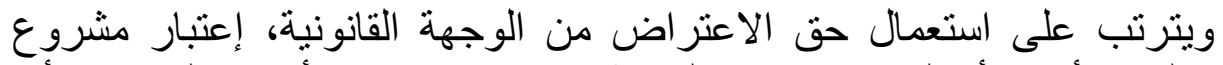

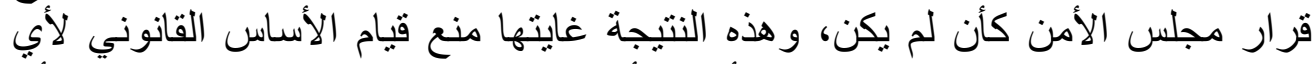

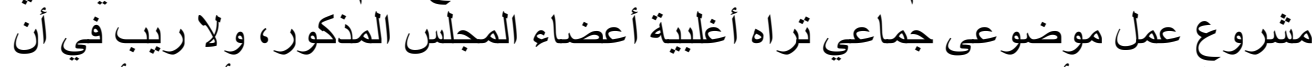

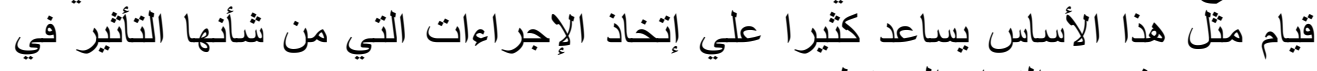
موضوع مشروع القرار المسقط.

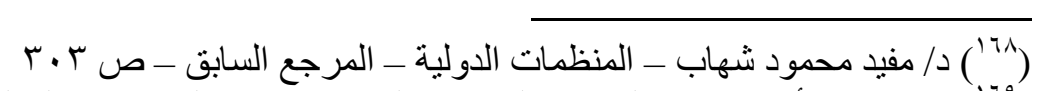

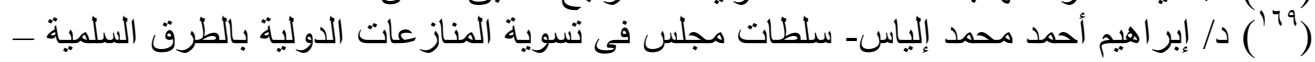

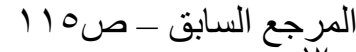

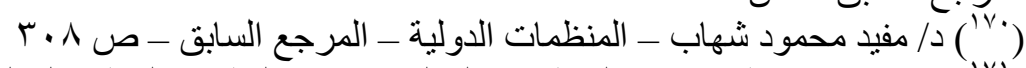

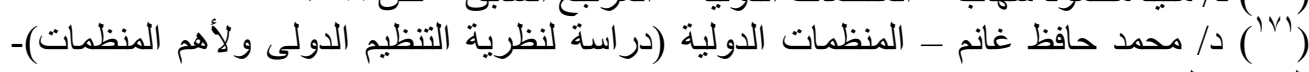

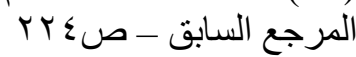




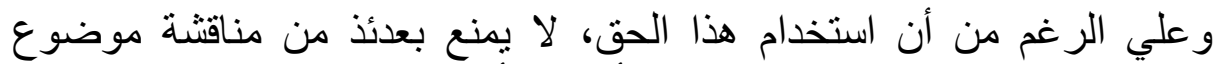

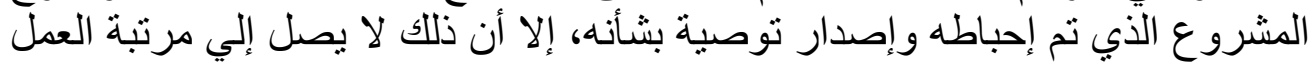

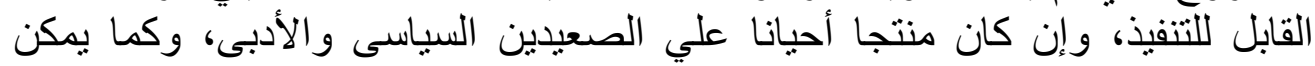

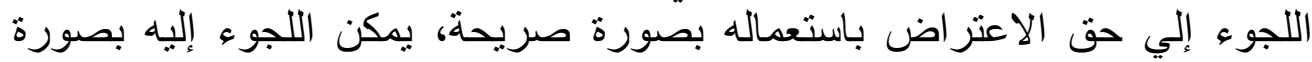

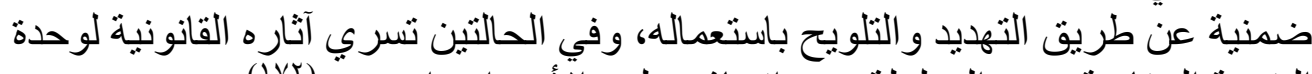

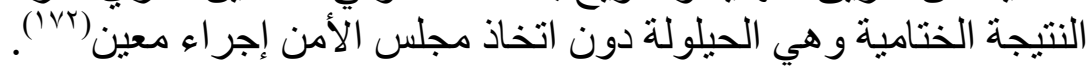

ومنذ دخول حق الاعتراض في دور التطبيق العملى، بدأت آثاره القانونية السلبية

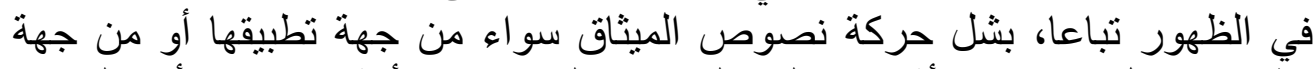

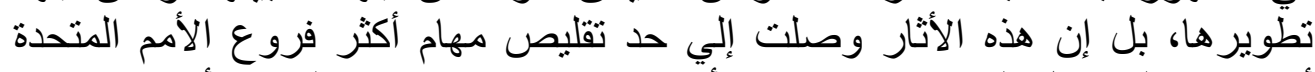

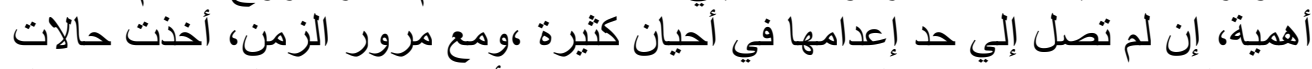

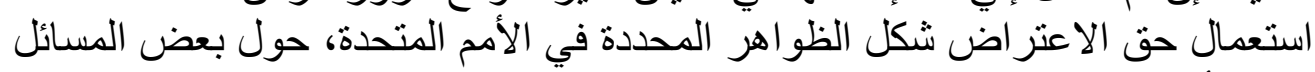

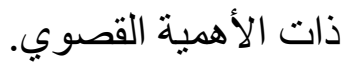

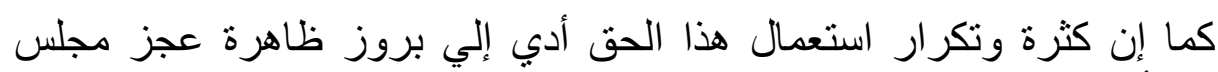

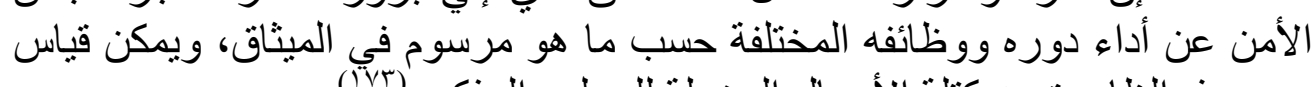

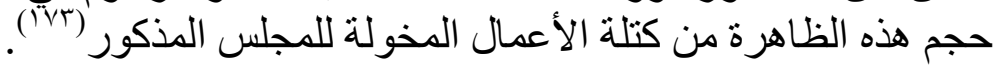

\section{r ـ التفرقة بين النزاع والموقف}

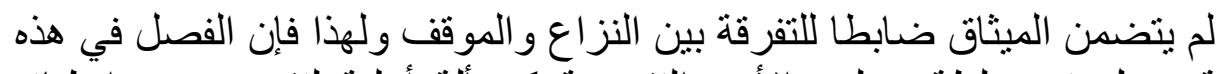

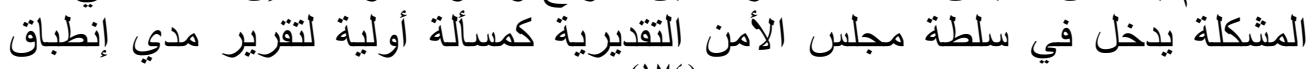

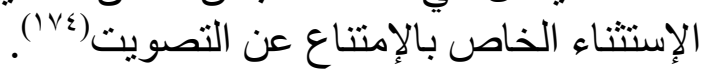

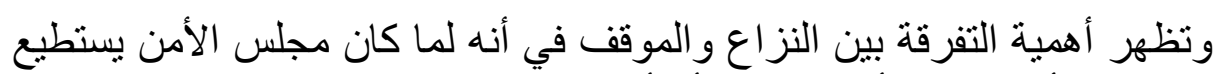

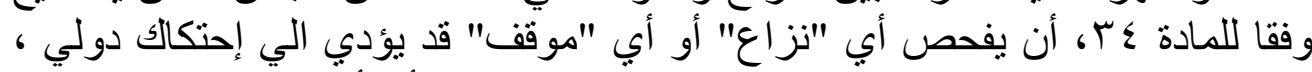

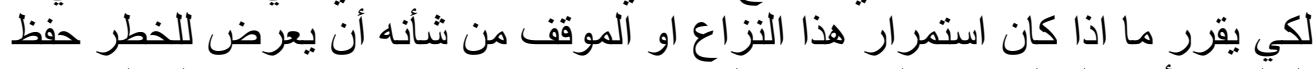

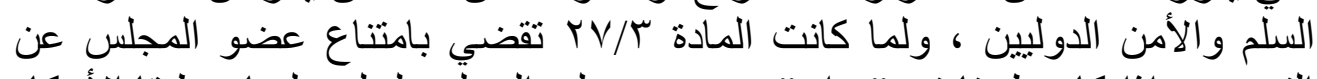

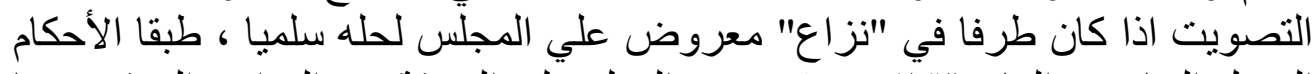

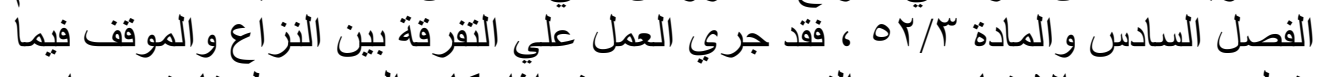

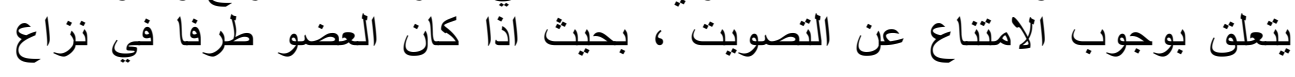

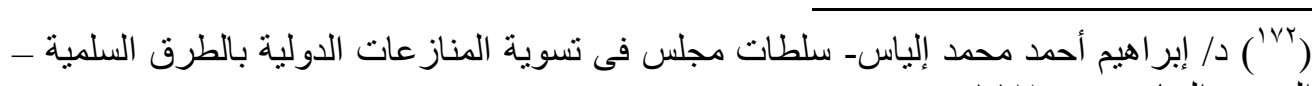

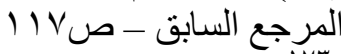

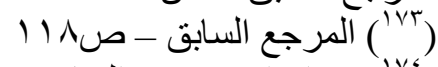

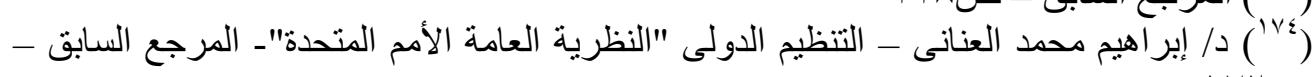


معين وجب عليه الامتناع عن التصويت ، احتر اما لمبدا عدم جواز (différend)

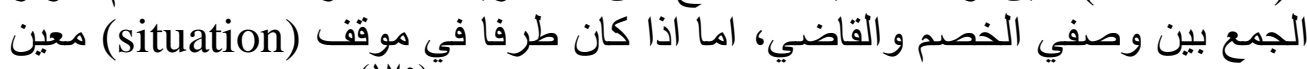

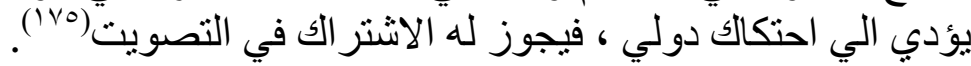

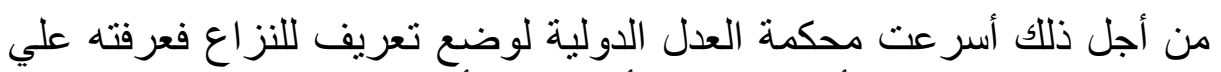

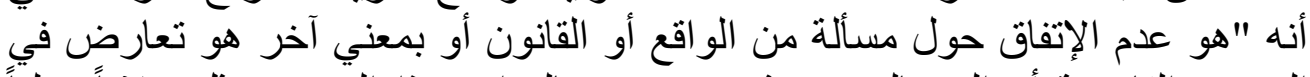

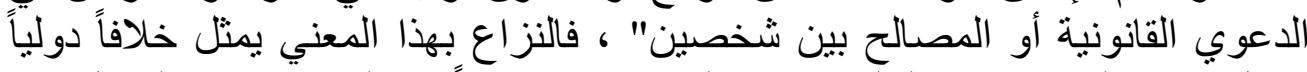

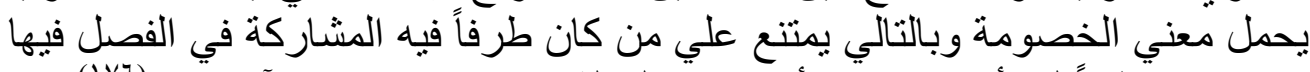

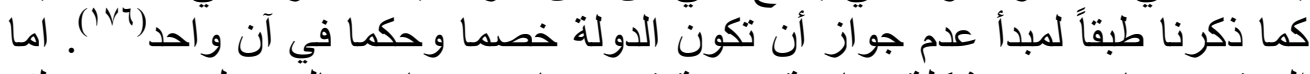

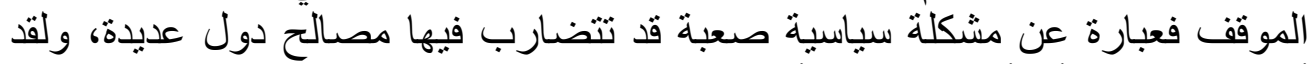

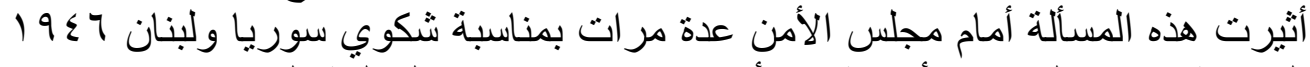

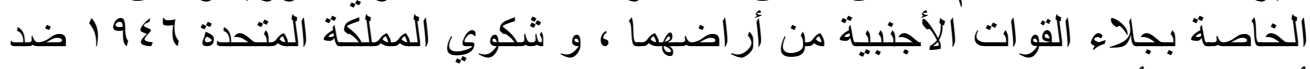

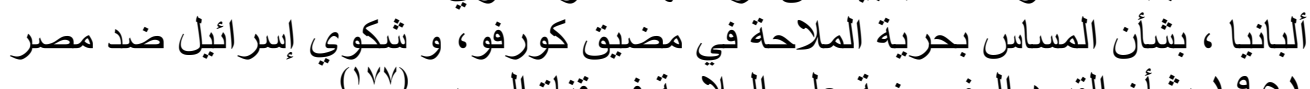

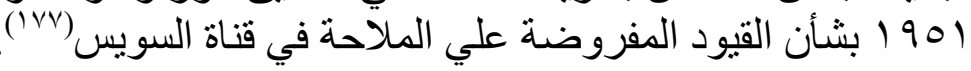

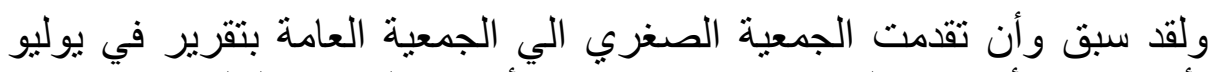

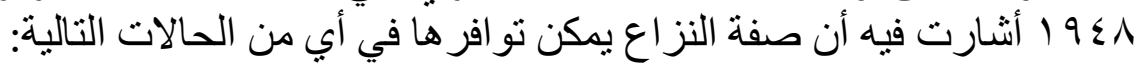

$$
\text { 1- ـ إتفاق أطر اف المشكلة علي أنها تمثل نزاعاً. }
$$

r- ـ إدعاء دولة بمخالفة دولة أو دول أخري لإلتز اماتها الدولية و إنكار الأخيرة ذلك.

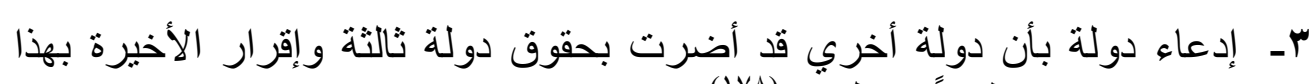

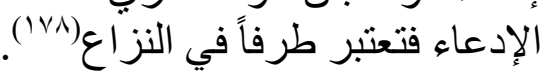

\section{الفرع الثالث

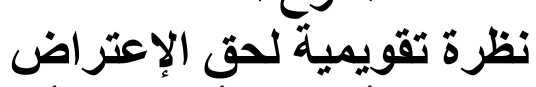

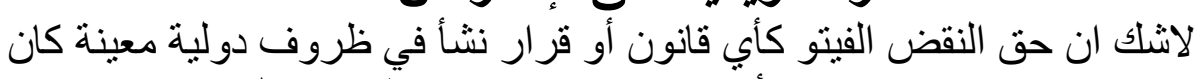

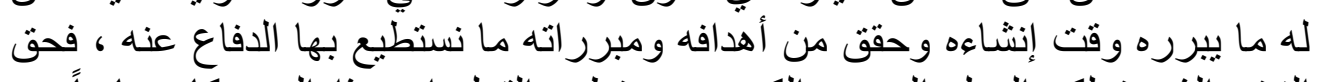

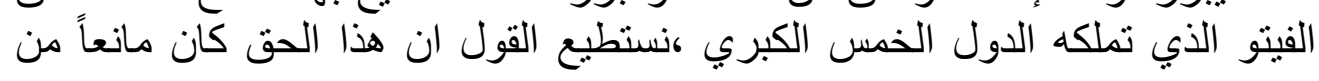

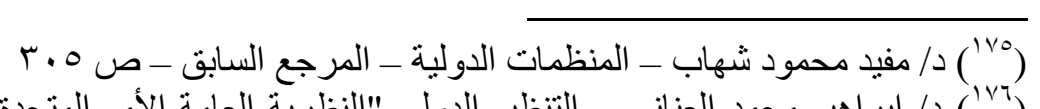

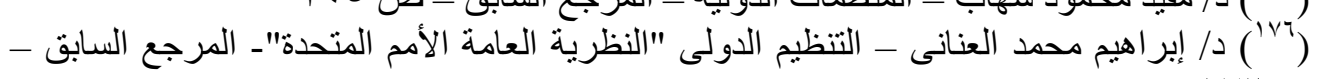

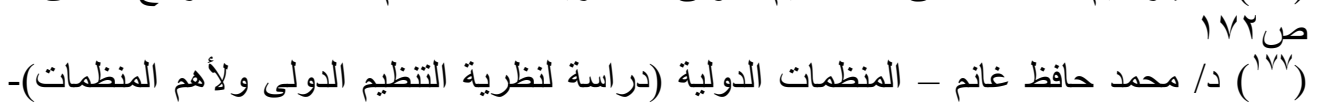

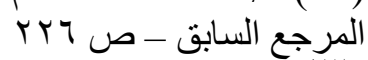

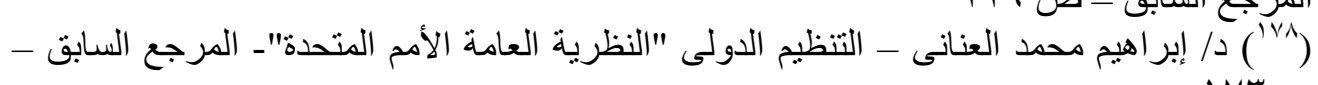




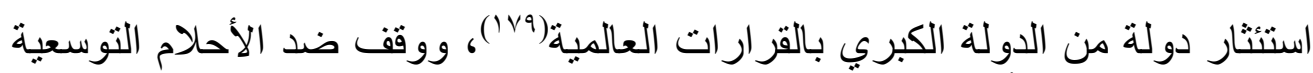

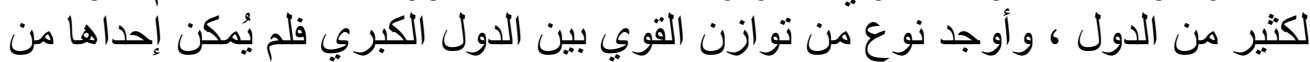

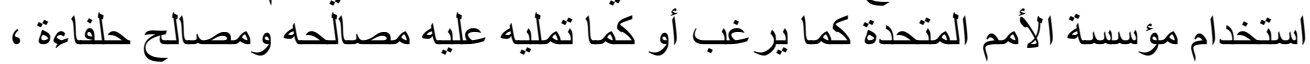

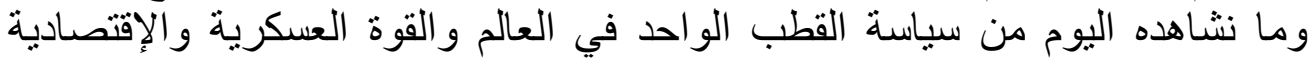

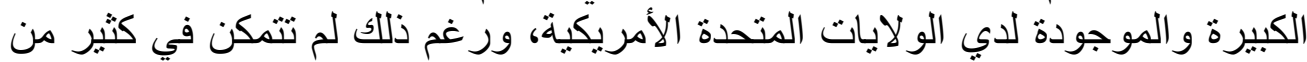

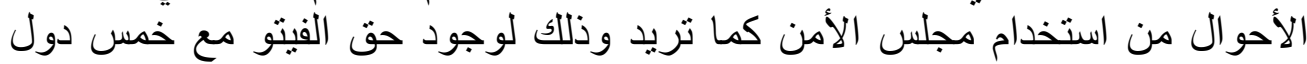

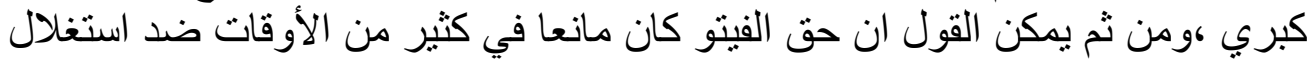

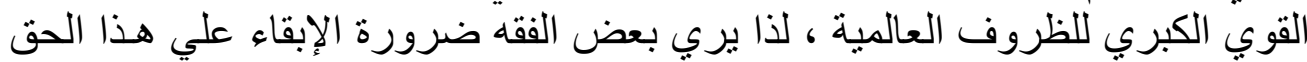

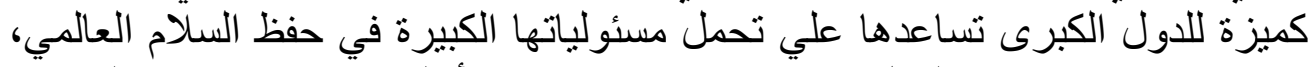

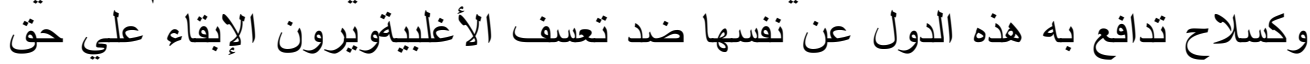

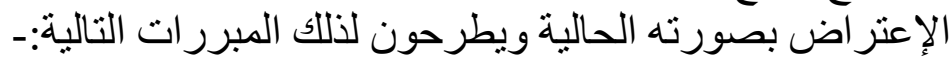

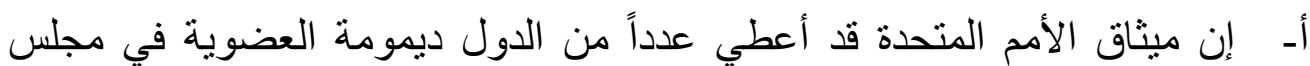

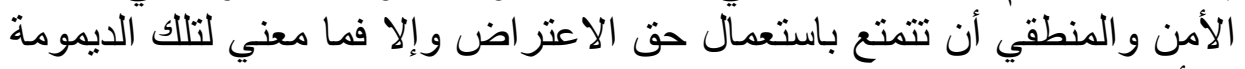

$$
\text { إلا أن تبقي ناقصة. }
$$

بـ إن استعمال حق الاعتر اض هو زيادة في السلطة تقابلها زيادة في المسؤولية،

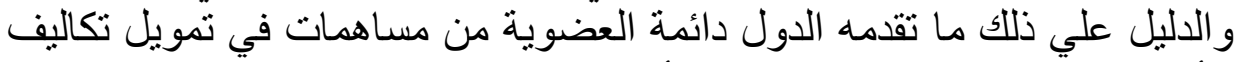
الأمم المتحدة للمحافظة علي السلم و الأمن الدوليين.

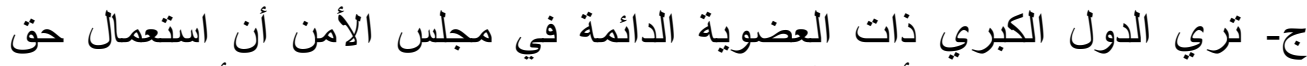

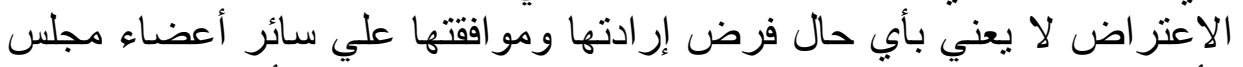

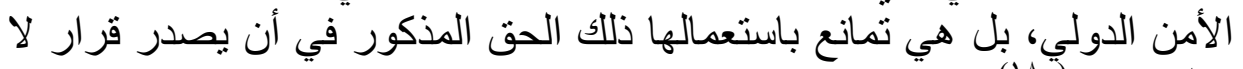

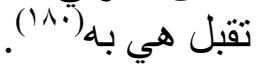

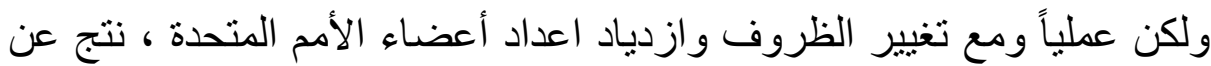

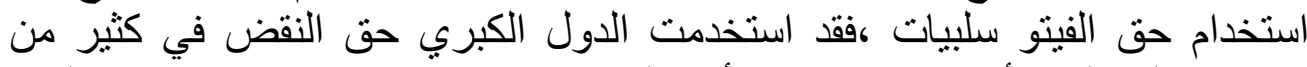

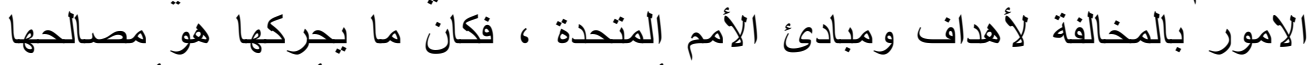

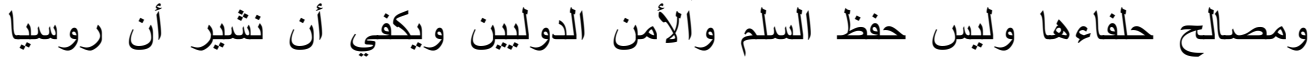

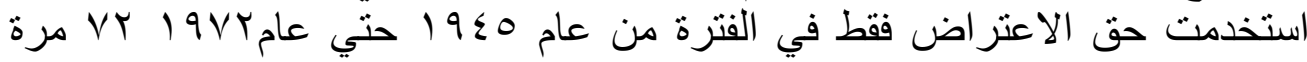

1. $\left({ }^{179}\right)$ Chrles G. Fenwich, International Law, New York :Appleton Century ,Crofts 1965.

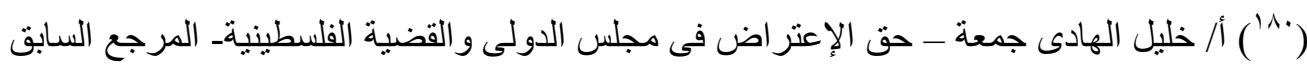
9^ ص- 


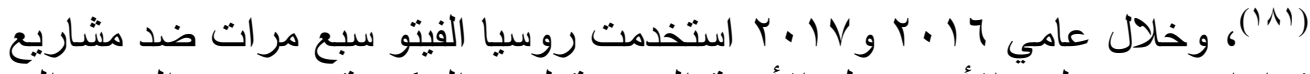

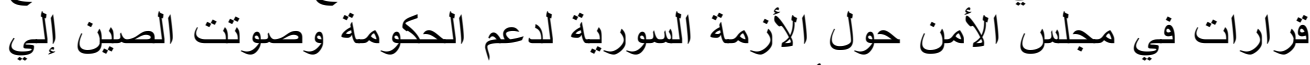

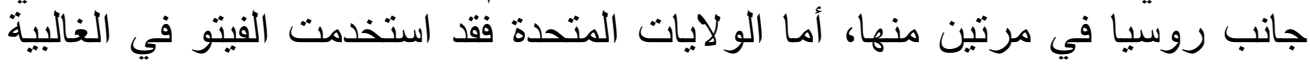

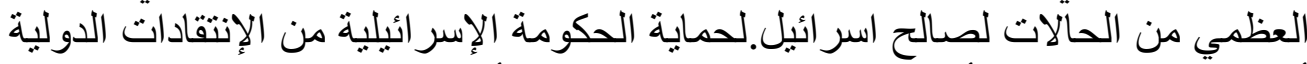

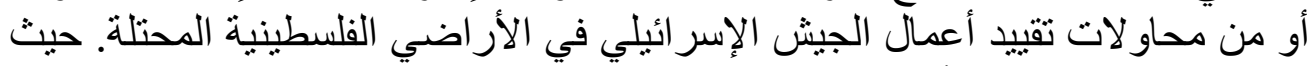

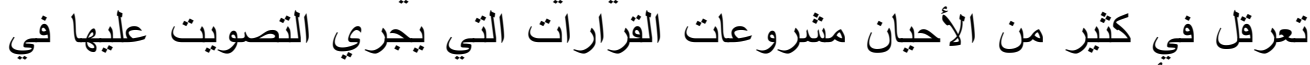

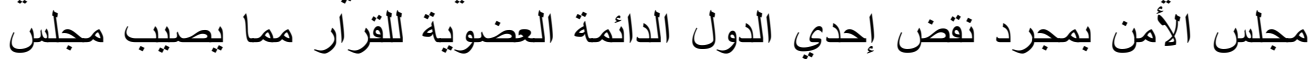
الأمن الدولي بالعجز الامن

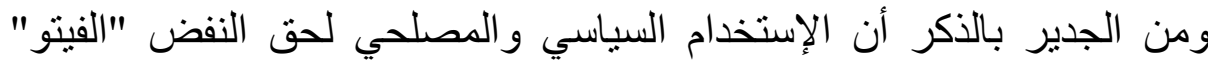

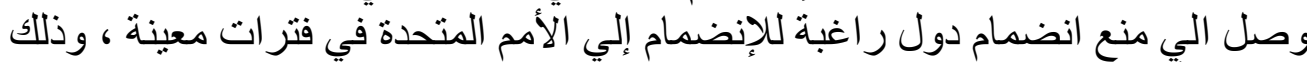

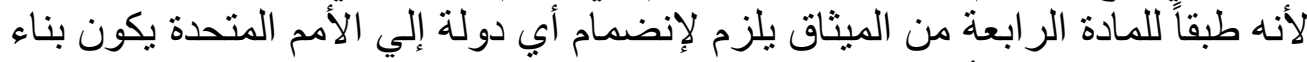

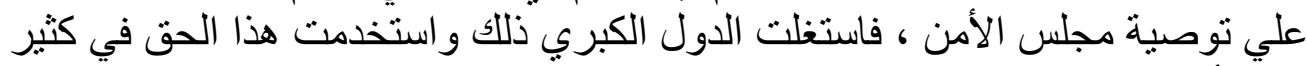

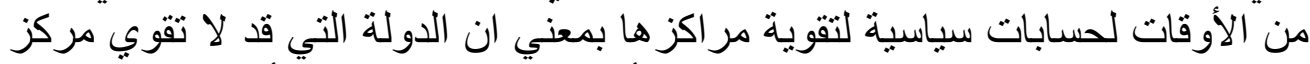

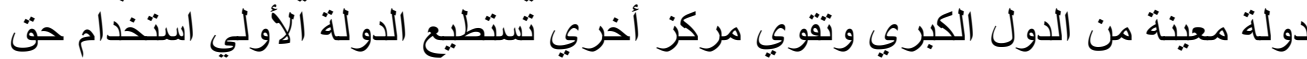

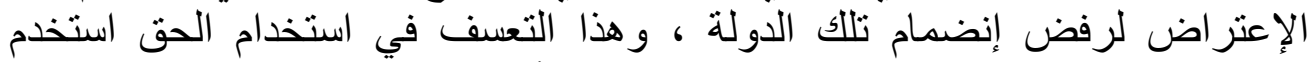

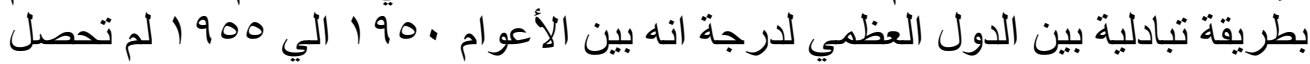

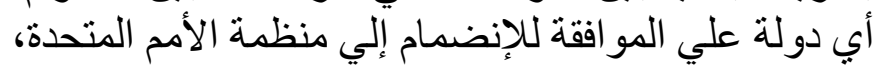

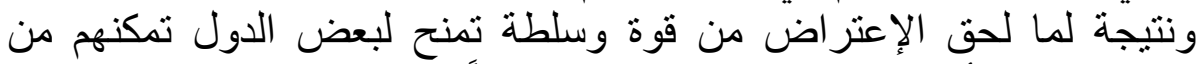

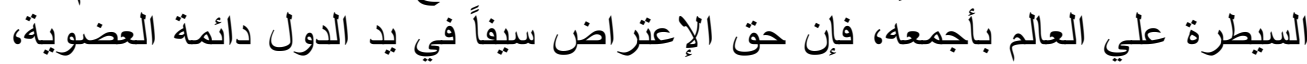

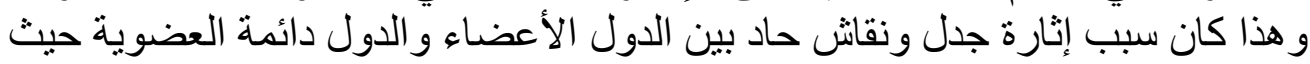

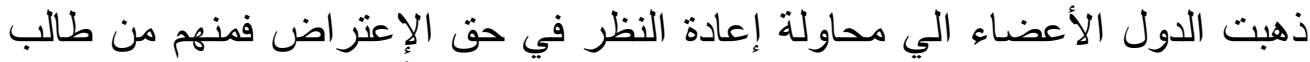

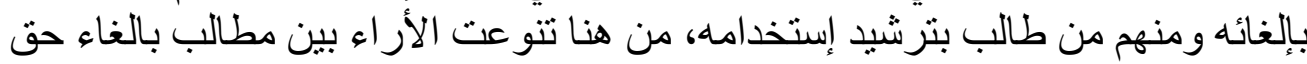

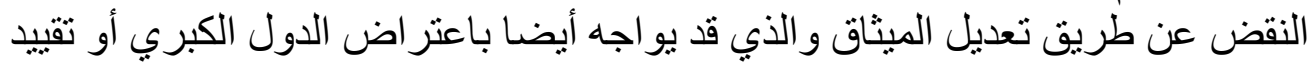

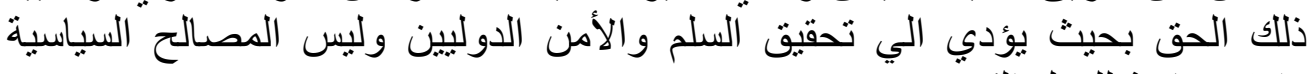

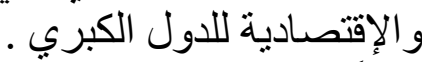
أولاً: تقييا حق الإعتراض

حاولت الجمعية العامة للأمم المتحدة تقييد حق الإعتر اض وذللك عندما رأت كثرة

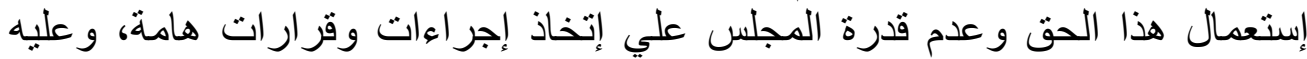

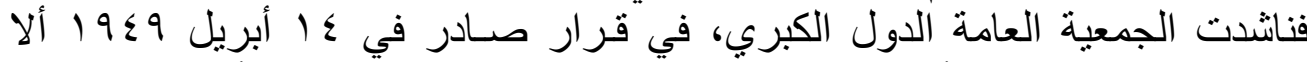

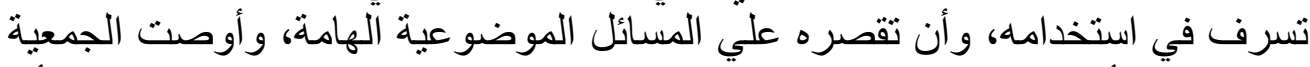

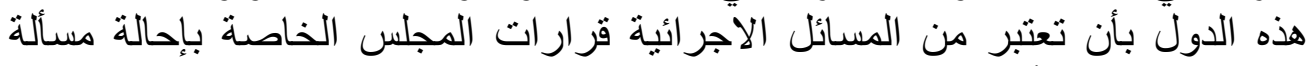

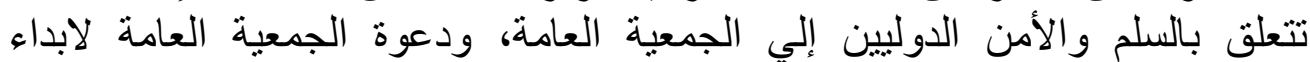


توصياتها في نزاع او موقف معروض علي مجلس الأمن، و إنشاء اللجان وتحديد الأناء

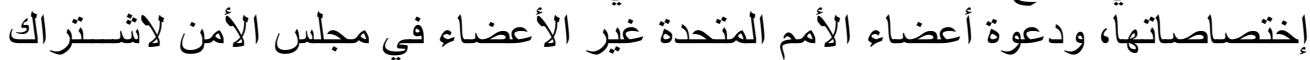

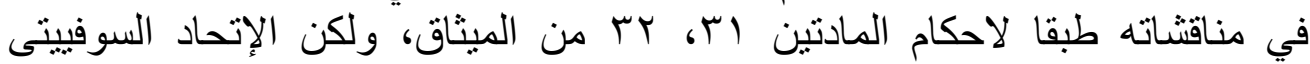

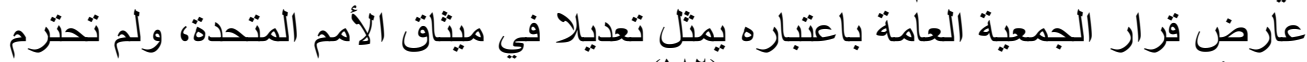

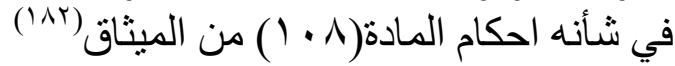

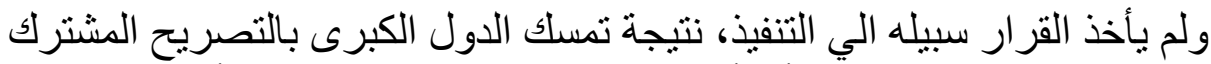

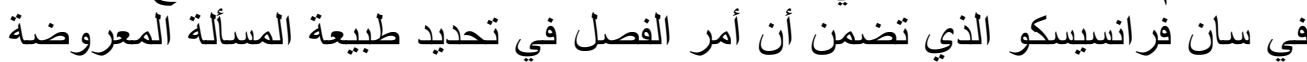

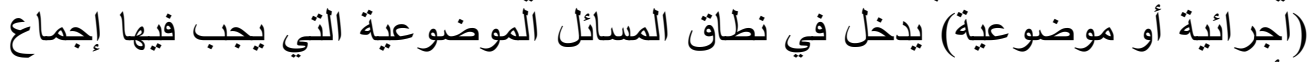

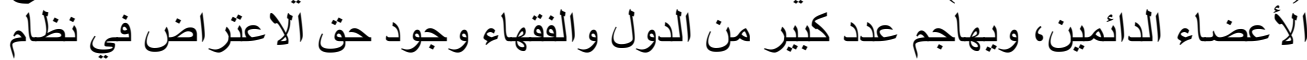

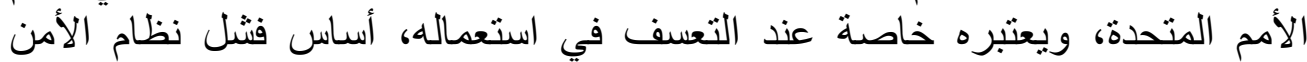

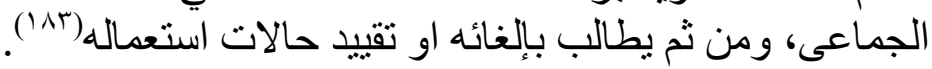

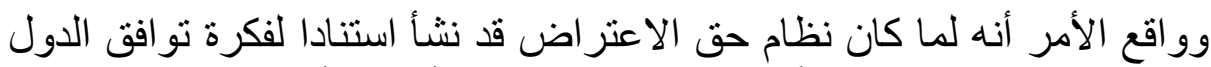

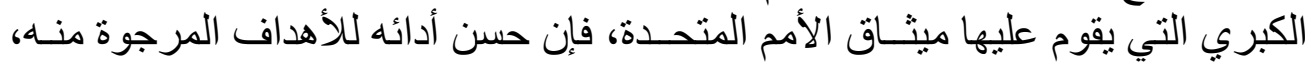

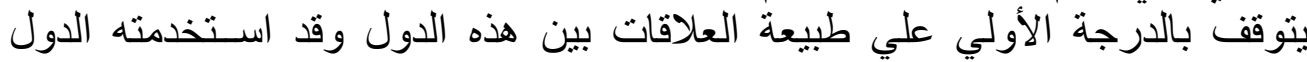

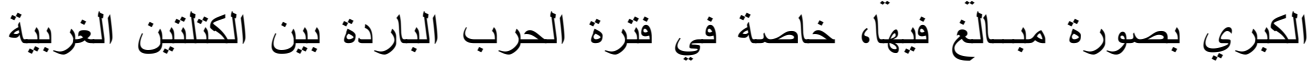

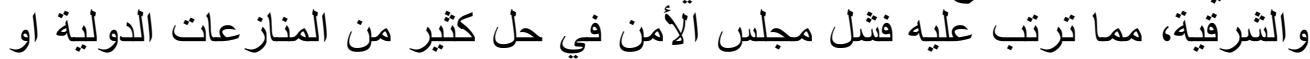

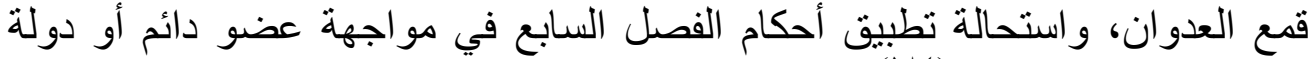

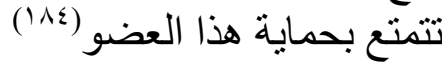

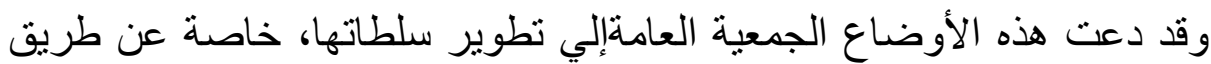

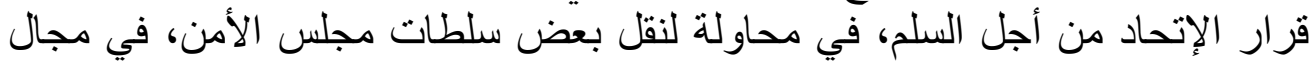

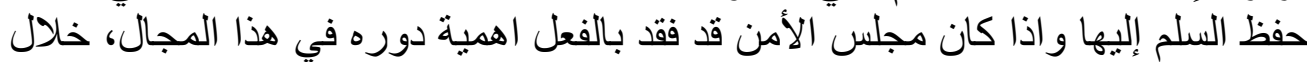

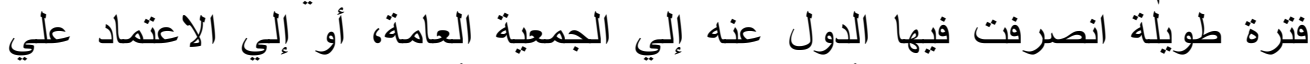

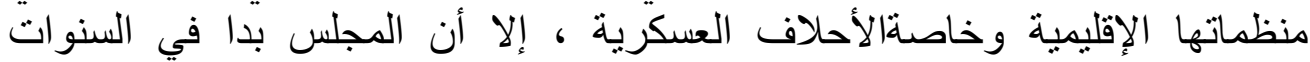

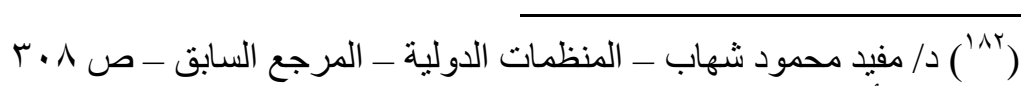
د/ إبر اهيم أحمد محمد إلياس- سلطات مجلس في في تسوية المناز عات الدولية بالطرق السلمية ــ المرجع

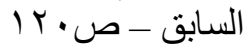

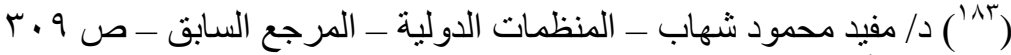

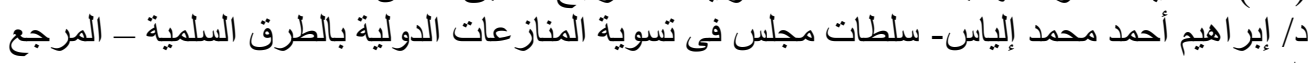

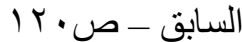

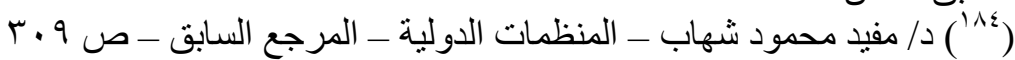
د/ إبر اهيم أحمد محمد إلياس- سلطات مجلس في تسوية المناز عات الدولية بالطرق الطية السلمية ــ المرجع

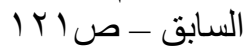


الأخيرة، وبفعل التقارب الذي يشهده المجتمع الدولى بين المعسكرين الشرقي و الغربي

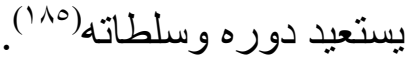

كذلك نري أنه قد تم تقييد استعمال حق الإعتر اض بالنسبة لمباشرة مجلس الأمن

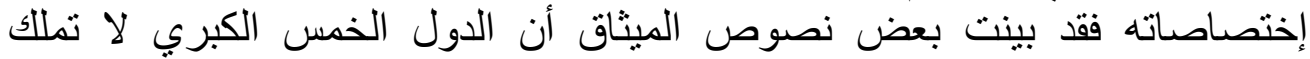

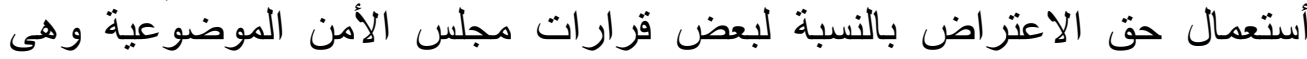

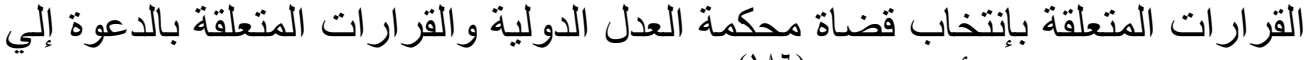

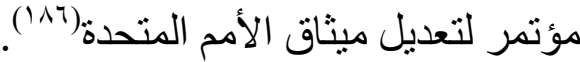

وينطلق إتجاه تقييد حق الإعتر اض من إعتبار ات عملية بحتة تري أن الدول التي

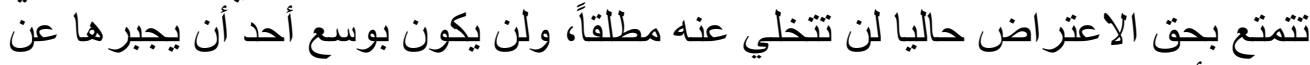

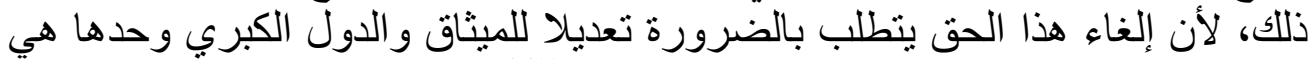

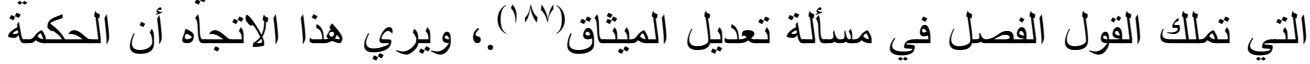

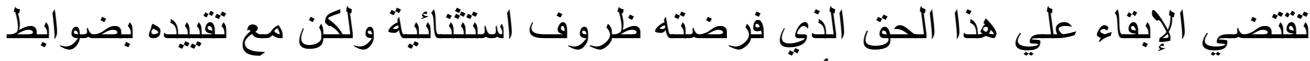

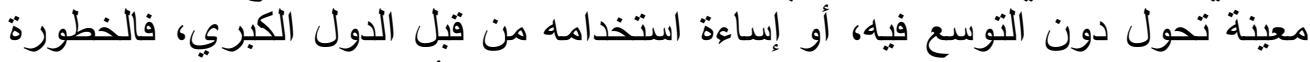

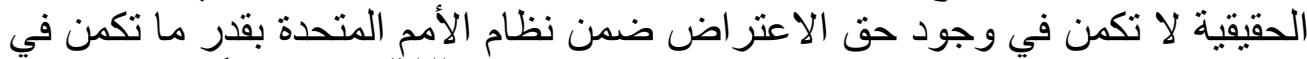

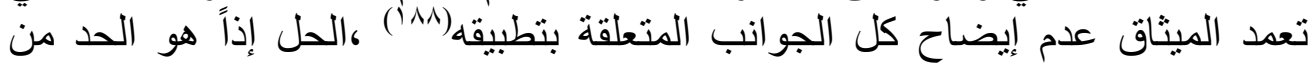

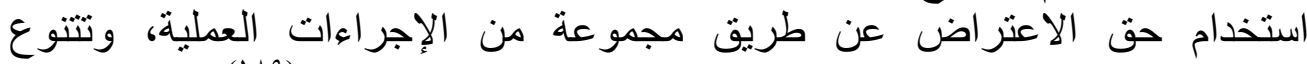

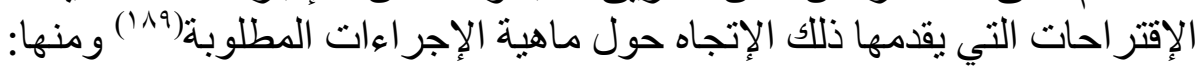

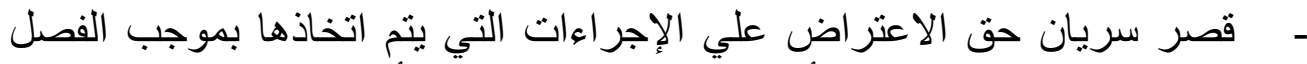

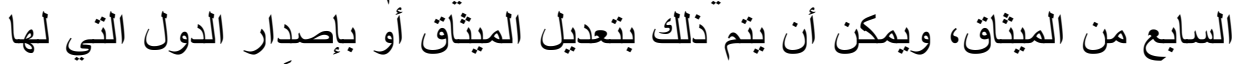

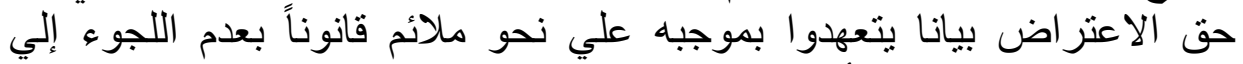

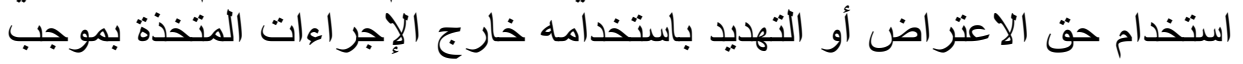
الفصل السابع من الميثاق. إلزام الدولة أو الدول التئي تستخدم حق الاعتر اض بتقديم تعليل لذلك ويمكن لهذا

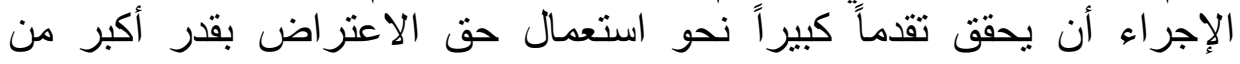
المسؤولية .

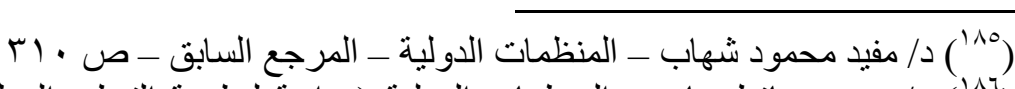

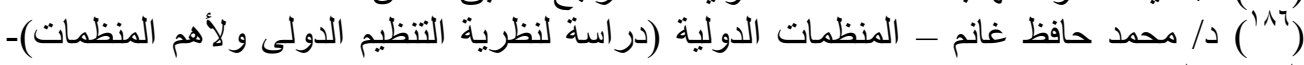

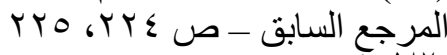

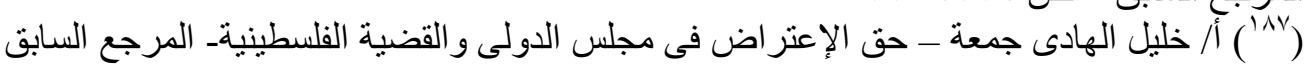
-

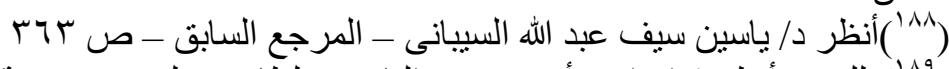

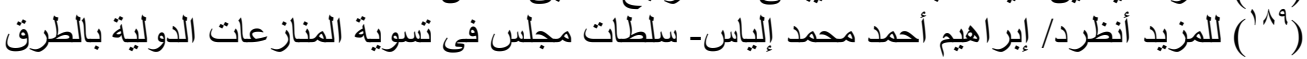

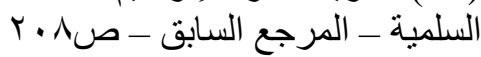




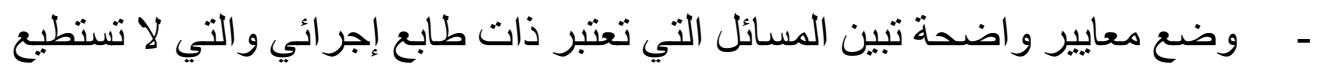

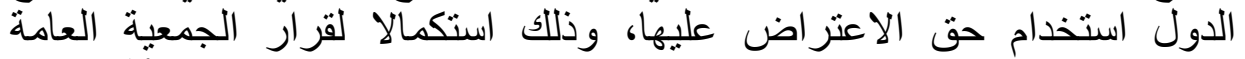

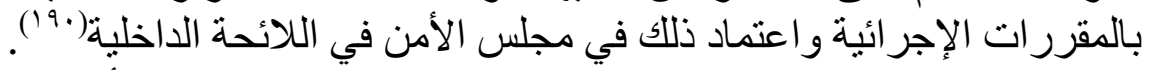

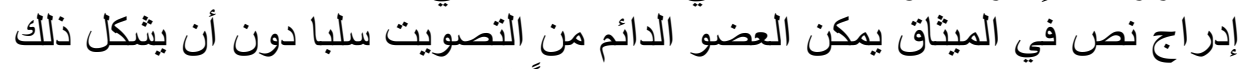

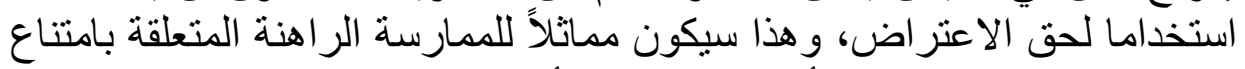

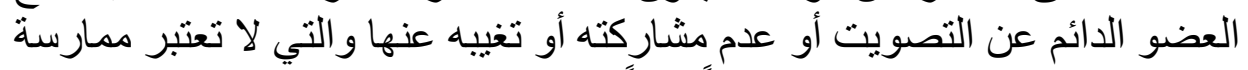

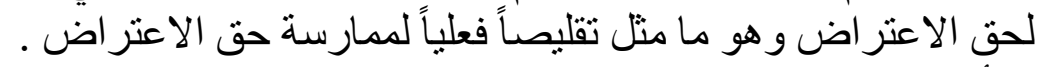

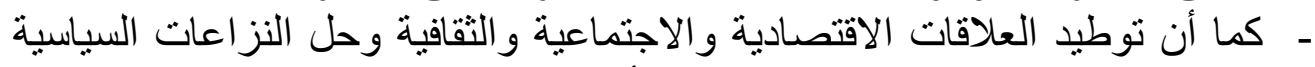

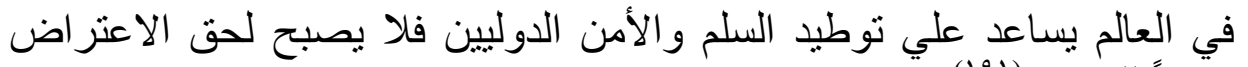

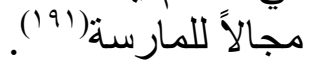
- كما أن تقييد حق الاعتراض يمكن أن يتم من خلال إعطاء حق الاعتر اض على الإني

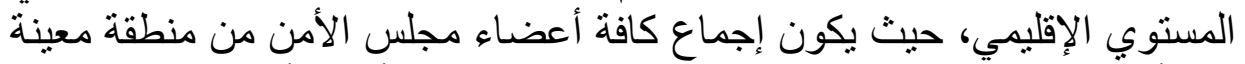

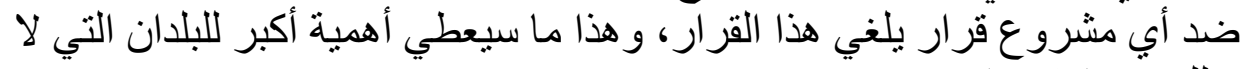

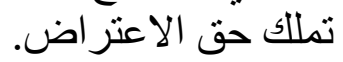

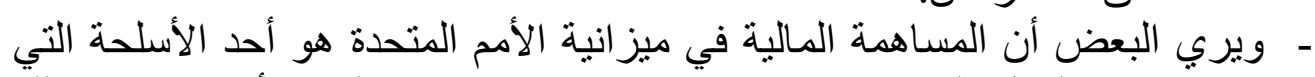

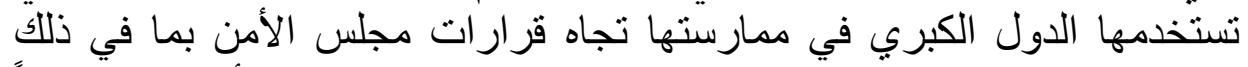

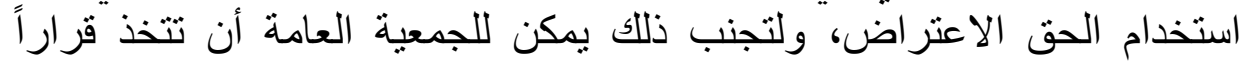

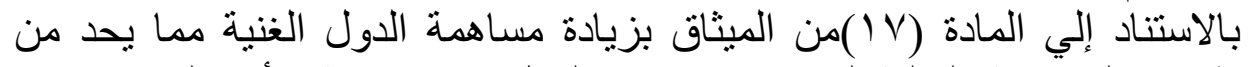

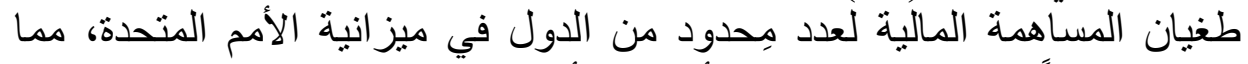

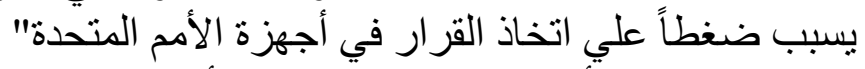

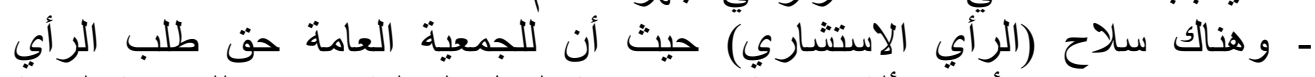

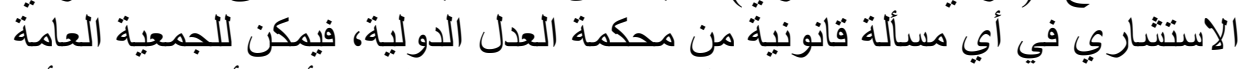

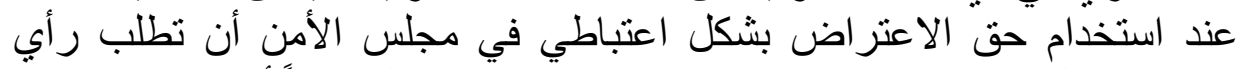

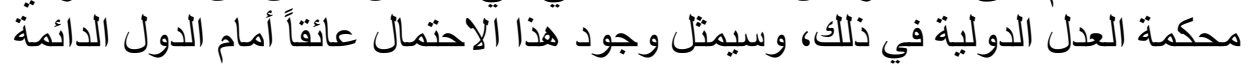

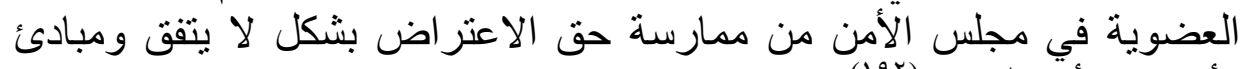

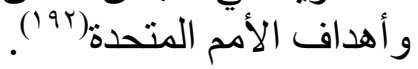

(19.1 أ/ خليل الهادى جمعة - حق الإعتر اض فى مجلس الدولى و القضية الفلسطينيةـ المرجع السابق - 90 (191) (1) خليل الهادى جمعة - حق الإعتر اض فى مجلس الدولى و القضية الفلسطينيةـ المرجع السابق

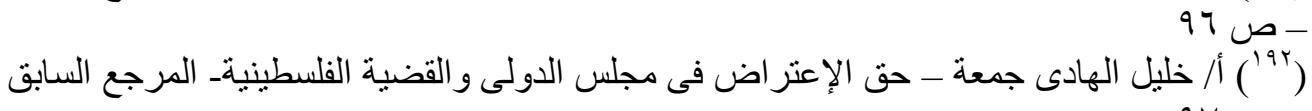
- 
ـ شرط اعتر اض أكثر من دولة لصحة حق الاعتر اض ، بري البعض (19 (1) أنه يمكن

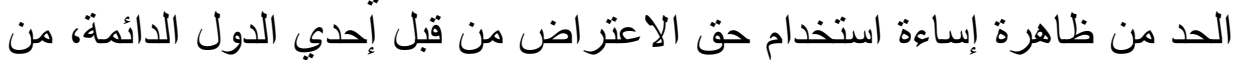

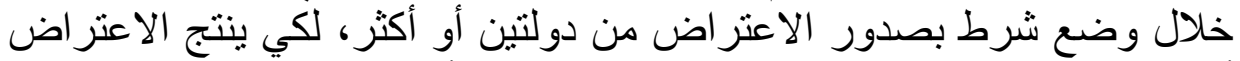

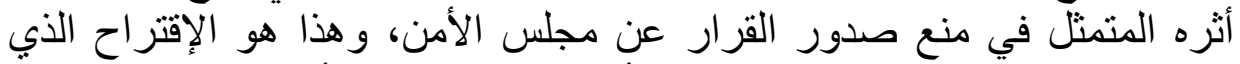

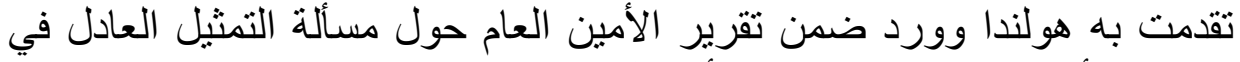

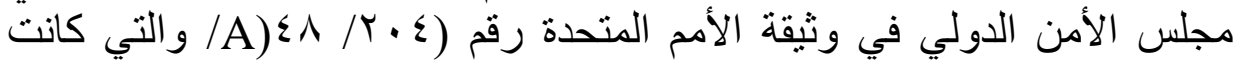

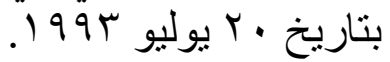

غير أن هذا الإقتراح البريء في ظاهره - يهدف إلي حرمان الصبين وروسيا

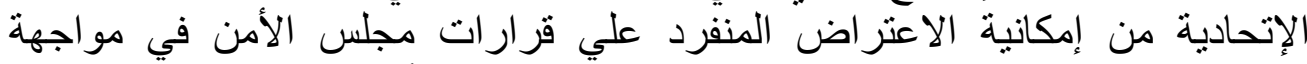

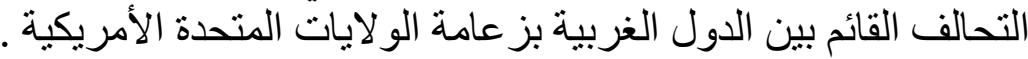

الإتجاه الثاني: إلغاء حق الفيتو

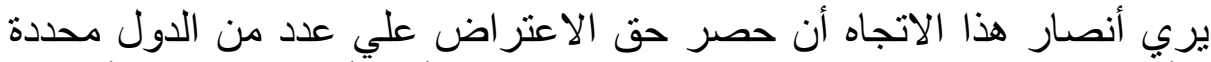

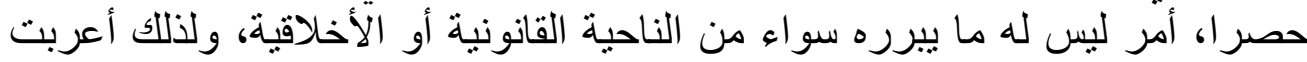

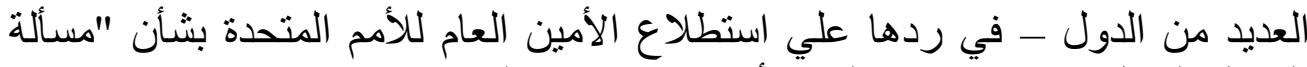

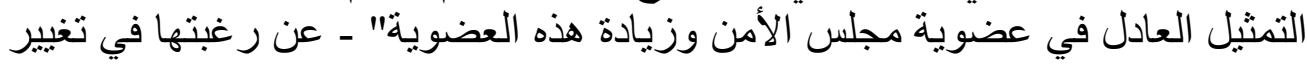

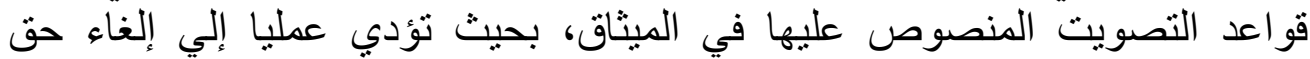

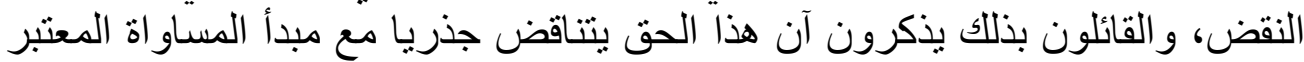

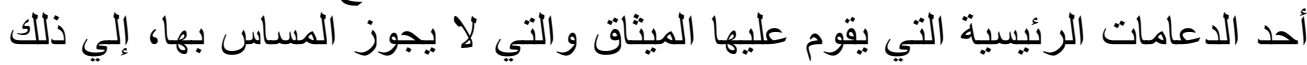

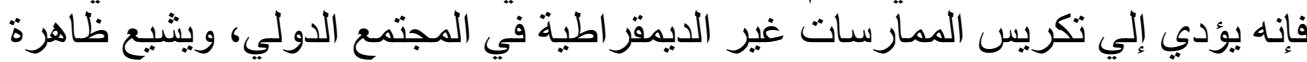

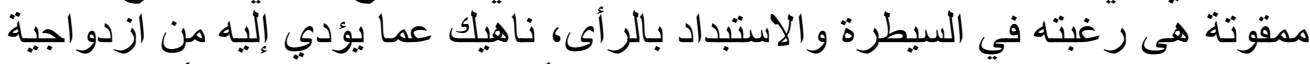

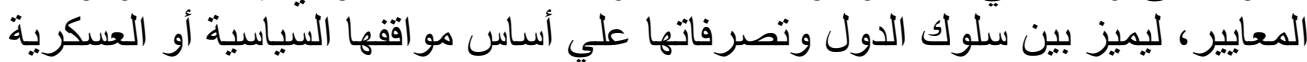

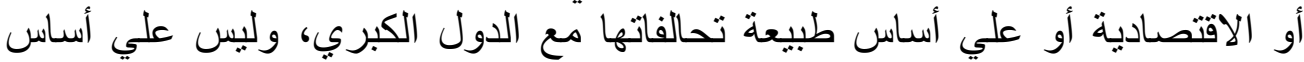

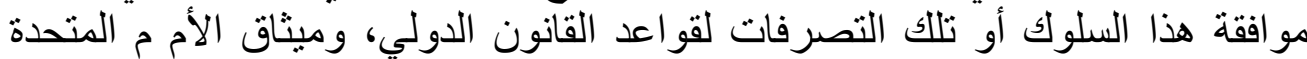

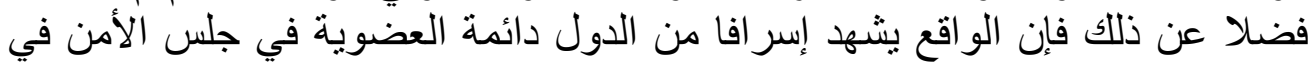

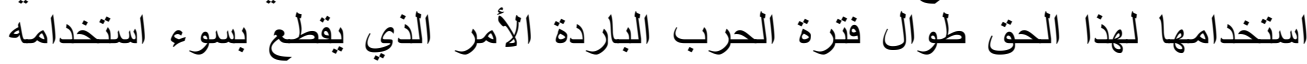

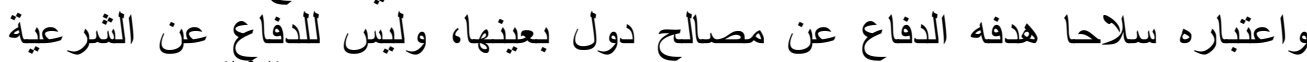

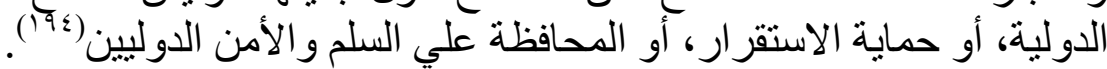

(19r1) (أنظر د/ إبر اهيم أحمد محمد إلياس- سلطات مجلس فى تسوية الهناز عات الدولية بالطرق السلمية

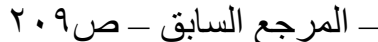

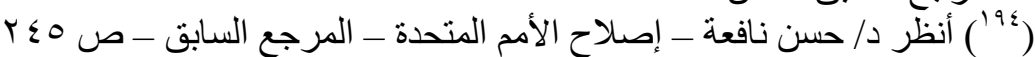

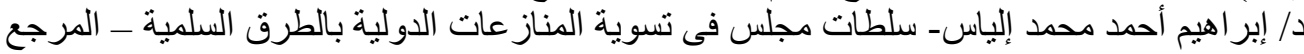

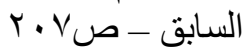


و الو اقع أن التطور ات التى طر أت علي النظام الدولى منذ الحرب العالمية الثانية

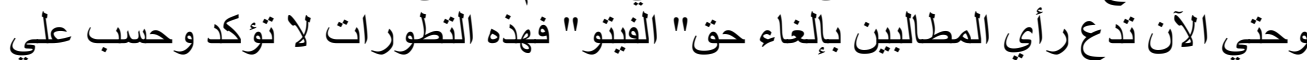

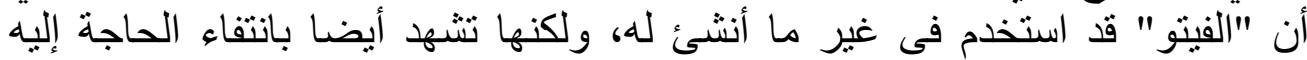

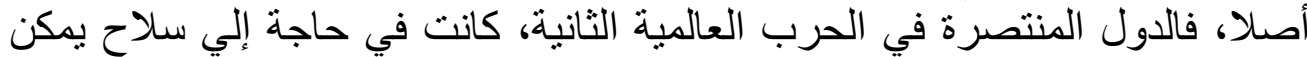

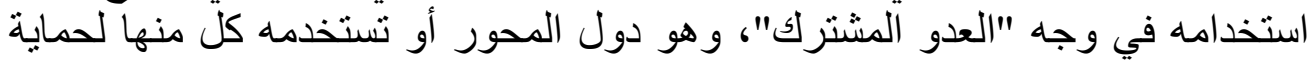

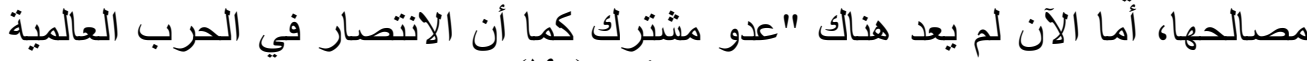
الثانية لم يعد في حد ذاته كافيا لإضفاء ميزة ألمدية (190) .

ومن جاتبنا نري أنه بنظرة موضو عية و عادلة لحق النقض نجد أنه يعد إنتهاكاً لمبدأ

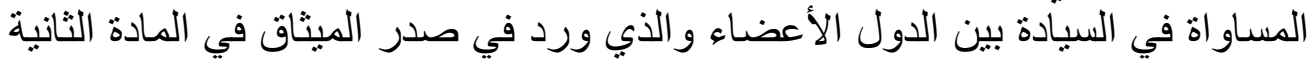

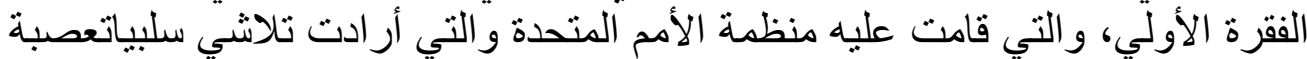

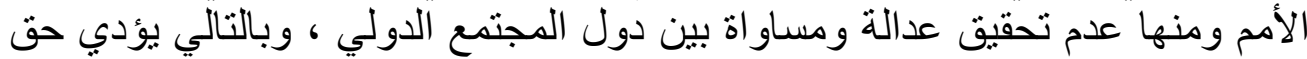

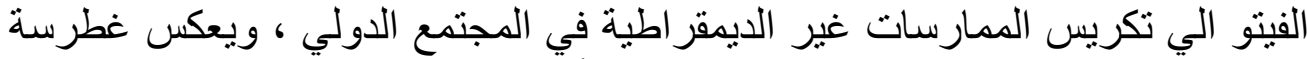

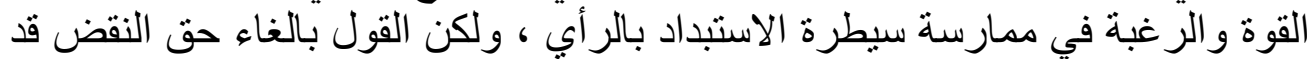

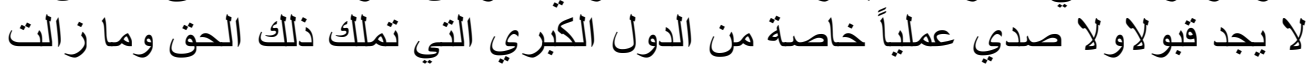

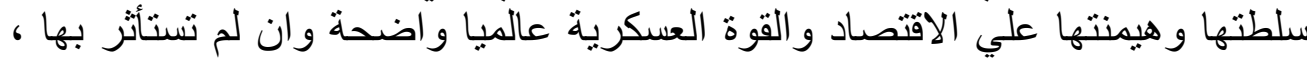

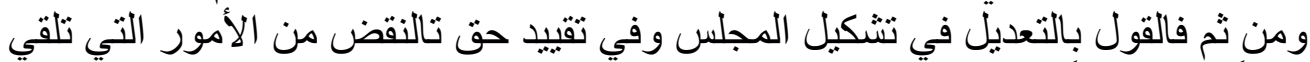

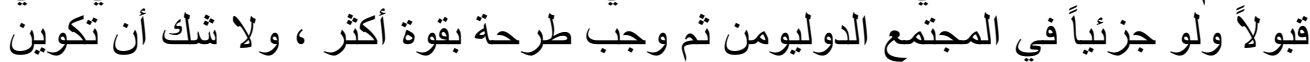

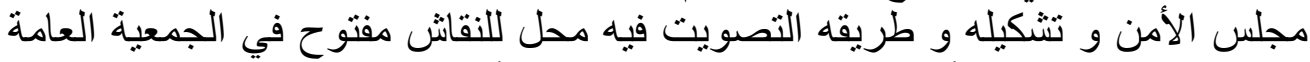

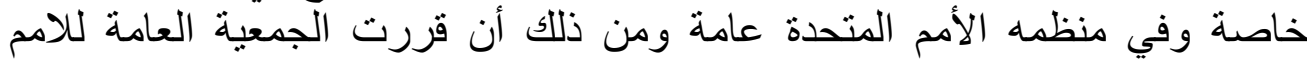

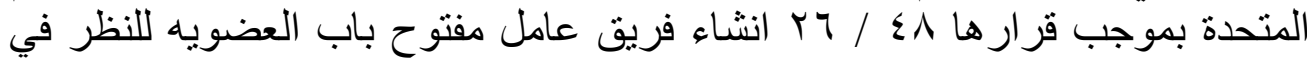

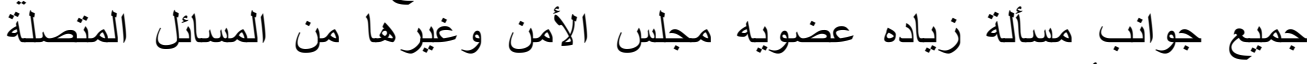

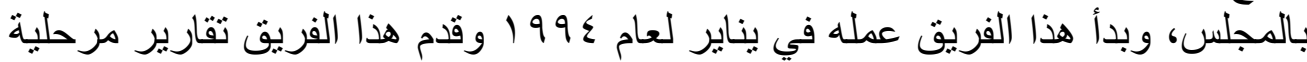

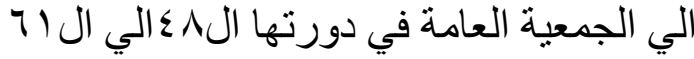

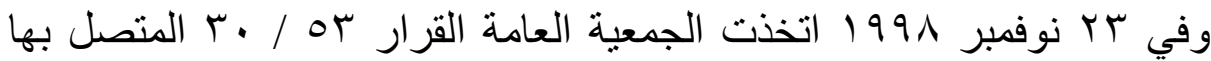

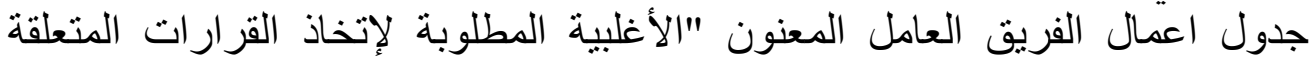

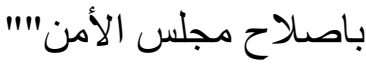

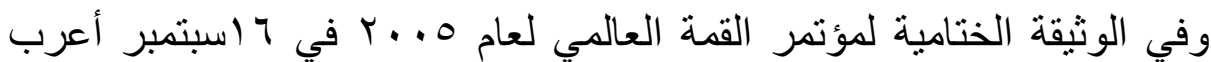

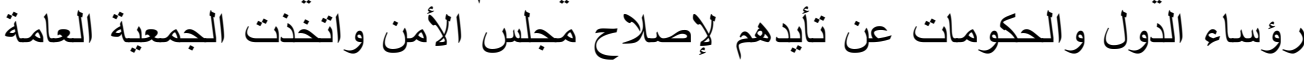
قرارا بمد عمل الفريق العامل حتي يقدم تقريره الي الجمعية العامة عن ما ير اهـ من الأن

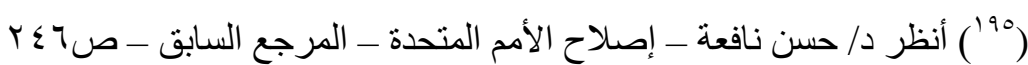

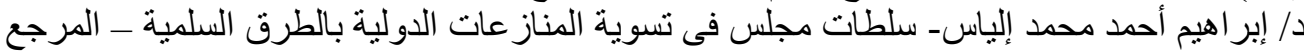

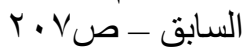


وسائل اصلاح لمجلس الأمن من ناحيه التشكيل او من ناحية التصويت و عليه ان يقدم

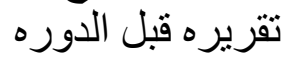

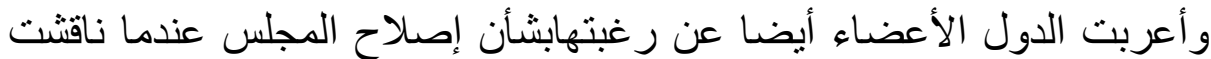

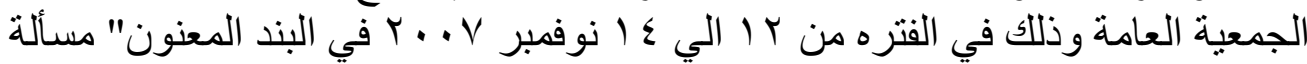

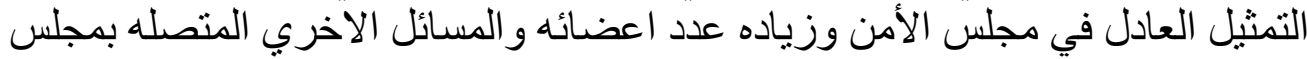

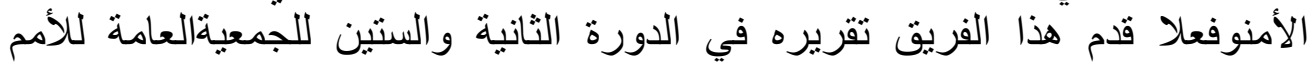

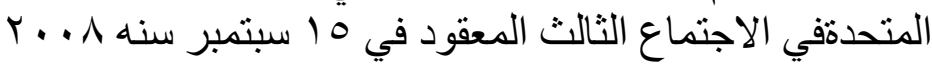

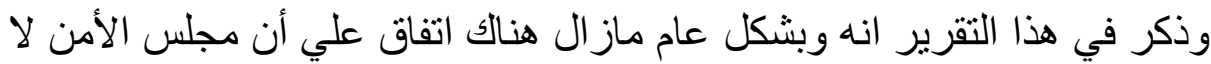

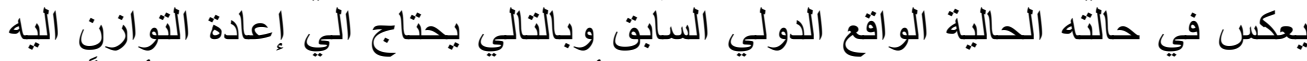

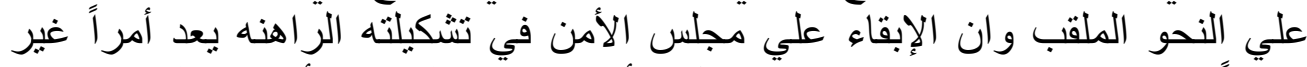

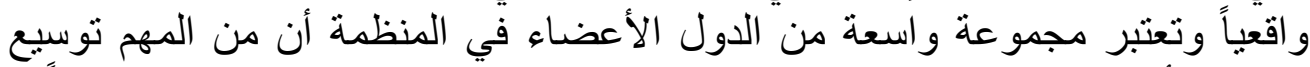

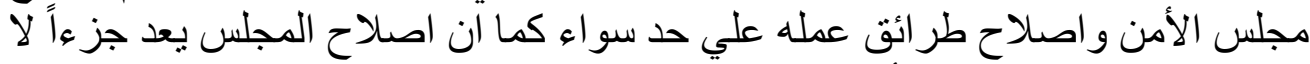

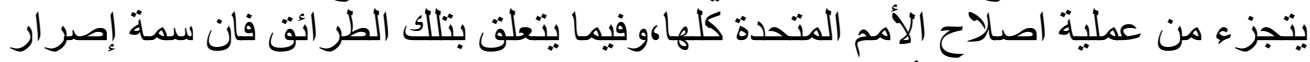

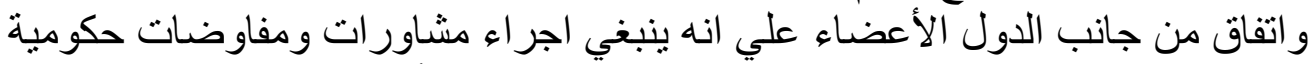

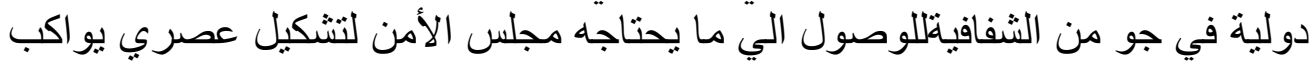
التغير ات الدولية ويساعد مجلس ان يؤدي دول دوره المنافي المنوط منه من الأمم المتحدة،

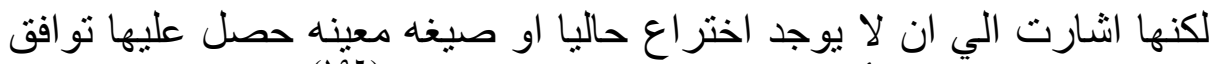

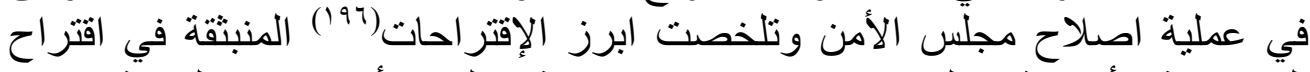

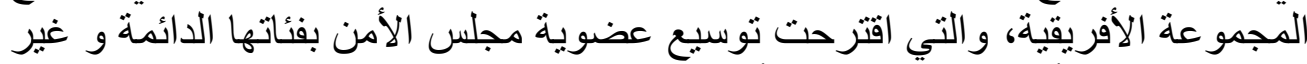

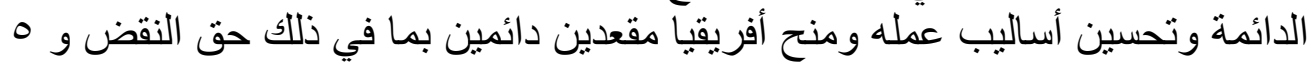

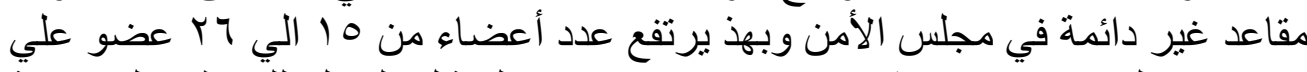

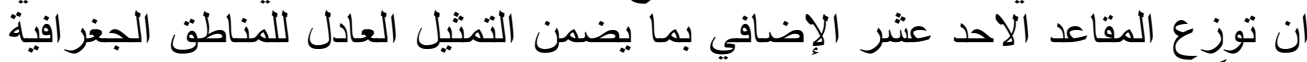
عالمياً.

أما مجموعة الأربعة فقد اقترحت زياده عدد أعضاء مجلس الأمن من 10 عضاء عضوا أعناء

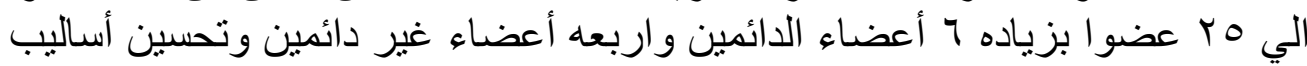

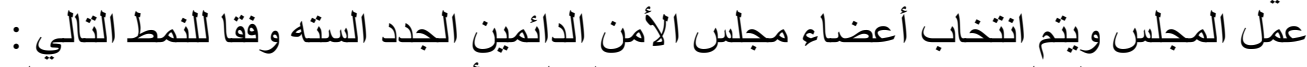

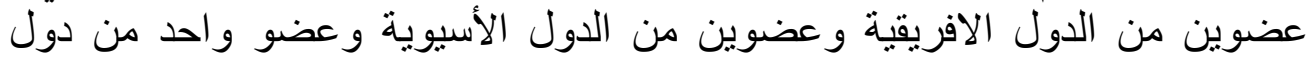

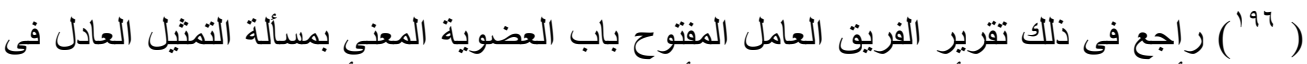

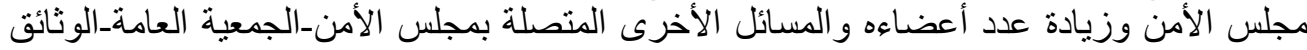

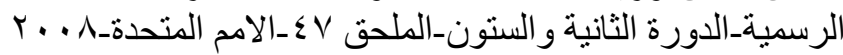
منشور على شبكة المعلومات الدولية على الموقع التالى النى https://www.undocs.org/pdf?symbol=ar/A/62/47(SUPP) 


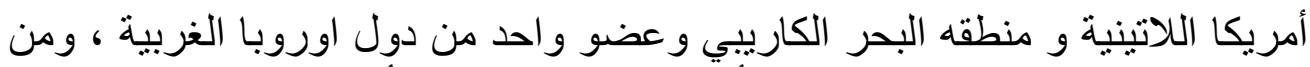

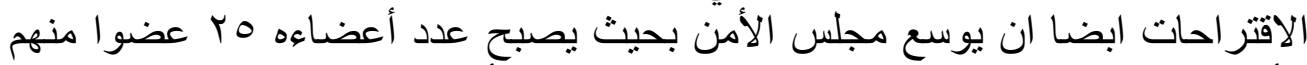

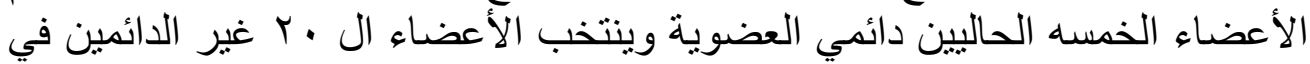

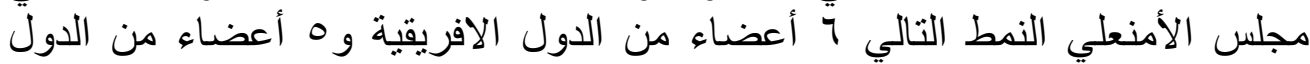

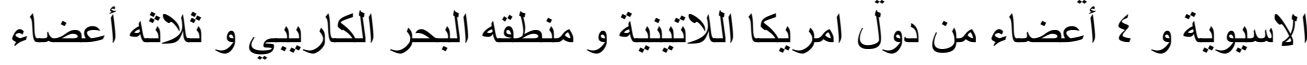

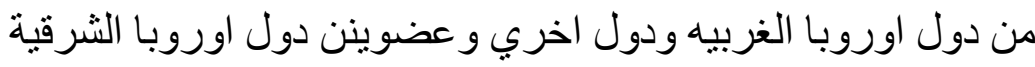

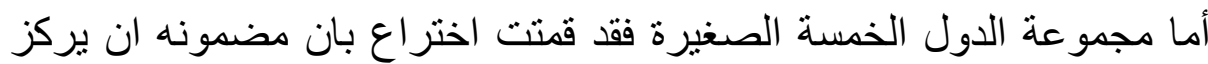

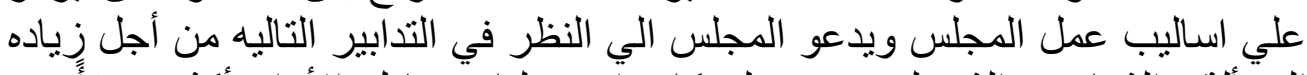

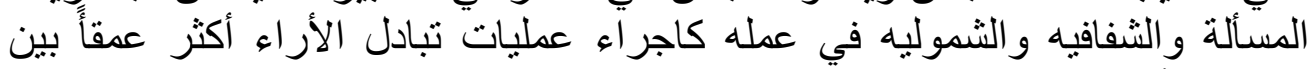

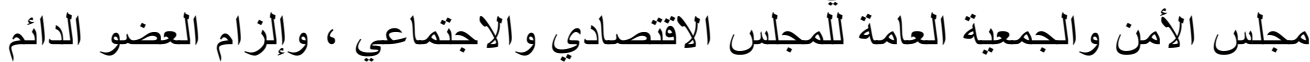

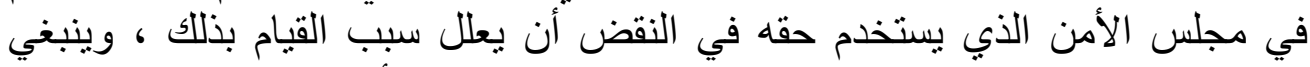

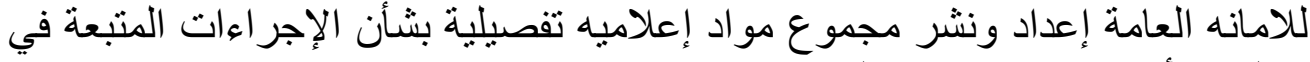
مجلس الأمن وممارساته و عمله

وسواء اتفقنا أواختلفنا مع بعض تلاك الإقتر احات ، إلا أن الإتفاق الأن في غالبية

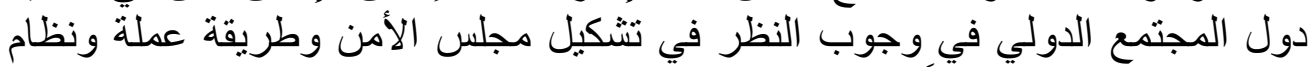

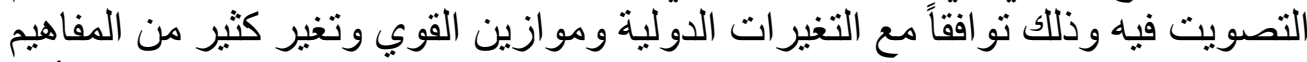

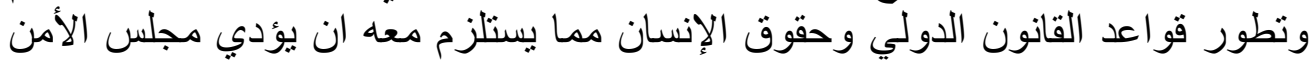

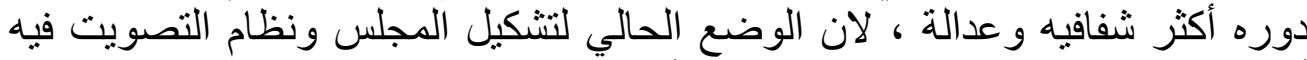

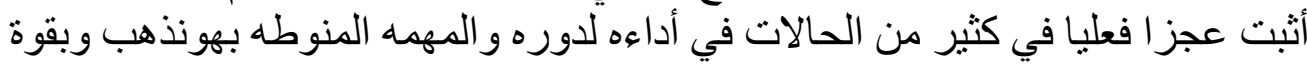

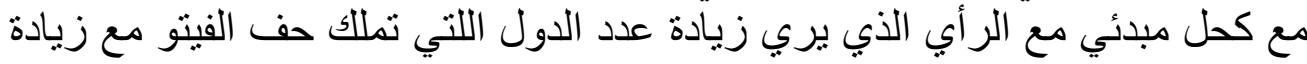

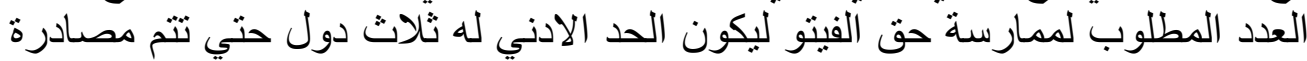

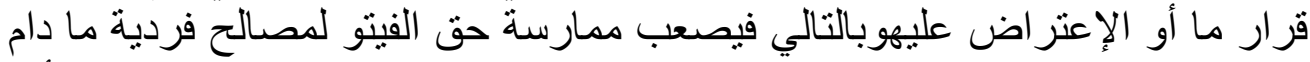

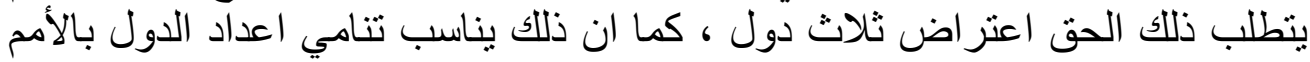

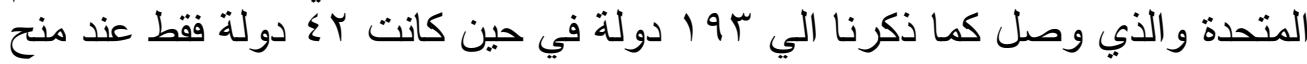

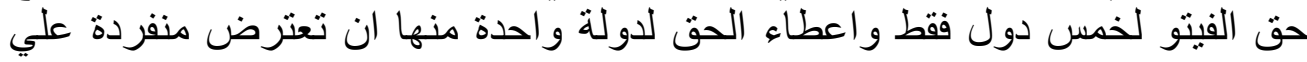

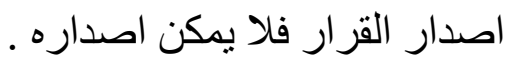

\section{المبحث الثالث

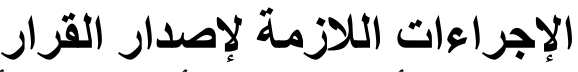

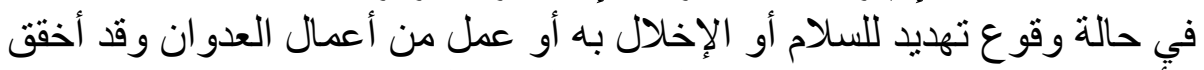

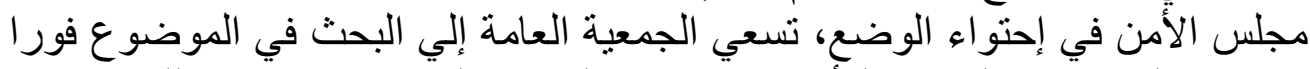

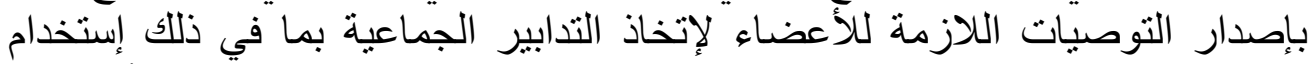

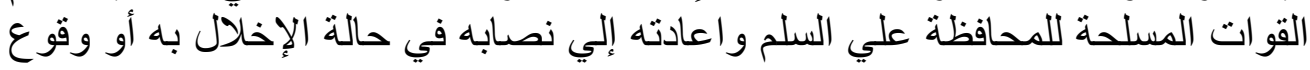




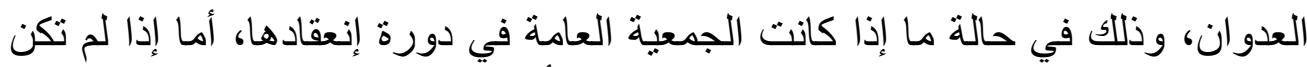

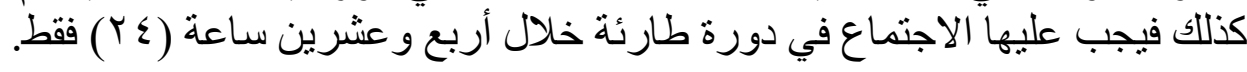

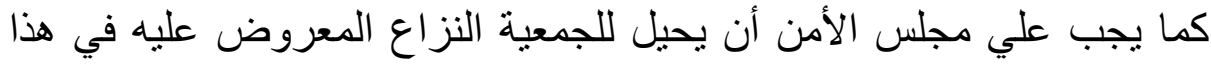

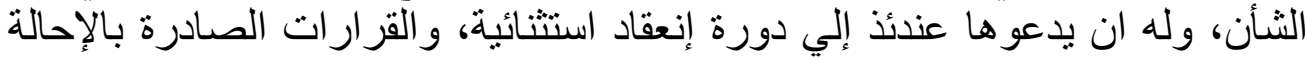

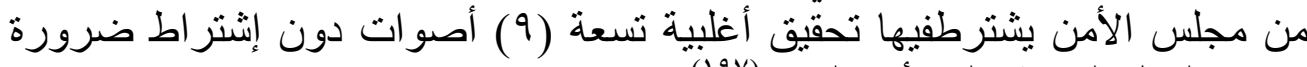
إجماع الدول الدائمة علي تأييد القرار (19v').

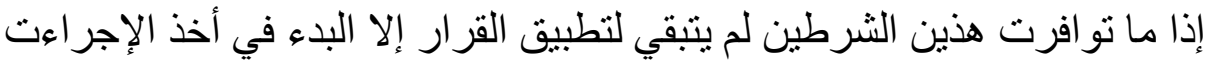

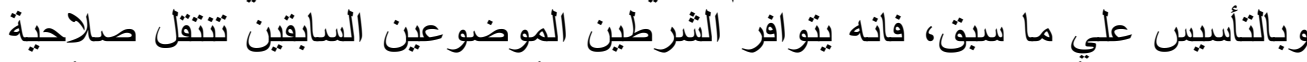

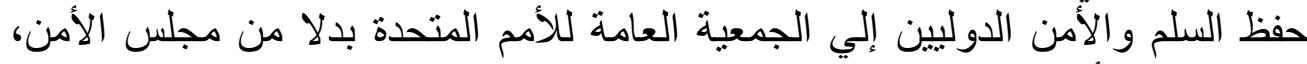

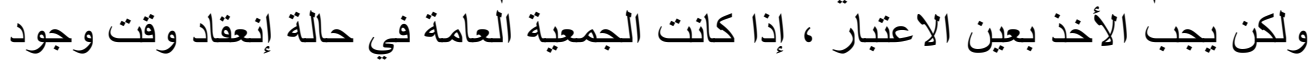

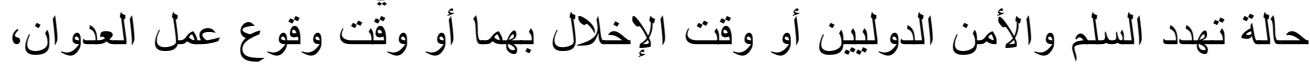

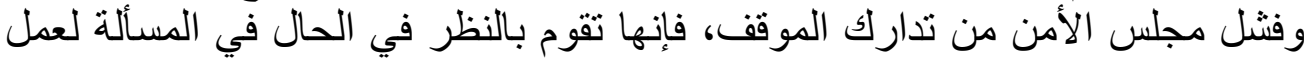

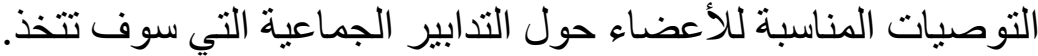

أما إذا لم تكن الجمعية العامة في هذا الوقت في حالة إنعقاد، فيمكن أن تجتمع في

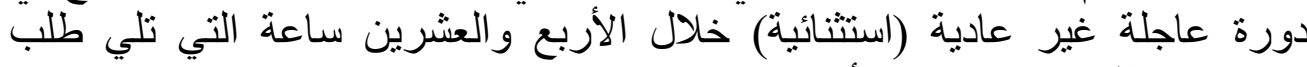
الإنعقاد، وطلب الإنعقاد يمكن أن يتم من جهتين:

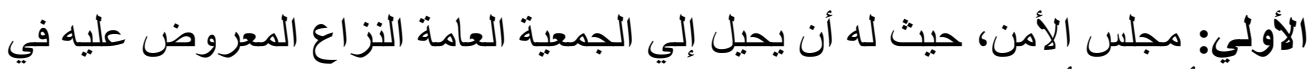
هذا الشّأن، وله أن يدعوها عندئذ إلي الإنعقاد في دورة غير الإني عادية استثنائية(91 (1). ووفقا لنص قرار "الإتحاد من أجل السلام"، ونص المادة (^/ب) من النظعام

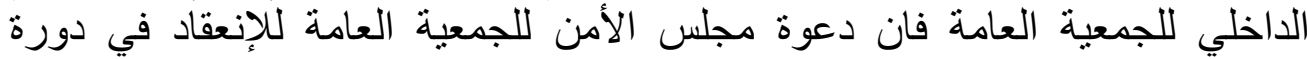

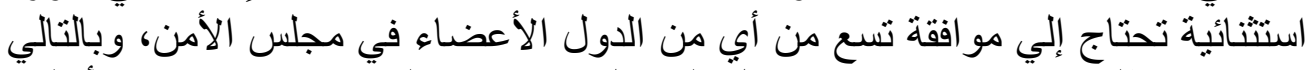

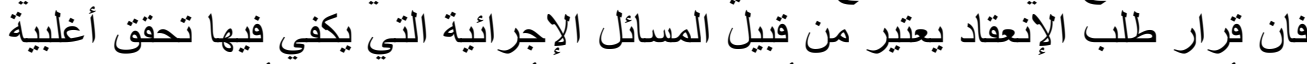

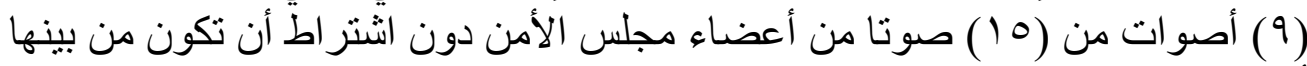

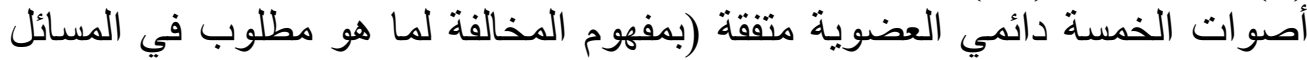

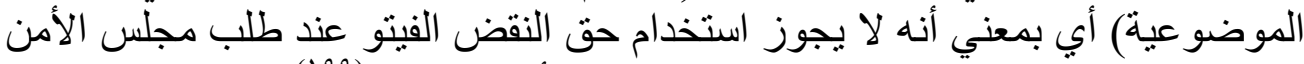

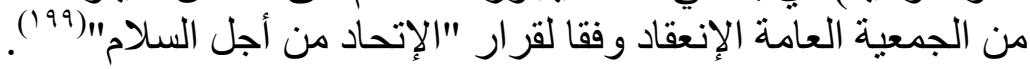

(19v) أ/حجريوة يانيس ، أ/ خلافى توفيق - دور الجمعية العامة للأمم المتحدة فى حفظ السلام والأمن

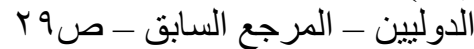

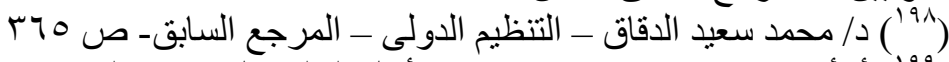

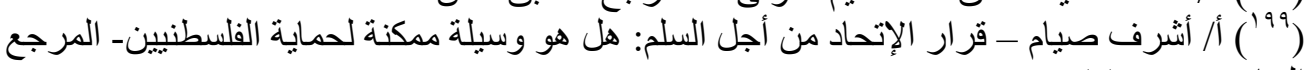




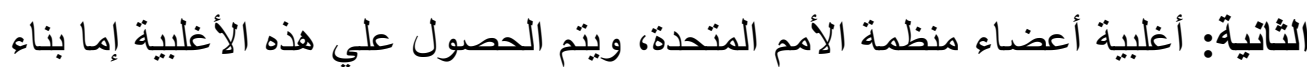

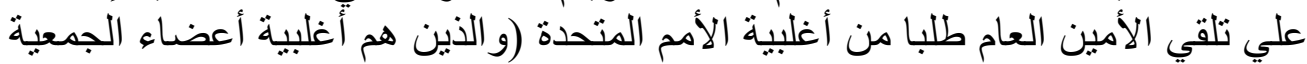

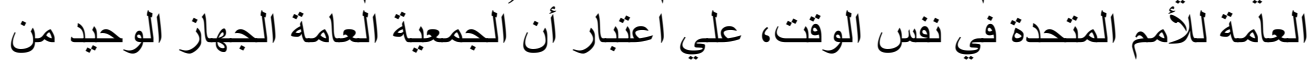

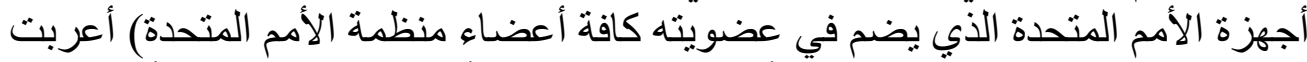

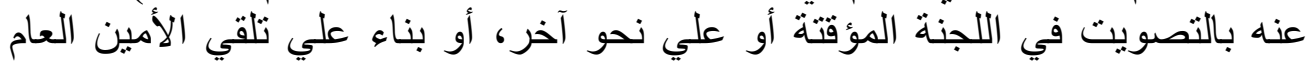

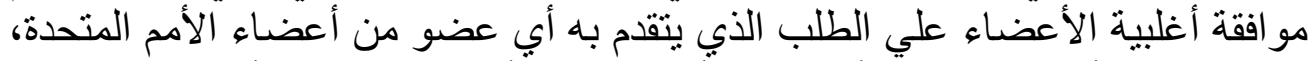

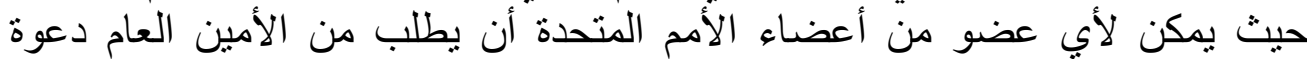

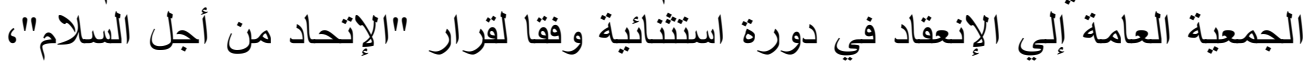

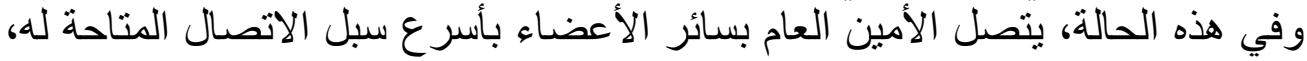
ومر اعيا في ذللك ما تتص عليه المادة (9) من النظام الداخلي للجمعية العامة. لألئ

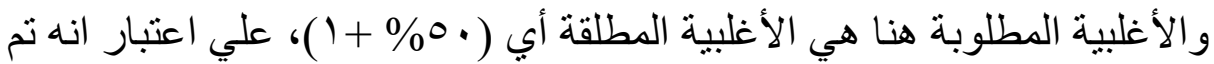

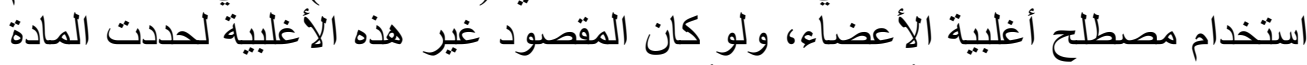

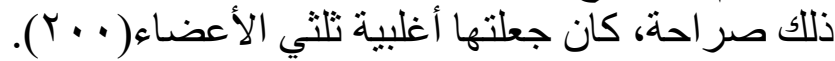

فاذا تو افرت الثروط الثلاثمن وجود حالة تهدد السلم والأمن الدوليين وتدخل

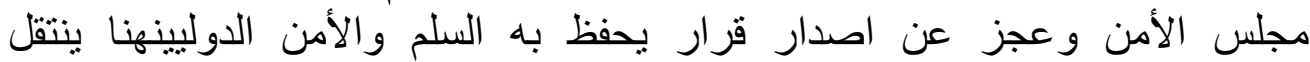

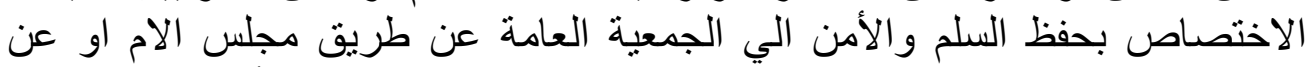

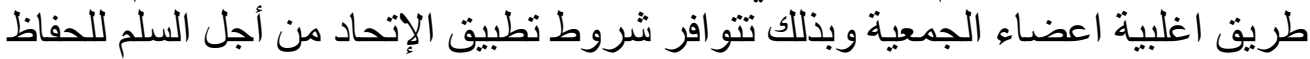
علي السلم الدولي وكذلكللحفاظ علي بقاء اكبر منظمة عالمية وهي ولئ الأمم المتحدة.

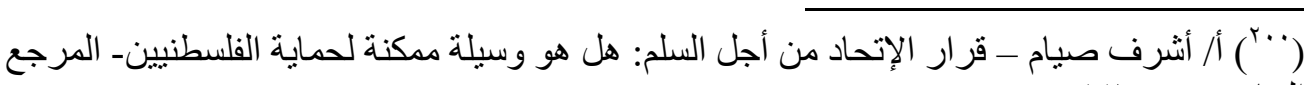

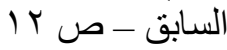




\section{الفصل الثالث}

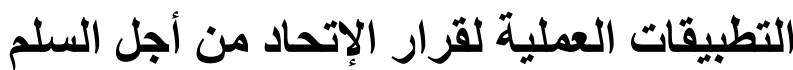

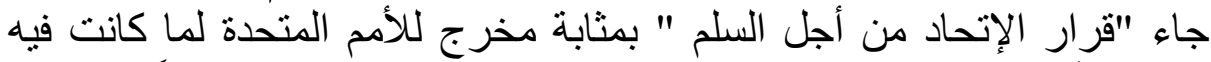

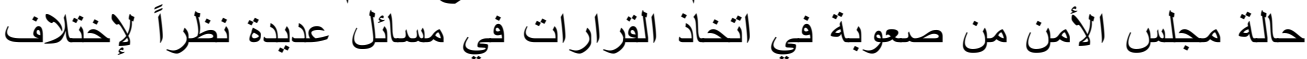

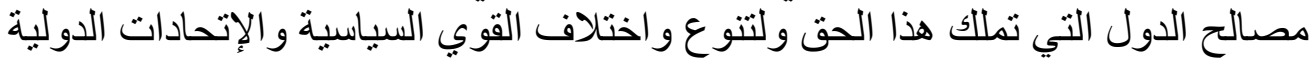

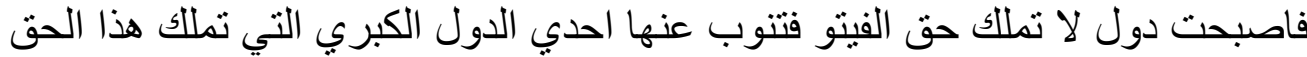

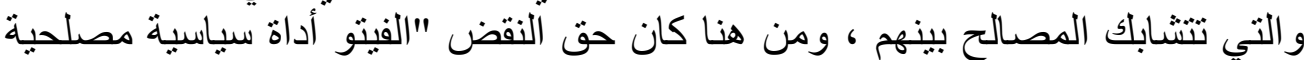

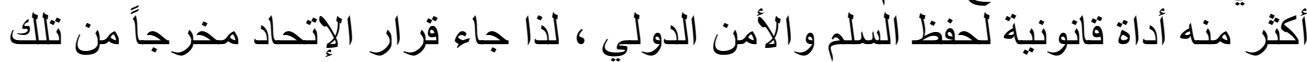

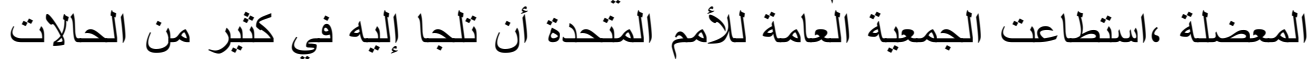

ومنها :-

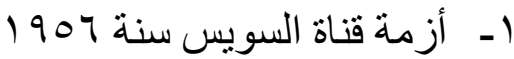

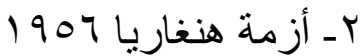

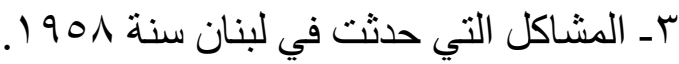

ع- أزمة الكونغو سنة . 197 1.

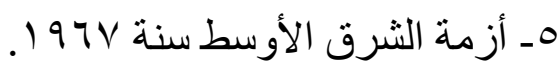

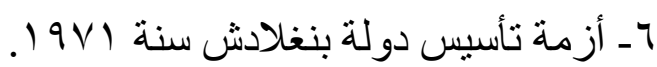

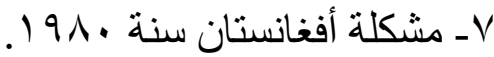

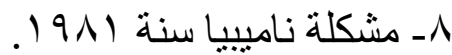

9ـ مشكلة بناء الجدار العازل في فلسطين المحتللة ب ...

• ـ ـ الجمعية العامة للام المتحدة تصوت لصالح الغاء قرار الرئيس الامريكي ترامب

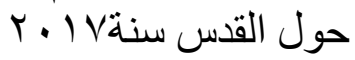

قامت الجمعية العامة باتخاذ عمليات إدارية و عمليات شبه عسكرية لصيانة السلام

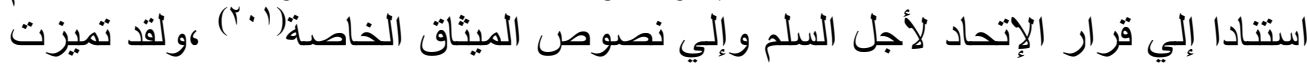

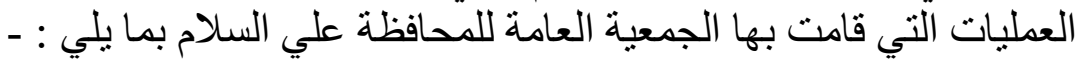

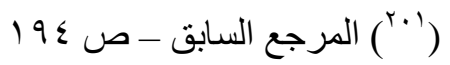


1 - تعتبر عمليات السلام التي تقوم بها الجمعية العامة مكملة لعمليات السلام التي يقوم

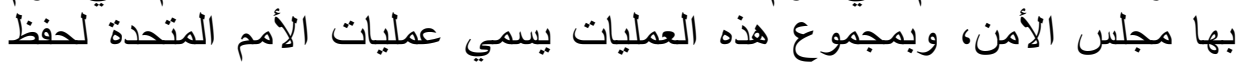

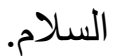

r- ت تمت العمليات شبه العسكرية التي قررتها الجمعية العامة بالاتفاق مع الدول التي جرت العمليات في إقليمها.

r- إن القوات التابعة للجمعية العامة لم تكن مخولة أصلا باستعمال القوة إلا في حالة

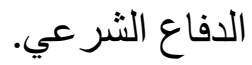

ـ - إن الاشتر الك في هذه العمليات كان له طابع اختياري، فلم يكن هناك إلتزام الم علي

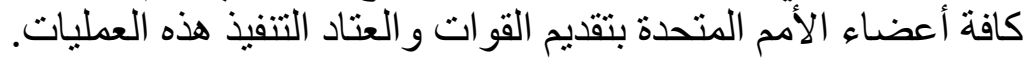

0ـ ـ ظهرت صعوبات تتصل بتمويل عمليات حفظ السلام التي تقررها الأمم المتحدة

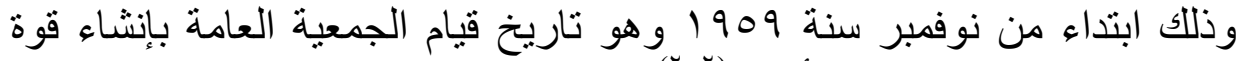

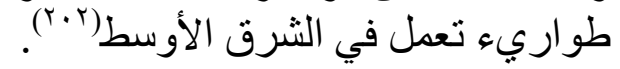

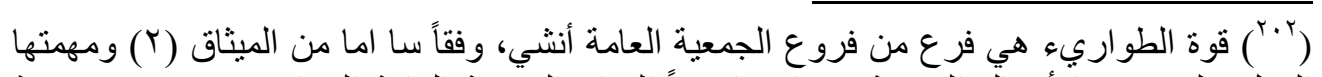

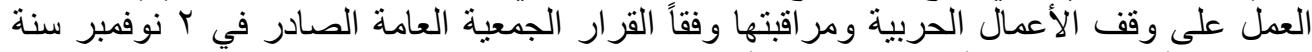

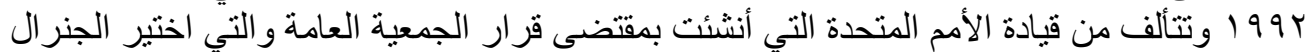

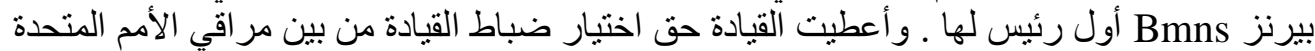

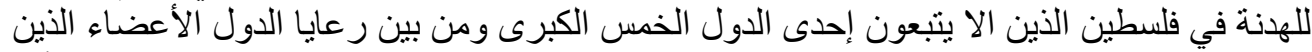

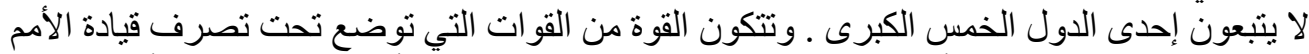

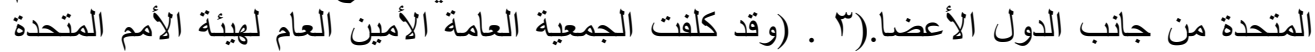

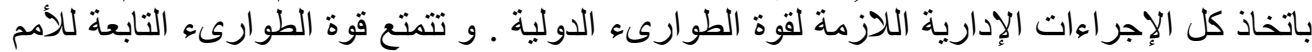

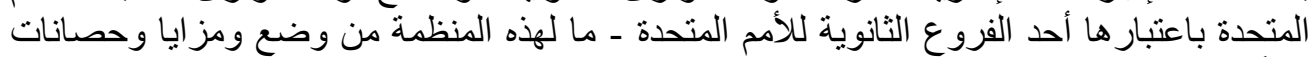

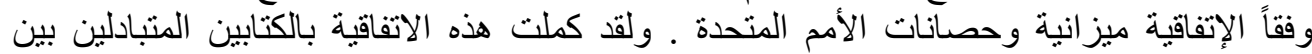

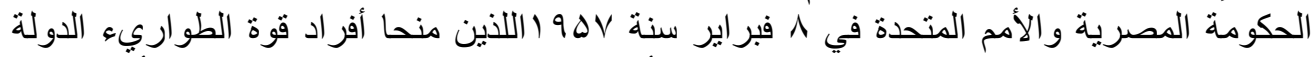

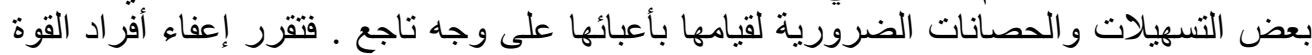

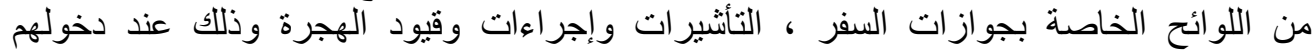

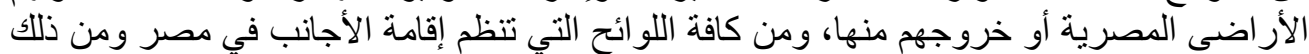

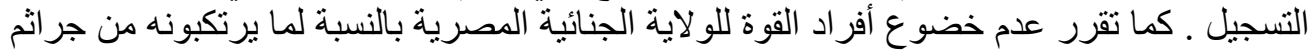

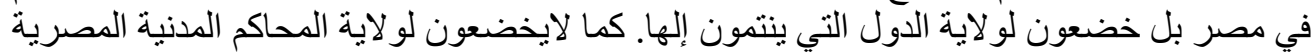

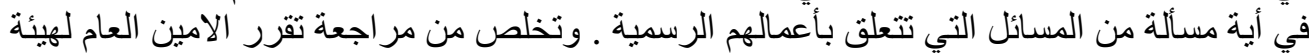

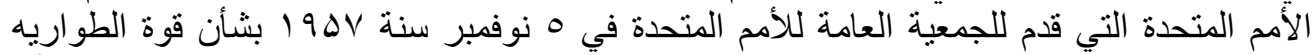

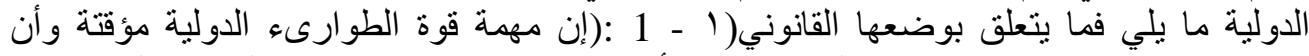

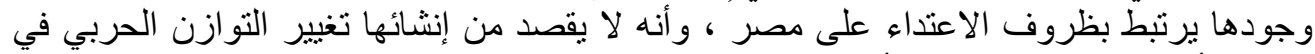

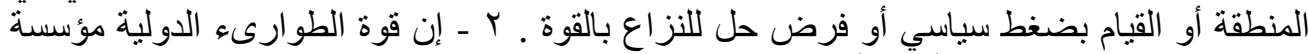

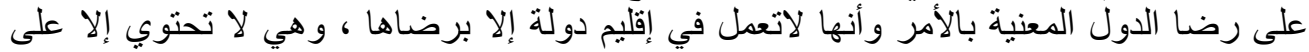

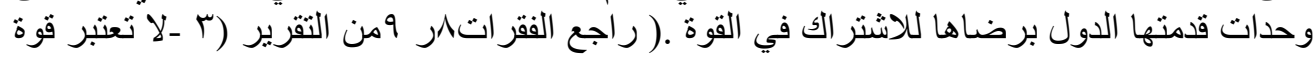


ولقد خولت الجمعية العامة في فبر اير سنة 970 ألئيس الجمعية العامة والأمين

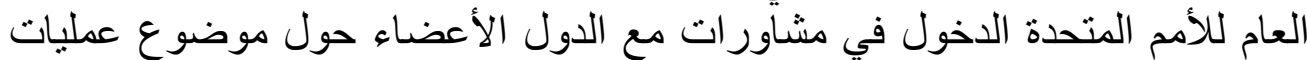

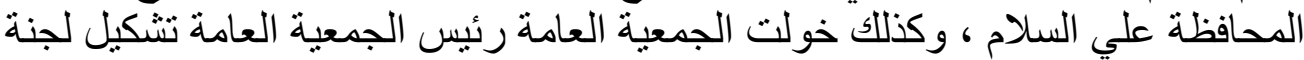

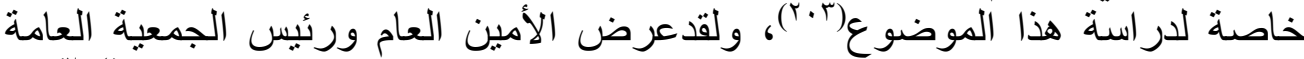

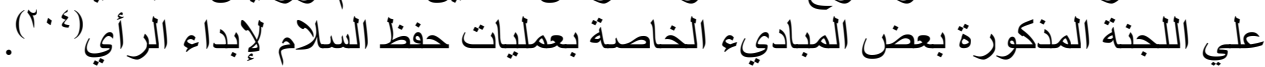

\section{و تتلخص أهم هذه المباديء فيما يلي}

أــ تقع المسئولية الأولي في اتخاذ إجر اءات المحافظة علي السلام علي مجلس الأمن

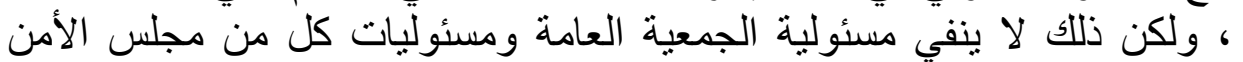

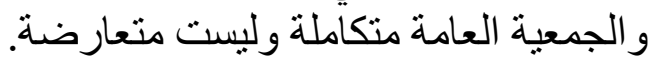

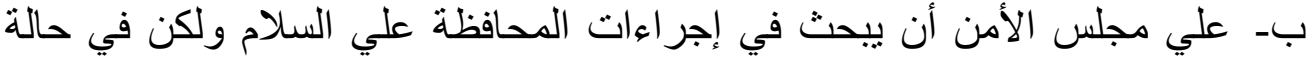

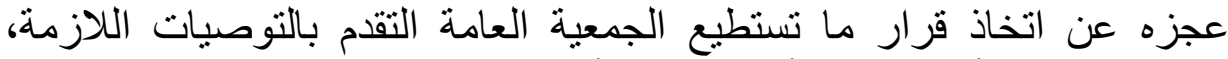
وللجمعية العامة أن تعيد المسألة لمجلس المئ الأمن.

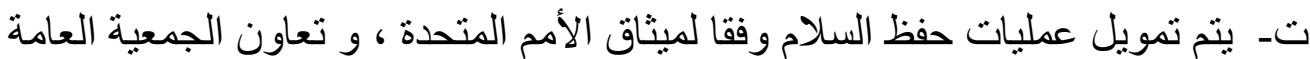

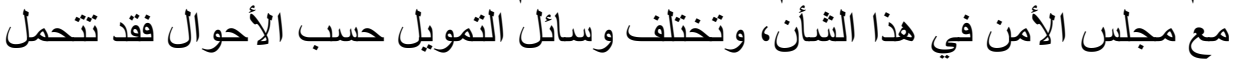

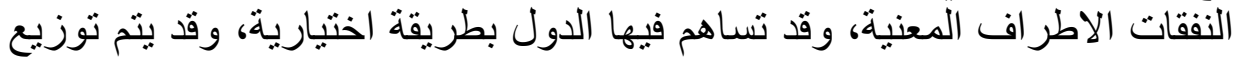

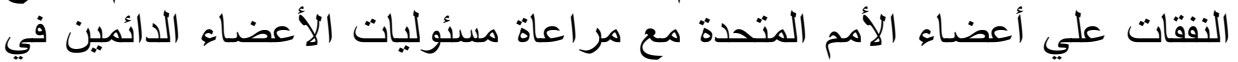

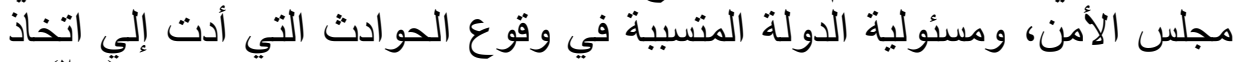

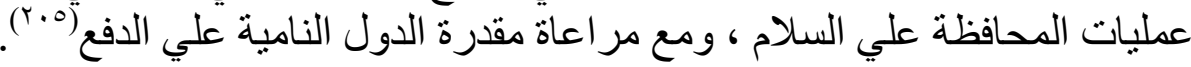

الطو اريء الدولية قوة تع موجهة ضد دولة من الدول وليست من قبل القوات الحربية ، و إنما تقتصر

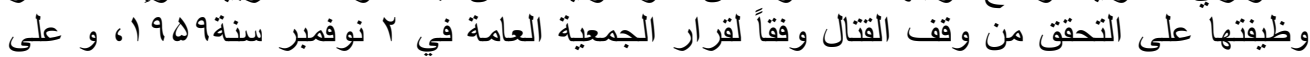

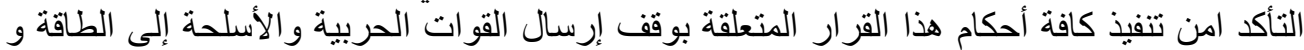

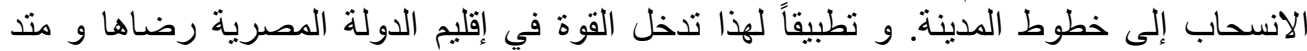

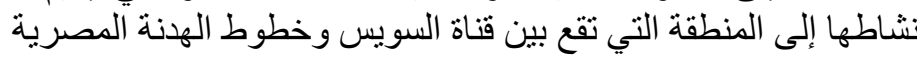

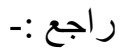

United Nations, Current Peacekeeping Operations , Department of Public Information, 30 June 2010, p02, DPI /2166/REV.81

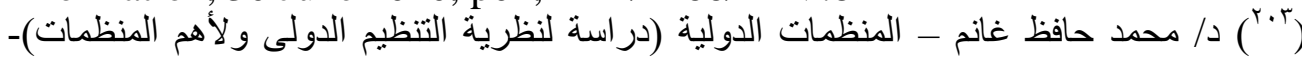

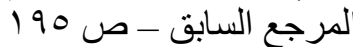

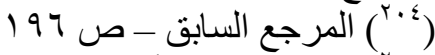

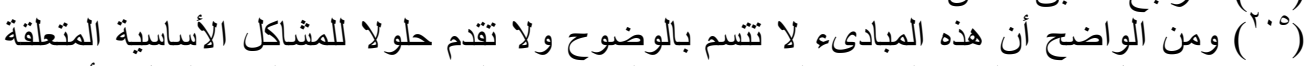

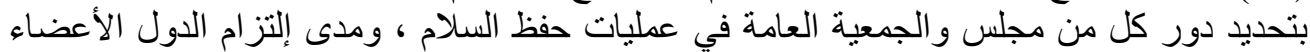

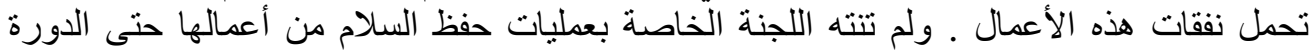

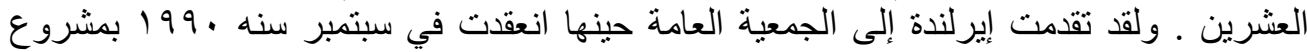
يتصل بتنظم عمليات حفظ السلام. 
وسنبين فيما يلي بعض الحالات التي طبق فيها قرار الإتحاد من أجل السلم علي سبيل فيليل

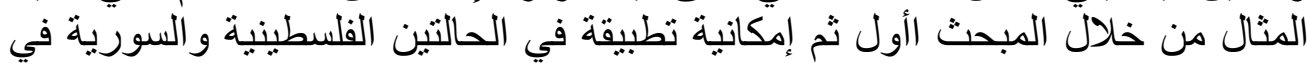

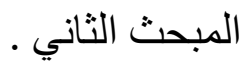

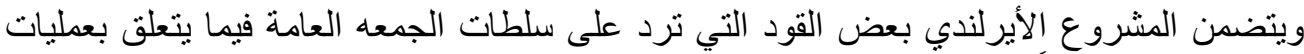

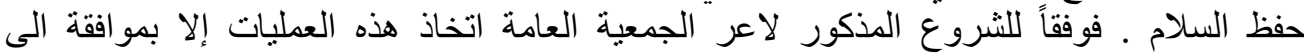

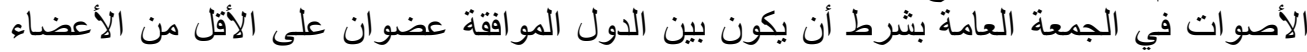

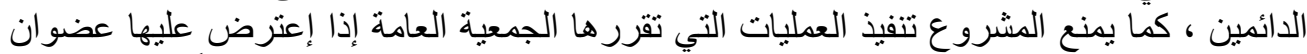

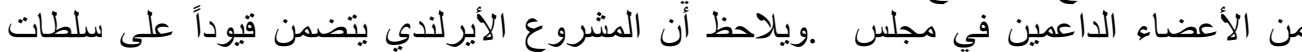

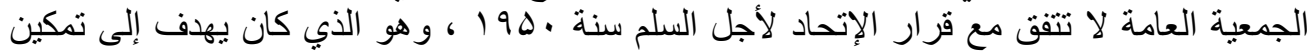

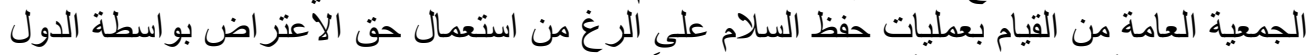

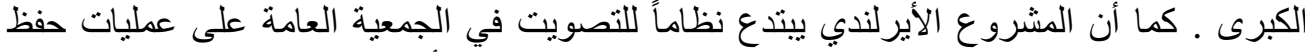

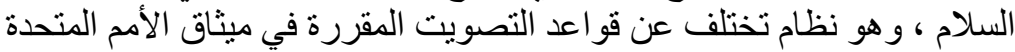

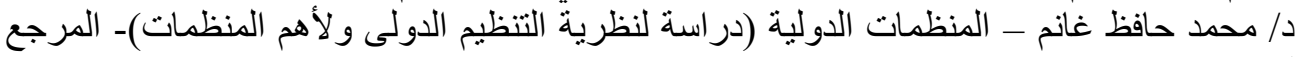
السابق - ص ح 197 


\section{المبحث الأول}

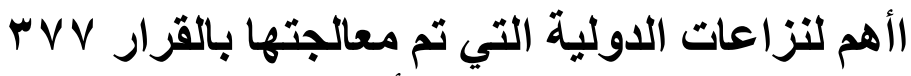

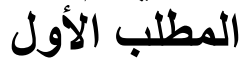

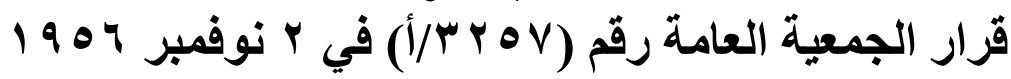

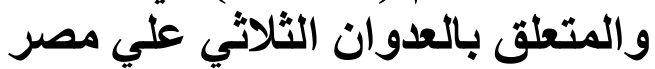

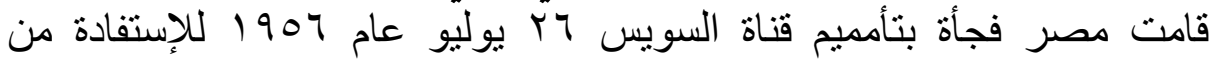

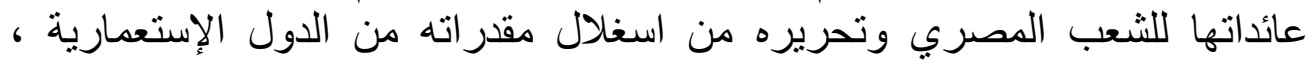

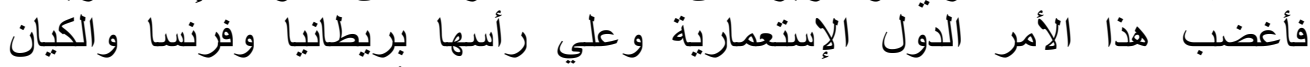

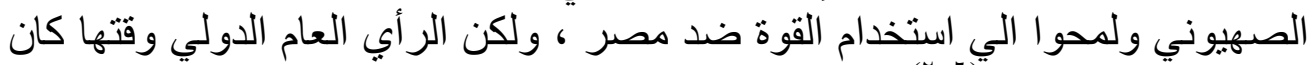

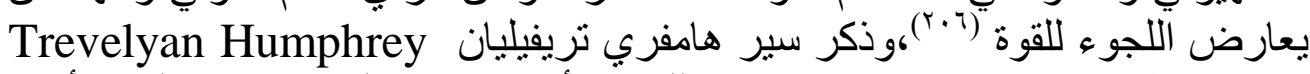

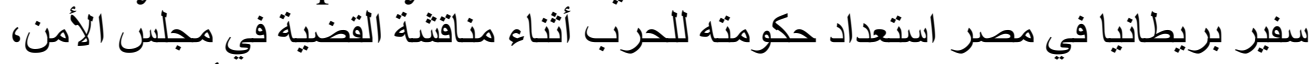
وكنوع من ادعاء السلمية تقدمت بريطانيا وفرنسا بشكوي الثياء الي مجلس الأمنتدعيان فيها

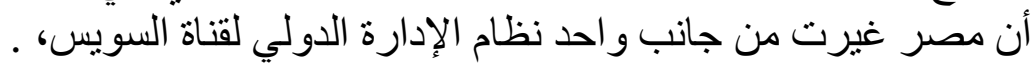

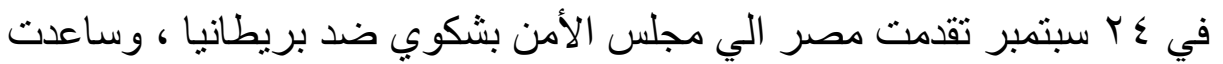

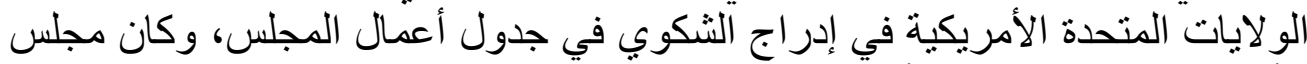

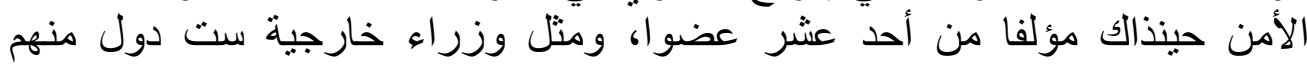

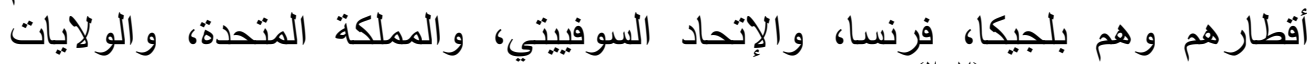

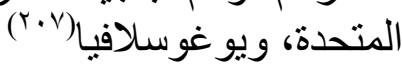

وتقرر عرض القضية علي مجلس الأمن الذي بدأ مناقتنها في ألقاء أكتوبر 1907

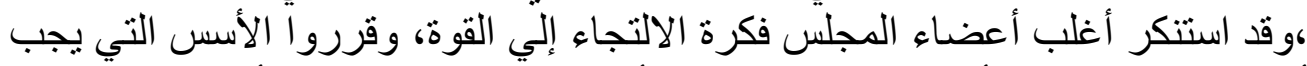

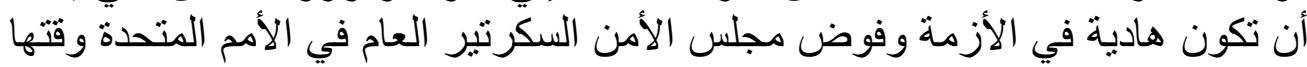

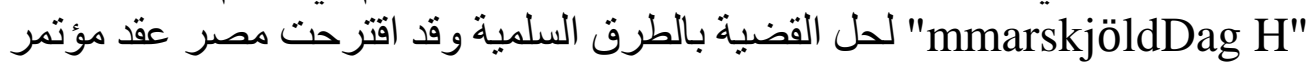
في جنيف

وفي الفترة من ه الي با اكتوبر اجتمع مجلس الأمن يوميا لمناقشة شكوي

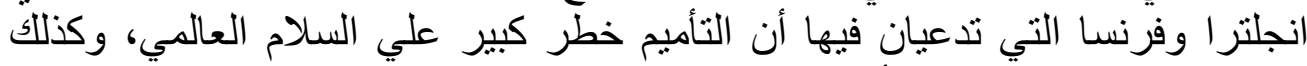

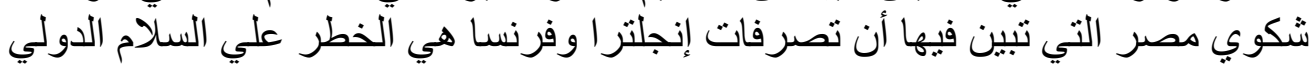

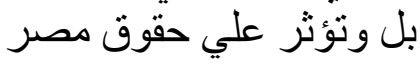

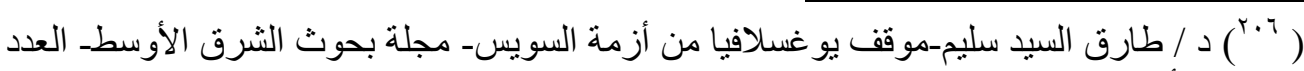

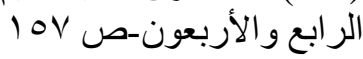
207_ Varble, D. : The Suez Crisis 1956, Osprey Publishing Osprey-United Kingdom,2003 
وقد وافقت الدول علي أن تقوم مفاوضات سرية بهدف إتاحة الفرصة للجانبين

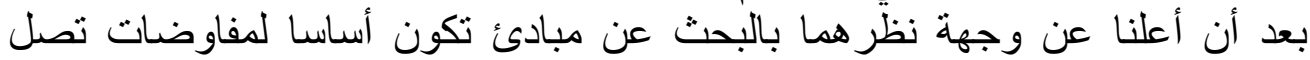

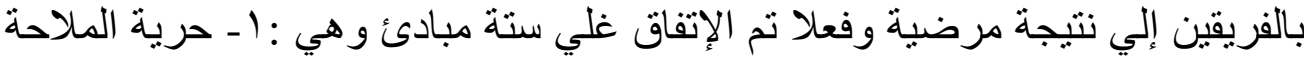

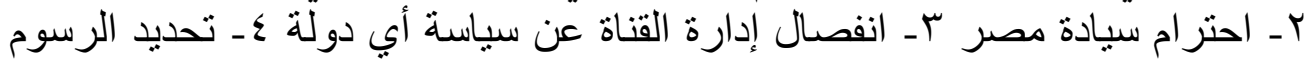

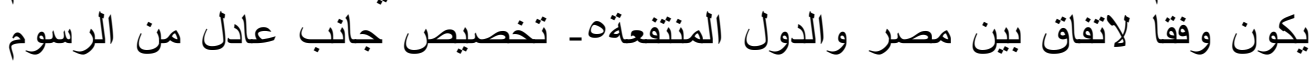
لتحسين القناة 7 ـ الالتجاء إلي التحكيم في حالة الخلاف بين مصر وشركة القناة السابقة

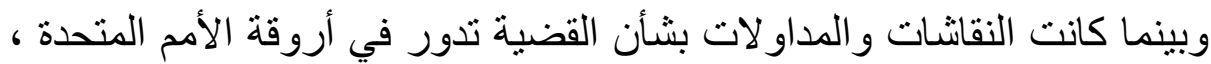

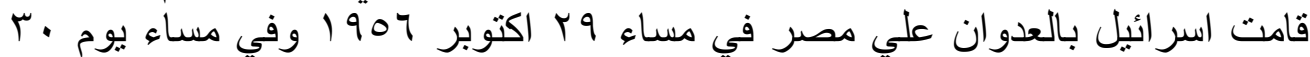

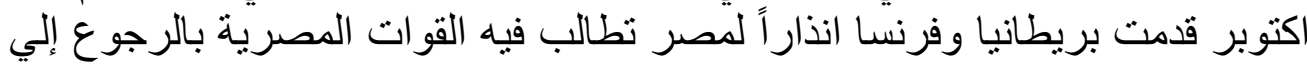

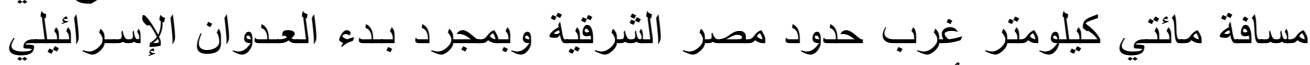

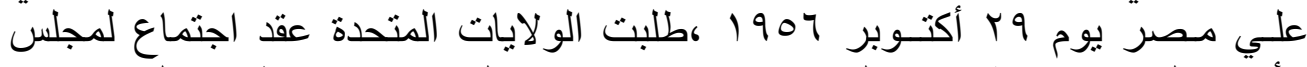

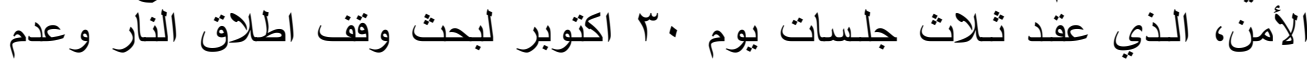

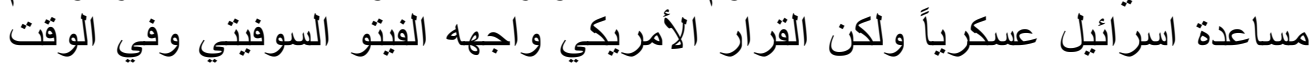

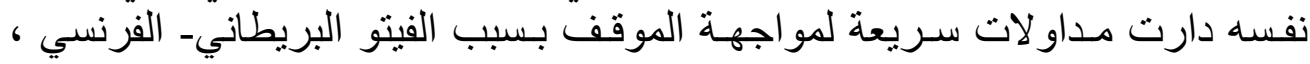

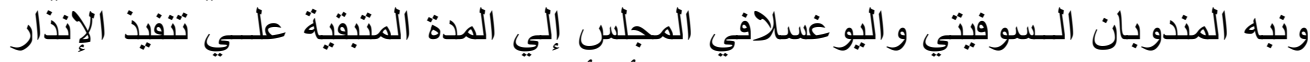

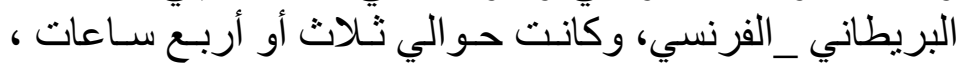

وفي ذات اليوم تقدم المندوب اليو غسلافي بإقتراح الي مجلس الأمن يطلب فيه

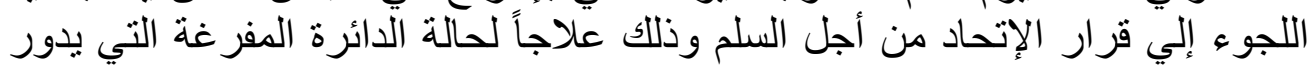

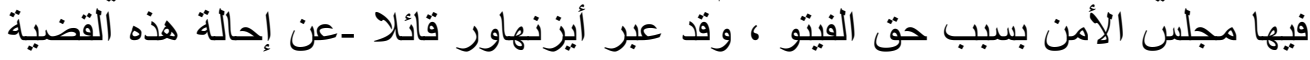

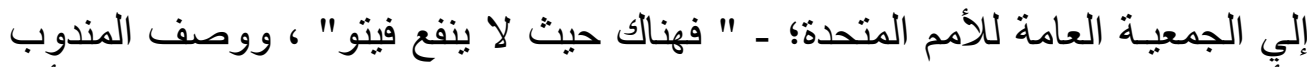

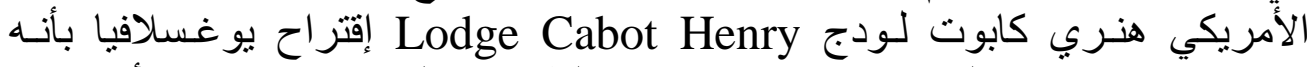

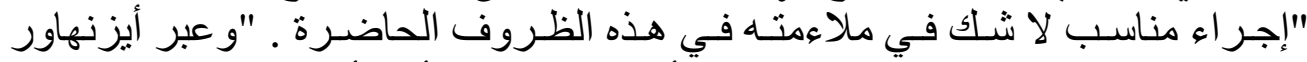

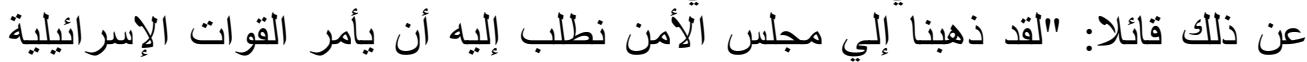

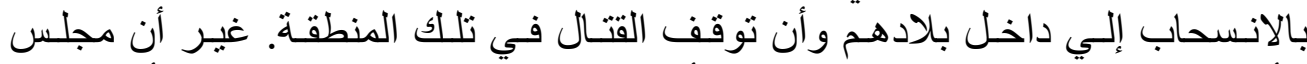

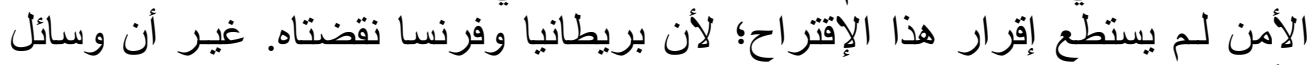

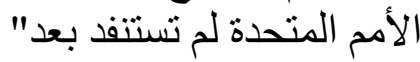

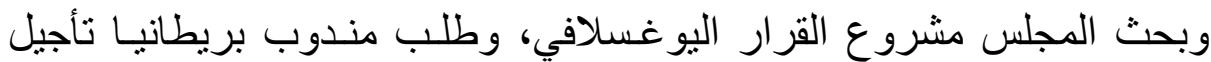

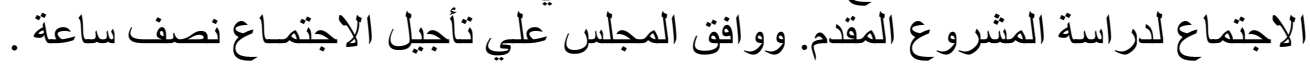

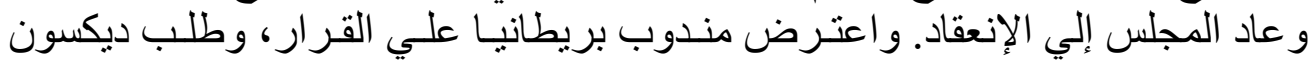

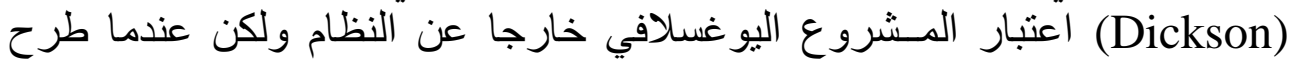

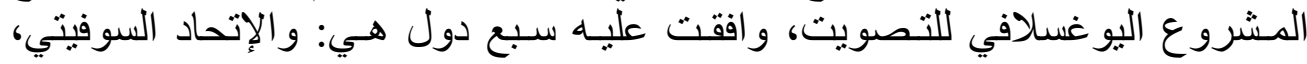

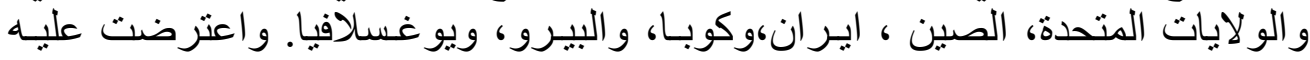

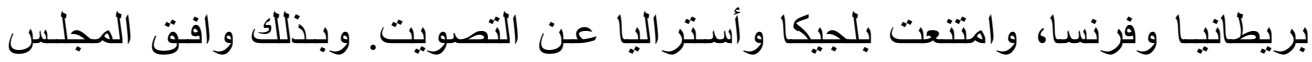




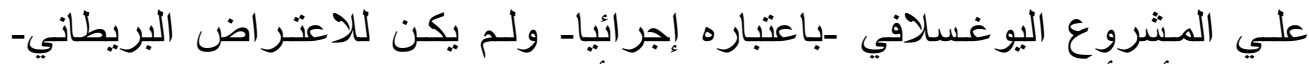

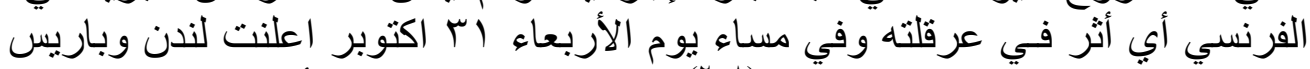

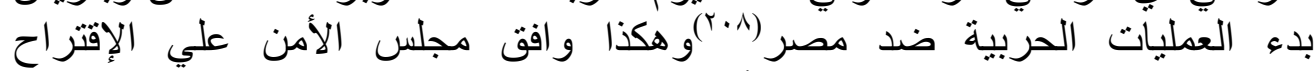

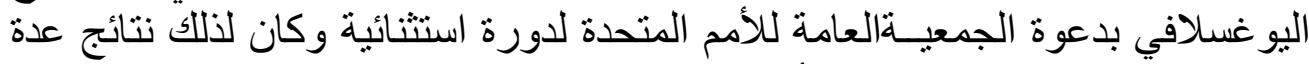
علي المستوي السياسي و القانوني أهمها:-

أولاً: أن إبقاء القضية في مجلس الأمن دون قرار كان هدف لبريطانيا وفرنسا وخاصة

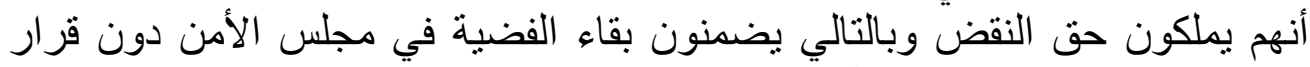

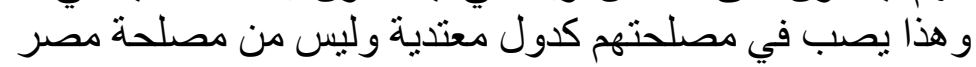

ثانياً: يعتبر هذا القرار من مجلس الأمن بمثابة اقرار ضمني وتفعيل لقرار الإتحاد من

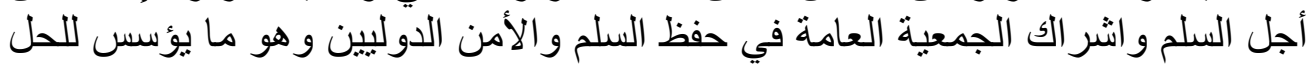

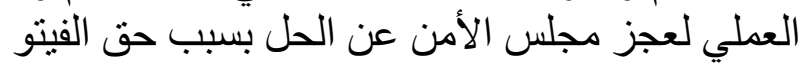

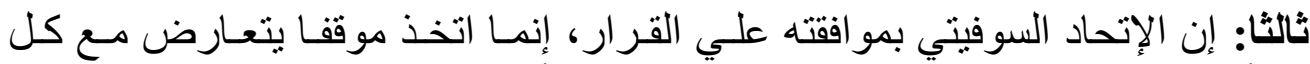

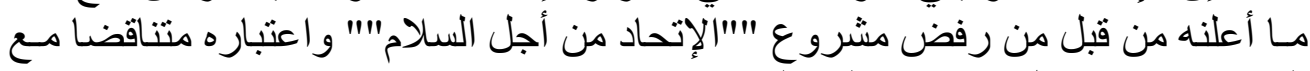

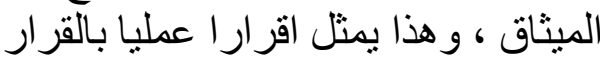

رابعاً: إن إحالة القضية إلي الجمعية العامة، ستسمح بأن تفتح الأبواب علي مصر اعيها

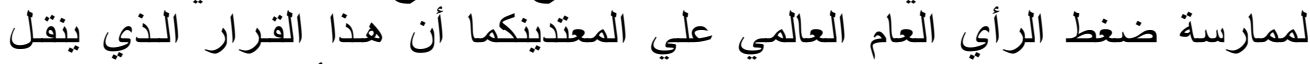

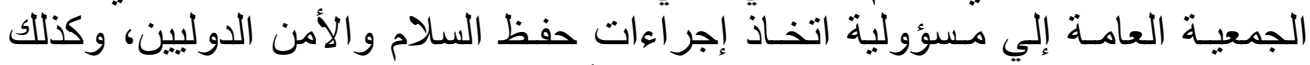

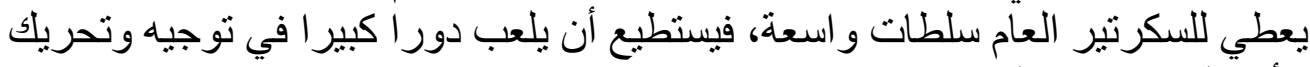
الأمم المتحدة ضد المبكر العامنين

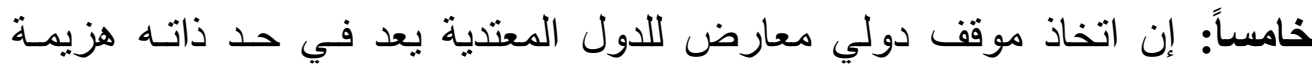

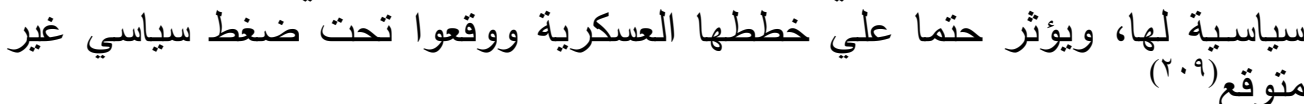

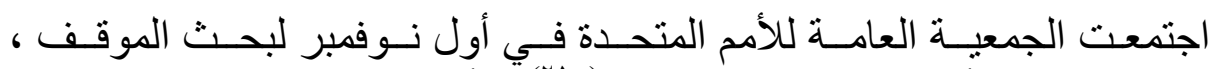

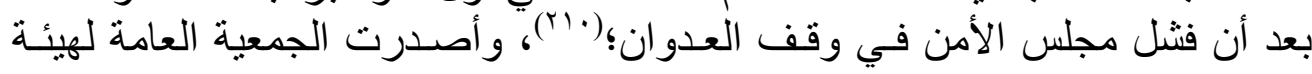

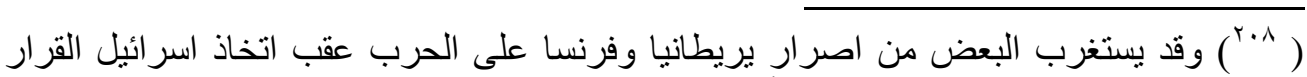

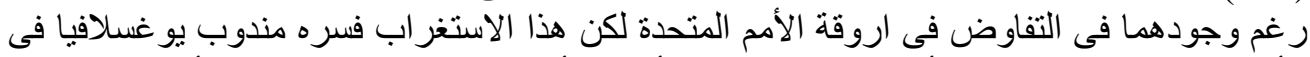

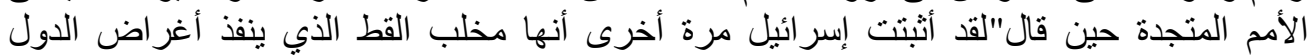

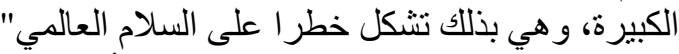

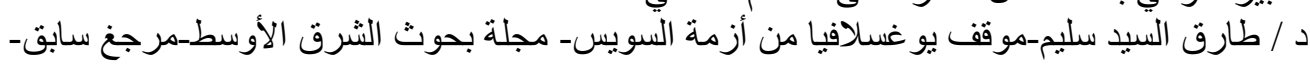

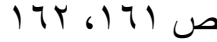

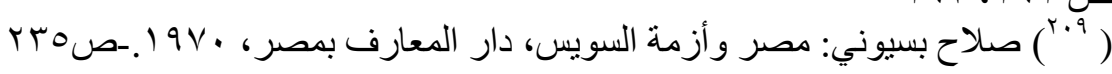




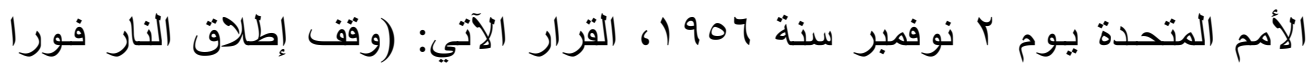

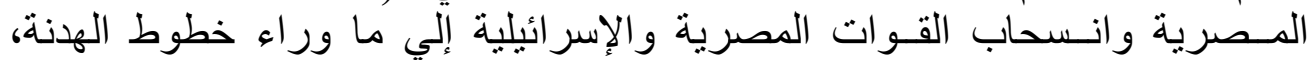

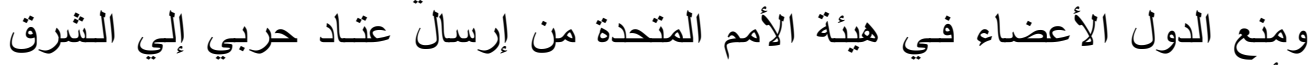

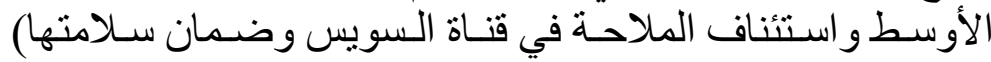

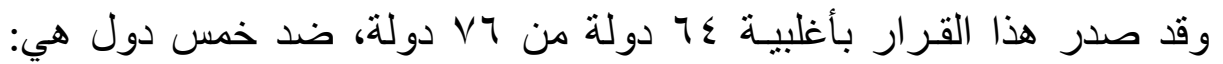

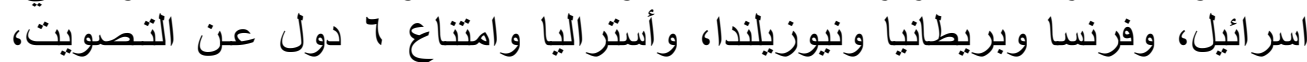

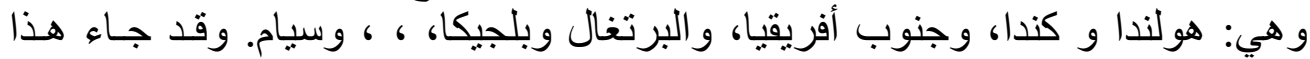

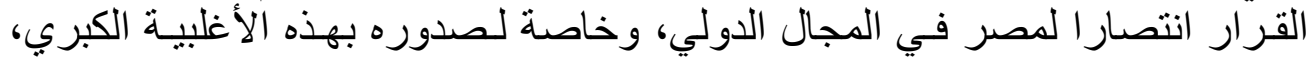

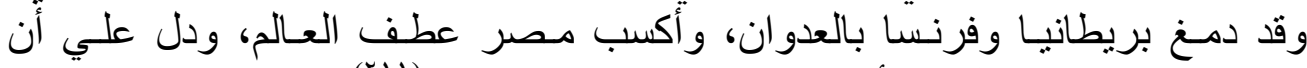

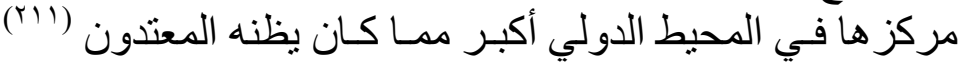

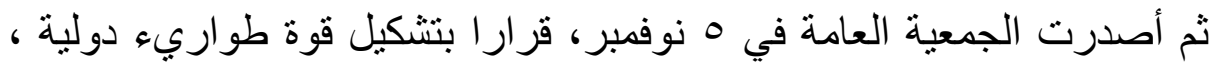

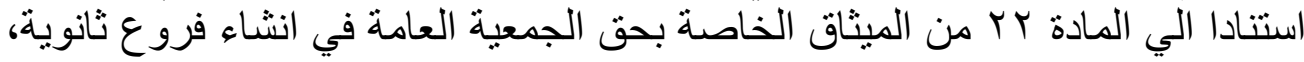

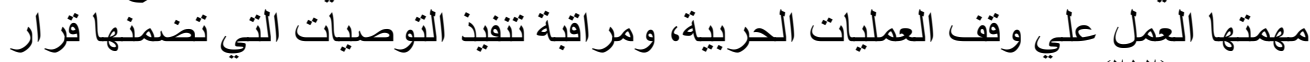

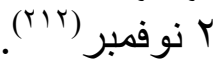

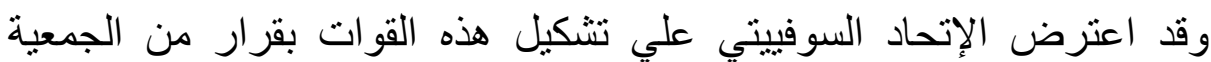

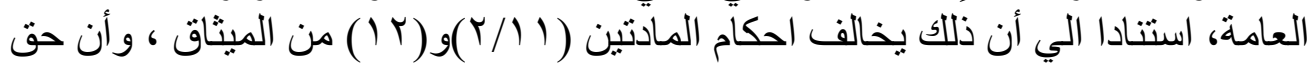

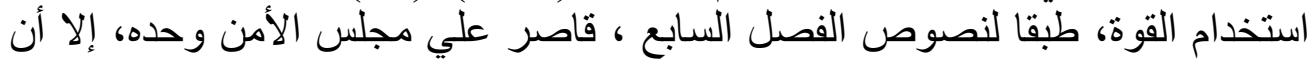

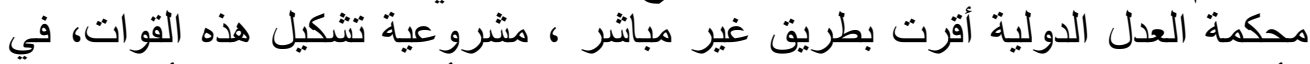

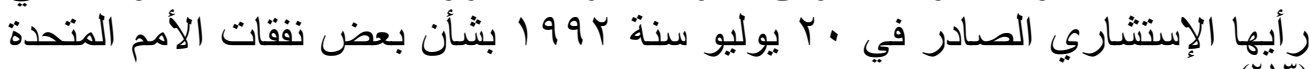

ومن خلال الوقائع السابقة وبانزال الثروط المتطلبة لتفعيل قرار الإتحاد من أجل

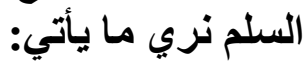

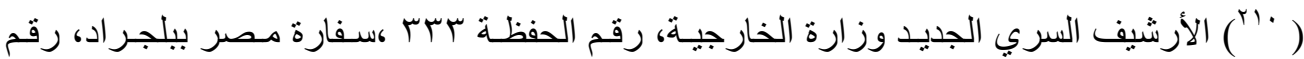

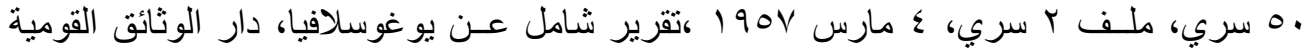

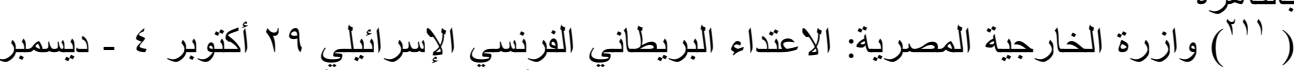

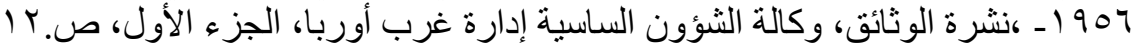

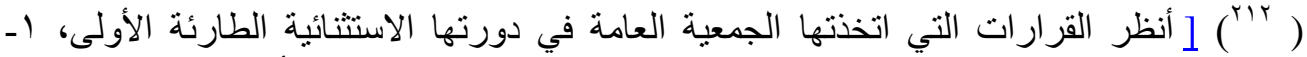

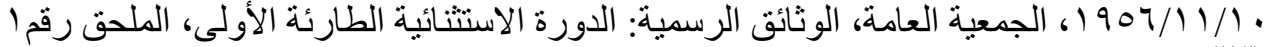

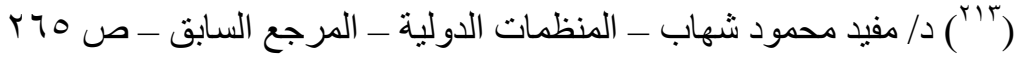




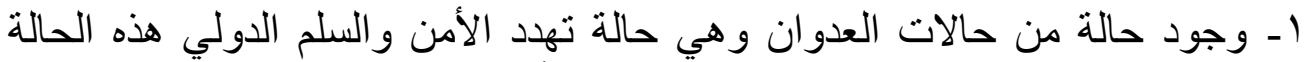

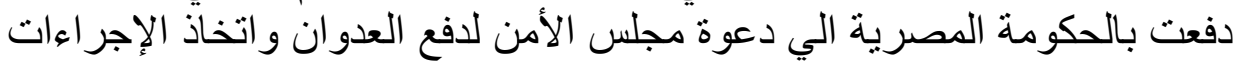

اللازمة لحفظ السلام

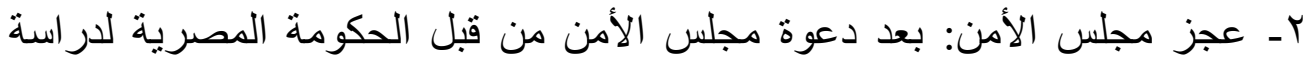

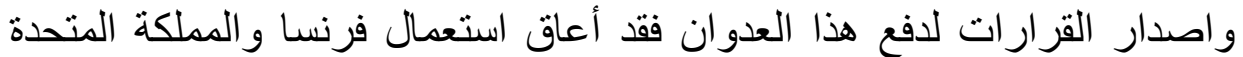

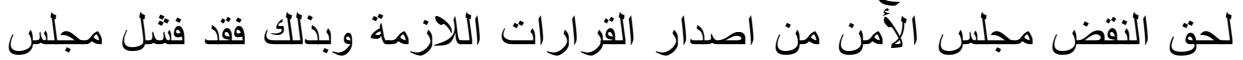

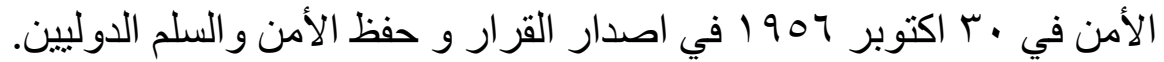

من هنا نجد أن الثروط المتطلبة لتفعيل قرار الإتحاد من أجل السلم منو افرة هذا

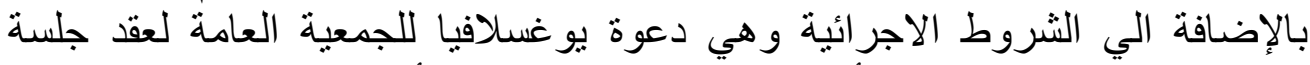

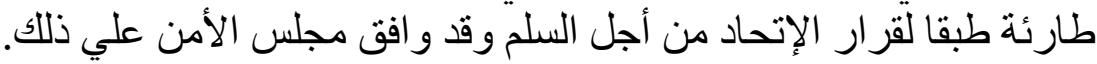

\section{المطلب الثاني \\ أزمة المجر عام 1907 (1)}

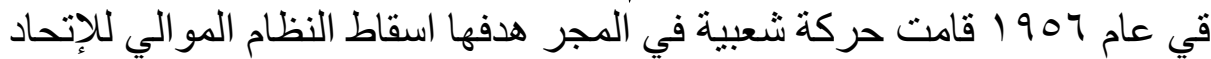

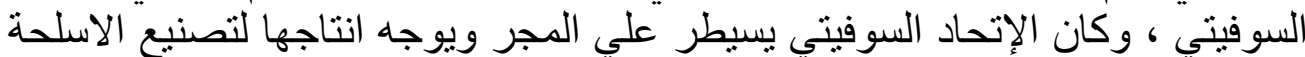

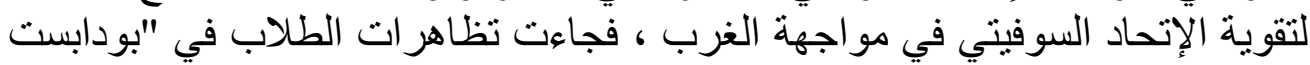

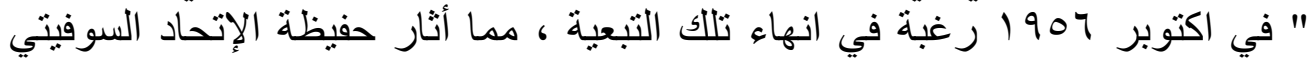

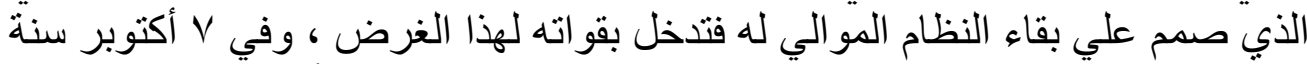

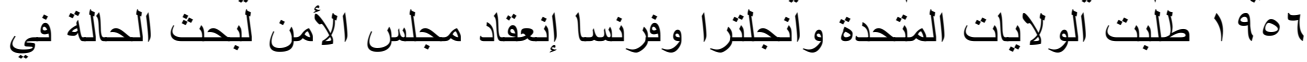

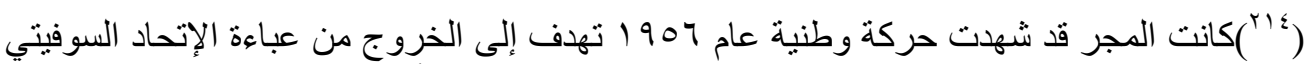

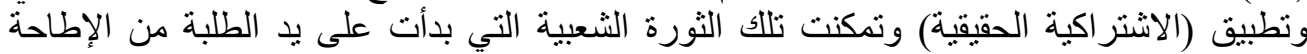

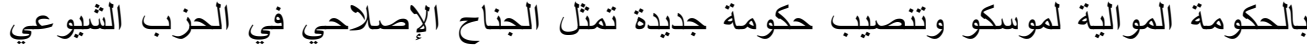

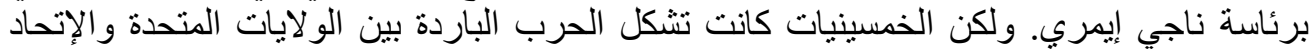

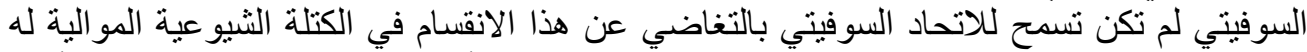

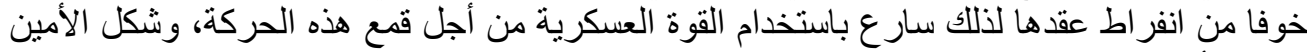

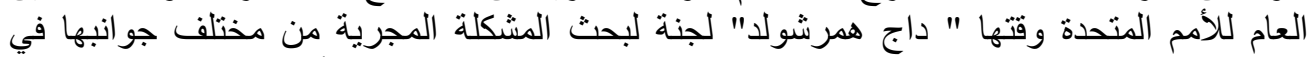

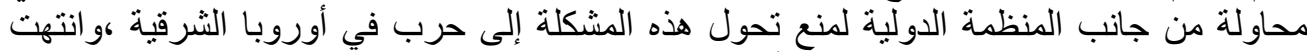

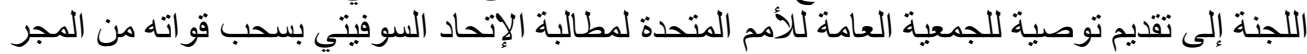

http://www.al-jazirah.com/2005/20050914/xh2.htm

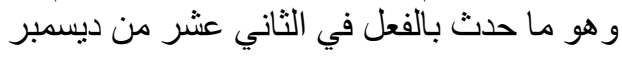

أنظر كذلك د/ محمد حافظ غانم - الدنظمات الدولية (دراسة لنظرية التنظيم الدولى ولأهم

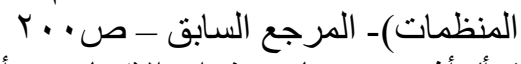

) أ/ أشرف صيات) - قرار الإتحاد من أجل السلم: هل هو وسيلة مدكنة لحماية الفلسطنيين- المرجع

السابق - صوف صود

د/ مفيد محمود شهاب - المنظمات الدولية ـ المرجع السابق - ص ع ب 
المجر ، وأشارت في طلبها إلي تدخل القوات السوفيتية و اعتدائها علي حقوق الشعب .

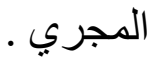

ولقد أعترض الإتحاد السوفيتي علي إدراج مشسكلة المجر في جدول أعمال

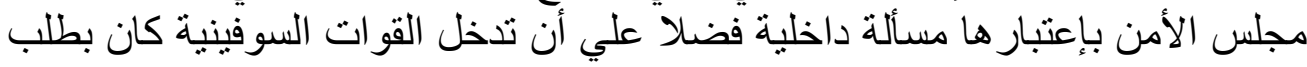

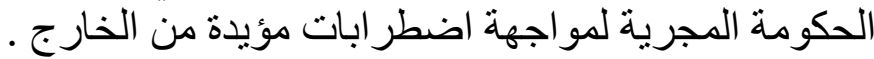

ولقد ناقش مجلس الأمن مشكلة المجر علي الرغم من معارضة الإتحاء السوفيتى الري

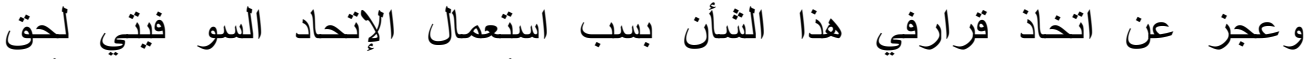

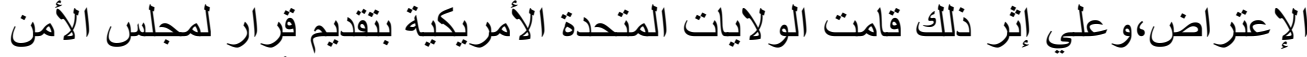

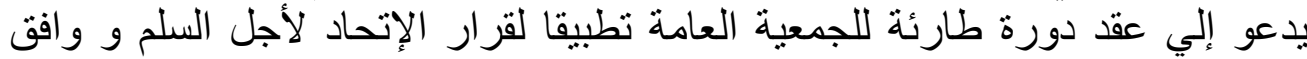
مجلس الأمن علي ذلك.

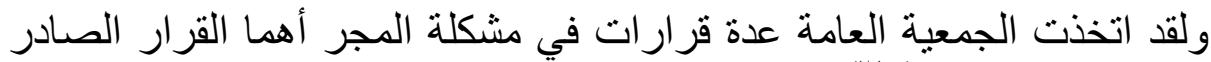

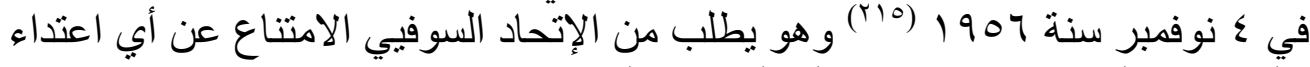
علي شعب المجر وسحب قو اته المسلحة من المجر.

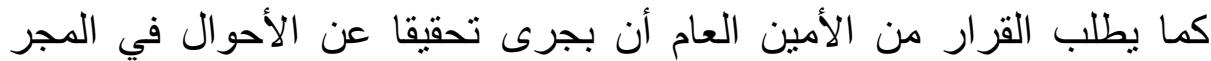

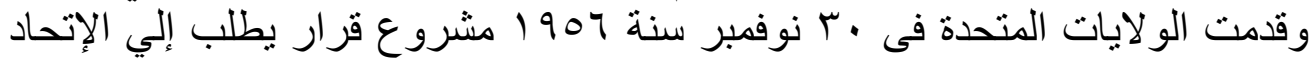

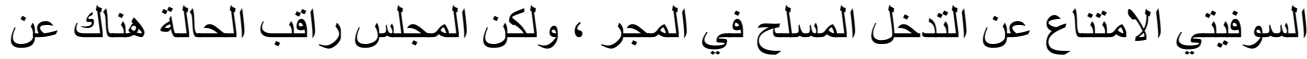

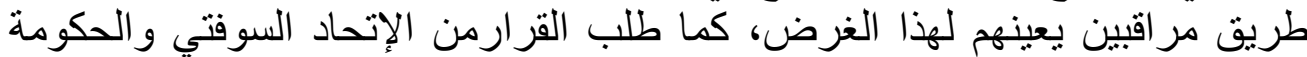

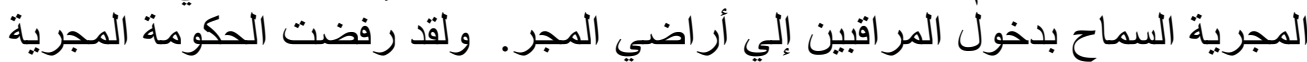

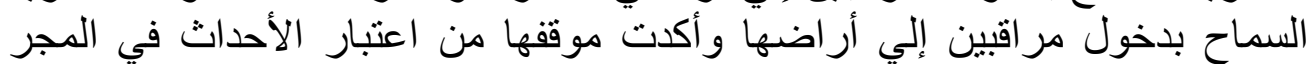

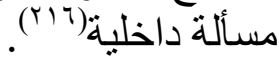

\section{و إذا ما حللنا هذه الوقائع ونظرنا في مدي تواققها مع شروط اعمال القرار نجد ما يلي}

ا - بالنسبة للشرط الاول وهو وجود حالة تهدد أو تخل بالأمن و السلام الدولي ويجد هذا

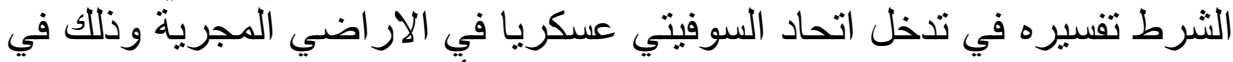

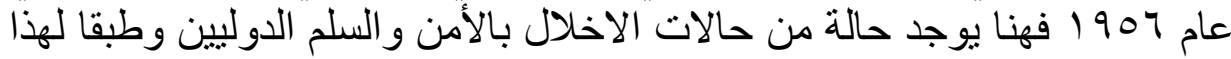

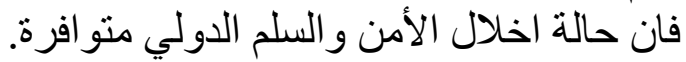

(الج (10) راجع موقع الجمعية العامة للأمم المتحدة على شبكة المعلومات الدولية "الإنترنت" على الموقع التالى https://www.un.org/ar/ga/sessions/emergency.shtml

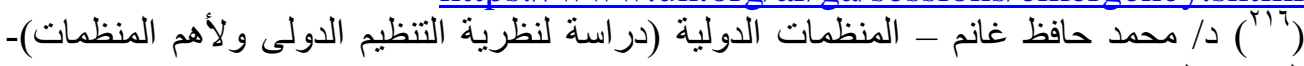

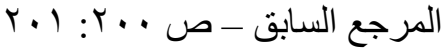




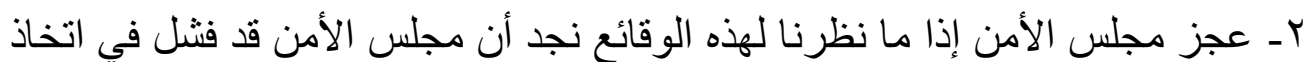

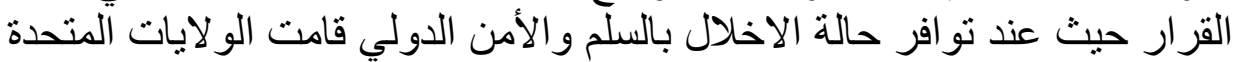

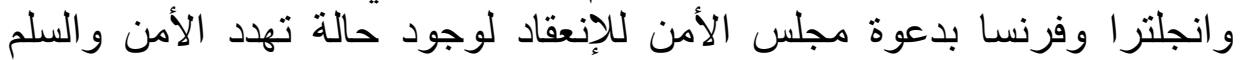

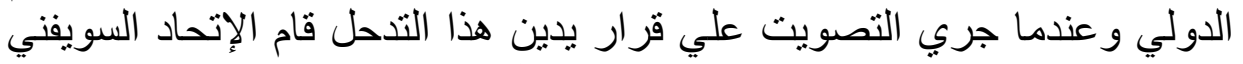
باستخدام حق النقض لإجهاض مشروع القرار الذي كان سيصدر.

هذا طبقا للشروط الموضو عية الخاصة لتطبيق قرار الإتحاد من أجل السلم أما

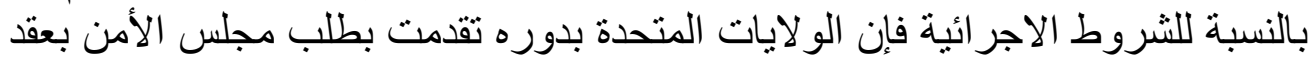

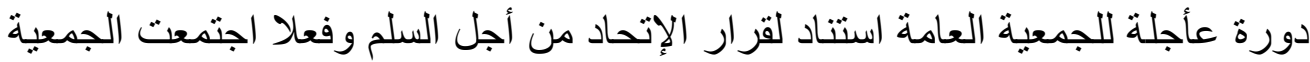

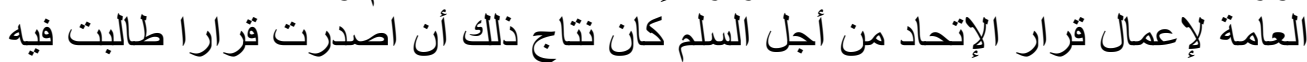

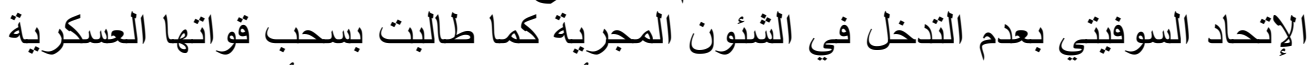

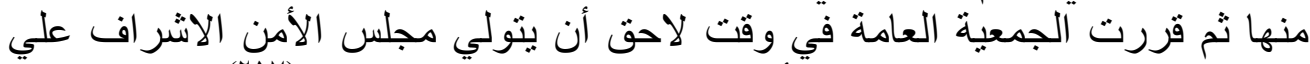

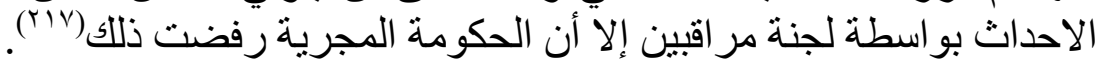

\section{المطاب الثالث

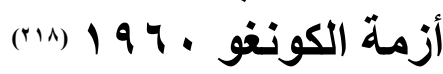

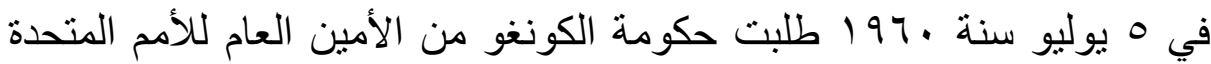

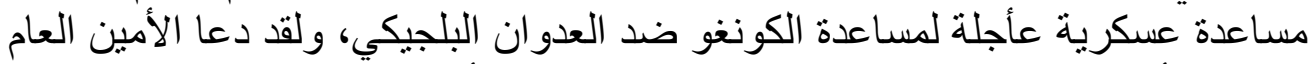

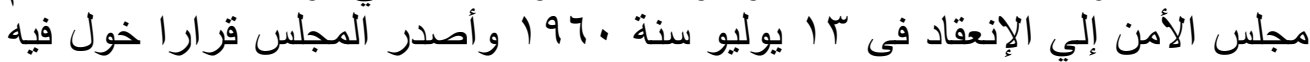

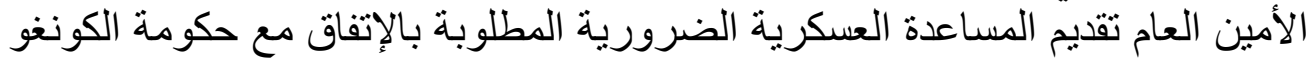

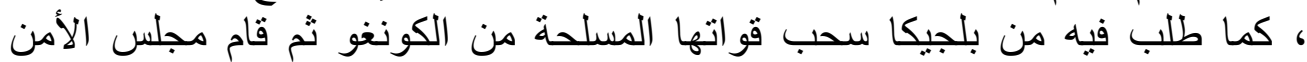

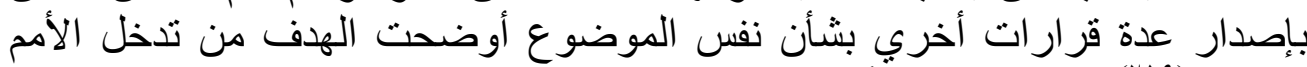

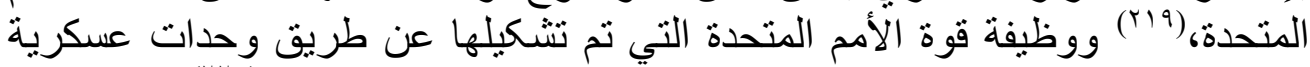

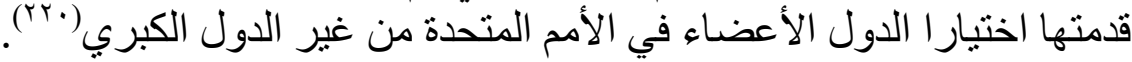
ولما تبين أن تدخل مجلس الأمن لم يكن ناجحا وذللك بسبب عدم مو افقة حكومة

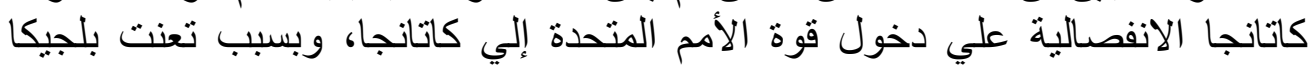

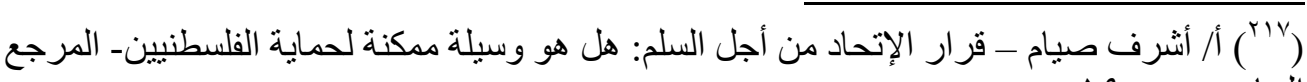

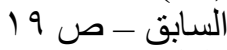

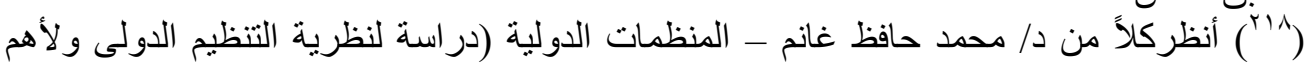

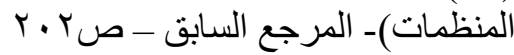

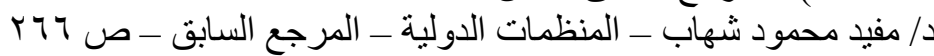

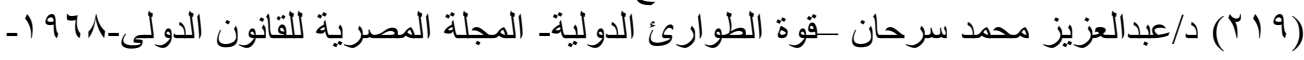

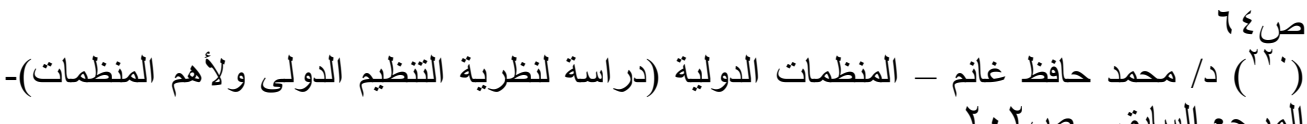


سحب قو اتها، دعا مجلس الأمن فى سبتمبر سنة ـ 97 إلبا إلي عقد دورة طارئة مستعجلة

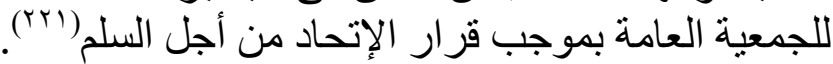

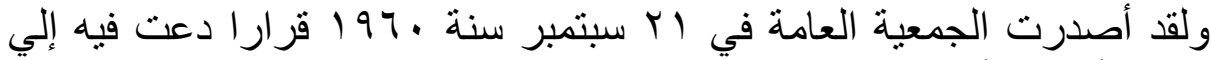

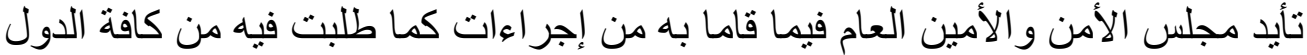

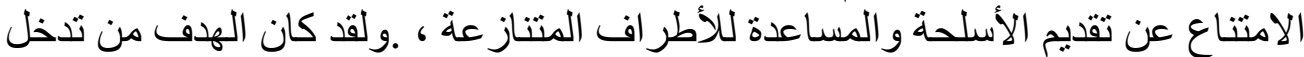

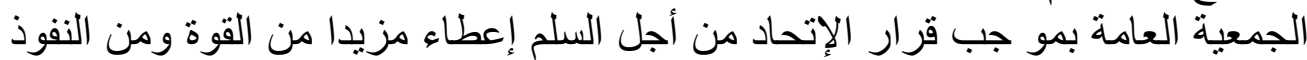

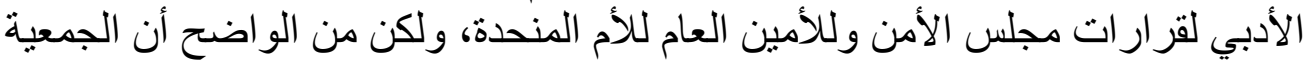

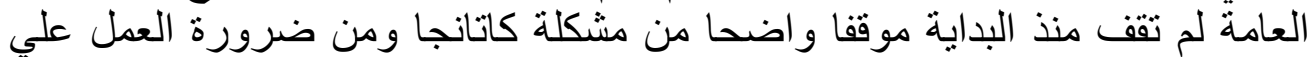

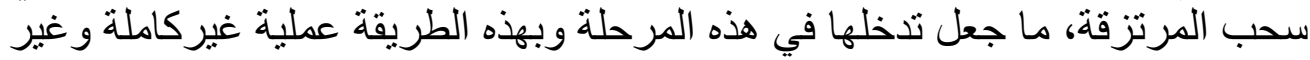

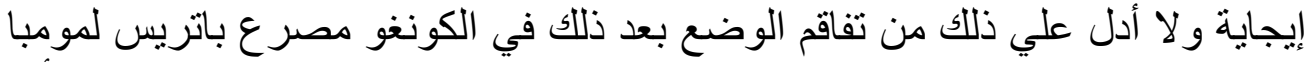

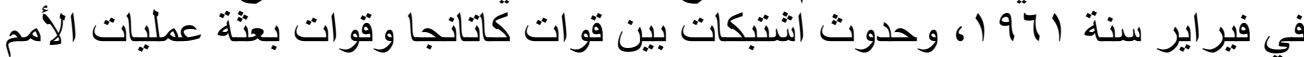

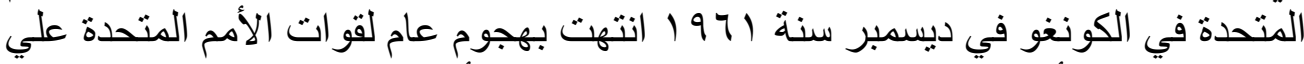

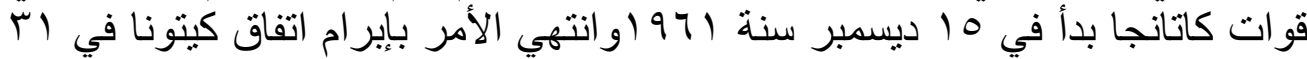

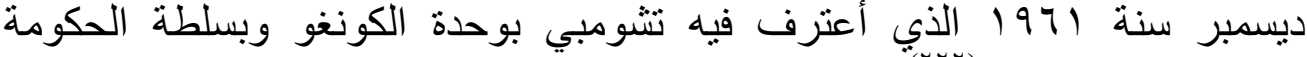

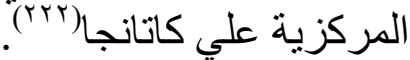

\section{المطاب الرابع الزابع}

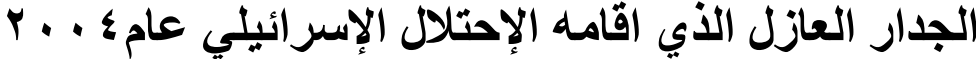

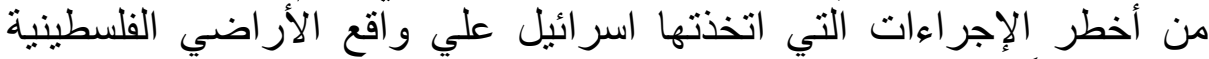

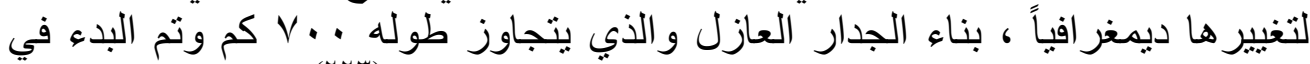

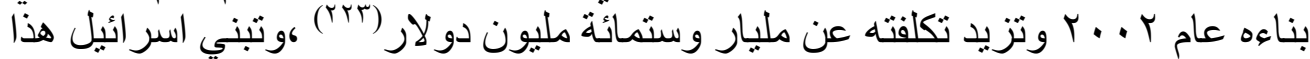

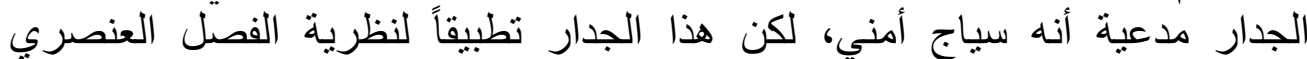

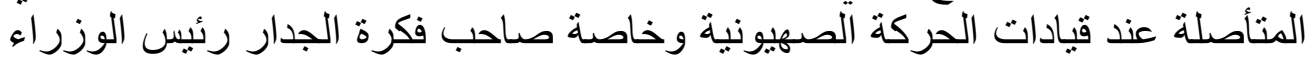

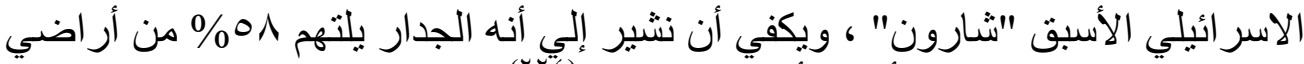

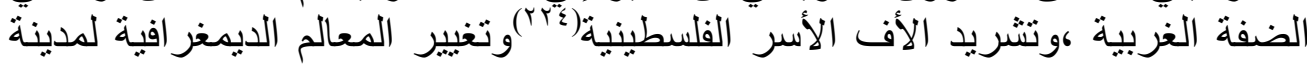

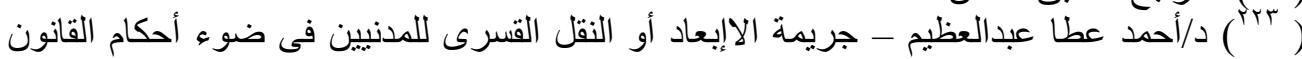

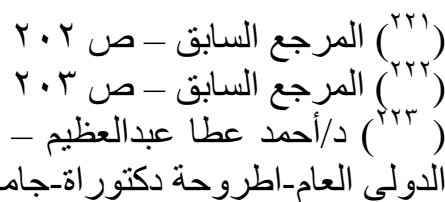

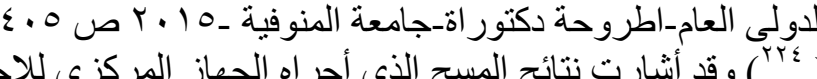

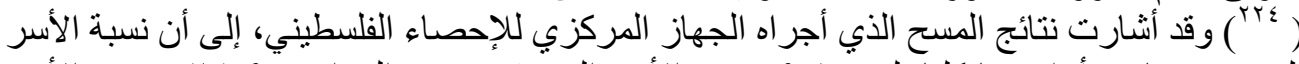

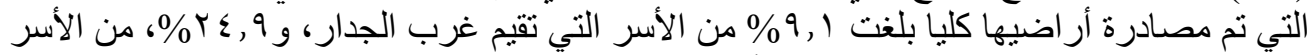

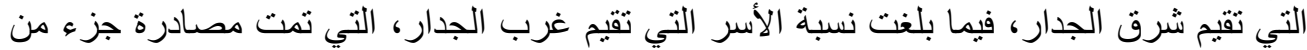

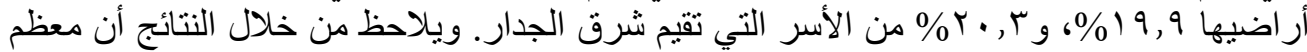

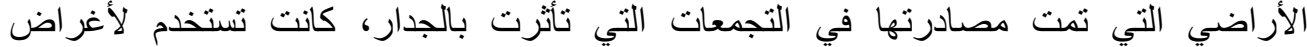

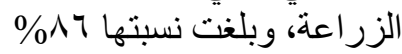


القس ،فضلا عن انه يمثل تضييقاً كبير ا علي حرة الفلسطينين ، فإنه يلتهم أر اضيم حتي لإني

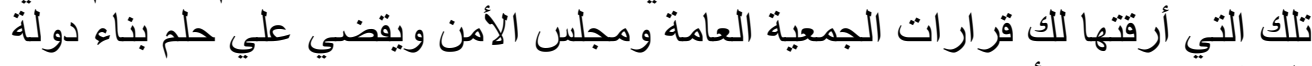

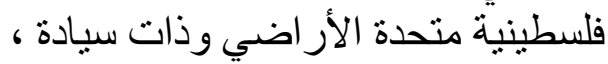

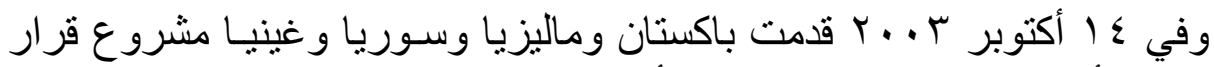

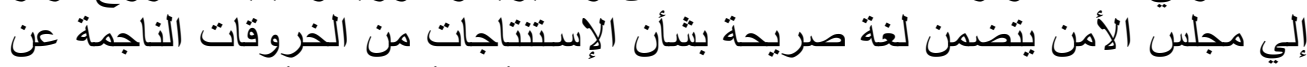

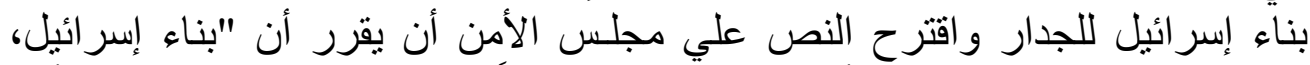

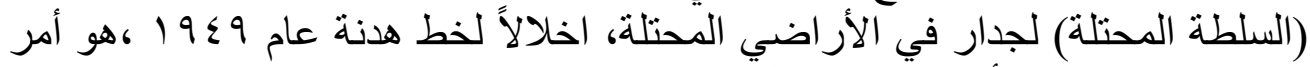

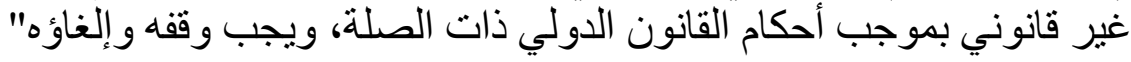

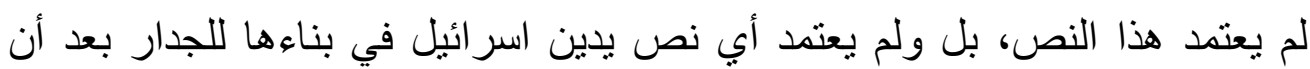

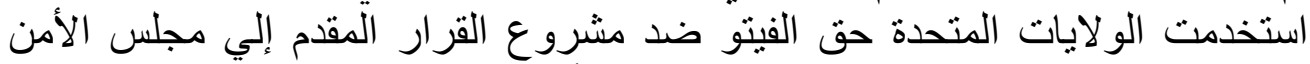

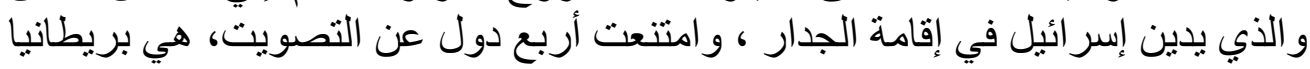

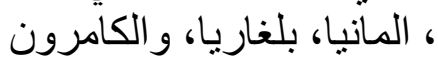

نتيجة لذلك، قام رئيس المجموعة العربية في الأمم المتحدة ددعوماً من قبل

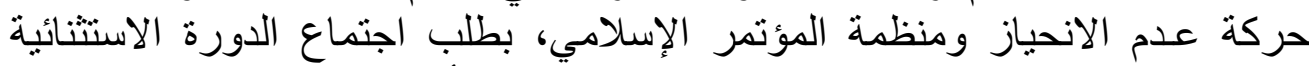

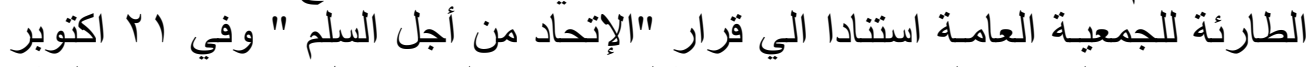

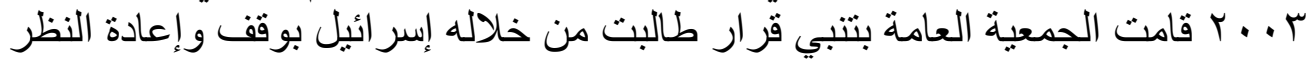

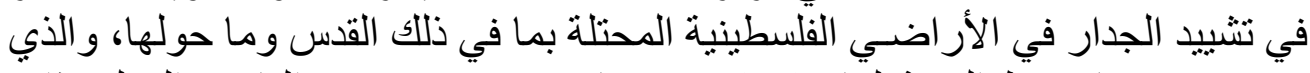

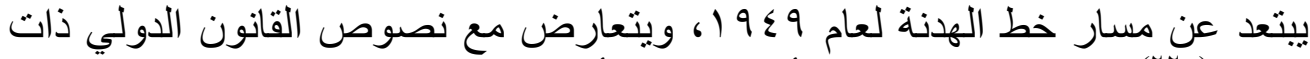

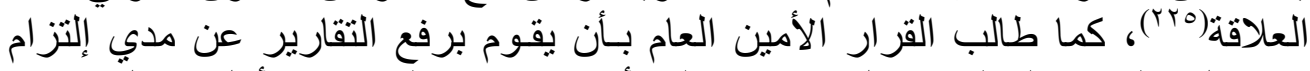

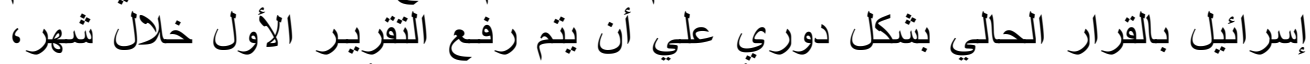

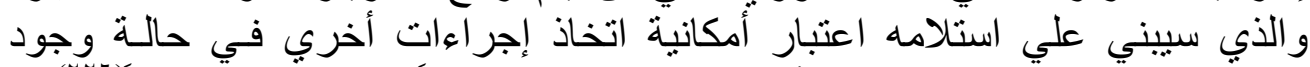

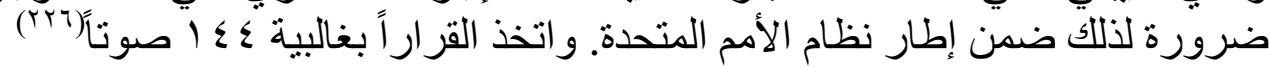

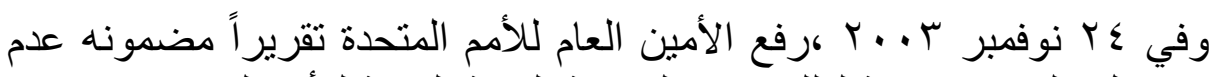

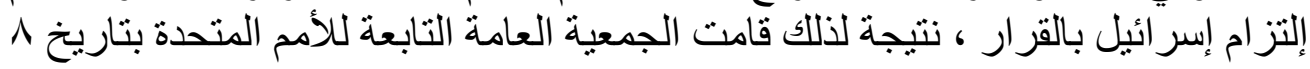

للإطلاع على أثار بناء الجدار العازل على الفلسطينين زيارة موقع ركز المعلومات الوطنى الفلسطينى http://www.wafainfo.ps/ar_page.aspx?id=4109

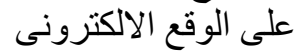

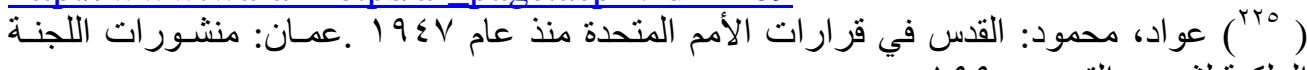

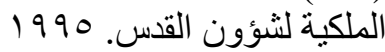

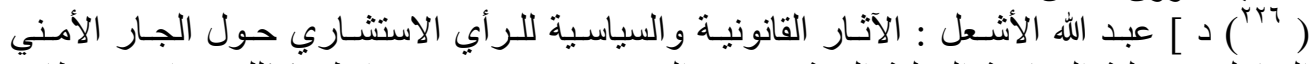

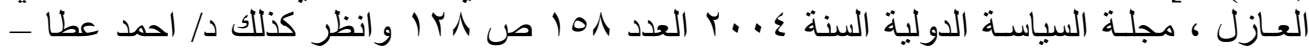

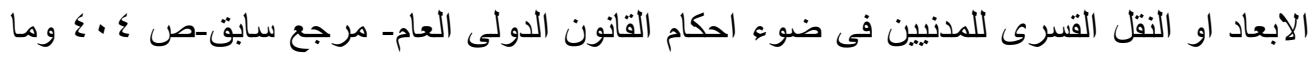




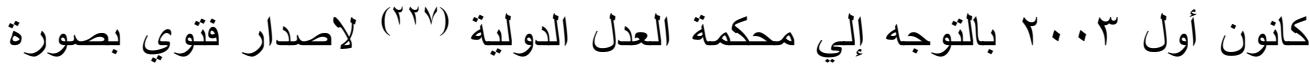

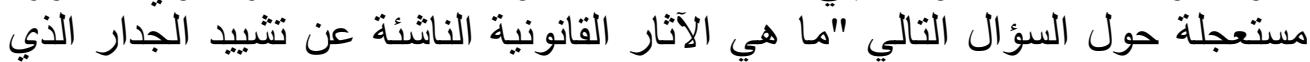

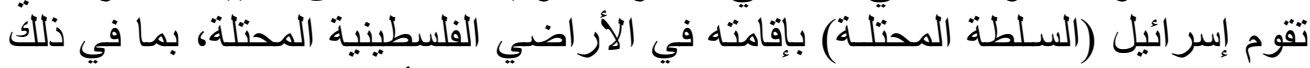

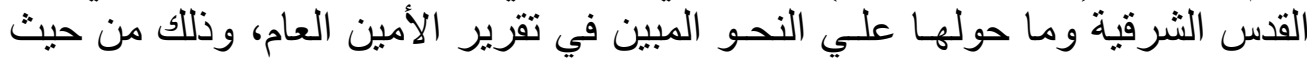

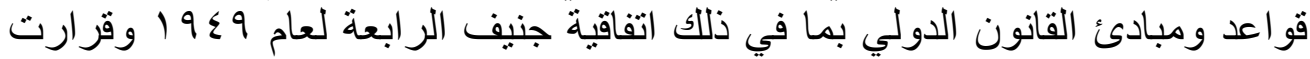

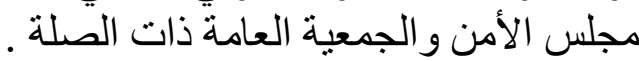

وقد أتت هذه الفتوي استجابة لطلب الجمعية العامة للأمم المتحدة في دورتها

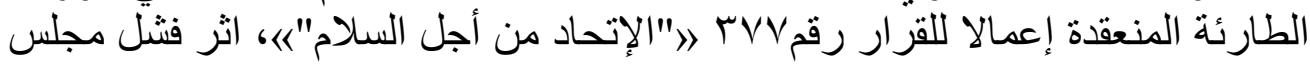

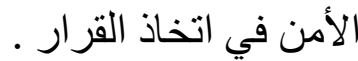

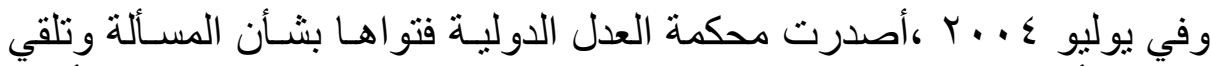

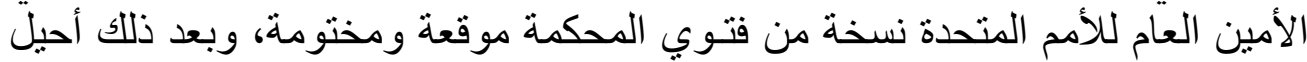

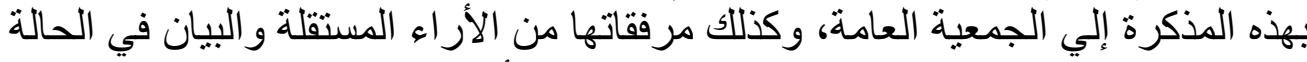
المتعلقة بالآثار القانونية الناشئة عن تشييد جدار في الأر اضي الفلسطينية المحتلة .

لقد مضت محكمة العدل الدولية في رأيها الاستشاري علي نحو منهجي لتأكيد

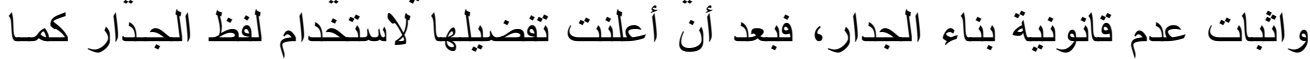

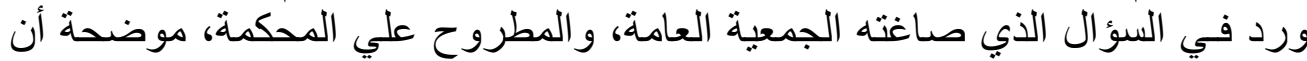

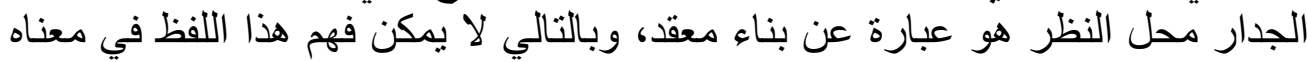

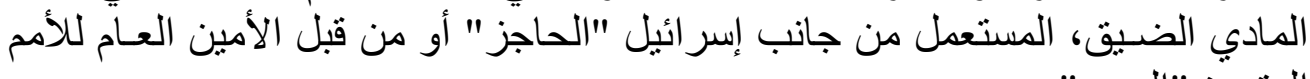

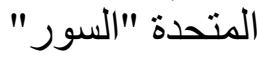

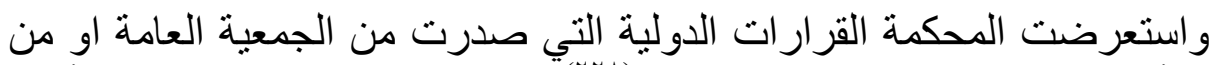

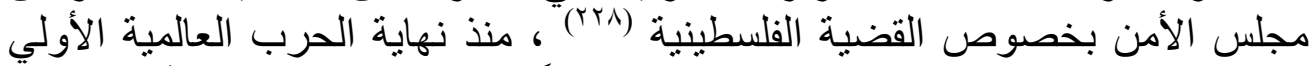

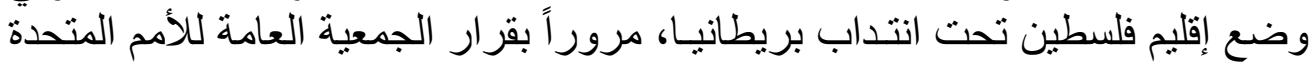

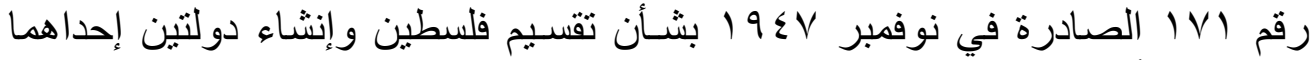

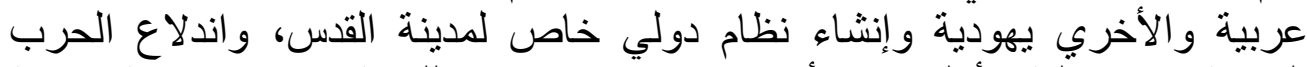

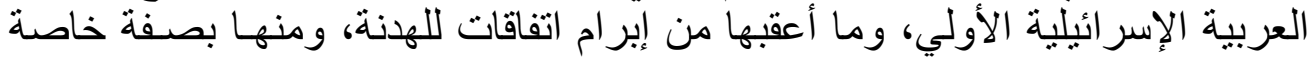

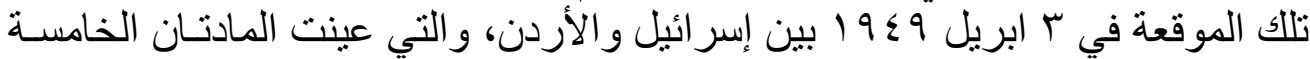

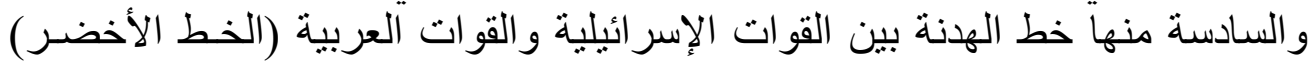

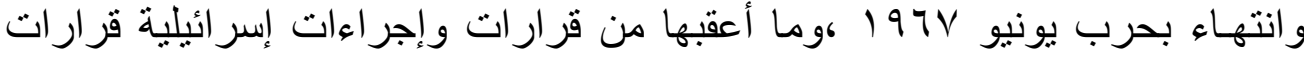

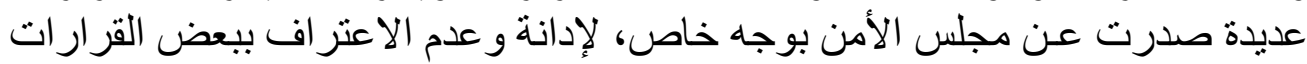

227 ) David (Eric), Avis de la cour internationale de justice sur l'emploi de 1 arme nucléaire, revue internationale de la croix rouge, $n^{\circ} 823,1997$, p.22-23

( ( ) راجع فى ذللك د/ حسين حنفي عمر: حق الثعوب في تقرير المصير. القاهرة: دار النهضة

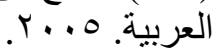


التشريعية والتدابير الإدارية التي استهدفت المساس بالوضع القانوني للأراضي إلتي

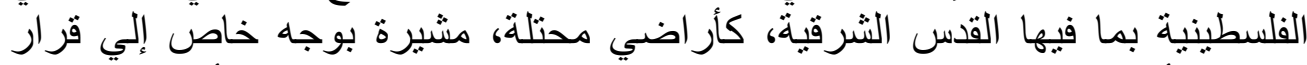

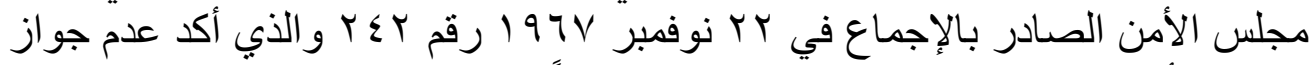

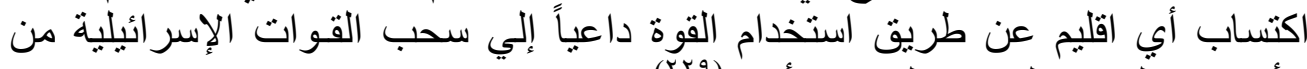

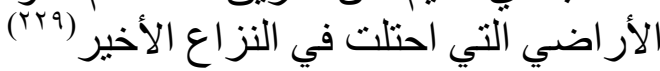

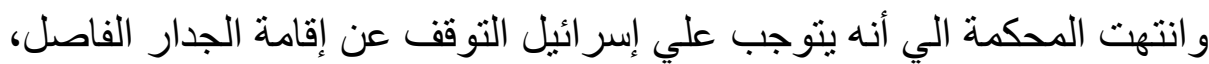

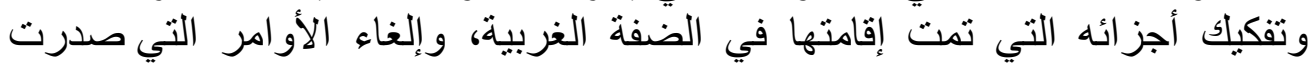

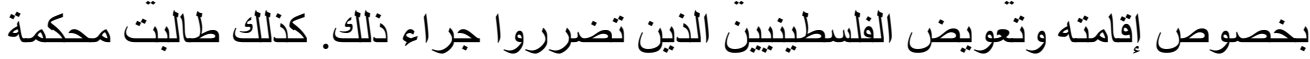

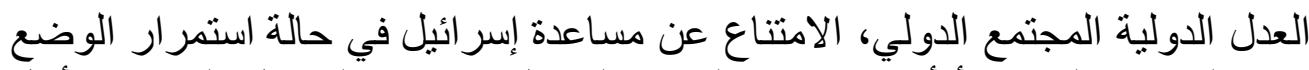

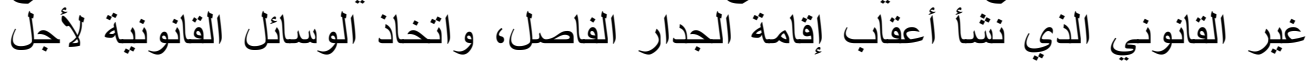
إيقاف الخروقات الإسر ائيلية، وضمان تطبيق أفئ اتفاقية جنيف الر ابعة.

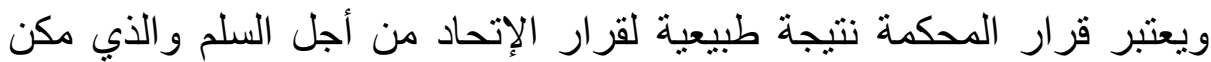

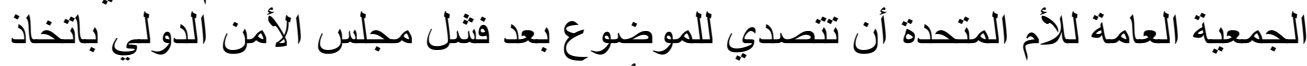

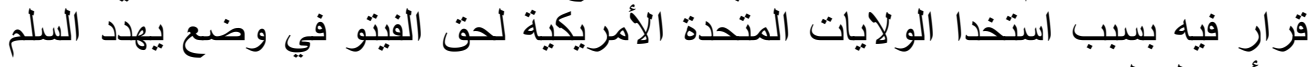

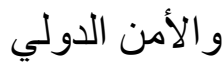

\section{المبحث الثاني

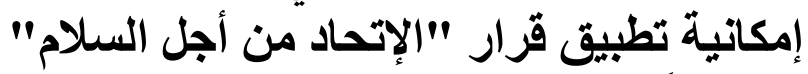

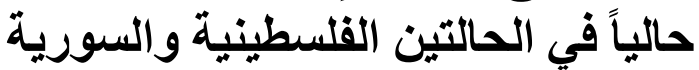

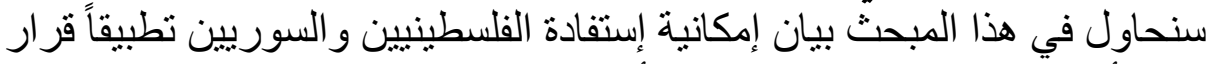

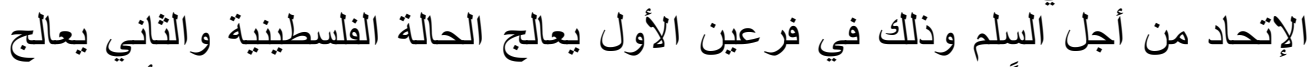

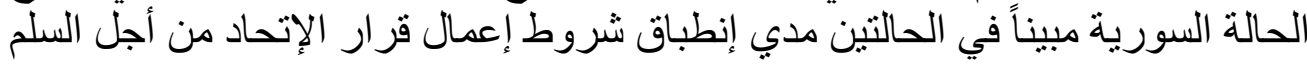
وذللك كما يلي:-

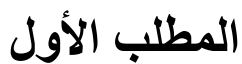

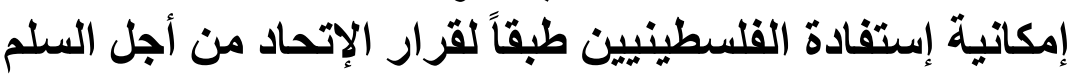

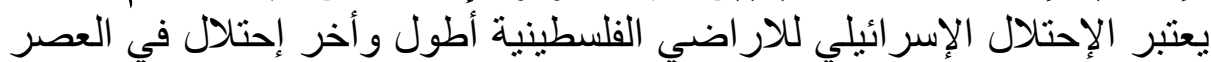

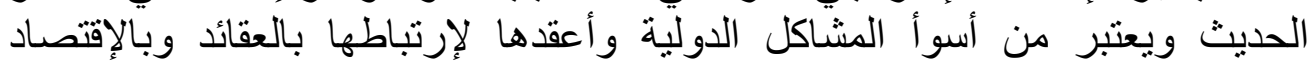

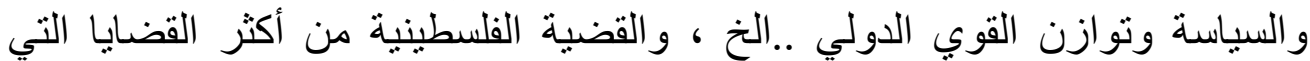

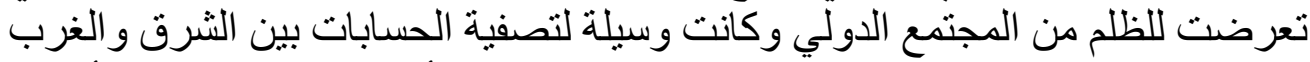
وتعرضت القضية الفلسطينية للتصفية التدريجية ، فبعد أن كانت القضية في أصلها

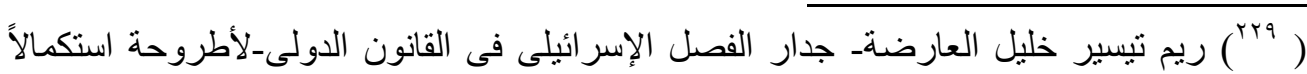

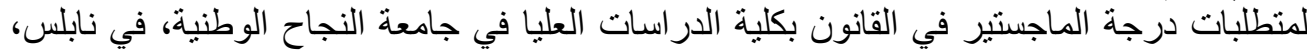

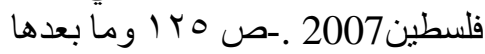




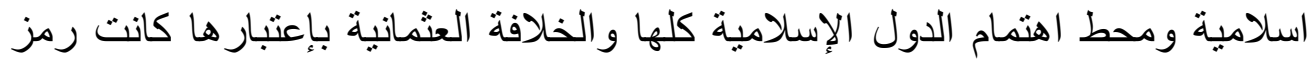

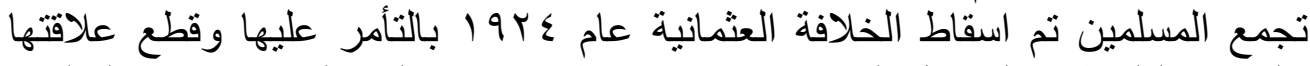

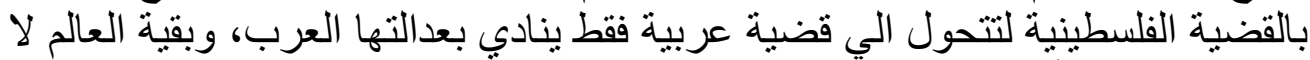

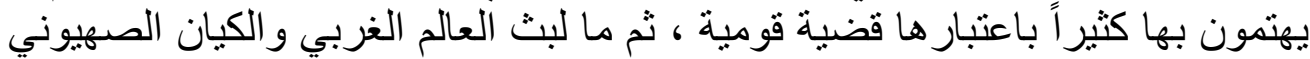

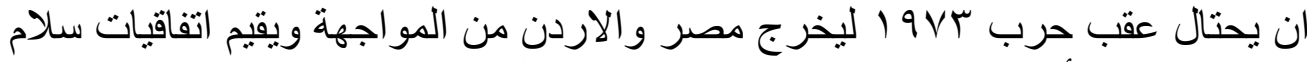

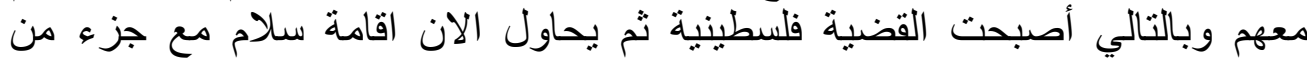

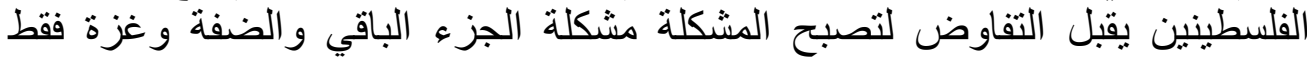

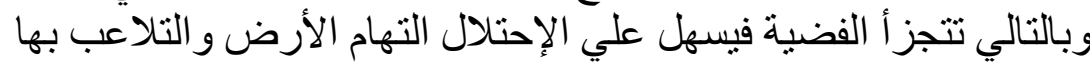

ومنذ الإحتلال الإسر ائيلي لفلسطين عقب وعد بلوفر وعقب اعلان قيام اسر ائيل

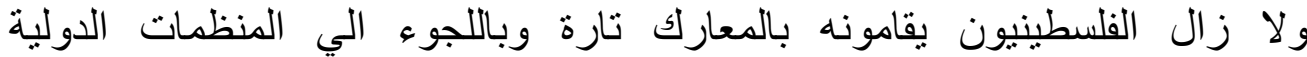

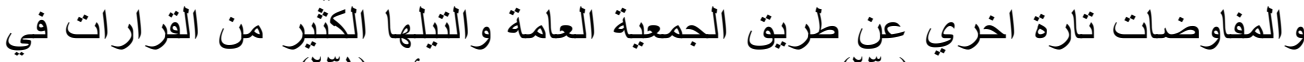

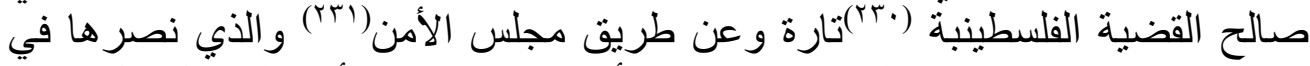

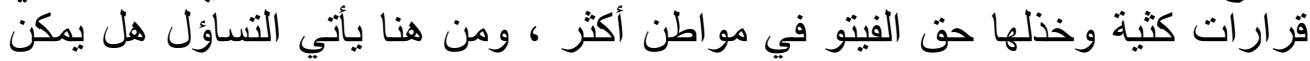

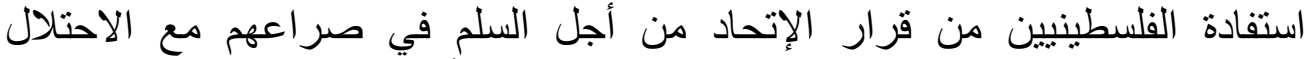

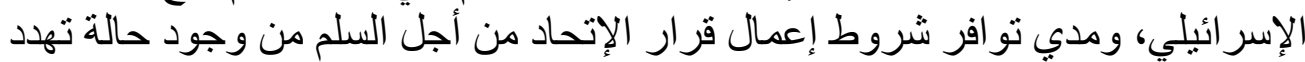

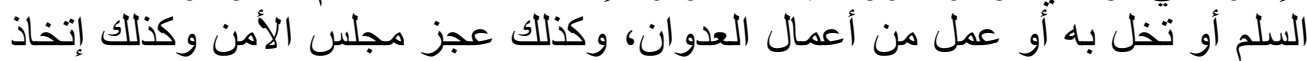
الإجر اءات اللازمة لجعل القر ار معل من اعمل التفيذ، وسنبين ذلك كما يلي:-

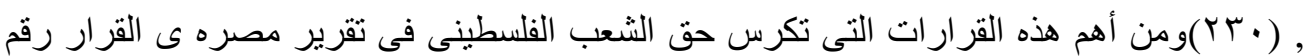
Ororo

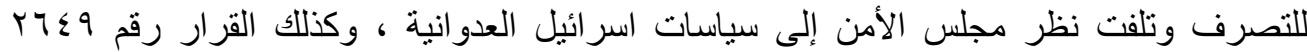

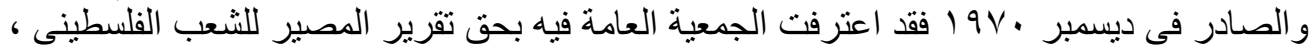

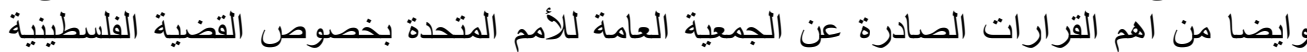

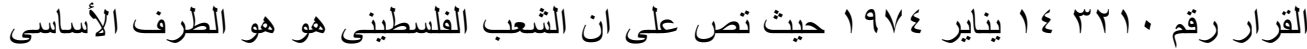

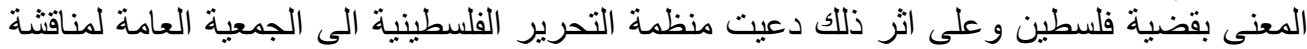

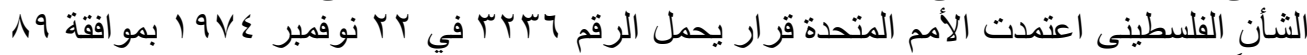

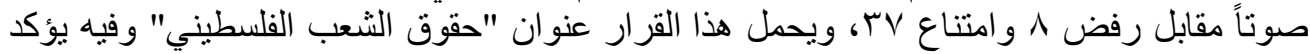

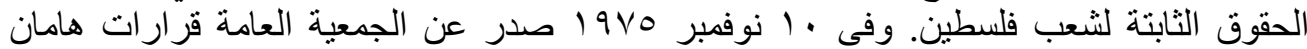

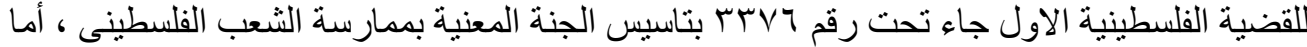

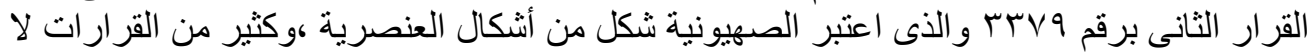

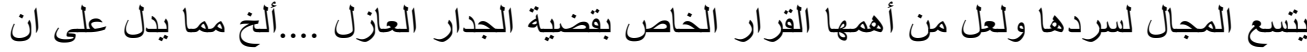

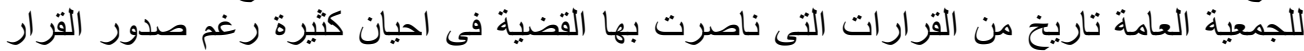

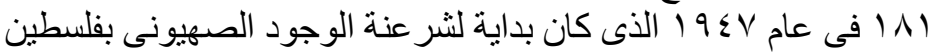

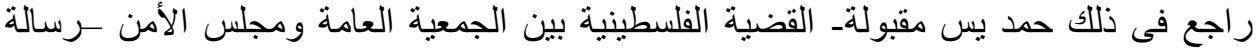

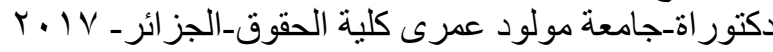

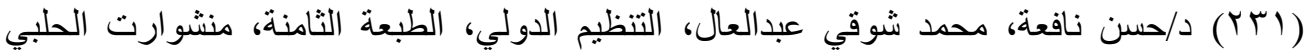




\section{الفرع الأول}

\section{وجود حالة تهدد السلم أو تخل به أو عمل من أعمال العدوان}

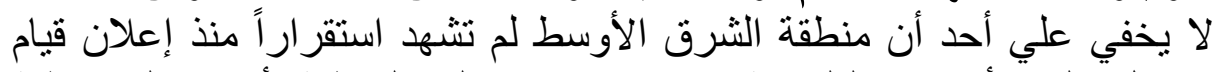

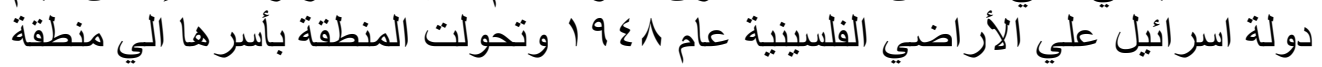

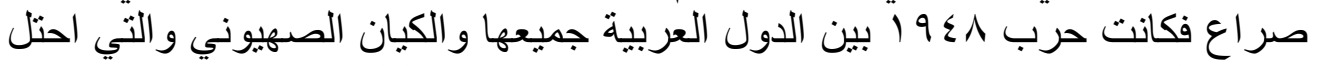

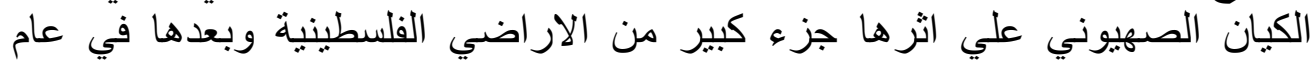

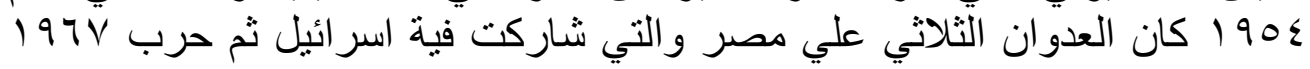

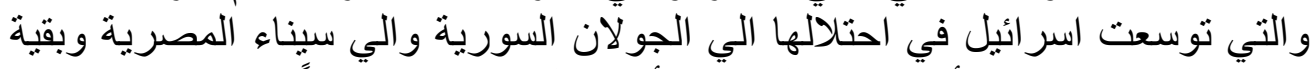

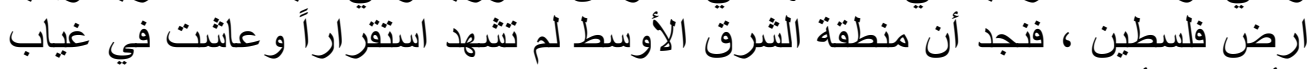

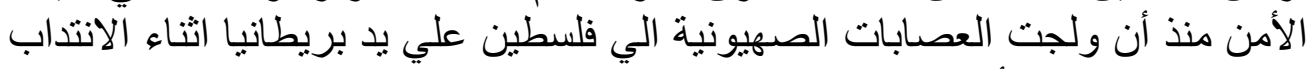

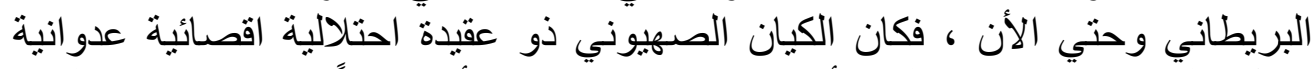

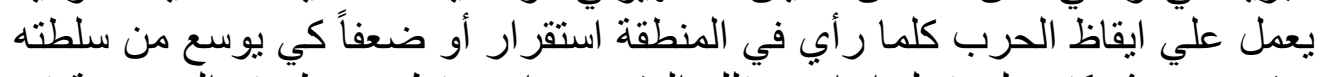

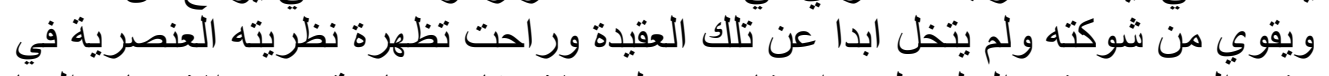

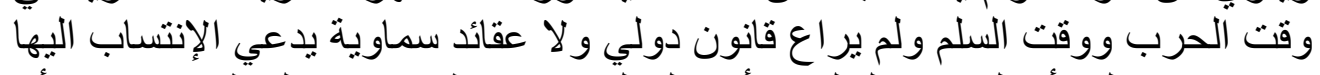

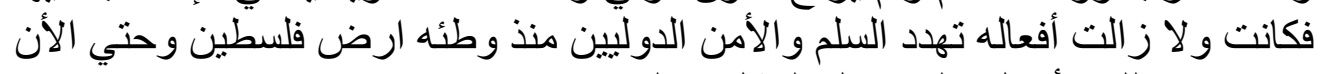

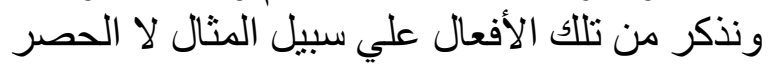

\section{1 - مذبحة دير ياسين(rr)}

وقعت هذه المذبحة في 9 ابريل 19 19 1 ، حيث فوجئ سكان قرية ( دير باسين)

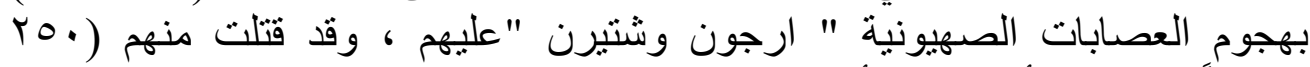

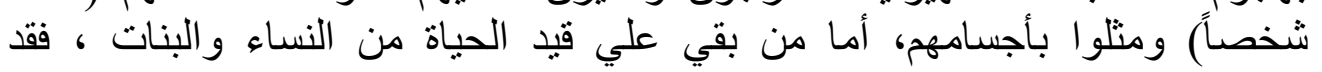

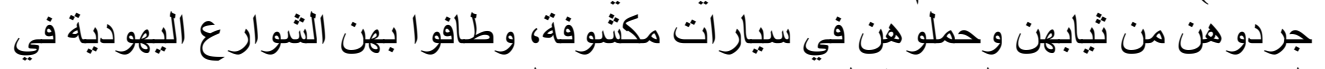
القس حيث تعرضن لئن وحرية الجماهير وي والاعتداء علي حيائهن .

وقد هزت هذه الجريمة المروعة العالم بأسره، فقال مندوب الصليب الأحمر

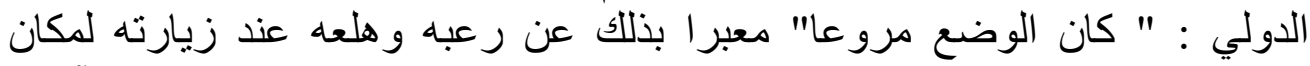

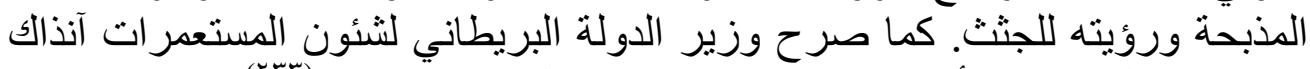

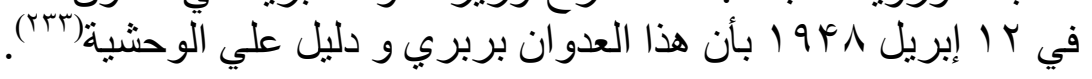

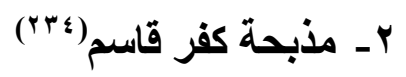

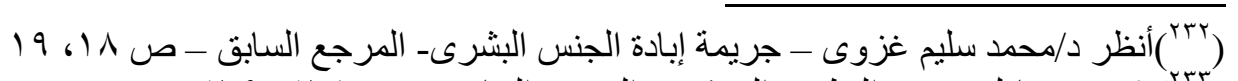

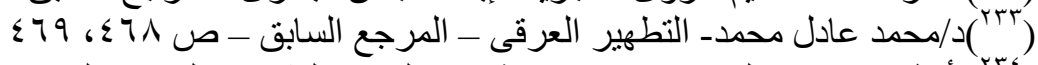

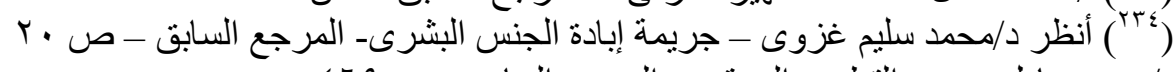

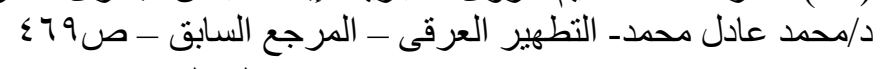
1.1 


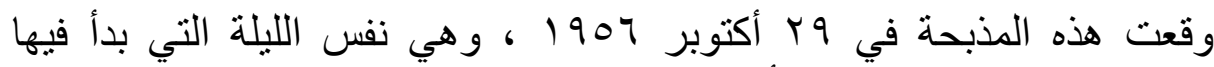

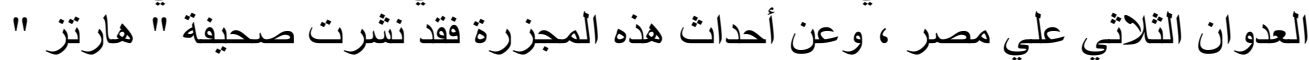

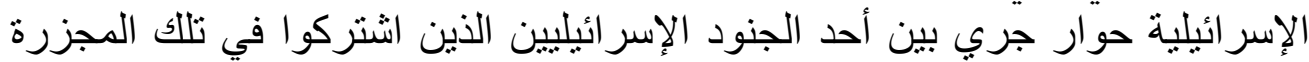
وبين أحد الضباط المسئولين عن المجزرة، فقد سأل الجندي ماذا الأنفا نفعل بالسجناء

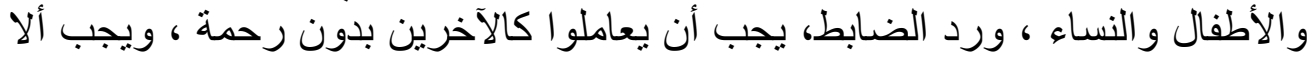

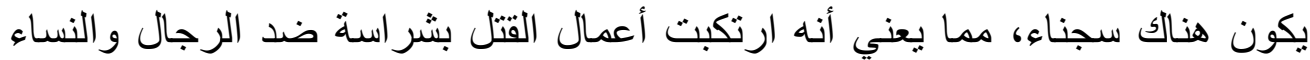

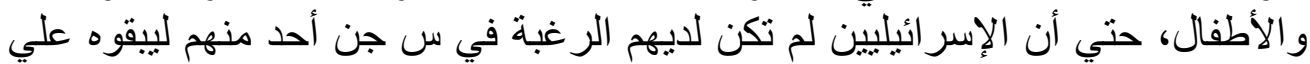
قيد الحياة.

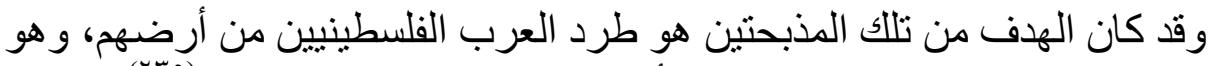

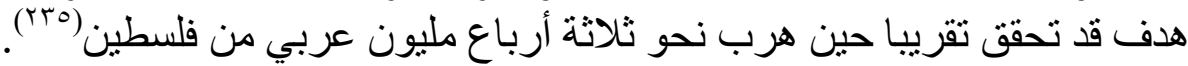

\section{1 - ـ مذبحة ملرسة بحر البقر}

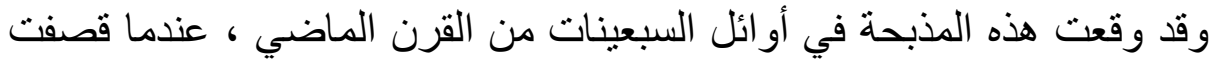

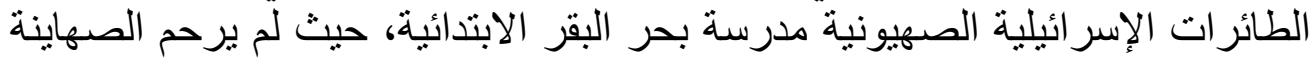

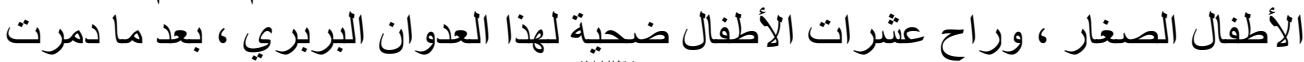

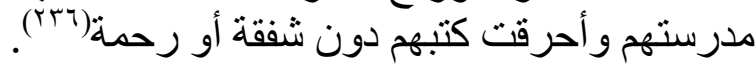

r - مذبحة صبرا وشاتيلا(rv

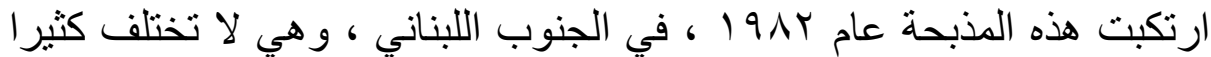

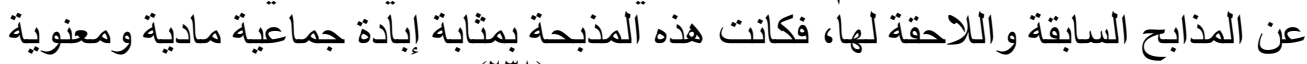

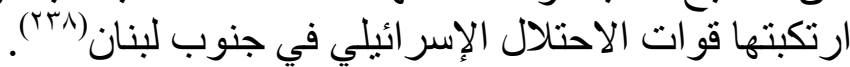

\section{r- مذبحة قانا الأولي(raq)}

تللك المذبحة التي وقعت في أبريل 999 أبراء في الجنوب اللبناني ، ور اح ضحيتها

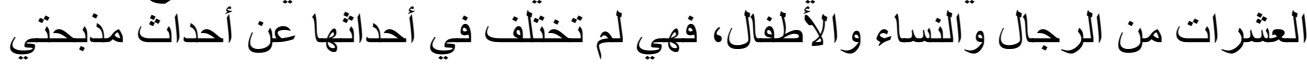
كفر قاسم ودير ياسين، حيث قامت إسر ائيل بإطلاق مدفعيتها الثقيلة علي مجمع لقوات الت الت

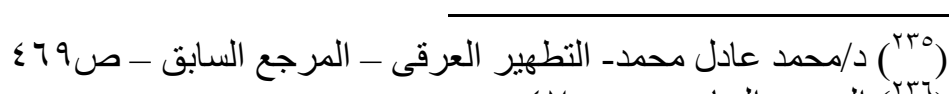

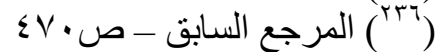

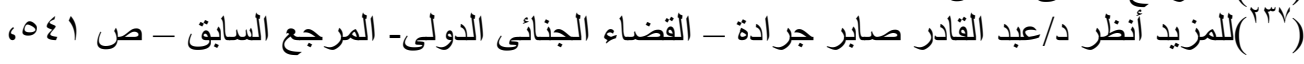

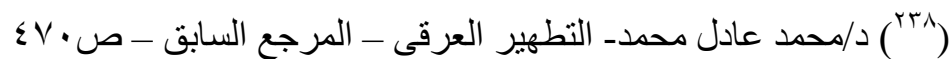

( )

$$
1 \cdot r
$$


حفظ السلام الدولية في جنوب لبنان و الذي كان يحتمي فيه مئات الأشخاص المدنبين

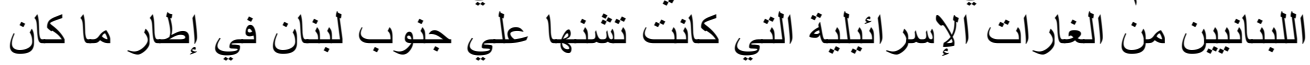

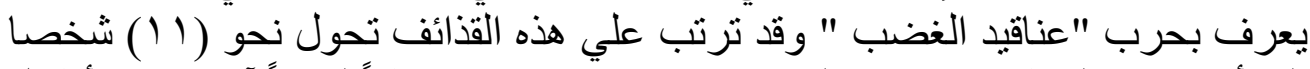

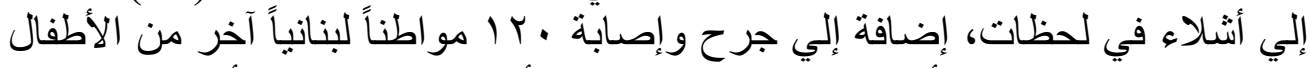

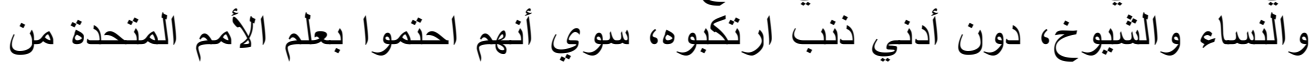

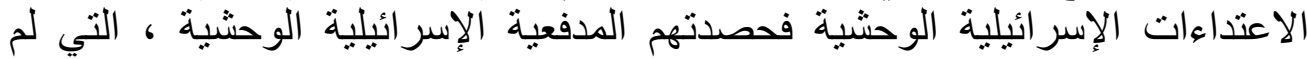

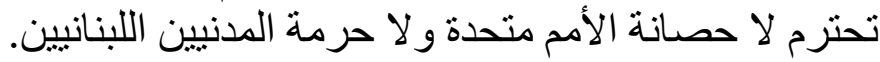

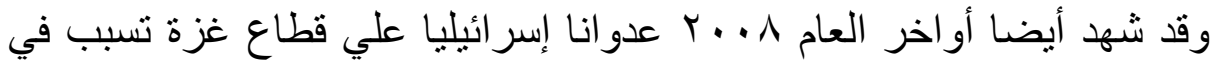

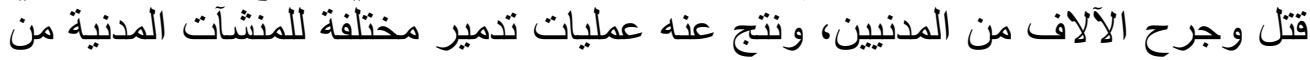

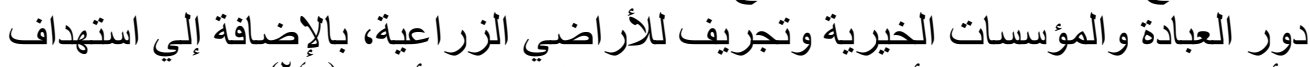

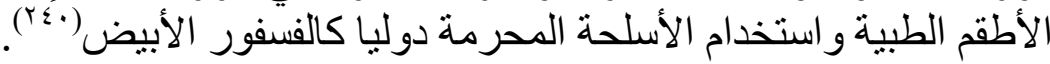

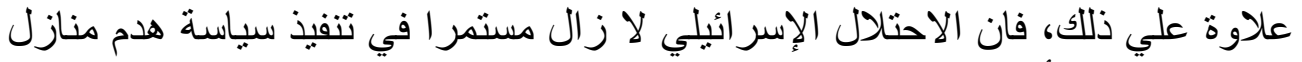

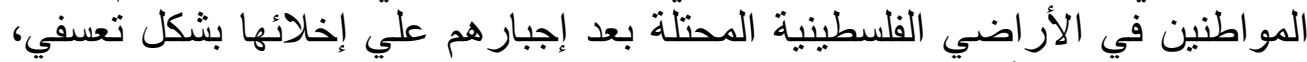

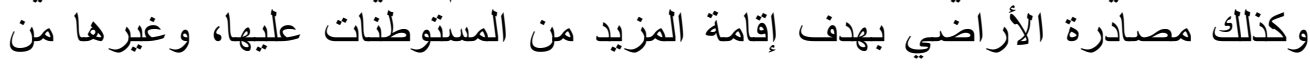

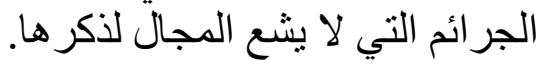

وقد أسفرت الهجمات العشوائية للقوات الإسرائيلية عن قتل وجرح ألعاد أعداد كبيرة

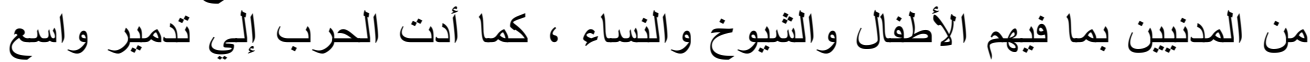

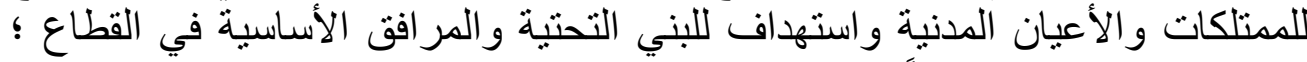

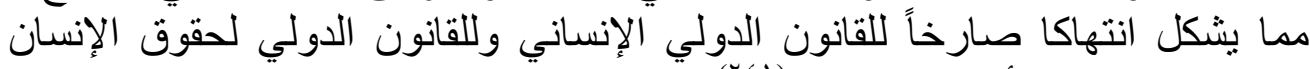

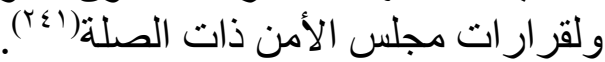

وقد كثفت تحقيقات المركز الفلسطيني لحقوق الإنسان بأن قوات الاحتبلال

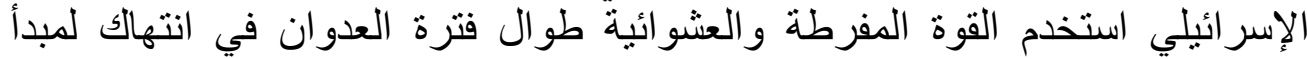

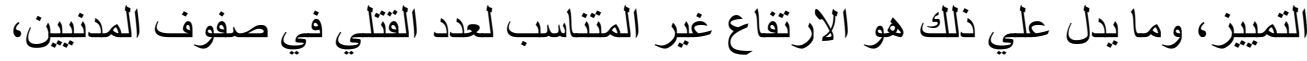

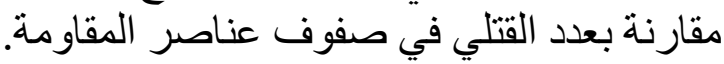

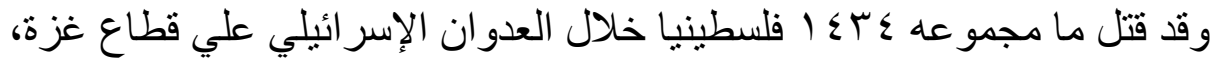

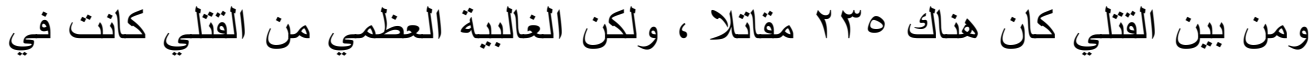

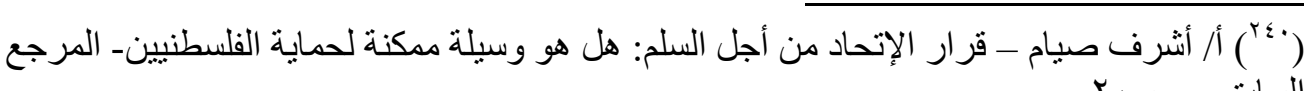

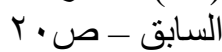

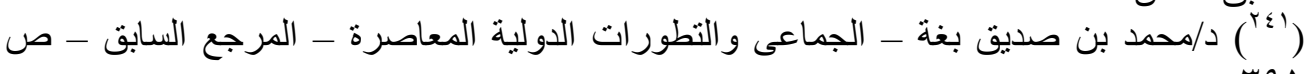


صفوف المدنيين وغير المقاتلين وهم أشخاص محميون بموجب القانون الدولي

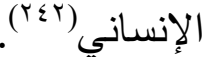

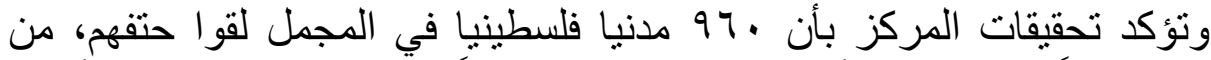

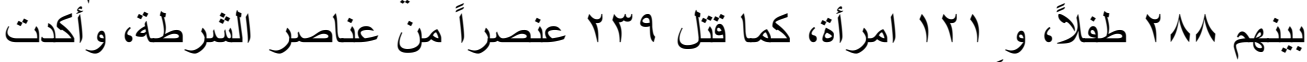

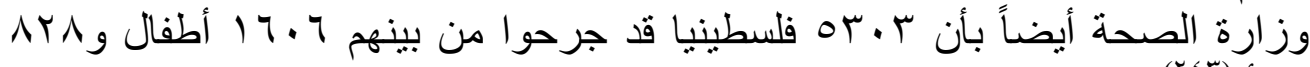

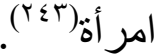

كما جاء في تقرير اللجنة المستقلة لتقصي الحقائق بشأن غزة المكلفة من الجامعة وبنة

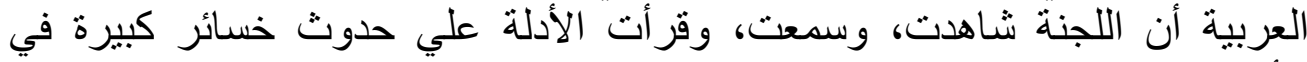

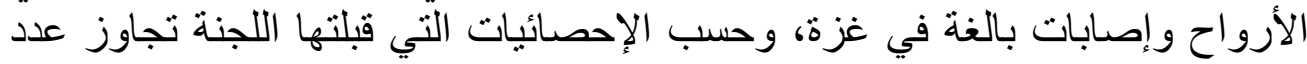

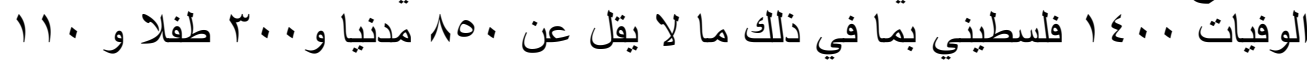

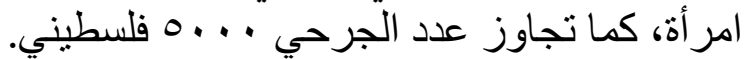

ولم تستطع اللجنة قبول الأرقام التي قدمتها إسر ائيل والتي تزعم أن أن عدد الوفيات

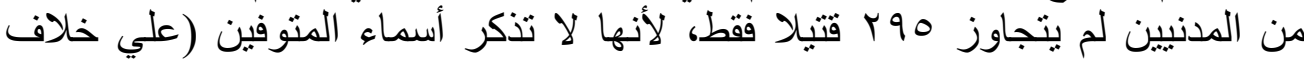
المصادر الفلسطينية).

وعلاوة علي ذلك فإن إسرائيل تحسب رجال الثرطة ضئ الثمن المحاربين، بينما

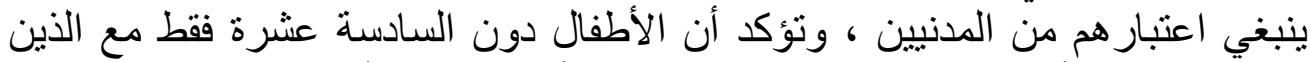

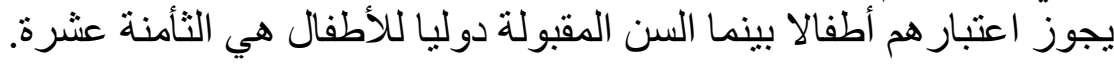

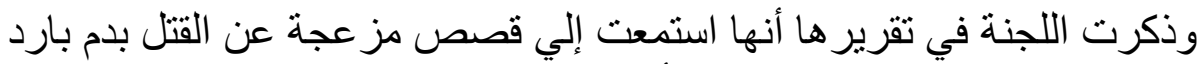

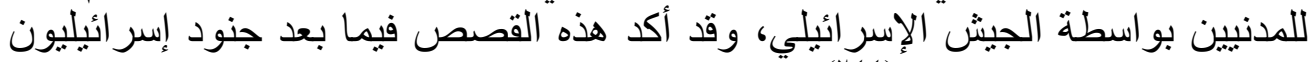

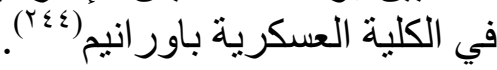

هذه بعض من الجر ائم التي ارتكبها الكيان المحتل بحق أبناء الثعب الفّاء الفلسطيني

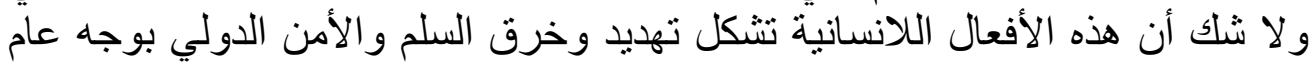
و السلم و الأمن الفلسطيني بوجه الأفي خاص.

و عليه فإن هذه الحروب الإسرائيلية لا تخرج من نطاق الحروب العدوانية، وهي الحي

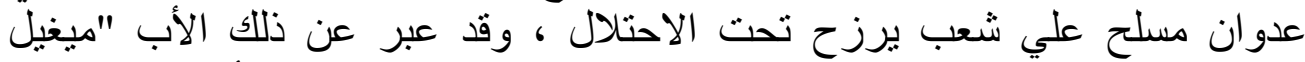
اديسكونو بروكمان "رئيس الدورة الثالثة والستين للجمعية العامة للأمح المتحدة في

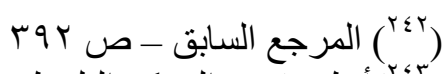

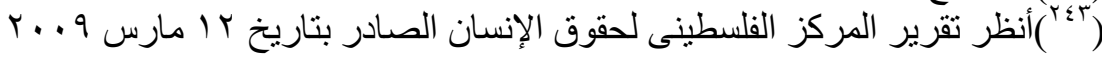

Www.pchrgaza.org

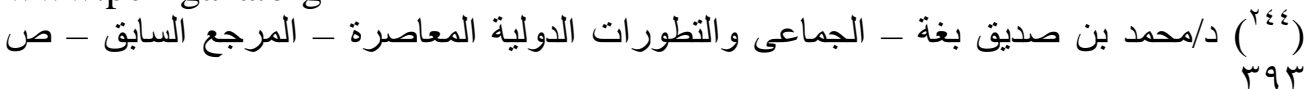




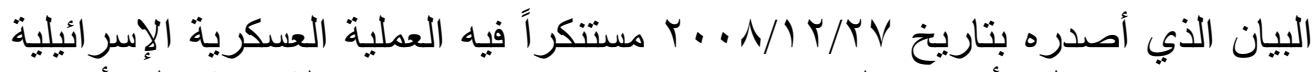

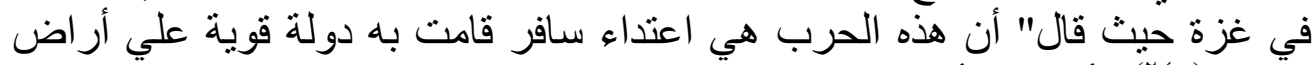

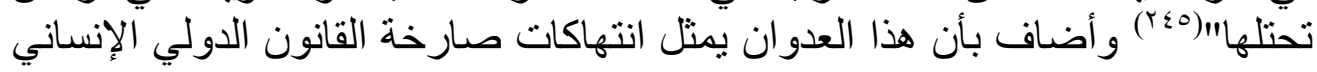

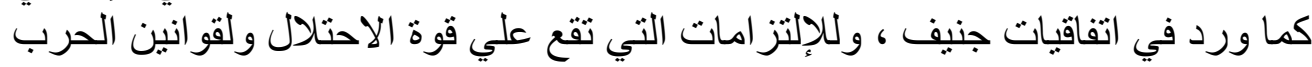

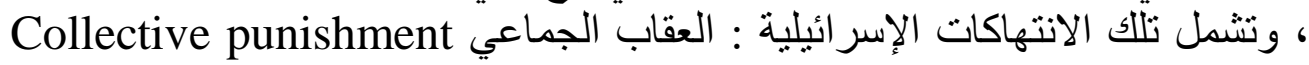
واستهداف المدنيين civilians Targeting والرد الإنهاب العسكري غير المتناسب . ${ }^{(\top \uparrow)}$ Disproportionate military response

ومما يال علي انطباق وصف العدوان علي الحرب الإسرائيلية علي غزة بصفة خاصة

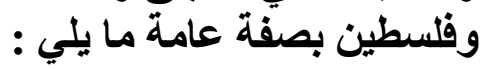

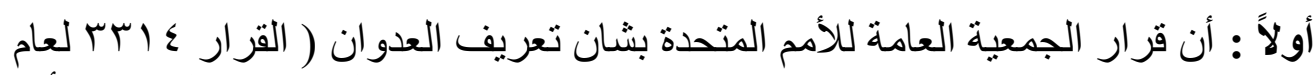

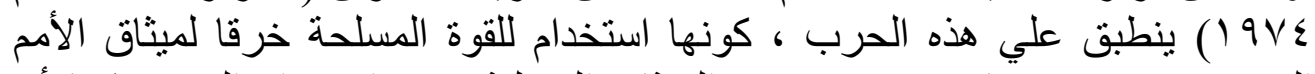

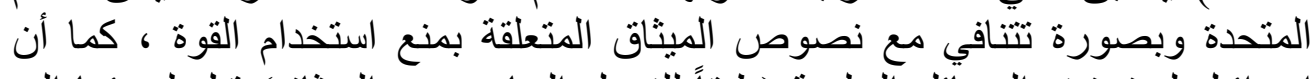

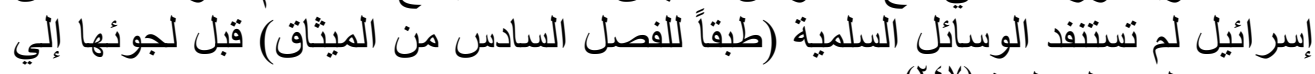

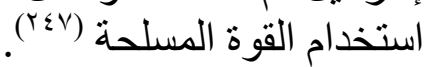

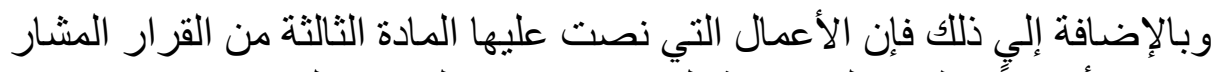

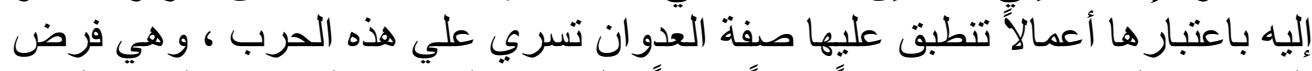

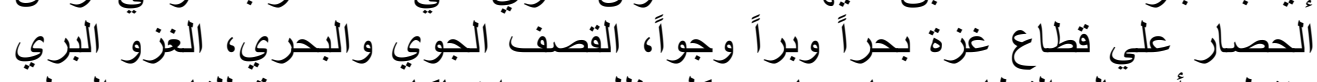

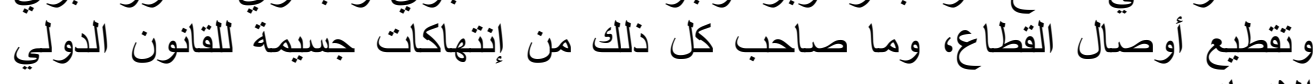
الإنساني.

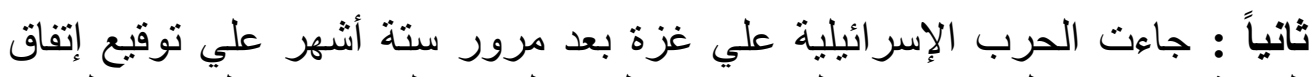

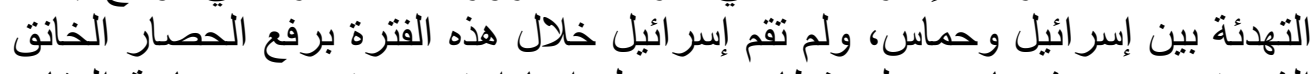

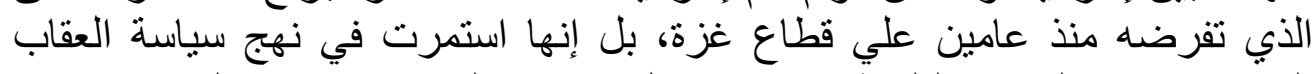

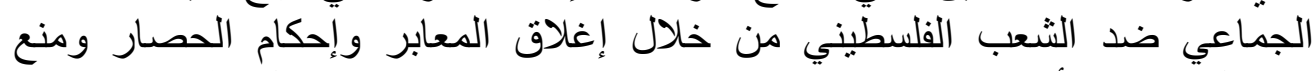

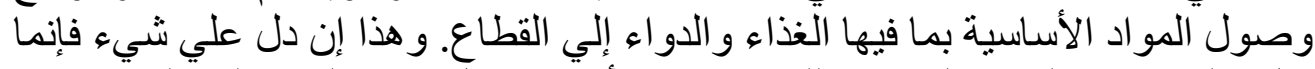

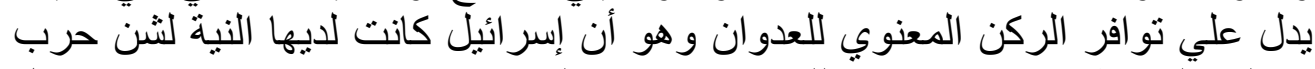

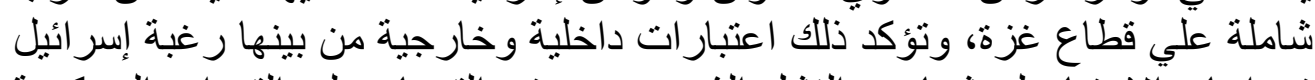

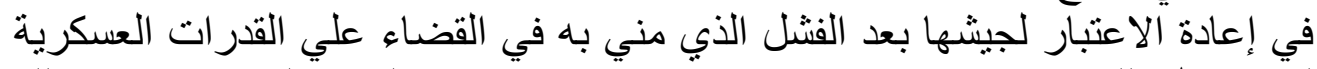

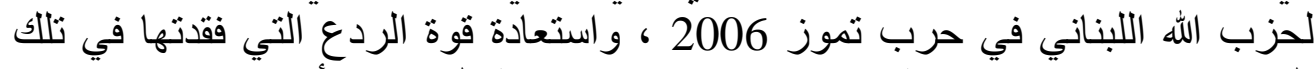

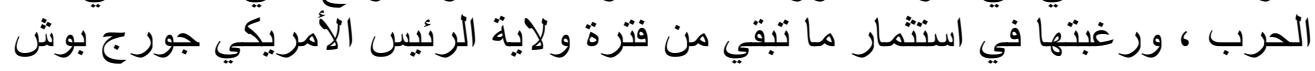

${ }^{245}$ ) (www.un.org/ga/president/63/statements/ongaza271208

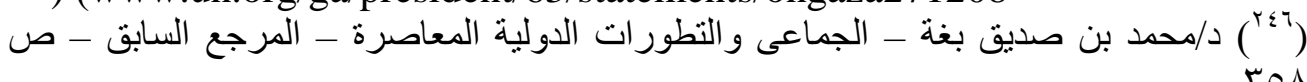

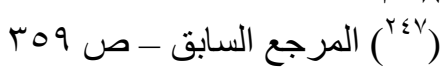




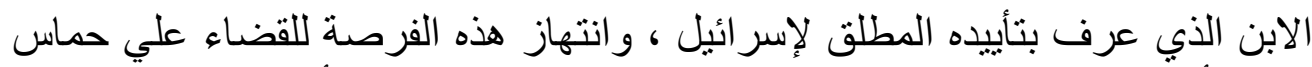

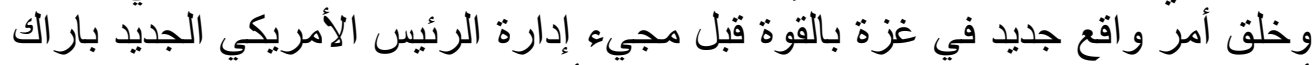

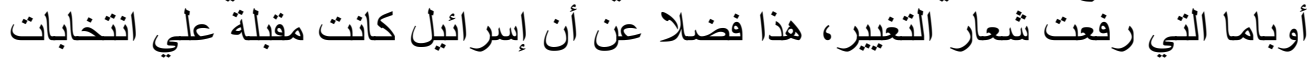

جديدة.

ثالثا : استهداف المدنيين و المنشآت المدنية بشكل مباثر في غزة ، فالحرب الإسر ائيلية

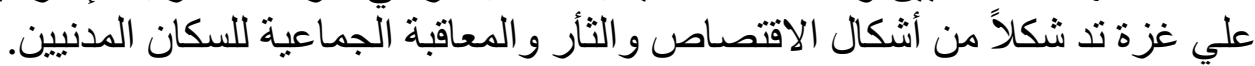

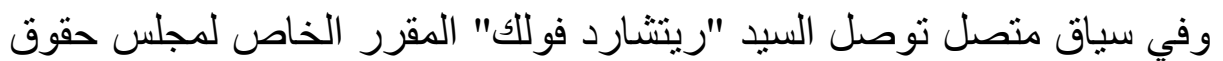

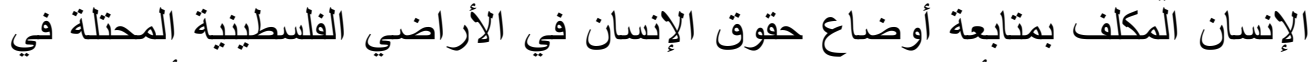

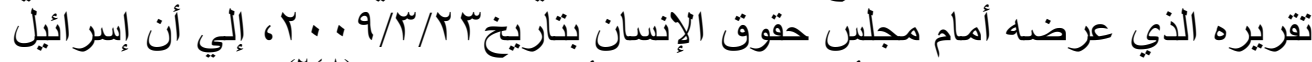

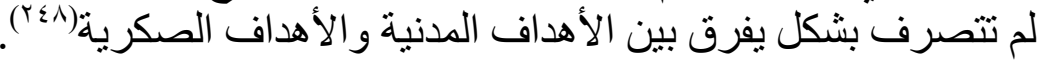

وبناء علي ما سبق يتضح أن الحرب الإسر ائيلية علي غزة بصفة خاصة و الدول

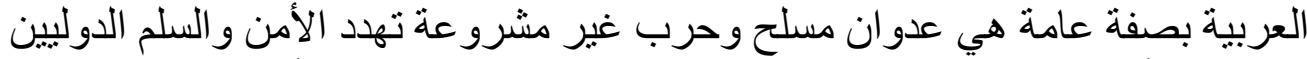

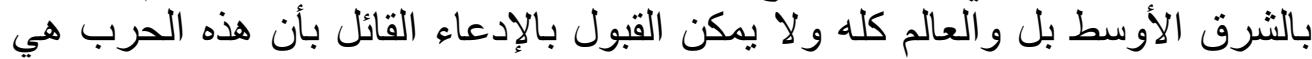

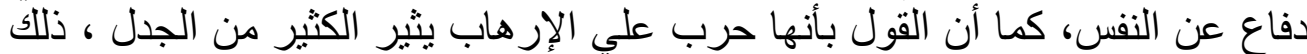

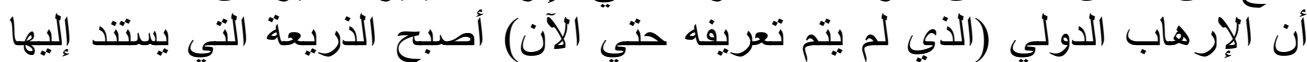

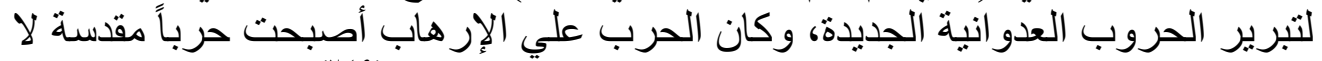

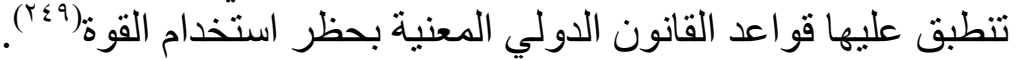

وبذلك فأننا نري إنطباق الثرط الاول وبصورة جلية وهو وجود حالة تهدد السلم وتخل به أو حالة من حالات العدوان وقد توان الفرت هذه العناصر الثثلاث وان كان وان وان واحدا يكفي و علي ذلك فنتنقل الي الثرط الثاني وهو وان وتو عجز مجلس الأمن.

\section{عجز مجلس الأمن الثزن}

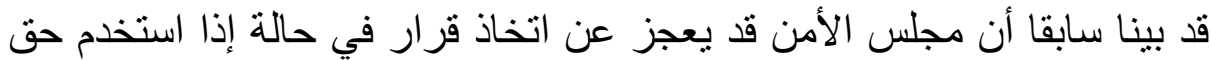

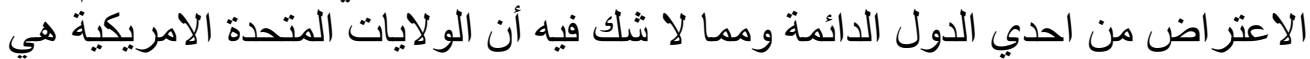

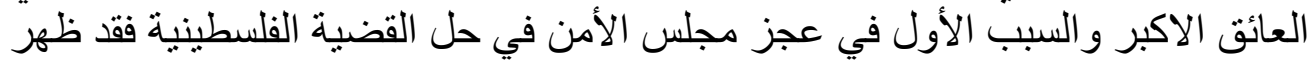

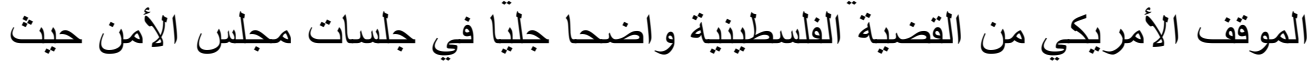

${ }^{248}$ )(www.swissinfo.ch/ara/swissinfo.html

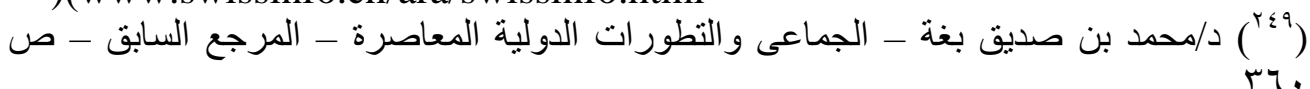




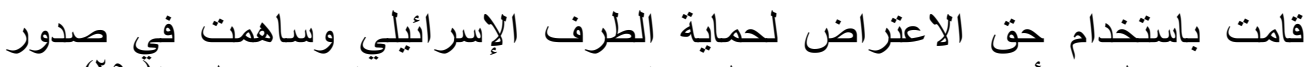

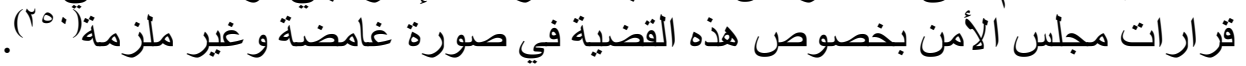
لقد حاول مجلس الأمن أن يصدر العديد من القرار ات لحل القضية الفلسطينية،

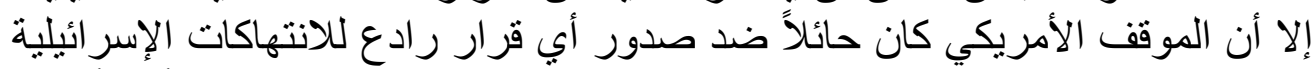

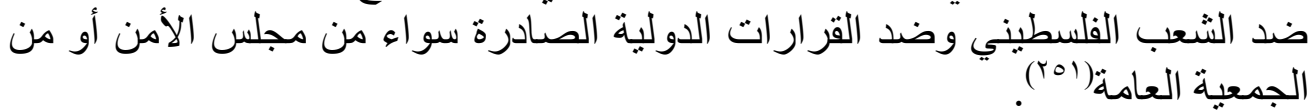

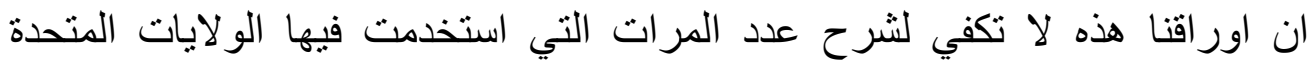

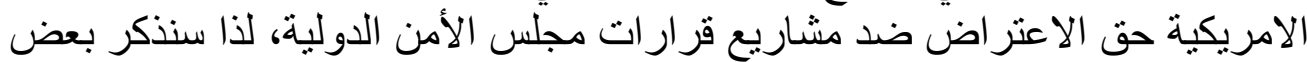
الامثلة بحق الاعتر اض في الاعتر في أزمنه متفاوتة:

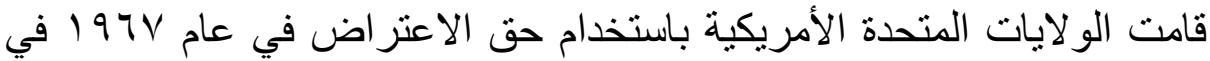

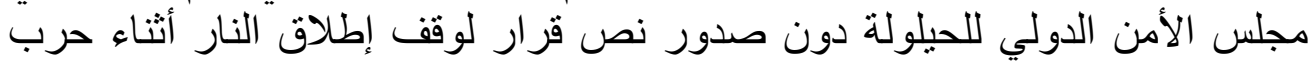

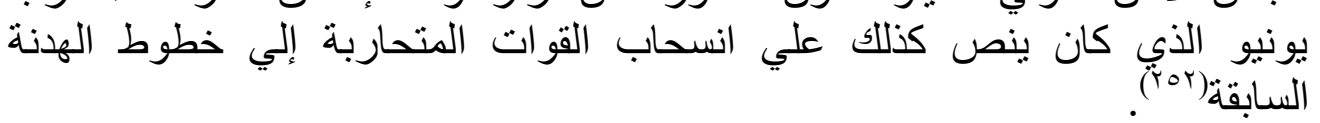

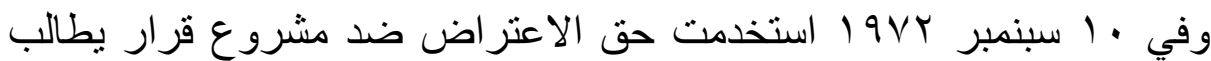

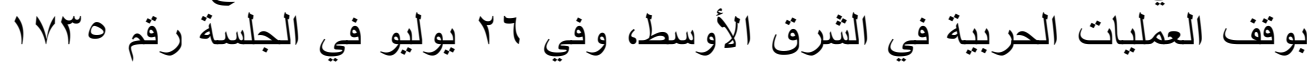

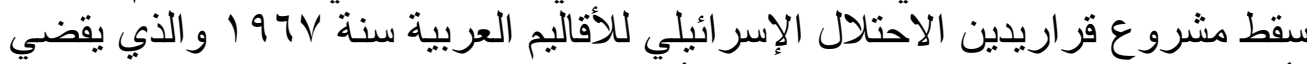

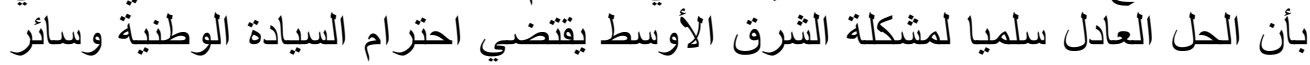

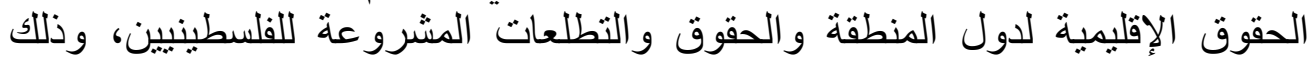

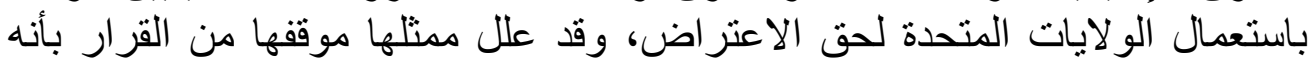

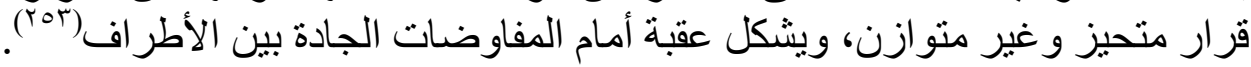

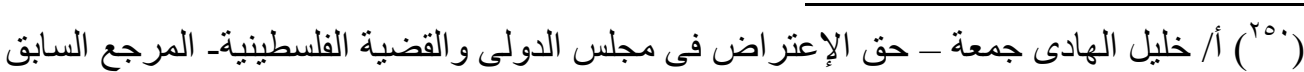

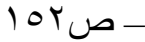
(أب) من الجدير بالذكر أن الولايات المتحدة الأمريكية استخدمت حق الفيتو لصالح اسر ائيل وضد

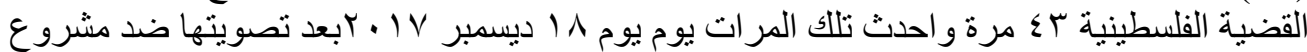

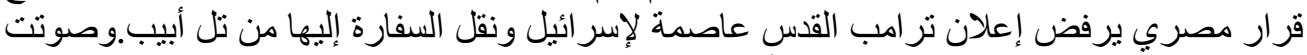

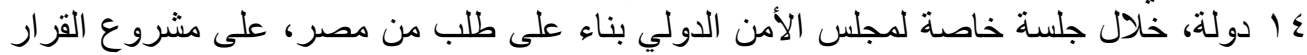

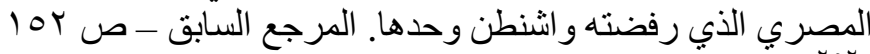

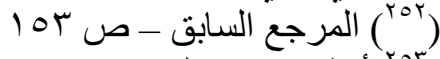

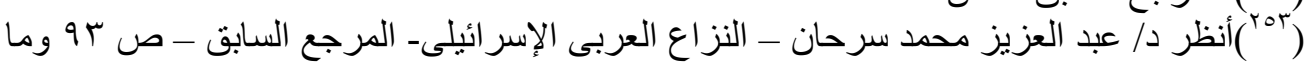




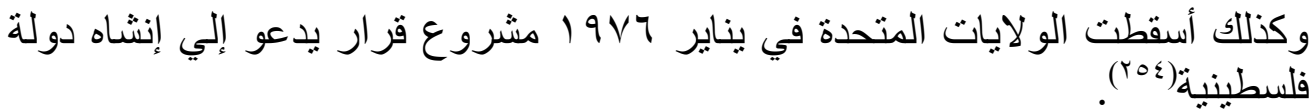

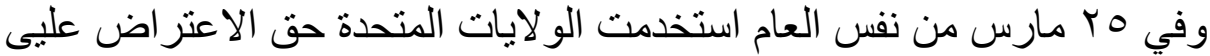

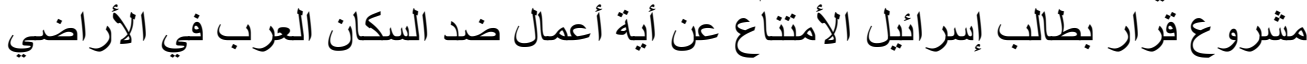

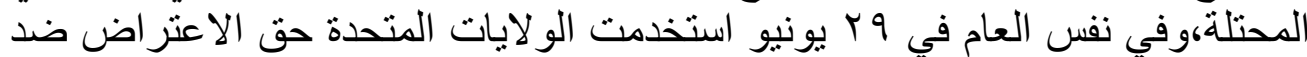

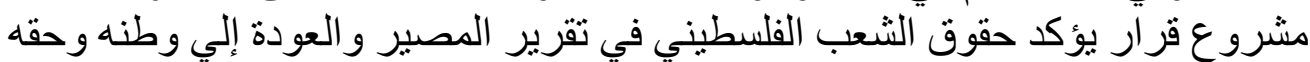

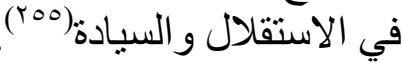

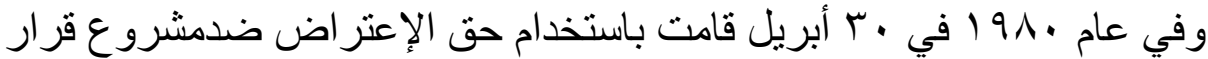

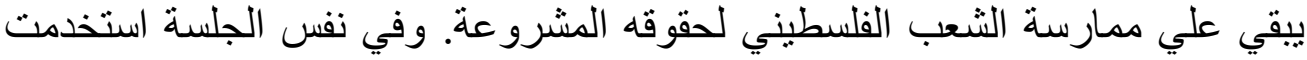

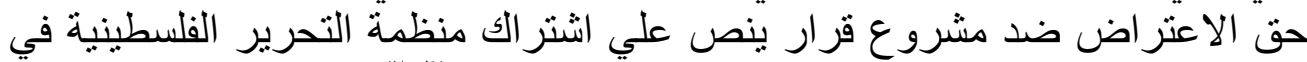

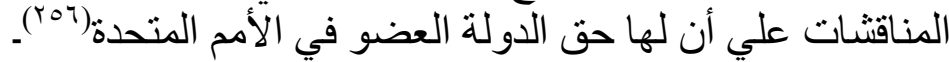

وفي ا فبراير 1919 أوقفت الولايات المتحدة جهود مجلس الأمن الدولي

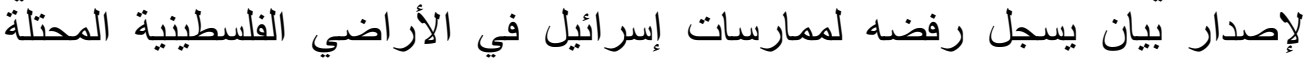

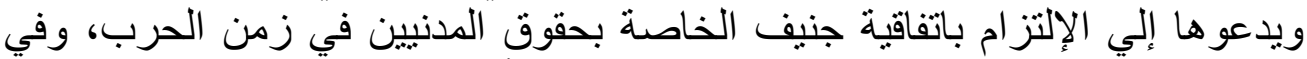

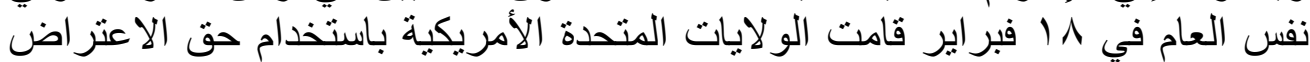
علي إدانة إسر ائيل لانتهاكها حقوق الإنسان في الر اضي الفات الفلسطينية المحتلة

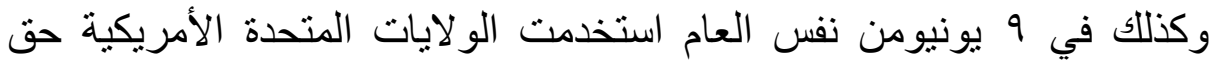

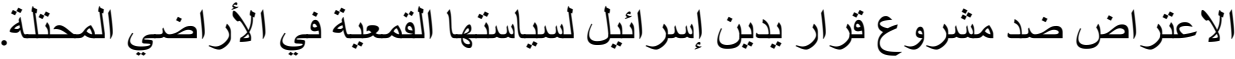

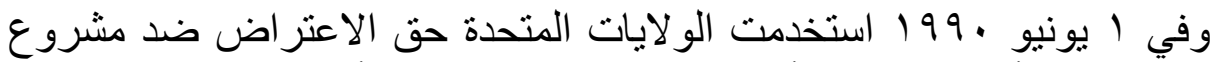

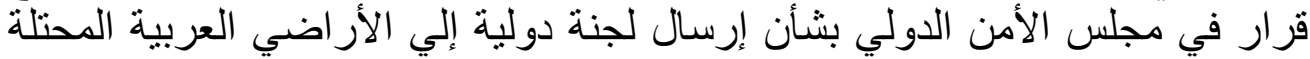

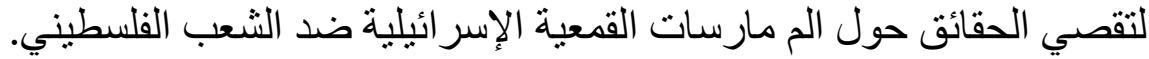

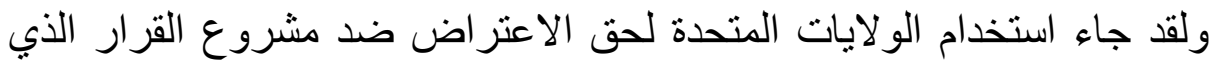

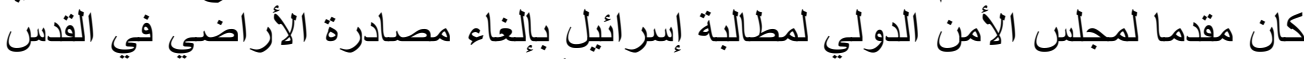

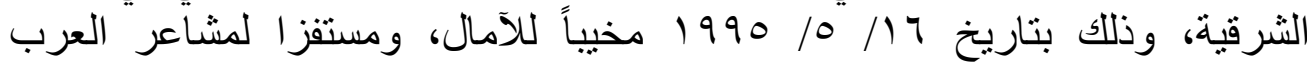

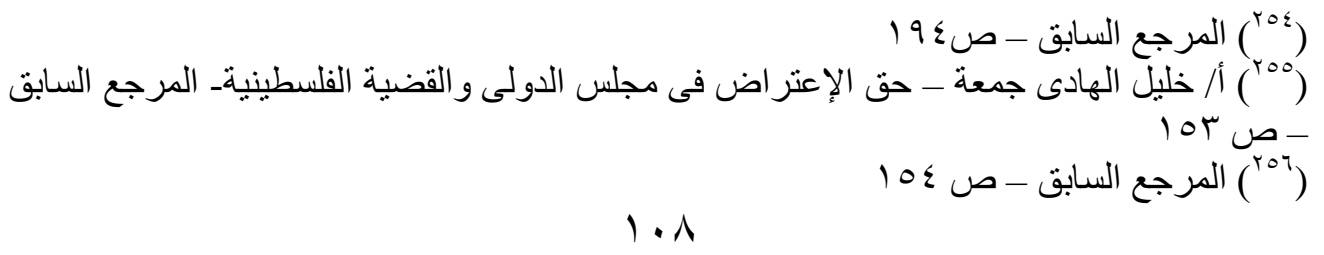


والمسلمين فضلا عن مخالفته الصريحة لإدارة المجتمع الدولي، ومخالفته لأحكام

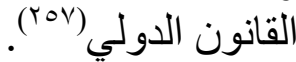

وفي نوفمبر 1997 قامت إسرائيل بحفر أنفاق تحت المسجد الأقصي تمهيدا

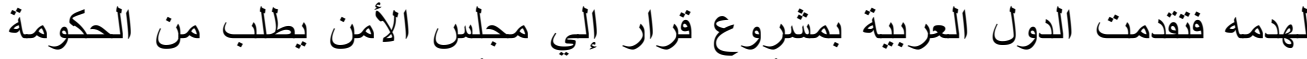

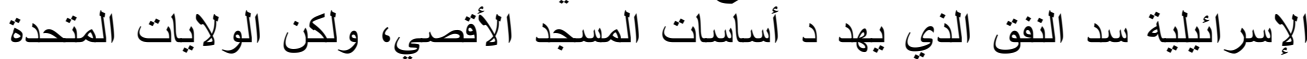
الأمريكية أحبطت المشروع و استخدمت ضده حق الاعتر اضل الأل

وفي 11 مارس 1997 أعلنت إسر ائيل أنها ستقوم بلناء مستعمرة جديدة اسمها

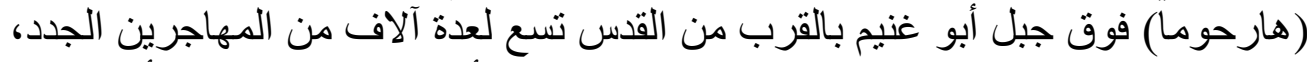

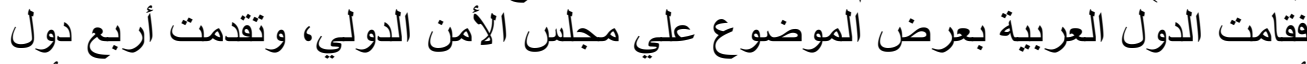

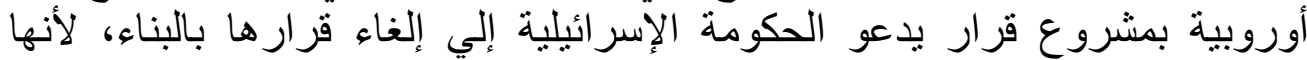

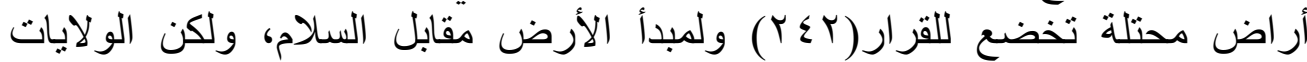

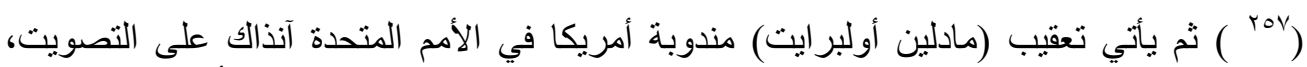

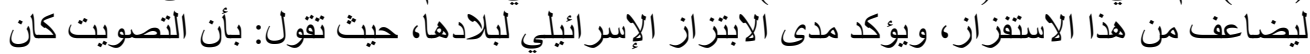

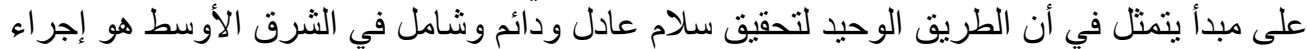

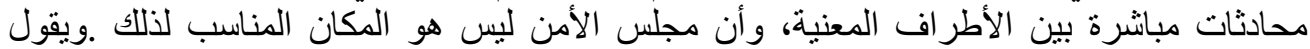

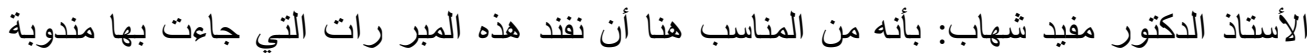

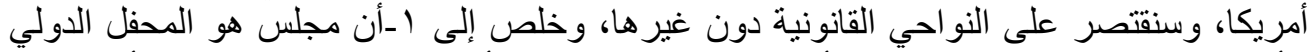

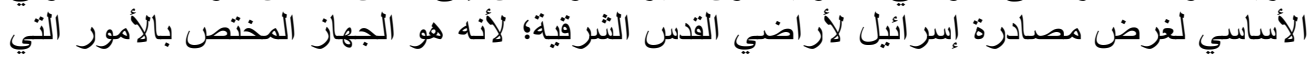

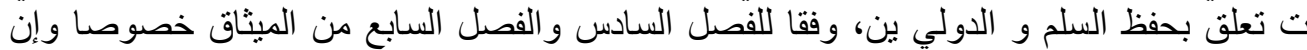

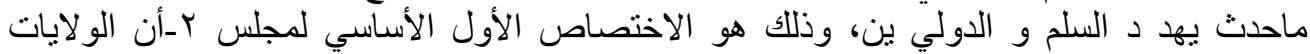

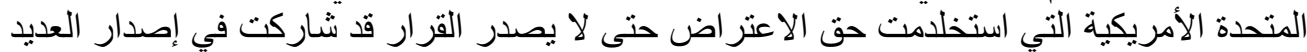

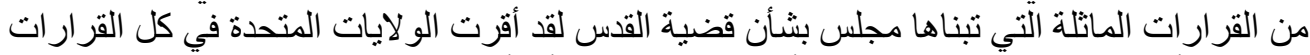

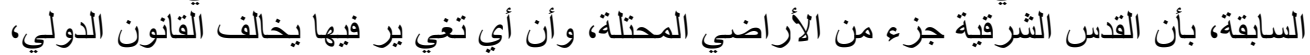

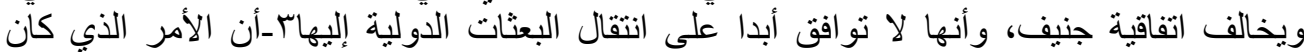

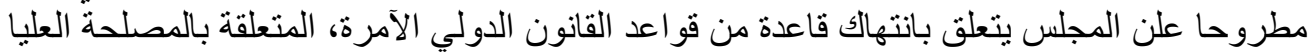

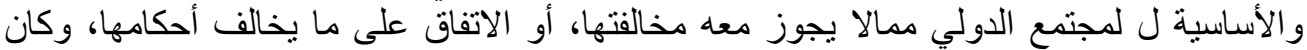

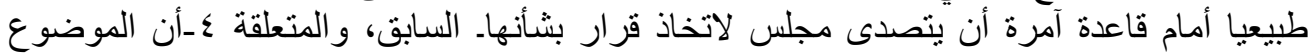

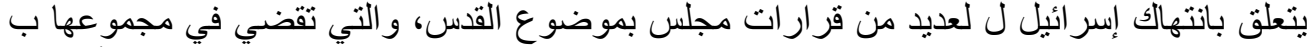

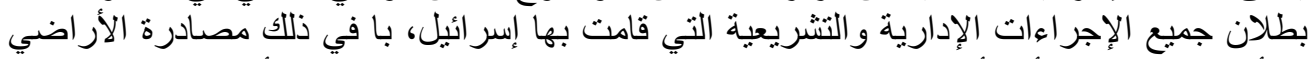

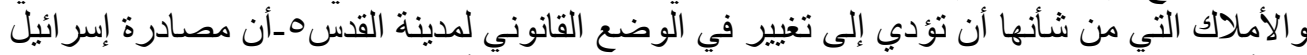

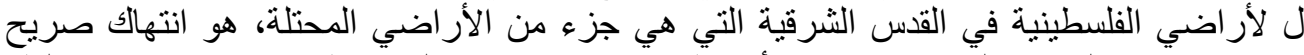

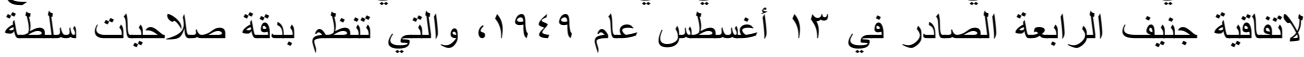

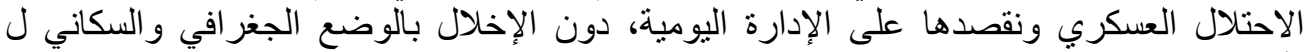


القرار(ros) استخدمت حق الاعتراض ضد المشروع الأوروبي وأحبطت صدور

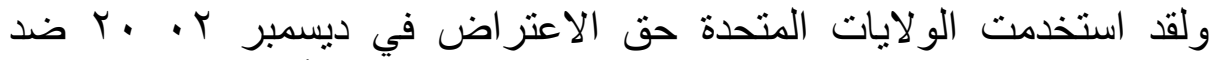

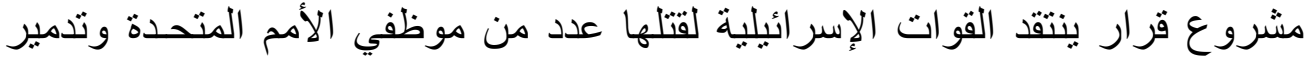
مخزن تابع لبرنامج الغذاء العالمي في الضفة الغئة الغربية.

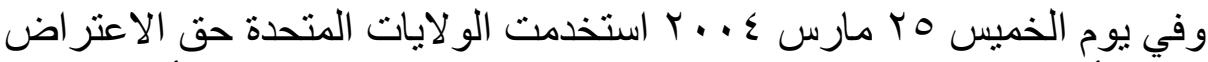

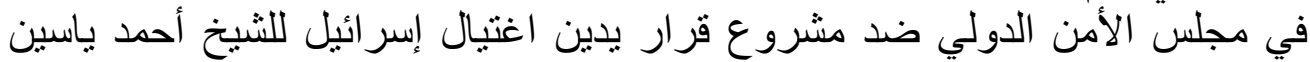

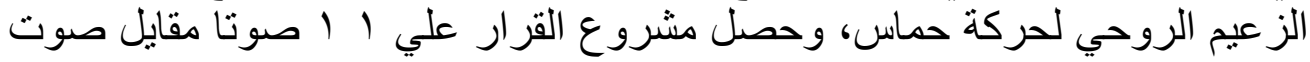

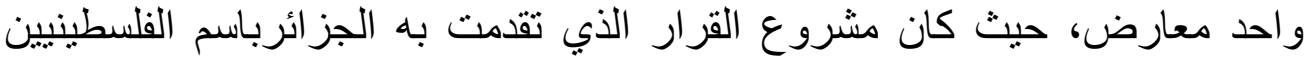

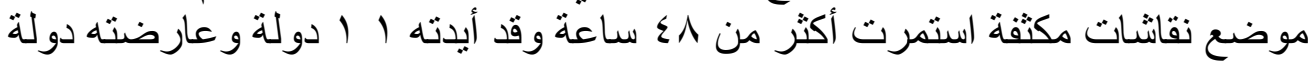

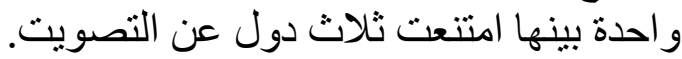

وفي أكتوبر ع . . ب كانت الو لايات المتحدة قد استخدمت حق الاعتر اض للحيلولة

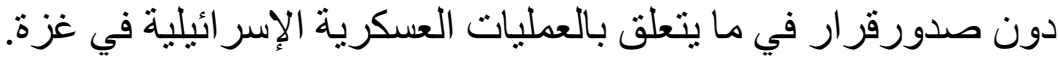

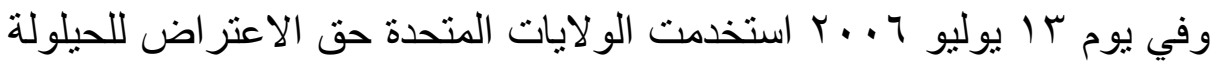

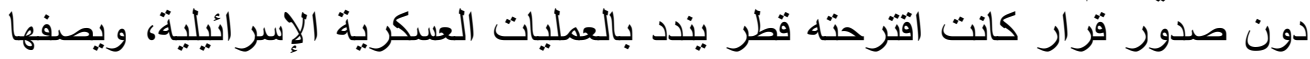

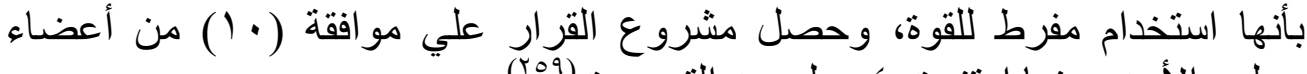

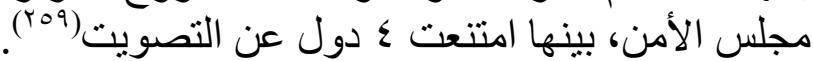

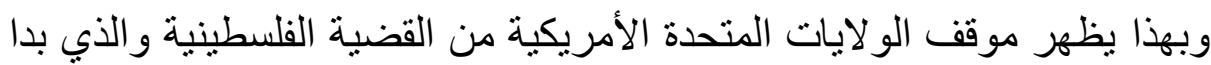

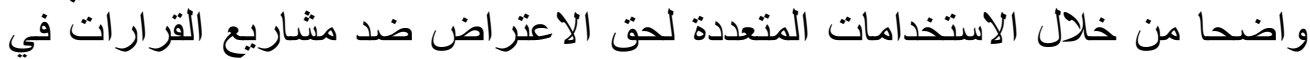
مجلس الأمن لحل هذه القضية.

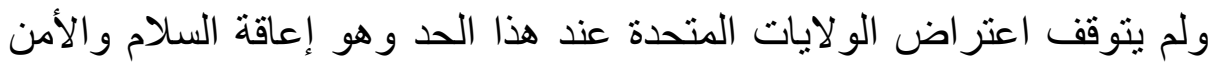

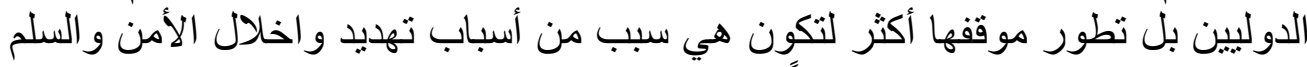

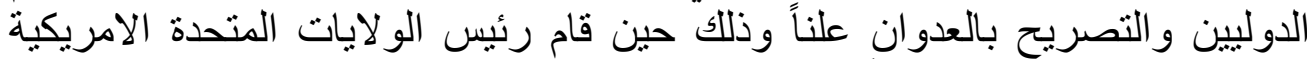

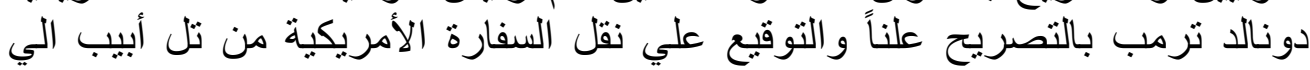
القدس و إعتبار القدس الفلسطينية عاصمة للكيان الإسر ائيلي.

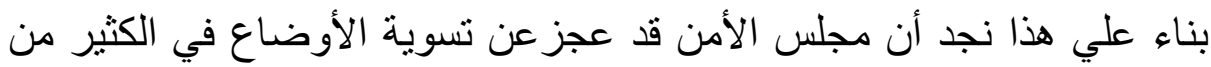

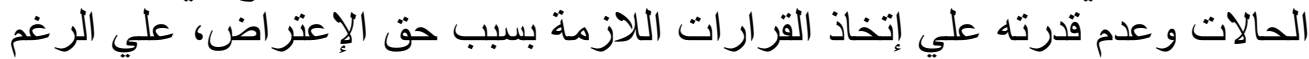

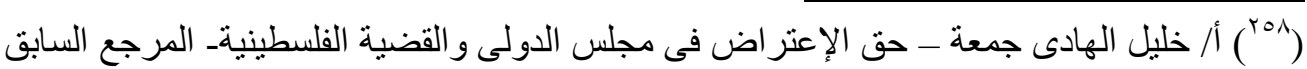
I0人 11. 
من وجود بعض حالات من الإجماع ووجود معارضة واحدة من الولايات المتحدة الأمريكية.

لذا فإننا نري تو افر الثرط الثاني أيضاً من شروط إعمال قرار ا "الإتحاد من أجل

السلام" ولم يتبقي سوي إتخاذ الإجر اءات اللازي النة لتطبيق القرار.

\section{الفرع الثالث: \\ الخطوات الإجرائية التأية}

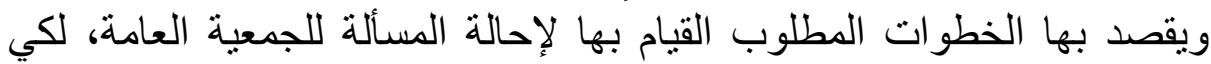

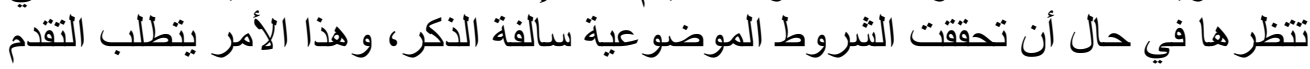
بطلب إلي الجمعية العامة للإنعقاد إذا لم تكن منعقدة (إذا كانت متعقدة فيتم تجاوز هذا لإنا

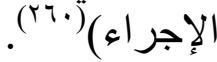

وبناء علي ما تقدم، فان تقديم طلب إنعقاد الجمعية العامة بصورة استثنائية يكون عبر جهتين هما:

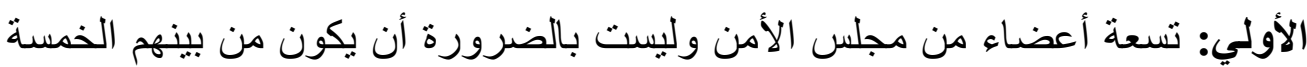
دائمي العضوية (أي لا مجال منال لإجهاض مشروع قرار الإن الإحالة إلي الجمعية العامة

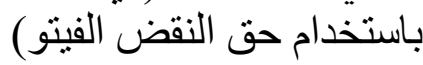

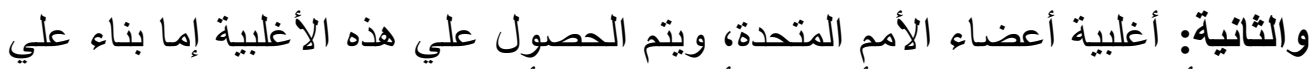

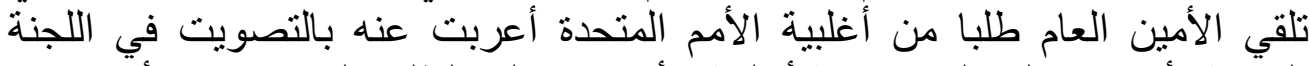

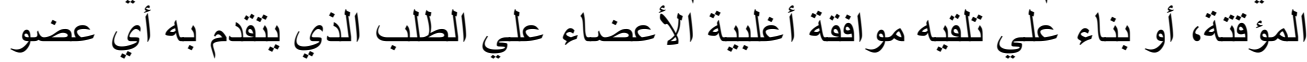

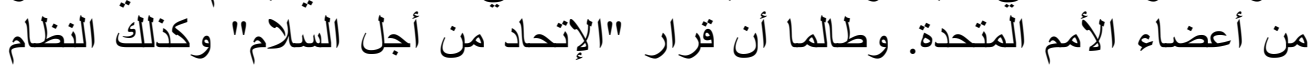

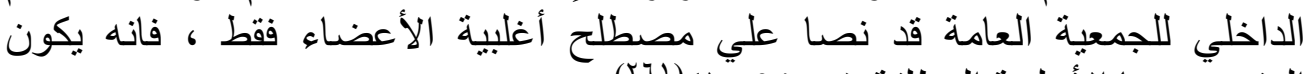

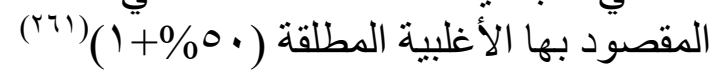

وتأسيساً علي ما سبق فأنه بإمكان الفلسطينيين الاستفادة من الأليتين السابقتين،

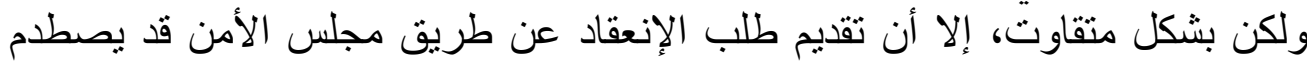

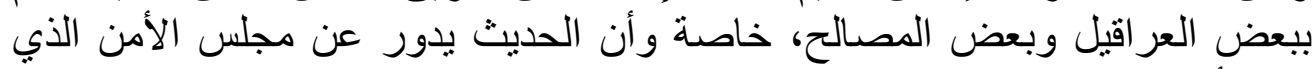

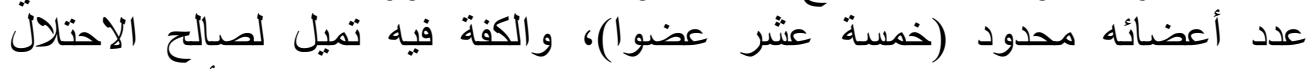
الإسرائيلي غالبا. ومع ذلك فان هذه الآلية تبقي ممكنة، ولكن بدرجة فئة أقلى من الآلية

التانية.

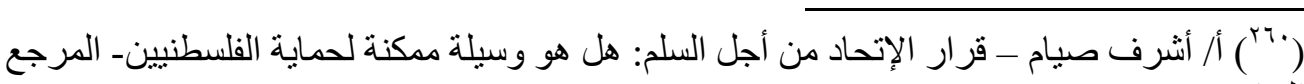

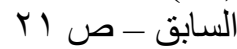
(البأن أ/ أشرف صيام - قرار الإتحاد من أجل السلم: هل هو وسيلة ممكنة لحماية الفلسطنيين- المرجع السابق - ص r r T 
114 


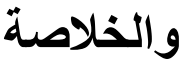

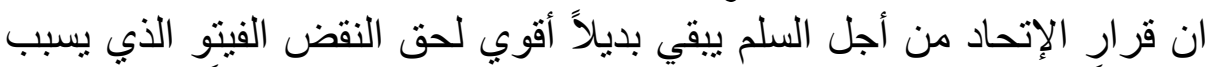

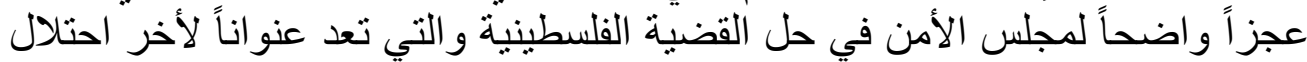

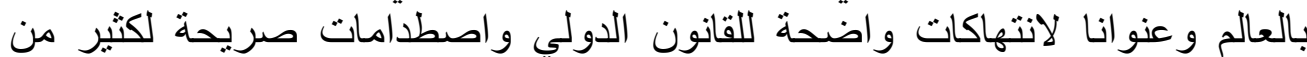

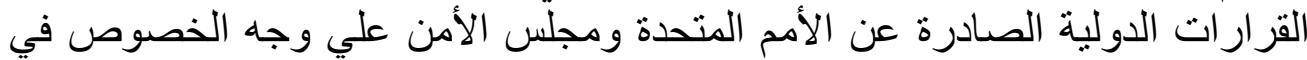

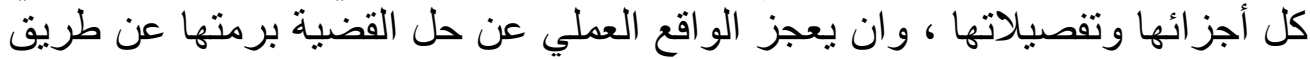

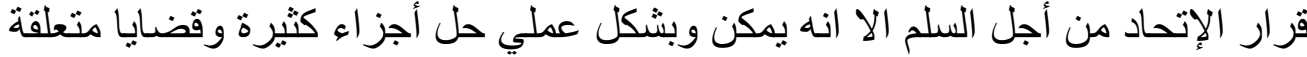

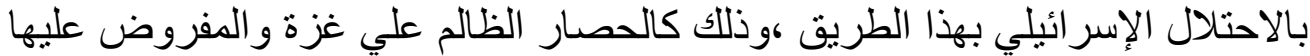

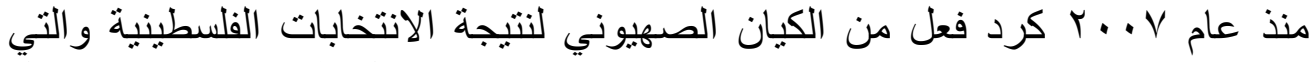

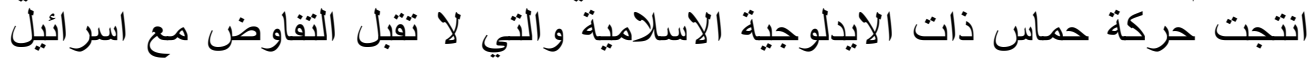

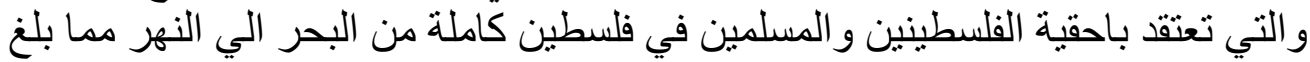

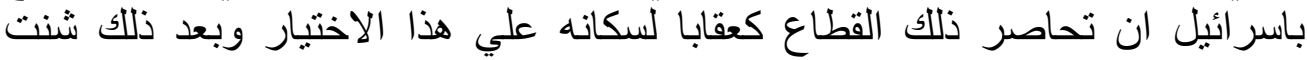

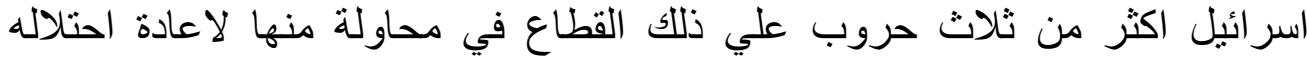

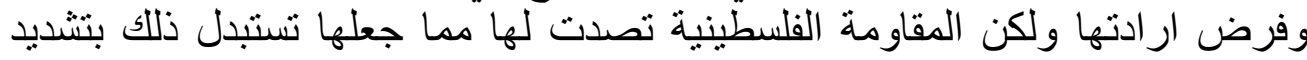

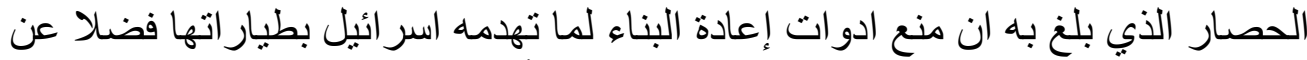

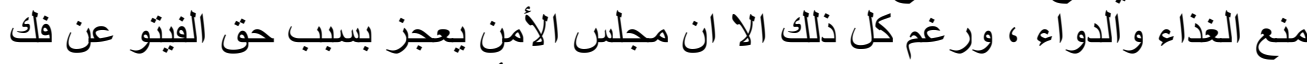

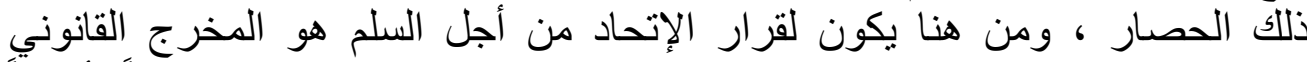

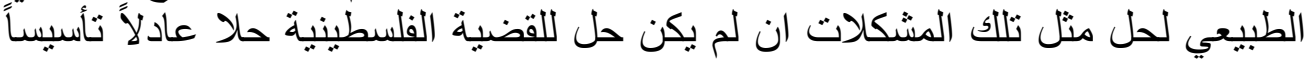

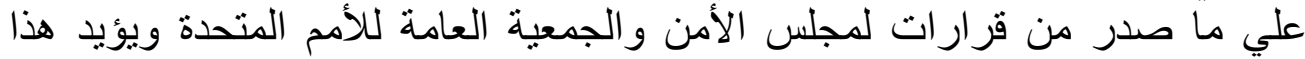

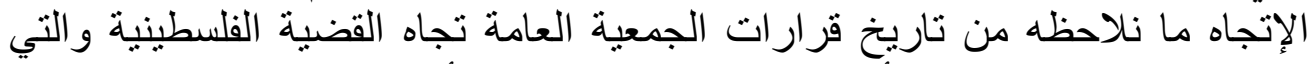

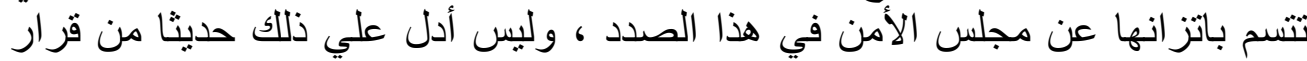

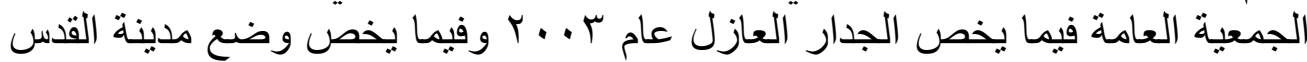

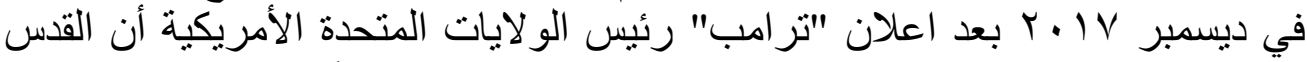

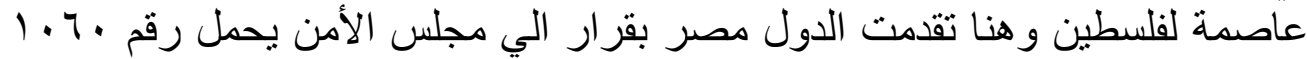

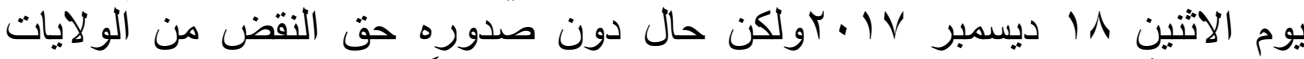

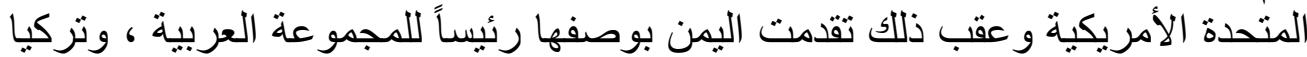

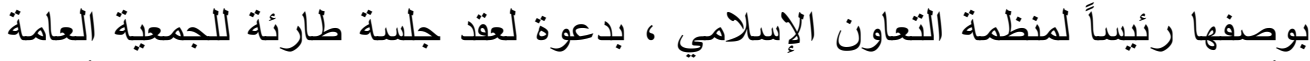

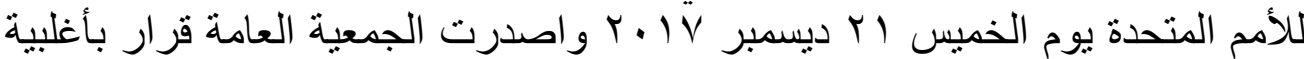

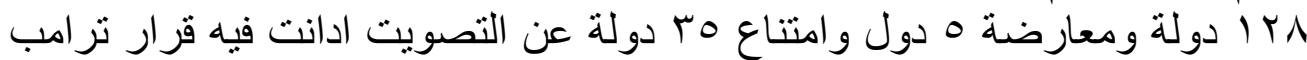

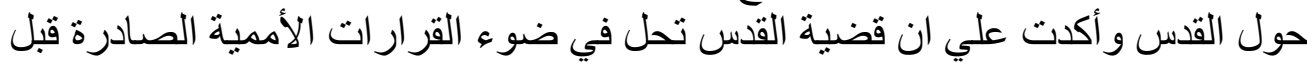

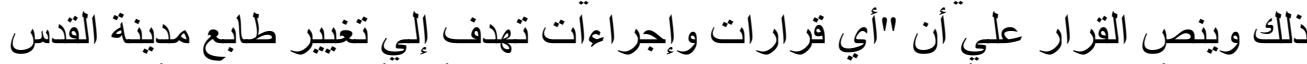

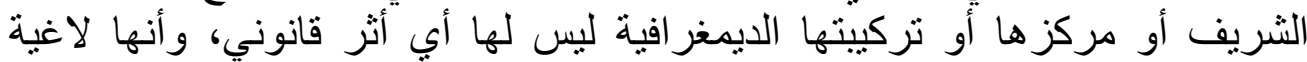

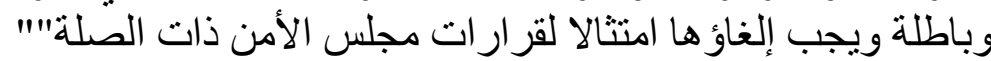

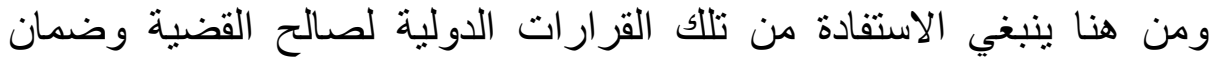

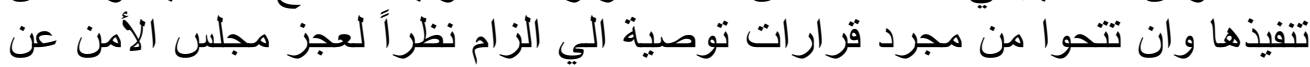


الحل ومن ثم وجب ان يحكم الأصيل في الامر وهو الجمعية العامة طبقاً لقرار الإتحاد

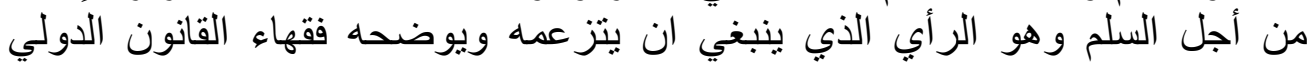

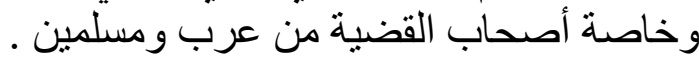

\section{المطلب الثاني}

مدي توافر شروط تطبيق قرار الإتحاد من أجل السلم في النزاع السوري

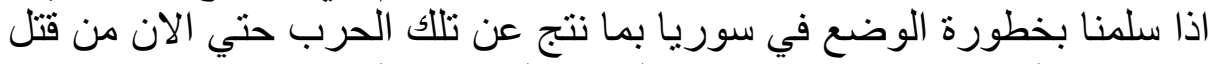

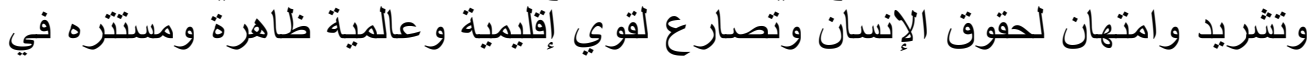

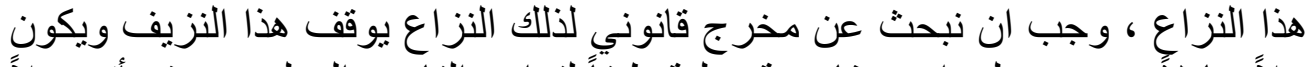

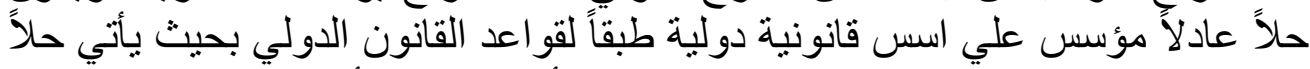

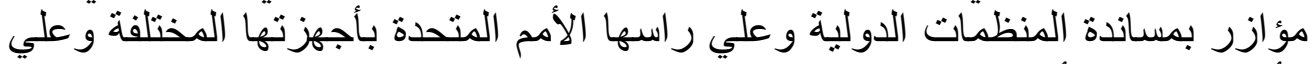

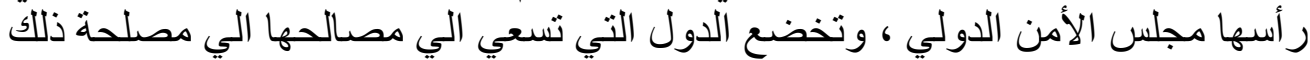

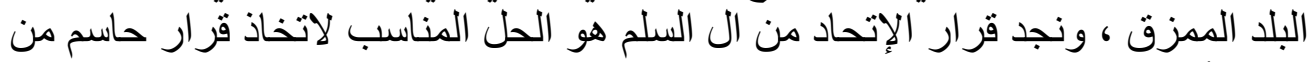

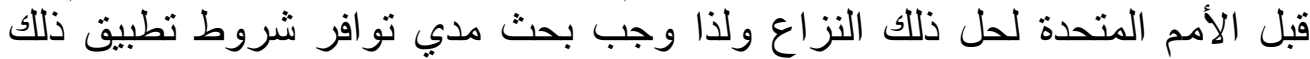
القرار في هذ ا النزاع علي النحو التالي :-

\section{أولا: وجود حالة تهدد السلم أو تخل به أو عمل من أعمال العدوان}

المتتبع لحاله النزاع السوري من الناحية القانونية يستنتج وبلا أدني تعمق في

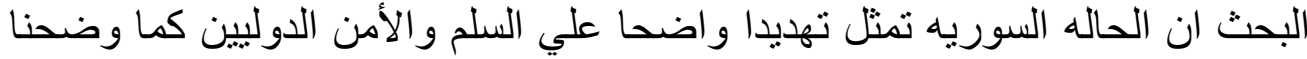

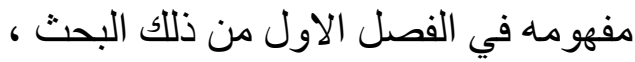

ومع اتفاقنا مع جانب من الفقه الذي ذهب الي ان الأمم المتحدة لم تضع في

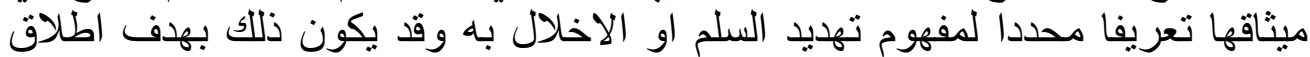

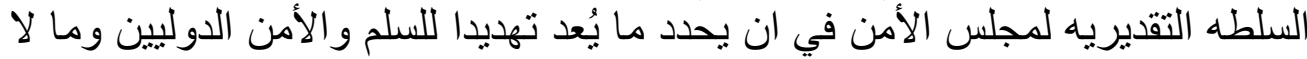

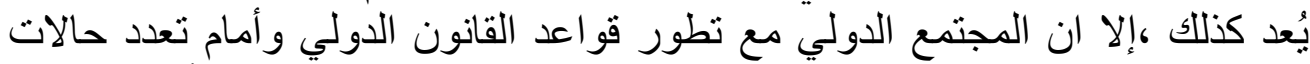

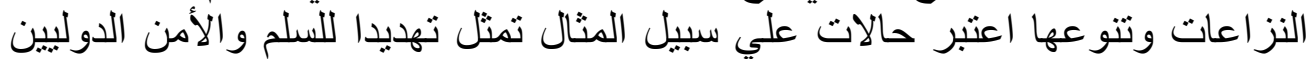
وتوسع في ذللك المفهوم

وبتطبيق مثل تلك الحالات و أراء مجلس الأمن الدولي في تعريفه و في نظرته

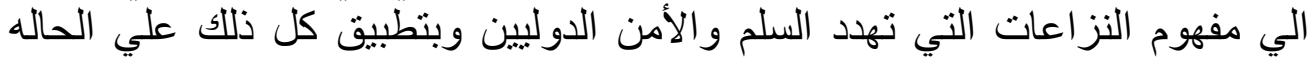

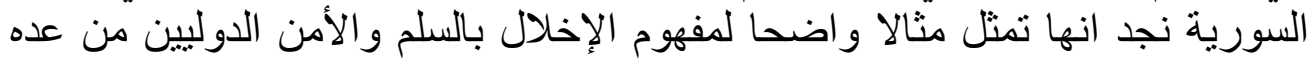
وجوهوذللك علي النحو التالي

\section{الوجه الأول: اتساع الحرب الأهلية وأخذها طابعاً تنظيمياً}

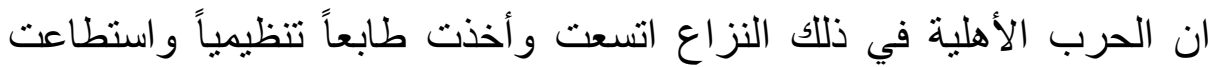

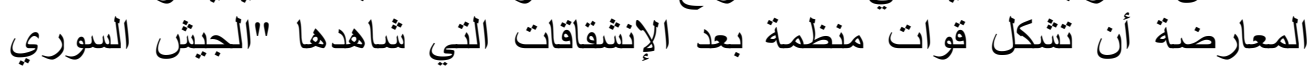


النظامي" ليتكون الجيش السوري الحر وكذلك وجدت مجمو عة كثيرة منظمة تقتل ضد فيد

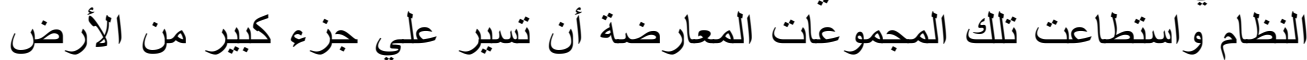

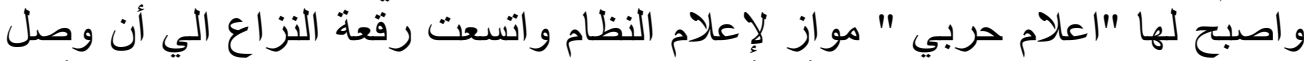

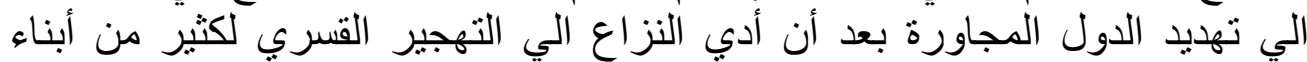

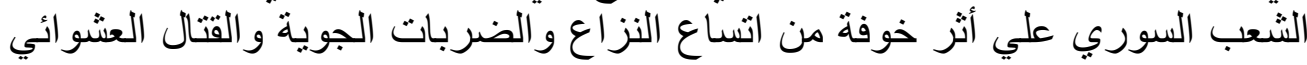
الذي طال مناطق عديدة اضطر اهلها الي اللجوء الئي الدولي الدول المجاورة

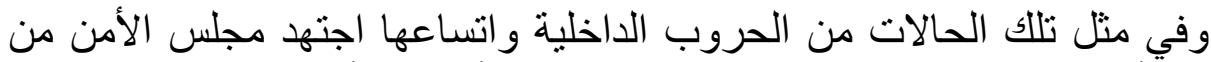

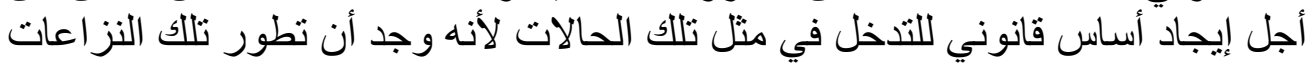
و اتساعها يؤدي بلا شك الي التأثير علي أمن الدول المجاورة للاني

ومن مثل تللك الحالات اعتبار مجلس الأمن ما حدث في "روديسيا" - زيمباوي

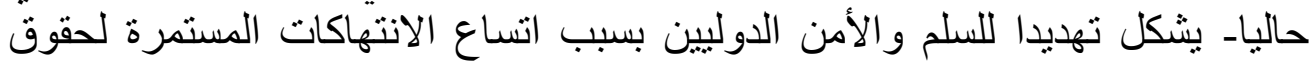
الانسان ابان نز اعها الداخلي عام

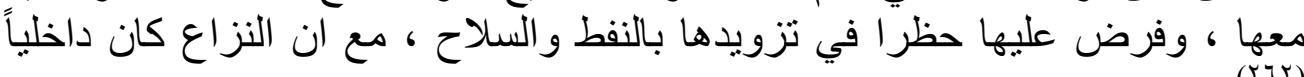

\section{الوجه الثاني : تخل قوات دولية وإقليمية في التزاع بطريقة مباشرة}

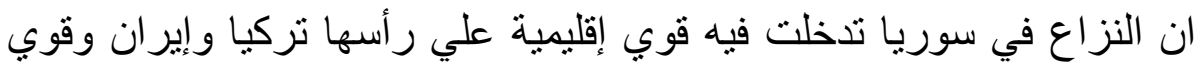
دولية علي رأسها الو لايات المتحدة الأمريكية وروسيا وتلك القوي المي المتعددة المصالح

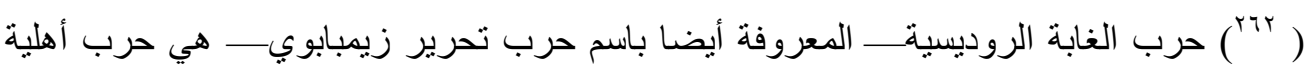

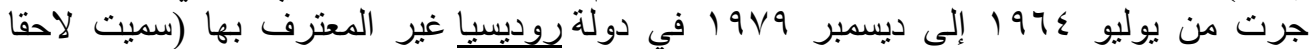

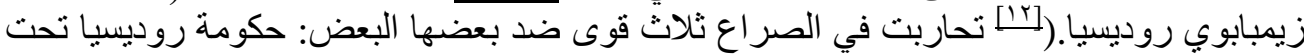

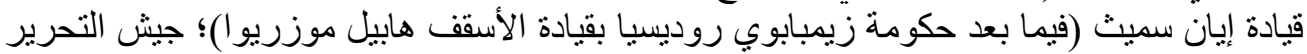

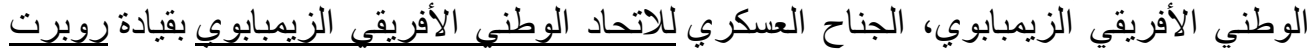

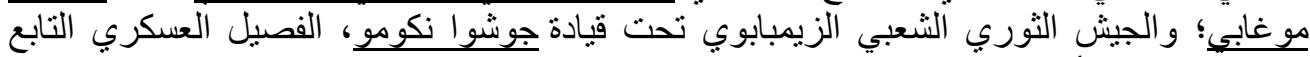

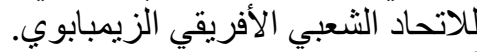

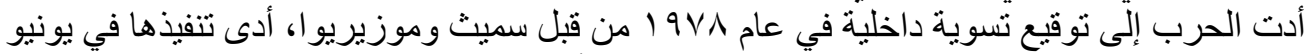

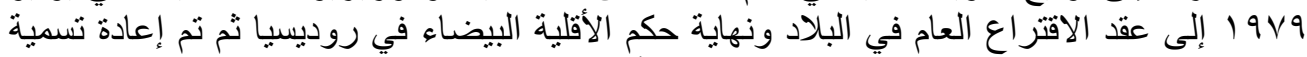

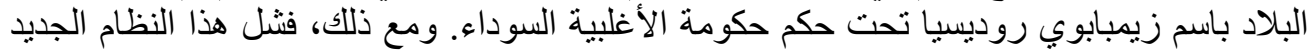

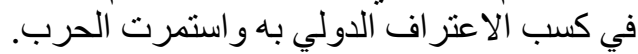

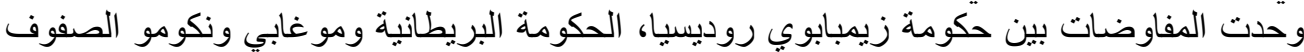

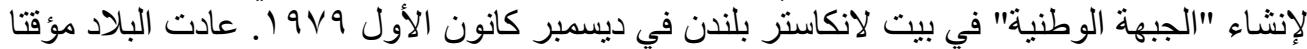

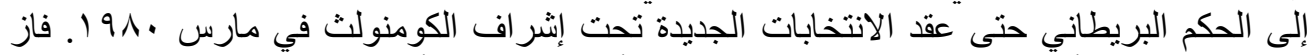

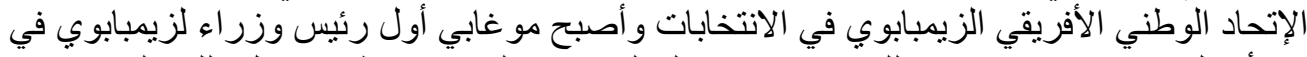

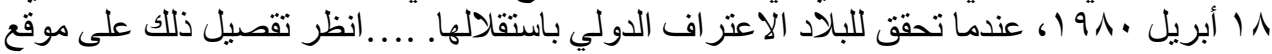
https://ar.wikipedia.org/wiki/\%D8 


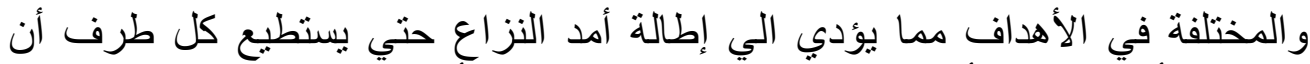

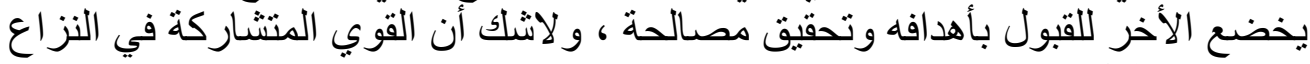

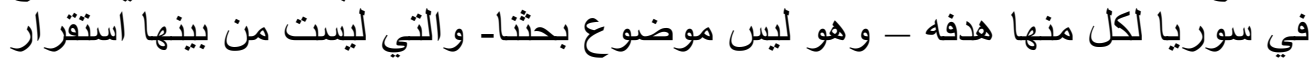

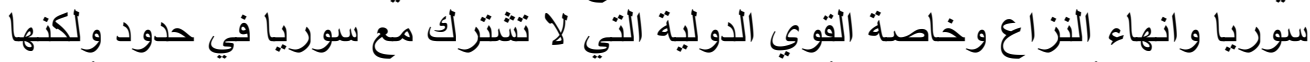

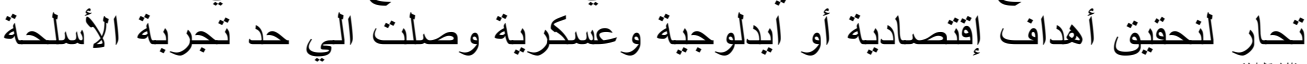

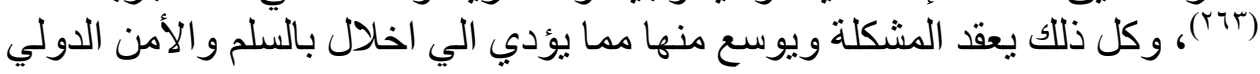

\section{الوجه الثالث: عدم امتثال اطراف النزاع لتنفيذ القرارات الدولية}

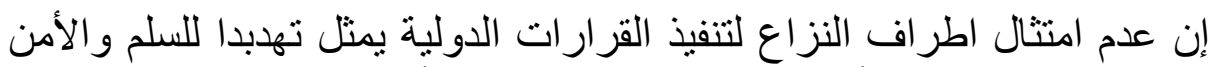

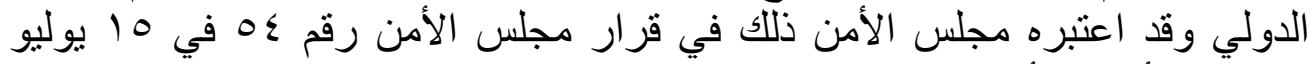

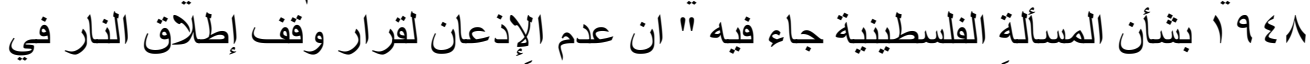

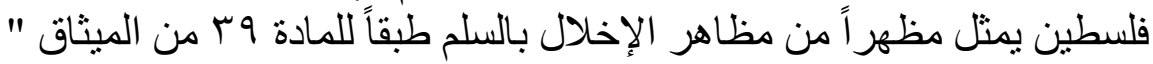

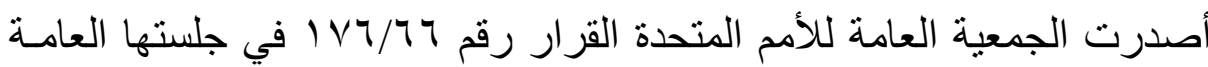

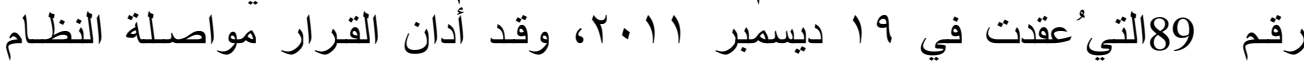

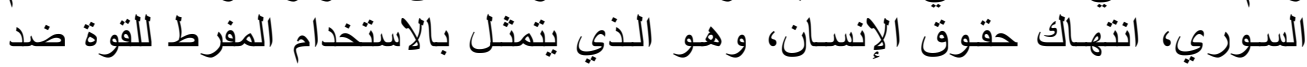

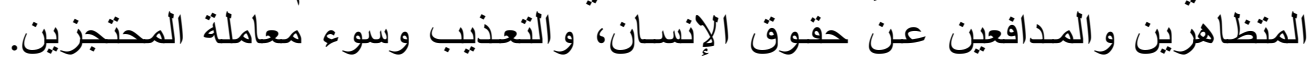

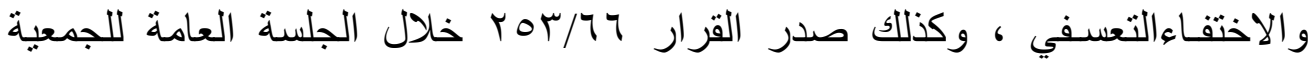

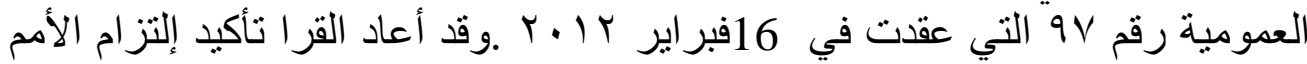

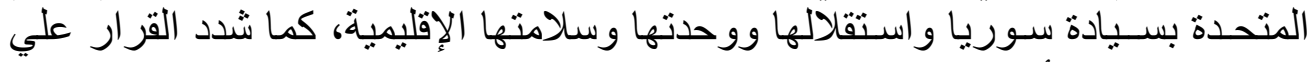

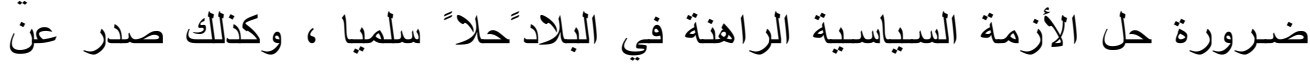

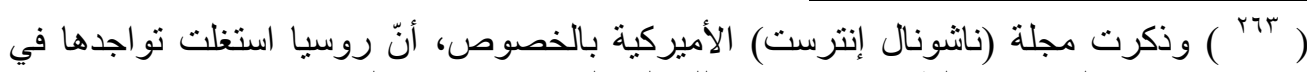

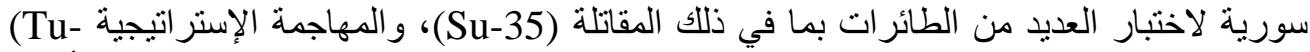

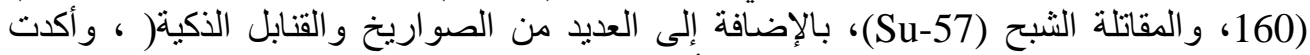

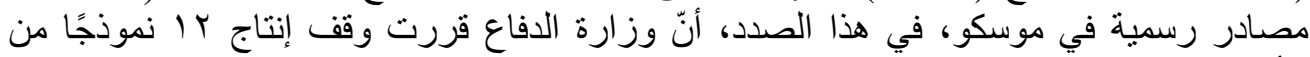

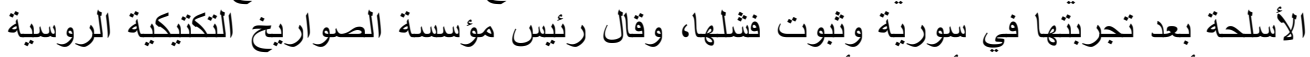

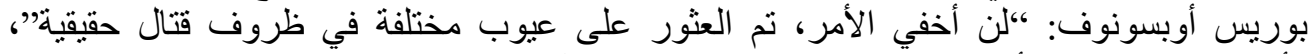

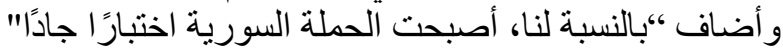

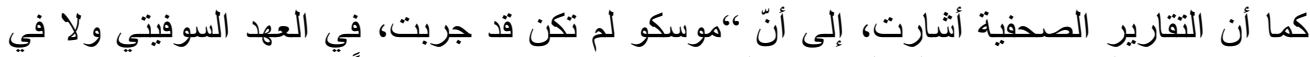

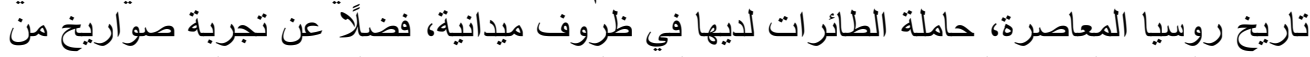

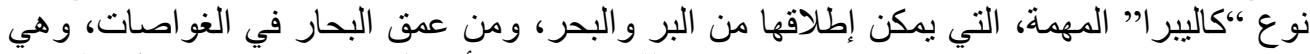

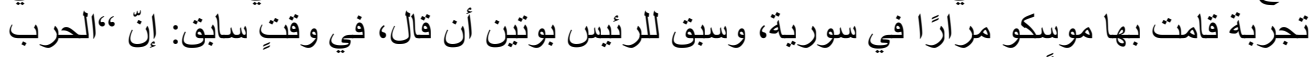

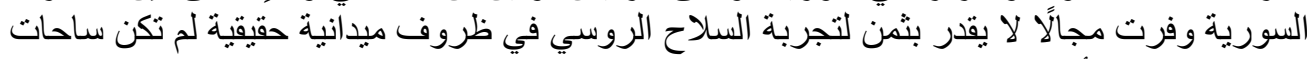

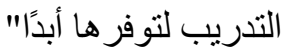

https://www.hespress.com/international/417615.html https://www.souriyati.com/ 


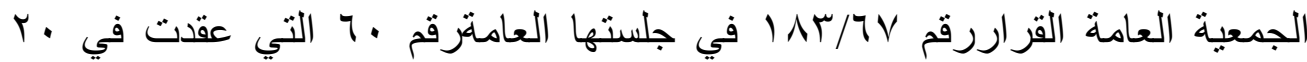

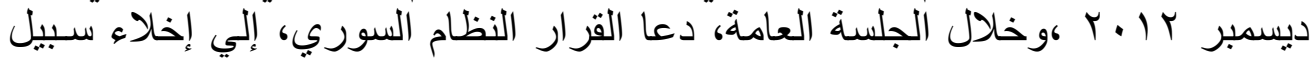

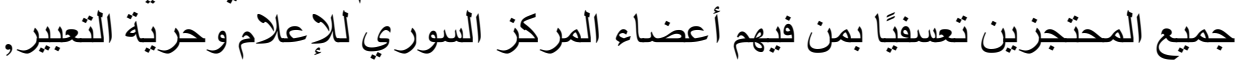

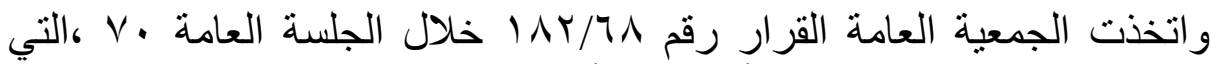

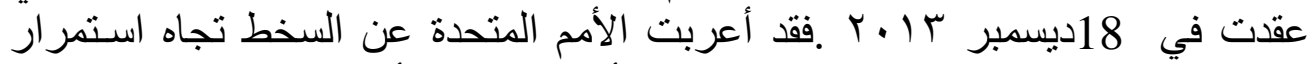

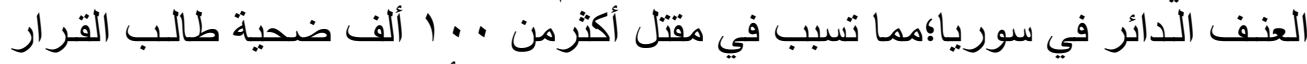

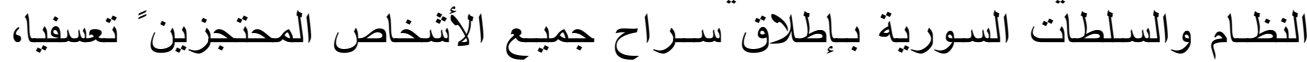

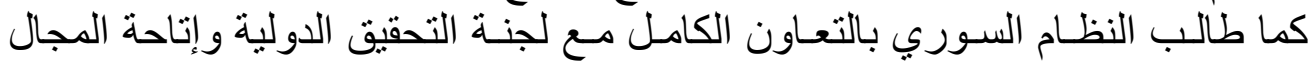

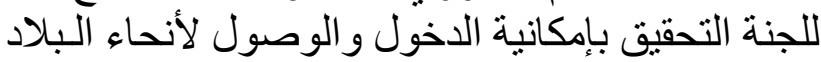

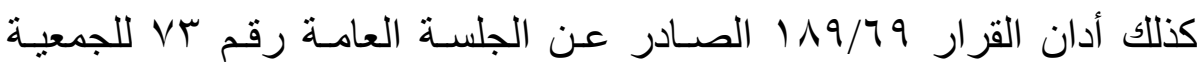

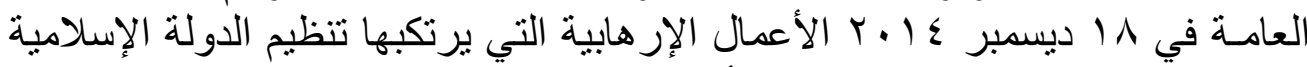

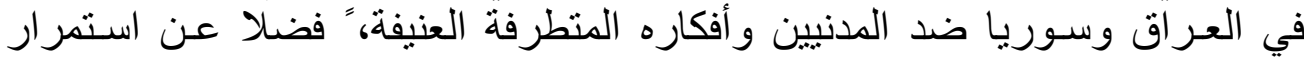
التجـاوز ات في مجـال حقوق الإنسان و الانتهاكات للقانون الدولي الإني الإنسان

وكذلك صدرت قرار ات عديدة عن مجلس الأمن بخصوص حل المشكلة السورية

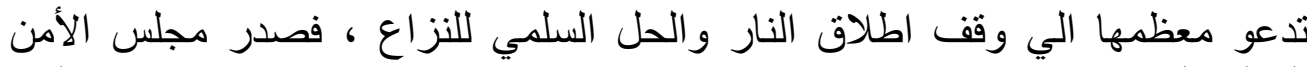

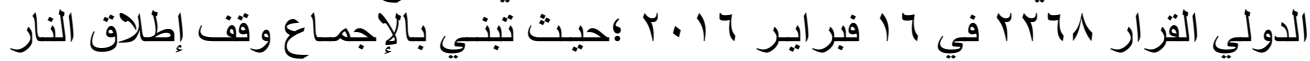

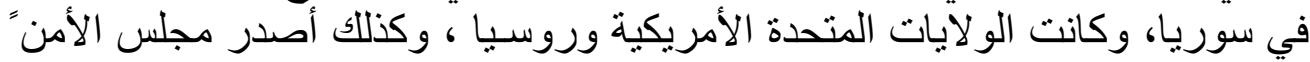

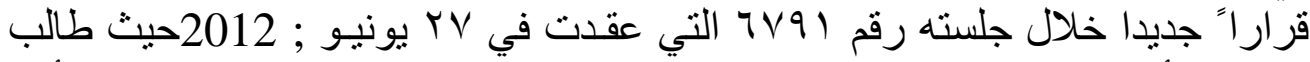

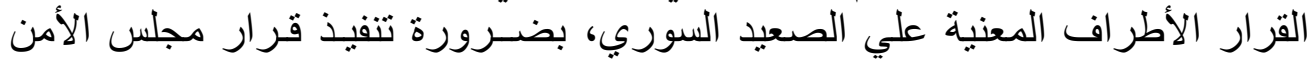

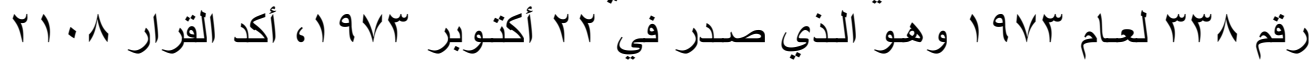

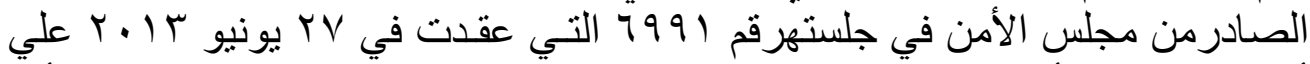

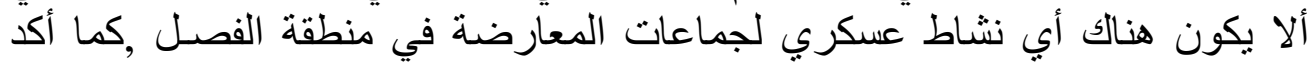

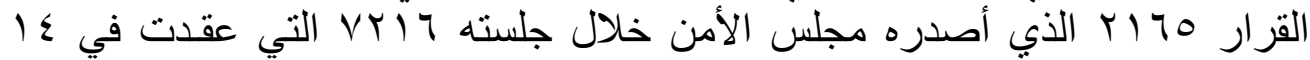

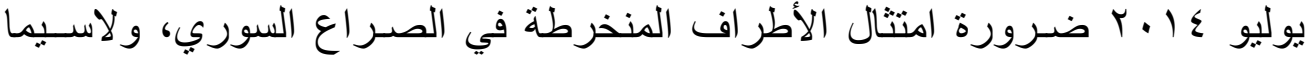

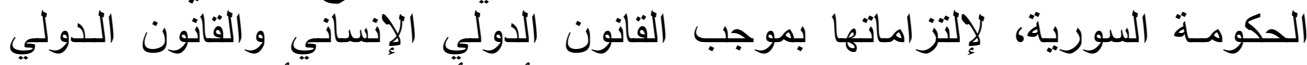

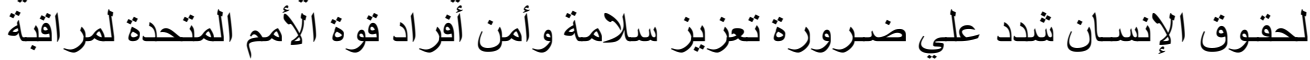

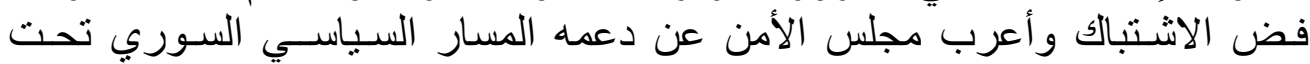

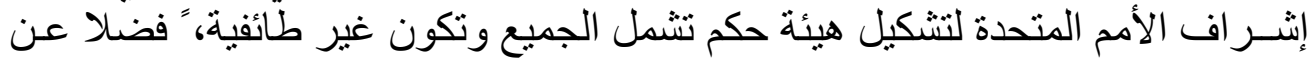

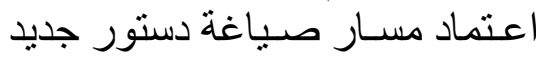

وكثير من القرارات التي صدرت عن الجمعية العامة للأمم المتحدة ومجلس الأمن لحل

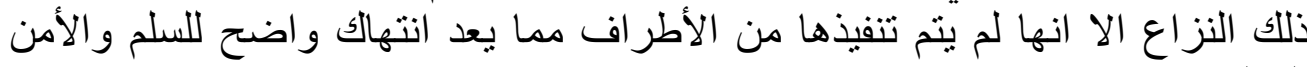
الدوليين 


\section{الوجه الرابع: انتهاك واسع لحقوق الإنسان}

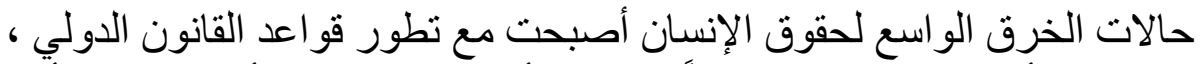

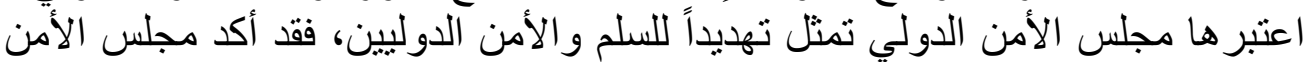

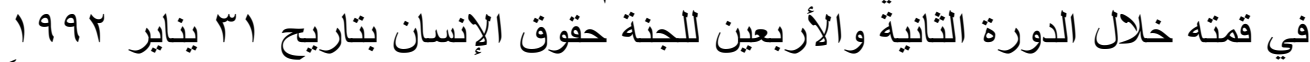

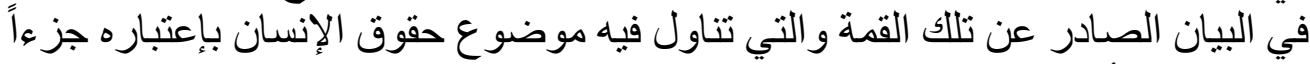
من السلم و الأمن الدوليين فجاء النص علي لئي

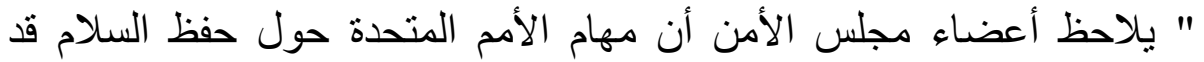

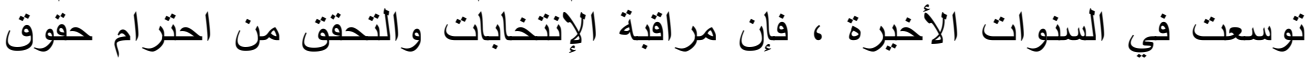

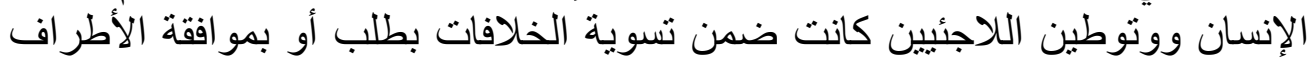

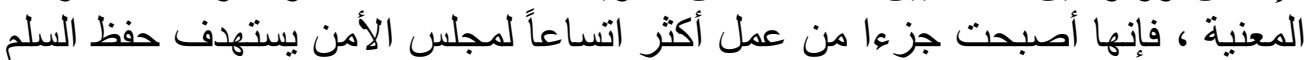

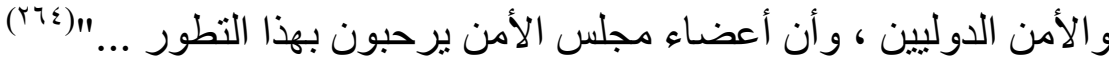

ويرجع اهتمام الأمم المتحدة ومجلس الأمن بالحريات و الديمقر اطية إلي الإيمان

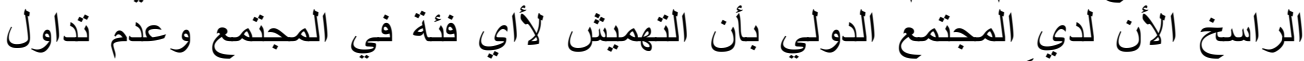

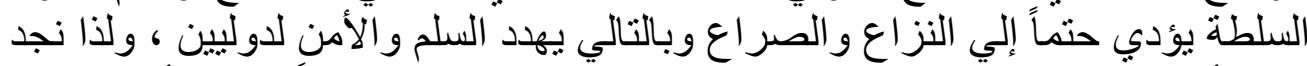

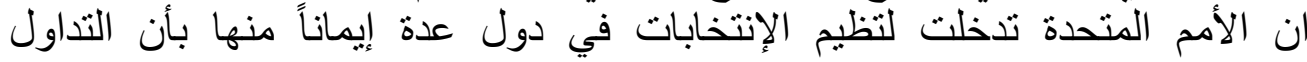

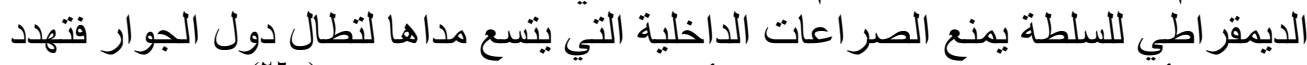

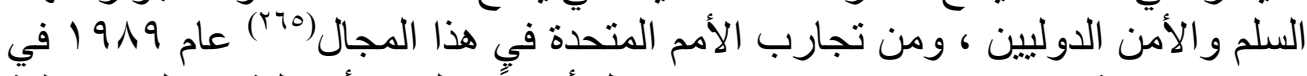

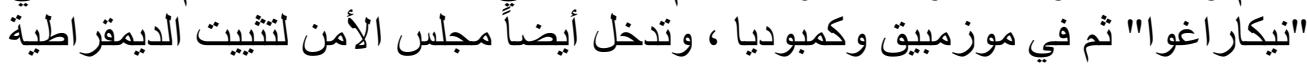

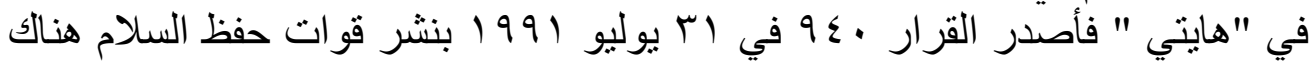

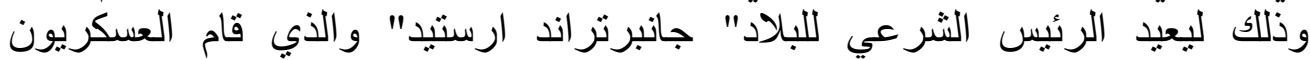

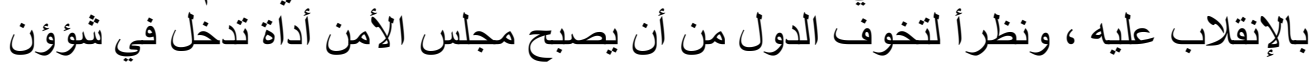

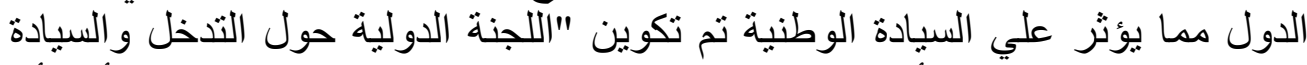

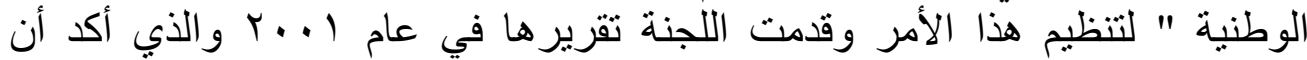

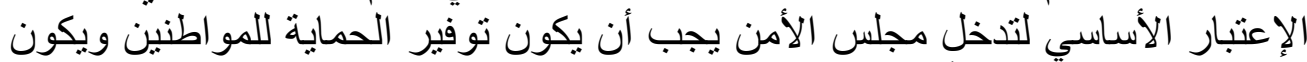

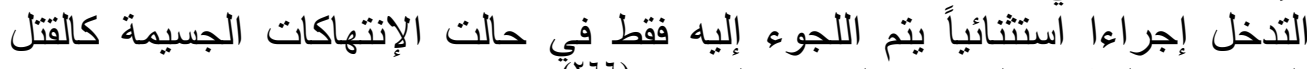

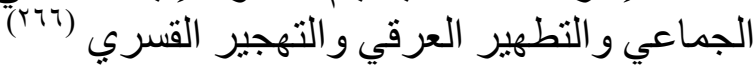

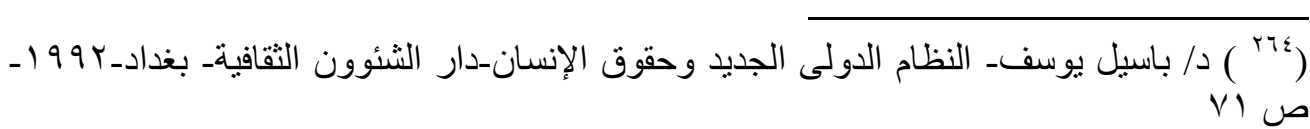

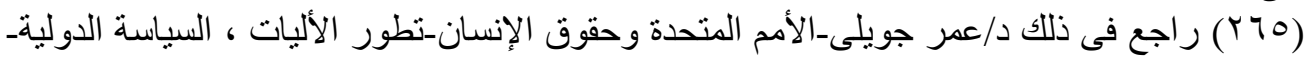

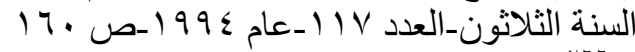

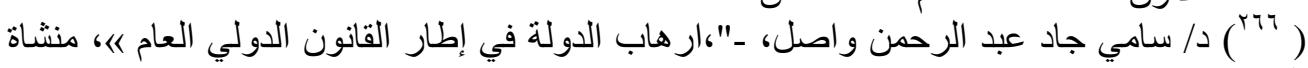

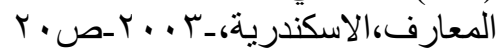




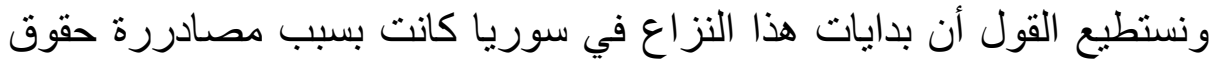

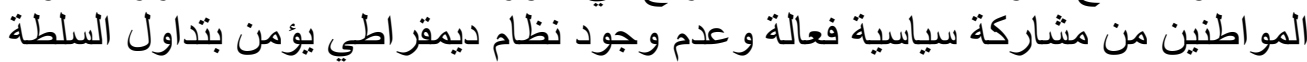

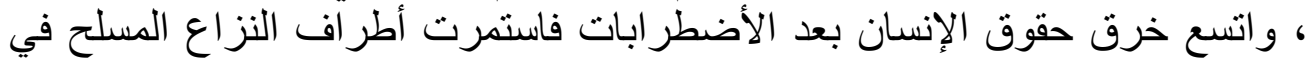

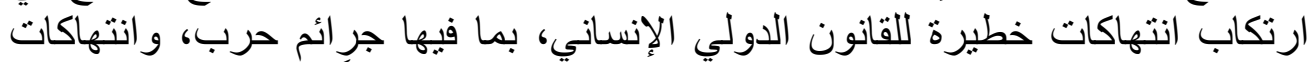

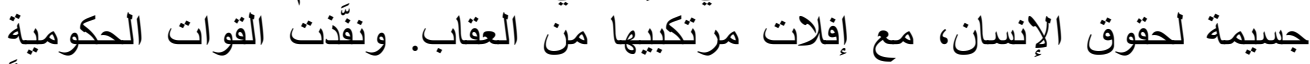
والحليفة لها هجمات عشوائية ومباشرة الأني علي المدنيين والأعيان المدنية، مستخدمةً

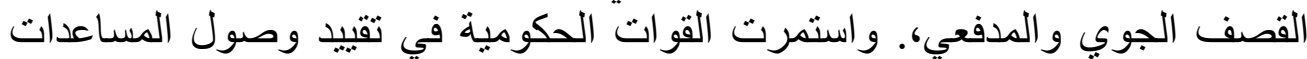

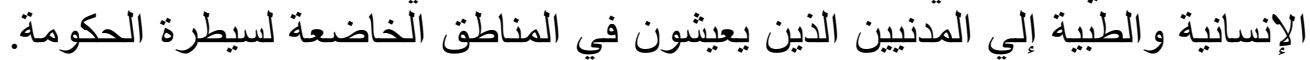

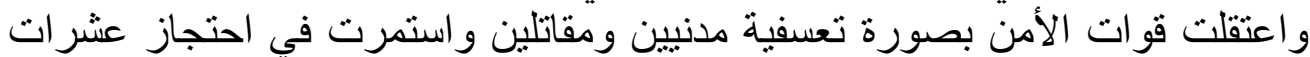

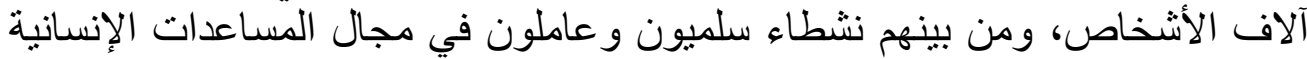

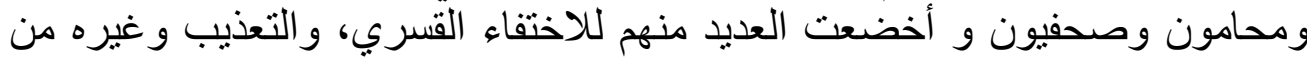

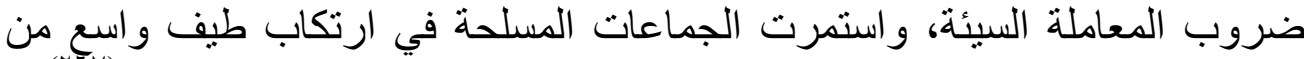

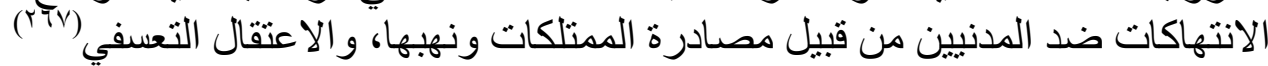

\section{الوجه الخامس: استخدام الأسلحة الكيماوية والبيولوجية المجرمة دولياً}

يعتبر استخدام الأسلحة المحرمة دوليا وخاصة الكيمائية والبيولوجية منها تخديداً

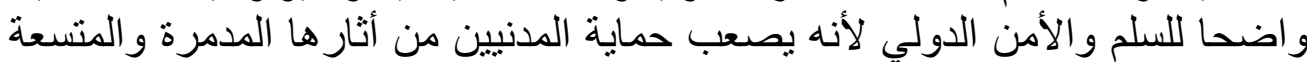

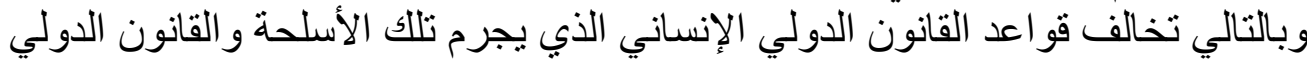

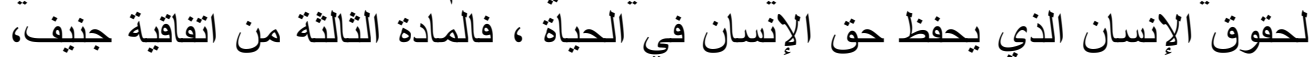

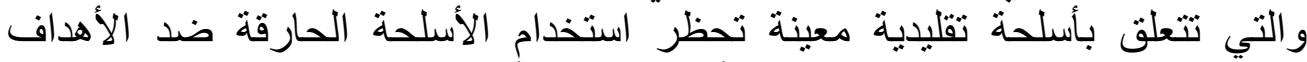

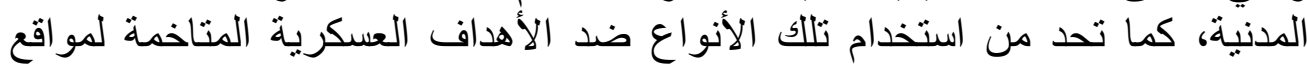

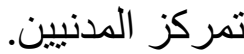

و هذا الخرق الواضح لقواعد القانون الدولي الإنساني وقواعد القانون الدولي

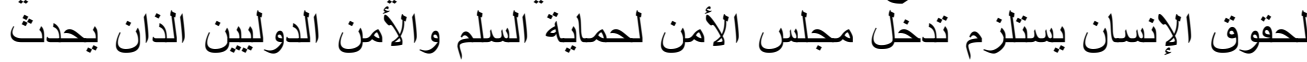

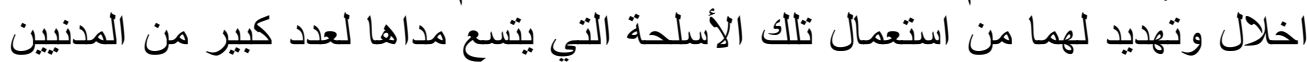

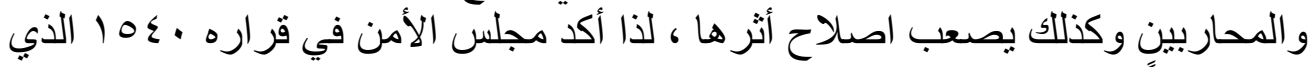

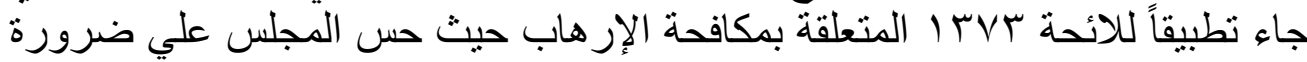

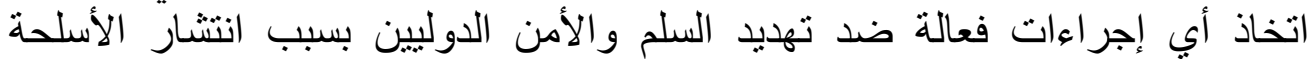

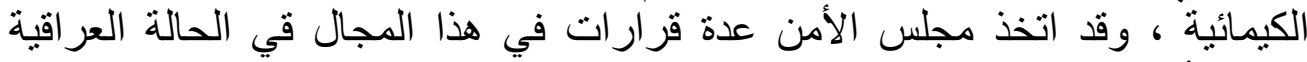

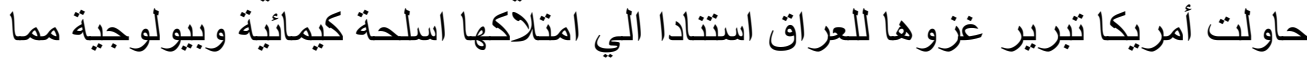

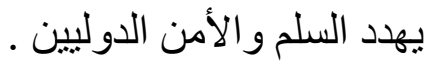

(") تقرير منظمة العفو الدولية على موقعها على شبكة المعلومات الدوليةـ https://www.amnesty.org/ar/countries/middle-east-and-northafrica/syria/report-syria/ 
وبالعودة الي الحالة السورية نجد أنه تم أستخدام الكثير من الأسلحة المحرمة

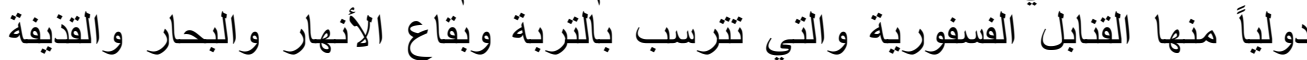

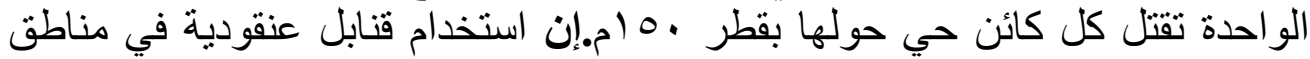

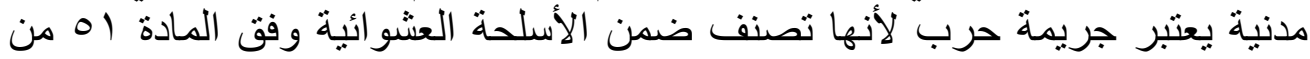

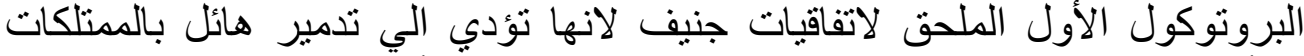

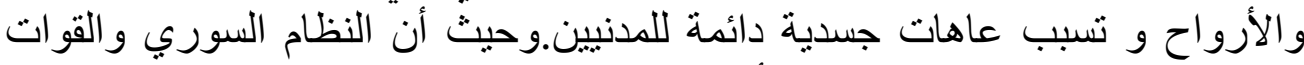

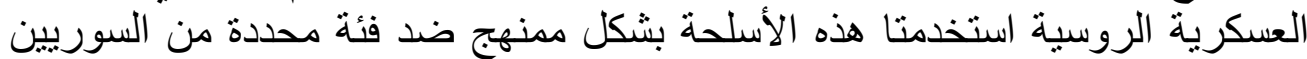

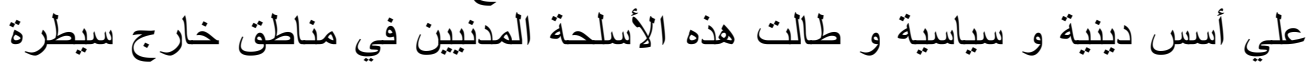

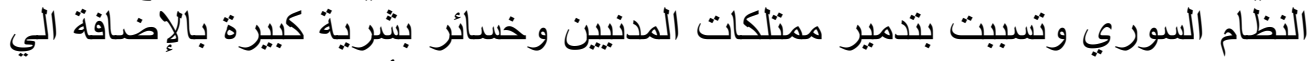
إحداث عاهات جسدية مستديمة ومازالت مخلفات هذه الأسلحة تحصد الكثير من بن الأنيات الأرواح فإن استخدامها يعتبر جريمة

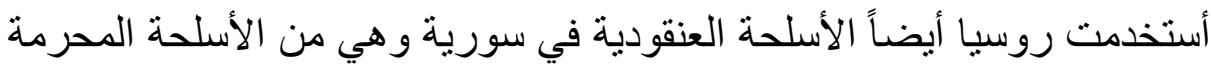

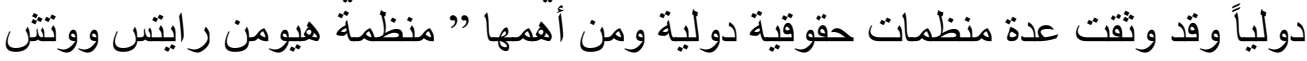

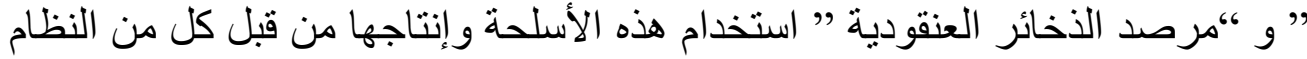

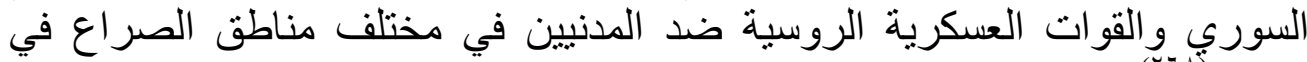

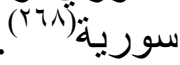

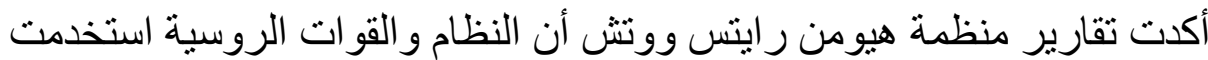

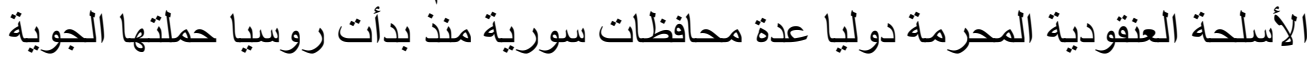

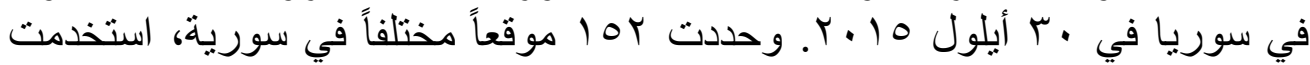

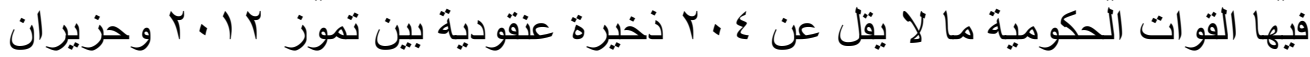

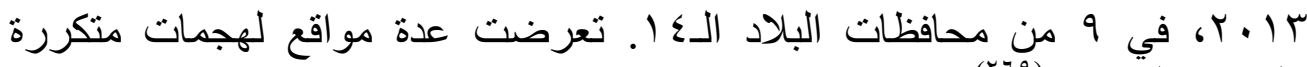

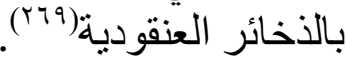

1 ـانظر فى ذللك شبكة المعلومات الدولية الموقع الالكترونى التالى:https://hamalawyers.com/\%D8\%A7\%D8\%B3\%D8\%AA\%D8\%AE

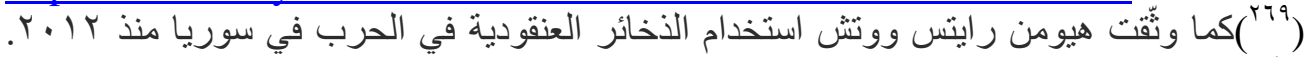

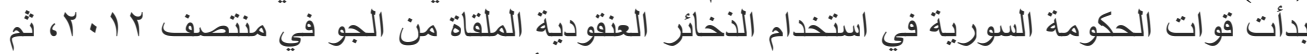

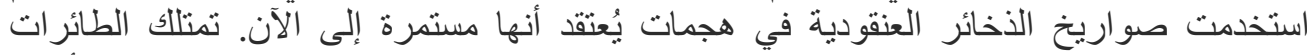

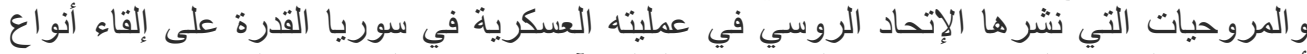

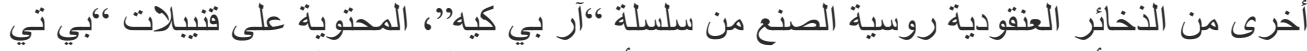

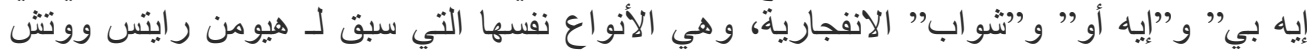
توثيق استخدام قوات الجو الو السورية إياها.

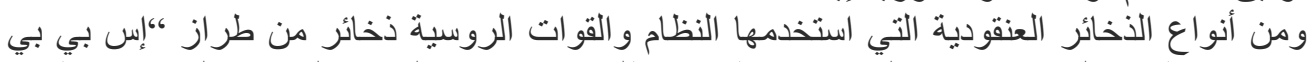

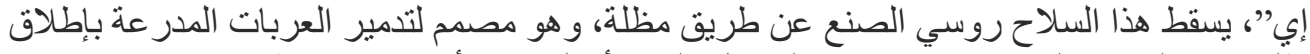

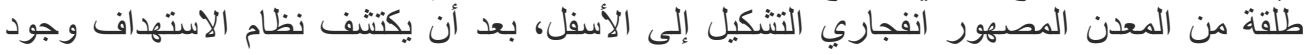


أيضاً من الأعمال غبر الإنسانية التي قام بها الروس و المخالفة لأحكام القانون

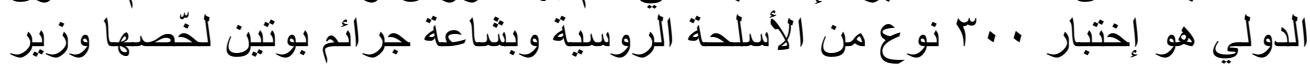

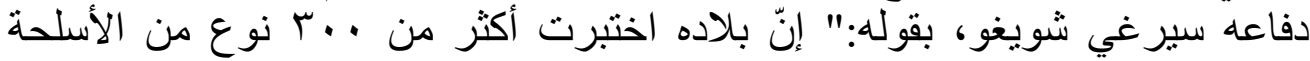

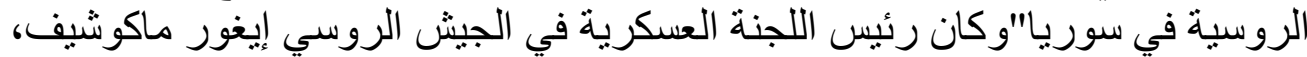

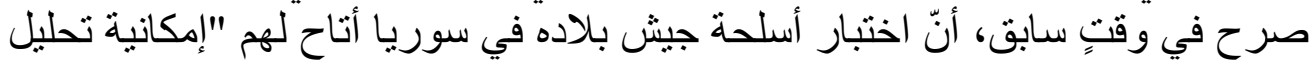

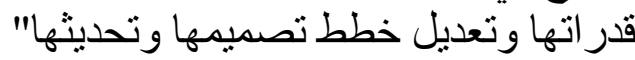

\section{الوجه السادس : توافر حالة العدوان}

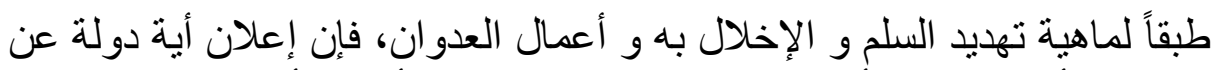

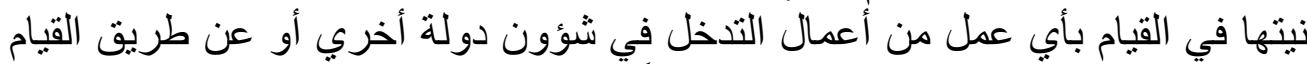

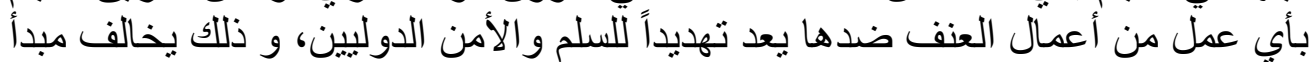

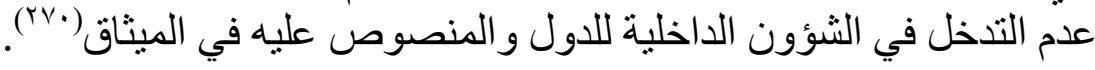

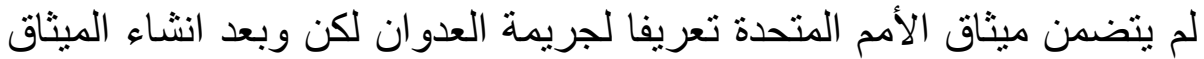

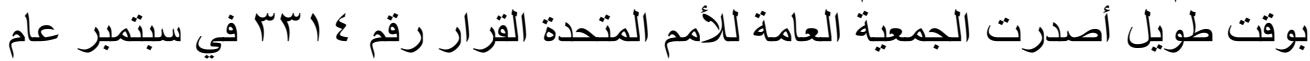

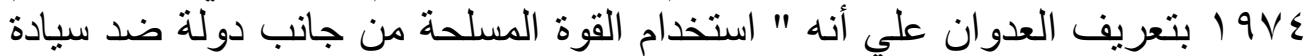

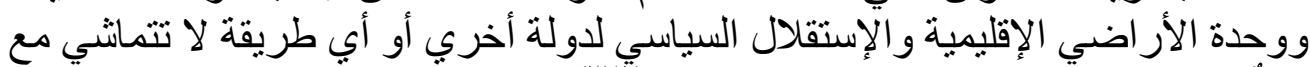

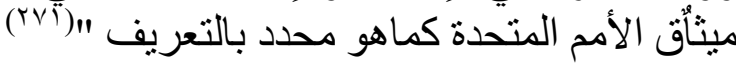

لا شك أن هذه الصور متوفرة في الحالة السورية فحالة تهديد السلم والأمن

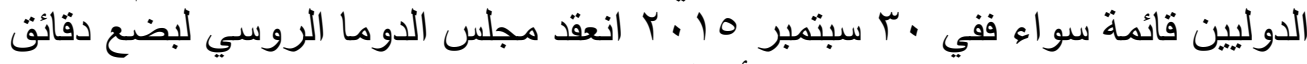

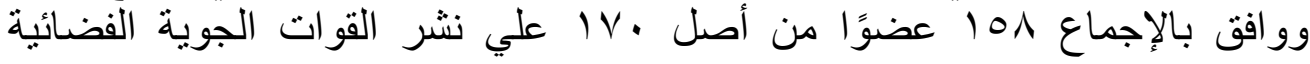

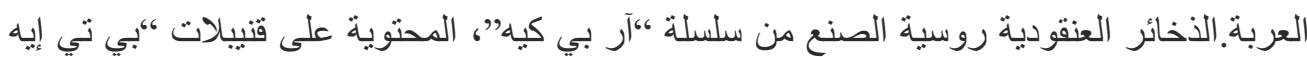

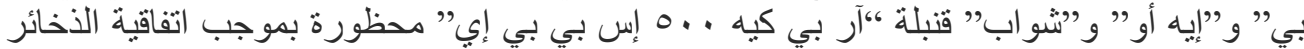
العنقودبة

ـ قالت هيومن رايتس وونش إن نوعا متقدما من الذخائر العنقودية الروسية استُخدم في غارة جوية

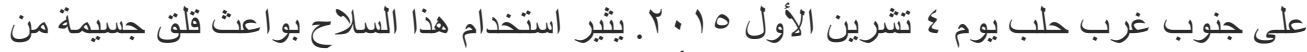

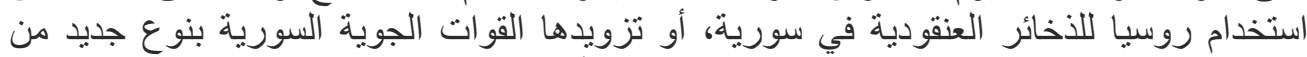
الذخائر العنقودية تلقى من الجو، علاموة على على صو اريخ أرضية تحمل ذخائر عنقودية روسية، كجزء

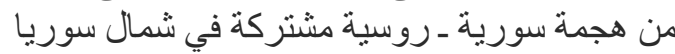

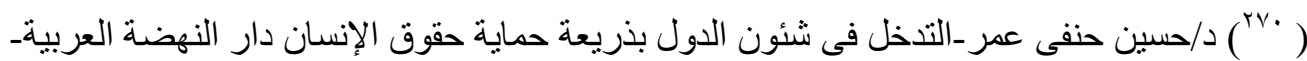

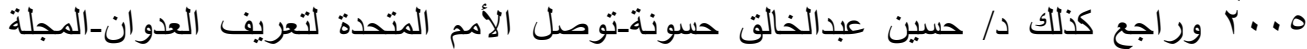

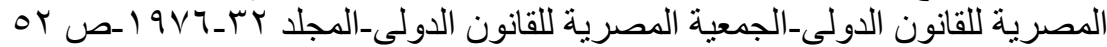

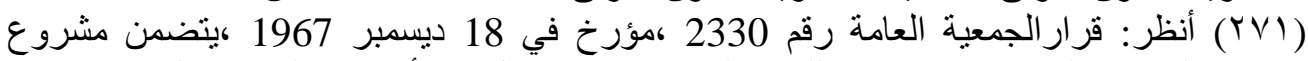
تعريف العدوان الذي اعتمدته A/ اللجنة الخاصة باتفاق الآارء وأوصت الجعة الجمعية العامة بإقراره

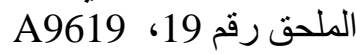




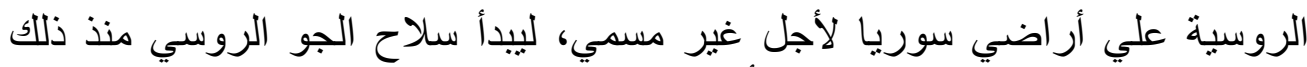

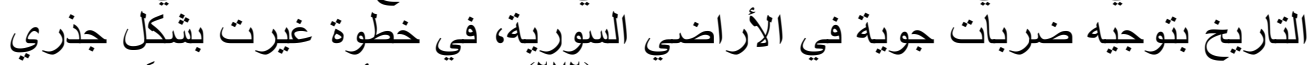

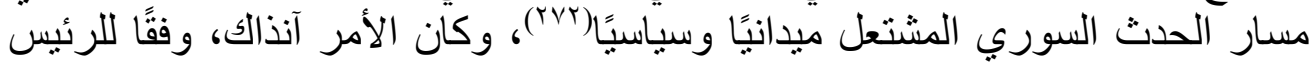

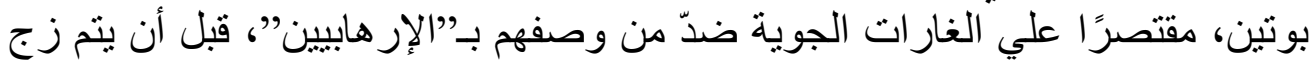

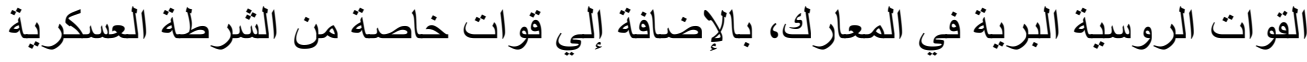

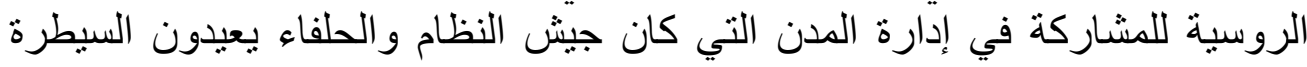
عليها بالحديد و النار.

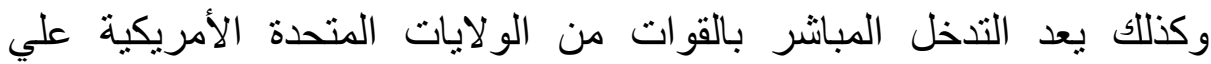

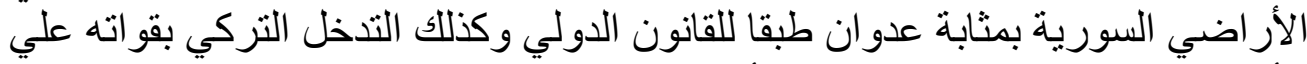

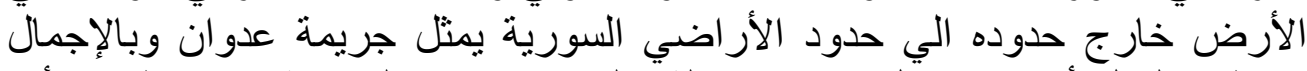

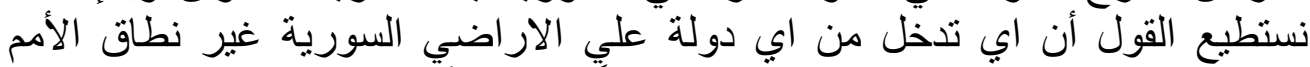

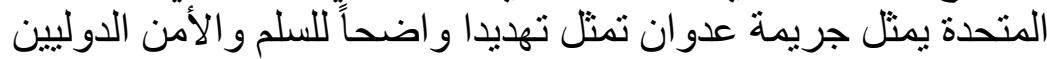

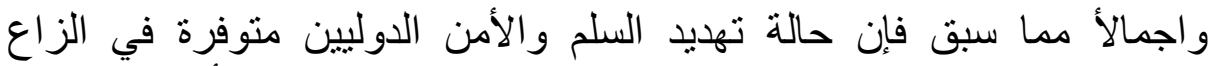

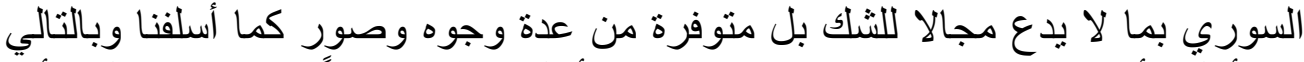

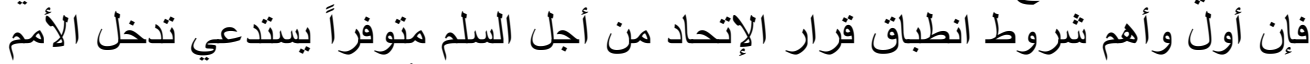

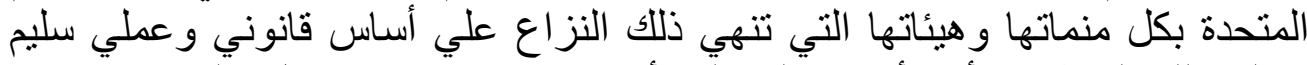

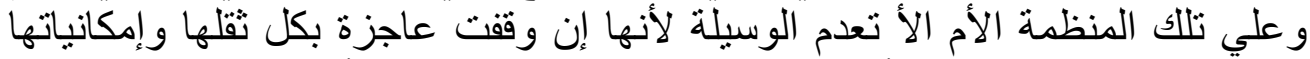

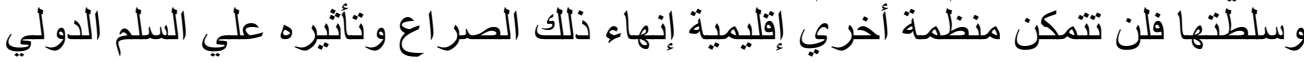

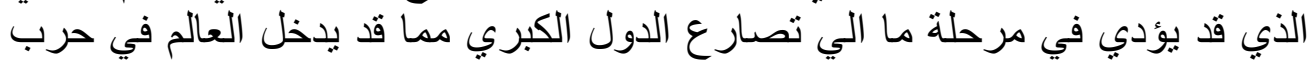
عالمية ثالثة .

\section{ثانياً : عجز مجلس الأمن}

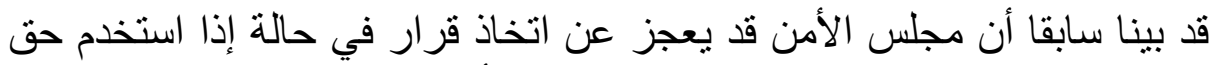

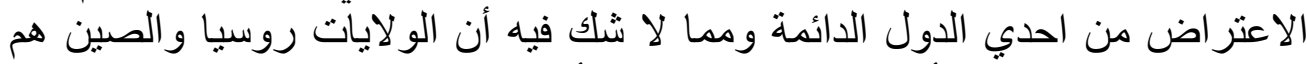

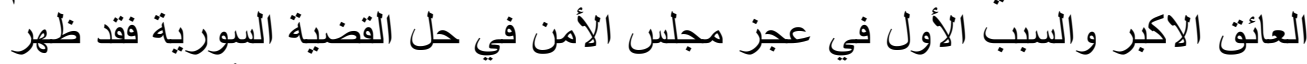

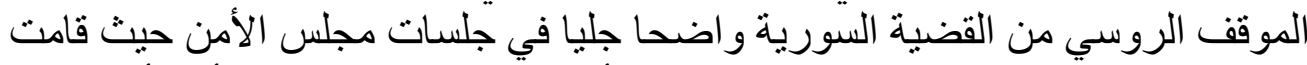

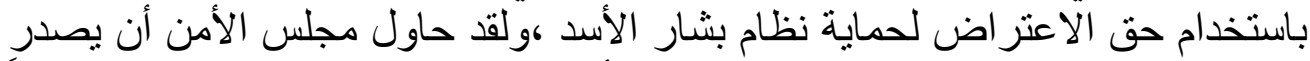

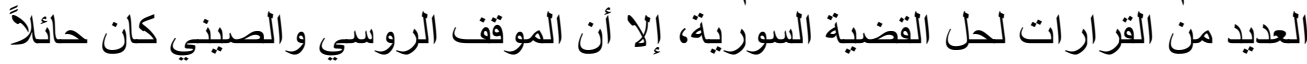


ضد صدور أي قرار رادع للإنتهاكات التي تحدث ضد الثعب السوري من جميع الجهات الداخليةٌ والخارجية.

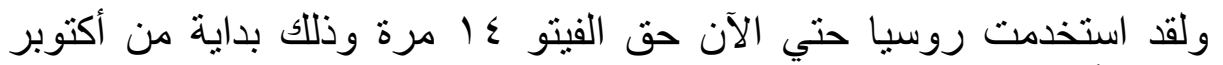

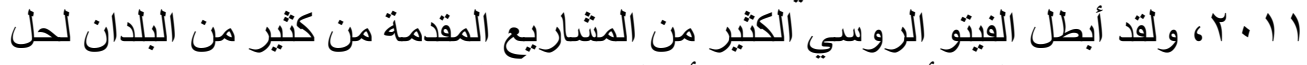

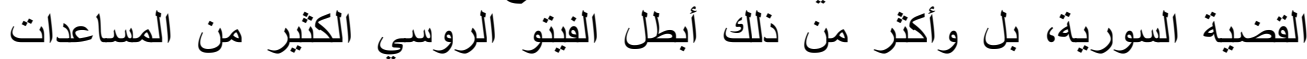
الإنسانية المقدمة للشعب السوري. بل والئر

وسنبين في هذا الصدد المشاريع المقدمة من الدول لحل القضية السورية وموقف مجلس الأمن من هذه المشاريع وذللك كما يلي:

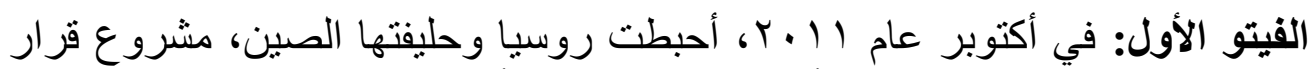

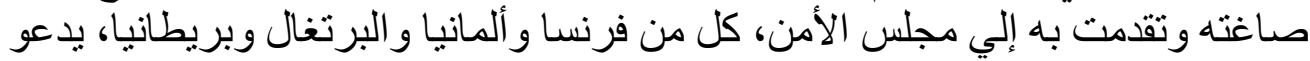

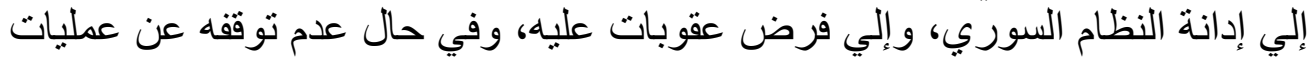

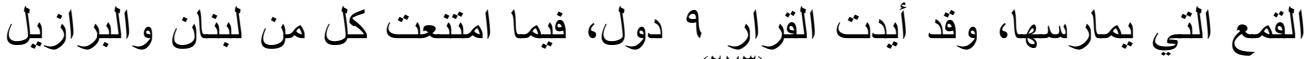

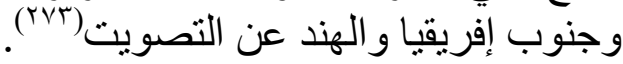

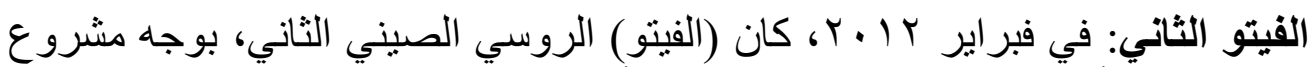

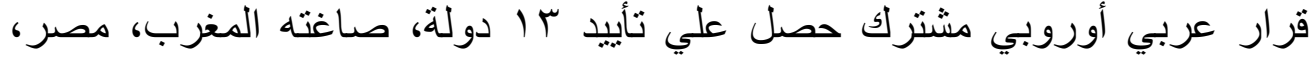
الأردن، ليبيا، نونس، تركيا، الولايات المتحدة الأمبركية، البرتغال، التوغولة التوب، فرنسا، ألمانيا، كولومبيا، ودول مجلونس تركيا، التعاون الخليجي.

ويدعم هذا القرار المشروع الذي اقترحته جامعة الدول العربية بشأن الحل السياسي في

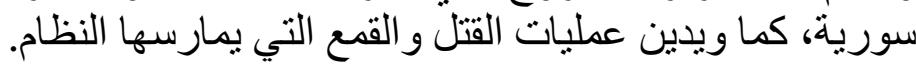

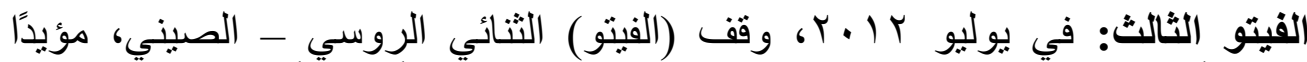

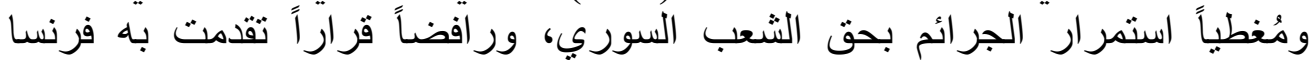

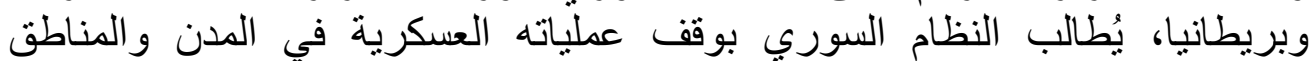

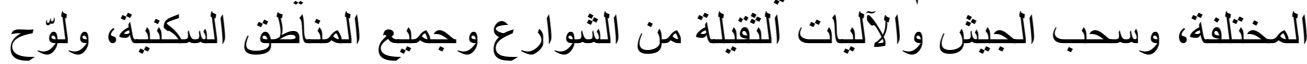

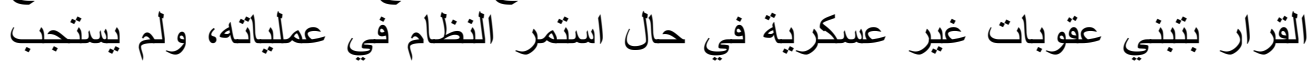

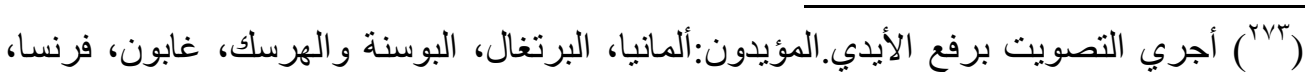

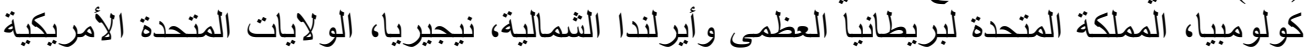

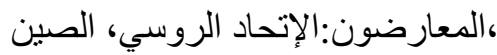
المتتعون عن التصويت:البرازيل، الريل، جنوب أفريقيا، لبنان، الهند

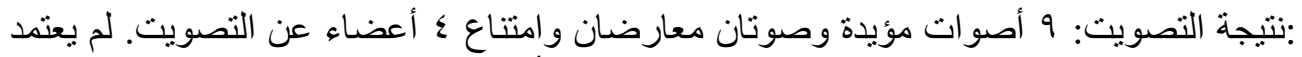
مشروع القرار بسبب التصويت السلبي لعضوين دائمين من أعضاء المجلس. 


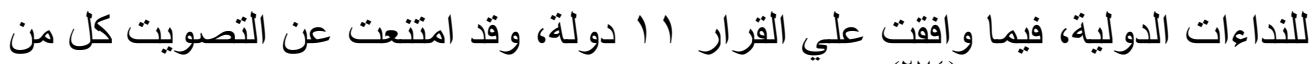

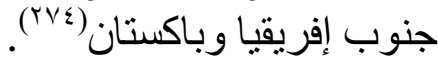

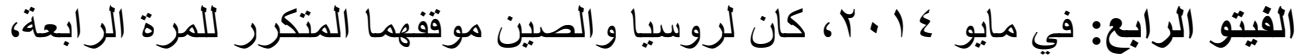

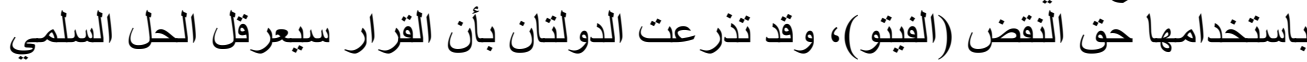

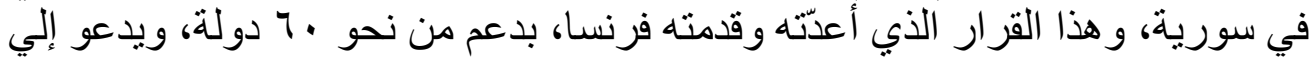

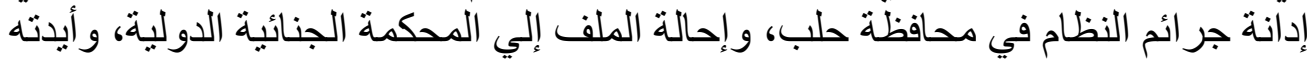

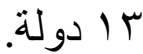

الفيتو الخامس: في أكتوبر 17 • Y، كان أمام مجلس الأمن قرارا جديدا، أعدّته إسبانيا

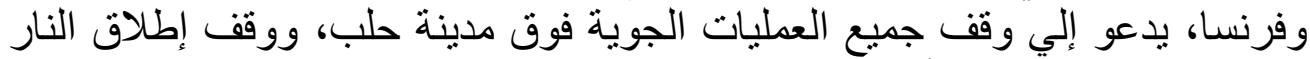

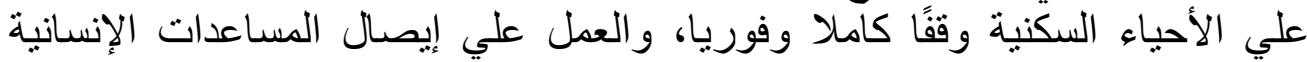

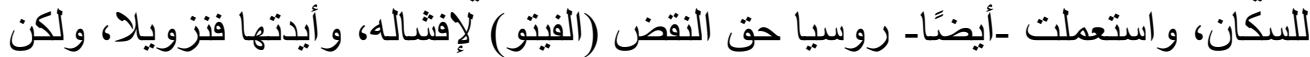

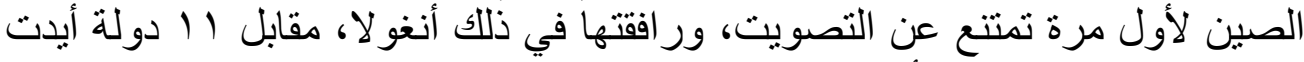

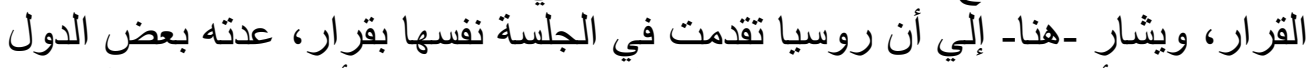

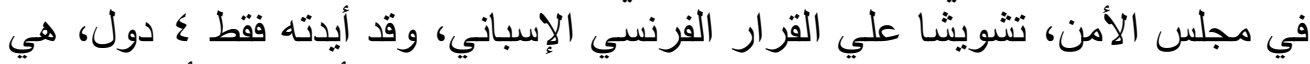

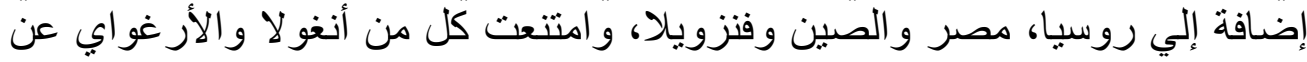

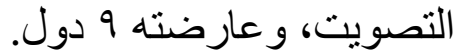

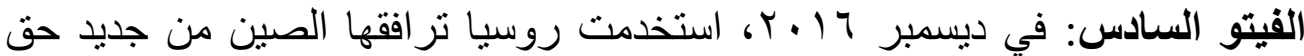

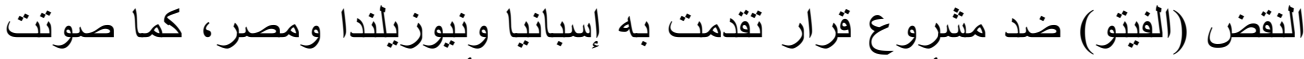

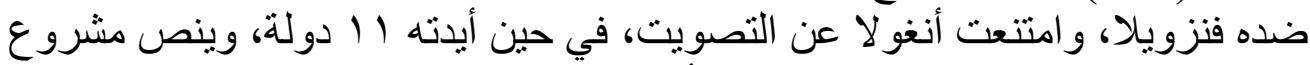

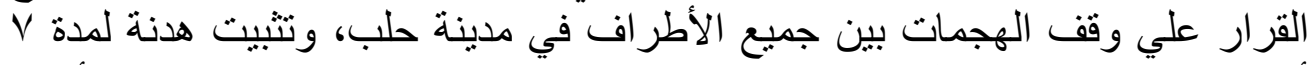

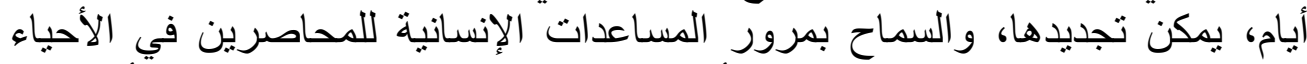

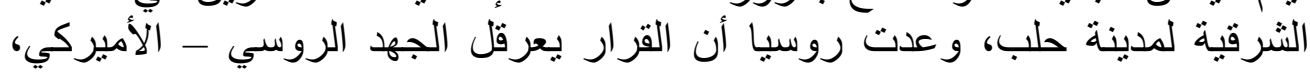

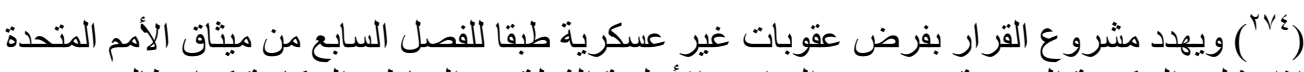

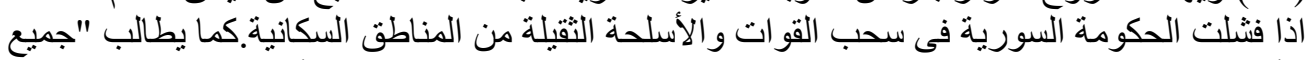

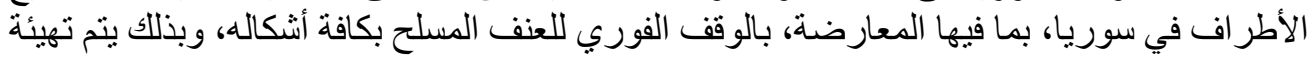

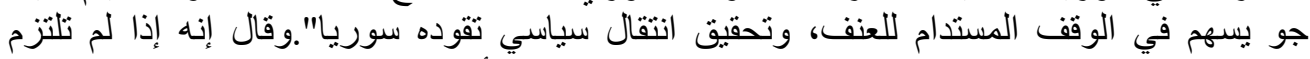

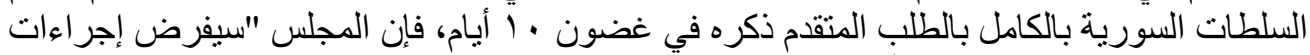
فورية طبقا للبند إ كن ميثاق الكامل الأمم المتحدة".

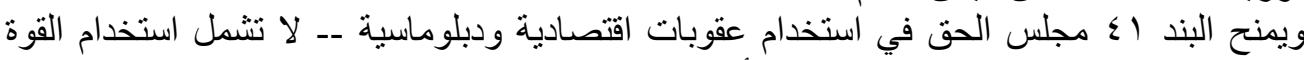
المسلحة ــ لتفعيل قرارهو وقد يدعو الدول الأعضاء الى تطبيق هذه الإجر اءات.

http://arabic.people.com.cn/31662/7882359.html 
لإيجاد حل لما يجري في سورية، وفي المقابل، أدانت أمريكا استخدام روسيا للفيتو،

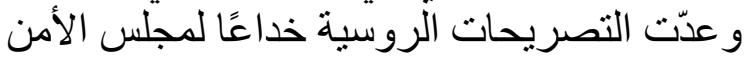

الفيتو السابع: في فبراير V V V أحبطت روسيا وتبيعتها الصين ضد مشروع قرار

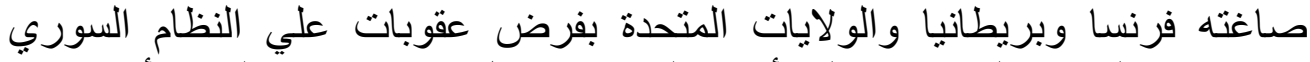

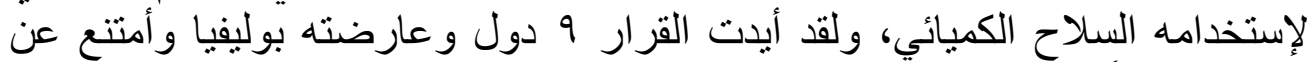

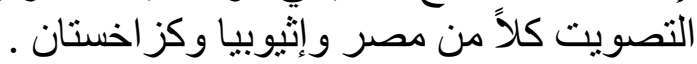

الفيتو الثامن: في إبريل V V I أحبطت روسيا مشروع قرار أمريكي بريطاني فرنسي

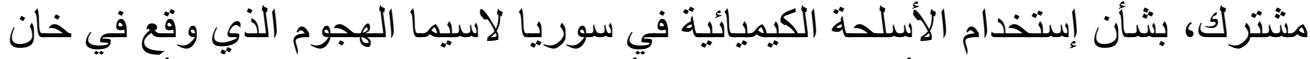

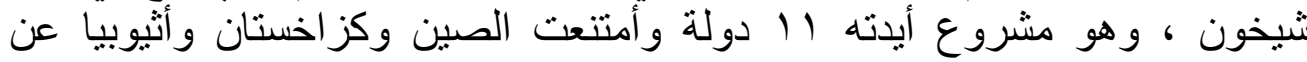

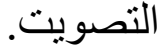

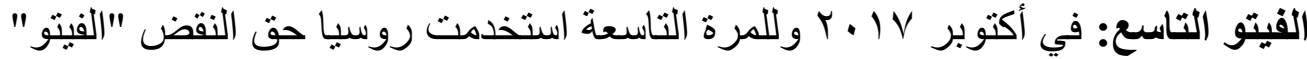

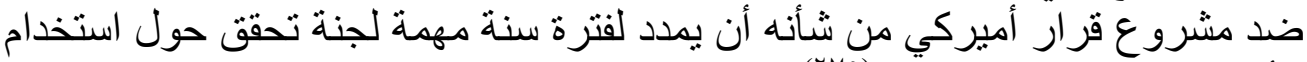

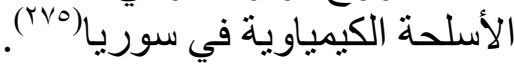
ولقد صوتت || دولة للمشروع فيما عارضت بوليفيا بجانب روسيا بينما إمتتعت

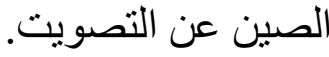

الفيتو العاشر: في سبتمبر r. VV استخدمت روسيا يوم حق النقض (الفيتو) العاثشر

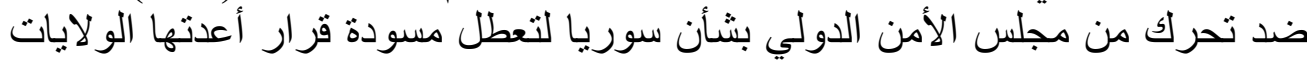
المتحدة لتجديد تفويض تحقيق دولي يسعي لتحديد المسؤول عن لتئن هجمات كيماوية بسوريا.

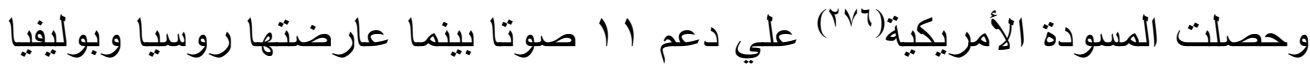
وامتنعت الصين ومصر عن التصويت. لامريك.

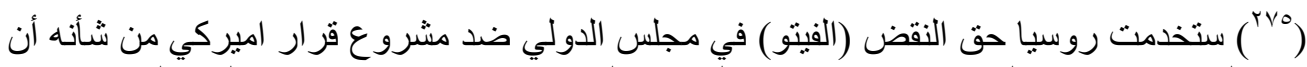

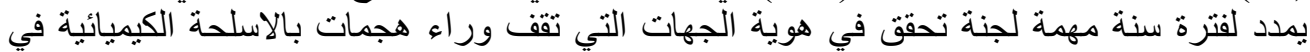

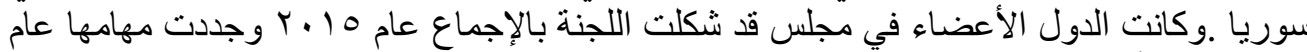

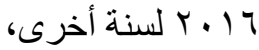

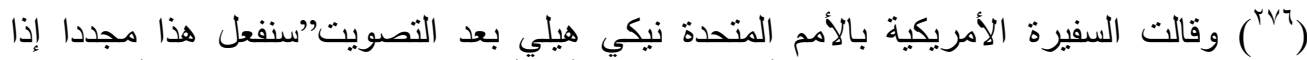

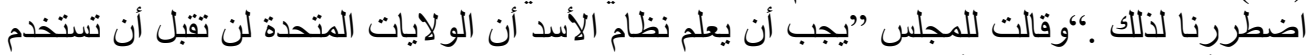

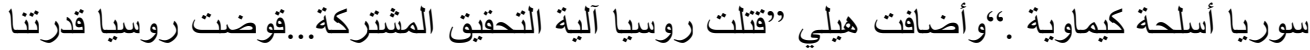

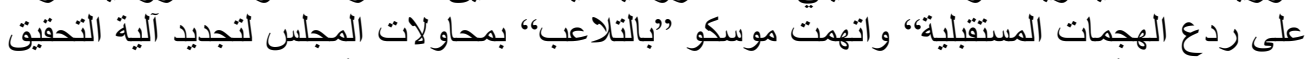

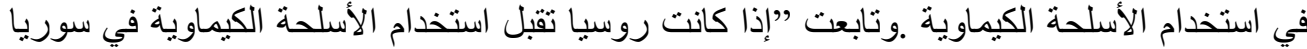

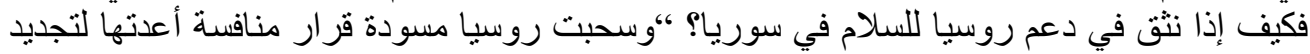




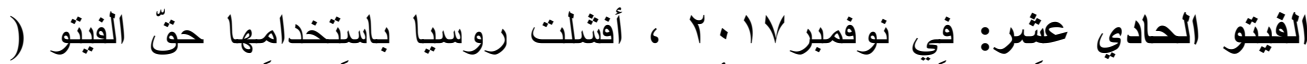

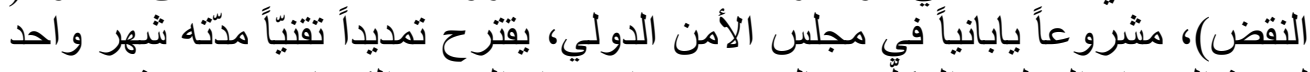

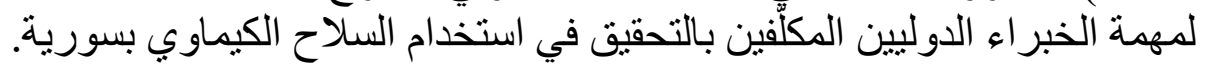

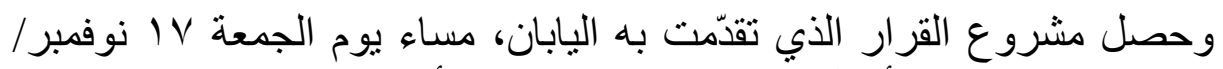

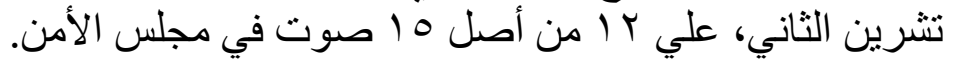

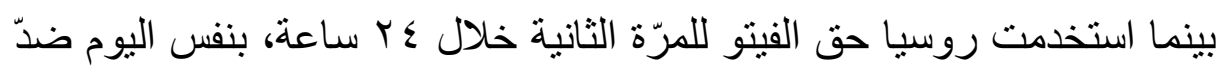

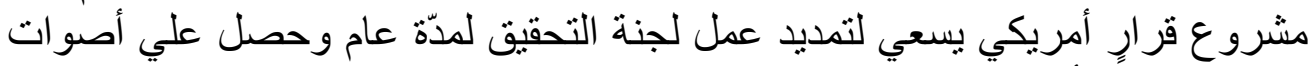

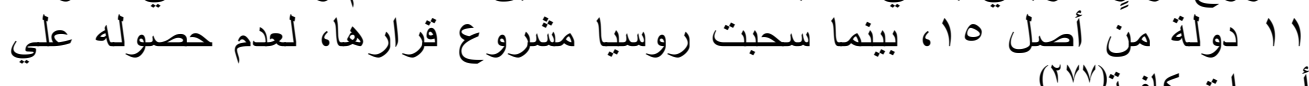
أصوات كافية)

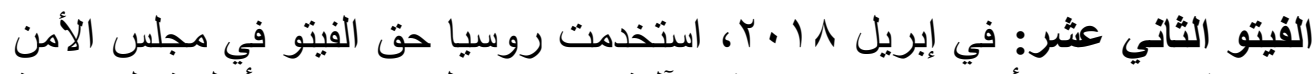

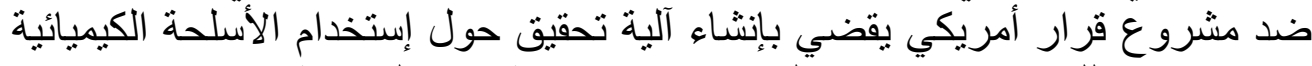

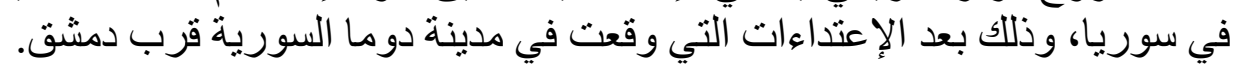

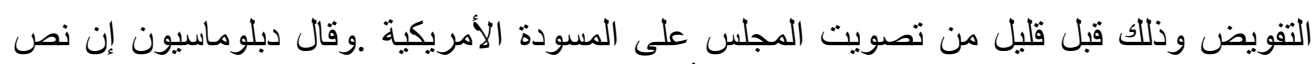

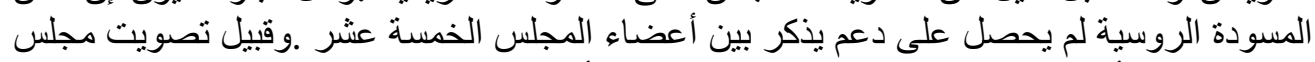

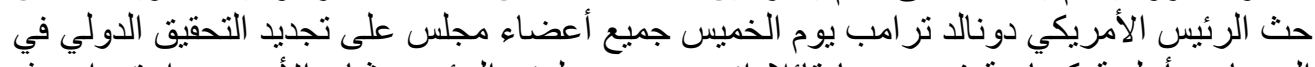

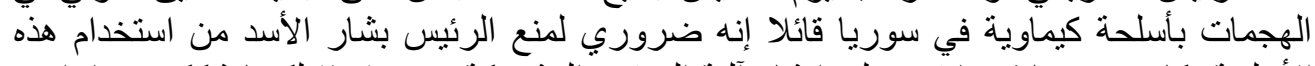

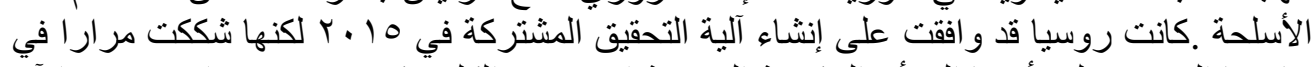

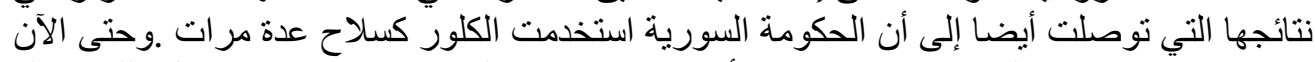

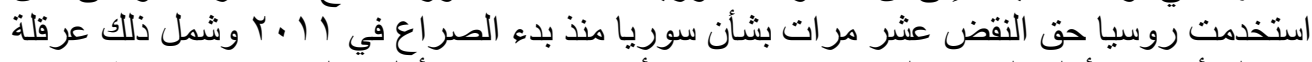

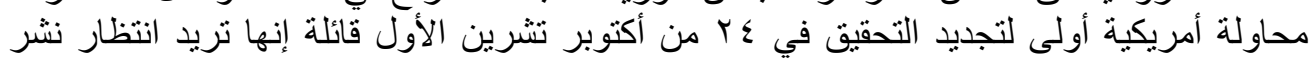

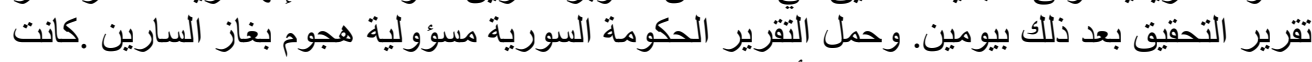

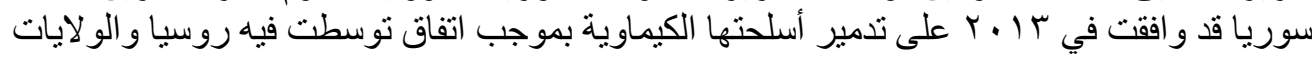

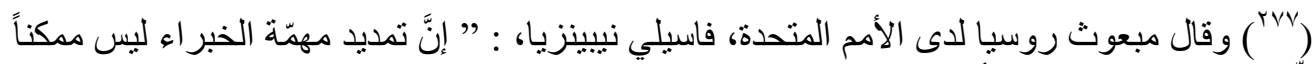

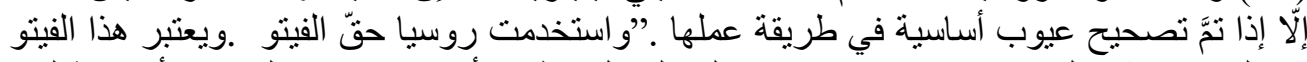

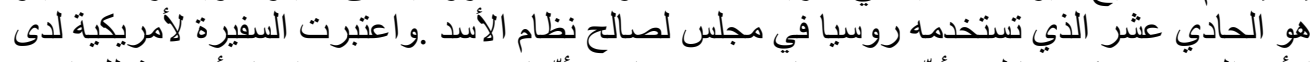

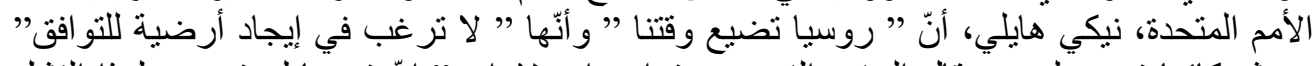

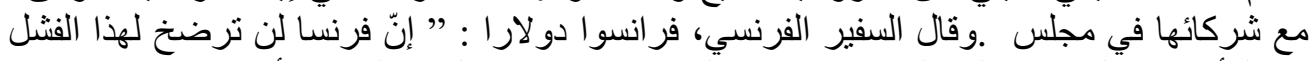

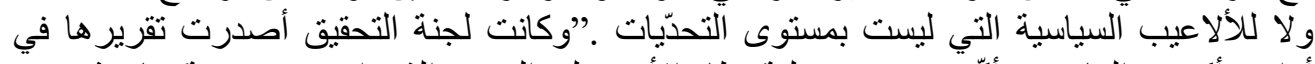

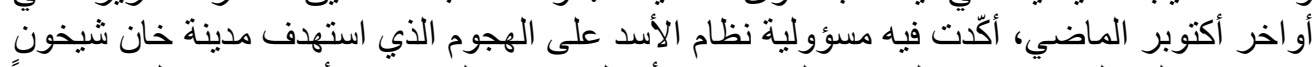

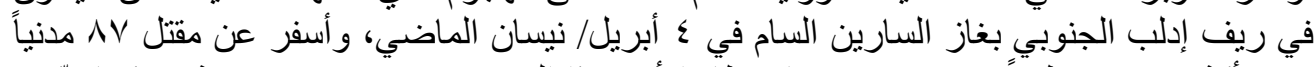

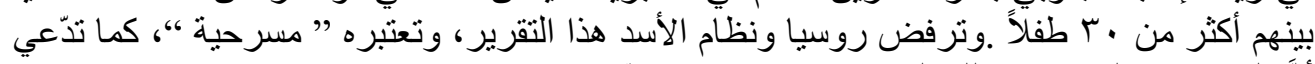

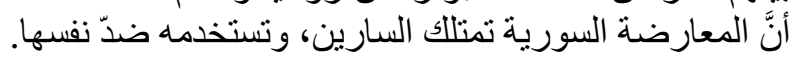


ووافقت با دولة علي مشروع القرار الأمريكي، في حين عارضته روسيا

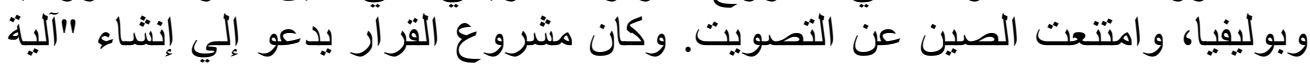
تحقيق مستقلة تابعة للأمم المتحدة" علي أن تعمل لمدة سنة للتحقيق في استخدام السلاح

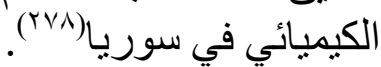

الفيتو الثالث عشر:استخدمت روسيا حق النقض (الفيتو) في مجلس الأمن الدولي للمرة

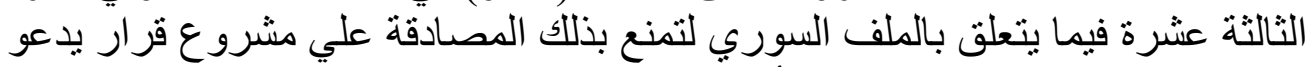

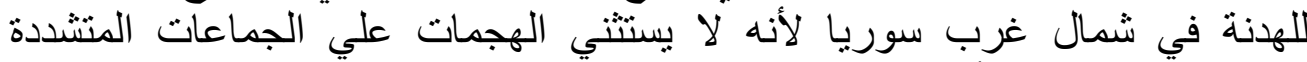

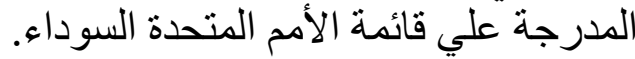

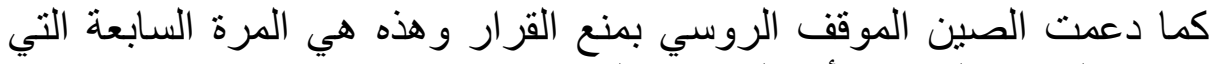

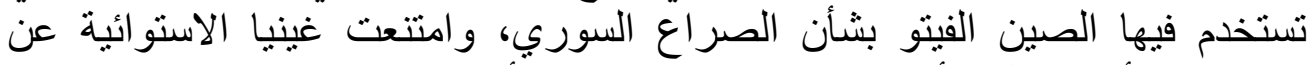

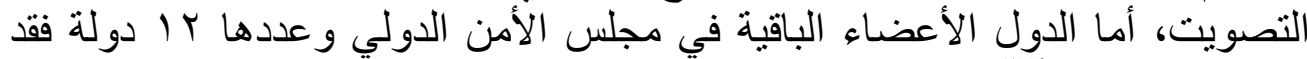

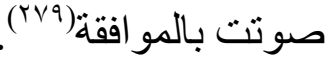

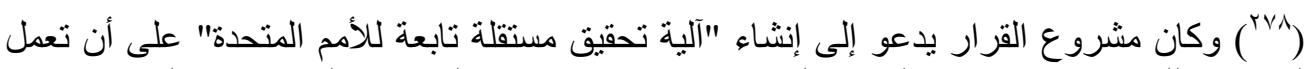

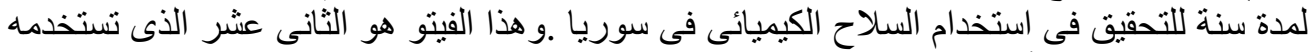

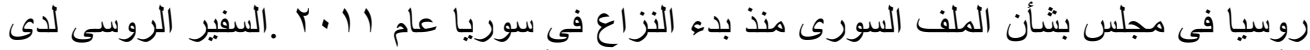

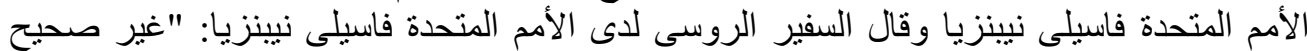

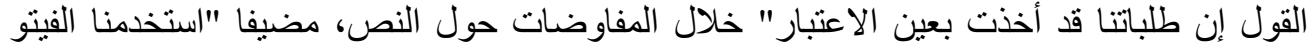

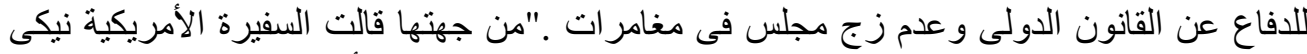

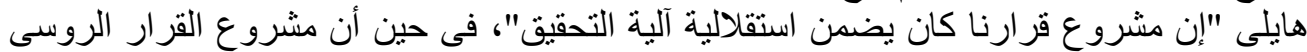

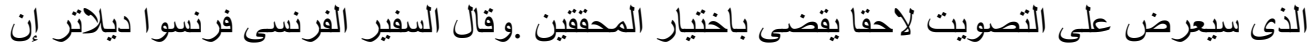

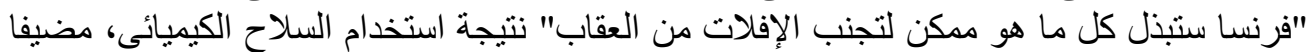

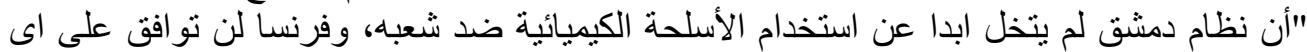

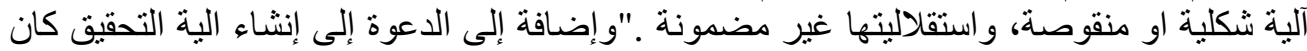

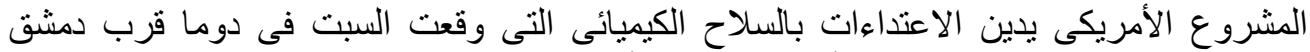

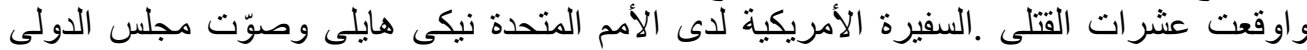

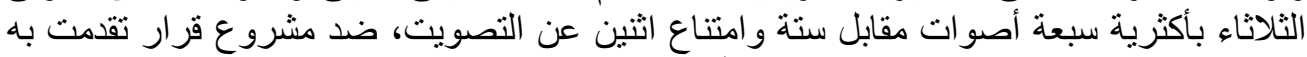

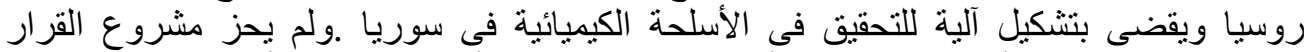

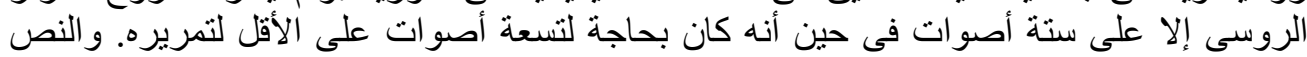

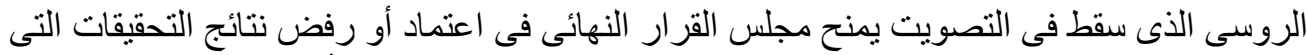

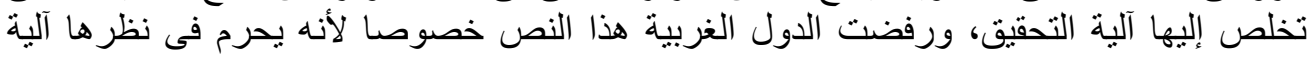
التحقيق من الاستقلالية اللازمة للقيام بعطها.

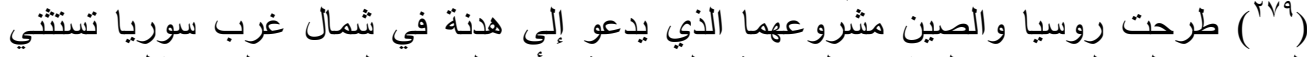

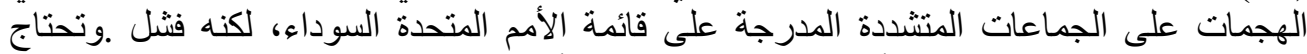

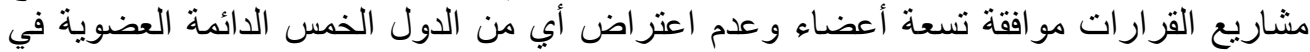

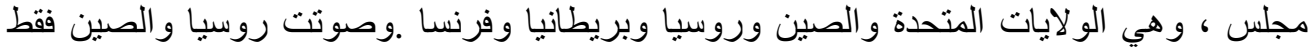




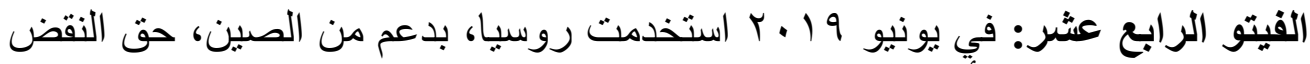

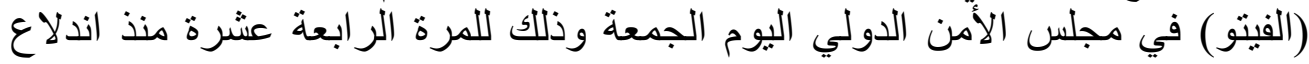

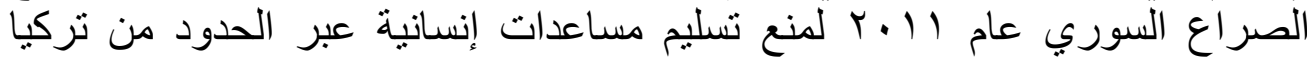
و العر اق لملايين المدنيين السوريين. و أيد القرار الدول الأعضاء و وعددها با ا دولة.

وكان القرار الذي أعدته بلجيكا والكويت و ألمانيا سيسمح بنقل مساعدات إنسانية

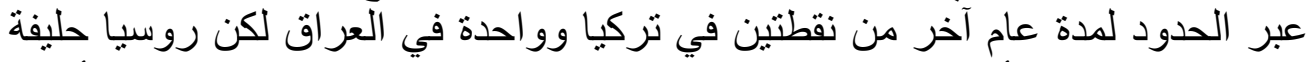

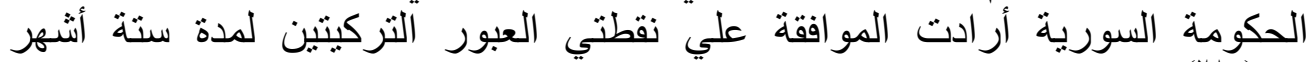
فقط) (rर.

يتبين مما سبق ان حق الفيتو يمثل حجر العثرة الاولي أمام الوصول الي حل

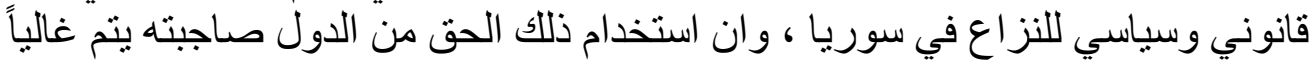

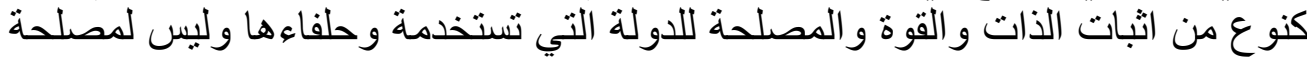

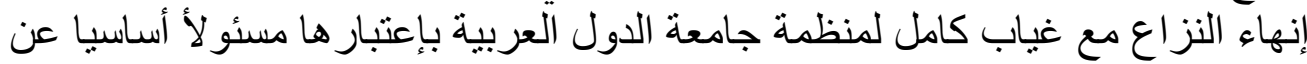

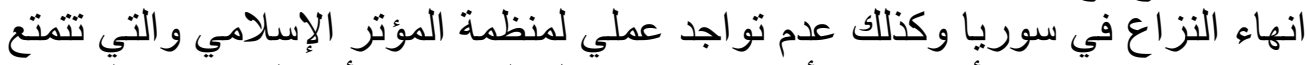

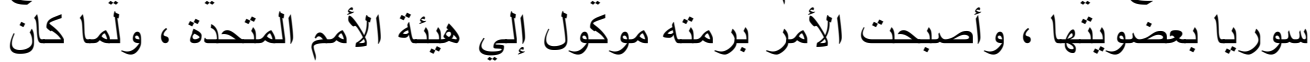

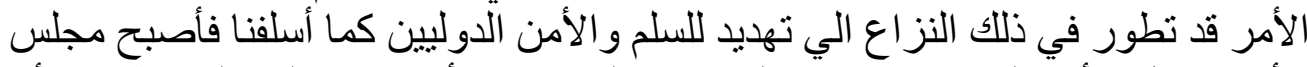

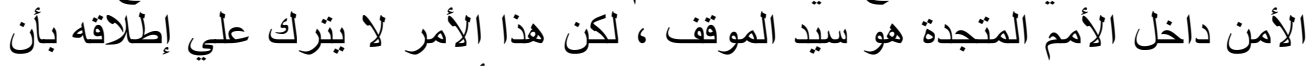

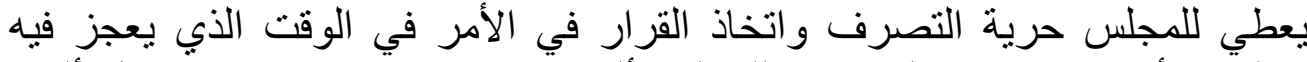

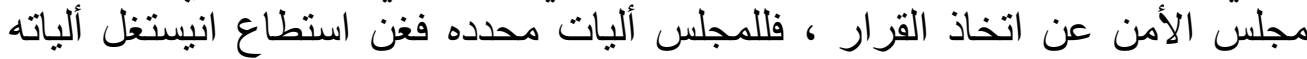

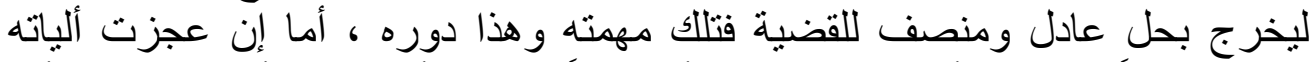

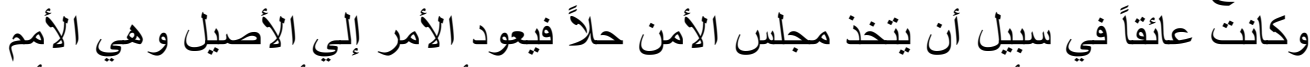

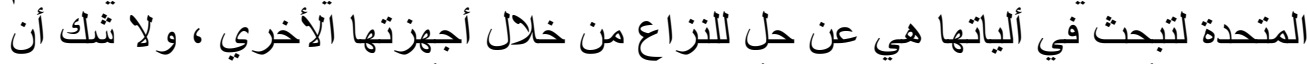

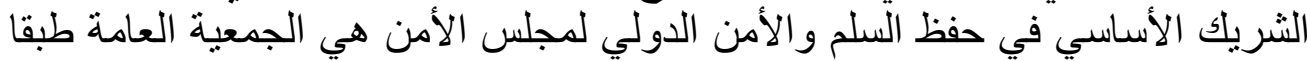

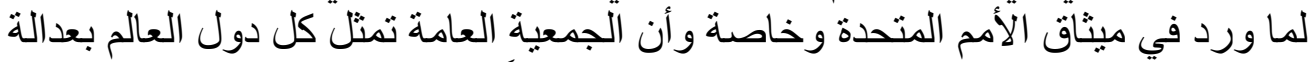

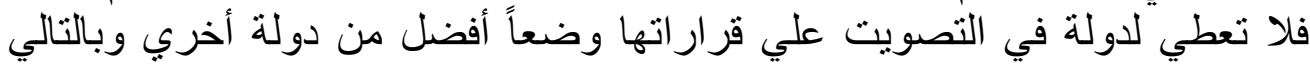

لصالح مشروع قرار هما. وصوت نسعة أعضاء ضد المشروع بينما امتتعت جنوب أفريقيا و إندونيسيا

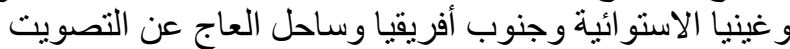

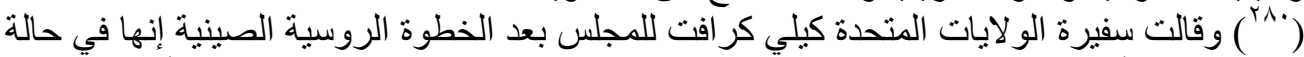

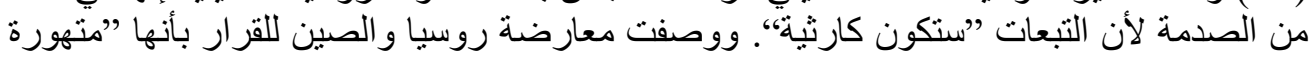

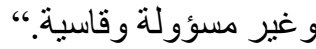
وصوت مجلس بعد ذللك على مسودة القرار الذي صاغته روسيا الذي يسمح بنقطتي عبور تركيتين

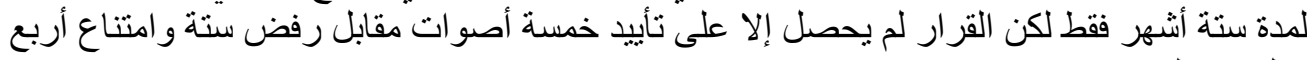

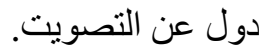




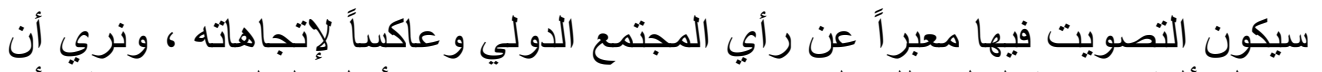

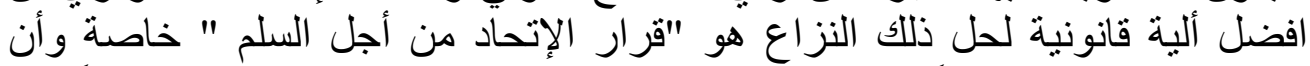

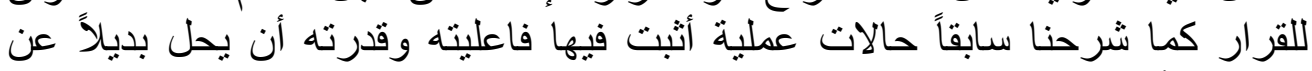

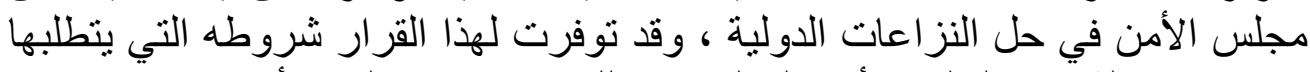

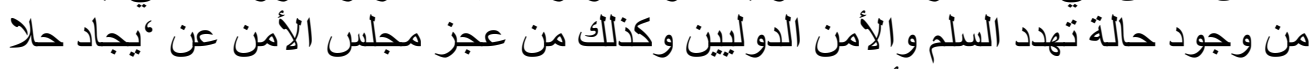

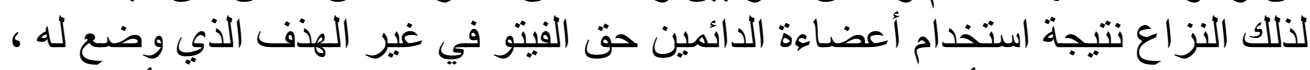

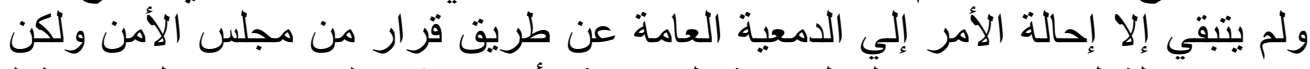

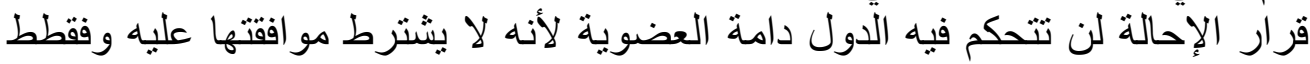

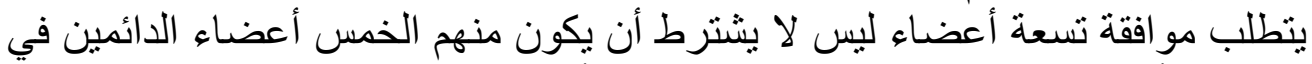

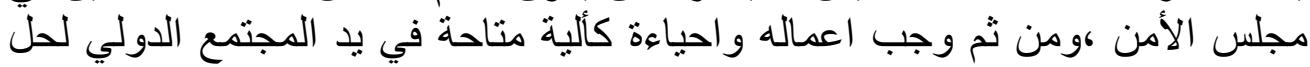

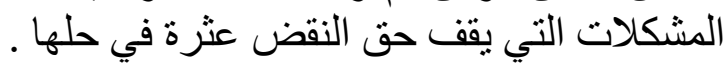




\section{الخاتمة والنتائج والتوصيات}

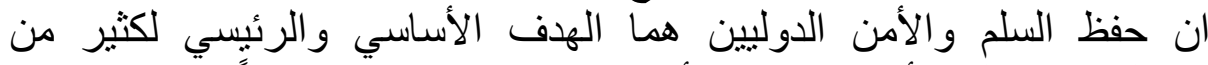

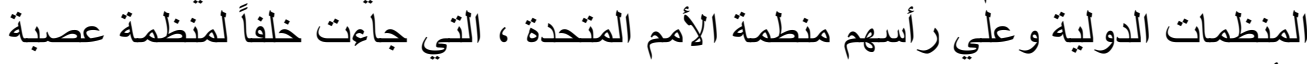

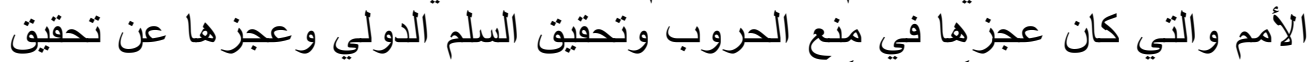

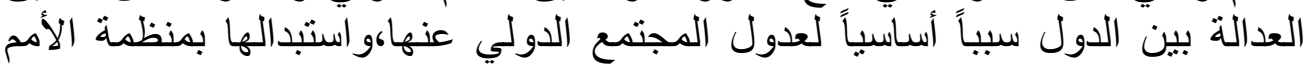

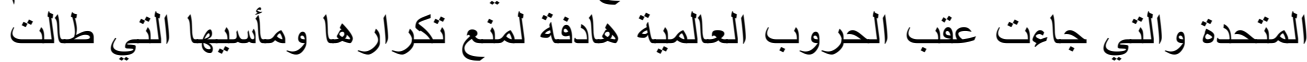

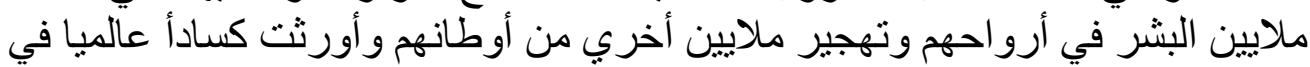

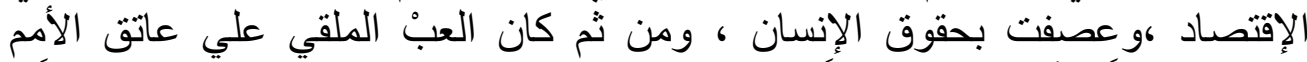

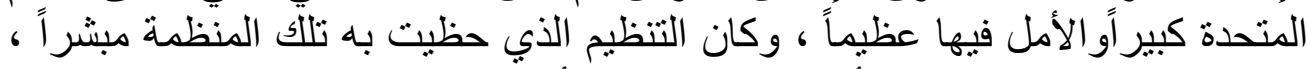

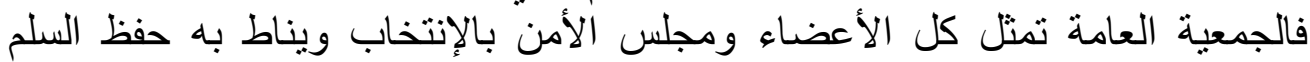

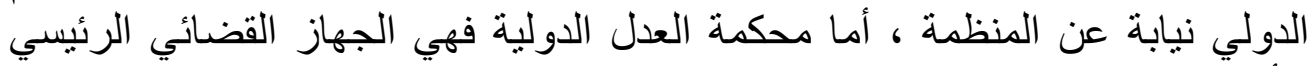

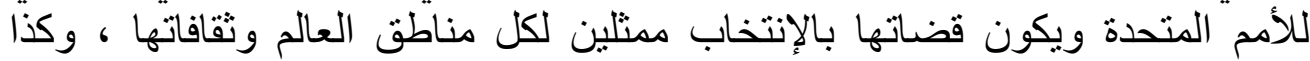

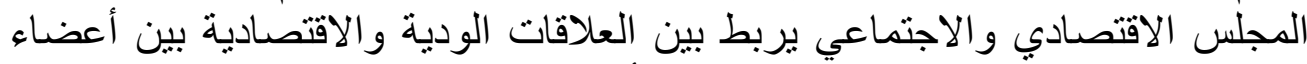

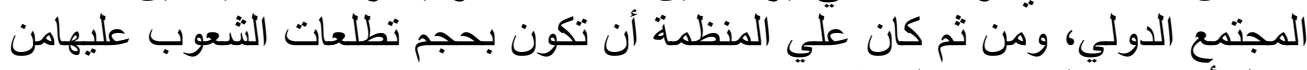

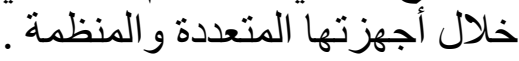

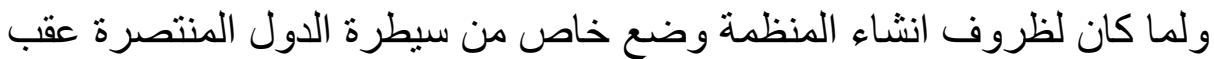

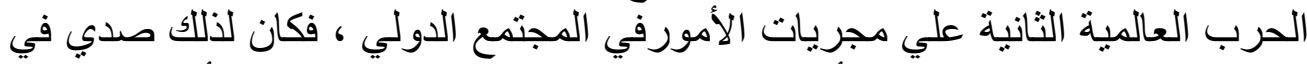

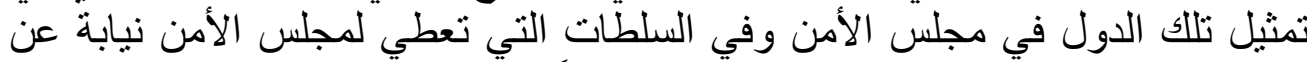

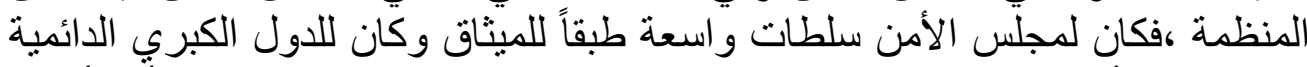

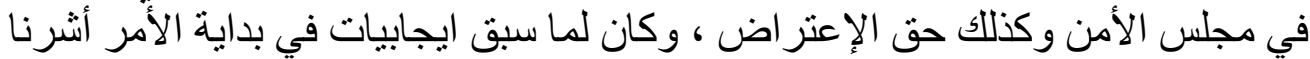

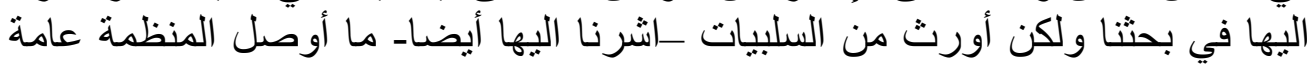

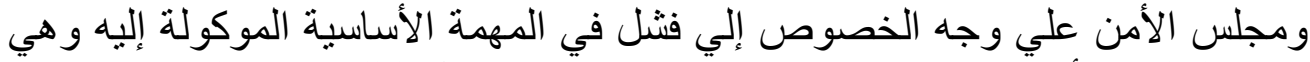

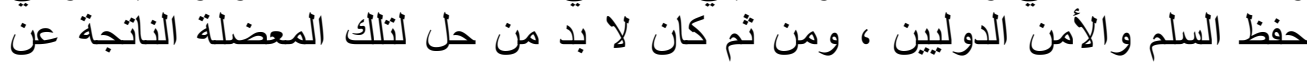

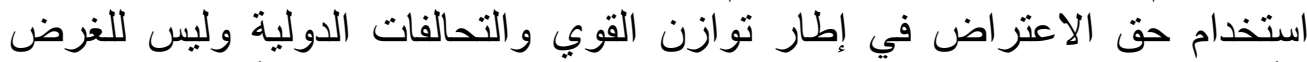

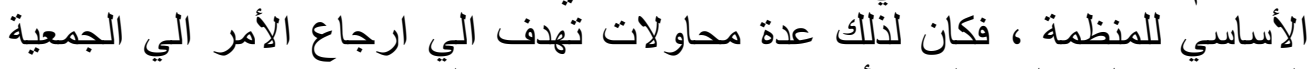

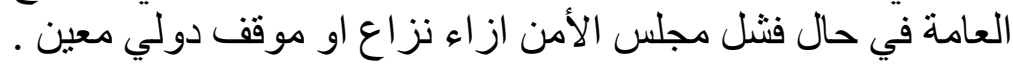

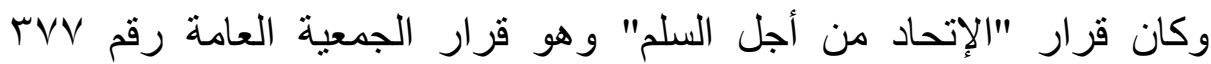

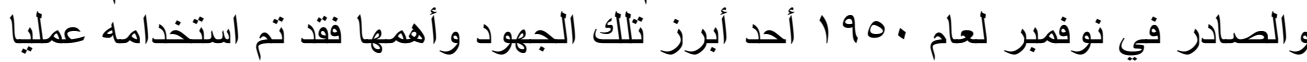

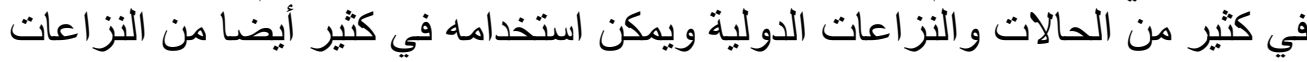
الحالية لتو افر شروطهفي كثير من النز اعات الحالية .

وقد توصلنا من خلال البحث الي النتائج والتوصيات التالية :أولاً: النتائج 


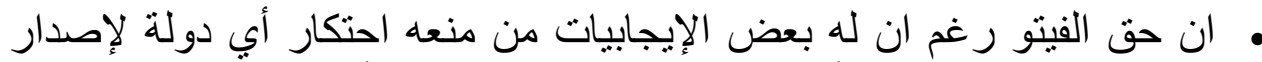

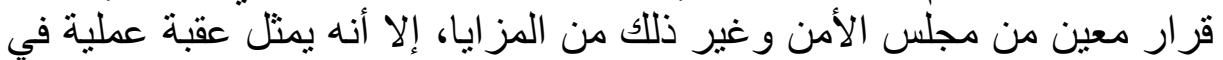
كثير من الحالات لإصدار قرار بحفظ السلم والأمن الدوليين يوقف الحروب التين

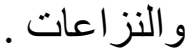

• إن الواقع العملي للتصويت في مجلس الأمن أثبت اسنخدامه علي غير الهدف

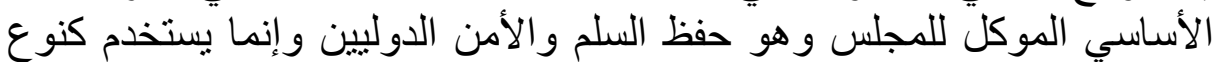

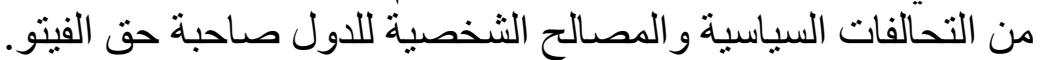

إن إصلاح مجلس الأمن عن طريق تغيير تشكيله وطريقة التصويت بهاء بما يلائم

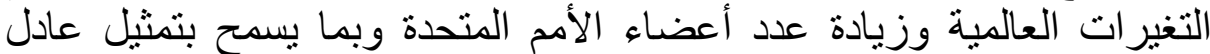

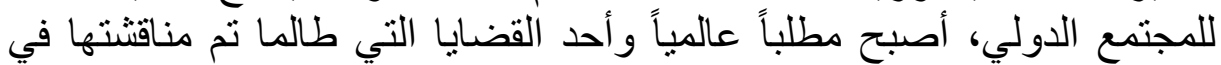

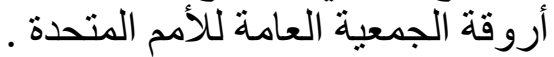

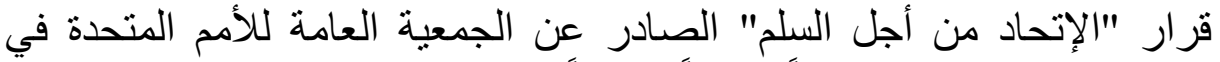

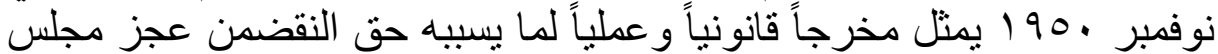

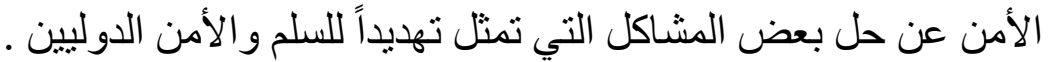

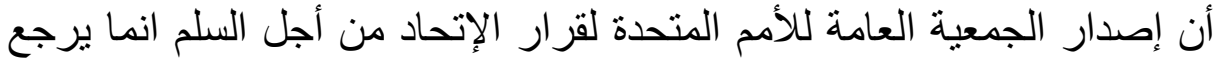

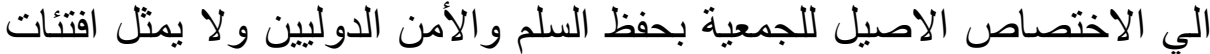
علّي سلطه مجلس الأمن .

ان مجلس الأمن باعضائه الخمس عشر الدائمين و غير الدائمين يعمل كنائب عن الأمم المتحدة في حفظ السلم والأمن الدوليين فاذا عجز عن عن ممارسة لإنين

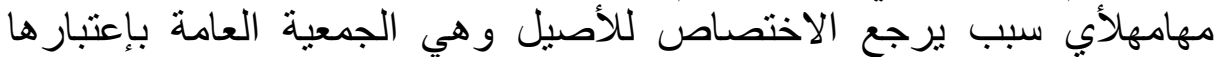

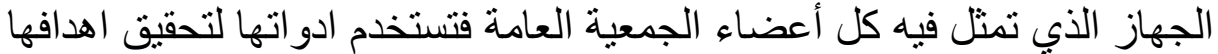
ومن أهم تللك الادوات قر ار الإتحاد من أجل السلم كبديل عن عجز مجلس العن الأمن .

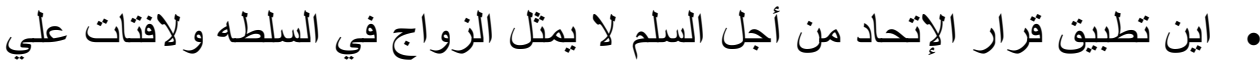

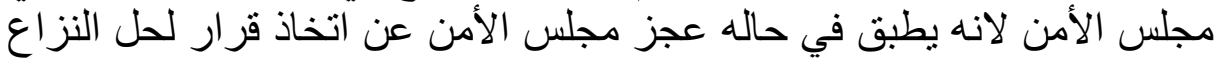

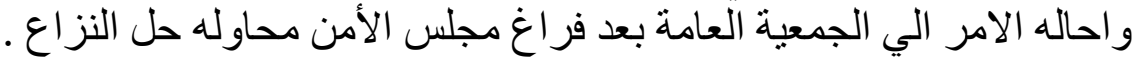
• ان شروط تطبيق قرار الإتحاد من أجل السلم في معظم نزاعات منطقه الثرق

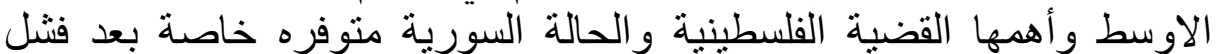
مجلس الأمن لحلها لعقود طويلة في القضيه الفلسطينية و لما يقارب عشر سنو اته

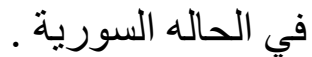




\section{ثانياً: التوصيات}

ـ نوصي بإصر اره دول العالم وخاصة دول الثرق الأوسط والعالم العربي و الإسلامي

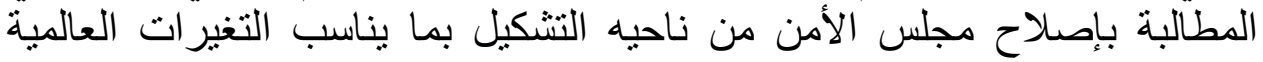

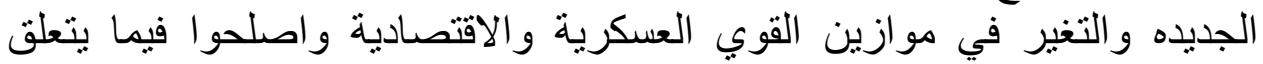

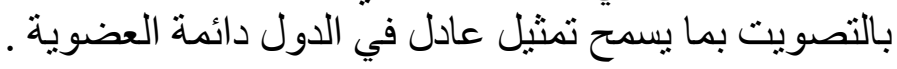

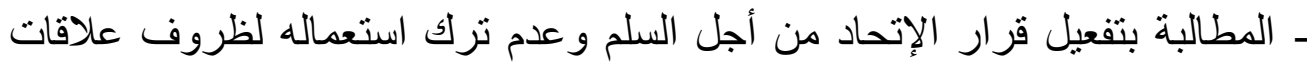

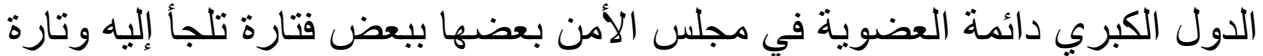

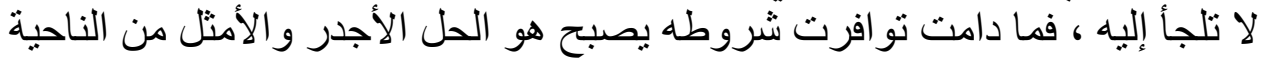
القانونية و العملية الانه

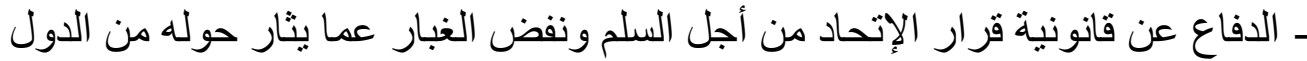

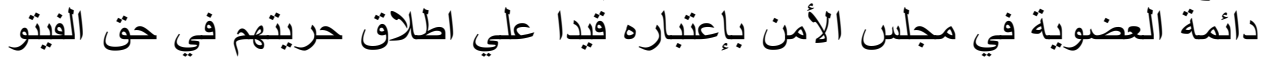

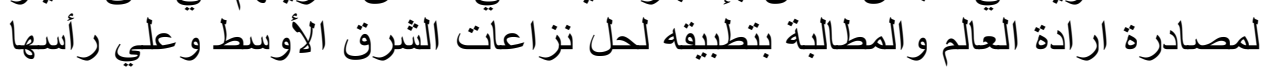

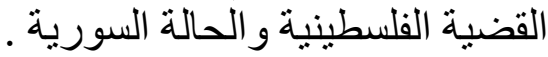




\section{المراجع}

أولاً: مراجع باللغة العربية

أحمد أبو الوفا، الوسيط في قانون المنظمات الدولية، دار النهضة العربة العربية، مصر

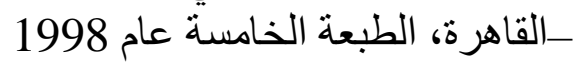

أحمد الرشيدي، الوظيفة الإفتائية لهحكمة العدل الدولية، الهيئة العامة الدصرية

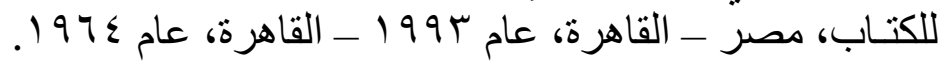

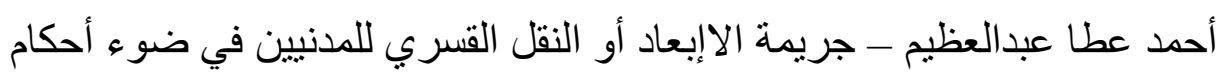

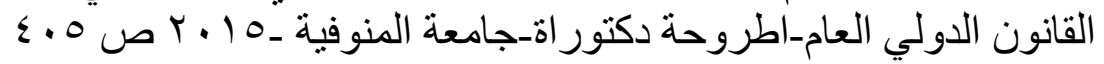

•اينيس كلود، النظام الدولي والسلام العالمي، ترجمة د. عبد الله العريان، دار

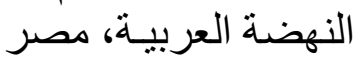

هابر ابراهيم الراوي-الأسس القانونية لقوات حفظ السلام الدولية، مطبعة دار

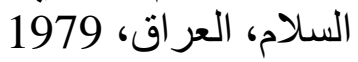

جعفر عبدالسلام، المنظمات الدولية، الطبعة السادسة، دار النهضة العربية،

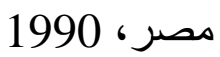

جيمس باروس - الأمم المتحدة ماضيهاو حاضرها ومستقبلها- مؤسسة سجل

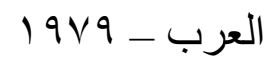

حسام أحمد محمد هنداوي، حدود سلطات مجلس الأمن في ضوء قون قو اعد النظام "العالمي الجديد، دون طبعة، دون دار نشر، القاهرة 1994

حسن نافعة - إصلاح الأمم المنحدة - مركز البحوث و الدراسات السياسية ـ

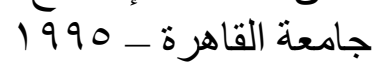

حسن نافعة، محمد شوقي عبدالعال، التنظيم الدولي، الطبعة الثامنة، منشوارت

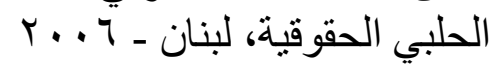

هـين حنفي عمر_التخخل في شئون الدول بذريعة حماية حقوق الإنسانـ دار

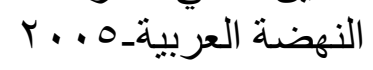

مون طبعة، منشأة المعارف بالإسكندرية، القاهرة ، 1970 ، ص235 
ر رشيد مجيد محمد الربيعي، دور محكمة العدل الدولية في تفسير وتطبيق ميثاق

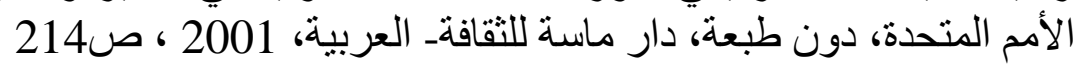

ريم تيسير خليل العارضة- جدار الفصل الإسر ائيلي في القانون الدولي-لأطروحة

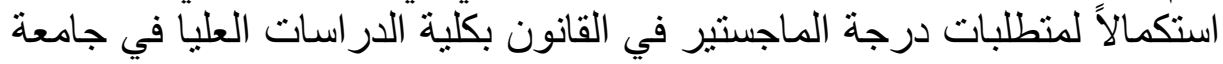

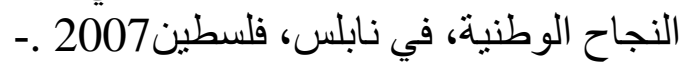

سامي محمد عبد العال، الجزاءات الجنائية في القانون الدولي العام دراسة

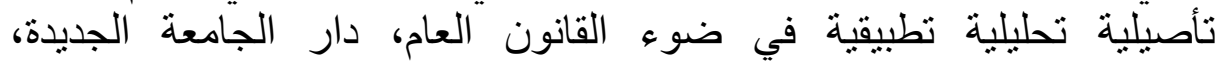

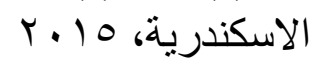

ستيف توليو وتوماس شمال برغر، نحو الاتفاق علي مفاهيم الأمن، قاموس الأناء

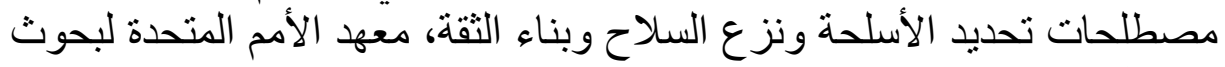

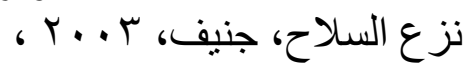

سهيل حسين الفتلاوي-أجهزة الأمم المتحدة_الجزء الثاني-دار الثقافة للنشر

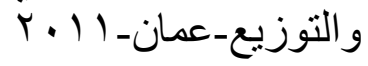

الثافعي محمد بشير، المنظمات الدولية در اسة قانونية سياسية للمنظمات الدولية و القواعد الأساسية في التنظيم الدولي . لمنظئ صلاح الدين فوزي عامر - القانون الدولي في عالم مضطرب. صلاح بسيوني: مصر وأزمة السويس، دار المعارف بمصر، ، و 19V. طارف السيد سليم-موقف يوغسلافيا من أزمة السويس- مجلة بحوث الثرق

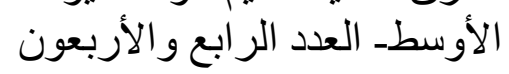

طارق عزت رخا - المنظمات الدولية المعاصرة - القاهرة - دار النهضة

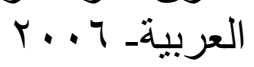

عامر عبدالفتاح الجومرد-تدخل الأمم المتحدة في شؤون الدول_مجلة الرافدين للحقوق_العدد 9 إعلية الحقوق_الموصل

عثمان عبد الرحمن إبراهيم- دور الأمم المتحدة المعاصر وفاعلية تنفيذ قرارات

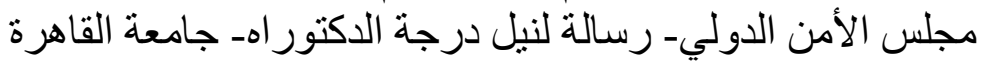
علي إبر اهيم، الحقوق و الواجبات الدولية في عالم متغير، دار النهضة العربيـة،

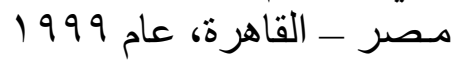


محمد الر اجحي - حول نظرية حق الإعتر اض في مجلس الأمن - دار الثقافةـ

محمد المجدوب، التنظيم الدولي، النمرية والمنظمات الدولية والاقليمية، الطبعة

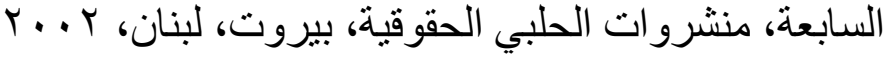

محمد المجذوب_القانون الدولي العام-منشورات حلبي الحقوقيه_الطبعة السادسةـ

محمد حسين كاظم العيسوي- حف النفض في مجلس "در اسة في منظور القانون

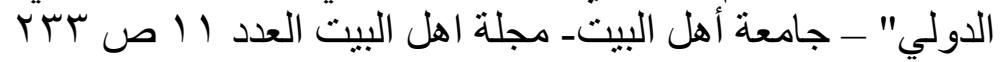

محمد سامح عمرو - محاضر ات في قانون التظيم الدولي _ 1991999 199

محمد سامي عبدالحميد، أصول القانون الدولي العام، الجزء الأول، الجماعة

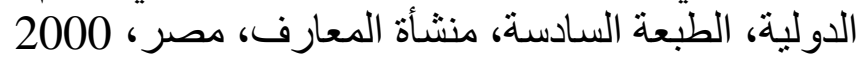

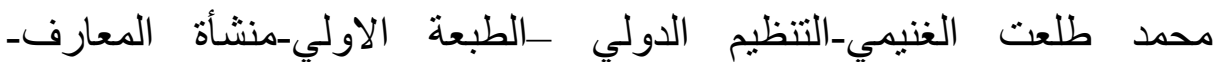

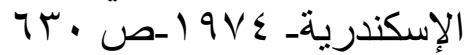

محمد وليد عبدالرحيم- الأمم المتحدة وحفظ السلم والأمن الدوليين-المكتبة

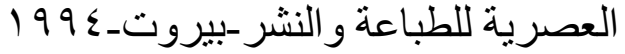

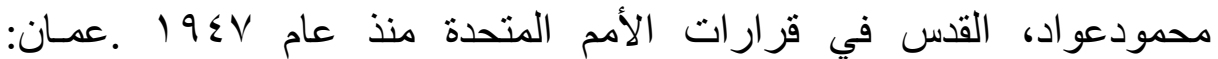
منشـور ات اللجنـة الملكية لثؤون القدس.

مسعد عبد الرحمان زيدان قاسم، تدخل الأمم المتحدة في النز اعات المسلحة ذات

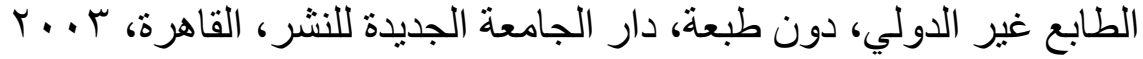

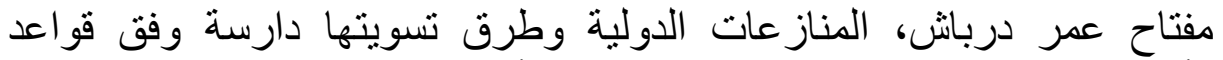

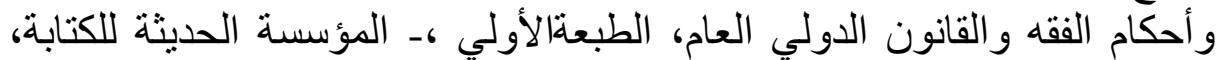
، بيروت،

مدوح شوقي مصطفي - الأمن القومي و الأمن الجماعي الدولي - رسالة لنيل

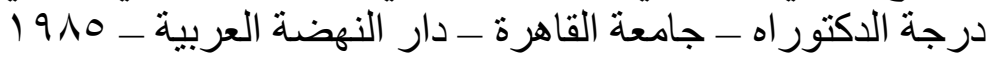


- Alex Bellamy, Paul Williams, Stuart Griffin Understanding Peacekeeping ,Polity Press , Cambridge, 2004

- AMINZADEH Elham, The United Nation and International peace and Security: A legalend pratical AnalysisPHD in International law thesis, University of Glasgow, 1997

- Andrzej Sitkowski, Peacekeeping Myth and Reality, First Published , Praeger Security International, London , 2006

- Anne Runiker «Respect du droit international humanitaire par les forces des nationsunies » International Review of the Red Cross, December 1999,

- John Terence O' Neill, Nicholas Rees, United Nations PeaceKeeping in the Post-Cold War Era, First published, Routledge, New York , 2005

- Manuel fröblich, Keeping Track of UN Peacekeeping Suez Srebrenica Rwanda and the Brahimi Report Yearbook of United Nation Law , Volume 5, 2001

- Max Hilaire, Role of the United Nations in the Post Cold War ERA ,Revue de droit international, Genève, Volume $78, \mathrm{~N}^{\circ} 02$, Mai-août 2000

- Ray Murphy , Katarina Mansson , Peace Operations and Human Rights , First Published, Routledge , London , 2008 
- . LAGRANGE Evelyne, Les opérations de maintien de la paix et le chapitre VII de la Charte des Nations-Unies, Edition Montchrestien -paris, 1999

- Aspect du systeme des Nations- unies dans Le cadre d,unnouvel ordre mondial(1991) et actualite des conflits internationaux (1992),colloques organises,par L,I.E.p. d,Aix en provence ,pedone ,paris,1991et1992

- BAN KI-Moon, à l'ouverture du débat général Conformément à la résolution $377(\mathrm{~V})$ : «L'union pour le maintien de la paix» adoptée par l'Assemblée générale en novembre 1950 ،

- David (Eric), Avis de la cour internationale de justice sur l'emploi de 1 arme nucléaire, revue internationale de la croix rouge, $n^{\circ} 823,1997$

- Elham Animzadeh, The United Nations and International Peace and Security : A legal and practical analysis , PHD in International Law Thesis , University of Glasgow , 1997 